Biomimetic Copper(I)-Mediated Activation of Dioxygen and Redox Non-Innocence in Copper(II) Complexes of Bis(oxazoline)s 



\title{
Biomimetic Copper(I)-Mediated Activation of Dioxygen and Redox Non-Innocence in Copper(II) Complexes of Bis(oxazoline)s
}

\author{
Dissertation \\ zur Erlangung des mathematisch-naturwissenschaftlichen \\ Doktorgrades \\ »Doctor rerum naturalium « \\ der Georg-August-Universität Göttingen \\ im Promotionsprogramm Catalysis for Sustainable Synthesis (CaSuS) \\ der Georg-August University School of Science (GAUSS) \\ vorgelegt von \\ Diplom-Chemiker AdAm WALLI \\ aus Herzberg am Harz
}

Göttingen, 2014 


\section{Betreuungsausschuss}

Prof. Dr. Franc Meyer, Prof. Dr. Dietmar Stalke, Dr. Sebastian Dechert; Institut für Anorganische Chemie, Georg-August-Universität Göttingen.

\section{Mitglieder der Prüfungskommission}

\section{Referent:}

Prof. Dr. Franc Meyer.

Korreferent:

Prof. Dr. Dietmar Stalke.

Weitere Mitglieder der Prüfungskommission:

Prof. Dr. Sven Schneider,

Prof. Dr. Guido Clever,

Dr. RajendRa S. Ghadwal,

Dr. INKE SIEWERT;

Institut für Anorganische Chemie, Georg-August-Universität Göttingen.

Tag der mündlichen Prüfung: 13. Oktober 2014 


\section{List of Chapters}

Symbols and Abbreviations

I. General Introduction 1

1. Biological and Chemical Background 3

2. Bioinorganic Chemistry and the Activation of Dioxygen 13

$\begin{array}{ll}\text { Objectives of this Work } & 31\end{array}$

II. Results 33

$\begin{array}{ll}\text { General Overview } & 35\end{array}$

$\begin{array}{ll}\text { 3. Bis(oxazoline) Ligands } & 37\end{array}$

4. Tautomerism in Bis(oxazoline)s $\quad 45$

5. Unexpected Non-Innocence in Copper(II) Complexes of BOXs 67

6. Biomimetic Activation of $\mathrm{O}_{2}$ by Copper( 1 ) Complexes of BOXs 111

7. A Bis $(\mu$-oxo $)$ Complex by Stepwise Conversion of a Peroxo Species 177

8. Summary and General Concluding Remarks 195

$\begin{array}{lr}\text { III. Experimental Part } & 199\end{array}$

$\begin{array}{ll}\text { 9. Materials and Methods } & 201\end{array}$

$\begin{array}{lr}\text { 10. Synthetic Procedures } & 207\end{array}$

11. Miscellaneous Experimental Procedures 233

12. Computational and X-Ray Absorption/Diffraction Methods 237 
LIST OF CHAPTERS

13. Bibliography

A. Appendix

List of Figures

List of Schemes

List of Tables

Index

283

Scientific contributions 


\section{Contents}

Symbols and Abbreviations ix

Abbreviations ................. . . ix

Physical and Other Symbols . . . . . . . . . . . . . . . . xi

I. General Introduction 1

1. Biological and Chemical Background 3

1.1. The Advent of Life . . . . . . . . . . . . . . . . . . . . . 3

1.2. Binding and Transport of Dioxygen by Copper Enzymes . . . . . 5

1.2.1. The Hemocyanin Family . . . . . . . . . . . . 5

1.3. Activation of Dioxygen by Catalytically Active Copper Enzymes . 7

1.3.1. The Tyrosinase and Catecholoxidase Families . . . . . . 7

1.3.2. Electrophilic Aromatic Substitution . . . . . . . . . . 9

2. Bioinorganic Chemistry and the Activation of Dioxygen 13

2.1. The Chemistry of Copper and Oxygen Interaction . . . . . . . . . 13

2.1.1. The Variety of Copper-Dioxygen Species . . . . . . . . . 14

2.1.2. Dioxygen Activation . . . . . . . . . . . . . . . . 16

2.2. Synthetic Dicopper-Dioxygen Complexes . . . . . . . . . . . . 16

2.2.1. Structure and Spectroscopy . . . . . . . . . . . . . . 17

2.2.2. The Isomeric Equilibrium of ${ }^{\mathrm{S}} \mathbf{P}$ and $\mathbf{O}$ Complexes . . . . . 22

2.2.3. Self-Assembly of the $\mathrm{Cu}_{2} \mathrm{O}_{2}$ Core . . . . . . . . . . . 23

2.2.4. Kinetics and Thermodynamics of $\mathrm{O}_{2}$ Activation . . . . . . 24

2.2.5. Functional Model Compounds . . . . . . . . . . . . . . 25

$\begin{array}{ll}\text { Objectives of this Work } & 31\end{array}$

$\begin{array}{ll}\text { II. Results } & 33\end{array}$

$\begin{array}{ll}\text { General Overview } & 35\end{array}$

3. Bis(oxazoline) Ligands $\quad 37$

3.1. Introduction . . . . . . . . . . . . . . . . 37 
3.2. Ligand Synthesis . . . . . . . . . . . . . . . . . . . 38

3.2.1. Synthesis of Bishydroxy Malonamides . . . . . . . . . 38

3.2.2. Synthesis of Bis(oxazoline)s . . . . . . . . . . . 40

4. Tautomerism in Bis(oxazoline)s 45

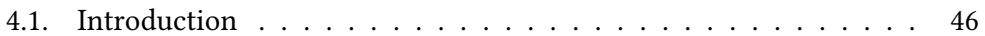

4.2. Solid-State Structures of $\left.\mathrm{H}_{\{}^{\mathrm{Ph}} \mathrm{BOX}\right\}$ and $\left.\mathrm{H}_{\{}{ }^{\mathrm{H}} \mathrm{BOX}\right\} \quad \ldots \ldots . .47$

4.3. Spectroscopic Characterisation of $\left.\mathrm{H}_{\{}{ }^{\mathrm{Ph}} \mathrm{BOX}\right\}$ Tautomers . . . . . 50

4.3.1. NMR Spectroscopy . . . . . . . . . . . . . . . . . 50

4.3.2. IR Spectra from DFT Computation and Experiment . . . . 52

4.4. Thermodynamic Parameters of the Equilibrium . . . . . . . . 53

4.5. Kinetic Parameters and Mechanistic Considerations . . . . . . . 55

4.5.1. Determination of Rate Constants . . . . . . . . . . . . 55

4.5.2. Determination of Activation Parameters . . . . . . . . . 59

4.6. DFT Computations . . . . . . . . . . . . . . . 61

4.7. Conclusion . . . . . . . . . . . . . . . . . . . . . 65

5. Unexpected Non-Innocence in Copper(II) Complexes of BOXs 67

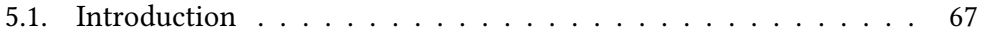

5.2. Copper(II)-Mediated Oxidative Dimerisation of BOXs . . . . . . 70

5.2.1. Motivation . . . . . . . . . . . . . . . . 70

5.2.2. Formation of $\mathrm{Me} \mathrm{BOX}_{2} \ldots \ldots \ldots \ldots 71$

5.2.3. Formation of ${ }^{\square} \mathrm{BOX}_{2} \ldots \ldots \ldots \ldots \ldots$

5.2.4. Ligand Recovery and Identification . . . . . . . . . . 78

5.3. Redox Innocent $\mathrm{H}_{\left\{{ }^{t \mathrm{Bu}} \mathrm{BOX}\right\}}$ and Its Thermochromic $\mathrm{CuCl}_{2}$ complex 80

5.3.1. Temperature Dependency of the Solid-State Structure . . 81

5.3.2. Coordination Geometry in BOXs and Catalytic Selectivity 85

5.4. Copper(II)-Mediated Aerobic Oxygenation of BOXs . . . . . . 87

5.4.1. Formation of $\left.\mathrm{HO}_{\{}{ }^{\mathrm{Ph}} \mathrm{BOX}\right\} \quad \ldots \ldots \ldots \ldots$

5.4.2. $\left.\mathrm{HO}_{\{}{ }^{\mathrm{Ph}} \mathrm{BOX}\right\}$ Ligand Recovery and Identification . . . . . . 94

5.4.3. Formation of $\mathrm{HO}_{\left\{{ }^{\mathrm{Me}} \mathrm{BOX}\right\}} \ldots \ldots \ldots \ldots$

5.4.4. Oxygenation of $\mathrm{H}_{\{}\left\{{ }^{\mathrm{H}} \mathrm{BOX}\right\} \ldots \ldots \ldots 7$

5.5. Mechanistic Considerations . . . . . . . . . . . . . . 97

5.5.1. An Intermediate Radical Species _ . . . . . . . . . . . 97

5.5.2. Electrochemistry . . . . . . . . . . . . . . . . 100

5.5.3. DFT Calculations . . . . . . . . . . . . . . . . 100

5.5.4. Spin-Trapping of a Transient Organic Radical . . . . . . 103

5.5.5. $\mathrm{DPPH}^{\bullet}$ Antiradical Assay . . . . . . . . . . . . . 105 
5.6. Conclusion . . . . . . . . . . . . . . . . . . . . . . . . 109

6. Biomimetic Activation of $\mathrm{O}_{2}$ by Copper(I) Complexes of BOXs 111

6.1. Introduction . . . . . . . . . . . . . . . . 112

6.2. Synthesis and Characterisation of Copper(I) Complexes of BOXs . 112

6.2.1. Spectroscopy . . . . . . . . . . . . . . 114

6.2.2. Solid-State Structures . . . . . . . . . . . . . . . . . . . 114

6.2.3. Electrochemistry . . . . . . . . . . . . . . . . 117

6.3. Activation of Dioxygen and Spectroscopic Analysis . . . . . . . . 120

6.3.1. Formation and Spectral Optical Properties of $\mathbf{R}_{\mathbf{P}}$. . . . . 120

6.3.2. Thermolability and Reversibility of $\mathrm{O}_{2}$ Binding . . . . . 125

6.4. Kinetic and Thermodynamic Analysis of $\mathrm{O}_{2}$ Activation . . . . . . 127

6.4.1. The Low Temperature (Cryo-)Stopped-Flow Technique . . 131

6.4.2. Determination of Rate Constants . . . . . . . . . . . . . 132

6.4.3. Activation and Equilibrium Parameters: Mechanism . . . 136

6.5. Isolation of Solid $\mathrm{Cu}_{2} \mathrm{O}_{2}$ Peroxo Compounds . . . . . . . . . . . 140

6.5.1. Solid-State UV-vis . . . . . . . . . . . . . . . . . . . . . 141

6.6. Resonance Raman Spectroscopy . . . . . . . . . . . . . . . . . . . 142

6.7. Structural Investigations: XAS, XANES and EXAFS Analysis . . . 148

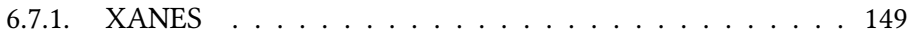

6.7.2. EXAFS ...................... 150

6.7.3. Comparison of XAS Structural Results . . . . . . . . . 154

6.8. DFT Computations . . . . . . . . . . . . . . . . 156

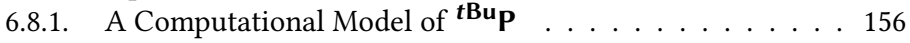

6.8.2. Simulation of Spectroscopic Data by TD-DFT . . . . . . . 158

6.9. Magnetic Properties . . . . . . . . . . . . . . . . . . . . 162

6.9.1. DFT Broken-Symmetry Magnetic Coupling . . . . . . . . 165

6.10. Thermal Degradation of Peroxo Complexes . . . . . . . . . . . . . 166

6.10.1. Bis( $\mu$-hydroxo)dicopper(II) Complexes . . . . . . . . . . 166

6.10.2. Ligand Oxygenation . . . . . . . . . . . . . . . . 172

6.11. Reactivity Towards External Substrates . . . . . . . . . . . . . . 173

6.12. Conclusion . . . . . . . . . . . . . . . . . . 174

7. $\mathrm{A}$ Bis $(\mu$-oxo) Complex by Stepwise Conversion of a Peroxo Species 177

7.1. Introduction . . . . . . . . . . . . . . . . . . 177

7.2. Preparation and Spectral Properties of ${ }^{\mathbf{P h}} \mathbf{O} \ldots \ldots . . . . . . .177$

7.3. Stepwise Conversion ${ }^{\mathbf{P h}} \mathbf{P} \rightarrow{ }^{\mathbf{P h}} \mathbf{O} \ldots \ldots . . \ldots . . \ldots 180$

7.4. Resonance Raman Spectroscopy . . . . . . . . . . . . . . . . . . . 184 


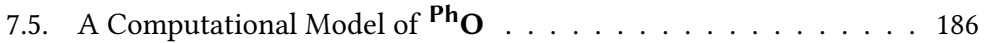

7.5.1. Simulation of Spectroscopic Data by TD-DFT . . . . . . . 187

7.6. Reactivity . . . . . . . . . . . . . . . . . . . 192

7.7. Conclusion . . . . . . . . . . . . . . . . . . 192

8. Summary and General Concluding Remarks 195

$\begin{array}{lr}\text { III. Experimental Part } & 199\end{array}$

9. Materials and Methods 201

9.1. General . . . . . . . . . . . . . . . . . . . . . 201

9.2. Physical Methods . . . . . . . . . . . . . . . . . . . 202

10. Synthetic Procedures $\quad 207$

10.1. Procedures and Physical Data for Bis(oxazoline) Ligands $\left.\mathrm{H}_{\{}{ }^{\mathrm{R}} \mathrm{BOX}\right\} 207$

10.1.1. General Procedure for the Synthesis of BOXs . . . . . . 207

10.1.2. $\left.\mathrm{H}_{\{\mathrm{H}}^{\mathrm{H}} \mathrm{BOX}\right\} \ldots \ldots \ldots \ldots . \ldots \ldots 20 . \ldots \ldots$

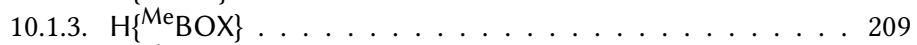

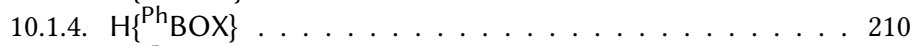

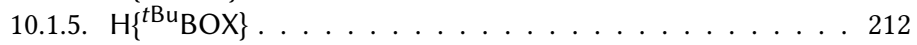

10.2. Copper(I) Complexes . . . . . . . . . . . . . . . . . . . 214

10.2.1. The $\left.\left[\left(\mathrm{H}^{\mathrm{R}}{ }^{\mathrm{R}} \mathrm{BOX}\right\}\right) \mathrm{Cu}^{\mathrm{I}}(\mathrm{MeCN})\right] \mathrm{PF}_{6}\left(\mathbf{C u}^{\prime} \mathbf{R}\right)$ Family $\ldots . . .214$

10.2.2. $\left(\mathrm{Me}_{\mathrm{BOX}}\right)_{2} \mathrm{Cu}_{2}^{\mathrm{I}} \mathrm{Cl}_{2} \ldots \ldots \ldots \ldots 216$

10.2.3. $\left({ }^{\square} \mathrm{BOX}_{2}\right) \mathrm{Cu}_{2}{ }_{2} \mathrm{Cl}_{2} \ldots \ldots \ldots \ldots . \ldots . \ldots 217$

10.3. Peroxodicopper(II) Complexes $\left({ }^{\mathbf{R}} \mathbf{P}\right) \ldots \ldots . . . . . . . .218$

10.3.1. $\left[\left\{(\mathrm{THF})\left(\mathrm{H}\left\{{ }^{t \mathrm{Bu}} \mathrm{BOX}\right\}\right) \mathrm{Cu}^{\mathrm{II}}\right\}_{2}\left(\mathrm{O}_{2}^{2-}\right)\right] \mathrm{PF}_{6}\left({ }^{t \mathbf{B u}} \mathbf{P}\right) \ldots \ldots . . .218$

10.3.2. $\left[\left\{(\mathrm{THF})\left(\mathrm{H}\left\{{ }^{\mathrm{H}} \mathrm{BOX}\right\}\right) \mathrm{Cu}^{\mathrm{I}}\right\}_{2}\left(\mathrm{O}_{2}^{2-}\right)\right] \mathrm{PF}_{6}\left({ }^{\mathrm{H}} \mathbf{P}\right) \ldots \ldots . . . .219$

10.3.3. $\left.\left[\left\{\left(\mathrm{H}_{\left\{{ }^{\mathrm{Me}}\right.} \mathrm{BOX}\right\}\right) \mathrm{Cu}^{\mathrm{II}}\right\}_{2}\left(\mathrm{O}_{2}^{2-}\right)\right] \mathrm{PF}_{6}\left({ }^{\mathbf{M e}} \mathbf{P}\right) \ldots \ldots . \ldots 20$

10.3.4. $\left.\left[\left\{\left(\mathrm{H}_{\{}{ }^{\mathrm{Ph}}{ }_{\mathrm{BOX}}\right\}\right) \mathrm{Cu}^{\mathrm{I}}\right\}_{2}\left(\mathrm{O}_{2}^{2-}\right)\right] \mathrm{PF}_{6}\left({ }^{\mathrm{Ph}} \mathbf{P}\right) \ldots \ldots . \ldots 220$

10.4. A Bis $(\mu$-oxo)dicopper(III) Complex . . . . . . . . . . . . . . 221

10.4.1. $\left[\left\{\left({ }^{\mathrm{Ph}} \mathrm{BOX}^{-}\right) \mathrm{Cu}^{\mathrm{III}}\right\}_{2}\left(\mathrm{O}^{2-}\right)_{2}\right] \mathrm{PF}_{6}\left({ }^{\mathrm{Ph}} \mathrm{O}\right) \ldots \ldots . \ldots . \ldots . \ldots 21$

10.5. Bis( $\mu$-hydroxo)dicopper(II) Compounds . . . . . . . . . . . . . . . 222

10.5.1. $\left.\left[(\mathrm{THF})_{0.85}(\mathrm{MeCN})_{0.15}\left(\mathrm{H}_{\{}^{\mathrm{tBu}} \mathrm{BOX}\right\}\right) \mathrm{Cu}^{\mathrm{II}}(\mathrm{OH})\right]_{2}\left(\mathrm{PF}_{6}\right)_{2} \ldots . .223$

10.5.2. $\left.\left[\left(\mathrm{H}_{2} \mathrm{O}\right)\left(\mathrm{H}_{\{}^{t \mathrm{Bu}} \mathrm{BOX}\right\}\right) \mathrm{Cu}^{\mathrm{II}}(\mathrm{OH})\right]_{2}\left(\mathrm{PF}_{6}\right)_{2} \ldots \ldots . \ldots . \ldots 223$

10.6. Further Copper(II) Complexes . . . . . . . . . . . . . . . . . . 224

10.6.1. $\left(\mathrm{H}_{\left\{{ }^{t \mathrm{Bu}} \mathrm{BOX}\right\}}\right) \mathrm{Cu}^{\mathrm{II}} \mathrm{Cl}_{2} \ldots \ldots \ldots . \ldots . \ldots 224$

10.6.2. $\left(\mathrm{H}_{\left\{{ }^{\mathrm{Ph}} \mathrm{BOX}\right\}}\right) \mathrm{Cu}^{\mathrm{II}} \mathrm{Cl}_{2} \ldots \ldots \ldots . \ldots . \ldots 224$ 
10.6.3. $\left[\left({ }^{\mathrm{Me}_{\mathrm{BOX}}}\right)\left\{\mathrm{Cu}^{\mathrm{II}}(\mathrm{OAc})\left(\mathrm{H}_{2} \mathrm{O}\right)\right\}_{2}\right]\left(\mathrm{ClO}_{4}\right)_{2} \ldots \ldots \ldots . . \ldots .225$

10.6.4. $\left({ }^{\left.\mathrm{Me} \mathrm{BOX}_{2}\right)\left(\mathrm{Cu}^{\mathrm{II}} \mathrm{Cl}_{2}\right)_{2} \ldots \ldots \ldots \ldots \ldots \ldots \ldots \ldots \ldots}\right.$

10.6.5. $\left(\mathrm{O}_{\{}{ }^{\mathrm{Ph}}{ }_{\mathrm{BOXX}}\right)_{2} \mathrm{Cu}^{\mathrm{II}}{ }_{3} \mathrm{Cl}_{4} \ldots \ldots \ldots \ldots \ldots . \ldots \ldots 226$

10.6.6. $\left(\mathrm{O}_{\{}^{\left.\mathrm{Me}_{\mathrm{BOX}}\right)_{2}}\right)_{2}(\mathrm{MeOH})_{2} \mathrm{Cu}_{4}^{\mathrm{II}} \mathrm{Cl}_{6} \ldots \ldots \ldots \ldots 228$

10.7. Ligand Recovery and Identification … . . . . . . . . . . 228

10.7.1. Isolation of ${ }^{\mathrm{Me} \mathrm{BOX}_{2}} \ldots \ldots \ldots \ldots . \ldots 228$

10.7.2. Isolation of ${ }^{\square} \mathrm{BOX}_{2} \ldots \ldots \ldots \ldots . \ldots . \ldots 229$

10.7.3. Isolation of $\left.\mathrm{HO}_{\{}{ }^{\mathrm{Ph}} \mathrm{BOX}\right\} \ldots \ldots \ldots . . \ldots 230$

10.7.4. Thermal Decomposition of ${ }^{\mathbf{H}} \mathbf{P}$ and Isolation of ${ }^{\mathrm{O}} \mathrm{BOX} \quad \ldots 231$

11. Miscellaneous Experimental Procedures 233

11.1. Equilibrium and Kinetics of $\mathrm{H}_{\{}\left\{{ }_{\mathrm{Ph}} \mathrm{BOX}\right\}$ Tautomerism . . . . . . 233

11.2. Cryo-Stopped-Flow Kinetics of Activation of $\mathrm{O}_{2}$ by ${ }^{\boldsymbol{t} \text { Bu }} \mathbf{P} \ldots . .234$

11.3. Beer's Law Plots for ${ }^{\mathbf{B} u \mathbf{P}} \ldots \ldots \ldots$. . . . . . . . . . . . . 234

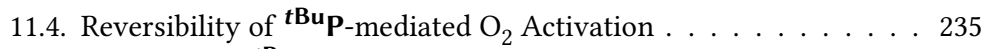

11.5. Reactivity of ${ }^{\mathbf{B} u \mathbf{P}}$ Towards External Substrates . . . . . . . 235

11.6. Spin-Trapping of a Short-lived Transient Radical . . . . . . . . . 236

11.7. $\mathrm{DPPH}^{\bullet}$ Antiradical Assay . . . . . . . . . . . . . . . 236

12. Computational and X-Ray Absorption/Diffraction Methods 237

12.1. DFT Calculations . . . . . . . . . . . . . . 237

12.1.1. Ligands $\left.\mathrm{H}_{\{}{ }^{\mathrm{Ph}} \mathrm{BOX}\right\}$ and $\left.\mathrm{H}_{\{}{ }^{\mathrm{H}} \mathrm{BOX}\right\} \quad \ldots \ldots . \ldots . . \ldots 238$

12.1.2. $\mathrm{Cu}^{\mathrm{II}}$ Complexes . . . . . . . . . . . . . . . . 238

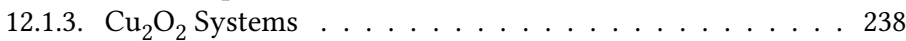

12.2. XAS, XANES and EXAFS . . . . . . . . . . . . . . . 240

12.3. X-Ray Crystallography . . . . . . . . . . . . . . . . 241

13. Bibliography 249

A. Appendix 269

A.1. Determination of Angular Structural Parameters $\tau_{5}$ and $\tau_{4} \quad \ldots 269$

A.2. Additional Figures and Tables . . . . . . . . . . . . 270

$\begin{array}{ll}\text { List of Figures } & 275\end{array}$

$\begin{array}{ll}\text { List of Schemes } & 279\end{array}$

$\begin{array}{ll}\text { List of Tables } & 281\end{array}$ 
Contents

Index

Scientific contributions

287

viii 


\section{Symbols and Abbreviations}

\section{Abbreviations}

AF anti-ferromagnetic

ARP antiradical power

ATP adenosine triphosphate

av average

$[\mathrm{BArF}]^{-}$tetrakis[3,5-bis(trifluoromethyl)phenyl]borate counterion

BOX bis(oxazoline) ligand

B3LYP Becke three-parameter exchange and Lee-Yang-Parr correlation

BP86 Becke exchange and Perdew correlation functional

BS broken symmetry

calc. calculated

$\mathrm{CO}$ catecholoxidase

${ }^{\mathrm{C}} \mathbf{P}$ 1,2-cis-peroxodicopper(II) species

$\mathrm{Cp} \eta^{5}\left(\mathrm{C}_{5} \mathrm{H}_{5}\right)^{-}$

$\mathrm{Cp}^{*} \eta^{5}\left(\mathrm{C}_{5} \mathrm{Me}_{5}\right)^{-}$

CSD Cambridge Structural Databank

CT charge transfer

CV cyclic voltammetry

$\mathrm{CW}$ continuous wave

Da Dalton $\left(\mathrm{g} \mathrm{mol}^{-1}\right)$

DCM methylene chloride

def2-SVP double- $\zeta$ split valence polarization basis set

def2-TZVPP valence triple- $\zeta$ plus polarization basis set

DFT density functional theory

DMPO 5,5-dimethyl-1-pyrroline-N-oxide

$\mathrm{DPPH}^{\bullet}$ 2,2-diphenyl-1-picrylhydrazyl radical

$E C_{50}$ half maximal effective concentration

EDTA ethylenediaminetetraacetic acid

EI electron impact ionisation

EPR electron paramagnetic resonance

eq. equivalents

ESI electron spray ionisation

EXAFS extended X-ray absorption fine structure

Fc ferrocene 


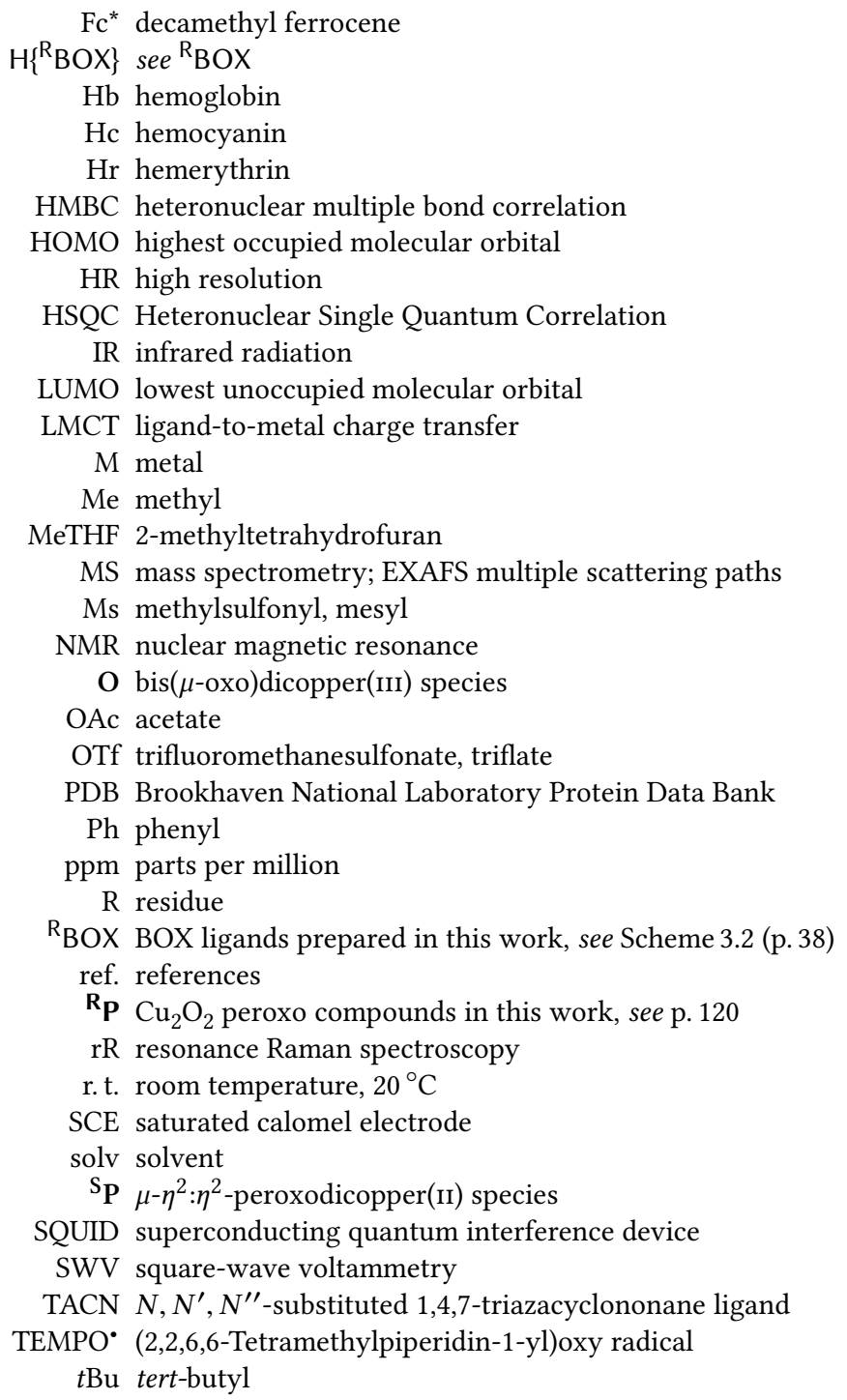


TD-DFT time-dependent density functional theory

${ }^{\mathrm{T}} \mathrm{P}$ 1,2-trans-peroxodicopper(II) species

Tp tris(pyrazolyl)borate ligand

TS transition state

TEMPO (2,2,6,6-tetramethylpiperidin-1-yl)oxy

THF tetrahydrofuran

tmpa tris[(2-pyridyl)methyl]amine ligand

Ty tyrosinase

UNO unrestricted natural orbital

UV-vis ultraviolet-visible radiation

XANES X-ray absorption near-edge structure spectroscopy

XAS X-ray absorption spectroscopy

ZPE zero point energy

\section{Physical and Other Symbols}

$\ominus$ standard state

$\ddagger$ transition state

I| parallel

$\perp$ perpendicular

$\measuredangle$ bond angle

$\square$ absence of the residue $\mathrm{R}$

$\% T$ \%transmission

a EPR hyperfine coupling constant

Abs absorbance

$\delta$ chemical shift; bending vibrational mode

$\Delta$ difference

$\Delta\left[{ }^{18} \mathrm{O}\right]{ }^{16} \mathrm{O}$ to ${ }^{18} \mathrm{O}$ isotope shift

$E, E_{\mathrm{pc}}, E_{\mathrm{pa}}$ energy, potential; cathodic and anodic peak potentials

$E_{1 / 2}$ half-wave potential

$\epsilon$ molar absorption coefficient

$\eta$ hapticity

$\theta, \vartheta$ plane angle

$g$ electron $g$-factor

$G$ Gibbs energy

$i, i_{\mathrm{pc}}, i_{\mathrm{pa}}$ current; cathodic and anodic peak currents

$H$ enthalpy

$\mathscr{H}$ Hamiltonian operator 
f NMR scalar/magnetic exchange coupling constant

$k$ reaction rate constant; bond force constant

$K$ equilibrium constant

L levo

$\lambda$ wavelength

$\lambda_{\text {ex }}$ wavelength of excitation

$\lambda_{\max }$ wavelength of maximal absorption

$m$ mass

M molarity, $\mathrm{mol} \mathrm{L}^{-1}$

$\mathrm{m} / \mathrm{z}$ mass to charge ratio

$\mu$ bridging ligand; reduced mass

$v$ rate of reaction; stretching vibration; frequency

$v^{\ddagger}$ imaginary frequency of the transition state

$v_{\mathrm{s}}, v_{\mathrm{a}}$ symmetric, asymmetric stretching vibration

$\tilde{v}$ wavenumber

$\bar{R}^{2}$ adjusted coefficient of determination

$R_{\mathrm{f}}$ retention factor

$S$ entropy; total spin

$\vec{S}_{\mathrm{A}}$ effective electron spin operator for »atom A«

$T_{2}$ spin-spin relaxation

$\tau_{5}, \tau_{4}$ angular structural $\tau$ parameters, see p. 269

$t_{1 / 2}$ half-life

$v$ scan rate

$\varphi$ dihedral angle

$\chi$ mole fraction

$\chi_{\text {mol }}$ molar magnetic susceptibility 


\section{Part I.}

General Introduction 



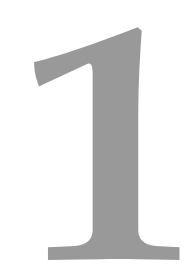

\section{Biological and Chemical Background}

$\mathbf{I}^{\mathrm{T}}$

$\mathrm{T}$ is assumed that the element copper was first discovered $9000 \mathrm{~B}$. C. In the course of time it was associated with planet and goddess Venus ( 9 ) due to its lustrous, gleaming appearance. The discovery of the element oxygen is not as old, it was around the year 1775 , and its discovery rendered the theory of phlogiston obsolete which attempted to explain burning processes. However, the biological history of oxygen on earth and its interplay with copper goes way back in time, up to the appearance of life on earth.

\subsection{The Advent of Life}

The formation of earth took place $4.5 \times 10^{9}$ years ago, $10^{9}$ years later, life appeared on the planet's surface. Cyanobacteria turned up later in the course of evolution and began to produce oxygen $\left(\mathrm{O}_{2}\right.$, dioxygen) by the process of photosynthesis. Dioxygen was poisonous for the early earth's living anaerobic organisms, due to its high reactivity. The other side of the coin is, that with dioxygen, life was provided with the ultimate oxidant. The arisen free dioxygen was however absorbed by the oceans and chemically captured, mainly by dissolved iron, and stored in seabed rock and later in the land surfaces. The oxidative power lead furthermore to redox state changes of redox active metals, such as iron, copper and molybdenum and hereby their bioavailability was modified. After the dioxygen sinks were saturated, it began to accumulate in the atmosphere. These events took place around $2.4 \times 10^{9}$ years ago and is called the Great Oxygenation Event (GOE, or the Oxygen Catastrophe). A concentration of $20.95 \% \mathrm{O}_{2}$ in the atmosphere was later reached and remained constant.

In the process of photosynthesis, energy from sunlight is harvested by living organisms. While in the course of this action, water is oxidised by four electrons to dioxygen, in the process of aerobic respiration, biochemical energy from nutrients is gained using $\mathrm{O}_{2}$ as the oxidising agent. This process is technically a combustion 


\section{Biological and Chemical Background}

reaction; with the ultimate oxidant $\mathrm{O}_{2}$, aerobic respiration is the most exergonic metabolism known. Upon the availability of dioxygen as oxidant, previously unavailable sources were made thermodynamically accessible for organisms. To take advantage of $\mathrm{O}_{2}$, proteins evolved to transport it, to store it and to exploit its nature of ubiquitous and strong oxidation agent. For the interaction with $\mathrm{O}_{2}$ some kind of binding and/or activation process is needed; this is where transition metals step in. Metalloproteins possess metals in their active sites to execute this crucial metal-oxygen interactions. ${ }^{[1]}$

While many atom-transfer reactions of $\mathrm{O}_{2}$ to organic substrates are highly exergonic, they do not occur spontaneously. In the ground state, the $\mathrm{O}_{2}$ molecule contains two unpaired electrons, i. e. it is in a triplet state $\left({ }^{3} \mathrm{O}_{2}\right)$; reactions with singlet molecules (like organic substrates) would need a quantum-mechanically forbidden triplet-to-singlet spin conversion, this causes the high kinetic reaction barrier. Now, binding of $\mathrm{O}_{2}$ to redox-active transition metal centres in proteins overcomes the spin restrictions of $\mathrm{O}_{2}$ interaction and leads to oxidation of the metal, concomitant with the reduction of $\mathrm{O}_{2}$ and scission of the $\mathrm{O}=\mathrm{O}$ bond(s). Furthermore, reactions of this activated (and metal-bound) $\mathrm{O}_{2}$ are highly selective with substrates which are bound to the enzyme in proper orientation.

Iron and copper are the prototypical redox-active and abundant metals for this purpose. The roles of copper in nature are electron transfer, $\mathrm{NO}_{2}^{-} / \mathrm{N}_{2} \mathrm{O}$ reduction, activation of substrates and interactions with $\mathrm{O}_{2}$, including binding, activation and reduction. ${ }^{[2]}$ Copper sites in metalloproteins for electron transfer are the mononuclear (»type $1 \ll$ ) »blue copper « and the binuclear » $\mathrm{Cu}_{\mathrm{A}} \ll$. The blue $\mathrm{Cu}$ has a highly covalent $\mathrm{Cu}^{\mathrm{II}}-\mathrm{S}_{\mathrm{Cys}}$ bond, responsible for the intense blue colour due to $\mathrm{Cu} \leftarrow \mathrm{S}$ ligand-to-metal charge-transfer (LMCT) transition in the visible region. In $\mathrm{Cu}_{\mathrm{A}}$, a delocalised $\mathrm{Cu}_{2}^{1.5}\left(\mu-\mathrm{S}_{\mathrm{Cys}}\right)_{2}$ core with a $\mathrm{Cu}-\mathrm{Cu}$ bond is present. ${ }^{[3-5]}$ For denitrification, bacteria utilize the mononuclear nitrite reductase $\left(\mathrm{NO}_{2}^{-} \rightarrow \mathrm{NO}\right)$ and the tetranuclear nitrous oxide reductase $\left(\mathrm{N}_{2} \mathrm{O} \rightarrow \mathrm{N}_{2}+\mathrm{H}_{2} \mathrm{O}\right)$, which features a unique $\mu_{4}-\mathrm{S}^{2-}$-bridge. Some enzymes use $\mathrm{Cu}^{\mathrm{II}}$ to activate bound substrates for reactions with $\mathrm{O}_{2}$; ${ }^{[2]}$ they overcome the spin-forbiddeness of the reaction between triplet $\mathrm{O}_{2}$ and singlet organic substrates; an alternative approach besides the activation of $\mathrm{O}_{2}$ by $\mathrm{Cu}^{\mathrm{I}}$. The reduction of $\mathrm{O}_{2}$ to $\mathrm{H}_{2} \mathrm{O}$ (a four electron process performed in one step) is done by either trinuclear »multicopper oxidases « or the heme- and copper-containing »cytochrome oxidases «, which use the energy for establishing a transmembrane difference of proton electrochemical potential (then used for ATP synthesis by the ATP synthase).

Finally, oxygen-activating copper proteins are the mononuclear »amine oxidase and »galactose oxidase«, and besides non-coupled binuclear systems with a large 
$\mathrm{Cu} \cdots \mathrm{Cu}$ separation, the coupled binuclear copper sites. This coupled binuclear (»type $3 \ll$ ) systems are the central point of this thesis.

\subsection{Binding and Transport of Dioxygen by Copper Enzymes}

For most animals, the circulatory transport of dioxygen is essential for their metabolism and they possess specific transport proteins. Besides the class of hemoglobins $(\mathrm{Hb})$, there are two other essentially different oxygen carriers, the non-heme iron proteins of the hemerythrin family $(\mathrm{Hr})$ and coupled binuclear (»type $3 \ll$ ) copper proteins, called hemocyanins $(\mathrm{Hc})$.

\subsubsection{The Hemocyanin Family}

Arthropods and Molluscs both make use of hemocyanins as their respiratory proteins. ${ }^{\left[{ }^{-10]}\right.}$ Members of the phylum Mollusca are, e. g. clams, mussels, squid, octopus, snails and slugs. Members of the phylum Arthropoda are, e. g. crabs and lobsters, centipedes, spiders, the horseshoe crab and insects. Insects however possess an elaborate tracheal system, that makes organs directly reachable for atmospheric oxygen and no oxygen-transport protein system is needed by them. Nevertheless, in 2004 the presence of an respiratory Hc in an insect was found for the fist time. ${ }^{[8,11]}$

Hemocyanins are giant molecules composed of multiple subunits, freely dissolved in the blood (hemolymph); with some representatives with masses of $>10^{7} \mathrm{Da}$. While the protein's active sites (where oxygen is bound by copper) are very similar between mollusc and arthropod Hc, at all levels their molecular structure is very different. Due to this diversity, mollusc Hc and arthropod Hc are now considered as two different proteins. ${ }^{[8]}$ The molecular structures of the active sites of arthropod and mollusc hemocyanins have been elucidated by means of X-ray absorption fine structure (EXAFS) and X-ray absorption near edge spectroscopy (XANES), as well as by X-ray crystallography. ${ }^{[12,13]}$ X-ray crystal structures of arthropod hemocyanin from the Atlantic horseshoe crab, Limulus polyphemus are depicted in Figure 1.1 (structural data for the deoxy, ${ }^{[6]}$ and oxy-states ${ }^{[7]}$ were obtained from the Brookhaven National Laboratory Protein Data Bank, PDB). ${ }^{[14]}$

As mentioned above, the active sites are very similar in both hemocyanins. The two copper atoms are coordinated in a trigonal-pyramidal geometry by three imidazoles from histidine amino acids, respectively. In deoxy-Hc (Figure 1.1a, $\mathrm{Cu}^{\mathrm{I}} \equiv$ yellow) the copper atoms are in $\mathrm{Cu}^{\mathrm{I}}$ oxidation state with $d^{10}$ electronic 


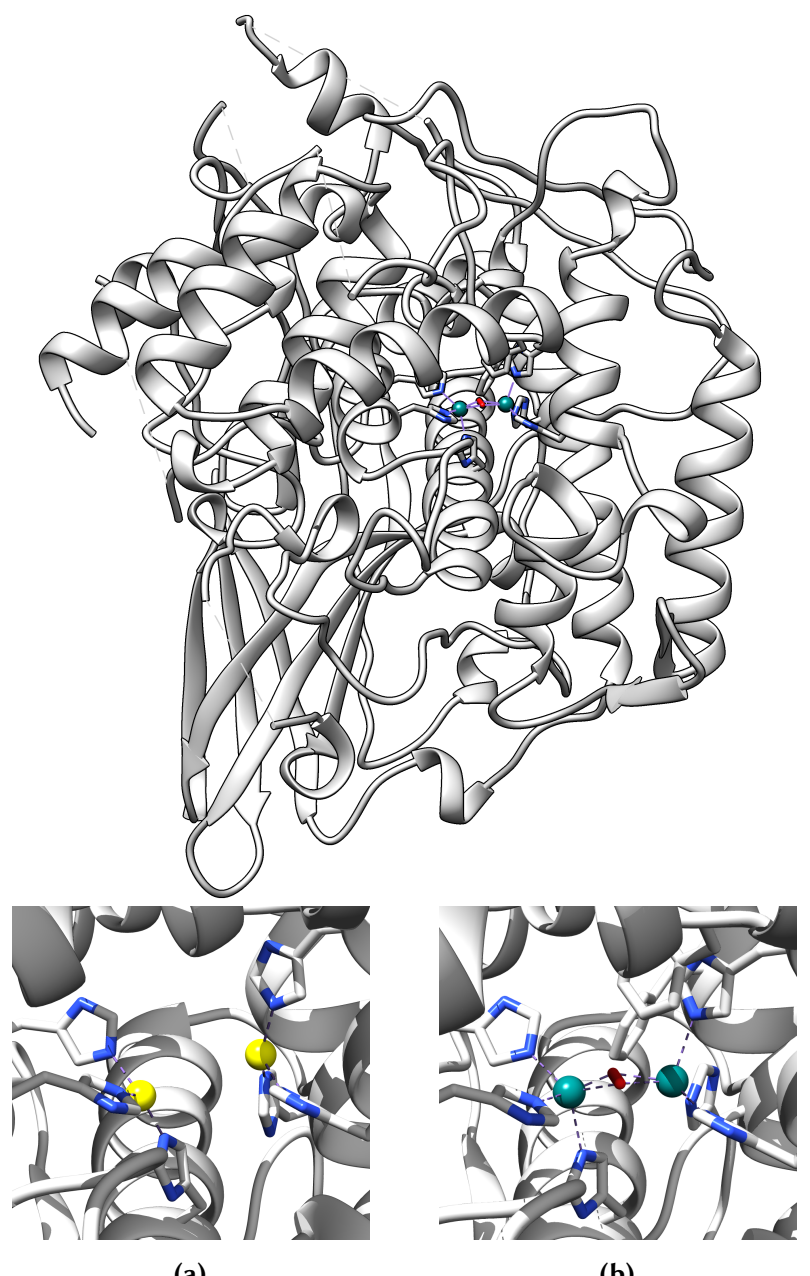

(a)

(b)

Figure 1.1. X-ray molecular structures of arthropod subunit II hemocyanin $(73 \mathrm{kDa})$ of the Atlantic horseshoe crab, Limulus polyphemus. (a) Deoxy-Hc at $2.2 \AA$ resolution (PDB ID: 1LLA) ${ }^{[6]} \mathrm{Cu} \cdots \mathrm{Cu} 4.61 \AA$ (b) Oxy-Hc $\left(\mu-\eta^{2}: \eta^{2}\right.$-peroxodicopper(II)) at $2.4 \AA$ resolution (PDB ID: $10 X Y),{ }^{[7]} \mathrm{Cu} \cdots \mathrm{Cu} 3.59 \AA$. Colour code: white, protein backbone/carbon; blue, nitrogen; red, oxygen; yellow, copper(I); teal, copper(II). 
configuration. The enzyme is colourless and the $\mathrm{Cu} \cdots \mathrm{Cu}$ separation is with $4.61 \AA$ quite large. Upon oxygenation, $\mathrm{O}_{2}$ is bound and the copper ions are oxidised to $\mathrm{Cu}^{\mathrm{II}}$, concomitant with an intense blue colouring of the oxy-Hc protein (Figure 1.1b, $\mathrm{Cu}^{\mathrm{II}}$ $\equiv$ teal). The intense colour arises from a $\mathrm{Cu}^{\mathrm{II}} \leftarrow \mathrm{O}_{\text {peroxo }}$ (ligand-to-metal) chargetransfer (LMCT) transition. The excitation into this absorption by resonance Raman (rR) spectroscopy shows an unusual weak $v(\mathrm{O}-\mathrm{O})$ stretching vibration at $\tilde{v}=750 \mathrm{~cm}^{-1}$, compared to $877 \mathrm{~cm}^{-1}$ for neat $\mathrm{H}_{2} \mathrm{O}_{2}$ (cf. Chapter 2 and Table 2.1, p. 16). ${ }^{[15]}$ Due to very strong anti-ferromagnetic coupling between both $d^{9} \mathrm{Cu}^{\text {II }}$ atoms over the peroxo-bridge, the protein is diamagnetic and EPR silent. The $\mathrm{Cu} \cdots \mathrm{Cu}$ separation in oxy-Hc is with $3.59 \AA$ much smaller than in deoxy-Hc.

The unusual spectroscopic parameters and the binding mode of dioxygen in hemocyanin were puzzling until in 1992 a small biomimetic model complex reproducing the spectroscopic properties was crystallographically elucidated by Kitajima, Moro-oka and colleagues (cf. Section 2.2.1 and the crystal structure in Figure 2.1a, p. 18). ${ }^{[16]}$ This spectroscopic and structural model revealed that the peroxide is bound in a novel side-on $\mu-\eta^{2}: \eta^{2}$ fashion (Scheme 1.1), a

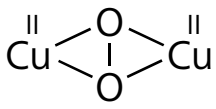

Scheme 1.1 side-on $\mu-\eta^{2}: \eta^{2}$ coordination mode coordination mode that was unknown up to then. Later, the structure of oxy-Hc was solved and was in accordance with the previous model compound. The details of dioxygen-copper interaction will be discussed in Chapter 2 .

\subsection{Activation of Dioxygen by Catalytically Active Copper Enzymes}

The reaction of dioxygen activation is extremely important for living organisms. In the course of time, a series of metalloproteins evolved to execute numerous critical oxidation reactions. Binding is the first step in the activation of oxygen. As it was shown above, hemocyanin reversibly binds dioxygen between two copper atoms, and it is not surprising that some dioxygen-activating copper enzymes share similar active sites with hemocyanin. ${ }^{[17]}$

\subsubsection{The Tyrosinase and Catecholoxidase Families}

Two enzyme families posses a very analogous active site to hemocyanin, tyrosinases (Ty) and catecholoxidases (CO). Both are type 3 copper enzymes, they participate in wound healing and in the immune defence in all known organisms. Ty is a key enzyme in the biosynthesis of the pigment melanin. The functions of 
Figure 1.2

X-ray molecular structure of bacterial oxy-tyrosinase (32 kDa) from Streptomyces castaneoglobisporus at $1.5 \AA$ resolution (PDB ID: 1WX4), ${ }^{[18]}$ $\mathrm{Cu} \cdots \mathrm{Cu} 3.55 \AA$. Colour code: white, protein backbone/carbon; blue, nitrogen; red, oxygen; teal, copper(II).

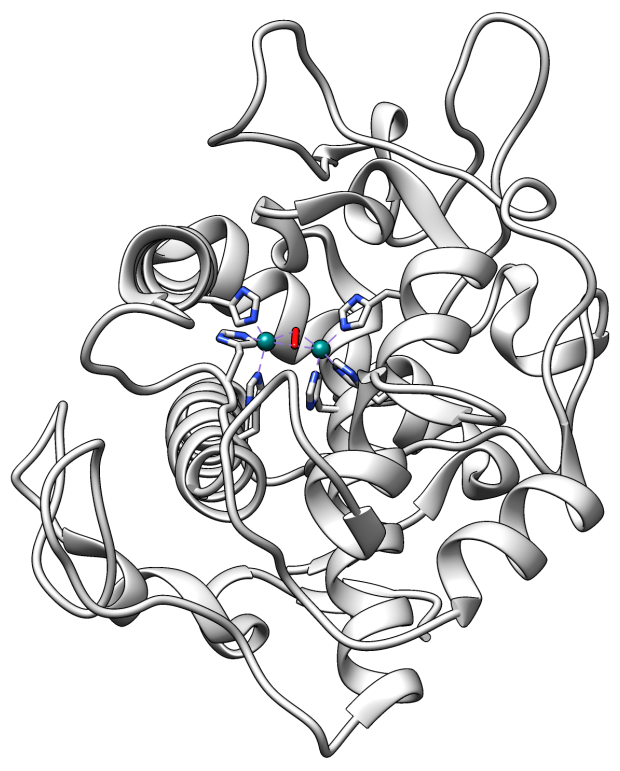

melanin in several organisms are numerous and diverse. Besides the determination of skin, hair and feather colour, it is involved in protection against various threats, such as UV radiation, chemical stresses and biochemical attacks. The enzymatic browning of damaged plant tissue is an example of a defence mechanism against pathogens and insects.

The structural similarities of the active sites are well evident between the crystal structures of Hc and Ty. The structure of oxy-Ty was only elucidated in $2006,{ }^{[18,19]}$ the protein from the bacteria streptomyces castaneoglobisporusis is depicted in Figure 1.2. Apparently, the active site equals that in hemocyanin depicted above.

Scheme 1.2a shows two reactions catalysed by Ty, the oxygenation of the amino acid L-tyrosine to L-DOPA (3,4-dihydroxy-L-phenylalanine), which is subsequently oxidised by Ty to the strong light absorbing L-dopaquinone (3-(3,4-dioxocyclohexa1,5-dien-1-yl)-L-alanine) ${ }^{[2,20,21]}$ The polymer eumelanin is the major (>75\%) component of melanin, besides pheomelanin. It consists of monomers derived from L-dopaquinone via the Mason-Raper pathway (Scheme 1.2b). ${ }^{[2]}$ L-dopaquinone 
(a)

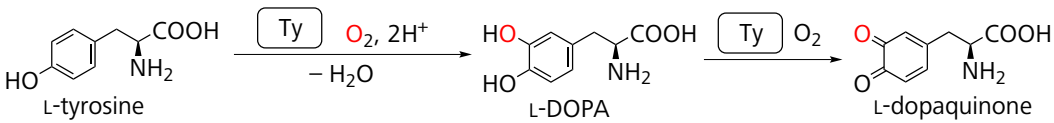

(b)
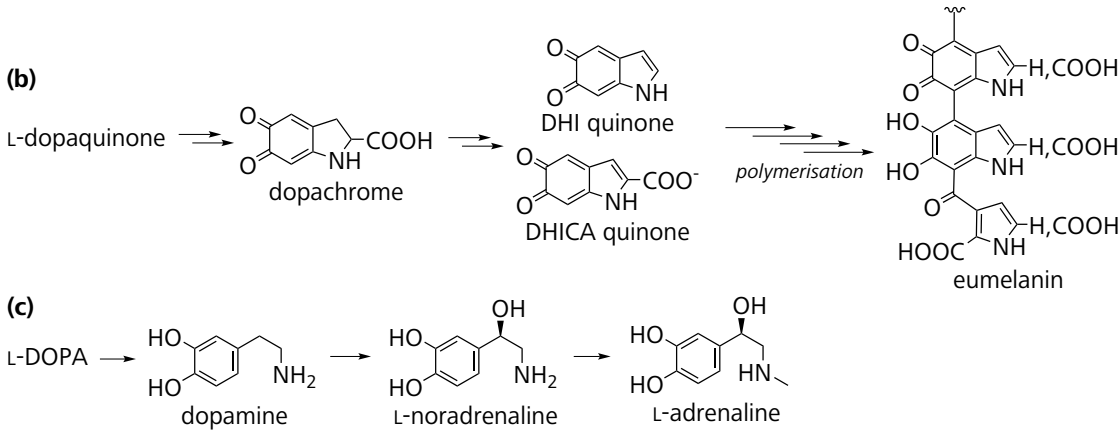

Scheme 1.2 Biosynthesis of L-DOPA, melanin and neurotransmitters. ${ }^{[2,20,21]}$ (a) Ty monooxygenates L-tyrosine to L-DOPA and oxidises L-DOPA to L-dopaquinone. (b) The polymer eumelanin consists of monomers which were formed from L-dopaquinone via the MasonRaper pathway. (c) L-DOPA is the precursor of several neurotransmitters.

forms dopachrome in two steps; dopachrome then decomposes to the catechols 5,6-dihydroxyindole (DHI) or to 5,6-dihydroxyindole-2-carboxylic acid (DHICA), which are then oxidised to the corresponding quinones by either Ty, $\mathrm{CO}$ or by L-dopaquinone. DHI quinone and DHICA quinone autopolymerise finally to form eumelanin. L-DOPA is furthermore the precursor of the neurotransmitters dopamine, L-noradrenalin and L-adrenalin, which are enzymatically synthesised in this sequence (Scheme 1.2c).

\subsubsection{Electrophilic Aromatic Substitution}

Tyrosinase catalyses two reactions, one is the ortho-hydroxylation of monophenols (monophenolase/cresolase activity, Scheme 1.3), yielding o-diphenols (catechols), the second reaction is the two-electron oxidation of catechols to o-quinones (diphenolase/catecholase activity). This reaction is also catalysed by catecholoxidase, which is not able to execute the phenol hydroxylation reaction step. ${ }^{[2,17,22]}$

It was later shown that under laboratory conditions, hemocyanins can indeed show tyrosinase and catecholoxidase activity, too. ${ }^{[23]}$ This finding simplified the 
research on this topic since the oxygen transporter hemocyanin is available in a much larger quantity.

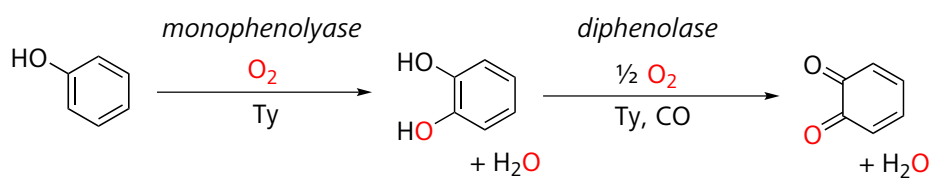

Scheme 1.3 Oxidation of phenols and catechols. Ty catalyses the oxygenation of phenols to $o$-catechols (monophenolase/monooxygenase/cresolase activity) and the subsequent step to $o$-quinones (diphenolase/catechol oxidase activity). CO catalyses only the second step.

\section{Mechanistic considerations}

The tyrosinase reaction in Scheme 1.3 can be described by the two interpenetrating catalytic cycles in Scheme 1.4. ${ }^{[2,19]}$ The diphenolase reaction (Scheme $\left.1.3 \mathrm{right}\right)$ requires two catechol molecules and one dioxygen for each turnover and yields two quinone and two water molecules (oxidation of catechol, no oxygenation reaction). In course of this reaction (outer green cycle in Scheme 1.4), the deoxy- $\mathrm{Cu}_{2}^{\mathrm{I}}$ state is left by the activation of dioxygen to form the $o x y-\mathrm{Cu}_{2}{ }_{2} \mathrm{O}_{2}$ state, which contains the side-on $\mu-\eta^{2}: \eta^{2}$-peroxodicopper(II) ( ${ }^{\mathrm{S}} \mathrm{P}$ ) core. The binding of ortho-catechol leads to the $x y y-D$ state; oxidation of catechol to quinone (reduction of oxygen) and release together with water leads then to the met- $\mathrm{Cu}_{2}{ }_{2}^{\mathrm{II}} \mathrm{OH}$ state (this part is the oxidative phase). The met-tyrosinase reacts further with a second ortho-catechol molecule, leading to the met- $D$ state. Oxidation of catechol (and release of quinone and water) and reduction of $\mathrm{Cu}_{2}{ }_{2}$ to $d e o x y-\mathrm{Cu}_{2}{ }_{2}$ finally closes the cycle (which is the reductive phase). In summary, two catechols are used as $2 \mathrm{e}^{-}$donors to reduce dioxygen by $4 \mathrm{e}^{-}$to water.

The monophenolase reaction (Scheme 1.3 left) has more structural requirements ( $\mathrm{CO}$ is not able to perform this reaction). One phenol and one dioxygen react in an oxygenation reaction to one quinone and one water molecule per turnover. In the course of the reaction (inner blue cycle in Scheme 1.4), the $o x y-\mathrm{Cu}_{2}{ }_{2} \mathrm{O}_{2}$ state is formed analogous to the diphenolase cycle. The phenol substrate is guided by $\pi \pi$ interaction with an imidazole ring of a histidine ligand. It is assumed that it binds directly to one copper atom $\left(\mathrm{Cu}_{\mathrm{A}}\right.$ in $\left.\mathrm{Ty}\right)$ to form the oxy-T state. The hydroxylation step itself is assumed to proceed by an electrophilic aromatic substitution mechanism. This assumption is based on the negative sign of the 
Hammet parameter $\rho$, indicating the building of positive charge in the transition state. However, the point of breakage of the $\mathrm{O}-\mathrm{O}$ bond is currently under debate, particularly to identify the exact nature of the oxygenating species itself (see Section 2.2.5 and ref. [2] for more details). Finally, the catalytic cycle proceeds by re-orientation/rotation of phenol/oxygen and the phenol ortho-carbon is oxygenated by electrophilic attack of oxygen. In the resulting met-D state, the catecholate bridges between both copper atoms together with $\mu-\mathrm{OH}$. Release of water, oxidation of catechol to quinone and reduction of $\mathrm{Cu}_{2}{ }_{2}$ rebuilds the deoxy- $\mathrm{Cu}_{2}^{\mathrm{I}}$ state.

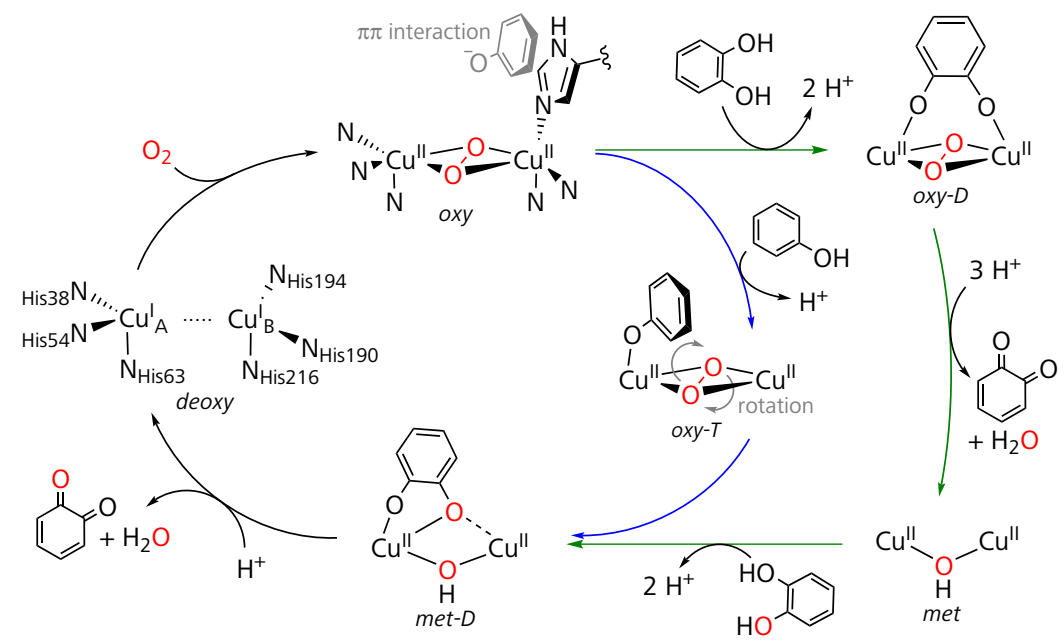

Scheme 1.4 Generally accepted interpenetrating catalytic cycles of mono-oxygenase (monophenolase) activity (blue) and catechol-oxidase (diphenolase) activity (green) in Ty. ${ }^{[2,19]}$ 



\title{
2
}

\section{Bioinorganic Chemistry and the Activation of the Small Molecule Dioxygen}

\begin{abstract}
$M$ ODELS of Metalloenzymes are small molecular synthetic reproductions of the active sites of metalloproteins. These mimics provide insights into the roles of transition metal ions in biology and into the geometric and electronic structures of the enzymes' active sites, thus explaining spectral features. They can furthermore also help to understand reaction pathways. ${ }^{[24,25]}$

In $70 \%$ of all industrially applied oxidation reactions, stoichiometric amounts of metal waste are produced in megaton scales (such as from permanganate and chromate oxidants). By contrast, biological systems provide metalloenzymes to control the oxidising power of atmospheric dioxygen in order to use it for chemical manipulations. Beyond the promotion of understanding of biological systems, model complexes of metalloenzymes might act as predecessors of novel biologically inspired catalysts. These desirable catalysts could eventually act in a sustainable manner, producing environmentally benign byproducts, such as the biological role models. Biomimetic copper-oxygen systems ${ }^{[26-28]}$ are attractive as catalysts for oxidation and oxygenation reactions, thus avoiding expensive transition metals or stoichiometric oxidants.
\end{abstract}

\subsection{The Chemistry of Copper and Oxygen Interaction}

Copper forms coordination compounds in oxidation states of 0 , I, II, III and IV. The most common states are the cuprous copper(I) and the cupric copper(II) states, from which the copper(II) is the by far predominant state. While only a few examples of copper(III) compounds are known, the 0 and IV states are extremely rare in complexes. ${ }^{[29]}$

The $d^{10} \mathrm{Cu}^{\mathrm{I}}$ ion favours linear, trigonal planar and tetrahedral geometries, while for $d^{9} \mathrm{Cu}^{\mathrm{II}}$ either elongated or shortened octahedral coordination geometries are 
most common. Also common are square planar to tetrahedral geometries and fivecoordinated trigonal bipyramidal and square pyramidal geometries. $\mathrm{Cu}^{\mathrm{I}}$ is usually readily oxidised to $\mathrm{Cu}^{\mathrm{II}}$ or disproportionates to $\mathrm{Cu}^{0}$ and $\mathrm{Cu}^{\mathrm{II}}$ in aqueous solution. $d^{8} \mathrm{Cu}^{\text {III }}$ is almost always encountered as a diamagnetic complex in a square planar geometry, although paramagnetic $(S=1)$ species are known. ${ }^{[30,31]}$ While $\mathrm{Cu}^{\mathrm{I}}$ compounds are usually colourless to yellow, $\mathrm{Cu}^{\mathrm{II}}$ complexes are blue to green due to $d \rightarrow d$ transitions around 600-900 $\mathrm{nm}$. Also known are charge-transfer compounds with intense colours, which include also red and brown.

$\mathrm{Cu}^{\mathrm{I}}$ and $\mathrm{Cu}^{\mathrm{II}}$ play crucial roles in biology, and are essential for most organisms. While organometallic $\mathrm{Cu}^{\mathrm{III}}$ complexes play an important role in homogeneous catalysis, ${ }^{[32]} \mathrm{Cu}^{\text {III }}$ was never observed in proteins or living organisms. However, $\mathrm{Cu}^{\mathrm{III}}$ species might play a significant role as reactive intermediates in some reactions catalysed by copper enzymes (see below).

\subsubsection{The Variety of Copper-Dioxygen Species}

Today, a variety of diverse binding modes of dioxygen to metals is known. Examples are $\mathrm{O}_{2}$ end-on-bound to iron in hemoglobin and myoglobin or side-on coordinated to iridium(III). However, all binding modes of $\mathrm{O}_{2}$ can be roughly divided into end-on and side-on bound; to one, two or even more metals. ${ }^{[33]}$ The classification of $\mathrm{Cu} / \mathrm{O}_{2}$ species depending on the $\mathrm{Cu}: \mathrm{O}_{2}$ ratio is additionally practical (as well as the $\mathrm{Cu}$ oxidation state). ${ }^{[34]}$ Scheme 2.1 shows an overview of important $\mathrm{Cu} / \mathrm{O}_{2}$ species sorted by their $\mathrm{Cu}: \mathrm{O}_{2}$ ratios and bonding topologies. Most of these compounds are thermolabile species, which could only be prepared and identified at low temperatures.

\section{$\mathrm{Cu}: \mathrm{O}_{2}$ ratio $=1: 1$}

Assuming the reaction of $\mathrm{O}_{2}$ with $\mathrm{Cu}^{\mathrm{I}}$, a $1 \mathrm{e}^{-}$or $2 \mathrm{e}^{-}$reduction of $\mathrm{O}_{2}$ is possible; indeed both cases are observed together with end-on and side-on binding topologies. The end-on mode $\left(\eta^{1}\right)$ is found in $\mathrm{Cu}^{\mathrm{II}}$ (superoxo) complexes ${ }^{\mathrm{E}} \mathrm{S},{ }^{[35-37]}$ while the side-on $\left(\eta^{2}\right)$ coordination is found in both, $\mathrm{Cu}^{\mathrm{II}}\left(\right.$ superoxo) ${ }^{\mathrm{S}} \mathrm{S}^{[38,39]}$ and $\mathrm{Cu}^{\text {III }}$ (peroxo) ${ }^{\mathrm{M}} \mathrm{P}^{[40-42]}$ complexes.

\section{$\mathrm{Cu}: \mathrm{O}_{2}$ ratio $=2: 1$}

The reaction of the above described $1: 1$ complexes with an additional $\mathrm{Cu}^{\mathrm{I}}$ leads to a final $2 \mathrm{e}^{-}$or $4 \mathrm{e}^{-}$reduction of $\mathrm{O}_{2}$. Three species have been structurally characterized by X-ray diffraction and are of essential importance in copper/dioxygen chemistry and biology. $\mathrm{O}_{2}$ is end-on bridging in the $\mu$-1,2-trans and 1,2-cis-peroxodicopper(II) species ${ }^{\mathrm{T}} \mathbf{P}^{[43]}$ and ${ }^{\mathrm{C}} \mathbf{P}^{[44]}$ and it is side-on coordinated in the $\mu-\eta^{2}: \eta^{2}$ - 


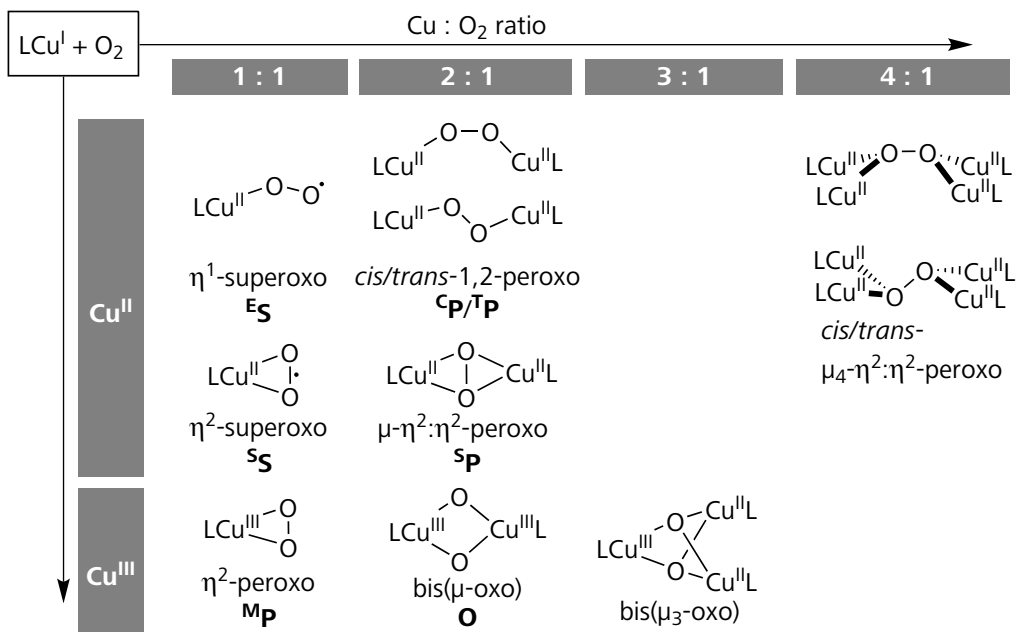

Scheme 2.1 Most important modes of $\mathrm{Cu}_{n}-\mathrm{O}_{2}$ coordination in complexes formed by a reaction of $n \mathrm{Cu}^{\mathrm{I}}$ and $\mathrm{O}_{2}$. ${ }^{\mathrm{E}} \mathbf{S}$, end-on superoxocopper(II); ${ }^{\mathbf{S}} \mathbf{S}$, side-on superoxocopper(II); ${ }^{\mathrm{M}} \mathbf{P}$, peroxocopper(III); ${ }^{\mathrm{C}} \mathbf{P}, \mu$-1,2-cis-peroxodicopper(II); ${ }^{\mathbf{T}} \mathbf{P}, \mu$-1,2-trans-peroxodicopper(II); ${ }^{\mathbf{S}} \mathbf{P}$, $\mu$-side-on peroxodicopper(II); $\mathbf{O}$, bis( $\mu$-oxo) dicopper(III). ${ }^{[28,34]}$

peroxodicopper(II) species ${ }^{S} \mathbf{P} .{ }^{[16,45]}$ Splitting of the O-O bond yields finally bis( $\mu$-oxo)dicopper(III) $\mathrm{O}$ complexes. ${ }^{[46-48]}$ Since complexes possessing $2: 1 \mathrm{Cu}: \mathrm{O}_{2}$ ratios are in focus in this thesis, they will be discussed in detail later.

\section{$\mathrm{Cu}: \mathrm{O}_{2}$ ratio $=3: 1$ and $4: 1$}

The $4 \mathrm{e}^{-}$reduction of $\mathrm{O}_{2}$ by $3 \mathrm{Cu}^{\mathrm{I}}$ leads to a $3: 1$ species comprising a compact mixed-valence trinuclear $\left[\mathrm{Cu}_{2}{ }_{2} \mathrm{Cu}^{\mathrm{III}}\left(\mu_{3}-\mathrm{O}^{2-}\right)_{2}\right]$ cluster. ${ }^{[49]}$ This species might be of relevance to the reduction of $\mathrm{O}_{2}$ at the trinuclear active sites of multicopper oxidases.

The tetranuclear $4: 1$ species $\mu_{4}$-peroxotetracopper(II), with the peroxide ${ } i s^{[50,51]}$ or trans ${ }^{[52]}$ coordinated, are different from the other species. They are indefinitely stable at room temperature and their composition does not equal the $\mathrm{Cu}^{\mathrm{I}} / \mathrm{O}_{2}$ stoichiometry needed for their generation $\left(\mathrm{O}_{2}\right.$ is reduced by $2 \mathrm{e}^{-}$and the $4 \mathrm{Cu}^{\mathrm{I}}$ oxidized by a total of $4 \mathrm{e}^{-}$). 


\subsubsection{Dioxygen Activation}

The $2 \mathrm{e}^{-}$reduction of $\mathrm{O}_{2}$ to peroxide and the $4 \mathrm{e}^{-}$reduction to oxide are both thermodynamically preferred over the $1 \mathrm{e}^{-}$reduction of $\mathrm{O}_{2}$ to the superoxide (Scheme 2.2). Due to this, dimeric complexes are usually yielded in the preparation of copper-oxygen compounds, as $2 \mathrm{Cu}^{\mathrm{I}}$ provide either $2 \mathrm{e}^{-}$or $4 \mathrm{e}^{-}$.

$$
\mathrm{O}_{2} \stackrel{\mathrm{e}^{-}}{\longrightarrow} \mathrm{O}_{2} \cdot-\stackrel{\mathrm{e}^{-}, 2 \mathrm{H}^{+}}{\longrightarrow} \mathrm{H}_{2} \mathrm{O}_{2} \stackrel{\mathrm{e}^{-}, \mathrm{H}^{+}}{\longrightarrow} \mathrm{H}_{2} \mathrm{O}+\mathrm{HO} \cdot \stackrel{\mathrm{e}^{-}, \mathrm{H}^{+}}{\longrightarrow} 2 \mathrm{H}_{2} \mathrm{O}
$$

Scheme 2.2 The four-electron reduction of dioxygen to water.

The extent of $\mathrm{O}_{2}$ reduction is reflected in the $v(\mathrm{O}-\mathrm{O})$ stretching frequency, which increases upon the stepwise weakening and elongation of the $\mathrm{O}-\mathrm{O}$ bond (Table 2.1). $v\left(\mathrm{O}-\mathrm{O}\right.$ ) frequencies determined for gaseous $\mathrm{HO}_{2}{ }_{2}$ and $\mathrm{H}_{2} \mathrm{O}_{2}$ fit well to the frequencies in the respective mononuclear metal-superoxide, $\mathrm{M}\left(\mathrm{O}_{2}^{--}\right)$, and metal-peroxide, $\mathrm{M}-\left(\mathrm{O}_{2}^{2-}\right)$, complexes, as well as the respective $\mathrm{O}-\mathrm{O}$ internuclear distances. However, the bonding situation is found to be more complicated in many $\mathrm{O}_{2}$ complexes. ${ }^{[53]}$

Table 2.1.

$v(\mathrm{O}-\mathrm{O})$ stretching frequencies and $\mathrm{O}-\mathrm{O}$ distances in neutral and reduced dioxygen in comparison with dioxygen dicopper species.

\begin{tabular}{lllllll}
\hline & $\mathrm{O}_{2}$ & $\mathrm{O}_{2}^{--}$ & $\mathrm{O}_{2}{ }^{2-}$ & ${ }^{\mathrm{T}} \mathbf{P}$ & ${ }^{\mathrm{S}} \mathbf{P}$ & $\mathrm{O}$ \\
\hline$v(\mathrm{O}-\mathrm{O}), \mathrm{cm}^{-1}$ & $1556^{a}$ & $1097^{b}$ & $877^{c}$ & $\sim 830$ & $\sim 740$ & $\mathrm{n} / \mathrm{a}$ \\
$r(\mathrm{O}-\mathrm{O}), \AA$ & 1.21 & 1.33 & 1.49 & $\sim 1.43$ & $\sim 1.42$ & $(\sim 2.32)$ \\
$S$ & 1 & $1 / 2$ & 0 & & & \\
\hline${ }^{a} \mathrm{O}_{2}$ vapour. ${ }^{[54]}$ & ${ }^{b} \mathrm{HO}_{2}{ }^{-}$in a discharge flow system. ${ }^{[55]}$ & ${ }^{c} \mathrm{H}_{2} \mathrm{O}_{2}$ vapour. ${ }^{[56]}$
\end{tabular}

\subsection{Synthetic Dicopper-Dioxygen Complexes}

Complexes with a $\mathrm{Cu} / \mathrm{O}_{2}$ stoichiometry of $2: 1$ are the most important and predominant complexes, especially ${ }^{\mathrm{S}} \mathbf{P}, \mathbf{O}$ and ${ }^{\mathrm{T}} \mathbf{P}$ systems. ${ }^{\left[{ }^{34]}\right.}$ Systems with a bis $(\mu$ oxo)dimetal $\left(\mathrm{M}_{2} \mathrm{O}_{2}\right)$ core similar to the $\mathrm{O}$ dicopper systems adopt a typical $\gg$ diamond « shape and these structures are known for manganese and iron as well. Interestingly, a system related to the isomeric ${ }^{\mathrm{S}} \mathbf{P}$ dicopper core is known for neither manganese nor iron compounds. ${ }^{[57]}$ 
The exact nature of $\mathrm{Cu} / \mathrm{O}_{2}$ interaction can depend on several subtleties. Modification of a ligand usually changes the reactivity of copper(I) complexes towards dioxygen dramatically. ${ }^{[58]}$ This can result in the formation of different species, while the ligands are very similar. Thus, the addition of a methyl group to the ligand backbone can yield an $\mathbf{O}$ complex over the ${ }^{\mathrm{S}} \mathbf{P}$ species for example. ${ }^{[59]}$

\subsubsection{Structure and Spectroscopy}

The archetypical spectroscopic and structural features for the important ${ }^{\mathrm{S}} \mathrm{P}, \mathrm{O}$, and ${ }^{\mathrm{T}} \mathbf{P}$ systems are compiled in Table 2.2, their molecular structures are depicted in Figure 2.1.

\section{Biomimetic and Related Structural Model Compounds}

TP mode KARLin et al. reported in $1988,{ }^{[43]}$ for the first time, the X-ray-crystallographically elucidated structure of a copper-dioxygen system. Furthermore, it was established that characterisation of thermally sensitive copper-oxygen compounds is feasible by standard techniques for inorganic complexes. ${ }^{[34]}$ The complex $\left[(\mathrm{tmpa})_{2} \mathrm{Cu}_{2}{ }_{2}\left(\mathrm{O}_{2}\right)\right]^{2+}$ was obtained by reaction of the $\mathrm{Cu}^{\mathrm{I}}$ complex of the tris(2-pyridylmethyl)amine (tmpa) ligand with $\mathrm{O}_{2} . \mathrm{O}_{2}$ is bound in the ${ }^{\mathrm{T}} \mathbf{P}$ coordination mode (Figure 2.1b). In ${ }^{\mathrm{T}} \mathbf{P}$ systems, a peroxide is bound between two copper(II) in a $\mu$-1,2-trans-mode. The $\mathrm{Cu}_{2} \mathrm{O}_{2}$ core in such systems was found to be quite elongated with a $\mathrm{Cu} \cdots \mathrm{Cu}$ separation of $\sim 4.4 \AA$ (Table 2.2). Both $\mathrm{Cu}$ are coordinated in a distorted trigonal-bipyramidal mode $\left(\tau_{5}=0.86\right)$ by the respective tetradentate mononucleating tmpa ligand and $\mathrm{O}_{2}$.

Table 2.2.

Archetypical spectroscopic features and structural parameters of peroxo and $\operatorname{bis}(\mu$-oxo $)$ dicopper species. ${ }^{[34]}$

\begin{tabular}{lllc}
\hline species & $\begin{array}{l}\text { UV-vis: } \lambda, \mathrm{nm} \\
\left(\varepsilon, \mathrm{mM}^{-1} \mathrm{~cm}^{-1}\right)\end{array}$ & $\begin{array}{l}\mathrm{rR}: \tilde{v}, \mathrm{~cm}^{-1} \\
\left(\Delta\left[{ }^{18} \mathrm{O}_{2}\right]\right)\end{array}$ & $\begin{array}{c}\mathrm{Cu} \cdots \mathrm{Cu}, \mathrm{O} \cdots \mathrm{O}, \\
\mathrm{Cu}-\mathrm{O}, \AA\end{array}$ \\
\hline${ }^{\mathrm{S}} \mathbf{P}$ & $360(24), 520(1)$ & $740(40),{ }^{a} 280(1)^{b}$ & $3.51,1.42,1.92$ \\
$\mathrm{~T}_{\mathbf{P}}$ & $530(10), 600(\mathrm{sh}, 7)$ & $830(45),{ }^{a} 555(24)^{c}$ & $4.36,1.43,1.85$ \\
${ }^{\mathrm{C}} \mathbf{P}^{[44]}$ & $500(3), 615(\mathrm{sh})$ & $795,{ }^{a} 445^{c}$ & $3.80,1.50,1.90$ \\
$\mathrm{O}$ & $300(20), 400(24)$ & $600(28)^{c}$ & $2.80,2.32,1.82$ \\
\hline${ }^{a} v(\mathrm{O}-\mathrm{O}) .{ }^{b} v(\mathrm{Cu} \cdots \mathrm{Cu}) .{ }^{c} v(\mathrm{Cu}-\mathrm{O})$. & &
\end{tabular}




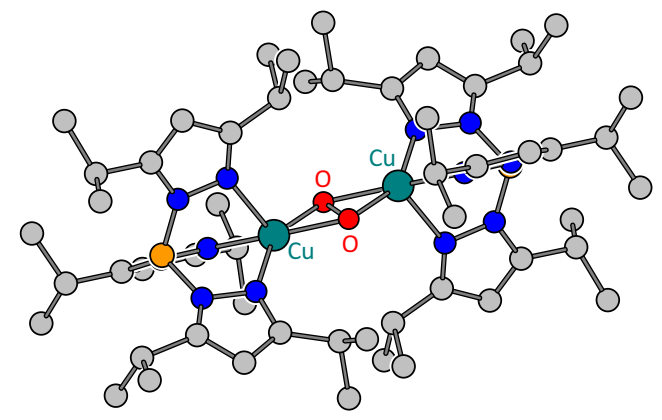

(a) $\mathbf{S} \mathbf{P}$ mode

$\mathrm{Cu} \cdots \mathrm{Cu} 3.56, \mathrm{O}-\mathrm{O} 1.41, \tau_{5}=0.03$

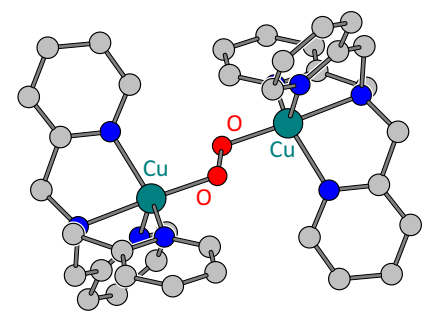

(b) ${ }^{\mathrm{T}} \mathbf{P}$ mode $\mathrm{Cu} \cdots \mathrm{Cu} 4.36, \mathrm{O}-\mathrm{O} 1.43, \tau_{5}=0.86$

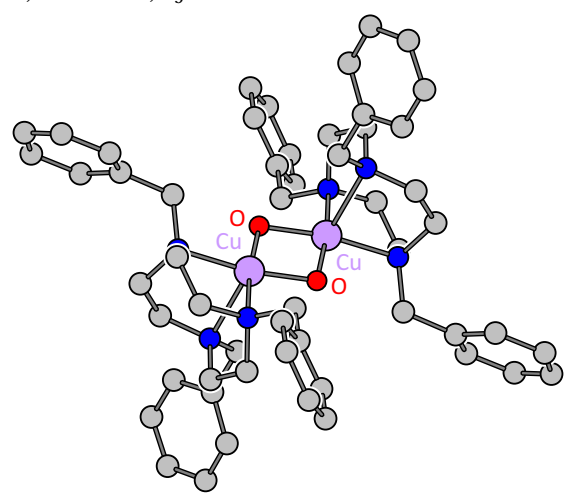

(c) $\mathbf{O}$ mode $\mathrm{Cu} \cdots \mathrm{Cu} 2.79, \mathrm{O} \cdots \mathrm{O} 2.29, \tau_{5}=0.02$

Figure 2.1. X-ray structures and interatomic distances $(\AA)$ of selected $\mathrm{Cu}_{2} \mathrm{O}_{2}$ complexes. (a) Species ${ }^{\mathbf{S}} \mathbf{P}$ : $\left[\left(\mathrm{Tp}^{i \mathrm{Pr} . i \mathrm{Pr}}\right)_{2} \mathrm{Cu}_{2}{ }_{2}\left(\mathrm{O}_{2}\right)\right]$, CSD ID: KECZEX. ${ }^{[16,45]}$ (b) Species ${ }^{\mathrm{T}} \mathbf{P}$ : $\left[(\text { tmpa })_{2} \mathrm{Cu}_{2}{ }_{2}\left(\mathrm{O}_{2}\right)\right]^{2+}$, CSD ID: GECRAH. ${ }^{[43]}(\mathbf{c})$ Species O: $\left[\left(\mathrm{Bz}_{3} \mathrm{tacn}\right)_{2} \mathrm{Cu}{ }^{\mathrm{III}}{ }_{2}(\mathrm{O})_{2}\right]^{2+}$, CSD ID: ZOSXI0. ${ }^{[46,47]}$ Hydrogens are omitted for clarity; colour code: carbon, grey; nitrogen, blue; oxygen, red; boron, orange; copper(II), teal; copper(III), lavender. 
Very recently, the first structurally characterised 1,2 -cis-coordinated $\left({ }^{C} \mathbf{P}\right)$ system was reported by MEYER et al. ${ }^{[44]}$ It is assumed that this coordination mode represents a biologically relevant transition state in the course of $\mathrm{O}_{2}$ activation.

$S_{\mathbf{P}}$ mode Only one year after the KARLIN system, Kitajima et al. reported the structure of a ${ }^{\mathrm{S}} \mathbf{P}$ system. ${ }^{[16,45]}$ The $\mu-\eta^{2}: \eta^{2}$ coordination mode of the peroxide was novel for a transition metal and was not previously anticipated. The complex $\left[\left(\mathrm{Tp}^{i \mathrm{Pr} . i \mathrm{Pr}}\right)_{2} \mathrm{Cu}_{2}{ }_{2}\left(\mathrm{O}_{2}\right)\right]$ (Figure 2.1a) contains anionic hydrotris(3,5diisopropylpyrazolyl)borate $\left(\mathrm{Tp}{ }^{i \mathrm{Pr} . i \mathrm{Pr}}\right)$ ligands. ${ }^{\mathrm{S}} \mathrm{P}$ systems have a $\mathrm{Cu} \cdots \mathrm{Cu}$ separation of $\sim 3.5 \AA$. The X-ray structure of hemocyanin was elucidated shortly after the publication of KITAJIMA's system and fulfilled the predicted ${ }^{S_{P}} \mathbf{P}$ coordination mode. ${ }^{[7]}$

Structural features of ${ }^{S} \mathbf{P}$ complexes will be discussed in more detail in Chapter 6.7. An overview of important features for all ${ }^{\mathrm{S}} \mathbf{P}$ complexes structurally characterized so far, is also provided in Chapter 6.7 (Table 6.9, p. 6.9).

O mode The third and last $\mathrm{Cu}_{2} \mathrm{O}_{2}$ system was discovered by Tolman et al. in 1996. ${ }^{[46,47]}$ The complex $\left[\left(\mathrm{Bz}_{3} \operatorname{tacn}\right)_{2} \mathrm{Cu}_{2}{ }_{2}(\mathrm{O})_{2}\right]^{2+}$ (Figure 2.1c) features an bis $(\mu-$ oxo)dicopper(III) system, which is different to the above, as it contains two $\mathrm{Cu}^{\text {III }}$ and two bridging oxo $\left(\mu-\mathrm{O}^{2-}\right)$ ligands, instead of peroxide and $\mathrm{Cu}^{\mathrm{II}}$. Evidence for the presence of $\mathrm{Cu}^{\mathrm{III}}$ in this system was gained from $\mathrm{Cu}$ K-edge XAS (XANES) measurements (cf. Section 6.7, p. 148). The $\mathrm{O}$ system consists of a quite compact $\mathrm{Cu}_{2} \mathrm{O}_{2}$ core, with a $\mathrm{Cu} \cdots \mathrm{Cu}$ separation of only $\sim 2.8 \AA$ and mononucleating tridentate ligands, aliphatic amine 1,4,7-tribenzyl-1,4,7-triazacyclononane ( $\mathrm{Bz}_{3}$ tacn). In both, ${ }^{\mathrm{S}} \mathbf{P}$ and $\mathrm{O}$ system, the $\mathrm{Cu}$ atoms are coordinated in a square-pyramidal fashion ( $\tau_{5}=0.03$ and 0.02 respectively). Each two nitrogen donors are roughly in plane with the peroxide and the third donor atom is coordinating from an apical position via a weak bonding interaction. Following the discovery of the $\mathrm{O}$ binding mode, an isomeric equilibrium between $\mathbf{O}$ and ${ }^{\mathrm{S}} \mathbf{P}$ systems was detected (outlined below) and more examples of $\mathbf{O}$ complexes are known today than for any other copper-oxygen species. ${ }^{[34]}$

An immense number of studies demonstrate, that $\mathrm{O}_{2}$ is usually coordinated in an end-on fashion in complexes incorporating tetradentate tripodal ligands, while side-on coordination is favoured in complexes with bi- and tridentate ligands. ${ }^{[34,60]}$ Despite all three systems being electronic isomers, they are fundamentally different in their coordination mode and geometric parameters, as well as in their spectroscopic features (cf. Table 2.2). ${ }^{[34]}$ 


\section{Bioinorganic Chemistry and the Activation of Dioxygen}

\section{Electronic Structure and Spectroscopic Features}

Since $\mathrm{Cu}_{2} \mathrm{O}_{2}$ compounds are usually very labile, the assignment as the respective species is based primarily on intense and distinctive UV-vis features at low temperatures. See Table 2.2 for a comparison of the respective UV-vis and resonance Raman (rR) features. The electronic structures of the peroxo species are quite related, and so are the origins of their UV-vis spectroscopic absorptions. The approximate molecular orbital diagram of ${ }^{\mathrm{S}} \mathrm{P}$ in Figure 2.2 is therefore quite similar to that of $\mathrm{a}^{\mathrm{T}} \mathbf{P}$ species. The optical spectra are directly related to the respective $\mathrm{Cu}_{2} \mathrm{O}_{2}$ binding modes.

${ }^{\mathbf{T}} \mathbf{P}$ mode 1,2 -bound $\left(\right.$ trans ${ }^{\mathrm{T}} \mathbf{P}$ and cis ${ }^{\mathrm{C}} \mathbf{P}$ ) peroxo species are usually purple and show a strong absorption at around $530 \mathrm{~nm}\left(\epsilon \approx 10000 \mathrm{M}^{-1} \mathrm{~cm}^{-1}\right)$ together with $\mathrm{a} \sim 600 \mathrm{~nm}\left(\sim 7000 \mathrm{M}^{-1} \mathrm{~cm}^{-1}\right)$ shoulder. ${ }^{[34,44]}$ These features have previously been ascribed to $\pi_{\sigma}^{*} \rightarrow d_{x^{2}-y^{2}}$ and $\pi_{v}^{*} \rightarrow d_{x^{2}-y^{2}}$ (peroxo $\rightarrow \mathrm{Cu}^{\mathrm{II}}$ ) charge transfer (CT) transitions, respectively. ${ }^{[61,62]}$ Irradiating into the CT transition with laser light results in $\mathrm{rR}$ spectra with two oxygen-isotope-sensitive bands, a $v(\mathrm{O}-\mathrm{O})$ stretch at $\sim 830 \mathrm{~cm}^{-1}\left(\Delta\left[{ }^{18} \mathrm{O}_{2}\right] \approx 45 \mathrm{~cm}^{-1}\right)$ and a $v(\mathrm{Cu}-\mathrm{O})$ vibration at $\sim 555 \mathrm{~cm}^{-1}\left(\Delta\left[{ }^{18} \mathrm{O}_{2}\right]\right.$ $\left.\approx 24 \mathrm{~cm}^{-1}\right)$. Compare also Table 2.1 on page 16 .

SP mode $\mu-\eta^{2}: \eta^{2}$-side-on-bound peroxo species show a high-energy and highintensity UV-vis CT transition at around 340-380 $\mathrm{nm}\left(\epsilon \approx 18000-25000 \mathrm{M}^{-1} \mathrm{~cm}^{-1}\right)$, together with a weaker transition at 510-550 $\mathrm{nm}\left(\sim 1000 \mathrm{M}^{-1} \mathrm{~cm}^{-1}\right) .{ }^{[34]}$ Solomon et al. assigned both transitions to peroxo $\rightarrow \mathrm{Cu}^{\mathrm{II}}$ transitions. The $\sim 350 \mathrm{~nm}$ feature as the in-plane $\pi_{\sigma}^{*} \rightarrow d_{x^{2}-y^{2}}$ and the $\sim 530 \mathrm{~nm}$ feature as the out-of-plane $\pi_{v}^{*} \rightarrow d_{x^{2}-y^{2}}$ transition (Figure 2.2, left). ${ }^{[62-65]}$ The $\sim 25$-times higher intensity of the highenergy feature is explained by a better overlap of the copper $d_{x^{2}-y^{2}}$ orbitals with the peroxo in-plane $\pi_{\sigma}^{*}$ orbital, than with the out-of-plane $\pi_{v}^{*}$ orbital. Compared to ${ }^{\mathrm{T}} \mathbf{P}$, the peroxide in ${ }^{\mathrm{S}} \mathbf{P}$ has two additional donor interactions with $\mathrm{Cu}^{\mathrm{II}}{ }_{2}$; this leads to the higher energy and intensity of the $\pi_{\sigma}^{*} \rightarrow d_{x^{2}-y^{2}}$ transition. Due to this stronger donor interaction, a higher energy $v(\mathrm{O}-\mathrm{O})$ stretch would be expected in the ${ }^{\mathrm{S}} \mathbf{P}$ species compared to ${ }^{\mathrm{T}} \mathbf{P}$, since more electron density is removed from the $\pi^{*}$ orbital. However, a decreased-energy vibration is found on the contrary at around $\sim 730-760 \mathrm{~cm}^{-1}\left(\Delta\left[{ }^{18} \mathrm{O}_{2}\right] \approx 40 \mathrm{~cm}^{-1}\right)$, which is typical for ${ }^{\mathrm{S}} \mathbf{P}$ species. The reason is an additional backbonding interaction, unique in the ${ }^{\mathrm{S}} \mathrm{P}$ species. The occupied copper-based HOMO shifts electron density into the unoccupied peroxo higher-energy $\sigma^{*}$ orbital (Figure 2.2, left), efficiently weakening the $\mathrm{O}-\mathrm{O}$ bond and providing a pathway to cleave this bond eventually. ${ }^{[5]}$ The large splitting 
between LUMO and HOMO results in a strongly antiferromagnetically-coupled singlet ground state.

O mode Moving from the ${ }^{\mathrm{S}} \mathrm{P}$ species to the $\mathrm{O}$ species, the $\mathrm{O}-\mathrm{O}$ bond is elongated and the peroxo $\sigma^{*}$ orbital, which is involved in backbonding as described above, decreases in energy (Figure 2.2, right). The $\sigma^{*}$ orbital finally oxidises the copper-based HOMO and becomes occupied resulting in a dicopper(III) system and fully reduced two $\mathrm{O}^{2-}$. This different electronic structure gives rise to a new lower-energy UV-vis feature at $\sim 400 \mathrm{~nm}\left(\epsilon \approx 24000 \mathrm{M}^{-1} \mathrm{~cm}^{-1}\right)$ resulting from a $\sigma^{*} \rightarrow d_{x^{2}-y^{2}}$ CT transition; with a high intensity due to a good overlap of the $\sigma^{*}$ and the $d_{x^{2}-y^{2}}$ orbitals. A second feature at $\sim 300 \mathrm{~nm}\left(\sim 10000 \mathrm{M}^{-1} \mathrm{~cm}^{-1}\right)$ results from a $\pi_{\sigma}^{*} \rightarrow d_{x^{2}-y^{2}}$ CT transition, similar to ${ }^{\mathrm{S}} \mathbf{P}$ and ${ }^{\mathrm{T}} \mathbf{P}$ species. ${ }^{[66]}$ A significant covalency in the $\mathrm{Cu}-\mathrm{O}$ bonds results in the observed high intensities of both features. No O-O stretch can be observed anymore by rR spectroscopy, $\mathrm{O}$ complexes

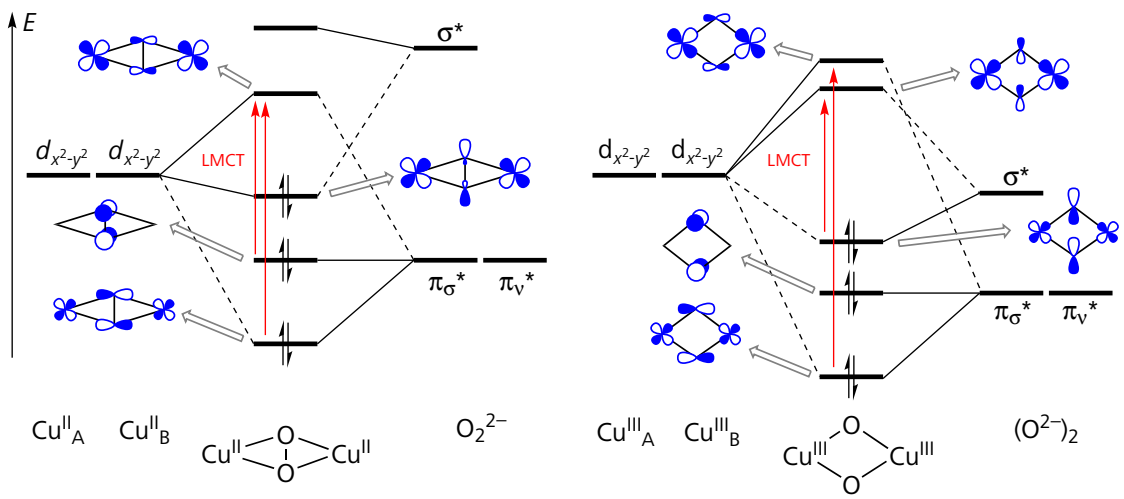

Figure 2.2. Schematic molecular orbital diagrams for the side-on $\left(\mu-\eta^{2}: \eta^{2}\right)$ peroxide-bridged dicopper(II) species ${ }^{\mathbf{S}} \mathbf{P}$ (left) and bis( $\mu$-oxo)-bridged dicopper(III) species $\mathbf{O}$ (right). The red arrows on the left indicate the assigned UV-vis features in ${ }^{\mathbf{S}} \mathbf{P}$, in-plane $\pi_{\sigma}^{*} \rightarrow d_{x^{2}-y^{2}}$ and out-of-plane $\pi_{v}^{*} \rightarrow d_{x^{2}-y^{2}}$ (peroxo $\rightarrow \mathrm{Cu}^{\prime \prime}{ }_{2}$ ) CT transitions for the $\sim 350$ and $\sim 530 \mathrm{~nm}$ features, respectively. The red arrows on the right indicate features in $\mathbf{O} ; \sigma^{*} \rightarrow d_{x^{2}-y^{2}}$ and $\pi_{\sigma}^{*} \rightarrow d_{x^{2}-y^{2}}$ (oxo $\rightarrow \mathrm{Cu}^{\text {III }}$ ) CT transitions for the $\sim 400$ and $\sim 300 \mathrm{~nm}$ transitions, respectively. The diagram is redrawn in analogy to refs. [5, 34]. 
show however a characteristic vibration at $\sim 600 \mathrm{~cm}^{-1}\left(\Delta\left[{ }^{18} \mathrm{O}_{2}\right] \approx 28 \mathrm{~cm}^{-1}\right)$. This feature was assigned as the $\mathrm{Cu}_{2} \mathrm{O}_{2}$ symmetric core stretch $v_{\mathrm{s}}(\mathrm{Cu}-\mathrm{O}) .{ }^{[57,66]}$

Regarding the phenol hydroxylation activity of copper-oxygen systems, copperbased LUMOs are available for an electrophilic attack onto an aromatic ring, such as contained in phenols. Namely the symmetric combination of $\mathrm{Cu} d_{x^{2}-y^{2}}$ and peroxo $\pi_{\sigma}^{*}$ in ${ }^{\mathrm{S}} \mathbf{P}$ species and the antisymmetric combination of $\mathrm{Cu} d_{x^{2}-y^{2}}$ and oxo $\sigma^{*}$ in $\mathrm{O}$ species in Figure 2.2, which have a significant oxygen character.

Spectroscopic features of ${ }^{\mathrm{S}} \mathbf{P}$ and $\mathbf{O}$ complexes will be additionally discussed in Chapters 6 and 7, respectively. An overview of important features for all ${ }^{S_{P}}$ complexes structurally characterized so far, will also be provided in Chapter 6.7 (Table 6.9, p. 6.9).

\subsubsection{The Isomeric Equilibrium of ${ }^{S} P$ and $O$ Complexes}

Tolman et al. evidenced that $\mathbf{O}$ species can be in an equilibrium with the isomeric ${ }^{\mathrm{S}} \mathrm{P}$ compound, ${ }^{\mathrm{S}} \mathrm{P} \rightleftharpoons \mathrm{O}$ (Scheme 2.3). ${ }^{[46]}$ Thus, the $\mathrm{O}-\mathrm{O}$ bond is reversibly made and broken. The rapid equilibrium was investigated by kinetic studies. ${ }^{[67,68]}$ OBIAs et al. reported that in phenol hydroxylation reactions with a complex, present with ${ }^{\mathrm{S}} \mathbf{P}$ and $\mathbf{O}$ in equilibrium, the active species is the ${ }^{\mathrm{S}} \mathbf{P}$ isomer (see below for further details on reactive $\mathrm{Cu}_{2} \mathrm{O}_{2}$ systems). ${ }^{[69]}$ The presence or absence of the $\mathrm{O}-\mathrm{O}$ bond and the position of the equilibrium is influenced by steric demand of the ligands, counteranion, solvent and electronic effects. ${ }^{[34,70]}$

Steric demand In a family of ligands, an increased steric demand destabilises $\mathrm{O}$ vs. ${ }^{\mathrm{S}} \mathbf{P}$ isomer, since the $\mathrm{O}$ core is more compact than the ${ }^{\mathrm{S}} \mathbf{P}$ core $(\mathrm{Cu} \cdots \mathrm{Cu} \sim 2.8$ vs. $\sim 3.5 \AA$ ). Formation of exclusively an $\mathrm{O}$ complex was found in particular for the

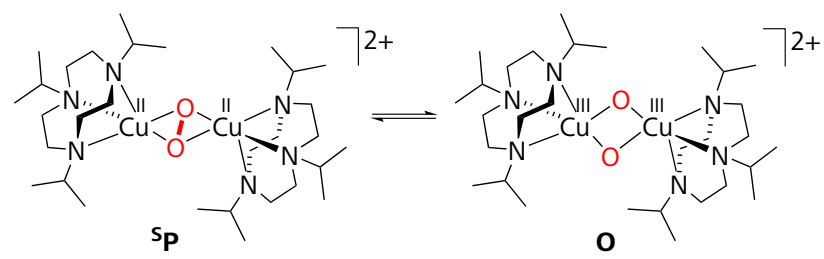

Scheme 2.3 Equilibrium of $\mu-\eta^{2}: \eta^{2}$-peroxodicopper(II) ${ }^{\mathbf{S}} \mathbf{P}$ and bis( $\mu$-oxo)dicopper(III) $\mathbf{O}$ isomers with $\mathrm{L}^{i \mathrm{Pr}_{3}}$ ligand. ${ }^{[46]}$ 
simplest tri- and bidentate aliphatic amine ligands, such as simple cyclohexyl- (cd) and propylene-diamines (pd), as well as for triazacyclononane (tacn) and -decane (tacd) ligands.

Counterion The weaker-coordinating the counterion is, the more the equilibrium is shifted towards the $\mathrm{O}$ isomer (weaker are $\mathrm{TfO}^{-}, \mathrm{MsO}^{-}$; stronger are $\mathrm{SbF}_{6}^{-}$, $\mathrm{BF}_{4}^{-}, \mathrm{BArF}^{-}$). The $\mathrm{Cu}^{\mathrm{II}}\left({ }^{\mathrm{S}} \mathrm{P}\right.$ isomer) has a higher tendency to bind axial ligands than $\mathrm{Cu}^{\mathrm{III}}$, and the smaller size of the $\mathrm{Cu}_{2} \mathrm{O}_{2}$ core in $\mathrm{O}$ also complicates their coordination.

Solvent polarity The more polar the solvent is, the more is the $\mathrm{O}$ isomer favoured. Assuming the counterion- $\mathrm{Cu}_{2} \mathrm{O}_{2}$ interaction, such adduct would be less stabilised in polar solvents, due to its lowered charge.

Electronic effects The more electron-donating the ligand or the substituents are, the more the higher charged $\mathrm{Cu}^{\mathrm{III}}$ oxidation state in the $\mathrm{O}$ isomer is stabilised.

\subsubsection{Self-Assembly of the $\mathrm{Cu}_{2} \mathrm{O}_{2}$ Core}

In analogy to the threefold coordination of $\mathrm{Cu}^{\mathrm{I}}$ in Type 3 copper enzymes, the samples in the preceding section showed that tridentate ligand systems, as well as ligands with two separated tridentate moieties, have been successfully applied in the synthesis of $\mathrm{Cu}_{2} \mathrm{O}_{2}$ complexes over the past few decades. Almost all complexes are only stable at low temperatures of $-80^{\circ} \mathrm{C}$, including the synthetic biomimetic peroxo $\left({ }^{\mathrm{S}} \mathrm{P}\right)$ systems.

The $\mathrm{Cu}_{2} \mathrm{O}_{2}$ core is formed in a self-assembly process out of two ligand-supported copper(I) and one $\mathrm{O}_{2}$. Self-assembly is widespread in living systems, prominent examples are lipid bilayers, DNA, the tobacco mosaic virus and iron-sulphur clusters in proteins; an example of a synthetic system are e. g. host-guest complexes. ${ }^{\text {[71-73] }}$ Recently it was shown by STACK and coworkers that ${ }^{S} \mathbf{P}$ complexes analogous to oxy-tyrosinase form through the self-assembly of two $\left[\mathrm{Cu}^{\mathrm{I}}(\mathrm{MeCN})_{4}\right] \mathrm{SbF}_{6}, \mathrm{O}_{2}$ and six simple imidazoles as monodentate ligands in 2-methyl-tetrahydrofuran (MeTHF) solvent (Scheme 2.4a). ${ }^{[74]}$ However, temperatures as low as $-125^{\circ} \mathrm{C}$ are necessary to accomplish the entropically disfavoured association. These ${ }^{\mathrm{S}} \mathbf{P}$ complexes were able to perform the electrophilic oxidation of exogenous phenolic substrates to catechols, too. It was suggested, that the role of the protein framework is mainly to preclude oxidative degradation pathways and to bear the entropic costs of $\mathrm{Cu}_{2} \mathrm{O}_{2}$ core assembly. 
This self-assembly reaction is reminiscent of the formation of iron-sulphur clusters (Scheme 2.4b). ${ }^{[75,76]}$ It could be shown that in the case of synthetic analogues, $\left[\mathrm{Fe}_{2} \mathrm{~S}_{2}\right]^{2+/+}$ and $\left[\mathrm{Fe}_{4} \mathrm{~S}_{4}\right]^{2+/+}$ clusters are the main products of self-assembly reactions with monodentate thiols and are stable in the absence of a protein matrix at room temperature. ${ }^{[77]}$

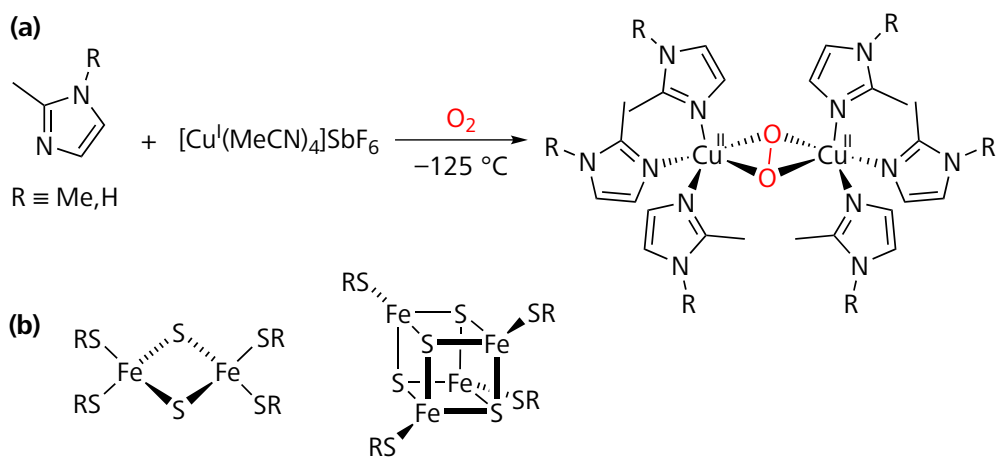

Scheme 2.4 (a) Self-Assembly of the $\mathrm{Cu}_{2} \mathrm{O}_{2}$ Core. ${ }^{[74]}$ (b) $\left[\mathrm{Fe}_{2} \mathrm{~S}_{2}\right]^{2+/+}$ and $\left[\mathrm{Fe}_{4} \mathrm{~S}_{4}\right]^{2+/+}$ clusters formed out of self-assembly reactions.

\subsubsection{Kinetics and Thermodynamics of $\mathrm{O}_{2}$ Activation}

The formation of copper-oxygen species from copper(I) and $\mathrm{O}_{2}$ is described by the general mechanistic framework in Scheme 2.5. ${ }^{[60]}$ Upon binding of $\mathrm{O}_{2}$ to a single $\mathrm{Cu}^{\mathrm{I}}$, a $1: 1$ complex is initially formed. This association is usually entropically strongly disfavoured due to the loss of translational and rotational degrees of freedom, while the strong copper-oxygen interaction is enthalpically favoured. Thus, the association process is usually only feasible at strongly decreased temperatures. Due to often very rapid reactions, the cryo-stopped-flow technique is predominately applied to enlighten kinetic problems in copper-oxygen chemistry (cf. Section 6.4.1). ${ }^{\text {78] }}$

While in some cases the $1: 1$ adduct is the final product, $\mathrm{LCu}\left(\mathrm{O}_{2}\right)$ usually reacts with an additional $\mathrm{LCu}^{\mathrm{I}}$ complex to form a dimeric $2: 1 \mathrm{Cu}_{2} \mathrm{O}_{2}$ complex. $3: 1$ and $4: 1 \mathrm{Cu} / \mathrm{O}_{2}$ species are formed from further reactions with $\mathrm{Cu}^{\mathrm{I}}$. Both processes are equilibria, respectively; they can be more or less balanced. Depending on the 
particular rate and equilibrium constants, several kinetic scenarios are possible, which allow detailed insights in the subtleties of copper and oxygen interaction. These scenarios will be discussed in more detail in Section 6.4.

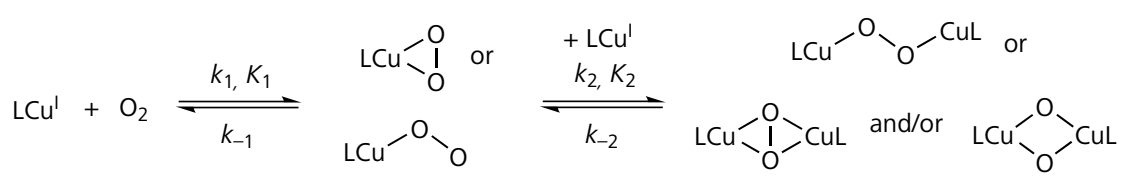

Scheme 2.5 Kinetics of $\mathrm{O}_{2}$ activation.

\subsubsection{Functional Model Compounds: Reactivity Towards Endogenous and Exogenous Substrates}

Dioxygen is an ubiquitously available and environmentally benign oxidant. Nevertheless, for oxygen-insertion reactions, synthetic chemists usually have to rely on particular reagents. Reagents, such as paraformaldehyde ${ }^{[79]}$ or 2-iodoxybenzoic acid (IBX) ${ }^{[80]}$ in the ortho-hydroxylation of phenols for example. Reactions that use dioxygen directly are still extremely rare. Therefore, it is well worth the effort, to emulate the reactions performed by metalloproteins, such as tyrosinase, exploiting $\mathrm{O}_{2}$ as an oxidant.

Behind the bioinorganic background of copper in metalloenzymes, catalysing oxidation and oxygenation reactions, the reactivity of synthetic copper-dioxygen systems towards exogenous substrates has been extensively investigated. ${ }^{[60,81-86]}$ Furthermore, reactions involving the oxidation of (endogenous) ligands have been observed in some systems and have also gained attention.

\section{Endogenous Arene Hydroxylation}

Binuclear ligand systems, consisting of two para- or meta-xylyl linked pockets are famous model systems for the study of $\mathrm{O}_{2}$ activation by a $\left\{\mathrm{Cu}^{1} \mathrm{Cu}^{1}\right\}$ complex. These systems are capable of forming ${ }^{\mathrm{S}} \mathrm{P}$ complexes and other $\mathrm{Cu}_{2} \mathrm{O}_{2}$ species. ${ }^{[34,60]}$

KARLIN et al. intensively investigated complexes with the Py2- $m$-XYL ${ }^{\mathrm{R}}(\mathrm{R} \equiv$ $\mathrm{H}, t \mathrm{Bu}, \mathrm{OMe}, \mathrm{CN}, \mathrm{NO}_{2}$ ) ligand system depicted in Scheme 2.6. ${ }^{\left[{ }^{[8-92]}\right.}$ These systems are additionally capable of arene hydroxylation in an intramolecular (ligand degradation) reaction, in analogy to intermolecular phenol hydroxylation. ${ }^{[60]}$ The stability of the $\mathrm{Cu}_{2} \mathrm{O}_{2}$ complex increases, the more the residue $\mathrm{R}$ is electron withdrawing. They were identified as ${ }^{\mathrm{S}} \mathbf{P}$ complexes by resonance Raman spec- 


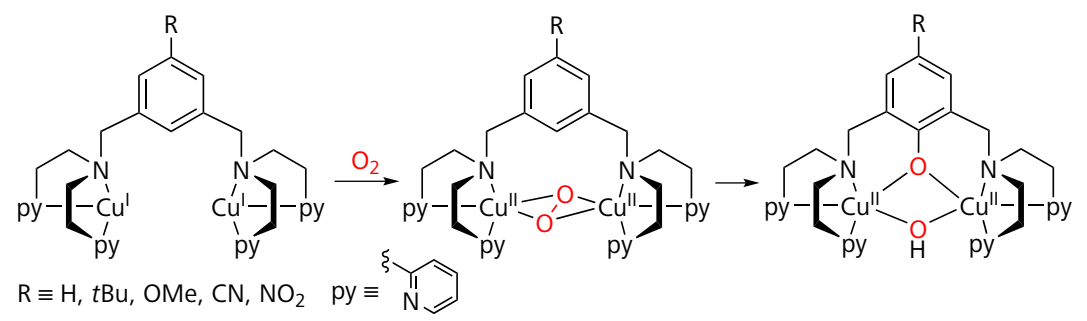

Scheme 2.6 Endogenous arene hydroxylation. $\mathrm{O}_{2}$ is activated by $\mathrm{Cu}^{\prime}$ complexes of Py2-m$\mathrm{XYL}^{\mathrm{R}}$ ligands yielding ${ }^{\mathbf{S}} \mathbf{P}$ complexes, which subsequently decay and hydroxylate the arene ligand.

troscopy with ligand $\mathrm{Py} 2-m-\mathrm{XYL} \mathrm{NO}_{2}$; at room temperature the arene ring was hydroxylated (thermal decay of the ${ }^{\mathrm{S}} \mathbf{P}$ complex) and it was evidenced that the active (hydroxylating) species is the ${ }^{\mathrm{S}} \mathbf{P}$ isomer. The presence of an $\mathrm{O}$ species could not be detected. ${ }^{[92]}$

\section{Catalytic Phenol Hydroxylation}

While the simple oxygenation of phenols to the respective catechols is regiospecifically performed by tyrosinase, this transformation is difficult to perform in the laboratory. In other words, only poor yields are usually gained from more or less non-selective multi-step reactions. ${ }^{[79,93-96]}$

Examples of biomimetic model systems, which are capable of stoichiometrically hydroxylating phenols by a ${ }^{\mathrm{S}} \mathbf{P}$ system, in analogy to tyrosinase, are quite limited. ${ }^{[74,97-100]}$ Systems, which catalytically perform the Phenol hydroxylation are extremely rare. In 1991, CASELLA et al. ${ }^{[100,101]}$ reported a system containing the binucleating $m$-xylene-bridged ligand $\alpha, \alpha^{\prime}$-bis\{bis[2-(1-methylbenzimidazol-2yl)ethyl]amino\}- $m$-xylene (L66, Scheme $2.7 \mathrm{a}$ ). However only a turnover number of TON = 1.2 could be achieved with electron-rich 2,4-di-tert-butylphenol (DBP). Shortly before, in 1990, RÉGLIER et al. ${ }^{[102]}$ developed another binucleating ligand, Bis-2,2' - [2-(pyrid-2-yl)ethyl]iminobiphenyl (BiPh(impy) $)_{2}$ ), with biphenyl spacer and pyridylethylimine sidearms (Scheme 2.7b). In the oxidation of DBP to 3,5-ditert-butyl-o-quinone (DBQ), in presence of $\mathrm{Et}_{3} \mathrm{~N}$, a turnover number (TON) of 16 was achieved.

Much later, in 2010, a third system was developed by TUCzEK et al., now applying mononucleating ligands. The ligands [2-(aryl)ethyl]imino-tert-butane, can be considered as a mononucleating part (side-arm) of the $\mathrm{BiPh}(\mathrm{impy})_{2}$ system 

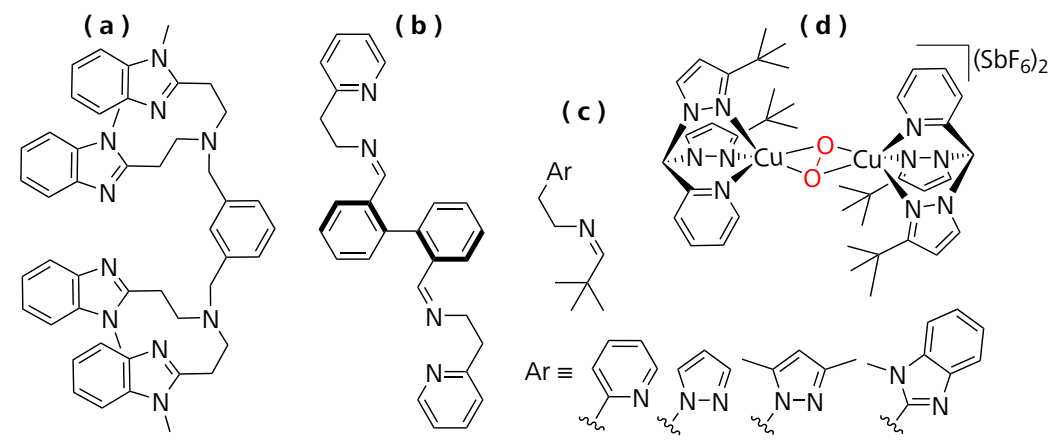

Scheme 2.7 Ligand systems used for catalytic phenol hydroxylation by $\mathrm{Cu}^{\prime}$ complexes and $\mathrm{O}_{2}$ as oxidant. (a) L66 binucleating ligand by CASELLA, ( b ) BiPh(impy) ${ }_{2}$ binucleating ligand by Réglier. (c) Mononucleating ligands by Tuczek. (d) The defined ${ }^{\mathbf{S}} \mathbf{P}$ complex used by Herres-Pawlis and Stack.

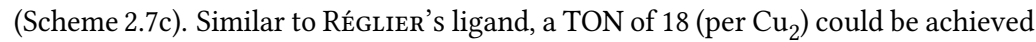
in the oxidation of DBP to DBQ and in presence of $\mathrm{Et}_{3} \mathrm{~N}$ with the aryl $\equiv 2$-pyridyl ligand. ${ }^{[103]}$ Based on these results, the highest TON of 31 was achieved with the aryl $\equiv$ 1-methyl-2-benzimidazolyl ligand. ${ }^{[104,105]}$

However, only in the case of the L66 ligand a copper-oxygen system could be identified as the active species, namely containing the ${ }^{\mathrm{S}} \mathbf{P}$ core. Just recently in 2013, Herres-Pawlis and StACK developed a new biomimetic $\mu-\eta^{2}: \eta^{2}$-peroxodicopper(II) system, ${ }^{[106]}$ based on a bis(pyrazolyl)(2-pyridyl)methane mononucleating ligand. ${ }^{[107]}$ The dimeric $\mathrm{Cu}_{2} \mathrm{O}_{2}$ complex (Scheme $2.7 \mathrm{~d}$ ) is formed from [ $\mathrm{Cu}^{\mathrm{I}}\left\{\right.$ bis(3-tert-butyl-pyrazolyl)pyridyl-methane\}] $\mathrm{SbF}_{6}$ and $\mathrm{O}_{2}$ in $\mathrm{CH}_{2} \mathrm{Cl}_{2}$ and was identified by UV-vis and resonance Raman spectroscopy, as well as by cryo-ESITOF mass spectrometry. Surprisingly, the complex is room-temperature-stable, but decays irreversibly with a half-life of $30 \mathrm{~min}$. The complex is capable to stoichiometrically oxygenate a range of para-substituted phenolates to the respective catecholates at $-78^{\circ} \mathrm{C}$ in a reaction that follows the enzymatic electrophilic aromatic substitution mechanism, based on a negative slope of the Hammett parameter $\rho$. Furthermore, the $\mathrm{Cu}_{2} \mathrm{O}_{2}$ complex is capable to catalytically oxidise phenols to quinones at room temperature in the presence of $\mathrm{Et}_{3} \mathrm{~N}$ with TONs up to 15 . 


\section{An Alternative Hydroxylation Mechanism}

As mentioned above, experiments agree with an electrophilic aromatic substitution mechanism as the main step in phenol hydroxylation by the ${ }^{\mathrm{S}} \mathrm{P} \mathrm{Cu}_{2} \mathrm{O}_{2}$ cores. This was confirmed in both, enzymatic systems and model compounds. There is some ambiguity about the nature of the hydroxylating $\mathrm{Cu}_{2} \mathrm{O}_{2}$ itself. As there is an equilibrium between ${ }^{\mathrm{S}} \mathrm{P}$ and $\mathrm{O}$ species which was observed in some synthetic compounds (as discussed above, Section 2.2.2), it might be assumed that the $\mathbf{O}$ species participates in some way in the substrate hydroxylation step.

STACK and coworkers indeed observed the vanishing of a secondary aminecoordinated ${ }^{\mathrm{S}} \mathbf{P}$ complex ${ }^{[99,108]}$ and formation of the respective $\mathbf{O}$ isomer in a phenol monooxygenation reaction (Scheme 2.8). ${ }^{[109]} \mathrm{O}-\mathrm{O}$ bond cleavage was evidenced spectroscopically by resonance Raman, upon substrate coordination to the ${ }^{\mathrm{S}} \mathrm{P} \mathrm{Cu} \mathrm{Cu}_{2}$ core. However, cryogenic temperatures as low as $-120^{\circ} \mathrm{C}$ were necessary to observe this discrete intermediate in the phenol hydroxylation mechanism in 2-methyltetrahydrofuran (MeTHF). The secondary amine ligand $N, N^{\prime}$-di-tertbutylethylenediamine was applied, which contains two steric demanding $t \mathrm{Bu}$ groups, shielding the sensitive $\mathrm{Cu}_{2} \mathrm{O}_{2}$ core. Upon warming, the phenol substrate, DBP was hydroxylated to the respective $o$-catechol $(30 \%)$ and $o$-quinone $(30 \%)$ products in an electrophilic aromatic substitution mechanism, by the newly formed $\mathbf{O}$ core, which is the active species in this reaction. ${ }^{[33,109]}$

DFT calculations of the reaction coordinate showed that phenolate is first axially bound and a subsequent rotation into the plane equatorial to the $\mathrm{Cu}_{2} \mathrm{O}_{2}$ core is necessary for formation of the active $\mathrm{O}$ species. This rotation orients the phenolate's ortho-carbon in a suitable position for the electrophilic attack. ${ }^{110]}$ 


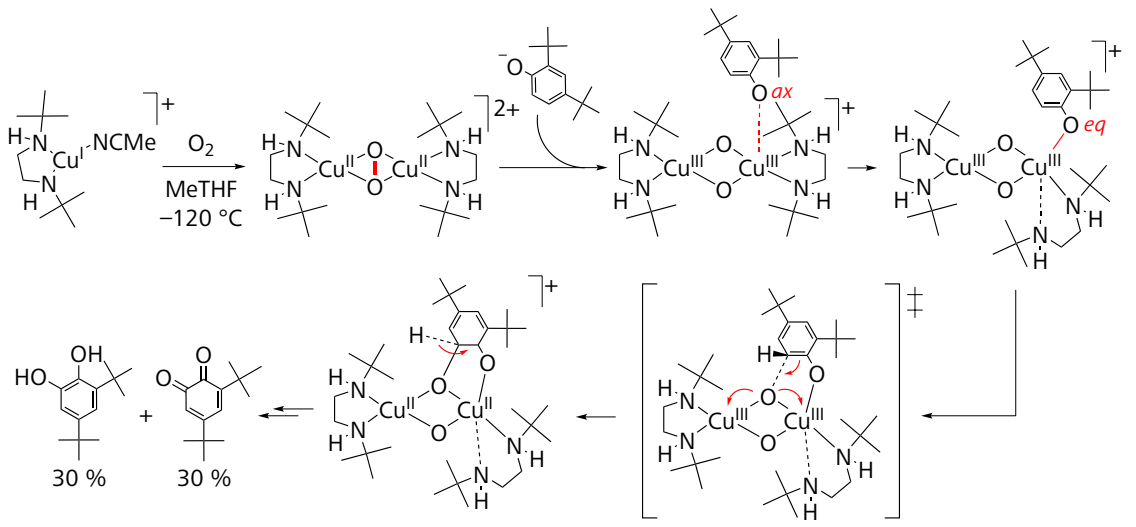

Scheme 2.8 Tyrosinase reactivity in a model complex, hydroxylation of DBP via a bis $(\mu$ -

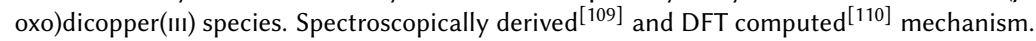





\section{Objectives of this Work}

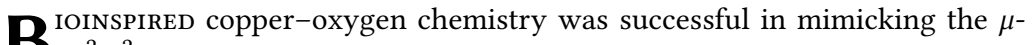
$\eta^{2}: \eta^{2}$-peroxodicopper(II) coordination found in prominent natural copper proteins. Furthermore, other synthetic copper-oxygen species have been identified, some of them with (assumed) relations to natural systems and a general comprehension of the basic copper-oxygen interactions could be gained.

Despite this vast background, several aspects of the mechanism of dioxygenactivation and substrate reactivity are not fully cleared. Also, most copper-oxygen systems known up to now still suffer from severe temperature sensitivity, resulting in decomposition or degradation of ligands. Examples of systems which (catalytically) oxidise substrates are still very rare and most of the applied ligand systems are not easily modifiable (e. g. for the purpose of tuning their reactivity). In order to increase the stability of a system at hand, vary the exact nature of a copper-oxygen species and to control its reactivity, versatile and readily accessible ligand systems are highly demanded.

Bis(oxazoline) (BOX) ligands are amongst the most common and versatile classes of ligands in catalytic asymmetric synthesis. This work has the scope to develop the first application of the very promising BOXs for the copper(I)-mediated activation of dioxygen. To meet the requirements of a flexible, easily accessible ligand system, new BOX ligands have been prepared and their coordination abilities towards copper(II) and copper(I) were systematically examined. Dioxygen activation experiments with the reactive copper(I) compounds have been conducted at very low temperatures; these systems were spectroscopically and structurally elucidated. Their stability and reactivity towards external substrates were tested. Additionally, the elucidation of the kinetic and thermodynamic aspects of $\mathrm{O}_{2}$ activation by cryo-stopped-flow techniques was also achieved. Furthermore, the variability of these systems and the effect of the protonation status of the ligand for the formation of copper-oxygen species was further investigated.

In addition, the ligands in this work exhibited further intriguing features, which were found while working on their copper-oxygen chemistry: redox non-innocence and tautomerism. Both features were evidenced and investigated for the first time in this prominent BOX ligand class and two larger parts of this work focus on them.

A general overview of the contents of this work is provided hereafter. 

Part II.

Results 



\section{General Overview}

Following the introduction to biomimetic copper-oxygen chemistry in the two preceding chapters, the synthesis of the BOX ligand system will be covered in Chapter 3. Bis(oxazoline) Ligands (page 37).

For one of these ligands, tautomerism has been evidenced, for the first time within this prominent ligand class. This special feature is highlighted in

Chapter 4. Tautomerism in Bis(oxazoline)s (page 45).

In the course of this work, an inherent redox non-innocence of the bis(oxazoline) ligands has been found, when they were exposed to copper(II) chloride. This non-innocence involves dimerisation reactions by $\mathrm{C}-\mathrm{C}$ coupling and ligand oxygenation in air. This behaviour is examined in

Chapter 5. Unexpected Non-innocence in Copper(II) Complexes of BOXs (page 67).

The central part of this work deals with the topic of biomimetic copper-oxygen chemistry of bis(oxazoline) ligands. The activation of $\mathrm{O}_{2}$ by the corresponding copper(I) complexes is spectroscopically studied at very low temperatures, including the respective kinetics, as well as theoretical and structural insights in

Chapter 6. Biomimetic Activation of Dioxygen by Copper(I) Complexes of BOXs (page 111).

On this basis, the transformation of one of the biomimetic $\mu-\eta^{2}: \eta^{2}$-peroxodicopper(II) species to the corresponding bis( $\mu$-oxo)dicopper(III) compound is described in the final part

Chapter 7. A Bis $(\mu$-oxo) Complex by Stepwise Conversion of a Peroxo Species (page 177). 



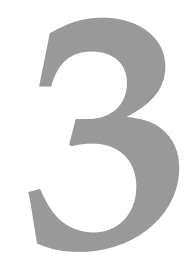

\section{Bis(oxazoline) Ligands}

Part of this chapter was published under the title: »Tautomerism in Bis(oxazoline)s« A. Walli, S. Dechert, F. Meyer, Eur. F. Org. Chem. 2013, 7044-7049 DOI: 10.1002 /ejoc. 201301282

\subsection{Introduction}

SINCE bis(oxazoline) (BOX) ligands were first developed by several groups $\checkmark$ around $1990,{ }^{[111-115]}$ their metal complexes have found use in a variety of metal-mediated catalytic reactions, in particular in asymmetric synthesis. BOXs have quickly developed into a high-performance ligand platform and are now classified among the so called »privileged ligands «. Some BOXs are commercially available, such as methylene- and isopropylidene-bridged ones $\left(\mathrm{R}=\mathrm{R}^{\prime}=\mathrm{H}\right.$ or Me; Scheme 3.1a). Besides metal complexes of neutral bis(oxazoline) ligands ${ }^{[116-122]}$ ex- $^{-}$ hibiting two alkyl substituents at the bridging backbone $C$ atom $\left(R=R^{\prime} \neq H\right)$, which are most common, complexes with deprotonated monoanionic bis(oxazolinate) are also well established (Scheme $3.1 \mathrm{~b}) .{ }^{[123]}$ The latter are closely related to the

(a)<smiles>[R20]C([R16])[R20]</smiles>

(b)<smiles>[R]C1=C2N=C(CO1)NC([R7])([R])CO2</smiles>

(c)<smiles>[R]C(=N[Al])N=C([R])C([R])=N[Al]</smiles>

$\mathrm{NacNac}$

Scheme 3.1 Structural motives of (a ) bis(oxazoline)s, ( b ) monoanionic bis(oxazolinates) and $\mathbf{( c )}$ the related $\beta$-diketiminates. 
bidentate $\beta$-diketiminate ( $\mathrm{NacNac}$ ) ligands (Scheme 3.1c) that are very popular in coordination chemistry.

In this work, a set of four bis(oxazoline) ligands $\left.\mathrm{H}_{\{}{ }^{\mathrm{R}} \mathrm{BOX}\right\}$ has been prepared (Scheme 3.2). To simplify, the residues $\mathrm{R}^{\prime}$ and $\mathrm{R}^{\prime \prime}$ are omitted in the shortened ligand names. These ligands comprise bulky dimethyl residues at the oxazoline rings to sterically shield the sensitive copper-oxygen moiety $\left(\mathrm{R}^{\prime \prime}=\mathrm{R}^{\prime \prime \prime}=\mathrm{Me}\right)$. To make the system feasible for the generation of monoanionic bis(oxazolinates) $\left(\mathrm{R}^{\prime}\right.$ $=\mathrm{H}$ ), a deprotonable hydrogen atom is provided at the backbone. The backbone residue $\mathrm{R}$ was modified to mainly examine its influence in ligand redox noninnocence, which was unexpectedly encountered in this work and was extensively investigated as discussed in Chapter 5. The influence of the backbone residue, however effects most of the chemistry investigated in this work. Its steric demand is rising in the order $\mathrm{R}=\mathrm{H}<\mathrm{Me}<\mathrm{Ph}<t \mathrm{Bu}$.<smiles></smiles>

$\mathbf{H}\left\{{ }^{\mathrm{H}} \mathrm{BOX}\right\}$<smiles>CC(C1=NC(C)(C)CO1)C1=NC(C)(C)CO1</smiles>

$\mathbf{H}\left\{{ }^{\mathrm{Me}} \mathrm{BOX}\right\}$<smiles>CC1(C)COC(C(C2=NC(C)(C)CO2)c2ccccc2)=N1</smiles>

$H_{\left\{{ }^{\mathrm{Ph}} \mathrm{BOX}\right\}}$<smiles>CC1(C)COC(C(C2=NC(C)(C)CO2)C(C)(C)C)=N1</smiles>

$\mathrm{H}\left\{{ }^{\mathrm{Bu}} \mathrm{BOX}\right\}$

Scheme 3.2 Set of BOX ligands used in this work.

\subsection{Ligand Synthesis}

Synthetic procedures were adapted in parts from literature methods for analogous BOXs (see the Experimental Section 10.1 for more details). ${ }^{[120,124,125]}$ The ligand $\mathrm{H}\left\{{ }^{\mathrm{Me}} \mathrm{BOX}\right\}$ shows some applications in the complexation of several metal ions. ${ }^{[124]}$ Although a preparation of $\mathrm{H}\left\{{ }^{\mathrm{H}} \mathrm{BOX}\right\}$ was reported before, ${ }^{[126]}$ no analytical data has been published. $\left.\mathrm{H}\left\{{ }^{\mathrm{H}} \mathrm{BOX}\right\}, \mathrm{H}_{\left\{{ }^{\mathrm{Me}}\right.} \mathrm{BOX}\right\}$ and the novel $\left.\mathrm{H}_{\{}{ }^{\mathrm{Ph}} \mathrm{BOX}\right\}$ and $\left.\mathrm{H}_{\{}{ }^{t \mathrm{Bu}} \mathrm{BOX}\right\}$ have been fully characterised.

\subsubsection{Synthesis of Bishydroxy Malonamides}

The (monoalkyl/-aryl)methylene-bridged bis(dimethyloxazoline)s $\left.\mathrm{H}_{\{}{ }^{\mathrm{R}} \mathrm{BOX}\right\}$ were prepared from the respective bishydroxy malonamide precursors. The malonamides were synthesized in a general applicable procedure, starting from their 
respective diethyl malonate and an amino alcohol (2-amino-2-methyl-1-propanol). The solvent-free mixtures were heated in an Ace Glass heavy-wall pressure tube together with a catalytic amount of sodium hydride to $160^{\circ} \mathrm{C}$ for 3 to 4 hours in an atmosphere of dry argon (Scheme 3.3). After removal of ethanol in vacuum, the respective malonamides were yielded quantitatively. However, this procedure was only reasonably practicable for the three $\left.\mathrm{H}_{\{} \mathrm{H}^{\mathrm{Me}} \cdot \mathrm{Ph}_{\mathrm{BOX}}\right\}$. The obtained malonamides could be further processed without purification. To obtain reasonable amounts of $\left.\mathrm{H}_{\{}{ }^{\mathrm{tBu}} \mathrm{BOX}\right\}$, the malondiamide had to be prepared via a different route (see below).<smiles>[R]C(C(=O)OCC)C(=O)OCC</smiles>

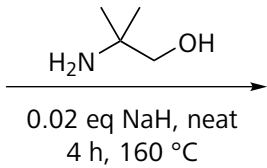<smiles>[R]C(C(=O)NC(C)(C)CO)C(=O)NC(C)(C)CO</smiles>

Scheme 3.3 Synthetic route to bishydroxy malonamides in the synthesis of $\left.\mathrm{H}_{\{}{ }^{\mathrm{H} . \mathrm{Me} . \mathrm{Ph}} \mathrm{BOX}\right\}$.

While diethyl malonate, diethyl methylmalonate and diethyl phenylmalonate were obtained from commercial suppliers, diethyl tert-butylmalonate was prepared from diethyl isopropylidenemalonate by the conjugate addition of methylmagnesium iodide Grignard (Scheme 3.4). ${ }^{[127]}$ The addition of 1 mole \% copper(I) chloride is useful in general to catalyse the conjugate addition of Grignard reagents to $\alpha, \beta$-unsaturated esters. ${ }^{[128]}$ The malonate was obtained upon hydrolysis.<smiles>CCOC(=O)C(C(=O)OCC)=C(C)C</smiles><smiles>CCOC(=O)C(C)(C)C(=O)OCC</smiles>

1. $\mathrm{KOH}, \mathrm{H}_{2} \mathrm{O} / \mathrm{EtOH}$

2. $\mathrm{HCl}, \mathrm{H}_{2} \mathrm{O}$

3. $\mathrm{SOCl}_{2,163 \mathrm{~h}, 50^{\circ} \mathrm{C}}^{\longrightarrow}$<smiles>CC(C)(C)C(=O)Cl</smiles>

Scheme 3.4 Synthetic route to diethyl tert-butylmalonate and tert-butylmalonyl dichloride as part of the synthesis of $\left.\mathrm{H}_{\left\{{ }^{t} \mathrm{Bu} B O X\right.}\right\}$. 


\section{Bis(oxazoline) Ligands}

In the case of $\left.\mathrm{H}_{\{}{ }^{t \mathrm{Bu}} \mathrm{BOX}\right\}$, the general procedure applied for the synthesis of the malondiamides always yielded only a minimal amount of the desired compound, likely due to the large sterical bulk of the tert-butyl group. It was then tried to overcome the reaction barrier by applying longer reaction times or by heating in a closed-vessel microwave apparatus. However, all attempted reaction conditions lead to a mixture of undefined side products, likely from decomposition reactions. With the help of mass-spectrometry-coupled gas chromatography (GC-MS) it was possible to gain further insights into the reaction. GC-MS in chemical ionisation (CI) and electron impact (EI) ionisation mode indeed indicated the presence of two major components, formed by decomposition processes (Scheme 3.5).

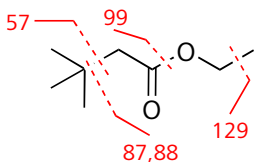

GCMS $(\mathrm{Cl})$ : $m / z=145\left[\mathrm{C}_{8} \mathrm{H}_{16} \mathrm{O}_{2}+\mathrm{H}\right]^{+}$

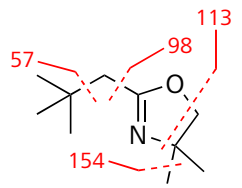

GCMS (Cl): $m / z=170\left[\mathrm{C}_{10} \mathrm{H}_{19} \mathrm{NO}+\mathrm{H}\right]^{+}$

Scheme 3.5 The two proposed major degradation products in the synthesis of $\mathrm{H}\left\{{ }^{t \mathrm{Bu}} \mathrm{BOX}\right\}$ when following the general route to the malondiamide intermediate. Products were identified by GC-MS analysis of the reaction mixture. Molecular masses were identified in the $\mathrm{Cl}$ mode. The proposed structures were assigned by fragmentation in EI mode, assigned fragments are indicated with red bars and masses.

It was yet possible to further process this crude reaction mixtures when applying the general method used for the other BOXs (described below) to obtain $\mathrm{H}_{\left\{{ }^{t \mathrm{Bu}} \mathrm{BOX}\right\}}$ in yields of $\sim 5 \%$. With regard to limited availability of diethyl tert-butylmalonate, an alternative route was developed: The prepared diethyl tert-butylmalonate was hydrolysed and the resulting tert-butylmalonic acid converted to the corresponding acyl chloride with thionyl chloride (Scheme 3.4). ${ }^{[129]}$ The corresponding malondiamide could be obtained in good yields by the reaction of tert-butylmalonic acid with 2-amino-2-methyl-1-propanol in presence of triethylamine.

\subsubsection{Synthesis of Bis(oxazoline)s}

The bis(oxazoline) ligands were finally prepared by treating a solution of the respective bishydroxy malondiamide and triethylamine with methanesulfonyl 
chloride $(\mathrm{MsCl})$, followed by heating of the obtained mesylates with sodium hydroxide under reflux (Scheme 3.6).<smiles>[R]C(C(=O)NC(C)(C)CO)C(=O)NC(C)(C)CO</smiles>

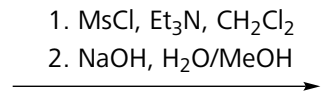

2. $\mathrm{NaOH}, \mathrm{H}_{2} \mathrm{O} / \mathrm{MeOH}$<smiles>[R]C(C1=NC(C)(C)CO1)C1=NC(C)(C)CO1</smiles>

$\mathrm{H}\left\{{ }^{\mathrm{R}} \mathrm{BOX}\right\}$

Scheme 3.6 Synthetic route to bis(oxazoline)s $\left.\mathrm{H}_{\{}{ }^{\mathrm{R}} \mathrm{BOX}\right\}(\mathrm{R} \equiv \mathrm{H}, \mathrm{Me}, \mathrm{Ph})$.

The ligands were yielded as colourless liquids after purification by bulb-tobulb kugelrohr vacuum distillation. While this usually was sufficient, additional purification by column chromatography was required in some batches. Contrary to the other bis(oxazoline)s, which were obtained as well soluble colourless liquids, $\mathrm{H}\left\{{ }^{\mathrm{Ph}} \mathrm{BOX}\right\}$ precipitated in the course of the latter step from the reaction solution. This can be attributed to the presence of the iminoenamine tautomer (unique) in the case of $\left.\mathrm{H}_{\{}{ }^{\mathrm{Ph}} \mathrm{BOX}\right\}$ which apparently is insoluble under the applied conditions and not present in other BOXs in general. The presence of this tautomer in $\left.\mathrm{H}_{\{}{ }^{\mathrm{Ph}} \mathrm{BOX}\right\}$ (and its absence in $\left.\mathrm{H}_{\{}{ }^{\mathrm{H}} \mathrm{BOX}\right\}, \mathrm{H}_{\{}\left\{{ }^{\mathrm{Me}} \mathrm{BOX}\right\}$ and $\left.\mathrm{H}_{\{}{ }^{t \mathrm{Bu}} \mathrm{BOX}\right\}$ ) is clearly evident in the NMR spectra; see Figures 3.1 and 3.2 for a comparison of ${ }^{1} \mathrm{H}$ NMR and ${ }^{13} \mathrm{C}$ NMR spectra of the four BOXs. The mechanism of tautomerism in $\left.\mathrm{H}_{\{}{ }^{\mathrm{Ph}} \mathrm{BOX}\right\}$ was extensively studied and is discussed in detail in Chapter 4, including the solid state structures of $\left.\mathrm{H}_{\{}{ }^{\mathrm{Ph}} \mathrm{BOX}\right\}$ and $\mathrm{H}_{\{}\left\{{ }^{\mathrm{H}} \mathrm{BOX}\right\}$ (p. 47) and additional IR spectroscopic data of all BOXs (p. 52). 

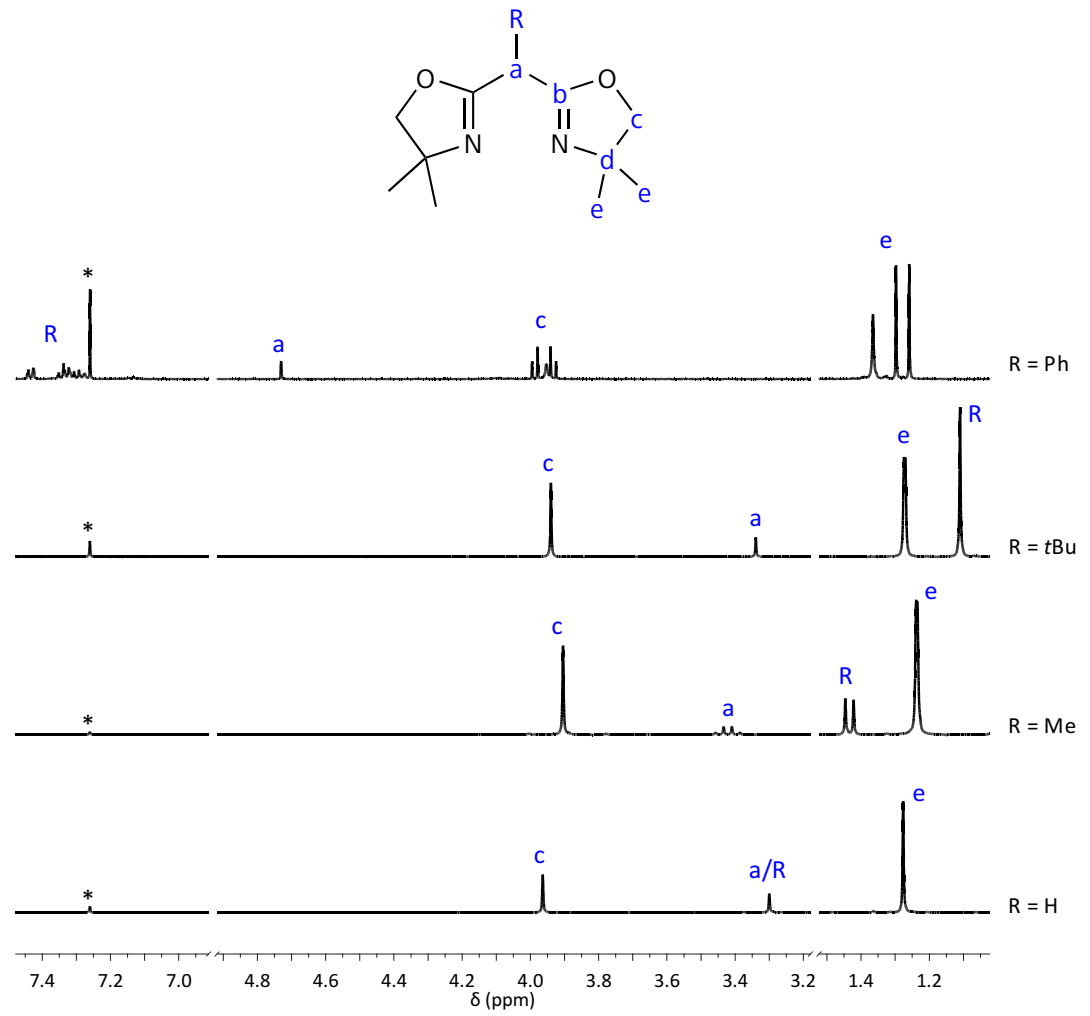

Figure 3.1. ${ }^{1} \mathrm{H}$ NMR spectra of bis(oxazoline)s $\mathrm{H}\left\{{ }^{\mathrm{R}} \mathrm{BOX}\right\}$ at $298 \mathrm{~K}$ in chloroform-d. Referenced to the residual solvent proton (*) at $7.26 \mathrm{ppm}$. $\left.\mathrm{H}_{\{}{ }^{\mathrm{Ph}} \mathrm{BOX}\right\}$ is present as a mixture of both tautomers, iminoenamine and diimine, whereas the others are solely in their diimine form. 


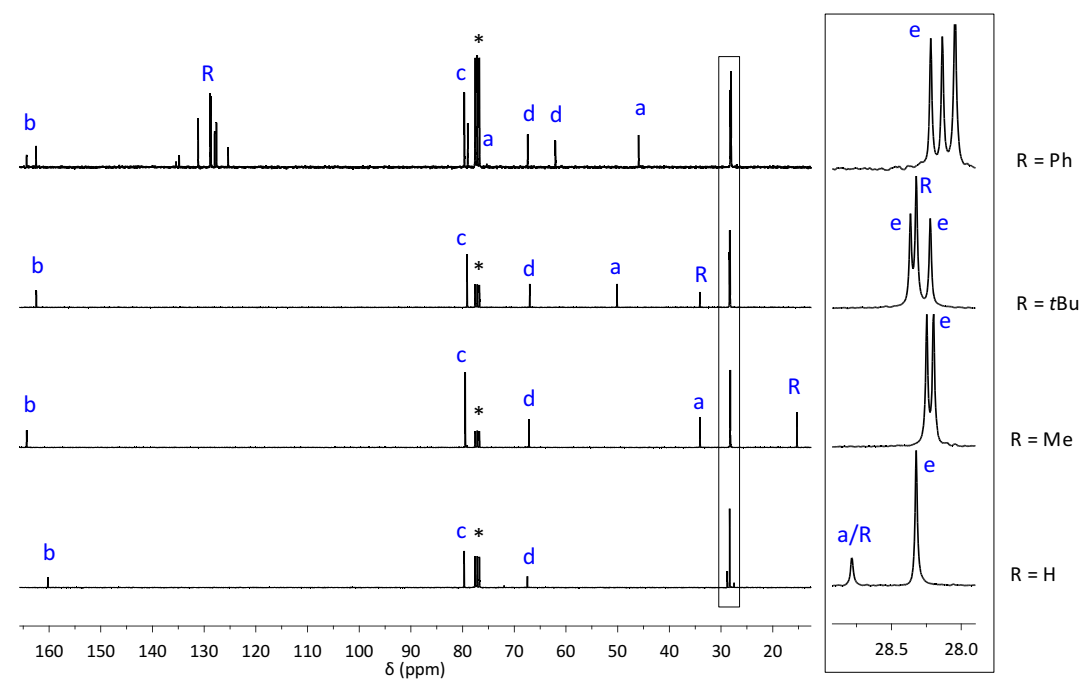

Figure 3.2. ${ }^{13} \mathrm{C}\left\{{ }^{1} \mathrm{H}\right\}$ NMR spectra of bis(oxazoline)s $\mathrm{H}\left\{{ }^{\mathrm{R}} \mathrm{BOX}\right\}$ at $298 \mathrm{~K}$ in chloroform-d. Referenced to the residual solvent proton triplet $(*)$ at $77.16 \mathrm{ppm} . \mathrm{H}\left\{{ }^{\mathrm{Ph}} \mathrm{BOX}\right\}$ is present as a mixture of both tautomers, whereas the others are solely in their diimine form. A magnified view of the high-field ${ }^{13} \mathrm{C}$ NMR region is depicted on the right. 



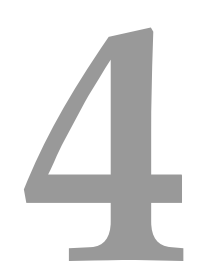

\section{Tautomerism in Bis(oxazoline)s}

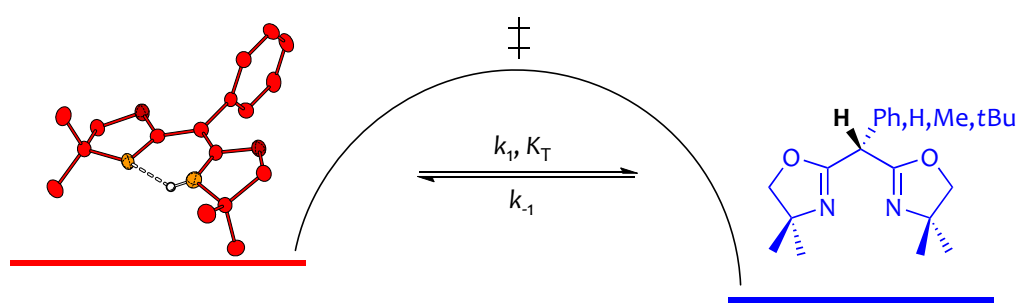

Part of this chapter was published under the same title: A. Walli, S. Dechert, F. Meyer, Eur. F. Org. Chem. 2013, 7044-7049 DOI: 10.1002 /ejoc. 201301282 


\subsection{Introduction}

N view of the widespread use of BOX ligands it is somewhat surprising that little is known about the tautomerism of BOXs containing a single substituent $\mathrm{R}$ at the backbone bridge, or BOXs with the parent methylene spacer (Scheme 4.1). In these diimine systems, the $\mathrm{H}$ atom may shift from the bridge- $\mathrm{C}$ to one of the oxazoline-N atoms, giving the iminoenamine form; the latter may have $E$ or $Z$ configuration.<smiles>[R]C(C1=NCCO1)C1=NCCO1</smiles><smiles>[R]/C(C1=NCCO1)=C1\NCCO1</smiles>

(E)-iminoenamine<smiles>[R]/C(C1=NCCO1)=C1\NCCO1</smiles>

(Z)-iminoenamine

Scheme 4.1 Potential tautomeric bis(oxazoline) isomers.

While in the related $\beta$-diketones, the enol isomer is usually far more stable than the keto isomer and $\beta$-diketimines ( $\mathrm{NacNac}$ ) are always regarded as iminoenamines (Scheme 4.2a), BOXs are encountered and described in the form of the diimine. The same is true for the closely related ligand class of aza-bis(oxazoline)s (aza$\mathrm{BOX}),{ }^{[130]}$ which also exist in the diimine form with the proton at the bridge-N. Exceptions from the predominant diimine tautomer are the ${ }^{\mathrm{CN}_{\mathrm{BOX}}}$ and related semicorrins ${ }^{[131]}$ featuring strongly electron-withdrawing cyano groups at the bridge-C. Some aza-semicorrins have been reported to exist in their iminoenamine form, too (Scheme 4.2a). ${ }^{[132]}$

Based on UV-vis spectra, Kovač et al. assumed that a small amount of an iminoenamine isomer is also present in solutions of ${ }^{\mathrm{H}, \mathrm{H}} \mathrm{BOX}-t \mathrm{Bu}, \mathrm{H}$ (Scheme $4.2 \mathrm{~b}$ ), but ${ }^{1} \mathrm{H}$ and ${ }^{13} \mathrm{C}$ NMR did not confirm this, as well as photoelectron spectroscopy (PES) revealed no tautomer in the gas phase. ${ }^{[133]}$ Just recently the protonated bis(oxazoline)s $\left[\mathrm{H}\left\{{ }^{\mathrm{Me}, \mathrm{H}} \mathrm{BOX}-\mathrm{Me}_{2}\right\}\right]^{+[134]}$ and $\left[\mathrm{H}\left\{{ }^{\mathrm{Me}, \mathrm{H}} \mathrm{BOX}-\mathrm{Ph}, \mathrm{H}\right\}\right]^{+},{ }^{[135]}$ which have been serendipitously isolated, were found to exist in the $(Z)$-iminoenamine form in the solid state. Even more recently, the bis(oxazoline) $p \mathrm{CF}_{3}\left(\mathrm{C}_{6} \mathrm{H}_{4}\right) \mathrm{CH}_{2}, \mathrm{H}$ BOX$\mathrm{H}_{2}$ was crystallised as the iminoenamine tautomer. Furthermore, two tautomers were observed in solution. ${ }^{[136]}$ These are the only BOXs with evidence for the presence of the iminoenamine tautomer, so far. However, related methylene-bridged bis(imidazoline)s (Scheme 4.2a) were found to undergo tautomerism depending 
(a)<smiles>O=[W]N/C=C\C=N/[Ga]Br</smiles><smiles>[R]C1COC(NC2=NC([R])CO2)=N1</smiles><smiles>[R]C1=NC(=C(C#N)C2=NC([R])CO2)OC1</smiles><smiles>[R]C1CCC(/C(C#N)=C2\CCC([R])N2)=N1</smiles><smiles>[R]C1CCC(N([R])C2CCC([R])N2)=N1</smiles>
aza-semicorrins<smiles>[R]C1CN([R])C(/C=C2\NC([R])CN2[R])=N1</smiles>

bis(imidazolines)

(b)<smiles>CC(C)(C)[C@H]1COC(CC2=N[C@@H]([13CH3])CO2)=N1</smiles><smiles>CC(C1=[NH+]C(C)(C)CO1)=C1NCC(C)(C)O1</smiles><smiles>CC(C1=[NH+][C@@H](c2ccccc2)CO1)=C1NC[C@H](c2ccccc2)O1</smiles><smiles>FC(F)(F)c1ccc(CC(C2=NCCO2)=C2NCCO2)cc1</smiles>

$H, H_{B O X}-t B u, H$ $\left[\mathrm{H}\left\{\mathrm{Me}, \mathrm{H} \mathrm{BOX}-\mathrm{Me}_{2}\right\}\right]^{+}$

$[\mathrm{H}\{\mathrm{Me}, \mathrm{H} \mathrm{BOX}-\mathrm{Ph}, \mathrm{H}\}]^{+}$

$p-\mathrm{CF}_{3} \mathrm{C}_{6} \mathrm{H}_{4} \mathrm{CH}_{2}, \mathrm{H}$ BOX-H, $\mathrm{H}$

Scheme 4.2 (a ) Ligand classes related to bis(oxazoline)s, represented is the respective predominant or sole tautomeric form. (b ) Examples from (presumed) iminoenamine tautomers of BOXs, see text for details.

on the solvent and protonation state, ${ }^{[137,138]}$ with the conjugated iminoenamine tautomer being thermodynamically more favourable. ${ }^{[138]}$

In this chapter, the tautomeric equilibrium of the neutral bis(oxazoline) $H\left\{{ }^{P h} B O X\right\}$ is studied in detail by NMR and IR spectroscopy. Moreover, crystallography and relevant thermodynamic and kinetic parameters, accompanied by DFT calculations are discussed. This information is important and fundamental for the understanding and rationalizing the reactivity of this prominent class of compounds.

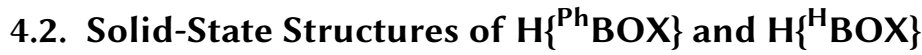

Small colourless needles of $\mathrm{H}\left\{{ }^{\mathrm{Ph}} \mathrm{BOX}\right\}$ were obtained by slow concentration of a $\mathrm{CH}_{2} \mathrm{Cl}_{2} /$ methanol $(9: 1)$ solution; a single crystal was analysed by X-ray diffraction. 


\section{Tautomerism in Bis(oxazoline)s}

The molecular structure of $\left.\mathrm{H}{ }^{\mathrm{Ph}} \mathrm{BOX}\right\}$, which crystallises in the monoclinic $P 2 / n$ space group, is depicted in Figure 4.1a (Table 4.1). Clearly, $\mathrm{H}\left\{{ }^{\mathrm{Ph}} \mathrm{BOX}\right\}$ exists in its $(E)$-iminoenamine form in the solid state.

The two oxazoline rings in $\mathrm{H}\left\{{ }^{\mathrm{Ph}} \mathrm{BOX}\right\}$ are roughly coplanar (the torsion angle between the $\mathrm{C} 6-\mathrm{N} 1$ and $\mathrm{C} 6^{\prime}-\mathrm{N} 1^{\prime}$ bonds is only $0.8^{\circ}$ ) and are bridged by $\mathrm{C} 1$ with an $\measuredangle\left(\mathrm{C} 6-\mathrm{C} 1-\mathrm{C}^{\prime}\right)$ angle of $117.7^{\circ}$, which is close to the $120^{\circ}$ expected for $s p^{2}$ hybridisation. The $\mathrm{C} 1-\mathrm{C} 6$ and $\mathrm{C} 6-\mathrm{N} 1$ distances of 1.40 and $1.31 \AA$ differ strongly from those found for oxazolines in their diimine form ${ }^{[117]}$ but are between typical values for $\mathrm{C}-\mathrm{C}$ and $\mathrm{C}=\mathrm{C}$ bonds and between $\mathrm{C}-\mathrm{N}$ and $\mathrm{C}=\mathrm{N}$ bonds respectively, and thus reflect delocalisation or disorder. ${ }^{[139]}$ The cavity between both oxazoline rings is widened at the front with an angle between both $\mathrm{C} \simeq \mathrm{N}$ bonds of $14.3^{\circ}$; the $\mathrm{N} \cdots \mathrm{N}$ separation is $2.73 \AA$. The backbone phenyl ring at $\mathrm{C} 1$ is rotated by approximately $71^{\circ}$ relative to the plane defined by the two oxazoline rings. The enamine H1 proton lies in the latter plane [0.1(1) $\AA$ distance] and forms a moderate to weak, resonanceassisted $^{[140]} \mathrm{N}-\mathrm{H} \cdots \mathrm{N}$ hydrogen bond with a length of $2.15 \AA$ and an angle of $131^{\circ}$ (cf. Table 4.2 for additional hydrogen-bonding parameters). The averaged $\mathrm{C}-\mathrm{C}$ and $\mathrm{C}-\mathrm{N}$ bond lengths within the $\mathrm{C} 1\left(-\mathrm{C} 6=\mathrm{N} 1 \cdots \mathrm{H} 1-\mathrm{N} 1^{\prime}-\mathrm{C} 6=\right)$ ring of $\left.\mathrm{H}_{\{}{ }^{\mathrm{Ph}} \mathrm{BOX}\right\}$ suggest complete delocalisation, but the two localized positions of the enamine hydrogen atom $\left(\mathrm{H} 1, \mathrm{H}^{\prime}\right)$ indicate that an overlay of an enamine-imine and an imine-enamine structure is more likely (Scheme 4.3).

\section{Scheme 4.3}

Autotrope interconverted tautomers disordered in the solid state structure of $\left.\mathrm{H}_{\{}{ }^{\mathrm{Ph}} \mathrm{BOX}\right\}$.

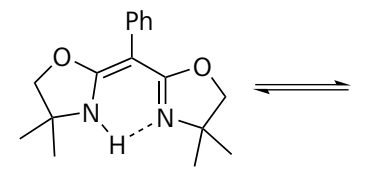<smiles>CC1(C)COC2=C(c3ccccc3)C3=[N+]([CH]N21)C(C)(C)CO3</smiles>

The nature of the crystallographic disorder remains unclear: the structure is either statically or dynamically disordered. However, dynamic disorder seems reasonable, as related compounds were found to show such phenomenon (see below). It should be emphasized that the two disordered structures are identical tautomers (autotrope interconverted, Scheme 4.3). ${ }^{[141]}$ Prototropic tautomerisation in the solid state is a relatively rare phenomenon found in, for example, cyclic hydrogenbonded pyrazole derivatives, which have been intensively studied by solid-state CPMAS (cross polarisation, magic angle spinning) NMR techniques. ${ }^{[142]}$ More closely related to $\mathrm{H}\left\{{ }^{\mathrm{Ph}} \mathrm{BOX}\right\}$ are dibenzoylmethane and analogous 1,3-diketones, ${ }^{[143-145]}$ whose degenerate, intramolecular hydrogen-bridged tautomers resemble the situation found here. However, the solid-state tautomerism of $\mathrm{H}\left\{{ }^{\mathrm{Ph}} \mathrm{BOX}\right\}$ was not further investigated in this work. 


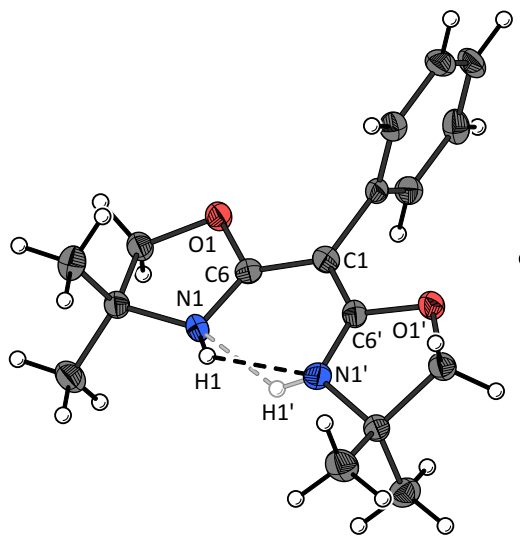

(a)

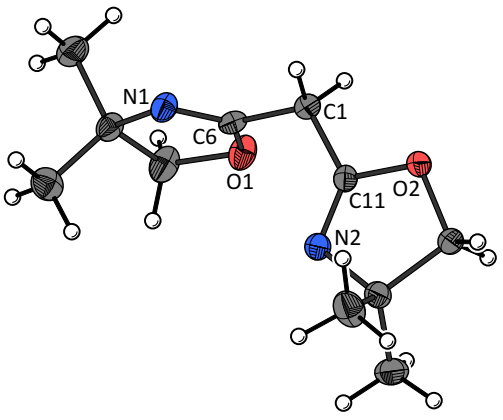

(b)

Figure 4.1. X-ray solid-state molecular structures of (a) the iminoenamine $\left.\mathrm{H}_{\{}{ }^{\mathrm{Ph}} \mathrm{BOX}\right\}$ and (b) the diimine $\left.\mathrm{H}_{\{}{ }^{\mathrm{H}} \mathrm{BOX}\right\}$ with selected atoms labelled. Displacement ellipsoids are drawn at the $50 \%$ probability level; symmetry transformation used to generate equivalent atoms $\left(^{\prime}\right)$ in (a): $1.5-x, y, 1.5-z$. The dotted line represents the hydrogen-bonding interaction between $\mathrm{H} 1$ and $\mathrm{N}^{\prime}$. Selected interatomic distances and angles are listed in Table 4.1

\section{Table 4.1.}

Selected metric parameters (bond lengths $[\AA]$ and angles $\left[{ }^{\circ}\right]$ ) of the bis(oxazoline)s $\left.\mathrm{H}_{\{}{ }^{\mathrm{Ph}} \mathrm{BOX}\right\}$ and $\left.\mathrm{H}_{\{}{ }^{\mathrm{H}} \mathrm{BOX}\right\} .{ }^{a}$

\begin{tabular}{ccc}
\hline & $\mathrm{H}\left\{{ }^{\mathrm{Ph}} \mathrm{BOX}\right\}^{b}$ & $\mathrm{H}\left\{{ }^{\mathrm{H}} \mathrm{BOX}\right\}$ \\
\hline $\mathrm{N} 1-\mathrm{C} 6, \mathrm{~N} 2-\mathrm{C} 11$ & $1.313(3)$ & $1.264(1), 1.260(1)$ \\
$\mathrm{C} 1-\mathrm{C} 6, \mathrm{C} 1-\mathrm{C} 11$ & $1.403(3)$ & $1.493(1), 1.497(1)$ \\
$\measuredangle\left[\mathrm{C} 6-\mathrm{C} 1-\mathrm{C}\left(6^{\prime} / 11\right)\right]$ & $117.7(3)$ & $113.88(8)$ \\
\hline
\end{tabular}

$\bar{a}$ Additional parameters are provided in the text. ${ }^{b}$ Bonds are symmetrically equivalent.

Table 4.2.

Hydrogen-bonding parameters (bond lengths $[\AA]$ and angles $\left[{ }^{\circ}\right]$ ) of the iminoenamine form of $\left.\mathrm{H}_{\{}{ }^{\mathrm{Ph}} \mathrm{BOX}\right\}$.

\begin{tabular}{ccccc}
\hline $\mathrm{D}-\mathrm{H} \cdots \mathrm{A}$ & $\mathrm{D}-\mathrm{H}$ & $\mathrm{D} \cdots \mathrm{A}$ & $\mathrm{H} \cdots \mathrm{A}$ & $\measuredangle(\mathrm{D}-\mathrm{H} \cdots \mathrm{A})$ \\
\hline $\mathrm{N} 1-\mathrm{H} 1 \cdots \mathrm{N} 1^{\prime}$ & $0.78(10)$ & $2.15(10)$ & $2.726(5)$ & $131(9)$ \\
\hline
\end{tabular}


For comparison, the solid-state molecular structure of $\mathrm{H}\left\{{ }^{\mathrm{H}} \mathrm{BOX}\right\}$ was determined in addition. Large single crystals were obtained by vacuum sublimation. $\left.\mathrm{H}_{\{}{ }^{\mathrm{H}} \mathrm{BOX}\right\}$ crystallises in the orthorhombic $P b c$ a space group; the molecular structure is shown in Figure 4.1b. $\left.\mathrm{H}_{\{}{ }^{\mathrm{H}} \mathrm{BOX}\right\}$ is clearly present in its diimine from; the two oxazoline rings are tilted by around $78.4^{\circ}$. The $\measuredangle(\mathrm{C} 2-\mathrm{C} 1-\mathrm{C} 11)$ angle at the bridging $\mathrm{CH}_{2}$ group equates to $113.9^{\circ}$, which reflects $s p^{3}$ hybridisation. Accordingly, the $\mathrm{C} 1-\mathrm{C}(6 / 11)$ bonds $(1.49 / 1.50 \AA)$ are distinctly longer and the $\mathrm{C}(6 / 11)-\mathrm{N}(1 / 2)$ bonds (both $1.26 \AA$ ) are shorter than those in $\mathrm{H}\left\{{ }^{\mathrm{Ph}} \mathrm{BOX}\right\}$, as expected for the diimine tautomer.

A search in the Cambridge Structural Database (CSD) ${ }^{[146]}$ revealed over 100 deposited structures containing a bis(oxazoline) moiety, most of which have BOXs as coordinating ligands. Only about 10 structures of free bis(oxazoline)s are known, including the iminoenamine and the two protonated $(Z)$-iminoenamines mentioned above. However, the rest are diimines, and only one of them has a $\mathrm{CH}_{2}$ spacer between the oxazoline rings, ${ }^{[147]}$ whereas all the others are bridged by a dialkylmethylene group.

\subsection{Spectroscopic Characterisation of $\mathrm{H}_{\{}\left\{{ }^{\mathrm{Ph}} \mathrm{BOX}\right\}$ Tautomers}

\subsubsection{NMR Spectroscopy}

NMR spectroscopy is the method of choice for studying tautomerism. ${ }^{[148]}$ Its main drawback is its limited sensitivity, as it is not possible to detect minority tautomers that are present in less than 1-2\%. In chloroform solution, in which $\mathrm{H}_{\{}\left\{\mathrm{Ph}_{\mathrm{BOX}}\right\}$ is only slightly soluble, it exists as a mixture of both tautomers, $(E)$-iminoenamine $(N$-protonated) and diimine ( $C$-protonated, Figure $4.2 \mathrm{a})$, with a ratio of about $1: 1$ at around room temperature. Although the formation of a $(Z)$-iminoenamine tautomer is in principle feasible, there was not any indication of its presence observed during this work.

The ${ }^{1} \mathrm{H}$ and ${ }^{13} \mathrm{C}$ NMR resonances of the different tautomeric forms of $\left.\mathrm{H}_{\{}{ }^{\mathrm{Ph}} \mathrm{BOX}\right\}$ are well resolved at $25^{\circ} \mathrm{C}$ (Figure $4.2 \mathrm{~b}$; see Figure 3.2, p. 43, for the ${ }^{13} \mathrm{C}$ NMR spectrum), evidencing rather slow interconversion. Unambiguous assignment was facilitated by the isolation of the pure iminoenamine tautomer: by dissolving an isomerically pure crystalline sample at low temperature, it was possible to record NMR spectra of the pure $(E)$-iminoenamine tautomer. A single set of signals and apparent $C_{2 v}$ symmetry reflect rapid proton exchange between both oxazoline $\mathrm{N}$ atoms and the degenerate autotrope tautomerism mentioned above. 
The enamine $\mathrm{NH}$ proton resonance is only observable at $-50{ }^{\circ} \mathrm{C}$ as a broad peak $\left(\delta_{\mathrm{H}} \approx 9.0 \mathrm{ppm}\right.$, line width $\approx 0.4 \mathrm{ppm}$ ); no $\mathrm{NH}$ resonance signal could be detected at e. g. $25^{\circ} \mathrm{C}$. The diimine tautomer, seen at elevated temperatures after equilibration, is $C_{s}$ symmetric and hence, its oxazoline $\mathrm{CH}_{2}$ protons are diastereotopic (and anisochronous) and give a typical AX spin system. Also, the methyl carbon atoms at each oxazoline are diastereotopic, which leads to two ${ }^{1} \mathrm{H}$ and ${ }^{13} \mathrm{C} N M R$ resonances, each. The $s p^{3}$ hybridisation of the bridge $\mathrm{C}$ atom in the diimine tautomer is reflected in its ${ }^{13} \mathrm{C}$ NMR spectrum by a shift of $\delta_{\mathrm{C}}=46 \mathrm{ppm}$ and a crosspeak with the $C$-bound proton that appears at $\delta_{\mathrm{H}}=4.74 \mathrm{ppm}$ in the $\left\{{ }^{13} \mathrm{C}\right.$, $\left.{ }^{1} \mathrm{H}\right\}$-HSQC spectrum. $\left\{{ }^{15} \mathrm{~N},{ }^{1} \mathrm{H}\right\}-\mathrm{HMBC}$ NMR analysis (Figure 4.3) confirmed the assignment and the identity of both isomers: only two distinct ${ }^{15} \mathrm{~N}$ resonances are observed in the expected regions at $\delta_{\mathrm{N}}=-132 \mathrm{ppm}$ (ketimine $\mathrm{N}$ of the diimine isomer)

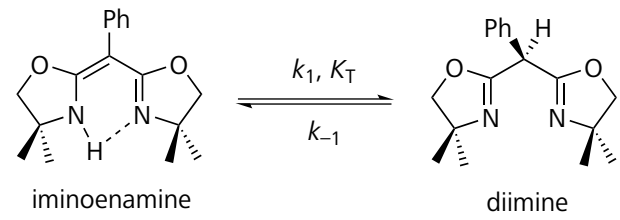

(a)

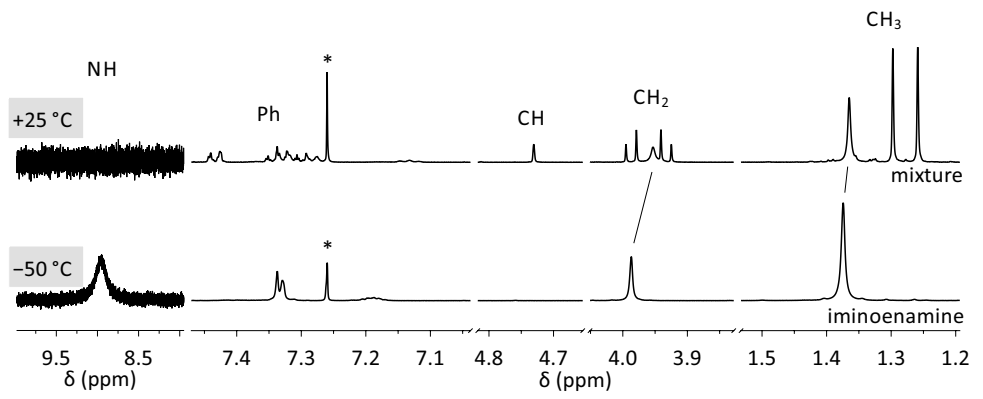

(b)

Figure 4.2. (a) Equilibrium of diimine and iminoenamine tautomers of $\mathrm{H}\left\{{ }^{\mathrm{Ph}} \mathrm{BOX}\right\}$. ( b ) Partial ${ }^{1} \mathrm{H}$ NMR spectrum of the pure iminoenamine tautomer at $-50^{\circ} \mathrm{C}$ and an equilibrated mixture after warming to $25^{\circ} \mathrm{C}$; the $\mathrm{NH}$ regions are magnified and resonance-free regions are omitted for the sake of clarity; the asterisks indicate the residual chloroform solvent peaks. See text for details. 
and $-216 \mathrm{ppm}$ (averaged signal for the iminoenamine isomer). ${ }^{[149]}$ The obvious tautomerism of $\left.\mathrm{H}_{\{}{ }^{\mathrm{Ph}} \mathrm{BOX}\right\}$ appears to be unique so far, as NMR spectroscopy of $\mathrm{H}\left\{{ }^{\mathrm{H}} \mathrm{BOX}\right\}, \mathrm{H}\left\{{ }^{\mathrm{Me}} \mathrm{BOX}\right\}$, and $\left.\mathrm{H}_{\{}{ }^{t \mathrm{Bu}} \mathrm{BOX}\right\}$ bis(oxazoline)s did not show any indication of the presence of an iminoenamine tautomer in solution. The ${ }^{15} \mathrm{~N} N \mathrm{NR}$ shifts are characteristic for the respective diimine tautomer; $\delta_{\mathrm{N}}=-133,-135,-131 \mathrm{ppm}$ for $\mathrm{R}=\mathrm{H}, \mathrm{Me}, t \mathrm{Bu}$ respectively (cf. also the ${ }^{1} \mathrm{H}$ NMR and ${ }^{13} \mathrm{C}$ NMR spectra on pp. 42 and 43).

Figure 4.3

Contour plot of a $\left\{{ }^{15} \mathrm{~N},{ }^{1} \mathrm{H}\right\}$ HMBC NMR spectrum from an equilibrated mixture of tautomers of $\mathrm{H}\left\{{ }^{\mathrm{Ph}} \mathrm{BOX}\right\}$ at $298 \mathrm{~K}$ in chloroform-d; the right side shows a magnified view of the high-field ${ }^{1} \mathrm{H}$ NMR region. The presence of two distinctive cross resonances shows clearly that both tautomers are present in the solution.

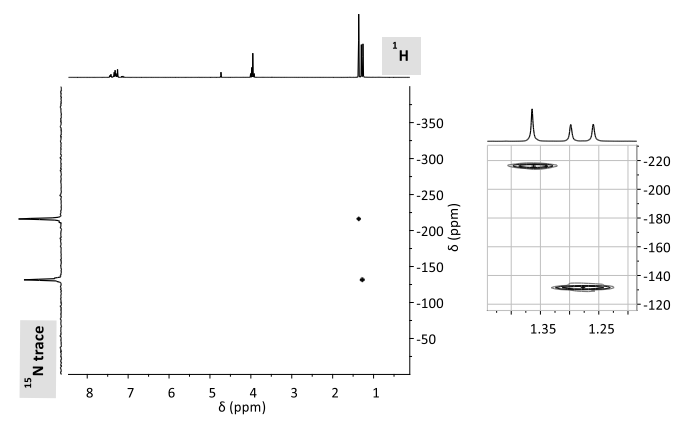

\subsubsection{IR Spectra from DFT Computation and Experiment}

IR spectroscopy can be used as a complementary tool to examine the tautomeric state of bis(oxazoline)s. Whereas the diimine tautomer gives rise to a single broad distinctive band at around $\tilde{v} \approx 1660 \mathrm{~cm}^{-1}$, which can be assigned to the asymmetric and symmetric stretching modes $\left(v_{\mathrm{a}}\right.$ and $\left.v_{\mathrm{s}}\right)$ of the $\{\mathrm{N}=\mathrm{C}-\mathrm{C}-\mathrm{C}=\mathrm{N}\}$ group, the iminoenamine tautomer in the crystalline material of $\left.\mathrm{H}_{\left\{{ }^{\mathrm{Ph}}\right.} \mathrm{BOX}\right\}$ is identified by two prominent and very strong bands at 1646 and $1558 \mathrm{~cm}^{-1}$ (Figure 4.4). Both bands were assigned respectively to $v_{\mathrm{a}}$ and $v_{\mathrm{S}}$ of the $\{\mathrm{C}=\mathrm{C}-\mathrm{C}=\mathrm{N}\}$ group, accompanied with in-plane bending $(\delta)$ of the $\mathrm{N}-\mathrm{H}$ bond (Figure 4.5 represents the characteristic DFT computed modes); they resemble similar modes found in the enol form of acetylacetone. ${ }^{[150]}$ DFT-calculated spectra of both tautomers of $\left.\mathrm{H}_{\{}{ }^{\mathrm{H}} \mathrm{BOX}\right\}$ and $\mathrm{H}\left\{{ }^{\mathrm{Ph}} \mathrm{BOX}\right\}$ show good agreement with experiment (see Section 4.6 for more details on DFT calculations). 


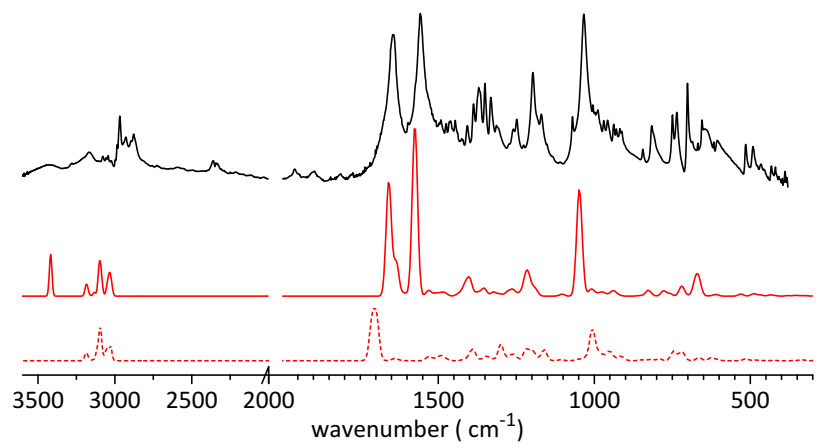

Figure 4.4. Experimental FTIR spectrum (-) and DFT-calculated vibrational spectra (red) of $\left.\mathrm{H}_{\{}{ }^{\mathrm{Ph}} \mathrm{BOX}\right\}$. Spectra were computed from the geometry-optimized structures of the diimine (---) and iminoenamine structure $(-)$ at the B3LYP/def2-TZVPP level of theory. The characteristic modes of the iminoenamine are represented in Figure 4.5. Figure A.2, p. 273, in the Appendix depicts spectra of all four BOXs.

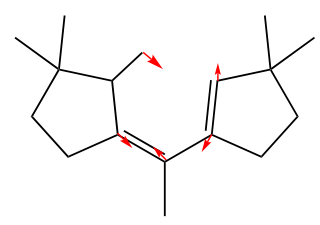

$v_{\mathrm{a}} \mathrm{C}=\mathrm{C}-\mathrm{C}=\mathrm{N}+\delta \mathrm{NH}$ exp. 1646 , calcd. $1659 \mathrm{~cm}^{-1}$

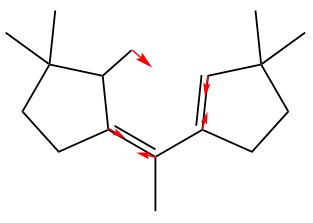

$\mathrm{v}_{\mathrm{S}} \mathrm{C}=\mathrm{C}-\mathrm{C}=\mathrm{N}+\delta \mathrm{NH}$ exp. 1558 , calcd. $1575 \mathrm{~cm}^{-1}$
Figure 4.5

Selected characteristic normal modes of the iminoenamine tautomer from DFT calculations. The modes are represented for $\left.\mathrm{H}_{\{}{ }^{\mathrm{Ph}} \mathrm{BOX}\right\}$.

Whereas $\left.\mathrm{H}_{\{}^{t \mathrm{Bu}} \mathrm{BOX}\right\}$ (which cannot convert into the planar iminoenamine form because of the bulky $t \mathrm{Bu}$ group) solely exists as the diimine tautomer as expected, the IR spectra of $\left.\mathrm{H}_{\{}{ }^{\mathrm{H}} \mathrm{BOX}\right\}$ and $\mathrm{H}\left\{{ }^{\mathrm{Me}} \mathrm{BOX}\right\}$ interestingly suggest the presence of some iminoenamine tautomer as a minor component. See the Appendix, Figure A.2, p. 273, for a comparison of all experimental and computed spectra.

\subsection{Thermodynamic Parameters of the Equilibrium}

The relative isomer concentrations were obtained by comparison of the integrals of the methyl ${ }^{1} \mathrm{H}$ resonance peaks. The samples were found equilibrated after reaction times of between $9 \mathrm{~min}$ and more than 10 hours. From the ratio of the 


\section{Tautomerism in Bis(oxazoline)s}

two tautomers of $\mathrm{H}_{\{}\left\{{ }^{\mathrm{Ph}} \mathrm{BOX}\right\}$, equilibrium constants $K_{\mathrm{T}}$ could be estimated. $K_{\mathrm{T}}$ is defined as the ratio of diimine to iminoenamine (Equation 4.1). Constants $K_{\mathrm{T}}$ $\left(\mathrm{p} K_{\mathrm{T}}\right)$ between $0.93(0.03)$ and $1.92(-0.28)$ could be estimated in the temperature range of 268-323 K (see the Experimental Part, Section 11.1, for more details).

$$
\text { iminoenamine } \stackrel{K_{\mathrm{T}}}{\rightleftharpoons} \text { diimine, } \quad K_{\mathrm{T}}=\frac{[\text { diimine }]}{[\text { iminoenamine }]}
$$

The thermodynamic parameters of the equilibrium were derived from a van't Hoff plot ( $\ln K_{\mathrm{T}}$ vs. $T^{-1}$, Figure 4.6) applying the linear form of the van 't Hoff equation

$$
\ln K_{\mathrm{T}}=-\frac{\Delta H^{\ominus}}{R T}+\frac{\Delta S^{\ominus}}{R}
$$

in which $\Delta H^{\ominus}$ and $\Delta S^{\ominus}$ represent each the standard enthalpy and entropy of reaction and $R$ the ideal gas constant. $\Delta H^{\ominus}$ and $\Delta S^{\ominus}$ were obtained from the slope, $-\Delta H^{\ominus} /(R T)$, and intercept, $\Delta S^{\ominus} / R$, of the linear fit (Table 4.3).

The obtained parameters reveal only small energy differences between the two tautomers. The balanced equilibrium demands for a small Gibbs energy of reaction and it was found experimentally that it is indeed exceptionally small at room temperature $(298 \mathrm{~K})$ with the diimine tautomer energetically slightly favoured: $\Delta G^{\ominus}=(-0.21 \pm 0.08) \mathrm{kcal} \mathrm{mol}^{-1}$. Furthermore, the diimine has a $\Delta H^{\ominus}=$

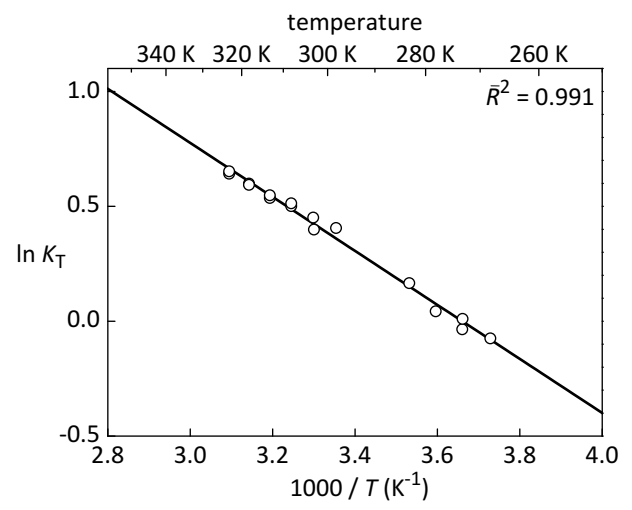

Figure 4.6. Van 't Hoff plot, $\ln K_{\mathrm{T}}$ vs. $T^{-1}$, with linear regression to determine the enthalpy and entropy changes in the equilibrium iminoenamine $\rightleftharpoons$ diimine. The obtained thermodynamic parameters are listed in Table 4.3. 
$(2.33 \pm 0.06) \mathrm{kcal} \mathrm{mol}^{-1}$ and a weakly positive $\Delta S^{\ominus}=(8.5 \pm 0.2) \mathrm{cal} \mathrm{K}^{-1} \mathrm{~mol}^{-1}$. These parameters are comparable to those of recent DFT calculations by MiLIONE and Bertolasi ${ }^{[134]}$ for $\left.\mathrm{H}_{\{}{ }^{\text {Me }} \mathrm{BOX}\right\}$ (BP86/TZVP level, Table 4.3). However, under the conditions applied in that study, only the diimine tautomer of $\left.\mathrm{H}_{\left\{{ }^{\mathrm{Me}}\right.} \mathrm{BOX}\right\}$ was observed experimentally. In comparison, our DFT calculations resulted in similar thermodynamic parameters for $\left.\mathrm{H}_{\{}{ }^{\mathrm{Ph}} \mathrm{BOX}\right\}$ and $\mathrm{H}\left\{{ }^{\mathrm{H}} \mathrm{BOX}\right\}$ (see below, Section 4.6). Finally, these parameters are reminiscent of the structurally related acetylacetone (equilibrium $\sim 90 \%$ on the enol side) ${ }^{[151]}$ and also of acetoacetates. ${ }^{[152]}$

Table 4.3.

Thermodynamic data of the equilibrium of iminoenamine and diimine tautomers. ${ }^{a}$ See Table 4.11 for additional DFT-calculated parameters.

\begin{tabular}{|c|c|c|c|c|c|}
\hline & $\begin{array}{c}\Delta H^{\ominus}, \\
\mathrm{kcal} \mathrm{mol}^{-1}\end{array}$ & $\begin{array}{c}\Delta S^{\ominus}, \\
\mathrm{cal} \mathrm{K}^{-1} \mathrm{~mol}^{-1}\end{array}$ & $\begin{array}{c}\Delta G_{298}^{\ominus} \\
\mathrm{kcal} \mathrm{mol}^{-1}\end{array}$ & $K_{\mathrm{T}}^{298}$ & ref. \\
\hline $\mathrm{H}\left\{{ }^{\mathrm{Ph}} \mathrm{BOX}\right\}^{b}$ & $2.33 \pm 0.06$ & $8.5 \pm 0.2$ & $-0.21 \pm 0.08$ & 1.43 & this work \\
\hline $\mathrm{H}\left\{{ }^{\mathrm{Me}} \mathrm{BOX}\right\}^{c}$ & 3.8 & & 0.7 & 0.31 & [134] \\
\hline
\end{tabular}

\subsection{Kinetic Parameters and Mechanistic Considerations}

\subsubsection{Determination of Rate Constants}

In the ${ }^{1} \mathrm{H}$ NMR spectra of $\left.\mathrm{H}_{\{}{ }^{\mathrm{Ph}} \mathrm{BOX}\right\}$, only narrow resonance peaks are observed over the examined temperature range, with no broadening due to spin-spin relaxation $T_{2}$, caused by the proton exchange. Consequentially, all measurements are far below the temperature of coalescence and the present exchange rates are rather slow $\left(k<1 \mathrm{~s}^{-1}\right)$. The activation (kinetic) parameters of the tautomerisation were determined by the equilibration method. ${ }^{[153]}$ An equilibrium displacement can be achieved by either a temperature jump or by the isolation of one species; the observation of the system's equilibration can than be used to determine the rate constants. Here, the equilibrium displacement has been achieved by crystallisation of the iminoenamine isomer in pure form (cf. Section 4.2).

The time-dependence of the relaxation was monitored by ${ }^{1} \mathrm{H}$ NMR spectroscopy; the equilibration was started by dissolving a crystalline sample of pure iminoenamine isomer in ice-cooled $\mathrm{CDCl}_{3}$. The NMR tube with the sample was 


\section{Figure 4.7}

${ }^{1} \mathrm{H}$ NMR $\left(500 \mathrm{MHz}, 0{ }^{\circ} \mathrm{C}\right)$ spectra of the thermal relaxation of bis(oxazoline) $\left.\mathrm{H}_{\{}{ }^{\mathrm{Ph}} \mathrm{BOX}\right\}$ (iminoenamine $\rightleftharpoons$ diimine tautomer), in chloroform-d. The methyl peaks used for kinetic and equilibrium studies are depicted. The time is referenced to the first measurement (0 $\mathrm{min})$.
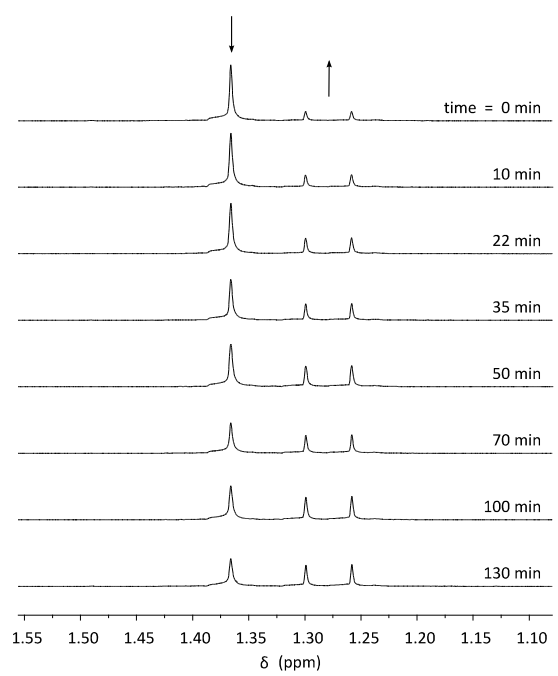

cooled to $0{ }^{\circ} \mathrm{C}$ and then inserted into the NMR magnet, adjusted to the desired temperature. The ${ }^{1} \mathrm{H}$ NMR spectrum was recorded immediately as a function of time (Figure 4.7), with longer intervals at the lower temperatures. The fraction of iminoenamine ( $[\mathrm{A}]$ ) is plotted versus time in Figure 4.8 (top). The reaction was studied in the range between 25 and $-5{ }^{\circ} \mathrm{C}$. Because of the poor solubility, additional experiments applying other solvents were not conducted.

The underlying tautomerisation is an example of the simplest reversible reaction (Scheme 4.4). »A« denotes the iminoenamine and $» B \ll$ the diimine tautomer in the following considerations. The integrated rate Equation 4.6 was derived from this equilibrium according to the literature. ${ }^{[153]}$

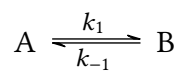

\section{Scheme 4.4}

$k_{1}$ is denoting the forward and $k_{-1}$ the backward steps. The related rate law is written as

$$
-\frac{d[\mathrm{~A}]}{d t}=k_{1}[\mathrm{~A}]-k_{-1}[\mathrm{~B}]
$$




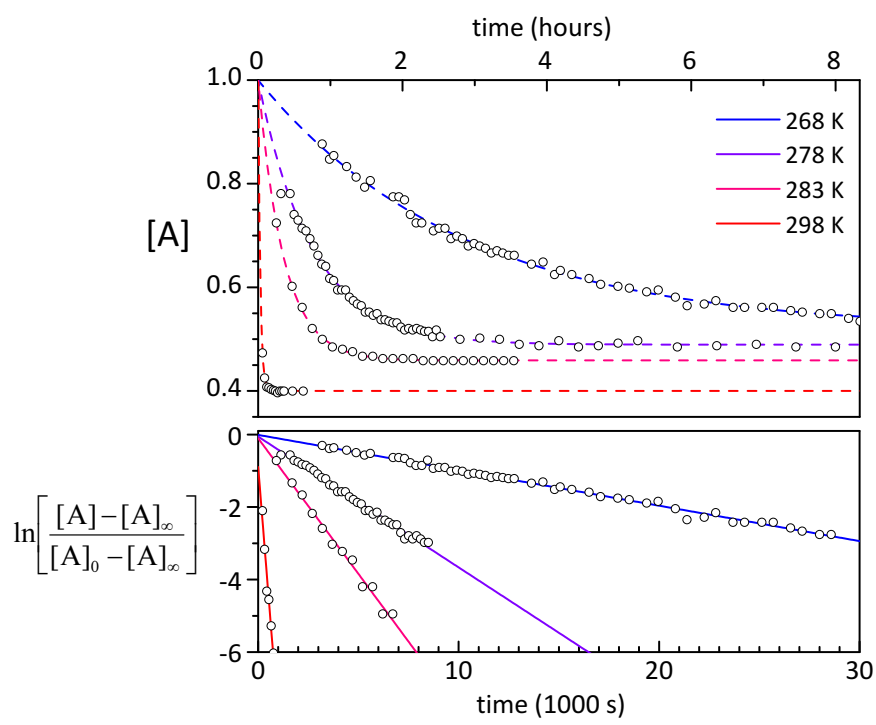

Figure 4.8. Time course of the equilibration of the iminoenamine form of $\left.\mathrm{H}_{\{}{ }^{\mathrm{Ph}} \mathrm{BOX}\right\}$ to the respective diimine at various temperatures (top). Linearised form with solid lines showing fits to the integrated rate law to obtain rate constants from the slope $k_{\mathrm{obs}}=k_{1}+k_{-1}$ (bottom). $\ln \ln \left[\left([\mathrm{A}]-[\mathrm{A}]_{\infty}\right) /\left([\mathrm{A}]_{0}-[\mathrm{A}]_{\infty}\right)\right],[\mathrm{A}]$ is the fraction of iminoenamine at time $t,[\mathrm{~A}]_{0}$ at $t=0$ and $[\mathrm{A}]_{\infty}$ at equilibrium.

The initial conditions are $[\mathrm{A}]=[\mathrm{A}]_{0}$ and $[\mathrm{B}]=0$. The mass balance relationship gives $[\mathrm{A}]_{0}=[\mathrm{A}]+[\mathrm{B}]$. Combined with Equation 4.3 it results

$$
-\frac{d[\mathrm{~A}]}{d t}=\left(k_{1}+k_{-1}\right)[\mathrm{A}]-k_{-1}[\mathrm{~A}]_{0}
$$

At equilibrium $d[A] / d t$ is 0 . With this condition, Equation 4.4 affords $\left(k_{1}+\right.$ $\left.k_{-1}\right)[\mathrm{A}]_{\infty}=k_{-1}[\mathrm{~A}]_{0} ;[\mathrm{A}]_{\infty}$ is the concentration of $\mathrm{A}$ at equilibrium. This in turn combined with Equation 4.4 gives

$$
-\frac{d[\mathrm{~A}]}{d t}=\left(k_{1}+k_{-1}\right)[\mathrm{A}]-[\mathrm{A}]_{\infty}
$$




\section{Tautomerism in Bis(oxazoline)s}

Separation of variables and integration finally yields the integrated rate law

$$
\ln \left[\frac{[\mathrm{A}]-[\mathrm{A}]_{\infty}}{[\mathrm{A}]_{0}-[\mathrm{A}]_{\infty}}\right]=-\left(k_{1}+k_{-1}\right) \cdot t
$$

The experimentally observed first-order rate constant equals the sum of two rate constants $\left(k_{\mathrm{obs}}=k_{1}+k_{-1}\right)$. The rate constants $k_{\mathrm{obs}}$ were calculated from the slope of a plot of $\ln \left[\left([\mathrm{A}]-[\mathrm{A}]_{\infty}\right) /\left([\mathrm{A}]_{0}-[\mathrm{A}]_{\infty}\right)\right]$ vs. time (Equation 4.6$)$, where $[\mathrm{A}]$ is here the fraction of the iminoenamine isomer at time $t$, at equilibrium $\left([\mathrm{A}]_{\infty}\right)$ and $t=0\left([\mathrm{~A}]_{0} \equiv 1\right)$, respectively. See Figure 4.8 (bottom) and Table 4.4. Values for $[\mathrm{A}]_{\infty}$ were taken from exponential regressions.

At equilibrium, $d[\mathrm{~A}] / d t$ equals 0 and $k_{1}[\mathrm{~A}]_{\infty}=k_{-1}[\mathrm{~B}]_{\infty}$ is obtained from Equation 4.3. This gives the equilibrium constant of the reaction:

$$
\frac{[\mathrm{B}]_{\infty}}{[\mathrm{A}]_{\infty}}=\frac{k_{1}}{k_{-1}}=K_{\mathrm{T}}
$$

The connection of the rate constants $k_{1}$ and $k_{-1}$ with the equilibrium constant (Equation 4.7) allows now the calculation of the respective rate constants from the measured $k_{\mathrm{obs}}$ and $K_{\mathrm{T}}$ values. At room temperature $(298 \mathrm{~K})$, the observed rate constant was determined as $k_{\mathrm{obs}}=(6.90 \pm 0.62) \times 10^{-3} \mathrm{~s}^{-1}$; together with the determined equilibrium constant of $K_{\mathrm{T}}=1.50$, the first-order constants $k_{1}=$ $(4.14 \pm 0.37) \times 10^{-3}$ and $k_{-1}=(2.76 \pm 0.25) \times 10^{-3} \mathrm{~s}^{-1}$ were calculated. As stated at the beginning of this section, the rate constants are exceptionally small and clearly $\ll 1 \mathrm{~s}^{-1}$, as expected from the NMR spectra.

\section{Table 4.4.}

Observed first order rate constants $\left(k_{\mathrm{obs}}\right)$ from the slope of the plot in Figure 4.8 (bottom) with fitting parameters $\bar{R}^{2}$. Deduced rate constants for the forward $\left(k_{1}\right)$ and backward steps $\left(k_{-1}\right)$ and associated equilibrium constants $\left(K_{\mathrm{T}}\right)$, used to calculate both rate constants from $k_{\mathrm{obs}} \cdot{ }^{a}$

\begin{tabular}{cccccc}
\hline$T, \mathrm{~K}$ & $k_{\mathrm{obs}}, \mathrm{s}^{-1}$ & $\bar{R}^{2}$ & $k_{1}, \mathrm{~s}^{-1}$ & $k_{-1}, \mathrm{~s}^{-1}$ & $K_{\mathrm{T}}$ \\
\hline 268.2 & $(9.66 \pm 0.09) \times 10^{-5}$ & 0.995 & $(4.65 \pm 0.05) \times 10^{-5}$ & $(5.01 \pm 0.06) \times 10^{-5}$ & 0.93 \\
278.2 & $(3.61 \pm 0.06) \times 10^{-4}$ & 0.992 & $(1.84 \pm 0.03) \times 10^{-4}$ & $(1.77 \pm 0.03) \times 10^{-4}$ & 1.04 \\
283.2 & $(7.48 \pm 0.24) \times 10^{-4}$ & 0.989 & $(4.04 \pm 0.13) \times 10^{-4}$ & $(3.43 \pm 0.11) \times 10^{-4}$ & 1.18 \\
298.2 & $(6.90 \pm 0.62) \times 10^{-3}$ & 0.961 & $(4.14 \pm 0.37) \times 10^{-3}$ & $(2.76 \pm 0.25) \times 10^{-3}$ & 1.50 \\
\hline
\end{tabular}

${ }^{a}$ Parameters are referred to the equilibrium: iminoenamine $\rightleftharpoons$ diimine. 


\subsubsection{Determination of Activation Parameters}

The temperature dependency of the respective rate constants can now be used to determine the reaction's activation parameters according to the Eyring equation

$$
k=\frac{k_{\mathrm{B}} T}{h} \cdot \exp \left(\frac{-\Delta G^{\ddagger}}{R T}\right)
$$

in which $\Delta G^{\ddagger}$ is the Gibbs energy of activation, $k_{\mathrm{B}}$ is the Boltzmann constant and $h$ is Planck's constant. With $\Delta G^{\ddagger}=\Delta H^{\ddagger}-T \Delta S^{\ddagger}$, it can be rewritten to

$$
k=\frac{k_{\mathrm{B}} T}{h} \cdot \exp \left(\frac{\Delta S^{\ddagger}}{R}\right) \cdot \exp \left(-\frac{\Delta H^{\ddagger}}{R T}\right)
$$

in which $\Delta H^{\ddagger}$ and $\Delta S^{\ddagger}$ are the enthalpy and entropy of activation, respectively. The activation parameters were determined from a plot of $\ln k / T$ vs. $T^{-1}$ according to the linear form of the Eyring equation

$$
\ln \frac{k}{T}=-\frac{\Delta H^{\ddagger}}{R} \cdot \frac{1}{T}+\ln \frac{k_{\mathrm{B}}}{h}+\frac{\Delta S^{\ddagger}}{R}
$$

Figure 4.9 shows the Eyring plot with the slope $-\Delta H^{\ddagger} / R$ and the intercept $\ln k_{\mathrm{B}} / h+$ $\Delta S^{\ddagger} / R$; the obtained parameters are compiled in Table 4.5 .

The first-order rate and the relatively small and positive entropy of activation for the iminoenamine $\longrightarrow$ diimine transformation, $\Delta S^{\ddagger}=(12 \pm 3) \mathrm{cal} \mathrm{K}^{-1} \mathrm{~mol}^{-1}$, suggest an unimolecular reaction in the rate-determining step (cf. Figure 4.10 for a proposed transition state). ${ }^{[153]}$ The experimental activation barrier, $\Delta G^{\ddagger}=$

\section{Table 4.5.}

\begin{tabular}{|c|c|c|c|c|c|}
\hline & & $\begin{array}{c}\Delta H^{\ddagger}, \\
\mathrm{kcal} \mathrm{mol}^{-1}\end{array}$ & $\begin{array}{c}\Delta S^{\ddagger}, \\
\operatorname{cal~K}^{-1} \mathrm{~mol}^{-1}\end{array}$ & $\begin{array}{c}\Delta G_{298}^{\ddagger}, \\
\mathrm{kcal} \mathrm{mol}^{-1}\end{array}$ & ref. \\
\hline $\mathrm{H}\left\{{ }^{\mathrm{Ph}} \mathrm{BOX}\right\}^{a}$ & $\begin{array}{l}k_{1}{ }^{b} \\
k_{-1}{ }^{c}\end{array}$ & $\begin{array}{l}24.1 \pm 0.9 \\
21.5 \pm 0.8\end{array}$ & $\begin{array}{r}12 \pm 3 \\
2 \pm 3\end{array}$ & $\begin{array}{l}20.7 \pm 1.3 \\
20.9 \pm 1.1\end{array}$ & $\begin{array}{l}\text { this work } \\
\text { this work }\end{array}$ \\
\hline $\mathrm{H}\left\{{ }^{\mathrm{Me}} \mathrm{BOX}\right\}^{d, b}$ & & 55.7 & & & [134] \\
\hline
\end{tabular}

Activation parameters of the equilibration of iminoenamine tautomers. See Table 4.5 for DFT-calculated values.

${ }^{a}$ Experimental data in $\mathrm{CDCl}_{3}$ solution, derived from the Eyring plot in Figure 4.9. ${ }^{b}$ Parameters refer to the reaction: iminoenamine $\rightarrow$ diimine. ${ }^{c}$ Parameters refer to the reaction: diimine $\rightarrow$ iminoenamine. ${ }^{d}$ ZPE-corrected energies from DFT calculation at the BP86/TZVP level. 


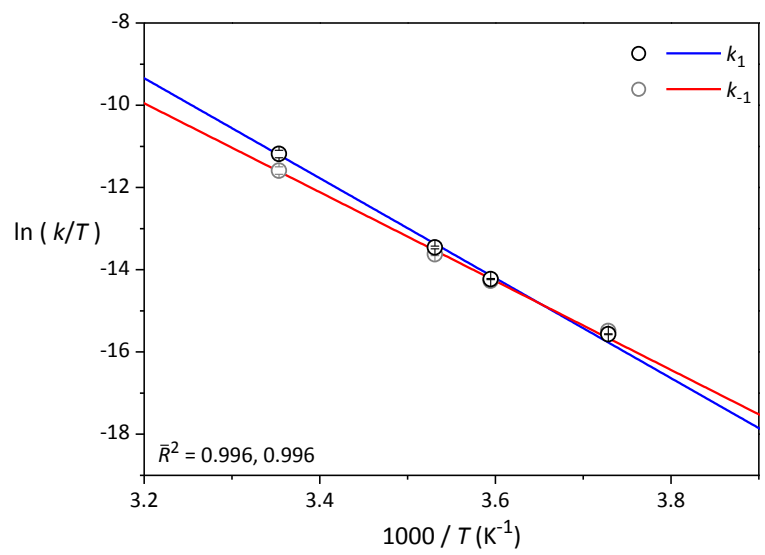

Figure 4.9. Eyring plot, $\ln \left(k \cdot T^{-1}\right)$ vs. $T^{-1}$, of the first order rate constants $k_{1}$ and $k_{-1}$ (Table 4.4) of the $\left.\mathrm{H}_{\{}{ }^{\mathrm{Ph}} \mathrm{BOX}\right\}$ tautomerisation with weighted linear regressions.

$(20.7 \pm 1.3) \mathrm{kcal} \mathrm{mol}^{-1}$, for $\left.\mathrm{H}_{\{}{ }^{\mathrm{Ph}} \mathrm{BOX}\right\}$ is relatively high, but in the expected range if tautomer interconversion can be observed. Since the definition of tautomerism includes that both isomers are $»$ readily interconvertible $«,{ }^{[154]}$ an energy barrier $\Delta G^{\ddagger}$ of less than $25 \mathrm{kcal} \mathrm{mol}^{-1}$ is generally expected to certainly consider two compounds as tautomers. On the other hand, with a barrier of about $40 \mathrm{kcal} \mathrm{mol}^{-1}$, two compounds would certainly not be considered as tautomers, since no interconversion is possible. Furthermore, the energy difference between two tautomers should not be too high, thus a $\mathrm{p} K_{\mathrm{T}}$ of 20 is considered as the limit, above which two isomers are not considered as tautomers. ${ }^{[155]}$

However, the activation energy is significantly lower in $\left.\mathrm{H}_{\left\{{ }^{\mathrm{Ph}}\right.} \mathrm{BOX}\right\}$, than the barrier (zero-point energy corrected, $\Delta E^{\ddagger}$ ) of $55.7 \mathrm{kcal} \mathrm{mol}^{-1}$ that was calculated for the analogous intramolecular tautomerisation reaction of $\mathrm{H}_{\left\{{ }^{\mathrm{Me}} \mathrm{BOX}\right\} .}{ }^{[134]}$ The latter value is likely too high, as possible solvent assistance or tunnelling effects were not considered. 


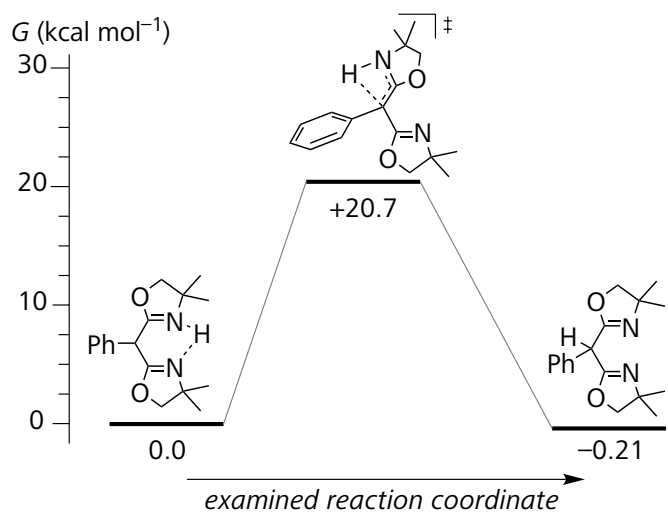

Figure 4.10

Experimental reaction profile of $\left.\mathrm{H}_{\{}{ }^{\mathrm{Ph}} \mathrm{BOX}\right\}$ tautomerisation.

\subsection{DFT Computations}

To gain deeper insights in the mechanism of the tautomerisation, computations using density functional theory (DFT) have been conducted. All computations were performed with the ORCA electronic structure program package. ${ }^{[156]}$ The coordinates of all inspected BOX tautomers were optimised applying the correlation functional of Lee, Yang, and Parr (B3LYP) ${ }^{[157,158]}$ together with the valence triple- $\zeta$ plus polarisation basis set def2-TZVPP. ${ }^{[159,160]}$ Solvent effects were considered by applying a conductor like screening model (COSMO) with the selection of chloroform as a solvent. Numerical frequency calculations using the optimised geometries afforded the respective thermodynamic energies and entropies together with the vibrational spectra depicted in Figure 4.4 and Figure A.2 (for further details, refer to the Experimental Part, Section 12.1).

The geometries and thermodynamic parameters of the diimine and iminoenamine tautomers of $\left.\mathrm{H}_{\{}{ }^{\mathrm{Ph}} \mathrm{BOX}\right\}$ and $\left.\mathrm{H}_{\{}{ }^{\mathrm{H}} \mathrm{BOX}\right\}$ have been inspected; the obtained structures are depicted in Figure 4.11. Superimposing the X-ray crystal structures of $\left.\mathrm{H}_{\{}{ }^{\mathrm{Ph}} \mathrm{BOX}\right\}$ and $\left.\mathrm{H}_{\{}{ }^{\mathrm{H}} \mathrm{BOX}\right\}$ from Figure 4.1 with the computed coordinates of the respective tautomers shows a good structural match (Figure 4.12).

\section{Ground States}

The computed thermodynamic parameters are summarised in Table 4.6. While the DFT-computed enthalpy for $\left.\mathrm{H}_{\{}{ }^{\mathrm{Ph}} \mathrm{BOX}\right\}, \Delta H_{\mathrm{DFT}}^{\ominus}=2.63 \mathrm{kcal} \mathrm{mol}^{-1}$, matches well to the experimental determined $\left(\Delta H_{\exp }^{\ominus}=2.33 \mathrm{kcal} \mathrm{mol}^{-1}\right)$, the entropy is 


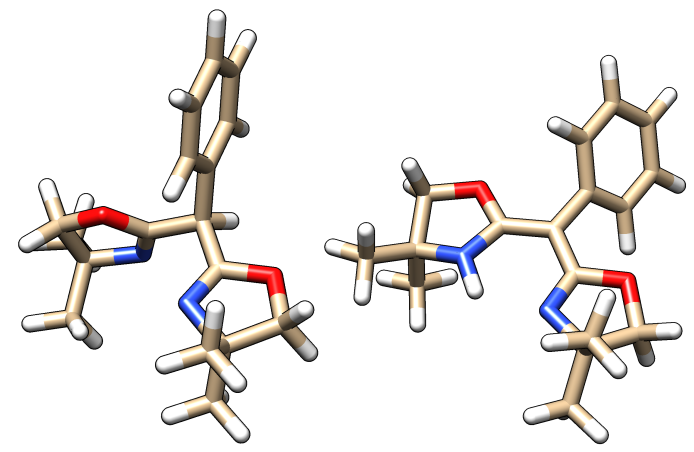

(a) diimine- $\mathrm{H}\left\{{ }^{\mathrm{Ph}} \mathrm{BOX}\right\}$

(b) iminoenamine- $\mathrm{H}\left\{{ }^{\mathrm{Ph}} \mathrm{BOX}\right\}$
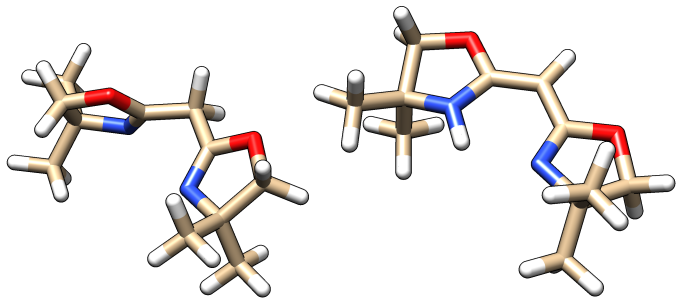

(c) diimine- $\mathrm{H}\left\{{ }^{\mathrm{H}} \mathrm{BOX}\right\}$

(d) iminoenamine- $\mathrm{H}\left\{{ }^{\mathrm{H}} \mathrm{BOX}\right\}$

Figure 4.11. Geometry-optimised coordinates of diimine (left side) and iminoenamine tautomers (right side) of $\left.\mathrm{H}_{\{}{ }^{\mathrm{Ph}} \mathrm{BOX}\right\}$ (top) and $\mathrm{H}\left\{{ }^{\mathrm{H}} \mathrm{BOX}\right\}$ (bottom). Structures were obtained from DFT geometry-optimisations on the B3LYP/def2-TZVPP level as described in text. Colour code: carbon, tan; hydrogen, white; nitrogen, blue, oxygen, red.

somewhat lower $\left(\Delta S_{\mathrm{DFT}}^{\ominus}=1.2\right.$ compared to $\left.\Delta S_{\mathrm{exp}}^{\ominus}=8.5 \mathrm{cal} \mathrm{K}^{-1} \mathrm{~mol}^{-1}\right)$, resulting in a higher Gibbs energy at $298 \mathrm{~K}$. This leads to the fact that the diimine tautomer would be only a minor component at $298 \mathrm{~K}\left(K_{\mathrm{T}}=0.02\right.$, compared to 1.43). Interestingly, in the case of $\left.\mathrm{H}_{\{}{ }^{\mathrm{H}} \mathrm{BOX}\right\}$, calculated enthalpy and entropy differences between the tautomers are both very small and lead to a relatively balanced $K_{\mathrm{T}}=1.73$ (cf. Table 4.6). This is also noteworthy due to the fact that no tautomerisation is observed experimentally in $\left.\mathrm{H}_{\{}{ }^{\mathrm{H}} \mathrm{BOX}\right\}$ but it resembles the results which were obtained elsewhere from DFT-computations for $\left.\mathrm{H}_{\left\{{ }^{\mathrm{Me}} \mathrm{BOX}\right.}\right\}^{[134]}$ (see above, Table 4.3). 


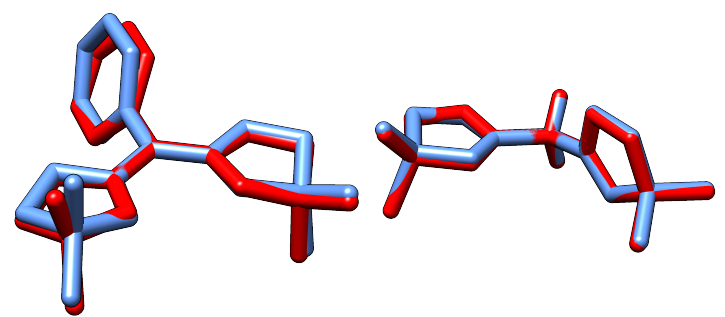
(a) iminoenamine- $\mathrm{H}\left\{{ }^{\mathrm{Ph}} \mathrm{BOX}\right\}$
(b) diimine- $\mathrm{H}\left\{{ }^{\mathrm{H}} \mathrm{BOX}\right\}$

Figure 4.12. Superimposed molecular structures of the determined X-ray crystal structures from Figure 4.1 and the DFT-optimised structures from Figure 4.11b and Figure 4.11c. The iminoenamine tautomer of $\left.\mathrm{H}_{\{}^{\mathrm{Ph}} \mathrm{BOX}\right\}$ is depicted left and the diimine tautomer of $\left.\mathrm{H}^{\mathrm{H}}{ }^{\mathrm{H}} \mathrm{BOX}\right\}$ on the right. Hydrogen atoms are omitted for the sake of clarity. Coordinates of DFT structures were inverted to fit $(1-x, 1-y, 1-z)$.

\section{Table 4.6.}

Comparison of thermodynamic data of the equilibrium of iminoenamine and diimine tautomers from DFT calculations. For computational details, see text; the geometryoptimised structures are depicted in Figure 4.11. ${ }^{a}$

\begin{tabular}{|c|c|c|c|c|c|}
\hline & & $\begin{array}{c}\Delta H^{\ominus}, \\
\mathrm{kcal} \mathrm{mol}^{-1}\end{array}$ & $\begin{array}{c}\Delta S^{\ominus} \\
\mathrm{cal} \mathrm{K}^{-1} \mathrm{~mol}^{-1}\end{array}$ & $\begin{array}{c}\Delta G_{298}^{\ominus} \\
\mathrm{kcal} \mathrm{mol}^{-1}\end{array}$ & $K_{\mathrm{T}}^{298 b}$ \\
\hline \multirow[t]{2}{*}{$\mathrm{H}\left\{{ }^{\mathrm{Ph}} \mathrm{BOX}\right\}$} & iminoenamine & 0 & 0 & 0 & - \\
\hline & dimine & 2.63 & 1.2 & 2.27 & 0.02 \\
\hline \multirow[t]{2}{*}{$\mathrm{H}\left\{{ }^{\mathrm{H}} \mathrm{BOX}\right\}$} & iminoenamine & 0 & 0 & 0 & - \\
\hline & diimine & -0.07 & 0.9 & -0.33 & 1.73 \\
\hline
\end{tabular}

${ }^{a}$ Parameters are referred to the equilibrium: iminoenamine $\rightleftharpoons$ diimine. DFT calculation at the B3LYP/def2-TZVPP level; chloroform is considered as the solvent by applying a continuum model (COSMO). ${ }^{b}$ Calculated using $\Delta G^{\ominus}=-\mathrm{R} T \ln K_{\mathrm{T}}$.

\section{Transition States}

A search for transition states afforded two states per $\mathrm{H}_{\left\{{ }^{\mathrm{Ph}} \mathrm{BOX}\right\}}$ and $\mathrm{H}\left\{{ }^{\mathrm{H}} \mathrm{BOX}\right\}$, respectively (Figure 4.13). In all four transition states, the proton is positioned between the bridging backbone carbon atom and the oxazoline-nitrogen. The proton is somewhat closer associated at the nitrogen atom $(\sim 1.3 \AA$ compared to $\sim 1.6 \AA$ ). All states posses a sole imaginary frequency $\left(v^{\ddagger}\right)$ as it is assumed by 


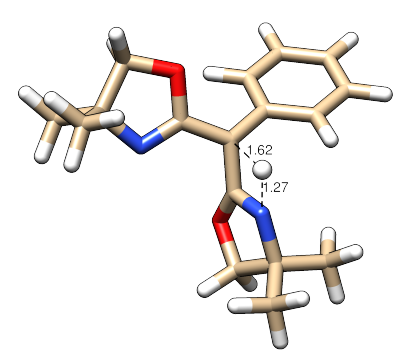

(a) TS1

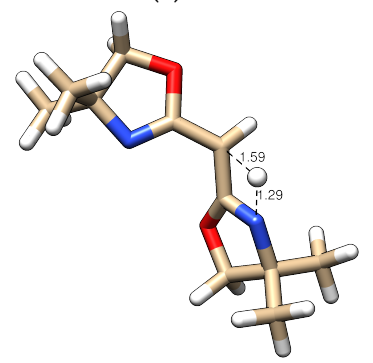

(c) TS1

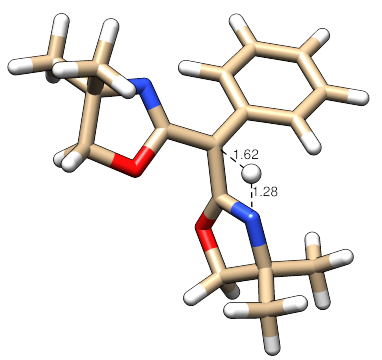

(b) TS2

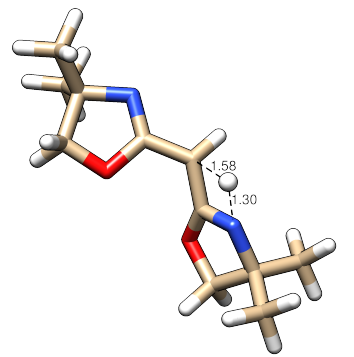

(d) TS2

Figure 4.13. DFT-computed transition states for the tautomerisation of $\left.\mathrm{H}_{\{}{ }^{\mathrm{Ph}} \mathrm{BOX}\right\}$ (top) and $\mathrm{H}\left\{{ }^{\mathrm{H}} \mathrm{BOX}\right\}$ (bottom). Distances are given in $\AA$. Structures were obtained from DFT calculations on the B3LYP/def2-TZVPP level as described in the text. Details and computed activation parameters are listed in Table 4.7. Colour code: carbon, tan; hydrogen, white; nitrogen, blue, oxygen, red.

transition state theory, which confirms that the calculated geometry is correctly at a saddle point; they are at around $v^{\ddagger} \approx 1850 i \mathrm{~cm}^{-1}$.

All four states are of equal activation enthalpy of about $\Delta H^{\ddagger} \approx 60 \mathrm{kcal} \mathrm{mol}^{-1}$ (Table 4.7). Intramolecular proton transfers lead to highly strained transition states with very high energy barriers of usually around $50 \mathrm{kcal} \mathrm{mol}^{-1}$ and it can be deduced that such a reaction will never occur. ${ }^{[155]}$ Though, the energies are quite comparable to the computed barrier for $\left.\mathrm{H}_{\left\{{ }^{\mathrm{Me}}\right.} \mathrm{BOX}\right\}$ (as stated above), in $\mathrm{H}_{\{}\left\{\mathrm{Ph}_{\mathrm{BOX}}\right\}$, the experimental barrier is significantly lower. This suggests that more complicated transition states should be considered upon inspecting the mechanism in greater depth. 
Table 4.7.

Comparison of activation parameters of the tautomerisation from DFT calculations. Geometry-optimised transition states are depicted in Figure 4.13; experimentally estimated parameters are listed in Table 4.5. ${ }^{a}$

\begin{tabular}{cccccc}
\hline & $\begin{array}{c}\Delta H^{\ddagger}, \\
\mathrm{kcal} \mathrm{mol}^{-1}\end{array}$ & $\begin{array}{c}\Delta S^{\ddagger}, \\
\mathrm{cal} \mathrm{K}^{-1} \mathrm{~mol}^{-1}\end{array}$ & $\begin{array}{c}\Delta G_{298}^{\ddagger}, \\
\mathrm{kcal} \mathrm{mol}^{-1}\end{array}$ & $\begin{array}{c}v^{\ddagger} b \\
\mathrm{~cm}^{-1}\end{array}$ \\
\hline $\mathrm{H}\left\{{ }^{\mathrm{Ph}} \mathrm{BOX}\right\}$ & TS1 & 60.1 & 2.8 & 59.2 & $1838.42 i$ \\
& TS2 & 61.0 & 7.4 & 58.8 & $1853.36 i$ \\
$\mathrm{H}\left\{{ }^{\mathrm{H}} \mathrm{BOX}\right\}$ & TS1 & 59.2 & 3.6 & 58.1 & $1854.31 i$ \\
& TS2 & 59.5 & 2.6 & 58.7 & $1874.52 i$ \\
\hline
\end{tabular}

${ }^{a}$ Parameters are referred to the equilibrium: iminoenamine $\rightleftharpoons$ diimine. DFT calculation at the B3LYP/def2-TZVPP level; chloroform is considered as the solvent by applying a continuum model (COSMO). ${ }^{b} v^{\ddagger}$ represents the sole imaginary frequency, which confirms that the calculated geometry is correctly at a saddle point.

Noteworthy is the analogous tautomerisation of malonaldehyde (and the structurally similar acetylacetone and malonic acid), for which it could be shown by DFT calculations that the inclusion of four water molecules can lower the transition-state energy of the highly strained four-membered ring significantly from 60 to $\sim 7 \mathrm{kcal} \mathrm{mol}^{-1}$; $[161]$ this low barrier is in agreement with experimental energies. ${ }^{[162,163]}$ It is likely that the aromatic phenyl ring in $\mathrm{H}\left\{{ }^{\mathrm{Ph}} \mathrm{BOX}\right\}$ has a significant stabilizing effect on such solvent aggregates, which probably also lowers the activation barrier to a comparable extent.

The determination of crystal structures of protonated $(Z)$-iminoenamine BOXs (see above) indicates that the protonation may play an important role in the mechanism, too. The role of $\mathrm{H}^{+}$on the tautomerism of $\mathrm{H}\left\{{ }^{\mathrm{Me}} \mathrm{BOX}\right\}$ was recently discussed; ${ }^{[134]}$ DFT calculations indicated an increase in the stability of the iminoenamine vs. the diimine tautomer upon protonation and in addition a slight lowering of the barrier of tautomerism. Yet, only the unimolecular and intramolecular proton transfer was analysed in that work. However, for $\left.\mathrm{H}_{\{}{ }^{\mathrm{Ph}} \mathrm{BOX}\right\}$, no indication for a role of $\mathrm{H}^{+}$was encountered in the present work.

\subsection{Conclusion}

Tautomerism in the prominent BOX ligand class was evidenced and studied in detail by X-ray diffractometry as well as by NMR and IR spectroscopies for the first 
time. By experiments and by DFT computation, IR spectroscopy was identified as an additional helpful tool to evidence and discriminate different BOX tautomers.

In addition, thermodynamic and kinetic data for the tautomerisation of $\left.\mathrm{H}_{\{}{ }^{\mathrm{Ph}} \mathrm{BOX}\right\}$ were provided by NMR experiments and DFT computation. It was found that both tautomers are in a balanced $(\sim 1: 1)$ equilibrium, characterized by a very small $\Delta G^{\ominus}$. And that the tautomerisation proceeds relatively slow via an intramolecular reaction pathway with a high reaction barrier $\Delta H^{\ddagger}$ for the transition state of this unimolecular reaction. The barrier is however low enough to observe tautomerism at room temperature; it is likely, that the energy of the transition state is lowered by the formation of solvent aggregates, supported by the phenyl group.

The phenyl group at the backbone spacer clearly favours the iminoenamine form in $\left.\mathrm{H}_{\{}{ }^{\mathrm{Ph}} \mathrm{BOX}\right\}$ and may also lower the activation barrier for tautomerisation, whereas other bis(oxazoline)s that lack the stabilising effect of the phenyl residue are observed in their diimine forms only. However, the iminoenamine tautomer may be present as a minor component in certain cases, as suggested by IR spectroscopy for $\left.\mathrm{H}_{\{}{ }^{\mathrm{H}} \mathrm{BOX}\right\}$ and $\mathrm{H}\left\{{ }^{\mathrm{Me}} \mathrm{BOX}\right\}$. The iminoenamine form of $\mathrm{H}\left\{{ }^{\mathrm{Ph}} \mathrm{BOX}\right\}$ is reminiscent of $\beta$-diketimines that are extensively used as anionic ligands, and a similarly rich coordination chemistry is indeed emerging in BOXs. ${ }^{[123]}$ 


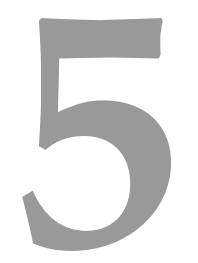

\section{Unexpected Non-Innocence in Copper(II) Complexes of BOXs: Dimerisation, Oxygenation and Radical Intermediates}

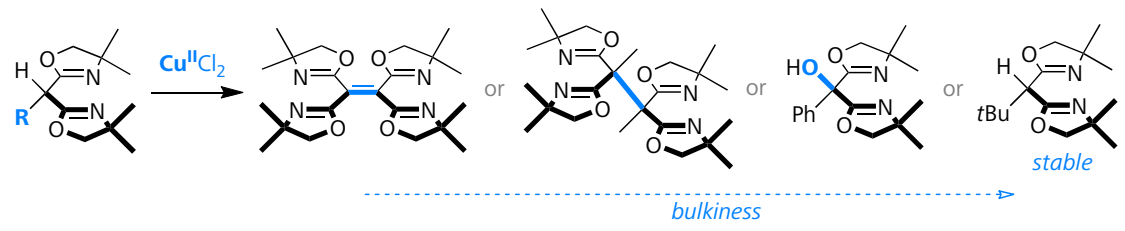

\subsection{Introduction}

$\mathrm{N}$ the course of explorational coordination experiments with the four BOX ligands described in the preceding chapters, not only the tautomerism of this ligand class was evidenced, but also an inherent non-innocent redox behaviour was discovered. Upon coordination of copper(II), the ligands are oxidised and - in the course of this reaction - they undergo consecutive reactions, such as dimerisation by $\mathrm{C}-\mathrm{C}$ radical coupling and mono-oxygenation.

Cross-coupling reactions forming $\mathrm{C}$-heteroatom or $\mathrm{C}-\mathrm{C}$ bonds mediated by copper compounds are widely known for longer than a century. Reactions of this type fall in categories coined $» U 1 l m a n n$ reactions ${ }^{[164]}$ (coupling between aryl halides) or the closely related »Ullmann-type reactions «. Furthermore, there are numerous reactions later evolved from this basis (cf. e. g. ref. [165, 166]). Related to bis(oxazoline)s and $\beta$-diketimines ( $\mathrm{NacNac}$ ) are other $\mathrm{CH}$-acidic compounds like ethyl cyanoacetate, malonodinitrile or acetylacetone, for which several coppermediated arylation reactions (coupling with aryl halides) have been developed. [166] Since copper ions usually take part in single-electron redox reactions, free radical mechanisms are often considered for copper-catalysed coupling reactions in general. 
Although bis(oxazoline)s are widely applied as ligands for redox active metals, coupling reactions mediated by copper were not reported up to now. So far, examples for the degradation of BOX ligands or for the related $\beta$-diketiminate ligands, are very scarce. Just recently, the oxygenation of $\left.\left[\left(\mathrm{H}_{\{}^{\mathrm{Me}} \mathrm{BOX}\right\}\right) \mathrm{Zn}\left(\mathrm{H}_{2} \mathrm{O}\right)_{3}\right]^{2+}$ by atmospheric dioxygen was reported by BELLEMIN-LAPONNAZ, GADE and coworkers, yielding a tetranuclear cluster with the corresponding alkoxy ligand $\left.\left(\mathrm{O}_{\{}{ }^{\mathrm{Me}} \mathrm{BOX}\right\}\right)^{-}$ (Figure 5.1, I). ${ }^{[167]}$ Here, a reaction time of $24 \mathrm{~h}$ was necessary to accomplish the oxygenation. An analogous oxygenation reaction was indicated by ESI-MS and EPR spectroscopy in a (BOX) $\mathrm{Cu}^{\mathrm{I}}$ complex after $24 \mathrm{~h}$ in air, subsequent with the formation of copper(II), by ČAPLAR and coworkers. ${ }^{[168]}$

More examples are known with the closely related $\beta$-diketiminate ligands, which were found being susceptible to oxidation reactions under particular conditions. The above mentioned oxygenation reactions of the BOX's methylene spacer are reminiscent of an oxidative degradation reaction of a $\beta$-diketiminate ligand with copper(II) or zinc(II) acetate, reported by ITOH and coworkers. ${ }^{[169]}$ Here, the bridging methylene was carbonylated (Figure 5.1, II). Furthermore, a cluster comprised of thallium(II/III) ions and the bisoxygenated $\beta$-diketiminate (as a bisimino acetal) was structurally identified after prolonged standing of a solution containing $\mathrm{Tl}^{\mathrm{I}}$ and $\beta$-diketiminate (III). ${ }^{[170]}$ Only recently, it was found that a $\beta$-diketiminate ligand can undergo one-electron oxidation (i. e. being redox »non-innocent $«)$ in a $\mathrm{Ni}^{\mathrm{II}}(\mathrm{NacNac})_{2}$ complex; however, no subsequent reactivity was reported for this complex. ${ }^{[176,177]}$ An insight into the dioxygen activation by metal- $\beta$-diketiminates was recently gained by GOLDBERG and coworkers: Exposure of a (NacNac) $\mathrm{Pt}^{\mathrm{tV}}$ complex to $\mathrm{O}_{2}$ yielded a $\mathrm{Pt}-\mathrm{O}-\mathrm{O}-\mathrm{C}_{\mathrm{NacNac}}$ (peroxo) intermediate, with the peroxide bound between the backbone carbon and platinum (IV). This ring system slowly converted to a bisoxygenated (hydroxy and alkoxy) (HO\{NacNac\}O) $\mathrm{Pt}^{\text {IV }}$ complex. ${ }^{[171]}$ Furthermore, analogous metallacyclic structures formed between alkenes, alkynes (or other unsaturated molecules), the $\beta$-diketiminate's backbone carbon and a variety of metals are known, demonstrating the nucleophilic character of the backbone carbon atom in metal-oxidised complexes. ${ }^{[171,178-184]}$

In contrast to the number of reported ligand-oxygenation reactions, there is only one example of a diketiminate undergoing oxidative dimerisation. The product of this reaction was first reported as the metal-free dimer being a minor product in addition to the simple complexation of $\mathrm{TiCl}_{4} \cdot{ }^{[172]}$ Structural evidence of sufficient quality was yielded later; ${ }^{[173]}$ in that report, the reaction was mediated by the lanthanides Er or Dy and the dimer was found in beside of clusters of the lanthanides and the mono-oxygenated ligand $(\mathrm{V})$. Two other examples addition- 

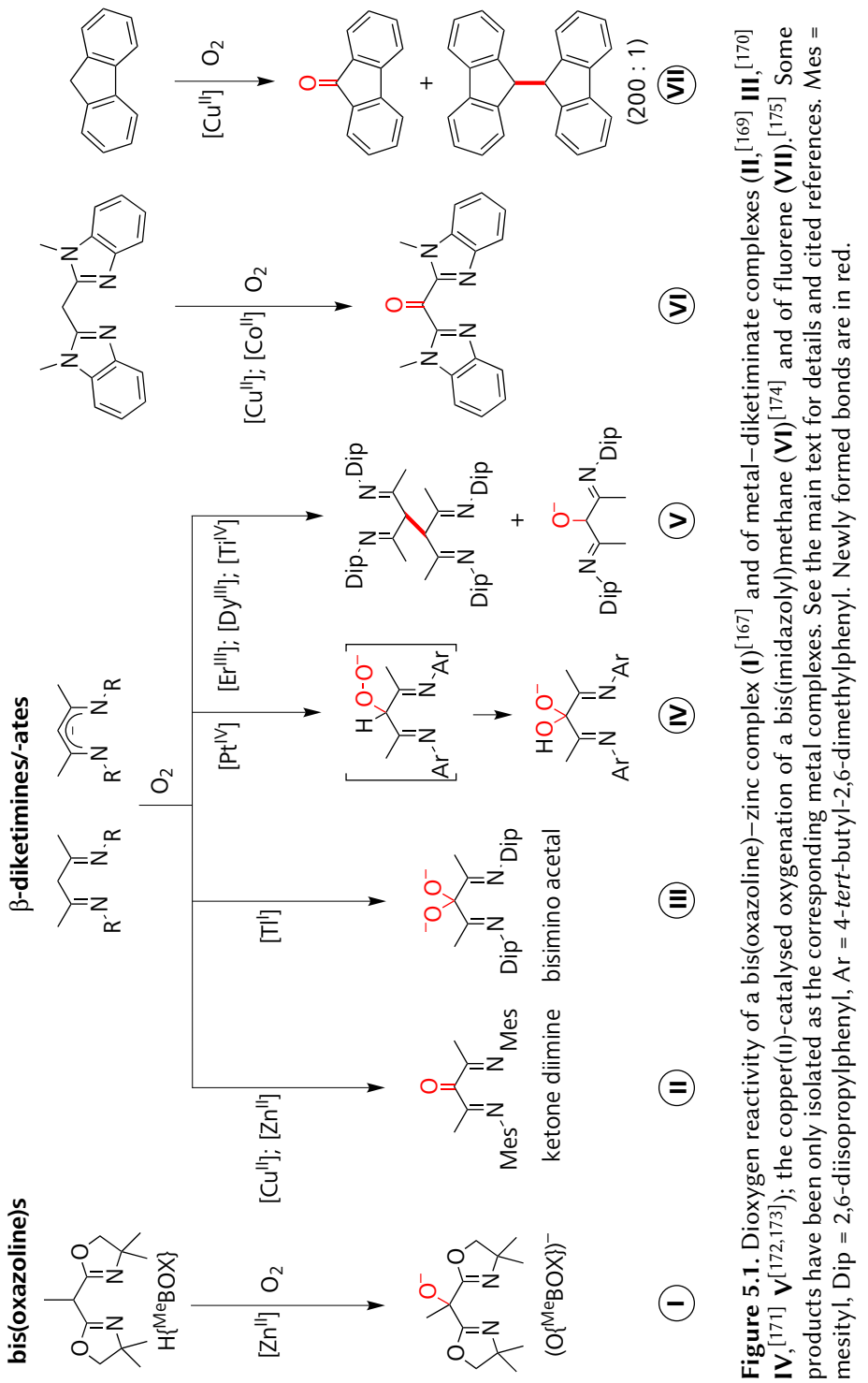
ally show the copper(II)-catalysed oxygenation of acidic benzylic positions in hydrocarbons. ${ }^{[185]}$ ZuBERBÜHLER reported, ${ }^{[174]}$ that bis(1-methyl-benzimidazol2-yl)methane can be quantitatively converted to the respective ketone with only $0.2 \mathrm{~mol} \% \mathrm{Cu}\left(\mathrm{ClO}_{4}\right)_{2}$ Figure 5.1, VI). This internal monooxygenase-like reaction is completed after 30 minutes in ethanol and under dioxygen atmosphere at room temperature. The reactivity with $\mathrm{Co}^{\mathrm{II}}$ is comparable to that of $\mathrm{Cu}^{\mathrm{II}}$. Other metal ions tested, showed no such reactivity. Analogous reactions were observed with bis(2-pyridyl)methane (BPM) and 6-methyl-PBM; ${ }^{[186]}$ and with the simple bis(imidazol-2-yl)methane, ${ }^{[187]}$ but in this case with iron(II or III). While these reactions proceed without basic conditions, in the oxidation of fluorene to fluorenone by $\mathrm{Cu}(\mathrm{OBz}) \mathrm{OMe}$ with triethylenetetramine ligand (VII), the deprotonation of fluorene was identified as the rate-limiting step. AlLARA, ${ }^{[175]}$ reported a conversion of $54 \%$ and proposed that the fluorenyl anion is oxidised by copper, followed by a reaction of the resulting radical with dioxygen and consecutive decomposition of the formed peroxide. As a byproduct, the homo-coupled 9,9'-bifluorene was obtained in $0.5 \%$.

\subsection{Copper(II)-Mediated Oxidative Dimerisation of BOXs}

\subsubsection{Motivation}

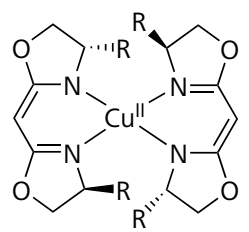

Scheme 5.1

The general coordination ability of the four $\left.\mathrm{H}_{\{}^{\mathrm{R}} \mathrm{BOX}\right\}$ ligands towards copper(I) and copper(II) was explored in the early stages of this work. In course of these investigations, the $\mathrm{ESI}^{+}$-MS analysis of reaction mixtures containing $\mathrm{H}_{\left\{{ }^{\mathrm{Me}} \mathrm{BOX}\right\}}$, base and copper(II) salts showed a base peak with a $\mathrm{m} / z 509$ which one could assign to a complex containing the copper ion coordinated by two bis(oxazolin)ates (BOXates): $\left({ }^{\mathrm{Me}_{\mathrm{BOX}}}\right)_{2} \mathrm{Cu}^{\mathrm{II}}$. A coordination which was found for example in a series of $\mathrm{Cu}^{\mathrm{II}}$ (BOXate) complexes from seven chiral BOXs containing a simple methylene bridge (complexes in Scheme 5.1 and related, see ref. [111] for details).

In the course of this work, unexpectedly a small amount of light-turquoise single crystals was obtained as the product from a reaction of $\mathrm{H}_{\left\{{ }^{\mathrm{Me}} \mathrm{BOX}\right\}}$ with $n$-butyl lithium and copper(II) perchlorate in tetrahydrofuran (see the experimental part for details). X-ray structure elucidation revealed, that the complex $\left[\left({ }^{\mathrm{Me}_{\mathrm{BOX}}}\right)\left\{\mathrm{Cu}^{\mathrm{II}}(\mathrm{OAc})\left(\mathrm{H}_{2} \mathrm{O}\right)\right\}_{2}\right]\left(\mathrm{ClO}_{4}\right)_{2}$ is present (Figure 5.2). Interestingly, the complex contains the unprecedented dimerised tetrakis(oxazoline) ligand ${ }^{\mathrm{Me}_{\mathrm{BOX}}}$ with 


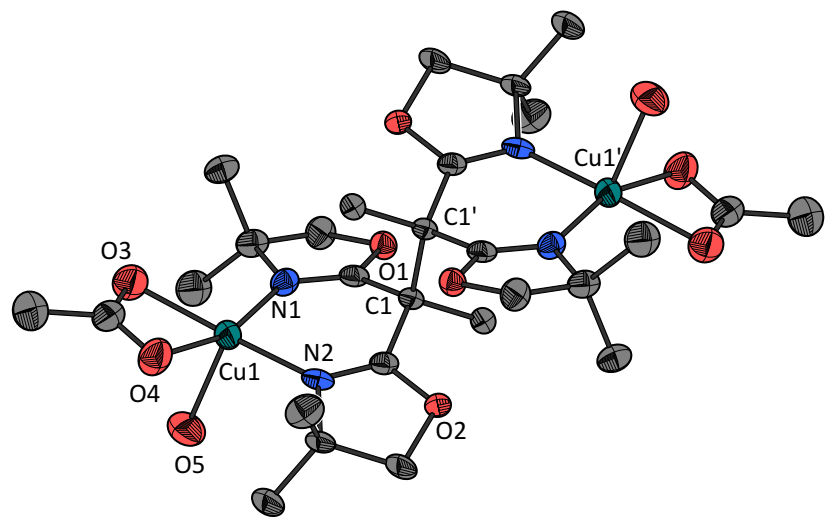

Figure 5.2. Solid-state molecular structure of $\left[\left({ }^{\mathrm{Me}} \mathrm{BOX} 2\right)\left\{\mathrm{Cu}(\mathrm{OAAc})\left(\mathrm{H}_{2} \mathrm{O}\right)\right\}_{2}\right]\left(\mathrm{ClO}_{4}\right)_{2}$ with important atoms labelled. Displacement ellipsoids are drawn at the $50 \%$ probability level; hydrogen atoms and perchlorate anions have been omitted for the sake of clarity; symmetry transformations used to generate equivalent atoms ('): $1-x, 1-y, 1-z$. Significant interatomic distances and angles are listed in Table 5.1.

the backbones of the ligands $\mathrm{C}-\mathrm{C}$ coupled. The source of the coordinating acetates remains unclear, but it could be presumed that the acetate was formed out of the $\mathrm{H}\left\{{ }^{\mathrm{Me}} \mathrm{BOX}\right\}$ ethylene backbone upon hydrolysation in the $\mathrm{Cu} / n \mathrm{BuLi}$ mixture.

\subsubsection{Formation of ${ }^{\mathrm{Me}} \mathrm{BOX}_{2}$}

In search of reasonable procedures to enlighten the ligand dimerisation, the following suitable conditions were found: The combination of a concentrated methanol solution of copper(II) chloride dihydrate with a concentrated solution of $\left.\mathrm{H}_{\{}{ }^{\mathrm{Me}} \mathrm{BOX}\right\}$ lead to the immediate precipitation of a colourless powder. Note that no base was added. The precipitated complex was identified as $\left({ }^{\mathrm{Me}_{\mathrm{BOX}}}\right)\left(\mathrm{Cu}^{\mathrm{I}} \mathrm{Cl}\right)_{2}$ (Scheme 5.2, step a). A good purity was indicated by combustion analysis, while the $[\mathrm{M}-$ $\left.\mathrm{CuCl}_{2}\right]^{+}$ion in high-resolution MS at $m / z 509.2186$ is in agreement with the formulation of a complex with the dimeric ligand ${ }^{\mathrm{Me}_{\mathrm{BOX}}}$, as well as ${ }^{1} \mathrm{H} \mathrm{NMR}$ spectroscopy is. Both copper atoms are present in the $\mathrm{Cu}^{\mathrm{I}}$ oxidation state as evidenced by NMR spectra characteristic for diamagnetic species and by the absence of a strong blue or green colour, typical to $\mathrm{Cu}^{\mathrm{II}}$. Intense coloured compounds were encountered in all $\mathrm{Cu}^{\text {II }}$ complexes in this work. 


\section{(a)}

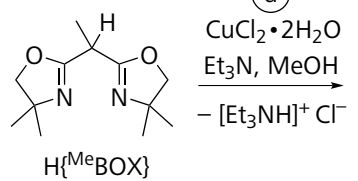

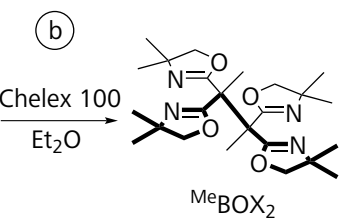

Scheme 5.2 (a) Formation of $\left({ }^{\mathrm{Me}} \mathrm{BOX}_{2}\right) \mathrm{Cu}_{2} \mathrm{Cl}_{2}$ from $\left.\mathrm{H}_{\{}{ }^{\mathrm{Me}} \mathrm{BOX}\right\}$ and copper(II) chloride, followed by (b) the recovery of ${ }^{\mathrm{Me}} \mathrm{BOX}_{2}$ upon removal of the inorganic metal salt.

The ${ }^{1} \mathrm{H}$ NMR spectrum of $\left({ }^{\mathrm{Me}_{\mathrm{BOX}}}\right) \mathrm{Cu}_{2} \mathrm{Cl}_{2}$ resembles the spectrum of $\left.\mathrm{H}_{\{}{ }^{\mathrm{Me}} \mathrm{BOX}\right\}$, but lacks the backbone proton peak and the backbone methyl group is shifted downfield by $0.3 \mathrm{ppm}$ as a result of the $\mathrm{C}-\mathrm{C}$ coupling. Oxazoline $\mathrm{CH}_{2}$ and $\mathrm{CMe}_{2}$ groups are also shifted downfield by $\sim 0.2 \mathrm{ppm}$ as a result of the copper coordination. Oxazoline $\mathrm{CH}_{3}$ and $\mathrm{CH}_{2}$ groups show both a distinct diastereotopicity, both peaks are split into two signals by $\Delta \delta_{\mathrm{H}}=0.05$ and $0.10 \mathrm{ppm}$ respectively. The ${ }^{2} J_{\mathrm{HH}}$ coupling in the $\mathrm{CH}_{2}$ groups is not resolved due to a slight band broadening, probably because of the presence of a paramagnetic impurity. The protons are either outside or inside of the two layers the dimeric ligand possesses (cf. Figure 5.3b below). Due to these two different surroundings, a distinct diastereotopicity is present. The neat ${ }^{{ }^{\mathrm{e}}} \mathrm{BOX}_{2}$ ligand is considered further below.

Yellow high-quality single crystals of the copper(I) complex could be obtained by the slow concentration of a solution in methylene chloride/acetone mixture and were analysed by X-ray crystal structure diffractometry. In the solid-state, the copper(I) ion in the coupled complex was found to be relatively sheltered from oxidation by air. However, the colourless to yellow solutions are turning slightly green in air over prolonged time, indicating oxidation to copper(II). The stoichiometry of the isolated complex indicates that the reaction occurs in the simple stoichiometry of one $\mathrm{CuCl}_{2}$ and one BOX molecule. However, a base would be needed to accept the proton released from the BOX ligand. In the case where no external base is present, presumably one equivalent of ligand acts as a base, accepting the released proton. The yield of $\left({ }^{\mathrm{Me}} \mathrm{BOX}_{2}\right)(\mathrm{Cu} C \mathrm{Cl})_{2}$ can be improved from $45 \%$ up to $96 \%$ when triethylamine is added as a base to scavenge the released protons. This role of the base is supported by the isolation of long colourless needles of triethylammonium chloride from the mother liquor as confirmed by a ${ }^{1} \mathrm{H}$ NMR analysis. The reaction was also executed in argon atmosphere instead of air, which additionally prevents unwanted secondary reactivity with dioxygen, which will be discussed later. 


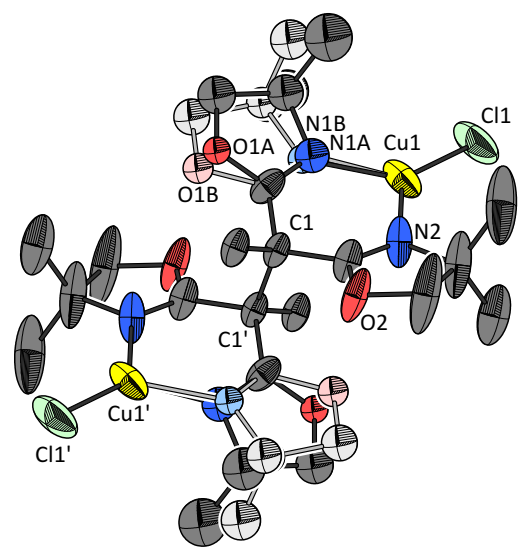

(a)

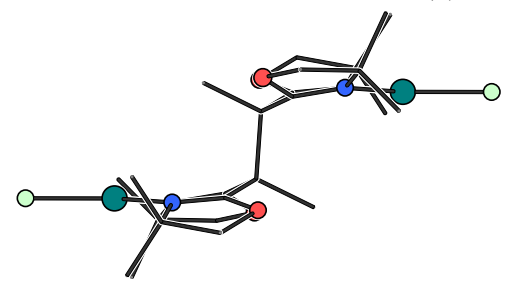

(b) side view

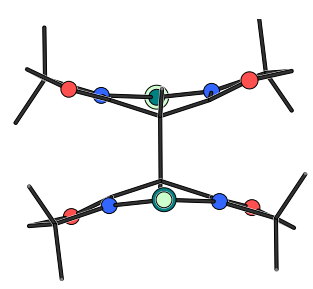

(c) front view

Figure 5.3. Solid-state molecular structure of the dimer $\left({ }^{\mathrm{Me}} \mathrm{BOX}{ }_{2}\right)\left(\mathrm{Cu} \mathrm{u}^{\prime} \mathrm{Cl}\right)_{2}$ with important atoms labelled. Displacement ellipsoids are drawn at the $50 \%$ probability level; hydrogen atoms have been omitted for the sake of clarity; symmetry transformations used to generate equivalent atoms $\left(^{\prime}\right):-x, 1-y, 1-z$. Atoms located at a second site $(\mathrm{B}, \sim 50 \%)$, due to crystallographic disorder, are drawn in lighter shade. Significant interatomic distances and angles are listed in Table 5.1. 
The X-ray structure confirmed the previous formulation of a complex comprised of the dimerised ligand $\left({ }^{{ }^{M}} \mathrm{BOX}_{2}\right)\left(\mathrm{Cu}{ }^{\mathrm{I}} \mathrm{Cl}\right)_{2}$. The solid-state structure is depicted in Figure 5.3. It is well evident, that incidentally to the $\mathrm{C}-\mathrm{C}$ coupling reaction both copper atoms have been reduced to copper(I). The complex crystallised in the monoclinic space group $P 2_{1} / c$. The dimerised nature of the complex is reflected by its solid-state structure: The binuclear complex resides on a crystallographically imposed inversion centre, maintaining a staggered conformation (considering the $\mathrm{C} 1-\mathrm{C} 1^{\prime}$ bond) with both metals in maximum distance and with two crystallographically equivalent bis(oxazoline) moieties. Both ligands are coupled between the $\mathrm{C} 1$ atoms; the $\mathrm{sp}^{3}$-hybridised atoms lead to an arrangement with two parallel levels ( $0^{\circ}$ between the planes spanned by the bis(oxazoline) moieties). This bilayer structure is reflected in the ${ }^{1} \mathrm{H}$ NMR spectrum of the complex in solution, leading to diastereotopic methyl carbons $\left(\mathrm{CMe}_{2}\right)$ and methylene protons, as described above. Although, the conformation at the $\mathrm{C} 1-\mathrm{C} 1^{\prime}$ bond does not have to be the same in solution. The copper(I) ions are coordinated in a trigonal-planar geometry, building a six membered, slightly boat-shaped ring with a mean ligand »bite« angle of $91^{\circ}$. The bis(oxazoline) moieties are bent away from each other, resulting in an angle between each two adjacent oxazoline rings of $40^{\circ}$. This leads to significant shielding of the copper(I) ions at the exterior sides by the $\mathrm{CMe}_{2}$ groups, while the interior is somehow protected by the methyl groups at $\mathrm{C} 1 / \mathrm{C} 1^{\prime}$. It is noteworthy, that the newly formed $\mathrm{C} 1-\mathrm{C} 1^{\prime}$ bond is exceptionally long with a length of $(1.62 \pm 0.01) \AA$, in contrast to $1.530 \AA$ for an average $\mathrm{C}_{\mathrm{sp}^{3}}-\mathrm{C}_{\mathrm{sp}^{3}}$ bond. ${ }^{[139]}$ The $\mathrm{C} 1-\mathrm{C} 1^{\prime}$ bond is even slightly longer in $\left[\left({ }^{\mathrm{Me}} \mathrm{BOX}_{2}\right)\left\{\mathrm{Cu}^{\mathrm{II}}(\mathrm{OAc})\left(\mathrm{H}_{2} \mathrm{O}\right)\right\}_{2}\right]\left(\mathrm{ClO}_{4}\right)_{2}$ with $(1.64 \pm 0.01) \AA$.

As a byproduct in some experiments, an orange precipitate was encountered, which was identified as the corresponding copper(II) complex of the coupled ligand $\left(\left({ }^{\mathrm{Me}_{\mathrm{BOX}}}\right) \mathrm{Cu}_{2} \mathrm{Cl}_{4}\right)$. This complex is particularly formed when an excess of copper(II) chloride is present; it can also be obtained by exposing the isolated copper(I) complex to copper(II) chloride, indicating the replacement of copper(I) with the more favoured coordination of copper(II). The molecular structure in Figure 5.4 was elucidated by means of X-ray diffraction using orange single crystals, which were obtained upon slow concentration of the mother liquor after the removal of precipitated $\left({ }^{\mathrm{Me}} \mathrm{BOX}_{2}\right) \mathrm{Cu}_{2} \mathrm{Cl}_{2}$ by filtration. The complex crystallised in the orthorhombic space group $P b c a$ and is structurally relatively similar to the other structures with ${ }^{\mathrm{Me}} \mathrm{BOX}_{2}$ ligand. $\mathrm{Cu}^{\mathrm{II}}$ atoms are coordinated by $2 \mathrm{Cl}^{-}$in a distorted tetrahedral fashion $\left(\tau_{4} \approx 0.7\right)$.

All in all, it was possible to structurally elucidate copper(I) and copper(II) complexes of ${ }^{\mathrm{Me}_{\mathrm{BOX}}}$ having three different molecular coordination geometries: 
Table 5.1.

Significant geometric information of the solid-state structures of complexes incorporating the dimerised ligand ${ }^{\mathrm{Me}_{\mathrm{BOX}}}$ in Figures 5.2, 5.3 and 5.4. Interatomic distances $(\AA)$, angles $\left({ }^{\circ}\right)$ and $\tau$ parameters. ${ }^{a}$

\begin{tabular}{|c|c|c|c|}
\hline Atoms 1,2 & $d 1,2(\AA)$ & Atoms $1,2,3$ & Angle $1,2,3\left({ }^{\circ}\right)$ \\
\hline \multicolumn{4}{|c|}{$\left.\left(\mathrm{Me}^{\mathrm{BOX}}\right)_{2}\right)\left(\mathrm{Cu}^{\prime} \mathrm{Cl}\right)_{2}$} \\
\hline $\mathrm{Cu} 1-\mathrm{N} 1 \mathrm{~A}$ & $1.9207(170)$ & $\mathrm{N} 1 \mathrm{~A}-\mathrm{Cu} 1-\mathrm{N} 2$ & $89.70(53)$ \\
\hline $\mathrm{Cu} 1-\mathrm{N} 2$ & $1.9986(59)$ & $\mathrm{N} 1 \mathrm{~B}-\mathrm{Cu} 1-\mathrm{N} 2$ & $92.09(41)$ \\
\hline $\mathrm{Cu} 1-\mathrm{N} 1 \mathrm{~B}$ & $2.0785(139)$ & $\mathrm{N} 1 \mathrm{~A}-\mathrm{Cu} 1-\mathrm{Cl} 1$ & $133.93(62)$ \\
\hline \multirow[t]{2}{*}{$\mathrm{Cu} 1-\mathrm{Cl} 1$} & $2.1359(26)$ & $\mathrm{N} 1 \mathrm{~B}-\mathrm{Cu} 1-\mathrm{Cl} 1$ & $131.83(38)$ \\
\hline & & $\mathrm{N} 2-\mathrm{Cu} 1-\mathrm{Cl} 1$ & $136.08(18)$ \\
\hline $\mathrm{C} 1-\mathrm{C}^{\prime}$ & $1.6245(97)$ & \multirow[t]{2}{*}{$\mathrm{N} 1 \mathrm{~A}-\mathrm{Cu} 1-\mathrm{N} 1 \mathrm{~B}^{b}$} & \multirow{2}{*}{$\begin{array}{r}130.00(10) \\
6.66(62)\end{array}$} \\
\hline $\mathrm{Cu} \cdots \mathrm{Cu}$ & $7.3765(13)$ & & \\
\hline \multicolumn{4}{|c|}{$\left({ }^{\mathrm{Me}} \mathrm{BOX}_{2}\right)\left(\mathrm{Cu}^{\mathrm{II}} \mathrm{Cl}_{2}\right)_{2}$} \\
\hline $\mathrm{Cu} 1-\mathrm{N} 1$ & $1.9857(18)$ & $\mathrm{N} 1-\mathrm{Cu} 1-\mathrm{N} 2$ & $88.49(7)$ \\
\hline $\mathrm{Cu} 1-\mathrm{N} 2$ & $2.0070(17)$ & $\mathrm{N} 1-\mathrm{Cu} 1-\mathrm{Cl} 1 \mathrm{~A}(\beta)$ & $131.92(6)$ \\
\hline $\mathrm{Cu} 1-\mathrm{Cl} 1 \mathrm{~A}$ & $2.2210(8)$ & $\mathrm{N} 1-\mathrm{Cu} 1-\mathrm{Cl} 1 \mathrm{~B}$ & $107.17(13)$ \\
\hline $\mathrm{Cu} 1-\mathrm{Cl} 1 \mathrm{~B}$ & $2.2588(57)$ & $\mathrm{N} 1-\mathrm{Cu} 1-\mathrm{Cl} 2 \mathrm{~A}$ & $102.48(6)$ \\
\hline $\mathrm{Cu} 1-\mathrm{Cl} 2 \mathrm{~A}$ & $2.2335(7)$ & $\mathrm{N} 1-\mathrm{Cu} 1-\mathrm{Cl} 2 \mathrm{~B}(\beta)$ & $126.62(13)$ \\
\hline \multirow[t]{2}{*}{$\mathrm{Cu} 1-\mathrm{Cl} 2 \mathrm{~B}$} & $2.0813(43)$ & $\mathrm{N} 2-\mathrm{Cu} 1-\mathrm{Cl} 1 \mathrm{~A}$ & $107.91(5)$ \\
\hline & & $\mathrm{N} 2-\mathrm{Cu} 1-\mathrm{Cl} 1 \mathrm{~B}(\alpha)$ & $121.66(15)$ \\
\hline $\mathrm{C} 1-\mathrm{C}^{\prime}$ & $1.6133(26)$ & $\mathrm{N} 2-\mathrm{Cu} 1-\mathrm{Cl} 2 \mathrm{~A}(\alpha)$ & $130.23(5)$ \\
\hline \multirow{6}{*}{$\mathrm{Cu} \cdots \mathrm{Cu}$} & $7.4442(4)$ & $\mathrm{N} 2-\mathrm{Cu} 1-\mathrm{Cl} 2 \mathrm{~B}$ & $110.04(12)$ \\
\hline & & $\mathrm{Cl} 1 \mathrm{~A}-\mathrm{Cu} 1-\mathrm{Cl} 2 \mathrm{~A}$ & $100.08(3)$ \\
\hline & & $\mathrm{Cl} 1 \mathrm{~B}-\mathrm{Cu} 1-\mathrm{Cl} 2 \mathrm{~B}$ & $104.10(20)$ \\
\hline & & $\mathrm{Cl} 1 \mathrm{~A}-\mathrm{Cu} 1-\mathrm{Cl}_{1} \mathrm{~B}^{b}$ & $26.15(13)$ \\
\hline & & $\mathrm{Cl} 2 \mathrm{~B}-\mathrm{Cu} 1-\mathrm{Cl} 2 \mathrm{~A}^{b}$ & $28.53(12)$ \\
\hline & & $\tau_{4}$ value & $0.69(\mathrm{~A}), 0.79(\mathrm{~B})$ \\
\hline \multicolumn{4}{|c|}{ 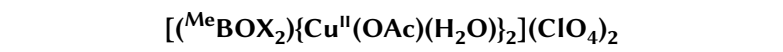 } \\
\hline $\mathrm{Cu} 1-\mathrm{N} 1$ & $1.9710(48)$ & $\mathrm{N} 1-\mathrm{Cu} 1-\mathrm{N} 2$ & $91.61(20)$ \\
\hline $\mathrm{Cu} 1-\mathrm{N} 2$ & $1.9697(51)$ & $\mathrm{O} 3-\mathrm{Cu} 1-\mathrm{O} 4$ & $65.42(20)$ \\
\hline $\mathrm{Cu} 1-\mathrm{O} 3$ & $2.0183(51)$ & $\mathrm{N} 1-\mathrm{Cu} 1-\mathrm{O} 3$ & $99.82(20)$ \\
\hline $\mathrm{Cu} 1-\mathrm{O} 4$ & $2.0163(51)$ & $\mathrm{N} 2-\mathrm{Cu} 1-\mathrm{O} 4$ & $100.64(21)$ \\
\hline \multirow{2}{*}{$\mathrm{Cu} 1-\mathrm{O} 5$} & $2.1894(53)$ & $\mathrm{N} 1-\mathrm{Cu} 1-\mathrm{O} 4(\alpha)$ & $161.78(20)$ \\
\hline & & $\mathrm{N} 2-\mathrm{Cu} 1-\mathrm{O} 3(\beta)$ & $162.70(21)$ \\
\hline $\mathrm{C} 1-\mathrm{C} 1^{\prime}$ & $1.6471(75)$ & $\mathrm{N} 1-\mathrm{Cu} 1-\mathrm{O} 5$ & $101.08(20)$ \\
\hline \multirow[t]{4}{*}{$\mathrm{Cu} \cdots \mathrm{Cu}$} & 7.3794(11) & $\mathrm{N} 2-\mathrm{Cu} 1-\mathrm{O} 5$ & $99.37(21)$ \\
\hline & & $\mathrm{O} 3-\mathrm{Cu} 1-\mathrm{O} 5$ & $91.19(22)$ \\
\hline & & $\mathrm{O} 4-\mathrm{Cu} 1-\mathrm{O} 5$ & $90.28(22)$ \\
\hline & & $\tau_{5}$ value & 0.15 \\
\hline
\end{tabular}

$\overline{{ }^{a} \text { See p. } 269 \text { for description of } \tau_{4} \text { and } \tau_{5} \text { parameters. }{ }^{b} \text { Angle between the two }}$ disordered moieties $\mathrm{A}$ and $\mathrm{B}$. 
trigonal planar, tetrahedral and square pyramidal. Compare Table 5.1 for more geometric parameters of all three structurally elucidated complexes with ${ }^{\mathrm{Me}_{\mathrm{BOX}}}$.

\subsubsection{Formation of ${ }^{\mathrm{B}} \mathrm{BOX}_{2}$}

In analogy to the dimerisation of $\left.\mathrm{H}_{\{}{ }^{\mathrm{Me}} \mathrm{BOX}\right\}$, the $\mathrm{CH}_{2}$-bridged ligand $\mathrm{H}\left\{{ }^{\mathrm{H}} \mathrm{BOX}\right\}$ was also exposed to $\mathrm{CuCl}_{2}$, in expectation of an analogous reactivity. Thus, equimolar amounts of $\mathrm{H}\left\{{ }^{\mathrm{H}} \mathrm{BOX}\right\}, \mathrm{Et}_{3} \mathrm{~N}$ and $\mathrm{CuCl}_{2} \cdot 2 \mathrm{H}_{2} \mathrm{O}$ were combined in deaerated methanol, under an atmosphere of dry argon. Upon addition of the copper salt, the solution turned dark blue and after $10 \mathrm{~min}$ a yellow powder was separated by filtration. Elemental analysis is in accordance with the complex $\left({ }^{\square} \mathrm{BOX}_{2}\right) \mathrm{Cu}_{2} \mathrm{Cl}_{2}$ and a yield of $45 \%$ was estimated (Scheme 5.3a). $» \square \ll$ in ${ }^{\square} \mathrm{BOX}_{2}$ stands for the absence of a residue $\mathrm{R}$.

The anticipated $\mathrm{C}=\mathrm{C}$ double bond, connecting both $\mathrm{BOX}$ moieties, is reflected in the IR spectrum at $\tilde{v}(\mathrm{C}=\mathrm{C})=1614 \mathrm{~cm}^{-1}$ with a medium intensity. Since this region is crowded by several other vibrations, Raman spectroscopy was additionally applied. The feature is very strong in the Raman spectrum at $\tilde{v}(\mathrm{C}=\mathrm{C})=1616 \mathrm{~cm}^{-1}$ as expected, since symmetric stretches tend to be strong Raman modes. According

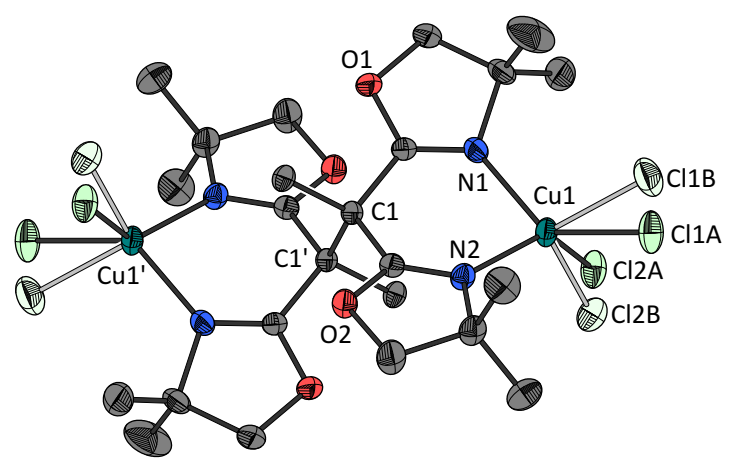

Figure 5.4. Solid-state molecular structure of $\left({ }^{\mathrm{Me}} \mathrm{BOX}_{2}\right)\left(\mathrm{Cu}^{\prime \prime} \mathrm{Cl}_{2}\right)_{2}$ with important atoms labelled. Displacement ellipsoids are drawn at the $50 \%$ probability level; hydrogen atoms have been omitted for the sake of clarity; symmetry transformations used to generate equivalent atoms ('): $1-x, 1-y, 1-z$. Chlorides located at a second site (B, $14 \%)$, due to crystallographic disorder, are drawn in lighter shade. Significant interatomic distances and angles are listed in Table 5.1. 

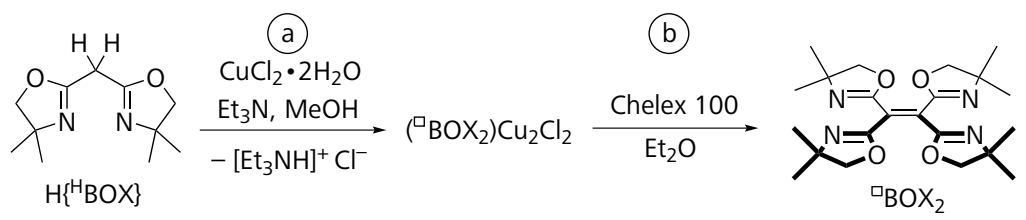

Scheme 5.3 (a) Formation of $\left({ }^{\square} \mathrm{BOX}_{2}\right) \mathrm{Cu}_{2} \mathrm{Cl}_{2}$ from $\mathrm{H}\left\{{ }^{\mathrm{H}} \mathrm{BOX}\right\}$ and copper(II) chloride, followed by (b) the recovery of ${ }^{\square} \mathrm{BOX}_{2}$ upon removal of the inorganic metal salt.

to the rule of mutual exclusion in centrosymmetric molecules, the copper complex is obviously not centrosymmetric in the solid state; it is furthermore likely that the ligand is not planar due to steric hindrance between the opposing oxygen atoms. The formation of a $\mathrm{C}=\mathrm{C}$ double bond and a diamagnetic copper(I) complex is furthermore supported by ${ }^{1} \mathrm{H}$ NMR and ${ }^{13} \mathrm{C}$ NMR spectroscopy. The ${ }^{1} \mathrm{H}$ NMR spectrum is remarkably featureless with only two singlets, arising from oxazoline$\mathrm{CH}_{3}$ and $\mathrm{CH}_{2}$ groups, respectively. A signal from the backbone $\mathrm{CH}_{2}$ group is absent and a cross peak is also not present in a ${ }^{1} \mathrm{H},{ }^{13} \mathrm{C}-\mathrm{HSQC}$ experiment.

The origin of the double bond raises questions, since the reduction of $2 \mathrm{Cu}^{\mathrm{II}} \mathrm{Cl}_{2}+$ $2 \mathrm{e}^{-} \rightarrow 2 \mathrm{Cu}^{\mathrm{I}} \mathrm{Cl}_{2}+2 \mathrm{Cl}^{-}$would only lead to a single-bond-connected dimeric complex ${ }^{\mathrm{H}} \mathrm{BOX}_{2}+2 \mathrm{HCl}$. Further oxidation of the $\mathrm{C}-\mathrm{C}$ single bond would however need two more $\mathrm{e}^{-}$, which could be provided upon oxidation of the $2 \mathrm{Cu}^{\mathrm{I}}$ in the complex by $\mathrm{O}_{2}$ or by other oxidants. The electrons might also be provided by two exogenous $\mathrm{Cu}^{\mathrm{II}}$, since $\mathrm{O}_{2}$ was excluded in the reaction; this could also account for the observed yields of only $\sim 50 \%$.

NMR spectroscopy of an inert sample showed also only two resonance singlets, in accordance with the formation of the complex containing the $\mathrm{C}=\mathrm{C}$ double bond. Addition of air to this sample lead not to a big change of the spectrum. Only two additional signals rose, slightly shifted by $\Delta \delta_{\mathrm{H}}=-0.20\left(\mathrm{CH}_{2}\right)$ and $-0.15 \mathrm{ppm}$ $\left(\mathrm{CH}_{3}\right)$ compared to the oxygen-free sample, while the original peaks shrunk. A broadening of all peaks was also evident. It can be assumed that the oxidation of a portion of copper(I) to copper(II) is responsible for the changes in the spectrum and not a modification of the ligand. Thus, both peaks are shifted highfield due to a stronger chemical shielding in the stronger charged complex. Also, ESI mass spectra of samples in air contained only peaks with the preserved ${ }^{\square} \mathrm{BOX}_{2}$ ligand. However, mass spectrometry of a solution, longer exposed to air, showed peaks most likely from ions of oxygenated ligands, such as $m / z 471.1\left(100 \%\right.$, $\left[{ }^{\square} \mathrm{BOX}_{2}+\right.$ 
$\left.\left.\mathrm{O}_{2}+\mathrm{Na}\right]^{+}\right)$and $\left.247.1\left(86 \%,\left[\mathrm{H}^{\mathrm{H}}{ }^{\mathrm{BOX}}\right\}-2 \mathrm{H}+\mathrm{O}+\mathrm{Na}\right]^{+}\right)$. For the oxygenation of the $\left.\mathrm{H}_{\{}{ }^{\mathrm{H}} \mathrm{BOX}\right\}$ ligand, see Section 5.4.4.

\subsubsection{Ligand Recovery and Identification}

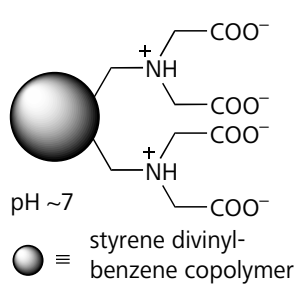

Scheme 5.4

Chelex 100 resin.

Dimerised ligands could be isolated from the respective complexes by demetallation, either by the repetitive extraction with EDTA- $\mathrm{Na}_{2}$ solution or by a chelating resin.

Chelex 100 chelating resin is a styrene divinylbenzene copolymer (Figure 5.4). The contained paired iminodiacetate ions are chelators for the binding of polyvalent metal ions with a high selectivity for divalent metals (similar to the selectivity of iminodiacetic acid). ${ }^{[188]}$ The selectivity is particularly high for $\mathrm{Cu}^{2+}$, which renders the resin well-suited for the removal of $\mathrm{Cu}^{2+}$ from the tetrakis(oxazoline) ligands.

\section{Isolation of ${ }^{\mathrm{Me}_{\mathrm{BOX}}}$}

The dimerised ligand ${ }^{\mathrm{Me}} \mathrm{BOX}_{2}$ was recovered from the copper complex by stirring a suspension of the dicopper(I) complex in diethyl ether with the chelating ion exchange resin Chelex 100 (Scheme 5.2, step b, p. 72). The copper(I) ions are oxidised during this process, leaving the copper-loaded resin deep blue (in contrast to the colourless copper-free polymer). The dimer ${ }^{\mathrm{Me}_{\mathrm{BOX}}}$ was isolated as an off-white powder in $82 \%$ yield and in analytically pure form. This additionally is proof of the uniformity of the precipitated dicopper complex (i. e. concerning the organic composition). Alternatively, the ligand could be isolated from the metal by the extensive washing of the copper(I) complex solution with EDTA$\mathrm{Na}_{2}$ solution, together with agitation with EDTA- $\mathrm{Na}_{2}$ solution in an ultrasonic bath for some hours. The ${ }^{1} \mathrm{H}$ NMR spectrum resembles the spectrum of the corresponding copper(I) complex described above. It can be assumed, that the ligand's conformation is unchanged in the neat ligand. Oxazoline $\mathrm{CH}_{3}$ and $\mathrm{CH}_{2}$ groups are shifted upfield by $\sim 0.3 \mathrm{ppm}$ due to the no longer existing copper coordination. Due to the diastereotopicity of carbon and hydrogen atoms in $\mathrm{CH}_{3}$ and $\mathrm{CH}_{2}$ groups respectively, the $\mathrm{CH}_{3}$ feature is split into two peaks separated by $\Delta \delta_{\mathrm{H}}=0.01 \mathrm{ppm}$ and the $\mathrm{CH}_{2}$ feature is split into two doublets separated by $\Delta \delta_{\mathrm{H}}=$ $0.07 \mathrm{ppm}$. The two doublets show a distinctive $»$ roof « effect and a ${ }^{2} J_{\mathrm{HH}}$ coupling of $13 \mathrm{~Hz}$. The scope and capabilities of ligation of this new ditopic tetrakis(oxazoline) ligand are currently under further investigation. 


\section{Isolation of ${ }^{{ }^{B}} \mathrm{BOX}_{2}$}

In analogy to ${ }^{\mathrm{Me}_{\mathrm{BOX}}}{ }_{2},{ }^{\mathrm{BOX}_{2}}$ was isolated from the copper(I) complex by the use of Chelex 100 chelating resin (Scheme 5.3, step b, p.77). The $\mathrm{C}=\mathrm{C}$ double bond, connecting both ligand moieties is evident in the ${ }^{13} \mathrm{C}$ NMR spectrum of ${ }^{{ }} \mathrm{BOX}_{2}$ at $\delta_{\mathrm{C}}=129 \mathrm{ppm}$, while the ${ }^{1} \mathrm{H}$ NMR spectrum is extremely featureless and exhibits only two singlets (for the $\mathrm{CH}_{2}$ and $\mathrm{CH}_{3}$ groups respectively) due to the averaged high symmetry $\left(D_{2 h}\right)$ in solution of ${ }^{\mathrm{BOX}_{2}}$. Signals from the backbone $\mathrm{CH}_{2}$ group are absent and a cross peak is also not present in a ${ }^{1} \mathrm{H},{ }^{13} \mathrm{C}-\mathrm{HSQC}$ experiment. All in all, the NMR spectra are closely related to that of the corresponding $\mathrm{Cu}^{\mathrm{I}} \mathrm{Cl}$ complex. A $v(\mathrm{C}=\mathrm{C})$ stretch is in addition present with a medium intensity in the IR spectrum at $1611 \mathrm{~cm}^{-1}$, which is quite similar to the stretch in the IR and Raman spectra of $\left({ }^{\square} \mathrm{BOX}_{2}\right) \mathrm{Cu}_{2} \mathrm{Cl}_{2}$.

While all attempts to obtain single crystals of $\left({ }^{\square} \mathrm{BOX}_{2}\right) \mathrm{Cu}_{2} \mathrm{Cl}_{2}$ failed so far, it was possible to obtain high quality single crystals of ${ }^{{ }_{\mathrm{BOX}}}{ }_{2}$, suitable for X-ray crystallography, upon the slow concentration of a solution in chloroform (Figure 5.5). ${ }^{\square O X_{2}}$ crystallised in the monoclinic point group $P 2_{1} / n$. The molecule resides on a crystallographically imposed inversion centre. Two oxazolines in $E$ position are parallel to each other. They are in-plane with the $\mathrm{C}=\mathrm{C}$ double bond, while the remaining two are tilted. The torsion angles $(\mathrm{N}=\mathrm{C}-\mathrm{C}=\mathrm{C})$ are $177^{\circ}$ and $98^{\circ}$

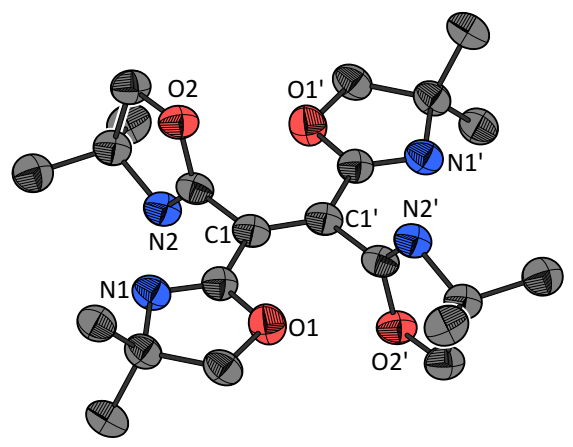

Figure 5.5. Solid-state molecular structure of the isolated dimerised ligand ${ }^{\square} \mathrm{BOX}_{2}$ with important atoms labelled. Displacement ellipsoids are drawn at the $50 \%$ probability level; hydrogen atoms have been omitted for the sake of clarity; symmetry transformations used to generate equivalent atoms $\left({ }^{\prime}\right): 2-x, 1-y, 1-z$. Significant interatomic distances $(\AA)$ : $\mathrm{C} 1=\mathrm{C} 1^{\prime} 1.3493(20), \mathrm{N} 1=\mathrm{C} 21.2680(18), \mathrm{N} 2=\mathrm{C} 7$ 1.2647(20); angles $\left({ }^{\circ}\right)$ : $\mathrm{C} 2-\mathrm{C} 1-\mathrm{C} 1^{\prime} 124.06(18)$, $\mathrm{C} 7-\mathrm{C} 1-\mathrm{C} 1^{\prime}$ 122.18(17), C2-C1-C7 113.70(12). 
respectively, while the angle between the main planes and the two tilted oxazolines is $84^{\circ}$ respectively. The $\sim 90^{\circ}$ tilt suggests a strong sterical clash between each two adjacent oxazolines and especially the $\mathrm{O} 1 \cdots \mathrm{O} 2^{\prime}$ atoms, which was already considered above. Although a conformation with all conjugated $\mathrm{C}=\mathrm{N}$ and $\mathrm{C}=\mathrm{C}$ double bonds in one plane would be electronically favourable, it is indicated that an all-planar conformation is not possible due to sterical conflicts and that a planar metal complex with such ligand conformation would additionally be not possible. In addition to solution spectroscopic data of ${ }^{\mathrm{BOX}_{2}}$ and its corresponding complex, the $\mathrm{C}=\mathrm{C}$ double bond is also well evident in the crystal structure by the short $\mathrm{C}=\mathrm{C}$ distance of $1.35 \AA$ and the $\mathrm{sp}^{2}$ geometry around the carbon atoms.

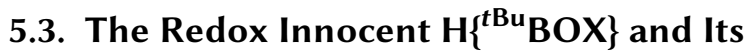 Thermochromic $\mathrm{CuCl}_{2}$ complex}

In contrast to the ligands $\left.\mathrm{H}_{\{}{ }^{\mathrm{R}} \mathrm{BOX}\right\}(\mathrm{R} \equiv \mathrm{H}, \mathrm{Me}, \mathrm{Ph})$, the ligand $\left.\mathrm{H}_{\{}^{t \mathrm{Bu}} \mathrm{BOX}\right\}$ showed no reactivity upon coordination of $\mathrm{CuCl}_{2}$ in air, neither a dimerisation reaction nor an oxygenation could be found. Since the only difference between the ligands is the backbone residue $\mathrm{R}$ and its sterical demand, it can be attributed to the large $t \mathrm{Bu}$ residue that this ligand is redox »innocent $«$ upon $\mathrm{CuCl}_{2}$ coordination. The mere reaction observed, is coordination of $\mathrm{CuCl}_{2}$ to form the complex $\left(\mathrm{H}^{t \mathrm{tBu}}{ }^{\mathrm{BOXX}\}}\right) \mathrm{Cu}^{\mathrm{II}} \mathrm{Cl}_{2}$ (Scheme 5.5). It was prepared by adding $\mathrm{CuCl}_{2} \cdot 2 \mathrm{H}_{2} \mathrm{O}$ in methanol to $\left.\mathrm{H}_{\{}{ }^{t \mathrm{Bu}} \mathrm{BOX}\right\}$ in $\mathrm{CH}_{2} \mathrm{Cl}_{2}$; the complex was yielded in the form of yellow needles upon precipitation by the addition of pentane in good yields.

Interestingly, the crystalline material showed a change in colour upon cooling with liquid $\mathrm{N}_{2}$. The colour changed reversibly from intense yellow to a more greenish-yellow colour, such an effect is described as »thermochromism «. This effects in known in several inorganic compounds; usually a change in the crystalline phase, in coordination geometry or in the number of coordinating

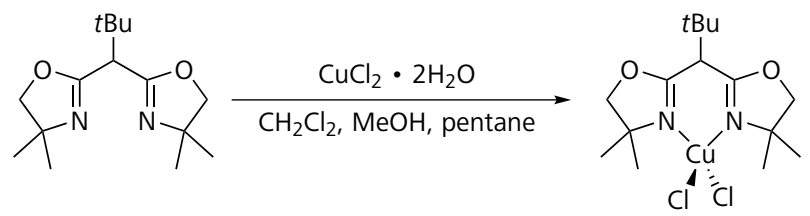

Scheme 5.5 Preparation of $\left(\mathrm{H}\left\{{ }^{t \mathrm{Bu}} \mathrm{BOX}\right\}\right) \mathrm{Cu}^{\prime \prime} \mathrm{Cl}_{2}$. 
solvent molecules is responsible for the colour change. ${ }^{[189]}$ An example similar to $\left.\left(\mathrm{H}_{\{}{ }^{t \mathrm{Bu}} \mathrm{BOX}\right\}\right) \mathrm{Cu}^{\mathrm{II}} \mathrm{Cl}_{2}$ is e. $\mathrm{g}$. $\left[\left(\mathrm{CH}_{3} \mathrm{CH}_{2}\right)_{2} \mathrm{NH}_{2}\right]_{2} \mathrm{CuCl}_{4}$. It is green at room temperature and undergoes a phase transition at $\sim 50{ }^{\circ} \mathrm{C}$, simultaneously with a change in colour to yellow. ${ }^{[190,191]}$ It could be shown crystallographically, that for the analogue $\left[\mathrm{PhCh}_{2} \mathrm{Ch}_{2} \mathrm{NH}_{2} \mathrm{CH}_{3}\right]_{2} \mathrm{CuCl}_{4}$ at lower temperature, the $\mathrm{CuCl}_{4}^{2-}$ ion is nearly square planar (green colour) and at higher temperature distorted towards tetrahedral ( $\sim D_{2 d}$ symmetry, yellow colour); ${ }^{[192]}$ and that the counterion stabilises the planar geometry by a strong hydrogen bond to chloride, withdrawing electron density and lowering the electrostatic repulsion. ${ }^{[193]}$ The coordination of the $\mathrm{CuCl}_{4}^{2-}$ ions has been described as »a delicate balance between crystal field stabilization, favoring a square planar geometry, and ligand-ligand electrostatic repulsions, favouring a tetrahedral geometry «. ${ }^{[191]}$

The structural similarity and the colour change to green at the lower temperature suggests, that a similar process can be expected in $\left.\left(\mathrm{H}_{\{}{ }^{t \mathrm{Bu}} \mathrm{BOX}\right\}\right) \mathrm{Cu}^{\mathrm{II}} \mathrm{Cl}_{2}$. However, the colour change is observed at significantly lower temperature as in the $\mathrm{CuCl}_{4}^{2-}$ compounds and is only quite subtle.

\subsubsection{Temperature Dependency of the Solid-State Structure}

Suitable single crystals for X-ray diffraction analysis were obtained from a concentrated $\mathrm{CH}_{2} \mathrm{Cl}_{2}$ solution upon slow concentration. Figure 5.6 shows the solid state structure of $\left.\left(\mathrm{H}_{\{}{ }^{t \mathrm{Bu}} \mathrm{BOX}\right\}\right) \mathrm{Cu}^{\mathrm{II}} \mathrm{Cl}_{2}$ at different temperatures. The $\mathrm{Cu}^{\mathrm{II}}$ ion is fourfold coordinated by $\left.\mathrm{H}^{t \mathrm{Bu}} \mathrm{BOX}\right\}$ and two chloride ligands in a distorted tetrahedral geometry. The BOX ligand coordinates in a slightly boat-shaped six-membered-ring geometry with a ligand $»$ bite $\ll$ angle of $90^{\circ}$.

The coordination geometry around a four-fold coordinated metal can be described by the geometric $\tau_{4}$ parameter (see Section A.1, p. 269 for more details). It ranges from $\tau_{4}=1.00$ for a perfect tetrahedral geometry $\left(T_{d}\right)$ to $\tau_{4}=0.00$ for a perfect square planar geometry $\left(D_{4 h}\right)$. The coordination sphere around the $\mathrm{Cu}^{2+}$ ion can only be described as seriously distorted from tetrahedral symmetry, or more precise as a distorted trigonal pyramid (it has $\tau_{4}=0.71$ at $133 \mathrm{~K}$, a perfect trigonal pyramid $\left(C_{3 v}\right)$ would have $\left.\tau_{4}=0.85\right)$. The $\tau_{4}$ value is quite similar to the value found for the related complex $\left({ }^{\mathrm{Me}} \mathrm{BOX}_{2}\right)\left(\mathrm{Cu}^{\mathrm{II}} \mathrm{Cl}_{2}\right)_{2}$, which was described above.

Upon going to $203 \mathrm{~K}$ the geometry changes slightly due to some disorder of the chlorides; the original positions (positions A, 94\% occupancy) are not changed with $\tau_{4}=0.71$ (see other geometric parameters in Table 5.2). However, the disordered chlorides at positions B ( $\sim 6 \%$ occupancy) have $\tau_{4}=0.80$ (the weighted 


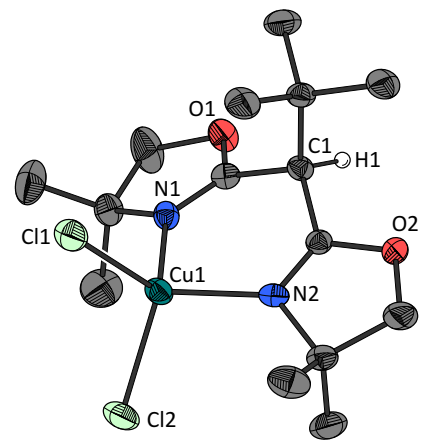

(a)

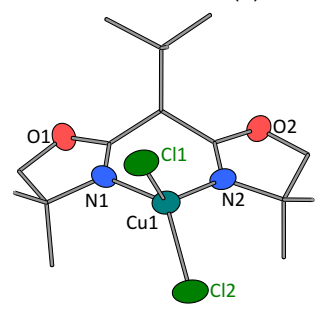

(c) $133 \mathrm{~K}$

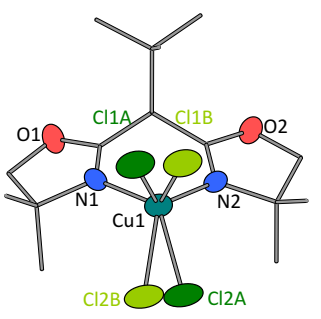

(d) $203 \mathrm{~K}$

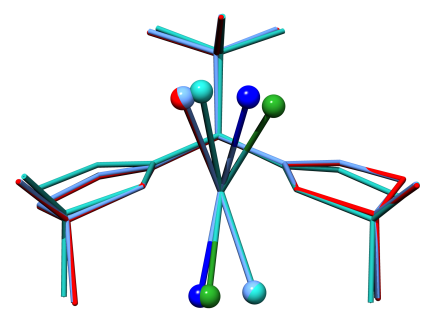

(b)

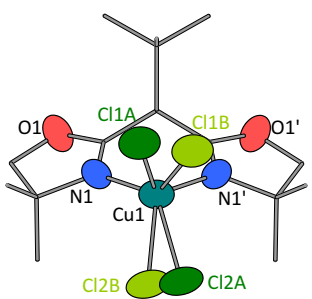

(e) $293 \mathrm{~K}$

Figure 5.6. Temperature dependent solid-state molecular structures of $\left.\left(\mathrm{H}_{\{}{ }^{t \mathrm{Bu}} \mathrm{BOX}\right\}\right) \mathrm{Cu}^{\prime \prime} \mathrm{Cl}_{2}$ with important atoms labelled. Displacement ellipsoids are drawn at the $50 \%$ probability level; most hydrogen atoms have been omitted for the sake of clarity. Chlorides located at a second site (B), due to crystallographic disorder, are drawn in lighter shade. Significant interatomic distances and angles are listed in Table 5.2. (a) ORTEP plot (133 K). (b) Structural match, $133 \mathrm{~K}$ (red), $203 \mathrm{~K}$ (light blue $\{\mathrm{A}\}$, blue $\{\mathrm{B}\}$ ), $293 \mathrm{~K}$ (turquoise $\{\mathrm{A}\}$, green $\{\mathrm{B}\}$ ). (c) Structure at 133 K. (d) Structure at $203 \mathrm{~K}$ (occupation $B \approx 6 \%$ ). (e) Structure at $293 \mathrm{~K}$, (occupation $\mathrm{B} \approx 30 \%$ ), symmetry transformations used to generate equivalent atoms ('): $x$, $1.5-y, z$. Symmetry transformed chlorides are omitted for clarity. 
Table 5.2.

Significant geometric information of the solid-state structures of $\left(\mathrm{H}\left\{{ }^{t \mathrm{Bu}} \mathrm{BOX}\right\}\right) \mathrm{Cu}^{\mathrm{II}} \mathrm{Cl}_{2}$ at different temperatures. Interatomic distances $(\AA)$, angles $\left({ }^{\circ}\right)$ and $\tau_{4}$ parameters. $^{a}$

\begin{tabular}{|c|c|c|c|}
\hline Atoms 1,2 & & $d 1,2(\AA)$ & \\
\hline & $133 \mathrm{~K}$ & $203 \mathrm{~K}$ & $293 \mathrm{~K}$ \\
\hline $\mathrm{Cu} 1-\mathrm{N} 1$ & $1.9746(22)$ & $1.9668(16)$ & $1.9786(20)$ \\
\hline $\mathrm{Cu} 1-\left(\mathrm{N} 2 / \mathrm{N} 1^{\prime}\right)$ & $1.9800(24)$ & $1.9879(17)$ & $1.9786(20)$ \\
\hline $\mathrm{Cu} 1-\mathrm{Cl} 1 \mathrm{~A}$ & $2.2263(8)$ & $2.2270(6)$ & $2.2539(57)$ \\
\hline $\mathrm{Cu} 1-\mathrm{Cl} 1 \mathrm{~B}$ & & $2.1531(95)$ & $2.1653(153)$ \\
\hline $\mathrm{Cu} 1-\mathrm{Cl} 2 \mathrm{~A}$ & $2.2428(8)$ & $2.2397(6)$ & $2.2460(83)$ \\
\hline $\mathrm{Cu} 1-\mathrm{Cl} 2 \mathrm{~B}$ & & $2.2100(102)$ & $2.2320(148)$ \\
\hline $\mathrm{H} 1 \cdots \mathrm{Cl} 2(\mathrm{av})$ & 2.602 & 2.630 & 2.661 \\
\hline \multirow[t]{2}{*}{ Atoms $1,2,3$} & \multicolumn{3}{|c|}{ Angle $1,2,3\left(^{\circ}\right)$} \\
\hline & $133 \mathrm{~K}$ & $203 \mathrm{~K}$ & $293 \mathrm{~K}$ \\
\hline $\mathrm{N} 1-\mathrm{Cu} 1-\left(\mathrm{N} 2 / \mathrm{N} 1^{\prime}\right)$ & $90.335(93)$ & $89.892(67)$ & $89.656(81)$ \\
\hline $\mathrm{Cl} 1 \mathrm{~A}-\mathrm{Cu} 1-\mathrm{Cl} 2 \mathrm{~A}$ & $103.686(29)$ & $103.415(24)$ & $103.143(199)$ \\
\hline $\mathrm{Cl} 1 \mathrm{~B}-\mathrm{Cu} 1-\mathrm{Cl} 2 \mathrm{~B}$ & & $105.527(387)$ & $101.602(481)$ \\
\hline $\mathrm{Cl} 1 \mathrm{~A}-\mathrm{Cu} 1-\mathrm{Cl} 2 \mathrm{~B}$ & & $99.027(289)$ & $101.399(349)$ \\
\hline $\mathrm{Cl} 1 \mathrm{~B}-\mathrm{Cu} 1-\mathrm{Cl} 2 \mathrm{~A}$ & & $97.758(258)$ & $92.186(371)$ \\
\hline $\mathrm{Cl} 1 \mathrm{~A}-\mathrm{Cu} 1-\mathrm{Cl} 1 \mathrm{~B}{ }^{b}$ & & $29.219(245)$ & $33.000(371)$ \\
\hline $\mathrm{Cl} 2 \mathrm{~A}-\mathrm{Cu} 1-\mathrm{Cl} 2 \mathrm{~B}^{b}$ & & $23.847(252)$ & $20.113(414)$ \\
\hline $\mathrm{N} 1-\mathrm{Cu} 1-\mathrm{Cl} 1 \mathrm{~A}$ & $101.291(68)$ & $102.017(49)$ & $107.722(168)$ \\
\hline $\mathrm{N} 1-\mathrm{Cu} 1-\mathrm{Cl} 1 \mathrm{~B}$ & & $124.062(276)$ & $133.878(414)$ \\
\hline $\mathrm{N} 1-\mathrm{Cu} 1-\mathrm{Cl} 2 \mathrm{~A}$ & $129.096(64)$ & $129.288(48)$ & $129.235(199)$ \\
\hline $\mathrm{N} 1-\mathrm{Cu} 1-\mathrm{Cl} 2 \mathrm{~B}$ & & $109.072(303)$ & $112.795(397)$ \\
\hline$\left(\mathrm{N} 2 / \mathrm{N1}^{\prime}\right)-\mathrm{Cu} 1-\mathrm{Cl} 1 \mathrm{~A}$ & $130.678(70)$ & $130.155(50)$ & $123.541(169)$ \\
\hline$\left(\mathrm{N} 2 / \mathrm{N}^{\prime}\right)-\mathrm{Cu} 1-\mathrm{Cl} 1 \mathrm{~B}$ & & $106.648(273)$ & $98.439(413)$ \\
\hline$\left(\mathrm{N} 2 / \mathrm{N}^{\prime}\right)-\mathrm{Cu} 1-\mathrm{Cl} 2 \mathrm{~A}$ & $105.186(62)$ & $105.463(47)$ & $105.579(188)$ \\
\hline$\left(\mathrm{N} 2 / \mathrm{N}^{\prime}{ }^{\prime}\right)-\mathrm{Cu} 1-\mathrm{Cl} 2 \mathrm{~B}$ & & $122.592(311)$ & $120.846(402)$ \\
\hline$\tau_{4}$ value & 0.71 & $0.71(\mathrm{~A}), 0.80(\mathrm{~B})$ & $0.76(\mathrm{~A}), 0.75(\mathrm{~B})$ \\
\hline
\end{tabular}

${ }^{a}$ See p. 269 for description of $\tau$ parameters. ${ }^{b}$ Angle between the two disordered moieties A and B. 
average value is slightly higher than at $133 \mathrm{~K}: \tau_{4}=0.72$ ). At $293 \mathrm{~K}$ the disordered chlorides on both positions differ more from the original positions, the values $\tau_{4}=$ 0.76 (position A, $70 \%$ occupancy) and $\tau_{4}=0.75$ (position B, $30 \%$ occupancy) were determined. From the geometric parameters it can be seen that subtle changes in geometry around the $\mathrm{Cu}^{2+}$ are responsible for the slight changes in colour. In analogy to well studied $\mathrm{CuCl}_{4}^{2-}$ systems, the geometry is changing from more tetrahedral coordination to more square planar upon cooling. However, the geometry is always quite distorted (from both, square planar and tetrahedral viewpoints) and the geometric changes are very subtle.

A magneto-chemical SQUID measurement furthermore excludes coupling between the $\mathrm{Cu}^{\mathrm{II}}$ ions to be the reason of the changes in colour (cf. the plot of $\mu_{\text {eff }}$ vs. temperature in Figure 5.7). However, the measurement shows a slight rise of $\mu_{\mathrm{eff}}$ at low temperatures, which might be attributed to an intermolecular interaction. A closer inspection of the X-ray structure shows indeed a weak interaction between the backbone hydrogen atom $\mathrm{H} 1$ and chloride $\mathrm{Cl} 2$ from a neighbour complex, which becomes stronger at lower temperature. The mean $\mathrm{H} 1 \cdots \mathrm{Cl} 2$ distance shortens from $2.661 \AA(293 \mathrm{~K})$ to $2.630 \AA$ (203 K) and further to $2.602 \AA(133 \mathrm{~K})$. This interaction might be a reason for the structural changes in $\mathrm{Cu}-\mathrm{Cl}$ coordination.

Attempts to gain further insights in the structural changes by differential scanning calorimetry (DSC) revealed only small changes in heat capacity, which could not be clearly assigned to phase transitions. This was observed in both, a

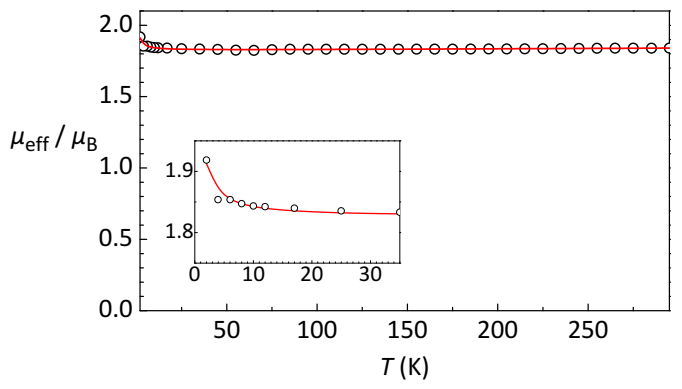

Figure 5.7. Plot of $\mu_{\text {eff }}$ vs. temperature for $\left.\left(\mathrm{H}^{t \mathrm{tBu}} \mathrm{BOX}\right\}\right) \mathrm{Cu}^{\mathrm{l}} \mathrm{Cl}_{2}$ (circles) obtained from a SQUID magnetic measurement at $0.5 \mathrm{~T}$. The red line represents the calculated best curve fit for a single $S=1 / 2$ ion with $g=2.1$. The additional fit parameter is a temperatureindependent paramagnetism $(T I P)$ of $25.2 \times 10^{-6} \mathrm{emu}$. 
powder and a crystalline sample. However, the related thermochromic tetrachlorocuprate(II) shows clearly phase transitions. ${ }^{[194]}$ It might be assumed, that phase transitions could not be observed in $\left.\left(\mathrm{H}_{\{}{ }^{t \mathrm{Bu}} \mathrm{BOX}\right\}\right) \mathrm{CuCl}_{2}$ due to the small structural changes here.

\subsubsection{Coordination Geometry in BOXs and Catalytic Selectivity}

An integral role for the asymmetric induction exhibited by bis(oxazoline)s is the coordination geometry around the metal ion, which can be elucidated by X-ray crystallography and allows drawing a picture of reaction mechanisms. Thus, the enantioselectivity of catalysed reactions can be predicted and tuned by virtue of the knowledge of the coordination chemistry, among electronic and other properties. ${ }^{[119,122]}$

In asymmetric catalysis, the known BOX complexes are chiral and display a $C_{2}$-axis and are of metal/BOX $1: 1$ stoichiometry; some of them feature a tetracoordinated metal centre similar to $\left.\left(\mathrm{H}_{\{}^{t \mathrm{Bu}} \mathrm{BOX}\right\}\right) \mathrm{Cu}^{\mathrm{II}} \mathrm{Cl}_{2}$, in a (more or less) squareplanar or tetrahedral geometry. Interestingly, for a given complex, the squareplanar and tetrahedral geometry show opposite selectivity and thus enantiomers of a substrate can be accessed. The reason is, that the accessible face of the coordinated substrate is shifted from the shielded to unshielded region of the complex upon rotation of $90^{\circ}$. ${ }^{[122]}$

Compared to the roughly tetrahedral complexes of $\mathrm{Fe}^{\mathrm{II}} \mathrm{Cl}_{2},{ }^{[195]} \mathrm{Ni}^{\mathrm{II}} \mathrm{Cl}_{2}{ }^{[196]}$ and $\mathrm{Zn}^{\mathrm{II}} \mathrm{Cl}_{2}$, ${ }^{[197]} \mathrm{Cu}^{\mathrm{II}} \mathrm{Cl}_{2}$ complexes are more distorted towards square planar. Besides the $\tau_{4}$ parameter, this can be described by the angles in Scheme 5.6; see Table 5.3 for a comparison of selected (BOX)metal $\left(\mathrm{X}_{2}\right)$ complexes against $\left(\mathrm{H}\left\{{ }^{t \mathrm{Bu}} \mathrm{BOX}\right\}\right) \mathrm{Cu}^{\mathrm{II}} \mathrm{Cl}_{2}$. It can be seen that the chlorides are oriented away from blocked quadrants as expected, and that the geometry is distorted away from tetrahedral, the more the steric demand of the residues $\mathrm{R}^{\prime}$ rise.
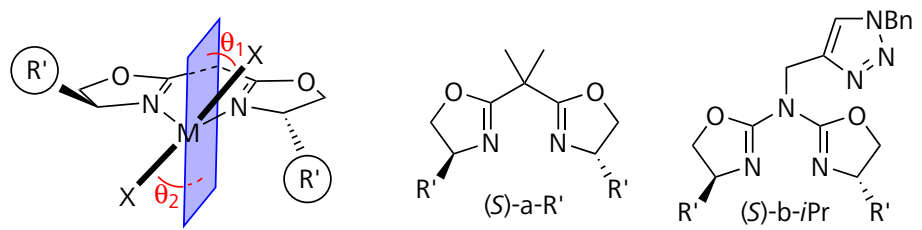

Scheme 5.6 Degree of distortion in (BOX)metal $\left(\mathrm{X}_{2}\right)$ complexes, definition of $\theta$ angles and ligands $\left(\mathrm{R}^{\prime} \equiv \mathrm{Ph}, t \mathrm{Bu}\right)$, referred to in Table 5.3. 
In the non-chiral $\left.\left(\mathrm{H}_{\{}{ }^{\mathrm{tBu}} \mathrm{BOX}\right\}\right) \mathrm{Cu}^{\mathrm{II}} \mathrm{Cl}_{2}$, with equal residues in all four quadrants, it was found that the geometry is more tetrahedral than one could expect. Although the geometric changes upon temperature change are quite small, it might be expected that similar changes could be detected in chiral catalytic-active BOX complexes and that these changes affect their catalytic activity and enantioselectivity.

So far, this effect could only be evidenced in the solid state and further investigation is needed to clarify how the coordination geometry in solution is affected by temperature changes. Nevertheless, it might be conceivable that known or new systems change their selectivity due to geometric changes, upon selecting a different temperature. However, studies considering temperature-dependent geometry and enantioselectivity of BOX-metal complexes have not been conducted so far, and this temperature-geometry relationship was investigated here for the first time in a BOX complex.

Table 5.3.

Degree of distortion in (BOX)metal $\left(\mathrm{X}_{2}\right)$ complexes. See Scheme 5.6 for definition of $\theta$ angles and ligands. More data can be found in ref. [122].

\begin{tabular}{|c|c|c|c|c|}
\hline Metal & $\mathrm{X}$ & BOX ligand & $\theta_{1} / \theta_{2}\left({ }^{\circ}\right)$ & Ref. \\
\hline $\mathrm{Cu}$ & $\mathrm{H}_{2} \mathrm{O}$ & $(S)-\mathrm{a}-\mathrm{Ph}$ & $79 / 66$ & [198] \\
\hline $\mathrm{Cu}$ & $\mathrm{H}_{2} \mathrm{O}$ & $(S)-\mathrm{a}-t \mathrm{Bu}$ & $52 / 50$ & [199] \\
\hline $\mathrm{Zn}$ & $\mathrm{Cl}$ & $(R)-\mathrm{a}-\mathrm{Ph}$ & $17 / 13$ & [197] \\
\hline $\mathrm{Zn}$ & $\mathrm{Cl}$ & $(S)-\mathrm{a}-t \mathrm{Bu}$ & $32 / 22$ & [197] \\
\hline $\mathrm{Ni}$ & $\mathrm{Cl}$ & $(S)-\mathrm{a}-t \mathrm{Bu}$ & $23 / 23$ & [196] \\
\hline $\mathrm{Fe}$ & $\mathrm{Cl}$ & $(S)-\mathrm{a}-t \mathrm{Bu}$ & $18 / 15$ & [195] \\
\hline $\mathrm{Cu}$ & $\mathrm{Cl}$ & $(R)-\mathrm{a}-\mathrm{Ph}$ & $45 / 38$ & [197] \\
\hline $\mathrm{Cu}$ & $\mathrm{Cl}$ & $(S)-\mathrm{a}-t \mathrm{Bu}$ & $45 / 45$ & {$[197,200]$} \\
\hline $\mathrm{Cu}$ & $\mathrm{Cl}$ & $(S)-\mathrm{b}-i \mathrm{Pr}$ & $31 / 25$ & [201] \\
\hline $\mathrm{Cu}$ & $\mathrm{Cl}$ & $\mathrm{H}\left\{{ }^{t \mathrm{Bu}} \mathrm{BOX}\right\}(133 \mathrm{~K})$ & $18 / 23$ & this work \\
\hline $\mathrm{Cu}$ & $\mathrm{Cl}$ & $\mathrm{H}\left\{{ }^{t \mathrm{Bu}} \mathrm{BOX}\right\}(203 \mathrm{~K})$ & $17 / 23(14 / 17)^{a}$ & this work \\
\hline $\mathrm{Cu}$ & $\mathrm{Cl}$ & $\mathrm{H}\left\{{ }^{t \mathrm{Bu}} \mathrm{BOX}\right\}(293 \mathrm{~K})$ & $11 / 26(25 / 9)^{b}$ & this work \\
\hline
\end{tabular}




\subsection{Copper(II)-Mediated Aerobic Oxygenation of BOXs}

\subsubsection{Formation of $\mathrm{HO}\left\{{ }^{\mathrm{Ph}} \mathrm{BOX}\right\}$}

In contrast to $\left.\mathrm{H}_{\{}{ }^{\mathrm{H}} \mathrm{BOX}\right\}$ and $\left.\mathrm{H}_{\{}{ }^{\mathrm{Me}} \mathrm{BOX}\right\}$, where the dimerisation and formation of a dicopper(I) complex is evident by its white to yellow colours, and in contrast

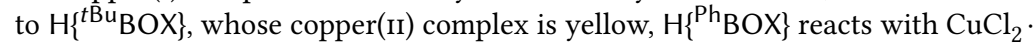
$2 \mathrm{H}_{2} \mathrm{O}$ to form an intense green compound. Upon combining equimolar solutions of $\mathrm{CuCl}_{2} \cdot 2 \mathrm{H}_{2} \mathrm{O}$ in methanol and $\left.\mathrm{H}_{\{}{ }^{\mathrm{Ph}} \mathrm{BOX}\right\}$ in $\mathrm{CH}_{2} \mathrm{Cl}_{2}$ or $\mathrm{CHCl}_{3}$, the immediate formation of an intense green charge-transfer complex is well evident (Scheme 5.7).

Due to the insolubility of $\left.\mathrm{H}_{2}{ }^{\mathrm{Ph}} \mathrm{BOX}\right\}$ in methanol, the ligand was dissolved in a chlorinated solvent and $\mathrm{CuCl}_{2}$ in methanol was added to this solution. No precipitate, composed of dimerised bis(oxazoline) was obtained. From the solution, green high quality single crystals could be obtained by slow concentration. Structure elucidation by $\mathrm{x}$-ray crystallography revealed that the crystalline material is a trinuclear aggregate with the composition $\left(\mathrm{O}_{\{}{ }^{\mathrm{Ph}}{ }_{\mathrm{BOX}}\right)_{2} \mathrm{Cu}_{3} \mathrm{Cl}_{4}$. Composed of two molecules of mono-oxygenated mono-anionic alkoxide ligand $\left.\left(\mathrm{O}_{\{}{ }^{\mathrm{Ph}} \mathrm{BOX}\right\}\right)^{-}$, three copper(II) ions and four chlorides.

The tricopper(II) complex crystallised in the triclinic space-group $P 1$ (Figure 5.8). In the cluster, the three copper atoms are arranged to form a roughly equilateral (equiangular) triangle with $\sim 60^{\circ}$ angles and $\sim 3.3 \AA \mathrm{Cu} \cdots \mathrm{Cu}$ separations. Two sides

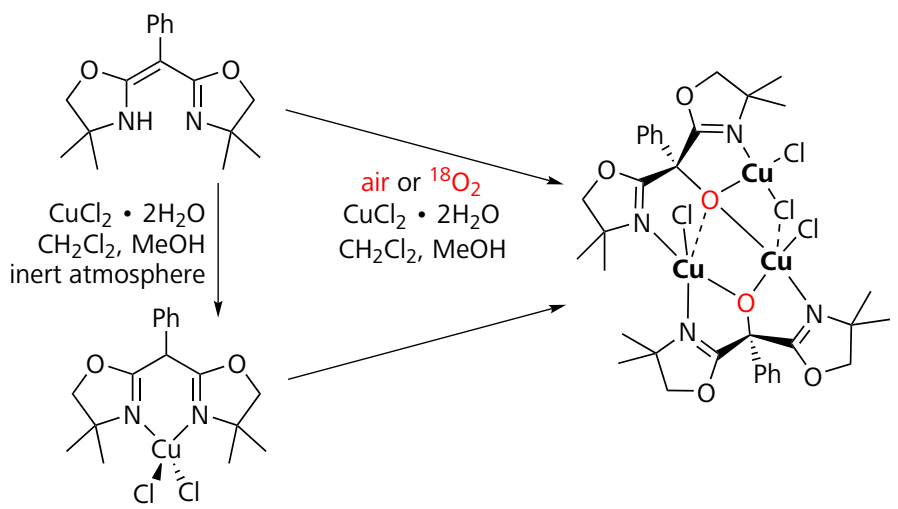

Scheme 5.7 Synthesis of $\left(\left\{{ }^{\mathrm{Ph}} \mathrm{BOX}\right\} \mathrm{O}\right)_{2} \mathrm{Cu}_{3} \mathrm{Cl}_{4}$. 
Figure 5.8 Solid-state molecular structure of $\left(\mathrm{O}\left\{{ }^{\mathrm{Ph}} \mathrm{BOX}\right\}\right)_{2} \mathrm{Cu}_{3} \mathrm{Cl}_{4}$ with important atoms labelled. Displacement ellipsoids are drawn at the $50 \%$ probability level; phenyl rings are drawn as sticks and hydrogen atoms have been omitted for the sake of clarity. Significant interatomic distances and angles are listed in Table 5.4.

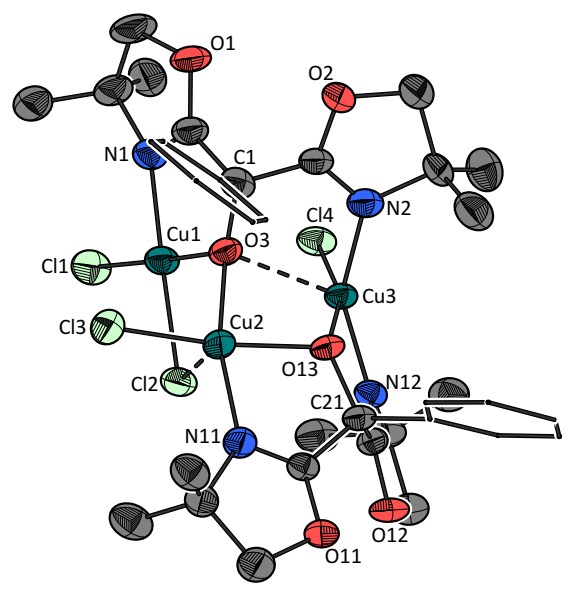

are each capped by a $\left.\left(\mathrm{O}_{\{}{ }^{\mathrm{Ph}} \mathrm{BOX}\right\}\right)^{-}$ligand, with the respective alkoxide oxygen atoms bound between two copper atoms and the nitrogens pointing towards the copper atoms. To facilitate this coordination, the oxazoline rings are $\sim 180^{\circ}$ flipped, compared to complexes of a »normal « (non-oxygenated) BOX ligand, and are now able to coordinate two metal ions.

Each copper atom is coordinated by nitrogen and oxygen atoms to form a fivering coordination pocket with ligand »bite « angles of $\sim 80^{\circ}$; each $\left(\mathrm{O}\left\{{ }^{\mathrm{Ph}} \mathrm{BOX}\right\}\right)^{-}$ ligand contains two of such contiguous pockets. One $\left\{{ }^{\mathrm{Ph}} \mathrm{BOX}\right\} \mathrm{O}^{-}$ligand coordinates copper atoms $\mathrm{Cu} 2$ and $\mathrm{Cu} 3$ in the twice bidentate manner $\mu-2 \kappa O^{13}: 3 \kappa O^{13}$, $2 \kappa N^{11}, 3 \kappa N^{12}$, with the newly introduced oxygen bridging between both metals. The second $\left.\left(\mathrm{O}_{\{}{ }^{\mathrm{Ph}} \mathrm{BOX}\right\}\right)^{-}$coordinates in a similar fashion $\left(\mu_{3}-1 \kappa O^{3}: 2 \kappa O^{3}: 3 \kappa O^{3}\right.$, $1 \kappa N^{1}, 3 \kappa N^{2}$ ), and additionally coordinates monodentate to the third copper ion via the alkoxide function. However, in this case the $\mathrm{Cu} 3-\mathrm{O} 3$ bond is longer $(2.5 \AA$ compared to the other $\mathrm{Cu}-\mathrm{O}$ bonds, which are $\sim 2.0 \AA$ long).

The remaining coordination sites at the copper atoms are occupied by four chlorides to form the neutral cluster-like coordination unit. Each of the three copper ions is coordinated by one chloride (i. e. each corner of the $\mathrm{Cu}_{3}$ triangle) and a fourth $\mu-\mathrm{Cl}$ is additionally bridging between $\mathrm{Cu} 1$ and $\mathrm{Cu} 2$ with a long $\mathrm{Cu} 2-\mathrm{Cl} 2$ bond of $2.650 \AA$ (compared to the other $\mathrm{Cu}-\mathrm{Cl}$ bonds with $\sim 2.2 \AA$ ) at the side of the $\mathrm{Cu}_{3}$ triangle, which is not occupied by $\left.\left(\mathrm{O}_{\{}{ }^{\mathrm{Ph}} \mathrm{BOX}\right\}\right)^{-}$. 
Table 5.4.

Significant geometric information of the solid-state structure of $\left(\left\{{ }^{\mathrm{Ph}} \mathrm{BOX}\right\} \mathrm{O}\right)_{2} \mathrm{Cu}_{3} \mathrm{Cl}_{4}$ in Figure 5.8. Interatomic distances $(\AA)$, angles $\left({ }^{\circ}\right)$ and $\tau$ parameters. ${ }^{a}$

\begin{tabular}{|c|c|c|c|}
\hline Atoms 1,2 & $d 1,2(\AA)$ & Atoms $1,2,3$ & Angle $1,2,3\left(^{\circ}\right)$ \\
\hline $\mathrm{Cu} 1 \cdots \mathrm{Cu} 2$ & $3.2397(10)$ & $\mathrm{N} 1-\mathrm{Cu} 1-\mathrm{O} 3$ & 79.985(188) \\
\hline $\mathrm{Cu} 1 \cdots \mathrm{Cu} 3$ & $3.3989(12)$ & $\mathrm{N} 1-\mathrm{Cu} 1-\mathrm{Cl} 1$ & 98.593(155) \\
\hline \multirow[t]{2}{*}{$\mathrm{Cu} 2 \cdots \mathrm{Cu} 3$} & $3.1630(10)$ & $\mathrm{N} 1-\mathrm{Cu} 1-\mathrm{Cl} 2$ & $163.617(147)$ \\
\hline & & O3-Cu1-Cl1 & $178.517(116)$ \\
\hline $\mathrm{Cu} 1-\mathrm{N} 1$ & $1.9923(40)$ & $\mathrm{O} 3-\mathrm{Cu} 1-\mathrm{Cl} 2$ & $85.913(109)$ \\
\hline $\mathrm{Cu} 1-\mathrm{O} 3$ & $1.9992(45)$ & $\mathrm{Cl} 1-\mathrm{Cu} 1-\mathrm{Cl} 2$ & $95.555(58)$ \\
\hline $\mathrm{Cu} 1-\mathrm{Cl} 1$ & $2.2253(21)$ & $\mathrm{N} 11-\mathrm{Cu} 2-\mathrm{O} 3$ & $162.552(158)$ \\
\hline $\mathrm{Cu} 1-\mathrm{Cl} 2$ & $2.2542(12)$ & $\mathrm{N} 11-\mathrm{Cu} 2-\mathrm{O} 13$ & $81.021(181)$ \\
\hline $\mathrm{Cu} 2-\mathrm{N} 11$ & $1.9686(35)$ & $\mathrm{N} 11-\mathrm{Cu} 2-\mathrm{Cl} 2$ & 98.599(138) \\
\hline $\mathrm{Cu} 2-\mathrm{O} 3$ & $1.9949(27)$ & $\mathrm{N} 11-\mathrm{Cu} 2-\mathrm{Cl} 3$ & 99.801(153) \\
\hline $\mathrm{Cu} 2-\mathrm{O} 13$ & $2.0106(51)$ & $\mathrm{O} 3-\mathrm{Cu} 2-\mathrm{O} 13$ & $83.142(154)$ \\
\hline $\mathrm{Cu} 2-\mathrm{Cl} 2$ & $2.6497(16)$ & $\mathrm{O} 3-\mathrm{Cu} 2-\mathrm{Cl} 2$ & 75.961(102) \\
\hline $\mathrm{Cu} 2-\mathrm{Cl} 3$ & $2.2320(21)$ & $\mathrm{O} 3-\mathrm{Cu} 2-\mathrm{Cl} 3$ & $97.357(124)$ \\
\hline $\mathrm{Cu} 3-\mathrm{N} 2$ & $1.9759(45)$ & $\mathrm{O} 13-\mathrm{Cu} 2-\mathrm{Cl} 2$ & $96.573(114)$ \\
\hline Cu3-N12 & $1.9679(38)$ & $\mathrm{O} 13-\mathrm{Cu} 2-\mathrm{Cl} 3$ & $165.689(129)$ \\
\hline $\mathrm{Cu} 3-\mathrm{O} 3$ & $2.4900(45)$ & $\mathrm{Cl} 2-\mathrm{Cu} 2-\mathrm{Cl} 3$ & $97.419(58)$ \\
\hline Cu3-O13 & $1.9798(31)$ & $\mathrm{N} 2-\mathrm{Cu} 3-\mathrm{N} 12$ & $149.709(210)$ \\
\hline \multirow[t]{2}{*}{$\mathrm{Cu} 3-\mathrm{Cl} 4$} & $2.2431(13)$ & $\mathrm{N} 2-\mathrm{Cu} 3-\mathrm{O} 3$ & $73.764(168)$ \\
\hline & & $\mathrm{N} 2-\mathrm{Cu} 3-\mathrm{O} 13$ & 92.444(173) \\
\hline$\tau_{4}$ value $(\mathrm{Cu} 1)$ & 0.13 & $\mathrm{~N} 2-\mathrm{Cu} 3-\mathrm{Cl} 4$ & 92.975(126) \\
\hline$\tau_{5}$ value $(\mathrm{Cu} 2)$ & 0.05 & $\mathrm{~N} 12-\mathrm{Cu} 3-\mathrm{O} 3$ & $131.162(164)$ \\
\hline \multirow[t]{5}{*}{$\tau_{5}$ value $(\mathrm{Cu} 3)$} & 0.19 & $\mathrm{~N} 12-\mathrm{Cu} 3-\mathrm{O} 13$ & $82.353(161)$ \\
\hline & & $\mathrm{N} 12-\mathrm{Cu} 3-\mathrm{Cl} 4$ & $101.533(124)$ \\
\hline & & $\mathrm{O} 3-\mathrm{Cu} 3-\mathrm{O} 13$ & $71.947(133)$ \\
\hline & & $\mathrm{O} 3-\mathrm{Cu} 3-\mathrm{Cl} 4$ & $92.311(81)$ \\
\hline & & O13-Cu3-Cl4 & $161.152(96)$ \\
\hline
\end{tabular}

${ }^{a}$ See p. 269 for description of $\tau_{4}$ and $\tau_{5}$ parameters. 
Oxazoline rings and $\mathrm{C}-\mathrm{O}^{-}$bonds are roughly coplanar, with torsion angles between $\mathrm{C}-\mathrm{O}^{-}$and $\mathrm{C}=\mathrm{N}$ bonds of only $0.6^{\circ} /-2.6^{\circ}$ in the first ligand and $4.5^{\circ} / 15.6^{\circ}$ in the second. Angles between the planes spanned by the oxazoline rings in the respective ligands are $56.1^{\circ}$ and $54.7^{\circ}$. The angles between the related $\mathrm{C}=\mathrm{N}$ bonds are $84.5^{\circ}$ and $85.6^{\circ}$

$\mathrm{Cu} 1$ is $\{\mathrm{NOClCl}\}$ coordinated in a square-planar geometry $\left(\tau_{4}=0.13\right)$, while $\mathrm{Cu} 2$ is five-fold coordinated in a square-pyramidal fashion with $\{\mathrm{NOOCl}\}$ basal ligands and the quite loosely coordinated apical $\mathrm{Cl} 2\left(\tau_{5}=0.05\right)$. The geometry around $\mathrm{Cu} 3 \mathrm{can}$ be described as a quite distorted square-pyramid with $\{\mathrm{NNOCl}\}$ base and distant apical oxygen $\left(\tau_{5}=0.19\right)$. The coordination polyhedra around $\mathrm{Cu} 1$ and $\mathrm{Cu} 3$ share both a mutual edge with the polyhedron around $\mathrm{Cu} 2$.

The structurally elucidated cluster is preserved in solution, as suggested by high resolution ESI-MS analysis of a solution of the green crystalline material in acetonitrile. The peak at $\mathrm{m} / z 957.9593$ corresponds to the molecular ion $\left[\left(\mathrm{O}\left\{{ }^{\mathrm{Ph}} \mathrm{BOX}\right\}\right)_{2} \mathrm{Cu}_{3} \mathrm{Cl}_{4}+\mathrm{Na}\right]^{+}$(calc. $m / z 957.9596$ for $\mathrm{C}_{34} \mathrm{H}_{42} \mathrm{Cl}_{4} \mathrm{Cu}_{3} \mathrm{~N}_{2} \mathrm{NaO}_{6}^{+}$) and is in accordance with the simulated isotope pattern. The observed ions clearly indicate incorporation of one oxygen atom into $\mathrm{H}\left\{{ }^{\mathrm{Ph}} \mathrm{BOX}\right\}$. Additional clusters with varying $\mathrm{BOX} / \mathrm{Cu} / \mathrm{Cl}$ stoichiometry are also evident in the mass spectrum, such as the $\left[\left(\left\{\mathrm{O}^{\mathrm{Ph}} \mathrm{BOX}\right\}\right)_{2} \mathrm{Cu}_{2} \mathrm{Cl}\right]^{+}$ion at $\mathrm{m} / z 763.1379$ (Figure 5.9 top). Additional ESI-MS experiments of reaction solutions showed further that the formation of the structurally characterized cluster happens not only in the course of crystallization, but directly after the addition of $\mathrm{CuCl}_{2}$ to the ligand in air.

To unambiguously confirm the incorporation of an oxygen atom originating from air, an isotope labelling experiment was carried out using ${ }^{18} \mathrm{O}_{2}$ instead of air (Figure 5.9 bottom). The spectrum clearly indicates incorporation of one oxygen atom into the ligand, originating from $\mathrm{O}_{2}$. The simulation of the isotope pattern shows that the amount of ${ }^{18} \mathrm{O}$ incorporation is $\sim 100 \%$ (an ion with the crystallised stoichiometry could not be observed for the ${ }^{18} \mathrm{O}$-labelled sample).

\section{Absence of $\mathrm{O}_{2}$}

The exclusion of dioxygen (argon atmosphere) prevents the oxygenation of the ligand and the formation of a yellow complex between $\left.\mathrm{H}_{\left\{{ }^{\mathrm{Ph}}\right.} \mathrm{BOX}\right\}$ and copper(II) chloride could be observed. This complex could be isolated as a small amount of yellow solid. Water and air excluded ESI-MS analysis with a mass spectrometer connected to a nitrogen dry box, confirmed the presence of solely the non-oxygenated and non-dimerised complex $\left.\left(\mathrm{H}_{\{}{ }^{\mathrm{Ph}} \mathrm{BOX}\right\}\right) \mathrm{CuCl}_{2}$ (Scheme 5.7, p. 87).

However, all attempts to obtain single crystals of sufficient quality failed so far. One reason might be the high reactivity in solution towards dioxygen, leav- 


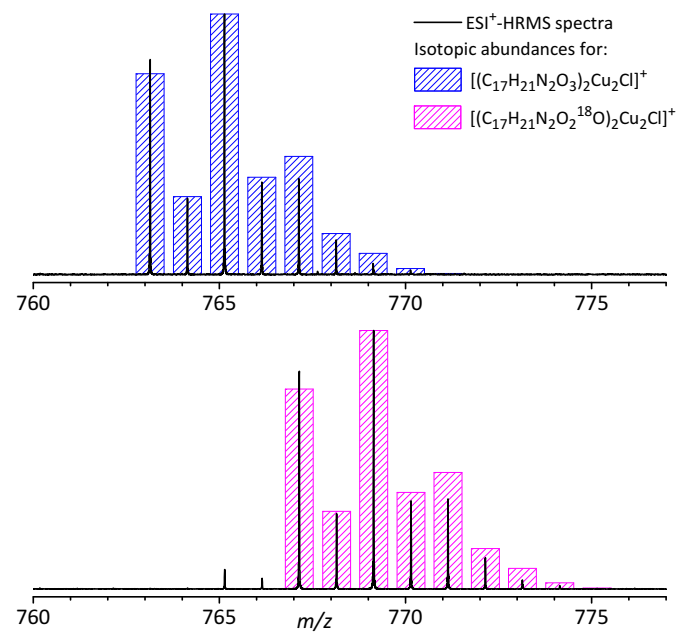

Figure 5.9. High-resolution $\mathrm{ESI}^{+}$mass spectra (black solid lines) of $\left(\mathrm{O}\left\{{ }^{\mathrm{Ph}} \mathrm{BOX}\right\}\right)_{2} \mathrm{Cu}_{3} \mathrm{Cl}_{4}$. The top spectrum is from a reaction with air; the blue striped columns represent the calculated isotope pattern for $\left[\left(\mathrm{C}_{17} \mathrm{H}_{21} \mathrm{~N}_{2} \mathrm{O}_{3}\right)_{2} \mathrm{Cu}_{2} \mathrm{Cl}\right]^{+}(\mathrm{m} / z$ 765.1356, calc. 765.1369). The bottom spectrum is from a reaction with ${ }^{18} \mathrm{O}_{2}$; the pink striped columns represent the calculated isotope pattern for $\left[\left(\mathrm{C}_{17} \mathrm{H}_{21} \mathrm{~N}_{2} \mathrm{O}_{2}{ }^{18} \mathrm{O}\right)_{2} \mathrm{Cu}_{2} \mathrm{Cl}\right]^{+},(\mathrm{m} / z$ 769.1429, calc. 769.1447).

ing green material in all crystallisation attempts, comprising the oxygenated ligand. An EPR spectrum of the yellow $\left.\left(\mathrm{H}_{\{}{ }^{\mathrm{Ph}} \mathrm{BOX}\right\}\right) \mathrm{CuCl}_{2}$ complex in frozen methylene chloride under inert conditions is quite similar to an EPR spectrum of the oxygen-inert $\left.\left(\mathrm{H}_{\{}{ }^{\mathrm{B} u} \mathrm{BOX}\right\}\right) \mathrm{CuCl}_{2}$ (Figure 5.10). Thus, an analogous structure can be expected for $\left.\left(\mathrm{H}_{\{}{ }^{\mathrm{Ph}} \mathrm{BOX}\right\}\right) \mathrm{CuCl}_{2}$, which was also found by DFT calculation (Section 5.5.3).

\section{Stoichiometry}

The composition of $\left(\mathrm{O}\left\{{ }^{\mathrm{Ph}} \mathrm{BOX}\right\}\right)_{2} \mathrm{Cu}_{3} \mathrm{Cl}_{4}$ (with the ligand to copper to chloride ratio of $2: 3: 4)$ suggests a reaction stoichiometry of two equivalents $\left.\mathrm{H}_{\{} \mathrm{Ph}_{\mathrm{BOX}}\right\}$ with three equivalents $\mathrm{CuCl}_{2} \cdot 2 \mathrm{H}_{2} \mathrm{O}$ and a single molecule $\mathrm{O}_{2}$ (Equation 5.1). It is likely, that the released protons, in the form of two equivalents $\mathrm{HCl}$, are then twice-protonating an additional molecule of the basic diimine BOX ligand (one proton per imine). Thus, the equation is balanced and reflects the applied $1: 1$ stoichiometry of ligand and metal salt. 


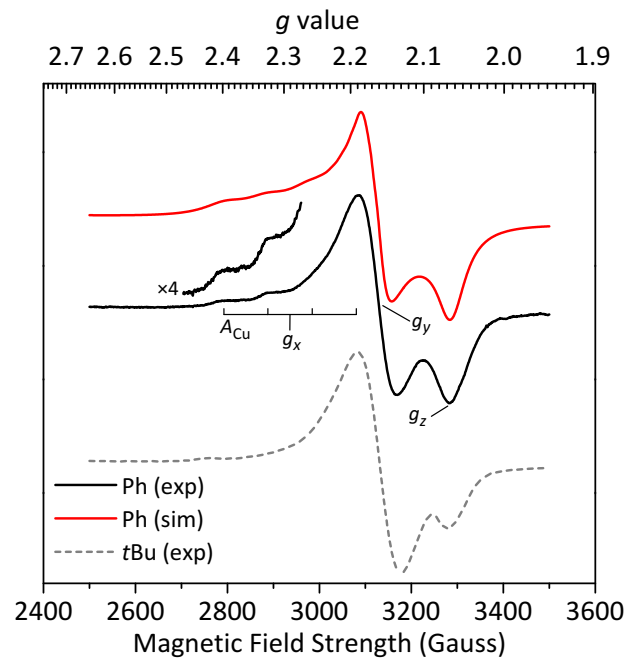

Figure 5.10. EPR spectrum of $\left.\left(\mathrm{H}_{\{}{ }^{\mathrm{Ph}} \mathrm{BOX}\right\}\right) \mathrm{Cu}^{\mathrm{II}} \mathrm{Cl}_{2}$ (black solid line), prepared under dioxygen exclusion in frozen DCM solution, recorded at $133 \mathrm{~K}\left(v_{\mathrm{c}}=9.43165 \mathrm{GHz}\right)$. The spectrum was simulated (red solid line) with spin Hamiltonian parameters $g_{x}=2.3006, g_{y}=2.1650, g_{z}$ $=2.0550\left(g_{\mathrm{av}}=2.1735\right), A_{x}\left({ }^{63,65} \mathrm{Cu}\right)=88.0$ Gauss, $A_{y}\left({ }^{14} \mathrm{~N}\right)=15.5$ Gauss. For comparison, the spectrum of the $\left.\left(\mathrm{H}_{\{}^{t \mathrm{Bu}} \mathrm{BOX}\right\}\right) \mathrm{Cu}^{11} \mathrm{Cl}_{2}$ analogue is depicted (grey dashed line), $150 \mathrm{~K}, v_{\mathrm{c}}=$ $9.42889 \mathrm{GHz}$.

$$
\begin{aligned}
& 2 \mathrm{H}\left\{{ }^{\mathrm{Ph}} \mathrm{BOX}\right\}+3 \mathrm{CuCl}_{2}+\mathrm{O}_{2} \longrightarrow\left(\mathrm{O}_{\left\{{ }^{\mathrm{Ph}} \mathrm{BOX}\right\}}\right)_{2} \mathrm{Cu}_{3} \mathrm{Cl}_{4}+2 \mathrm{HCl} \\
& \left.\mathrm{H}_{\{}{ }^{\mathrm{Ph}} \mathrm{BOX}\right\}+2 \mathrm{HCl} \longrightarrow\left[\left\{{ }^{\mathrm{Ph}} \mathrm{BOX}\right\} \mathrm{H}_{3}\right] \mathrm{Cl}_{2}
\end{aligned}
$$

To gain a first insight into the reaction mechanism, $\mathrm{H}\left\{{ }^{\mathrm{Ph}} \mathrm{BOX}\right\}$ was titrated with $\mathrm{CuCl}_{2} \cdot 2 \mathrm{H}_{2} \mathrm{O}$ in air, monitored by UV-vis spectroscopy (Figure 5.11). Upon addition of $\mathrm{CuCl}_{2}$, an intense and broad peak grows at $\lambda_{\max }=700 \mathrm{~nm}\left(\epsilon=3.2 \mathrm{mM}^{-1} \mathrm{~cm}^{-1}\right)$.

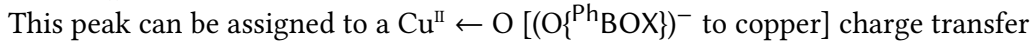
transition and is responsible for the intense green colour. The peak however grows only until 0.5 eq. $\mathrm{CuCl}_{2} \cdot 2 \mathrm{H}_{2} \mathrm{O}$ are added (Figure 5.11 , - ). Upon the addition of more $\mathrm{CuCl}_{2} \cdot 2 \mathrm{H}_{2} \mathrm{O}$, the feature decreases in intensity by $\sim 1 / 3$ until 0.75 eq. are 

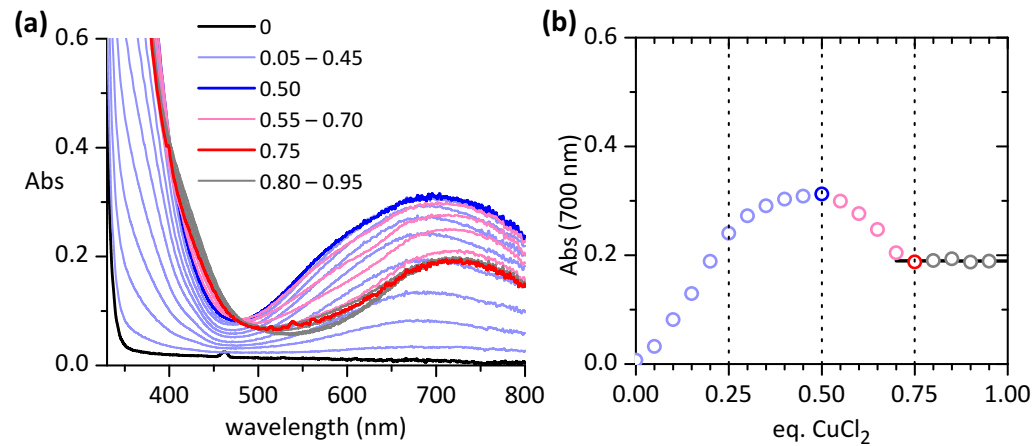

Figure 5.11. Titration of $\mathrm{H}_{\{}\left\{{ }^{\mathrm{Ph}} \mathrm{BOX}\right\}$ with $\mathrm{CuCl}_{2} \cdot 2 \mathrm{H}_{2} \mathrm{O}$. (a) Spectral changes (eq. $\mathrm{CuCl}_{2}$ are indicated). (b ) Titration curve at $700 \mathrm{~nm}$. Rising (blue), descending (red) and steady (gray) sections are indicated.

reached (-). The further addition of $\mathrm{CuCl}_{2}$ has no more influence on the UV-vis spectral features (-).

The spectral changes might be explained by the following scenario: Addition of $\mathrm{CuCl}_{2}$ induces oxygenation of $\left.\mathrm{H}_{\{}{ }^{\mathrm{Ph}} \mathrm{BOX}\right\},\left(\mathrm{HO}\left\{{ }^{\mathrm{Ph}} \mathrm{BOX}\right\}\right)$ is formed. A proton is released upon binding of $\left.\left(\mathrm{O}_{\{}{ }^{\mathrm{Ph}} \mathrm{BOX}\right\}\right)^{-}$to copper. The released proton is captured by an additional $\left.\mathrm{H}_{\{}{ }^{\mathrm{Ph}} \mathrm{BOX}\right\}$ or a corresponding $\mathrm{HO}\left\{{ }^{\mathrm{Ph}} \mathrm{BOX}\right\}$ ligand to form $\left[\left(\mathrm{H}_{\{}\left\{{ }^{\mathrm{Ph}} \mathrm{BOX}\right\}\right) \mathrm{H}\right] \mathrm{Cl}$ or $\left.\left[\left(\mathrm{HO}_{\{}{ }^{\mathrm{Ph}} \mathrm{BOX}\right\}\right) \mathrm{H}\right] \mathrm{Cl}$. At 0.5 eq. $\mathrm{CuCl}_{2}$, a maximum is reached, since all released protons are captured by a second ligand in accordance with the 2:1 ligand to metal stoichiometry. The formed new complex would have the stoichiometry of $\left.\left(\mathrm{O}_{\{}^{\mathrm{Ph}} \mathrm{BOX}\right\}\right)_{n} \mathrm{Cu}_{n} \mathrm{Cl}_{n}$ with e. $\mathrm{g}$. $n=2$ for a binuclear cluster (the corresponding $\left.\left(\mathrm{O}_{\{}\left\{{ }^{\mathrm{Ph}} \mathrm{BOX}\right\}\right)_{2} \mathrm{Cu}_{2} \mathrm{Cl}\right]^{+}$ion was observed by mass spectrometry of the final complex). Further addition of $\mathrm{CuCl}_{2}$ results in the formation of the characterised $\left.\left(\mathrm{O}_{\{}{ }^{\mathrm{Ph}} \mathrm{BOX}\right\}\right)_{2} \mathrm{Cu}_{3} \mathrm{Cl}_{4}$ until 0.75 eq. are added. This reorganisation might encourage the breakage of some $\mathrm{Cu}-\mathrm{O}_{\mathrm{BOX}}$ bonds and the intensity of the $\mathrm{CT}$ feature drops slightly. Additional $\mathrm{CuCl}_{2}$ cannot be bound anymore and leads not to higher nuclearity complexes, the UV-vis spectrum remains therefore unchanged. The titration finally implies a slightly simpler reaction stoichiometry than assumed above: 


$$
\begin{aligned}
\left.\mathrm{H}_{\{}{ }^{\mathrm{Ph}} \mathrm{BOX}\right\}+\mathrm{CuCl}_{2}+1 / 2 \mathrm{O}_{2} & \longrightarrow 1 / n\left[\left(\mathrm{O}\left\{{ }^{\mathrm{Ph}} \mathrm{BOX}\right\}\right) \mathrm{CuCl}\right]_{n}+\mathrm{HCl} \\
\mathrm{H}_{\{}\left\{{ }^{\mathrm{Ph}} \mathrm{BOX}\right\}+\mathrm{HCl} & \longrightarrow\left[\left\{{ }^{\mathrm{Ph}}{ }_{\mathrm{BOX}}\right\} \mathrm{H}_{2}\right] \mathrm{Cl}
\end{aligned}
$$

\subsection{2. $\mathrm{HO}\left\{{ }^{\mathrm{Ph}} \mathrm{BOX}\right\}$ Ligand Recovery and Identification}

Removal of copper chloride and isolation of the organic ligand with the Chelex polymer, as applied for the dimerised ligands ${ }^{\mathrm{Me}} \mathrm{BOX}_{2}$ and ${ }^{\square} \mathrm{BOX}_{2}$, was not successful for unknown reason. However, it might be attributed to the polarity of the alcohol/-ate residue. As an alternative approach, the intensively green reaction solution was washed with $\mathrm{NH}_{4} \mathrm{OH}$ to remove all inorganic copper and chloride ions (Scheme 5.8). The hydroxylated ligand $\mathrm{HO}^{\mathrm{Ph}} \mathrm{BOX}$ was obtained as a colourless to light-blue oil in reasonable purity; further purification by column chromatography was however not successful so far. Hence, a yield of $\sim 60 \%$ was determined by the addition of 1,2,4,5-tetrabromobenzene as an internal standard for ${ }^{1} \mathrm{H}$ NMR peak area analysis. The determined yield is however consistent with the anticipated reaction stoichiometry.<smiles>CC1(C)COC(/C(=C2/NC(C)(C)CO2)c2ccccc2)=N1</smiles>
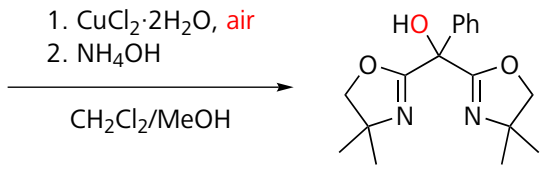

Scheme 5.8 Preparation and isolation of $\mathrm{HO}\left\{{ }^{\mathrm{Ph}} \mathrm{BOX}\right\}$.

Some line broadening in the NMR spectra can be attributed to the presence of a paramagnetic impurity. Stirring of an NMR sample over Chelex polymer led unfortunately not to a significantly improved quality of the sample. The hydroxylation of the $\left.\mathrm{H}_{\{}{ }^{\mathrm{Ph}} \mathrm{BOX}\right\}$ ligand is well evident in the ${ }^{1} \mathrm{H} N \mathrm{NM},{ }^{13} \mathrm{C} \mathrm{NMR}$ as well as in ${ }^{1} \mathrm{H},{ }^{13} \mathrm{C}$-HSQC spectroscopy by the absence of both, the ${ }^{1} \mathrm{H}$ and ${ }^{13} \mathrm{C}$ resonance peaks and the ${ }^{1} \mathrm{H},{ }^{13} \mathrm{C}$ correlation peak of the bridging- $\mathrm{CH}$ group.

\subsubsection{Formation of $\mathrm{HO}\left\{{ }^{\mathrm{Me}} \mathrm{BOX}\right\}$}

In the synthesis of $\left({ }^{\mathrm{Me}} \mathrm{BOX}_{2}\right) \mathrm{Cu}_{2} \mathrm{Cl}_{2}$ (cf. Section 5.2.2), a small amount of green single crystals of $\left(\mathrm{O}_{\left\{{ }^{\mathrm{Me}} \mathrm{BOX}\right\}}\right)_{2}(\mathrm{MeOH})_{2} \mathrm{Cu}_{4} \mathrm{Cl}_{6}$ have been obtained as a minor 
<smiles>CC(C1=NC(C)(C)CO1)C1=NC(C)(C)CO1</smiles>

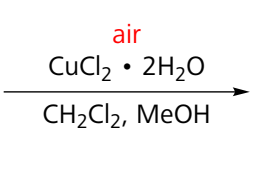

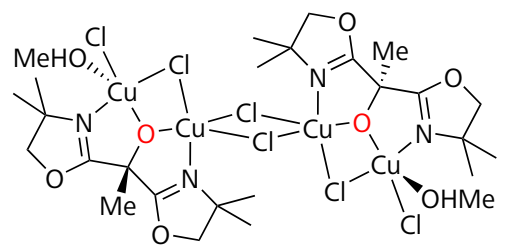

Scheme 5.9 In air, $\left(\mathrm{O}\left\{{ }^{\mathrm{Me}} \mathrm{BOX}\right\}\right)_{2}(\mathrm{MeOH})_{2} \mathrm{Cu}_{4} \mathrm{Cl}_{6}$ is a minor byproduct in the dimerisation reaction of $\mathrm{H}\left\{{ }^{\mathrm{Me}} \mathrm{BOX}\right\}$ and $\mathrm{CuCl}_{2} \cdot 2 \mathrm{H}_{2} \mathrm{O}$.

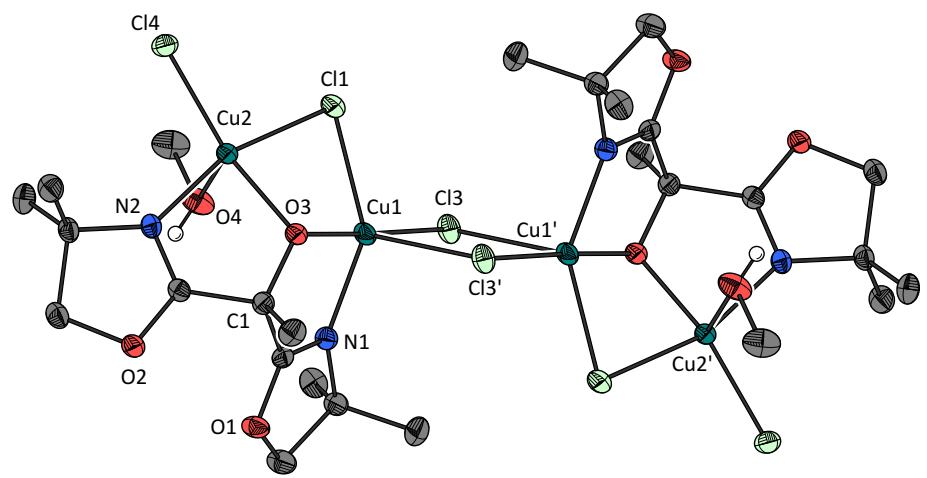

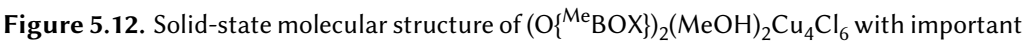
atoms labelled. Displacement ellipsoids are drawn at the $50 \%$ probability level; most hydrogen atoms have been omitted for the sake of clarity; symmetry transformations used to generate equivalent atoms ('): $1-x, 1-y, 1-z$. Significant interatomic distances and angles are listed in Table 5.5 .

byproduct in the dimerisation reaction of $\left.\mathrm{H}_{\left\{{ }^{\mathrm{Me}}\right.} \mathrm{BOX}\right\}$, side by side to crystalline material of yellow $\left({ }^{\mathrm{Me}} \mathrm{BOX}_{2}\right) \mathrm{Cu}_{2}^{\mathrm{I}} \mathrm{Cl}_{2}$, when the reaction was conducted in air instead of an inert atmosphere (Scheme 5.9). Analysis by X-ray crystallography

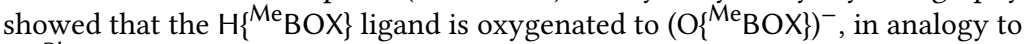
$\left.\left(\mathrm{O}_{\{}{ }^{\mathrm{Ph}} \mathrm{BOX}\right\}\right)^{-}$. The complex crystallised in the monoclinic space group $P 2_{1} / c$ (Figure 5.12).

The tetranuclear complex $\left(\mathrm{O}\left\{{ }^{\mathrm{Me}} \mathrm{BOX}\right\}\right)_{2}(\mathrm{MeOH})_{2} \mathrm{Cu}_{4} \mathrm{Cl}_{6}$ is composed of two bidentate $\left(\mathrm{O}\left\{{ }^{\mathrm{Me}} \mathrm{BOX}\right\}\right)^{-}$ligands and builds a coordination dimer with a bis $(\mu-$ 
Table 5.5.

Significant geometric information of the solid-state structures of $\left(\left\{{ }^{\mathrm{Me}} \mathrm{BOX}\right\} \mathrm{O}\right)_{2}(\mathrm{MeOH})_{2} \mathrm{Cu}_{4} \mathrm{Cl}_{6}$ in Figure 5.12. Interatomic distances $(\AA)$, angles $\left({ }^{\circ}\right)$ and $\tau$ parameters. ${ }^{a}$

\begin{tabular}{lllr}
\hline Atoms 1,2 & $d 1,2(\AA)$ & Atoms 1,2,3 & Angle $1,2,3\left(^{\circ}\right)$ \\
\hline $\mathrm{Cu} 1 \cdots \mathrm{Cu} 1^{\prime}$ & $3.6218(3)$ & $\mathrm{N} 1-\mathrm{Cu} 1-\mathrm{O} 3$ & $81.750(61)$ \\
$\mathrm{Cu} 1 \cdots \mathrm{Cu} 2$ & $3.0268(3)$ & $\mathrm{N} 1-\mathrm{Cu} 1-\mathrm{Cl} 1$ & $145.296(49)$ \\
$\mathrm{Cl} 3 \cdots \mathrm{Cl}^{\prime}$ & $3.4326(8)$ & $\mathrm{N} 1-\mathrm{Cu} 1-\mathrm{Cl} 3$ & $101.292(49)$ \\
& & $\mathrm{N} 1-\mathrm{Cu} 1-\mathrm{Cl} 3^{\prime}$ & $99.927(48)$ \\
$\mathrm{Cu} 1-\mathrm{O} 3$ & $1.9611(13)$ & $\mathrm{O} 3-\mathrm{Cu} 1-\mathrm{Cl} 1$ & $81.322(40)$ \\
$\mathrm{Cu} 1-\mathrm{N} 1$ & $1.9967(16)$ & $\mathrm{O} 3-\mathrm{Cu} 1-\mathrm{Cl} 3$ & $176.133(43)$ \\
$\mathrm{Cu} 1-\mathrm{Cl} 3$ & $2.2397(5)$ & $\mathrm{O} 3-\mathrm{Cu} 1-\mathrm{Cl} 3^{\prime}$ & $90.263(39)$ \\
$\mathrm{Cu} 1-\mathrm{Cl} 1$ & $2.3447(6)$ & $\mathrm{Cl} 1-\mathrm{Cu} 1-\mathrm{Cl} 3$ & $97.235(19)$ \\
$\mathrm{Cu} 2-\mathrm{O} 3$ & $1.9542(13)$ & $\mathrm{Cl} 1-\mathrm{Cu} 1-\mathrm{Cl} 3^{\prime}$ & $110.211(19)$ \\
$\mathrm{Cu} 2-\mathrm{N} 2$ & $1.9805(14)$ & $\mathrm{Cl} 3-\mathrm{Cu} 1-\mathrm{Cl} 3^{\prime}$ & $86.867(17)$ \\
$\mathrm{Cu} 2-\mathrm{Cl} 4$ & $2.2334(6)$ & $\mathrm{N} 2-\mathrm{Cu} 2-\mathrm{O} 3$ & $82.448(61)$ \\
$\mathrm{Cu} 2-\mathrm{Cl} 1$ & $2.3116(5)$ & $\mathrm{N} 2-\mathrm{Cu} 2-\mathrm{O} 4$ & $85.188(61)$ \\
$\mathrm{Cu} 2-\mathrm{O} 4$ & $2.3735(18)$ & $\mathrm{N} 2-\mathrm{Cu} 2-\mathrm{Cl} 1$ & $160.587(50)$ \\
& & $\mathrm{N} 2-\mathrm{Cu} 2-\mathrm{Cl} 4$ & $100.947(49)$ \\
$\tau_{5}(\mathrm{Cu} 1)$ & 0.51 & $\mathrm{O} 3-\mathrm{Cu} 2-\mathrm{Cl} 4$ & $156.979(41)$ \\
$\tau_{5}(\mathrm{Cu} 2)$ & 0.06 & $\mathrm{O} 3-\mathrm{Cu} 2-\mathrm{Cl} 1$ & $82.326(42)$ \\
& & $\mathrm{O} 3-\mathrm{Cu} 2-\mathrm{O} 4$ & $96.113(55)$ \\
& & $\mathrm{O} 4-\mathrm{Cu} 2-\mathrm{Cl} 1$ & $84.533(42)$ \\
& & $\mathrm{O} 4-\mathrm{Cu} 2-\mathrm{Cl} 4$ & $106.835(41)$ \\
& & $\mathrm{Cl} 1-\mathrm{Cu} 2-\mathrm{Cl} 4$ & $97.777(19)$ \\
& & $\vartheta\left(\mathrm{Cu} 1-\mathrm{Cl} 3-\mathrm{Cl} 3^{\prime}-\mathrm{Cu} 1^{\prime}\right)$ & 180 \\
\hline
\end{tabular}

${ }^{a}$ See p. 269 for description of $\tau_{4}$ and $\tau_{5}$ parameters.

chlorido)dicopper(II) core, which resides on a crystallographic inversion centre of symmetry. The $\mathrm{Cu}_{2} \mathrm{Cl}_{2}$ core is planar (torsion angle $\varphi\left(\mathrm{Cu} 1-\mathrm{Cl} 3-\mathrm{Cl} 3^{\prime}-\mathrm{Cu} 1^{\prime}\right)=180^{\circ}$ ) and roughly square $\left(\mathrm{Cu} 1 \cdots \mathrm{Cu} 1^{\prime} \approx 3.6 \AA, \mathrm{Cl} 3 \cdots \mathrm{Cl} 3^{\prime} \approx 3.4 \AA, \angle \mathrm{Cl} 3-\mathrm{Cu} 1-\mathrm{Cl} 3^{\prime} \approx 87^{\circ}\right)$. A second copper atom $(\mathrm{Cu} 2)$ is coordinated in the second pocket of $\left(\mathrm{O}_{\left\{{ }^{\mathrm{Me}} \mathrm{BOX}\right\}}\right)^{-}$ in a distance of $\mathrm{Cu} 1 \cdots \mathrm{Cu} 2 \approx 3.0 \AA$, analogous to the coordination of $\left(\mathrm{O}_{\{}\left\{{ }^{\mathrm{Ph}} \mathrm{BOX}\right\}\right)^{-}$ (see above); it is furthermore coordinated by $\mathrm{Cl}$ and $\mathrm{MeOH}$ solvent, a $\mu-\mathrm{Cl}$ is finally bridging between both $\mathrm{Cu}$ atoms.

$\mathrm{Cu} 1$ is five-fold coordinated by $\left\{\mathrm{NOCl}_{3}\right\}$ donors in a geometry right between square pyramidal and trigonal bipyramidal $\left(\tau_{5}=0.51\right), \mathrm{Cu} 2$ is square pyramidal coordinated by $\{\mathrm{NOClCl}\}$ basal donors and a loosely bound apical $\mathrm{MeOH}$ solvent molecule $\left(\mathrm{Cu}-\mathrm{O}\right.$ bond length $\left.\sim 2.4 \AA, \tau_{5}=0.06\right)$. 
The ligand's coordination ability resembles that of $\left(\mathrm{O}\left\{{ }^{\mathrm{Ph}} \mathrm{BOX}\right\}\right)^{-}$, with a fivering coordination and ligand $»$ bite $«$ angles of $\sim 82^{\circ}$ and coplanar $\mathrm{C}=\mathrm{N} / \mathrm{C}-\mathrm{O}^{-}$ bonds (torsion angles $0.8^{\circ}$ and $5.0^{\circ}$ ). The angle between the planes spanned by the oxazoline rings is $61.3^{\circ}$. The angle between the $\mathrm{C}=\mathrm{N}$ bonds is $81.8^{\circ}$

\subsubsection{Oxygenation of $\left.\mathrm{H}^{\mathrm{H}} \mathrm{BOX}\right\}$}

In addition to the oxygenation reactions described above, first indications of an oxygenation of the $\left.\mathrm{H}_{\{}^{\mathrm{H}} \mathrm{BOX}\right\}$ ligand could be obtained. From attempts to crystallise the copper complex of ${ }^{\square} \mathrm{BOX}_{2}$, crystalline material could be obtained. The quality of the single crystals was unfortunately not sufficient for a satisfactory refinement of structure. Since chloroform is incorporated in the crystalline material, partial evaporation of $\mathrm{CHCl}_{3}$ might be the reason for the poor quality. In the complex structure of ligands and copper chloride, the two oxygenated ligands depicted in Scheme 5.10 are contained.
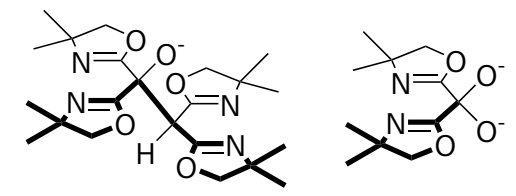

Scheme 5.10 Oxygenation products of $\left.\mathrm{H}_{\{}{ }^{\mathrm{H}} \mathrm{BOX}\right\}$.

The observation of a dimerised and oxygenated ligand seems interesting, since it shows that there might be a second path to an oxygenated ligand, starting not from the monomeric, but a dimeric ligand. The twice-oxygenated BOX ligand on the other hand is most likely unstable without copper ligation, as other organic geminal diols are, and would readily dehydrate to form a carbonyl group. Interestingly, the carbonylation of $\left.\mathrm{H}_{\{}{ }^{\mathrm{H}} \mathrm{BOX}\right\}$ to ${ }^{\mathrm{O}} \mathrm{BOX}$ was indeed observed in Section 6.10.2, p. 172.

\subsection{Mechanistic Considerations}

\subsubsection{An Intermediate Radical Species}

In a mechanistic scenario, one could propose that after coordination of $\mathrm{CuCl}_{2}$, the acidic proton at the ligand's backbone is released and a resonance-stabilized bis(oxazolin)ate- $\mathrm{Cu}^{\text {II }}$ complex is formed. Subsequently, the ligand shows noninnocence redox activity and is oxidised by one electron, concomitant with the 
reduction of the copper ion to consequentially form a (ligand radical) $-\mathrm{Cu}^{\mathrm{I}}$ complex. $\left(\mathrm{BOX}^{-}\right) \mathrm{Cu}^{\mathrm{II}}$ and $\left(\mathrm{BOX}^{\bullet}\right) \mathrm{Cu}^{\mathrm{I}}$ can be described as resonance structures of each other (Scheme 5.11).

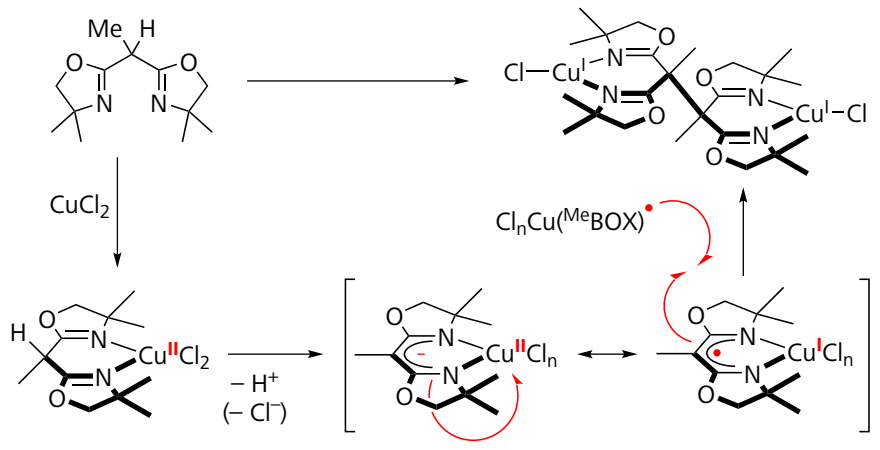

Scheme 5.11 Formation and proposed mechanism of ${ }^{\mathrm{Me}} \mathrm{BOX}_{2}(\mathrm{CuCl})_{2}$ from $\left.\mathrm{H}_{\{}{ }^{\mathrm{Me}} \mathrm{BOX}\right\}$ and $\mathrm{CuCl}_{2}$.

The delocalisation of spin density in this radical, through the electron-withdrawing $\mathrm{C}=\mathrm{N}$ substituents and the electron-releasing alkyl residue, provides enhanced persistence of this organic radical. Radicals, stabilized by this effect are coined captodative radicals. ${ }^{[203,208]}$ An example is the remarkably stable dicyano(dimethylamino)methyl radical (Scheme 5.12a). ${ }^{\text {[202] }}$

The formation of dehydro-dimer $\left({ }^{\square} \mathrm{BOX}_{2}\right) \mathrm{Cu}_{2} \mathrm{Cl}_{2}$ indicates that the dimerisation reaction is of a radical nature. In free-radical reactions, applied in the synthesis of amino acids, the formation of dimers via coupling of captodative $\alpha$-carbon-centred radicals is regularly observed. ${ }^{[209]}$ As a synthetic principle, dimerisation reactions through dehydrogenation typically give good yields and are very selective. ${ }^{[210,211]}$

Presumably, the reaction sequence comprises the homocoupling of two such free radical intermediates via recombination (Scheme 5.11). This reaction is known for several captodative radicals, thus this reaction has some applications in organic synthesis: ${ }^{[203]}$ one example is the dimerisation of methyl pyroglutamate (Scheme 5.12b). ${ }^{[204]}$ The formation of the double bond in ${ }^{{ }^{\circ}} \mathrm{BOX}_{2}$ resembles the classical indigo synthesis (Scheme 5.12c). ${ }^{[205]}$ Furthermore, the reaction of a captodative radical with dioxygen has its applications (Scheme 5.12d) ${ }^{[206]}$ and is related to the oxygenation of $\mathrm{H}\left\{{ }^{\mathrm{Ph}} \mathrm{BOX}\right\}$. Moreover, the solid-state structure of the $\sigma$ dimer of a persistent 9,10-dialkoxyanthracene radical cation (Scheme 5.12e) was 
(a)<smiles>CNC(C#N)C#N</smiles>

(b)

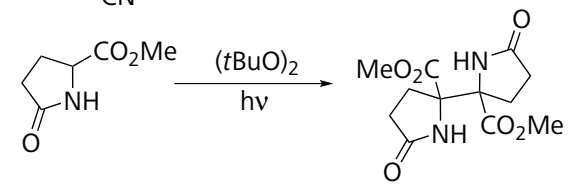

(c)

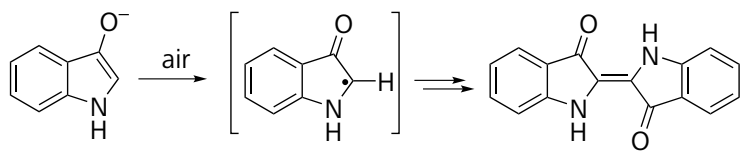

(d)

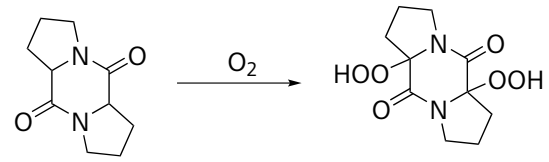

(e)<smiles></smiles>

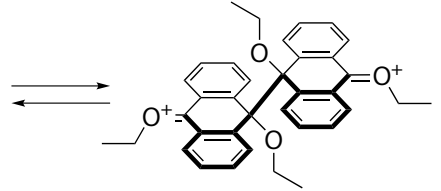

Scheme 5.12 (a) The remarkably persistent dicyano(dimethylamino)methyl radical. ${ }^{[202]}$ Synthetic applications of the captodative effect: ${ }^{[203]}$ ( b ) Homocoupling of methyl pyroglutamate by tert-butyloxy radicals, ${ }^{[204]}$ (c) of 3-oxoindolin-2-ide to indigo by oxygen, ${ }^{[205]}$ (d) reaction of a piperazinedione with dioxygen. ${ }^{[206]}$ (e) Reversible $\sigma$-dimerisation of persistent 9,10-dialkoxyanthracene radical cations. ${ }^{[207]}$ 
investigated recently and is remarkably similar to the solid-state structure of $\left({ }^{\mathrm{Me}} \mathrm{BOX}_{2}\right) \mathrm{Cu}_{2} \mathrm{Cl}_{2}$. In this case, the monomeric radical was found in solution and as the respective $\sigma$-dimer in the solid state. ${ }^{[207]}$ However, for the BOX-copper(II) reactions, no indication for reversibility was found.

\subsubsection{Electrochemistry}

Figure 5.13 shows cyclic voltammograms $(\mathrm{CV})$ of $\left.\mathrm{H}_{\{}{ }^{t \mathrm{Bu}} \mathrm{BOX}\right\}$ and $\left.\mathrm{H}_{\{}{ }^{\mathrm{Me}} \mathrm{BOX}\right\}$ over the full range in $\mathrm{MeCN}$. It is well evident that the curves are nearly identical, with no significant peaks arising from ligand oxidation. However, this shows that $\mathrm{H}\left\{{ }^{\mathrm{Me}} \mathrm{BOX}\right\}$ can not be oxidised electrochemically via an outer-sphere mechanism and that presumably only an inner-sphere oxidation upon coordination of the oxidant $\left(\mathrm{Cu}^{\mathrm{II}}\right)$ is feasible here.

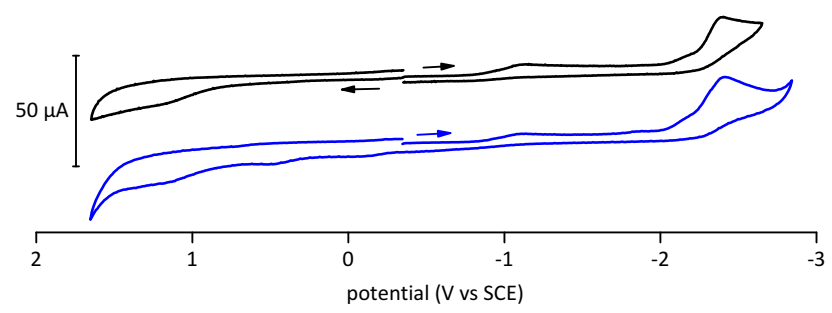

Figure 5.13. Cyclic voltammograms of $\left.\mathrm{H}_{\{}^{\{\mathrm{tBu}} \mathrm{BOX}\right\}$ (black solid lines) and $\mathrm{H}\left\{{ }^{\mathrm{Me}} \mathrm{BOX}\right\}$ (blue solid line) in $\mathrm{MeCN}$ containing $0.1 \mathrm{M}\left[\mathrm{NBu}_{4}\right] \mathrm{PF}_{6}$, at a glassy carbon electrode; scan rate $100 \mathrm{mV} \mathrm{s}^{-1}$.

\subsubsection{DFT Calculations}

The anticipated radical recombination step and the reactivity towards dioxygen demand a reasonable spin density at the bridging carbon atom (C1). Spin unrestricted density functional theory (DFT) calculations were carried out on the B3LYP/def2-TZVPP level of theory to gain insights into the molecular and electronic structure of the proposed intermediates. As a first approach, the geometries of complexes $\left.\left(\mathrm{H}_{\{}{ }^{\mathrm{R}} \mathrm{BOX}\right\}\right) \mathrm{CuCl}_{2}$ were optimised. The computed structure of $\left.\left(\mathrm{H}_{\{}^{t \mathrm{tBu}} \mathrm{BOX}\right\}\right) \mathrm{CuCl}_{2}$ is in good conformity with the crystal structure from Figure 5.6 (see Figure 5.14a for a representation of the structural match). Furthermore, the obtained coordinates of the four complexes $\left.\left(\mathrm{H}_{\{}{ }^{\mathrm{R}} \mathrm{BOX}\right\}\right) \mathrm{CuCl}_{2}$ are consistent with 
each other (Figure 5.14b, see Table A.1 for geometric parameters). Only in the case of $\left.\left(\mathrm{H}_{\{}{ }^{\mathrm{Ph}} \mathrm{BOX}\right\}\right) \mathrm{CuCl}_{2}$, the geometry is more different. Here, the shape of the chelate ring is relatively planar, while in the other complexes a boat-shaped geometry is adopted. However, the geometries around the copper atoms are reasonably equal, which was also reflected in the similar EPR spectra of $\left(\mathrm{H}_{\{}\left\{\mathrm{Ph}_{\mathrm{BOX}}\right\}\right) \mathrm{CuCl}_{2}$ and $\left(\mathrm{H}\left\{{ }^{t \mathrm{Bu}} \mathrm{BOX}\right\}\right) \mathrm{CuCl}_{2}$. While it was possible to record the EPR spectrum of $\left(\mathrm{H}\left\{{ }^{\mathrm{Ph}} \mathrm{BOX}\right\}\right) \mathrm{CuCl}_{2}$, in the cases of $\left.\left(\mathrm{H}_{\{}{ }^{\mathrm{Me}} \mathrm{BOX}\right\}\right) \mathrm{CuCl}_{2}$ and $\left.\left(\mathrm{H}_{\{}{ }^{\mathrm{H}} \mathrm{BOX}\right\}\right) \mathrm{CuCl}_{2}$, both complexes are proposed as transient intermediates following the complexation of $\mathrm{CuCl}_{2}$, which then vanish in the fast dimerisation reactions.

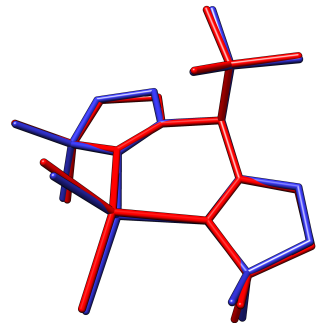

(a)

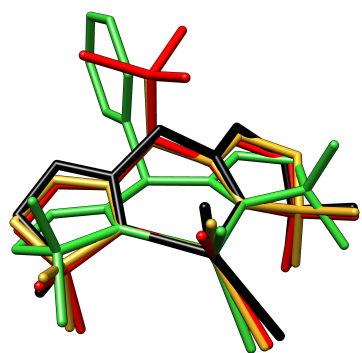

(b)

Figure 5.14. (a) Overlay of the X-ray crystal structure (blue) and the DFT-optimised coordinates (red) of $\left.\left(\mathrm{H}_{\{}{ }^{t \mathrm{Bu}} \mathrm{BOX}\right\}\right) \mathrm{CuCl}_{2}$. ( b ) Superimposed geometry-optimized structures of the four complexes $\left.\left(\mathrm{H}_{\{}{ }^{\mathrm{R}} \mathrm{BOX}\right\}\right) \mathrm{CuCl}_{2} ; \mathrm{R} \equiv \mathrm{H}$ (black), Me (gold), $t \mathrm{Bu}$ (red), $\mathrm{Ph}$ (green). Note that the structure of $\left(\mathrm{H}\left\{{ }^{\mathrm{Ph}} \mathrm{BOX}\right\}\right) \mathrm{CuCl}_{2}$ differs since it adopts a planar coordination geometry compared to the boat-shaped geometry of the other complexes.

The computed structures for the proposed deprotonated or dehydrochlorinated intermediates gave further insights (See Figure A.1 for a full overview and Table A.1 for geometric parameters). Mulliken spin-populations in the DFT-computed structures (Figure 5.15 and Figure A.1, Table A.2) support the proposed mechanism from Scheme 5.11. In the $\left.\left(\mathrm{H}_{\{}{ }^{\mathrm{R}} \mathrm{BOX}\right\}\right) \mathrm{CuCl}_{2}$ structures, the single electron located mainly at the copper atom is significantly spread over the coordinating nitrogen atoms and chloride ligands (58.7\% density at the copper atom, $\mathrm{Cu}, \mathrm{N}$ and $\mathrm{Cl}$ atoms claim $99.2 \%$ of the overall density in the case of $\mathrm{R} \equiv \mathrm{Me}$ ). Whereas at the bridging $\mathrm{C} 1$ no spin $(\lesssim 0.0 \%)$ is located in the cases of the four $\left.\left(\mathrm{H}_{\{}{ }^{\mathrm{R}} \mathrm{BOX}\right\}\right) \mathrm{CuCl}_{2}$ complexes, the situation in the deprotonated and dehydrochlorinated compounds is different. In $\left[\left({ }^{\mathrm{Me}} \mathrm{BOX}\right) \mathrm{CuCl}_{2}\right]^{-}$, the spin-density at $\mathrm{C} 1$ is increased to $3.0 \%$ and in $\left({ }^{\mathrm{Me}} \mathrm{BOX}\right) \mathrm{CuCl}$, 
$4.1 \%$ density is at $\mathrm{C} 1$ (Figure 5.15). In $\left({ }^{\mathrm{H}} \mathrm{BOX}\right) \mathrm{CuCl}$ and $\left({ }^{\mathrm{Ph}} \mathrm{BOX}\right) \mathrm{CuCl}$ the situation is similar, although the computed density at $\mathrm{C} 1$ is lower in both cases. Interestingly, no spin-density is located at the phenyl ring in $\left({ }^{\mathrm{Ph}} \mathrm{BOX}\right) \mathrm{CuCl}$ and in agreement with this, no indication for reactivity including the phenyl ring was observed. The presumed reason might be simply the absence of conjugation between the phenyl ring and the bis(oxazolin)ate moiety, due to the non-planarity of the system.

It should be emphasized, that the molecular structure of the proposed transient $\left({ }^{\mathrm{Me}} \mathrm{BOX}\right) \mathrm{CuCl}$ (Figure 5.15) not only represents the dehydrochlorinated $\left(\mathrm{H}\left\{{ }^{\mathrm{Me}} \mathrm{BOX}\right\}\right) \mathrm{CuCl}_{2}$, but in addition is identical to a subunit of the isolated dimer $\left({ }^{\mathrm{Me}} \mathrm{BOX}_{2}\right) \mathrm{Cu}_{2} \mathrm{Cl}_{2}$ (structurally and electronically; after hypothetical homolytic cleavage). Although a similar distribution of spin density was computed in the compounds with $\left.\mathrm{H}_{\{}{ }^{t \mathrm{Bu}} \mathrm{BOX}\right\}$, the complex showed no reactivity in experiments. This can furthermore be attributed to the sterical demand of the $t \mathrm{Bu}$ residue, preventing deprotonation and the adoption of a planar conformation.
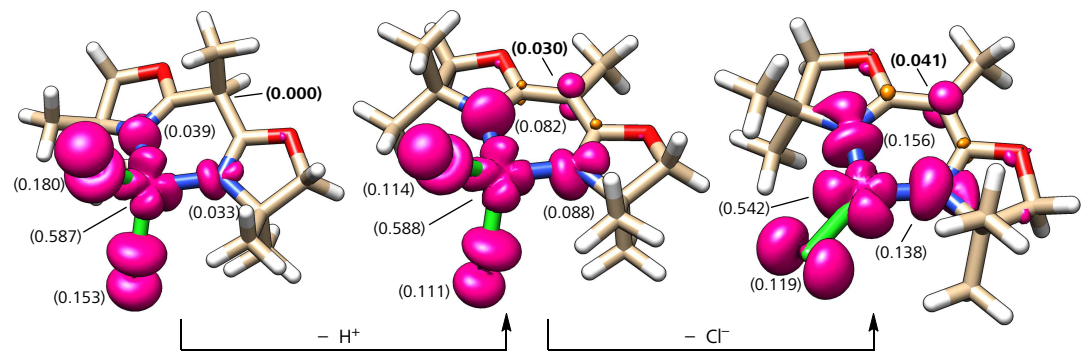

Figure 5.15. Proposed formation of the transient $\left[\left({ }^{\mathrm{Me}} \mathrm{BOX}\right) \mathrm{CuCl}_{2}\right]^{-}$(middle) from the intermediate $\left(\mathrm{H}\left\{{ }^{\mathrm{Me}} \mathrm{BOX}\right\}\right) \mathrm{CuCl}_{2}$ (left) by deprotonation at backbone carbon $\mathrm{C} 1$. The neutral $\left({ }^{\mathrm{Me}} \mathrm{BOX}\right) \mathrm{CuCl}$ (right) is moreover identical to a single moiety of the dimeric $\left({ }^{\mathrm{Me}} \mathrm{BOX}_{2}\right) \mathrm{Cu}_{2} \mathrm{Cl}_{2}$ and might be considered as its direct precursor (cf. Scheme 5.11). The computed spin-density maps of the DFT-optimized structures (B3LYP/def2-TZVPP level) are drawn with an isovalue of \pm 0.002 ; majority and minority densities are plotted in magenta and orange respectively. Colour code for atoms: C (tan), $\mathrm{H}$ (white), N (blue), O (red) and $\mathrm{Cl}$ (green). The Mulliken spin populations for $\mathrm{C} 1, \mathrm{Cu}, \mathrm{Cl}$ and $\mathrm{N}$ are indicated in parentheses. See Table A.1 for geometric parameters and Table A.2 for spin density data as well as Figure A.1 for structures of the other BOX complexes. 


\subsubsection{Spin-Trapping of a Transient Organic Radical}

The radical nature of the $\mathrm{C}-\mathrm{C}$ coupling reaction was investigated by performing the reaction in presence of the radical scavenger (2,2,6,6-tetramethylpiperidin-1yl)oxyl (TEMPO'). From this reaction mixture, the coupled dimer could not be obtained, although all other reaction parameters remained unchanged.

The presence of the anticipated short-living organic radical was proven by experiments using 5,5-dimethyl-1-pyrroline-N-oxide (DMPO, Figure 5.16c). DMPO is the most popular spin trap due to its superior redox inactivity and the resulting EPR spectra of ${ }^{\circ} \mathrm{DMPO}-\mathrm{R}$, which are dependent on the structure of the trapped radical $\mathrm{R}^{\circ}$. Copper(II) chloride was added under an atmosphere of argon to a methanol solution containing an excess of $\mathrm{H}_{\left\{{ }^{\mathrm{Me}} \mathrm{BOX}\right.} \mathrm{B}$, DMPO and triethylamine (see the experimental section for details). The EPR spectrum of a sample was measured under argon atmosphere, the spectrum (Figure 5.16a) clearly shows the presence of an organic radical. Resonance peaks from remaining copper(II) are also present when the spectrum is recorded over a broader range (Figure 5.16b).

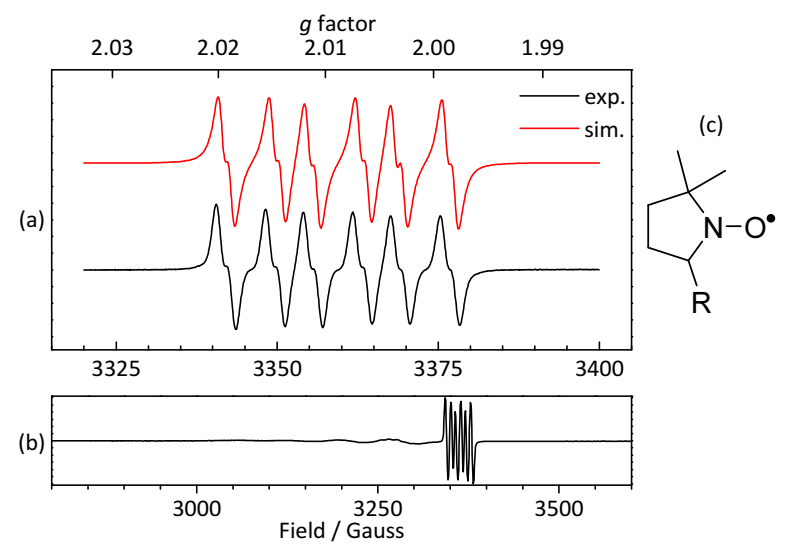

Figure 5.16. EPR spectra of a transient organic radical species scavenged by DMPO spin trap (black lines): X-band spectrometer, in $\mathrm{MeOH}$ solution at $297 \mathrm{~K}$. (a) EPR spectrum with resolved couplings and simulation (red line), $v_{\mathrm{c}}=9.4455 \mathrm{GHz}$; the spectrum was fitted with $g=2.009, A_{\mathrm{N}}=13.40$ Gauss, $A_{\mathrm{H}}^{\beta}=7.90$ Gauss $\left(A_{\mathrm{N}} / A_{\mathrm{H}}^{\beta}=1.70\right), A_{\mathrm{H}}^{\gamma}=1.41$ Gauss, line shape function used is Lorentzian (line width 1.20). (b) Broad range spectrum with additional resonance peaks from remaining copper(II), $v_{\mathrm{c}}=9.4510 \mathrm{GHz}$. (c) A long living nitroxide radical after scavenging of a transient radical with DMPO spin trap. 
Furthermore, the absence of a strong copper(II)-centred electron resonance in the EPR spectrum is consistent with the reduction of copper(II) to copper(I). This suggests that the proposed transient species $\left({ }^{\mathrm{Me}} \mathrm{BOX} \cdot\right) \mathrm{Cu}^{\mathrm{I}} \mathrm{Cl}$ was successfully scavenged by DMPO to form a persistent organic radical adduct, presumably of the type ('DMPO- $\left.{ }^{\mathrm{Me}} \mathrm{BOX}\right) \mathrm{Cu}{ }^{\mathrm{I}} \mathrm{Cl}$.

The spectrum is composed of six lines arising from hyperfine coupling to the DMPO nitrogen nucleus ( $A_{\mathrm{N}}=13.40$ Gauss $)$ and $\beta$-hydrogen $\left(A_{\mathrm{H}}^{\beta}=7.90\right.$ Gauss $)$, in addition a small $\gamma$-splitting $\left(A_{\mathrm{H}}^{\gamma}=1.41 \mathrm{Gauss}\right)$ is present. The EPR parameters were compared with reported parameters from the Spin Trap Database (STDB). ${ }^{[212]}$ DMPO is most frequently used to trap oxygen radical species ${ }^{\circ} \mathrm{OH}$ and ${ }^{\circ} \mathrm{OOH}$. Spectra of DMPO trapped adducts of ${ }^{\circ} \mathrm{OH}$ for example show a characteristic four line EPR spectrum due to equal coupling constants $\left(A_{\mathrm{N}}=A_{\mathrm{H}}^{\beta}=14.9\right.$ Gauss $\left(A_{\mathrm{N}} / A_{\mathrm{H}}^{\beta}\right.$ =1.00). A ratio of $A_{\mathrm{N}} / A_{\mathrm{H}}^{\beta} \approx 0.6-0.8$ for DMPO adducts is found for adducts with carbon centred radicals due to very large $A_{\mathrm{H}}^{\beta}$ coupling constants ( $\sim 20-24$ Gauss). However, radicals similar to the transient BOX radical considered in this work are not reported. Regarding the ratio of $A_{\mathrm{N}} / A_{\mathrm{H}}^{\beta}=1.70$ found with $\left.\mathrm{H}_{\left\{{ }^{\mathrm{Me}}\right.} \mathrm{BOX}\right\}$, some alkoxy radicals show a similar ratio of 1.6. However, the range seems to be relatively broad for adducts with alkoxy radicals. For a trapping experiment of methoxy radicals $\left({ }^{\circ} \mathrm{OCH}_{3}\right)$ in benzene, the parameters $A_{\mathrm{N}}=13.58$ Gauss, $A_{\mathrm{H}}^{\beta}=7.61$ Gauss $\left(A_{\mathrm{N}} / A_{\mathrm{H}}^{\beta}=1.78\right), A_{\mathrm{H}}^{\gamma}=1.85$ Gauss have been reported ${ }^{[213]}$ for 2-methoxy-5,5-dimethyl-1-pyrrolidinyloxy ( $\left.{ }^{\circ} \mathrm{DMPO}-\mathrm{OCH}_{3}\right)$ and are comparable to the parameters obtained here.

In the present work and in the reported methoxy adduct, a weak $\gamma$-splitting is present. The origin of this feature is discussed in the case of the prominent - DMPO-OOH adduct, where a similar splitting is observed ( $A_{\mathrm{H}}^{\gamma}=1.25$ Gauss). Here, three different explanations are considered. The first explanation is that the splitting arises from coupling to one of the $\mathrm{CH}_{2}$ hydrogen atoms in DMPO. The second is, that it results from coupling to hydrogen at the bound $-\mathrm{OOH}$ residue. However, it was shown that in this case the splitting results not from any proximal hydrogen, but from conformers of ${ }^{*} \mathrm{DMPO}-\mathrm{OOH}$, which are additionally present. $^{[214]}$

It can be concluded, that the nature of the trapped radical species is not clear, whether it is some kind of BOX-derived radical or perhaps a methoxy radical. Nevertheless, the presence of methoxy radicals is feasible when taken into account a fast hydrogen atom abstraction reaction, in which a BOX organic radical species, such as the intermediates proposed previously, abstracts hydrogen from methanol 
solvent. However, in the course of this work no adducts of BOXs or DMPO incorporating a methoxy residue could be isolated or observed, nor could other indications for the presence of methoxy radicals be obtained.

\subsubsection{DPPH $^{\bullet}$ Antiradical Assay}

Scavenging of 2,2-diphenyl-1-picrylhydrazyl persistent free radical (DPPH ${ }^{\bullet}$ ) is the basis of a common assay for the determination of antiradical and antioxidant (AO) activity (Scheme 5.13). ${ }^{[215-219]}$ The BOX ligands were subjected to this assay to evaluate the antiradical properties of this compound class and to elucidate the influence of the backbone residue $\mathrm{R}$.<smiles>O=[N+]([O-])c1cc([N+](=O)[O-])c(NN(c2ccccc2)c2ccccc2)c([N+](=O)[O-])c1</smiles>

Scheme 5.13 2,2-diphenyl-1picrylhydrazyl (DPPH*) persistent radical.

In methanolic solutions $\mathrm{DPPH}^{\bullet}$ has a deep purple colour with $\lambda_{\max }=517 \mathrm{~nm}$. The reduction of $\mathrm{DPPH}^{\bullet}$ with a free radical scavenger, an antioxidant $(\mathrm{A}-\mathrm{H})$ or a radical species $\left(\mathrm{R}^{\bullet}\right)$, causes decline of this absorbance according to

$$
\begin{aligned}
\mathrm{DPPH}^{\bullet}+\mathrm{A}-\mathrm{H} & \longrightarrow \mathrm{DPPH}-\mathrm{H}+\mathrm{A}^{\bullet} \\
\mathrm{DPPH}^{\bullet}+\mathrm{R}^{\bullet} & \longrightarrow \mathrm{DPPH}-\mathrm{R}
\end{aligned}
$$

The use of this assay became very popular for the study of natural oxidants, such as phenols, especially in food and agricultural sciences. The antioxidant L-ascorbic acid was used as a positive control and shows nearly instant decolouration of the $\mathrm{DDPH}^{\bullet}$ solution. However, reactions with $\left.\mathrm{H}_{\{}{ }^{\mathrm{R}} \mathrm{BOX}\right\}$ are relatively slow secondorder reactions at room temperature (Figure 5.17).

Ligands $\left.\mathrm{H}_{\left\{{ }^{\mathrm{Me}}\right.} \mathrm{BOX}\right\}(-)$ and $\mathrm{H}_{\{}\left\{{ }^{\mathrm{Ph}} \mathrm{BOX}\right\}(-)$ react with $\mathrm{DPPH}^{\bullet}$ in methanol, and $\mathrm{DPPH}^{\bullet}$ is presumably quenched via $\mathrm{H}$ atom abstraction from the ligands' backbones. The reactions have been found to obey a second-order rate law

$$
\text { rate of disappearance of } \mathrm{DPPH}^{\bullet}=k_{2}\left[\mathrm{DPPH}^{\bullet}\right][\mathrm{BOX}]
$$

The addition of $\mathrm{CuCl}_{2} \cdot 2 \mathrm{H}_{2} \mathrm{O}$ to the mixture of $\mathrm{DPPH}^{\bullet}$ and $\mathrm{H}\left\{{ }^{\mathrm{Me}} \mathrm{BOX}\right\}$ slightly slows down the DPPH degradation (---), presumably by the dimerisation reaction 
of $\mathrm{H}\left\{{ }^{\mathrm{Me}} \mathrm{BOX}\right\}$ initiated by $\mathrm{Cu}^{\mathrm{II}}$. The reaction is faster with $\mathrm{H}\left\{{ }^{\mathrm{Me}} \mathrm{BOX}\right\}$ than with $\mathrm{H}\left\{{ }^{\mathrm{Ph}} \mathrm{BOX}\right\}$ (the rate constant is $\sim 4.5$ times larger), most likely due to the smaller sterical demand of the backbone residue (Table 5.6). It is also evident that $\left.\mathrm{H}_{\{} \mathrm{Ph}_{\mathrm{BOX}}\right\}$ degrades $\mathrm{DPPH}^{\bullet}$ to a higher extent than $\mathrm{H}_{\left\{{ }^{\mathrm{Me}} \mathrm{BOX}\right\}}$ (see below).

As expected, no reaction was observed with the bulky $\left.\mathrm{H}_{\left\{{ }^{t B u}\right.} \mathrm{BOX}\right\}$ after up to 17 hours (-), while with the other ligands the reaction was finished after a few hours. A small decrease of only $\sim 4 \%$ was evident in the case of $\left.\mathrm{H}_{\{}{ }^{t \mathrm{Bu}} \mathrm{BOX}\right\}$ after 17 hours, the stability of $\mathrm{DPPH}^{*}$ in solution is however limited ${ }^{[217]}$ and this is the likely reason for this decrease.

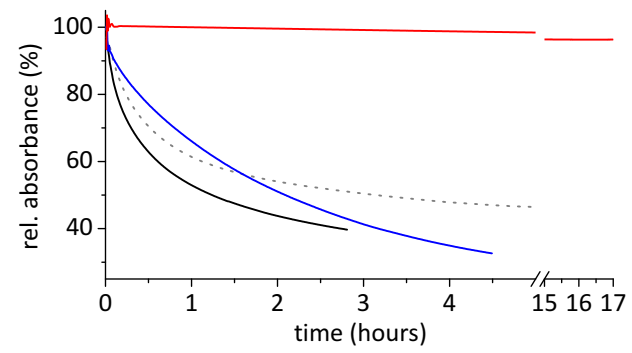

Figure 5.17. Kinetic curves of the scavenging of $\mathrm{DPPH} \cdot$ by $\mathrm{H}_{\left\{{ }^{\mathrm{R}} \mathrm{BOX}\right\}}$ ligands; $\mathrm{H}_{\left\{{ }^{\mathrm{Me}} \mathrm{BOX}\right\}}$ $\left.\left.\left.(-), \mathrm{H}_{\{}{ }^{\mathrm{Ph}} \mathrm{BOX}\right\}(-), \mathrm{H}_{\{}{ }^{\mathrm{Bu}} \mathrm{BOX}\right\}(-), \mathrm{H}^{\mathrm{Me}}{ }^{\mathrm{BOOX}}\right\}+\mathrm{CuCl}_{2} \cdot 2 \mathrm{H}_{2} \mathrm{O}(---) . \lambda=517 \mathrm{~nm}$, methanol, DPPH ${ }^{*}$ at the starting concentration of $\left.0.1 \mathrm{~mm}, \mathrm{H}_{\{}{ }^{\mathrm{R}} \mathrm{BOX}\right\}$ at $0.2 \mathrm{~mm}$. See Table 5.6 for rate constants.

Table 5.6.

Radical scavenging parameters for $\left.\mathrm{H}_{\{}{ }^{\mathrm{R}} \mathrm{BOX}\right\}$.

\begin{tabular}{llll}
\hline ligand & $k_{2}, \mathrm{M}^{-1} \mathrm{~min}^{-1}$ & $E C_{50}$ & $\mathrm{ARP}$ \\
\hline $\mathrm{H}\left\{{ }^{\mathrm{Me}} \mathrm{BOX}\right\}$ & $295^{a}$ & 1.29 & 0.78 \\
$\mathrm{H}\left\{{ }^{\mathrm{Ph}} \mathrm{BOX}\right\}$ & 64 & 0.365 & 2.74 \\
$\mathrm{H}\left\{{ }^{\mathrm{Bu}} \mathrm{BOX}\right\}$ & no reaction & & \\
\hline${ }^{a}$ With $\mathrm{CuCl}_{2} \cdot 2 \mathrm{H}_{2} \mathrm{O}, k_{2}=275 \mathrm{~m}^{-1} \mathrm{~min}^{-1}$ was found.
\end{tabular}


Radical scavenging activity The percentage of the radical scavenging activity is calculated by the following equation

$$
\text { radical scavenging activity }(\%)=\frac{A b s_{0}-A b s_{\mathrm{BOX}}}{A b s_{0}} \times 100
$$

$A b s_{0}$ and $A b s_{\mathrm{BOX}}$ correspond to the absorbances at $517 \mathrm{~nm}$ of the $\mathrm{DPPH}^{\bullet}$ radical in the absence (control) and presence of the respective bis(oxazoline).

Effective concentration $\left(E C_{50}\right)$ and antiradical power (ARP) The concentrations of the test compounds leading to $50 \%$ reduction of the initial $\mathrm{DPPH}^{\circ}$ concentration are defined as the $E C_{50}$ (effective concentration) values. They were calculated from the regression curve of $\log _{10}$ concentration of the respective $\mathrm{H}\left\{{ }^{\mathrm{R}} \mathrm{BOX}\right\}$ against the radical scavenging activity (Figure 5.18, Table 5.6). For comparison, the $\mathrm{DPPH}^{*}$ concentration was also taken into account, giving $E C_{50} \equiv$ $\left.\left(\operatorname{mol~L}{ }^{-1} \mathrm{H}_{\{}{ }^{\mathrm{R}} \mathrm{BOX}\right\}\right) /\left(\mathrm{mol} \mathrm{L}^{-1} \mathrm{DPPH}^{*}\right)$. The reciprocal of this $E C_{50}$ values is used to define the effect of an antioxidant, this is the antiradical power (ARP).

$$
A R P=\frac{1}{E C_{50}}
$$

$E C_{50}$ of ascorbic acid was $0.258(\mathrm{ARP}=3.87)$ under the conditions applied, which is similar to a literature value of $\mathrm{ARP}=3.70 .{ }^{[219]}$ In the case of $\mathrm{H}\left\{{ }^{\mathrm{Ph}} \mathrm{BOX}\right\}$, extended incubation was necessary to transcend a sufficient amount of reaction half-life periods and reach a steady-state; in this experiment, the samples were incubated for eight times the length of the first half-life $(\sim 19.5 \mathrm{~h})$.

While for $\left.\mathrm{H}_{\{}^{t \mathrm{Bu}} \mathrm{BOX}\right\}$, no reaction with $\mathrm{DPPH}^{\bullet}$ is observable at varying concentrations, for $\left.\mathrm{H}_{\left\{{ }^{\mathrm{Me}}\right.} \mathrm{BOX}\right\}$ and $\left.\mathrm{H}_{\{}{ }^{\mathrm{Ph}} \mathrm{BOX}\right\}$ the $E C_{50}$ and $\mathrm{ARP}$ parameters could be estimated (Table 5.6). Interestingly, while in $\left.\mathrm{H}_{\{}{ }^{\mathrm{Ph}} \mathrm{BOX}\right\}$, the reaction is slower, the ARP is significantly higher, i. e. it can degrade more molecules $\mathrm{DPPH}^{\circ}$. In the case of $\left.\mathrm{H}_{\left\{{ }^{\mathrm{Me}}\right.} \mathrm{BOX}\right\}, \sim 0.5$ eq. of $\mathrm{DPPH}^{\bullet}$ are reduced (according to $1 /\left(2 \times E C_{50}\right)=0.39$ ). This indicates, that one molecule $\left.\mathrm{H}_{\{}{ }^{\mathrm{Me}} \mathrm{BOX}\right\}$ could react with $\mathrm{DPPH}^{*}$ and the resulting ${ }^{\mathrm{Me}} \mathrm{BOX} \cdot$ radical likely reacts with a second $\left.\mathrm{H}_{\left\{{ }^{M e}\right.} \mathrm{BOX}\right\}$ in the observed dimerisation reaction. However, further reactivity of this or the resulting radicals can also be expected with $\mathrm{O}_{2}$, solvent or $\mathrm{DPPH}^{\bullet}$. In $\left.\mathrm{H}_{\{}{ }^{\mathrm{Ph}} \mathrm{BOX}\right\}$, no dimerisation can occur and the resulting ${ }^{\mathrm{Ph}_{\mathrm{BOX}}}$ radicals react further with solvent or $\mathrm{O}_{2}$ or $\mathrm{DPPH}^{*}$ radicals, resulting in the stoichiometry of 1.37 eq. reduced $\mathrm{DPPH}^{\bullet}$ per $\left.\mathrm{H}_{\{}{ }^{\mathrm{Ph}} \mathrm{BOX}\right\}$. The $\mathrm{DPPH}^{\bullet}$ assay nicely reproduces the trends observed for the reactions of $\mathrm{H}\left\{{ }^{\mathrm{R}} \mathrm{BOX}\right\}+\mathrm{CuCl}_{2}$, described in the sections above. Insofar, that the reactivity of the BOXs is strongly influenced by the backbone residue, i. e. no reaction is 
5. Unexpected Non-Innocence in Copper(II) Complexes of BOXs

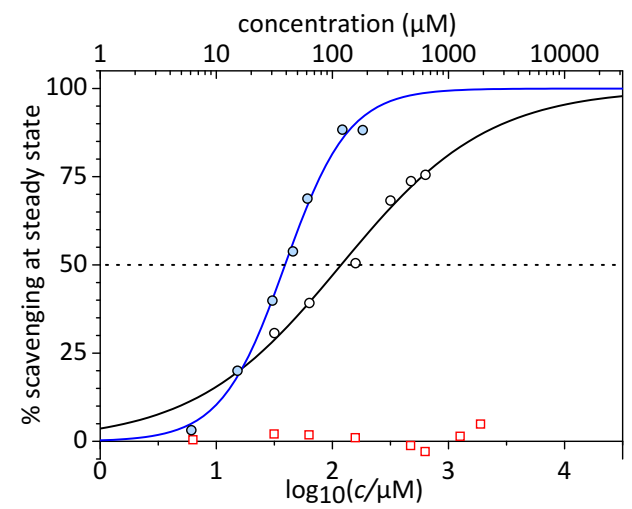

Figure 5.18. Plot of radical scavenging activity vs. $\log _{10}$ concentration of $\left.\mathrm{H}_{\{}{ }^{\mathrm{R}} \mathrm{BOX}\right\}$ ligands with dose-response regressions. $\left.\left.\mathrm{H}_{\{}{ }^{\mathrm{Me}} \mathrm{BOX}\right\}(-), \mathrm{H}_{\left\{{ }^{\mathrm{Ph}} \mathrm{BOX}\right\}}(-), \mathrm{H}_{\{}{ }^{\mathrm{B} \mathrm{Bu}} \mathrm{BOX}\right\}(\square)$. The $\mathrm{DPPH}^{*}$ concentration was $107 \mu \mathrm{M}$. The mixtures were left to equilibrate for several hours, due to the slow reaction rates.

observed for $\left.\mathrm{H}_{\{}^{t \mathrm{Bu}} \mathrm{BOX}\right\}$ at all and the limited stability of the less bulky BOXs is evidenced by the antiradical assay. In addition, the smaller $\left.\mathrm{H}_{\{}{ }^{\mathrm{Me}} \mathrm{BOX}\right\}$ reacts faster than the larger $\left.\mathrm{H}_{\{}{ }^{\mathrm{Ph}} \mathrm{BOX}\right\}$. 


\subsection{Conclusion}

The non-innocence of a number of simple bis(oxazoline)s was evidenced upon the coordination of redox-active copper(II) chloride (Scheme 5.14). This finding has strong implications due to the widespread application of bis(oxazoline)-copper complexes, in particular in asymmetric synthesis as catalysts.

The investigated reactions are highly selective, leading to aerobic oxygenation of the sterically more demanding $\left.\mathrm{H}_{\{}{ }^{\mathrm{Ph}}{ }_{\mathrm{BOX}}\right\}$ and to dimerisation by $\mathrm{C}-\mathrm{C}$ coupling of the sterically unhindered $\left.\mathrm{H}_{\{}{ }^{\mathrm{Me}} \mathrm{BOX}\right\}$ and $\left.\mathrm{H}_{\{}{ }^{\mathrm{H}} \mathrm{BOX}\right\}$. The latter were also oxygenated in side reactions. Finally, the most-bulky ligand $\left.\mathrm{H}_{\{}^{t \mathrm{Bu}} \mathrm{BOX}\right\}$ successfully prevents the present reaction pathways and forms a stable copper(II) complex. In addition, the thermochromic behaviour of this complex was structurally investigated. The oxygenation and coupling reactions were investigated by means of NMR and EPR spectroscopy, mass spectrometry, as well as structural information could
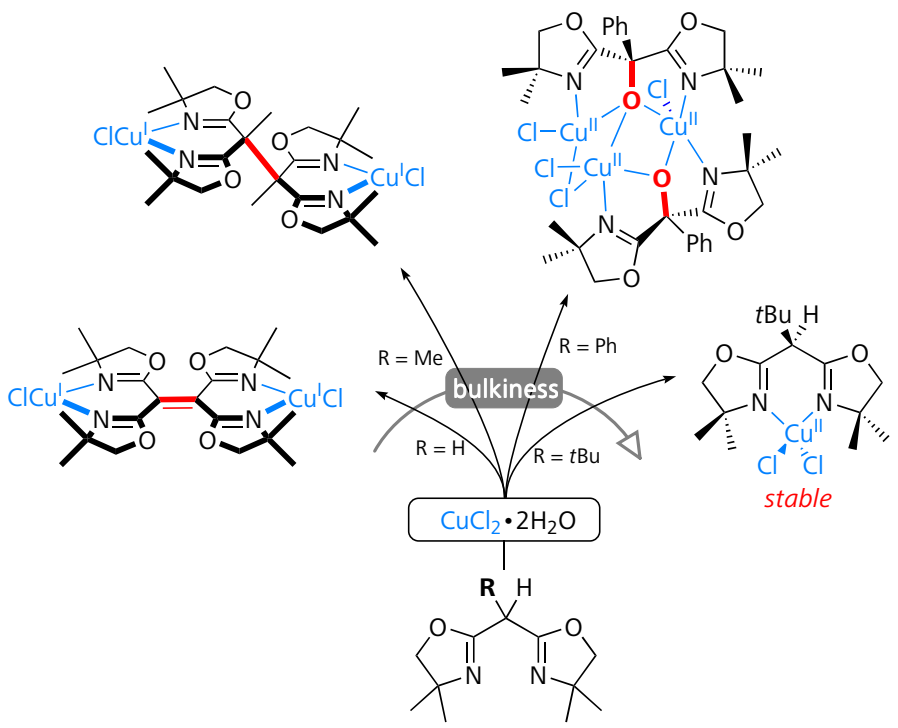

Scheme 5.14 Overview of the main reactions upon exposure of $\left.\mathrm{H}_{\{}^{\mathrm{R}} \mathrm{BOX}\right\}$ ligands towards $\mathrm{CuCl}_{2}$. 
be obtained by X-ray crystallography. Ligand recovery of the oxygenated and dimerised ligands after demetallation, as well as ${ }^{18} \mathrm{O}$ isotope labelling experiments, finally confirmed the observations.

As transient intermediates, species with reasonable organic radical/copper(I) character are proposed and are supported by DFT calculations. To prove their presence in the reactions at hand, spin-trap experiments in conjunction with EPR spectroscopy were conducted and confirmed the presence of an organic radical species.

As a first attempt to evaluate the redox stability of ligands regarding the presented reactivities, the anti-oxidant $\mathrm{DPPH}^{*}$ free radical assay successfully validated the found trends in the BOX-copper(II) reactivities and a fundamental capability of this assay to screen promising ligands and catalysts can be predicted with a certain potential for further investigation. 


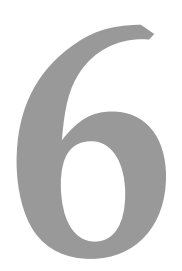

\section{Biomimetic Activation of Dioxygen by Copper( I) Complexes of Bis(oxazoline)s}
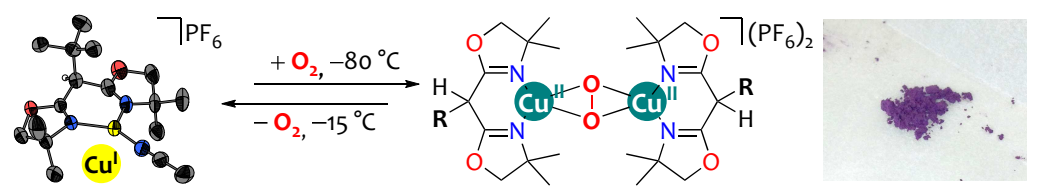

Part of this chapter was published as »BOX Ligands in Biomimetic Copper-Mediated Dioxygen Activation - A New Hemocyanin Model « A. Walli, S. Dechert, M. Bauer S. Demeshko, F. Meyer, Eur. F. Inorg. Chem. 2014, accepted, DOI: 10.1002/ejic. 201402378. 


\subsection{Introduction}

$\mathbf{E}^{\prime}$ ARLY investigations on copper-oxygen adducts were conducted at ambient temperatures and involved stronger coordinating anions to counterbalance the $\mathrm{Cu}^{+}$charge. These conditions however led to the full reduction of $\mathrm{O}_{2}$ by $\mathrm{Cu}^{\mathrm{I}}$ in a $1: 4$ stoichiometry. From these reactions, $\mathrm{Cu}^{\mathrm{II}}$ complexes were formed, incorporating $\mathrm{O}^{2-}$ in the form of oxide, hydroxide and water and the desired copper-oxygen intermediates, such as peroxo or superoxo complexes, were not found under these conditions. ${ }^{[34]}$

Over the time, a different approach to study the activation of dioxygen and to synthesise copper-oxygen species was developed. As a general method, a copper(I) complex is reacted in aprotic solvents (most common are, e. g., THF, $\mathrm{CH}_{2} \mathrm{Cl}_{2}$, acetone) with dissolved $\mathrm{O}_{2}$ gas at low temperature $\left(\approx-80^{\circ} \mathrm{C}\right)$. As the reactivity of $\mathrm{Cu}^{\mathrm{I}}$-complexes is often strongly inhibited by coordination of anions, the exclusive use of »weakly-coordinating anions « ${ }^{a[221,222]}$ is found to give complexes, whose reactivity is relatively high. This is particularly important as the reactivity in general is decreased due to the lowered reaction temperatures.

However, low temperature is the essential requirement for the formation of almost all known copper-oxygen species with a stoichiometry of $\mathrm{Cu} / \mathrm{O}_{2}, 1: 1,2: 1$ or $3: 1$. Moreover, the yielded species are usually quite thermally sensitive. The lifetime of the initially formed copper-oxygen adducts is enhanced due to two main reasons:

- reduction of entropic expense for the formation

- suppressing of subsequent reactivity

The impact of low-temperature investigations is furthermore emphasized by recent discoveries, which were only possible at even more extreme temperatures, as low as $-125^{\circ} \mathrm{C} .^{[74,109]}$

\subsection{Synthesis and Characterisation of Copper(I) Complexes of Bis(oxazoline)s}

The four bis(oxazoline) ligands $\left.\mathrm{H}_{\{}{ }^{\mathrm{R}} \mathrm{BOX}\right\}(\mathrm{R} \equiv t \mathrm{Bu}, \mathrm{Ph}, \mathrm{Me}, \mathrm{H})$, introduced in the Chapters above, react with $\left[\mathrm{Cu}(\mathrm{MeCN})_{4}\right] \mathrm{PF}_{6}$ and $\left[\mathrm{Cu}(\mathrm{MeCN})_{4}\right] \mathrm{OTf}^{[223]}$ in THF and other solvents under an inert atmosphere to give the respective airsensitive copper(I) complexes $\left.\left[\left(\mathrm{H}_{\{}{ }^{\mathrm{R}} \mathrm{BOX}\right\}\right) \mathrm{Cu}(\mathrm{MeCN})\right] \mathrm{PF}_{6}\left(\mathbf{C} \mathbf{u}^{\prime} \mathbf{R}\right)$ as colourless

a. Sometimes referred to as »non-coordinating anions«, cf. also ref. [220] for a general quantification of coordinating ability. 
solutions (Scheme 6.1). The complexes are comprised of the BOX-coordinated $\mathrm{Cu}^{\mathrm{I}}$, a single $\mathrm{MeCN}$ solvent molecule and are counterbalanced by a weaklycoordinating $\mathrm{PF}_{6}$ anion. The short forms $\gg \mathbf{C} \mathbf{u}^{\prime} \mathbf{R}$ « will be used for the complexes $\left.\left[\left(\mathrm{H}_{\{}{ }^{\mathrm{R}} \mathrm{BOX}\right\}\right) \mathrm{Cu}^{\mathrm{I}}(\mathrm{MeCN})\right] \mathrm{PF}_{6}$ throughout this work.
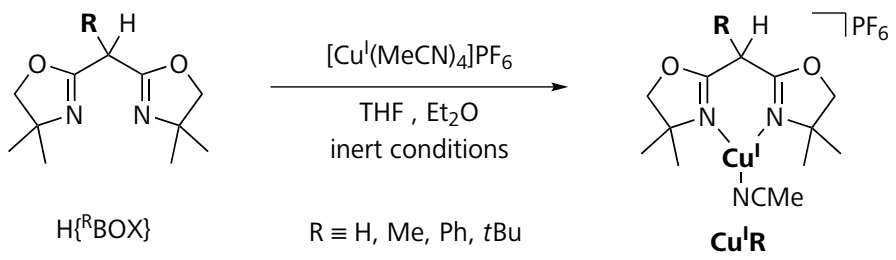

Scheme 6.1 Synthesis of copper $(\mathrm{I})$ complexes $\left.\left[\left(\mathrm{H}_{\{}{ }^{\mathrm{R}} \mathrm{BOX}\right\}\right) \mathrm{Cu}^{\prime}(\mathrm{MeCN})\right] \mathrm{PF}_{6}\left(\mathbf{C u}^{\prime} \mathbf{R}, \mathrm{R} \equiv t \mathrm{Bu}\right.$, $\mathrm{Ph}, \mathrm{Me}, \mathrm{H})$. X-ray structures were obtained from single crystals grown from $\mathrm{THF} / \mathrm{Et}_{2} \mathrm{O}$ solutions.

For further reactions, the complexes $\mathbf{C} \mathbf{u}^{\prime} \mathbf{R}$ were generally not isolated, but their solutions used in situ, or a stock solution of a mixture of copper(I) salt and ligand was used. Furthermore, all experiments indicated that additional purification is not required. However, to establish their identity, $\mathbf{C u}^{\prime} \mathbf{t} \mathbf{B u}$ and $\mathbf{C} \mathbf{u}^{\prime} \mathbf{H}$ have been isolated and characterized, and the molecular structures of $\mathbf{C} \mathbf{u}^{\prime} \mathbf{t} \mathbf{B u}$ and $\mathbf{C} \mathbf{u}^{\prime} \mathbf{P h}$ were ascertained by X-ray diffraction analysis.

$\mathbf{C} \mathbf{u}^{\prime} \mathbf{R}$ were obtained by dissolving the respective ligand in dry degassed THF under an atmosphere of argon or nitrogen and the solutions were sparged once again with inert gas to ensure the absence of all dioxygen. 1 eq. of $\left[\mathrm{Cu}(\mathrm{MeCN})_{4}\right] \mathrm{PF}_{6}$ was added and the solutions stirred for $\gtrsim 15 \mathrm{~min}$, followed by removal of all volatiles in vacuum. $\mathbf{C} \mathbf{u}^{\prime} \mathbf{R}$ were obtained quantitatively by this method in the form of white powders. Alternatively, a $5 \%$ excess of ligand was used in case of $\mathbf{C u}^{\prime} \mathbf{t} \mathbf{B u}$; and the excess of ligand could be removed in vacuum at $80^{\circ} \mathrm{C}$.

Solutions of $\mathbf{C} \mathbf{u}^{\prime} \mathbf{R}$ are sensitive towards $\mathrm{O}_{2}$ or air, and the colourless solutions quickly turn blue. This is also well evident for the respective solid compounds exposed to air, the white powders are colouring blue. Apart from that, the copper(I) complexes appear to be stable under air-free conditions, without any indication of decomposition or disproportionation after prolonged time. Even the clear, colourless solutions of $\mathbf{C} \mathbf{u}^{\prime} \mathbf{R}$ remain unchanged after several weeks at $0^{\circ} \mathrm{C}$ under an atmosphere of argon. 


\subsubsection{Spectroscopy}

NMR analysis of $\mathbf{C} \mathbf{u}^{\prime} \mathbf{t} \mathbf{B u}$ and $\mathbf{C} \mathbf{u}^{\prime} \mathbf{H}$ is in agreement with the solid state structures (see below) being maintained in solution and is consistent with an overall $C_{S}$ molecular symmetry; due to the $\mathrm{CH}_{2}$ backbone in $\mathbf{C} \mathbf{u}^{\prime} \mathbf{H}$, it is of higher symmetry $\left(C_{2 v}\right)$.

While upon coordination of $\mathrm{Cu}^{\mathrm{II}} \mathrm{Cl}_{2}$, the ligands reacted and showed noninnocent redox behaviour (Chapter 5), it is clear that the ligands are not affected by $\mathrm{Cu}^{\mathrm{I}} \mathrm{PF}_{6}$ coordination. As an example, in $\mathbf{C} \mathbf{u}^{\prime} \mathbf{H}$, the integral ratio of $2: 1$ (2 oxazoline $\mathrm{CH}_{2}$ 's : 1 bridging $\mathrm{CH}_{2}$ ) for the $\mathrm{CH}_{2}$ groups is found for the copper(I) complex, in analogy to the neat ligand. ${ }^{1} \mathbf{H}$ resonances are slightly shifted downfield in $\mathbf{C u}^{\prime} \mathbf{H}$ and $\mathbf{C u}^{\prime} \mathbf{t} \mathbf{B u}$ (except the $t \mathrm{Bu}$ singlet) by $0.05-0.25 \mathrm{ppm}$ in comparison to the neat ligands. In $\mathbf{C u} \mathbf{u}^{\mathbf{t}} \mathbf{B u}$, one hydrogen of each $\mathrm{CH}_{2}$ group is located in the moiety shared with the $t \mathrm{Bu}$ residue; the diastereotopicity of these $\mathrm{CH}_{2}$ protons is resolved in the copper(I) complex, while this is not the case in the neat ligand. The singlet in the ${ }^{1} \mathrm{H}$ NMR spectrum of $\left.\mathrm{H}_{\{}^{t \mathrm{Bu}} \mathrm{BOX}\right\}$ is split into two weakly coupled doublets with a distinct $»$ roof effect $«\left(\Delta \delta=0.05 \mathrm{ppm},{ }^{2} J_{\mathrm{HH}}=8.9 \mathrm{~Hz}\right)$. An ${ }^{15} \mathrm{~N},{ }^{1} \mathrm{H}-\mathrm{HMBC}$ NMR spectrum of $\mathbf{C u}^{\prime} \mathbf{t} \mathbf{B u}$ shows the $\mathrm{C}=\mathrm{N}$ nitrogen feature is shifted upfield from $-130.5 \mathrm{ppm}$ to $-161.4 \mathrm{ppm}$ upon $\mathrm{Cu}^{\mathrm{I}}$ coordination, due to stronger shielding of the ${ }^{15} \mathrm{~N}$ nucleus in the complex. Furthermore, the base peak of an ESI mass measurement of $\mathbf{C u}^{\prime} \mathbf{t} \mathbf{B u}$ under inert conditions shows the $\left.\left[\left(\mathrm{H}_{\{}{ }^{t \mathrm{Bu}} \mathrm{BOX}\right\}\right) \mathrm{Cu}(\mathrm{MeCN})\right]^{+}$ ion at $m / z=370.0$, in accordance with NMR features and X-ray structure. The respective $\mathbf{C} \mathbf{u}^{\prime} \mathbf{R}$ complexes are colourless, both in solid state and in solution, and UV-vis spectroscopy of the solutions shows no absorptions in the $300-800 \mathrm{~nm}$ range.

\subsubsection{Solid-State Structures}

High-quality single crystals of $\mathbf{C u}^{\mathbf{l}} \mathbf{t} \mathbf{B u}$ and $\mathbf{C} \mathbf{u}^{\prime} \mathbf{P h}$ were obtained by letting an excess of dry $\mathrm{Et}_{2} \mathrm{O}$ slowly diffuse over the gas phase into a $\sim 0.2 \mathrm{M}$ solution of $\mathrm{H}\left\{{ }^{t \mathrm{Bu}} \mathrm{BOX}\right\}$ or $\left.\mathrm{H}_{\{}{ }^{\mathrm{Ph}}{ }_{\mathrm{BOX}}\right\}$ and 1 eq. $\left[\mathrm{Cu}(\mathrm{MeCN})_{4}\right] \mathrm{PF}_{6}$ in THF under an atmosphere of argon. Small turbid-white rods were obtained after some days and were subjected to X-ray diffraction. $\mathbf{C u}^{\mathbf{t}} \mathbf{t} \mathbf{B u}$ and $\mathbf{C} \mathbf{u}^{\prime} \mathbf{P h}$ crystallise in the monoclinic space groups $C 2 / c$ and $P 2_{1}$, respectively. Structural similarity between both complexes is well evident. The copper ions are coordinated in a trigonal planar fashion (Y shape) by the $\mathrm{BOX}$ ligands and an exogenous $\mathrm{MeCN}$ solvent molecule. The structure of $\mathbf{C} \mathbf{u}^{\prime} \mathbf{t} \mathbf{B u}$ is depicted in Figure 6.1 and the structure of $\mathbf{C} \mathbf{u}^{\prime} \mathbf{P h}$ in Figure 6.2a, geometric parameters are listed in Table 6.1. 

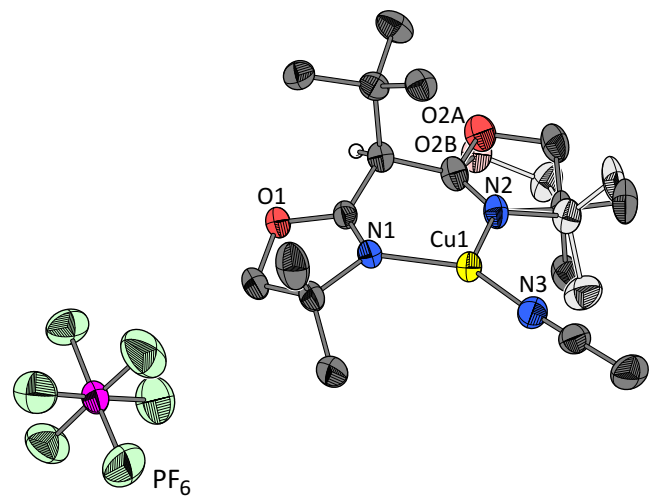

(a)

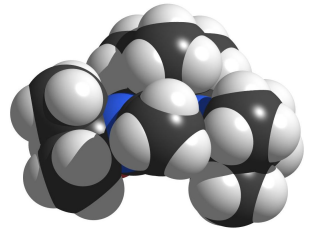

(b) front view

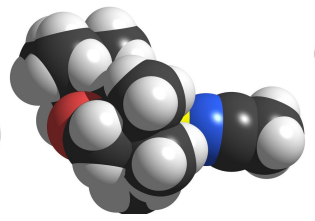

(c) side view

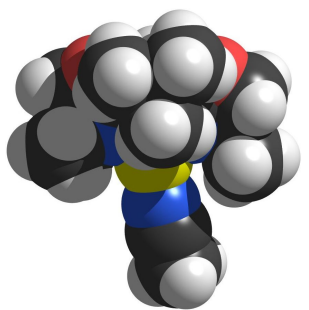

(d) top view

Figure 6.1. X-ray solid-state molecular structure of $\left.\left[\left(\mathrm{H}^{\{\mathrm{tBu}} \mathrm{BOX}\right\}\right) \mathrm{Cu}^{\prime}(\mathrm{MeCN})\right] \mathrm{PF}_{6}\left(\mathbf{C u} \mathbf{u}^{\prime} \mathbf{t B u}\right)$. (a) ORTEP plot with important atoms labelled. Displacement ellipsoids are drawn at the $50 \%$ probability level; most hydrogen atoms have been omitted for the sake of clarity; atoms located at a second site (B) due to crystallographic disorder are drawn in lighter shade and only one moiety of the disordered $\mathrm{PF}_{6}^{-}$anion is drawn. ( b,c,d) Van-der-Waals representations for clarification of the coordination wedge. Significant interatomic distances and angles are listed in Table 6.1. 


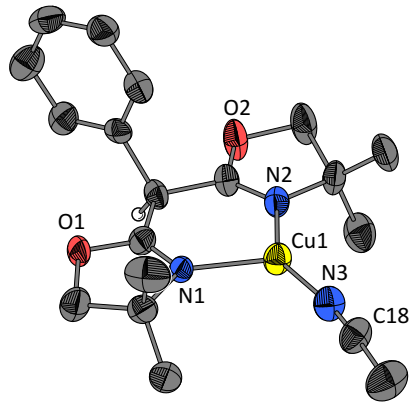

(a)

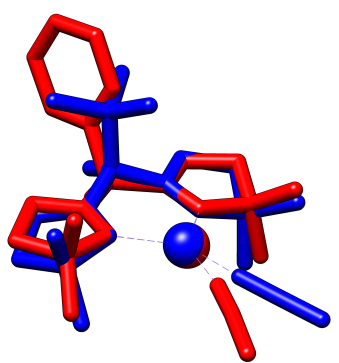

(b)

Figure 6.2. (a) X-ray solid-state molecular structure of $\left.\left[\left(\mathrm{H}_{\{}{ }^{\mathrm{Ph}} \mathrm{BOX}\right\}\right) \mathrm{Cu}(\mathrm{MeCN})\right]-$ $\mathrm{PF}_{6}\left(\mathbf{C} \mathbf{u}^{\prime} \mathbf{P h}\right)$. ORTEP plot with important atoms labelled. Displacement ellipsoids are drawn at the $50 \%$ probability level; $\mathrm{PF}_{6}^{-}$anions and most hydrogen atoms have been omitted for the sake of clarity. Significant interatomic distances and angles are listed in Table 6.1. (b) Overlay of the crystal structures of $\left.\mathrm{H}_{\{}^{t \mathrm{Bu}} \mathrm{BOX}\right\}$ (blue) and $\left.\mathrm{H}_{2}{ }^{\mathrm{Ph}} \mathrm{BOX}\right\}$ (red) from Figures 6.1 and 6.2a.

\section{Table 6.1.}

Significant geometric information of the solid-state structures of $\mathbf{C} \mathbf{u}^{\prime} \mathbf{P h}$ and $\mathbf{C u}^{\mathbf{l}} \boldsymbol{t} \mathbf{B u}$ in Figures 6.1 and 6.2a, respectively. Interatomic distances $(\AA)$ and angles $\left({ }^{\circ}\right)$.

\begin{tabular}{|c|c|c|c|}
\hline Atoms 1,2 & $d 1,2(\AA)$ & Atoms $1,2,3$ & Angle $1,2,3\left({ }^{\circ}\right)$ \\
\hline \multicolumn{4}{|c|}{$\mathrm{Cu}^{\prime} t \mathrm{Bu}$} \\
\hline $\mathrm{Cu} 1-\mathrm{N} 1$ & $1.9630(17)$ & $\mathrm{N} 1-\mathrm{Cu} 1-\mathrm{N} 2$ & $93.56(7)$ \\
\hline $\mathrm{Cu} 1-\mathrm{N} 2$ & $2.0037(18)$ & $\mathrm{N} 1-\mathrm{Cu} 1-\mathrm{N} 3$ & $142.62(8)$ \\
\hline $\mathrm{Cu} 1-\mathrm{N} 3$ & $1.8649(19)$ & $\mathrm{N} 2-\mathrm{Cu} 1-\mathrm{N} 3$ & $123.64(8)$ \\
\hline $\mathrm{N} 3 \equiv \mathrm{C} 16$ & $1.1316(32)$ & $\mathrm{Cu} 1-\mathrm{N} 3 \equiv \mathrm{C} 16$ & $175.00(20)$ \\
\hline \multicolumn{4}{|c|}{$\mathrm{Cu}^{\prime} \mathrm{Ph}$} \\
\hline $\mathrm{Cu} 1-\mathrm{N} 1$ & $2.0033(24)$ & $\mathrm{N} 1-\mathrm{Cu} 1-\mathrm{N} 2$ & $93.42(10)$ \\
\hline $\mathrm{Cu} 1-\mathrm{N} 2$ & $1.9554(29)$ & $\mathrm{N} 1-\mathrm{Cu} 1-\mathrm{N} 3$ & $120.75(12)$ \\
\hline $\mathrm{Cu} 1-\mathrm{N} 3$ & $1.8831(33)$ & $\mathrm{N} 2-\mathrm{Cu} 1-\mathrm{N} 3$ & $145.73(12)$ \\
\hline $\mathrm{N} 3 \equiv \mathrm{C} 18$ & $1.1091(49)$ & $\mathrm{Cu} 1-\mathrm{N} 3 \equiv \mathrm{C} 18$ & $172.47(32)$ \\
\hline
\end{tabular}


Both complexes adopt a boat-shaped coordination geometry and have very similar small ligand bite angles $\mathrm{N}-\mathrm{Cu}-\mathrm{N}$ of $\left.93.6^{\circ}\left(\mathrm{H}_{\{}{ }^{\mathrm{BBu}}{ }_{\mathrm{BOX}}\right\}\right)$ and $\left.93.4^{\circ}\left(\mathrm{H}_{\{}{ }^{\mathrm{Ph}}{ }_{\mathrm{BOX}}\right\}\right)$ and both have nearly the same $\mathrm{Cu}-\mathrm{N}_{\mathrm{BOX}}$ bond lengths of 1.96 and $2.00 \AA$. Due to the small bite angles, the trigonal-planar geometries deviate from the ideal $\mathrm{N}-\mathrm{Cu}-\mathrm{N}$ angles of $120^{\circ}$, while one of the remaining angles is at $\sim 120^{\circ}$, the second is at around $\sim 140^{\circ}$. In both complexes, one $\mathrm{CMe}_{2}$ group points more above and one more below the $\left\{\mathrm{N}_{3} \mathrm{Cu}\right\}$ plane. Although, the structures are very similar, there are some notable differences between both complexes. While both oxazoline planes are relatively flat in $\left.\mathrm{H}_{\{}{ }^{\mathrm{Ph}} \mathrm{BOX}\right\}$, in $\left.\mathrm{H}_{\{}{ }^{t \mathrm{Bu}} \mathrm{BOX}\right\}$ they are curved away from the $t \mathrm{Bu}$-backbone, an indication for the large sterical demand of this residue. Owing to the steric bulk of the $t \mathrm{Bu}$ group, the angle between this residue $\mathrm{R}$ and the $\left\{\mathrm{N}_{3} \mathrm{Cu}\right\}$ coordination plane is larger in the case of $\mathbf{C u}^{\prime} \mathbf{t} \mathbf{B u}: \sim 50^{\circ}$ in the case of $\mathrm{H}_{\{}\left\{{ }^{\mathrm{Ph}} \mathrm{BOX}\right\}$ and $\sim 80^{\circ}$ in the case of $\left.\mathrm{H}_{\{}{ }^{\mathrm{tBu}} \mathrm{BOX}\right\}$ (see the overlay of both structures in Figure 6.2b). In $\mathbf{C} \mathbf{u}^{\prime} \mathbf{P h}$ the phenyl ring is rotated by only $\sim 10^{\circ}$, while in the free ligand it is rotated by approximately $71^{\circ}$ (cf. Section 4.2, p. 47). In $\mathbf{C} \mathbf{u}^{\prime} \mathbf{P h}$, the $\mathrm{Cu}-\mathrm{N}_{\mathrm{MeCN}}$ bond is $0.02 \AA$ longer and the $\mathrm{C} \equiv \mathrm{N}$ bond in the $\mathrm{MeCN}$ ligand is $0.02 \AA$ shorter than in $\mathbf{C u}^{\mathbf{l}} \mathbf{t} \mathbf{B u}$, indicating that in $\mathbf{C u}^{\mathbf{}} \mathbf{t} \mathbf{B u}, \mathbf{M e C N}$ is more loosely bound. The $\mathrm{MeCN}$ is bound slightly tilted in both cases, the $\mathrm{Cu}-\mathrm{N} \equiv \mathrm{C}$ angles are $175^{\circ}$ $\left.\left(\mathrm{H}_{\{}{ }^{t \mathrm{Bu}} \mathrm{BOX}\right\}\right)$ and $172^{\circ}\left(\mathrm{H}_{\left\{{ }^{\mathrm{Ph}} \mathrm{BOX}\right\}}\right)$.

The copper(I) coordination is shielded to some extent by the oxazoline-CMe ${ }_{2}$ groups and by the backbone residue. This is illustrated by the Van-der-Waals representations in Figure 6.1b-d. The shielding oxazoline- $\mathrm{CMe}_{2}$ groups are intended to protect the copper(I) atom and possible copper-oxygen coordinations and to render the complexes more stable. The presence of tautomerism, in the ligand $\left.\mathrm{H}_{\{}{ }^{\mathrm{Ph}} \mathrm{BOX}\right\}$ (as described in Chapter 4) has apparently no influence in the coordination abilities. $\left.\mathrm{H}_{\{}{ }^{\mathrm{Ph}} \mathrm{BOX}\right\}$ in $\mathbf{C} \mathbf{u}^{\prime} \mathbf{P h}$ is present in the form of the diimine in contrast to the solid-state of the neat ligand, where it is present in the form of the iminoenamine tautomer.

\subsubsection{Electrochemistry}

Against the background of dioxygen activation (reduction of $\mathrm{O}_{2}$, concomitant with the oxidation of $\mathrm{Cu}^{\mathrm{I}}$ to $\mathrm{Cu}^{\mathrm{II}}$ ), the redox properties of $\mathbf{C u}^{1} \mathbf{t} \mathbf{B u}$ were investigated electrochemically by cyclic voltammetry $(\mathrm{CV})$ and the differential pulse technique, square-wave voltammetry (SWV), to get more insights in the complexes $\mathbf{C} \mathbf{u}^{\prime} \mathbf{R}$ as potential type 3 copper protein mimics.

The depicted CV curves (Figure 6.3) were recorded at a scan rate of $100 \mathrm{mV} \mathrm{s}^{-1}$ in different scan directions, first measuring either cathodic or anodic scans. A 
$0.1 \mathrm{M}$ solution of $\left[\mathrm{NBu}_{4}\right] \mathrm{PF}_{6}$ as the supporting electrolyte in $\mathrm{MeCN}$ was used. The decamethylferrocene couple, $\left[\mathrm{FeCp}_{2}^{*}\right]^{+1 / 0}\left(E_{1 / 2}=-0.59 \mathrm{~V}\right.$ vs. ferrocene, $\left[\mathrm{FeCp}_{2}\right]^{+1 / 0}$ in $\mathrm{MeCN})^{[224,225]}$ was used as an internal standard to avoid the potential overlap of the $\mathrm{FeCp}_{2}$ redox signal with other redox processes. The potential was furthermore converted to $E$ vs. SCE (saturated calomel electrode) by adding $0.40 \mathrm{~V}$.

Figure 6.3 shows cyclic voltammograms and a square-wave voltammogram of $\mathbf{C} \mathbf{u}^{\prime} \mathbf{t} \mathbf{B u}$ in $\mathrm{MeCN}$ under anaerobic conditions (Ar). A measurement over the broad range from -2.3 to $+1.3 \mathrm{~V}$ vs. SCE shows redox processes, which are not present in the voltammogram of the neat $\left.\mathrm{H}_{\left\{{ }^{t}{ }^{\mathrm{Bu}}\right.} \mathrm{BOX}\right\}$ ligand (cf. Figure 5.13, p. 100). $\mathbf{C u}^{\prime} \mathbf{t} \mathbf{B u}$ shows an electrochemically irreversible reduction with a cathodic peak potential, $E_{\mathrm{pc}}=-1.22 \mathrm{~V}$ vs. SCE. This reduction can most likely be assigned to the process $\mathrm{Cu}^{\mathrm{I}}+\mathrm{e}^{-} \longrightarrow \mathrm{Cu}^{0}$. An associated oxidation in the reverse anodic backscan with peak potential $E_{\mathrm{pa}}=-0.45 \mathrm{~V}$ vs. $\operatorname{SCE}\left(\Delta E_{\mathrm{p}}=0.77 \mathrm{~V}\right)$ likely corresponds to a $»$ copper stripping peak « $\left(\mathrm{Cu}^{0} \longrightarrow \mathrm{Cu}^{\mathrm{I}}+\mathrm{e}^{-}\right)$.

Furthermore, a quasi-reversible electrochemical oxidation of $\mathbf{C u}^{\mathbf{l}} \mathbf{t} \mathbf{B u}$ takes place at $E_{\mathrm{pa}}=0.63 \mathrm{~V}$ vs. SCE and is assigned to the process $\mathrm{Cu}^{\mathrm{I}} \longrightarrow \mathrm{Cu}^{\mathrm{II}}+\mathrm{e}^{-}$. Some known factors influencing redox potentials of copper complexes include the types of donor atoms, the geometry in tetracoordinate complexes and the flexibility/rigidity of a chelating ligand. ${ }^{[226]}$ The absence of a proximal $\left(\Delta E_{\mathrm{p}}=\right.$ $0.059 \mathrm{~V})$ reduction peak renders the oxidation electrochemically irreversible. The corresponding reduction in the reverse scan occurs at $E_{\mathrm{pa}}=0.33 \mathrm{~V}$ vs. SCE and

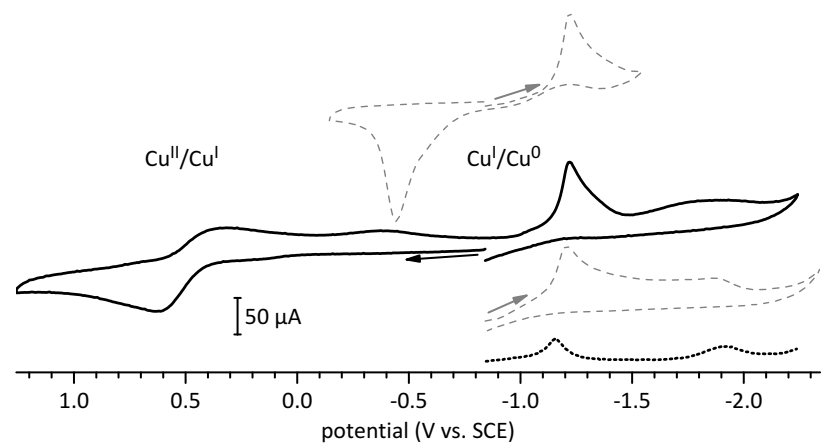

Figure 6.3. Cyclic voltammograms of $\mathbf{C u}^{\mathrm{l}} \mathbf{t} \mathrm{Bu}$ in $\mathrm{MeCN}$ containing $0.1 \mathrm{M}\left[\mathrm{NBu}_{4}\right] \mathrm{PF}_{6}$; scan rate $100 \mathrm{mV} \mathrm{s}^{-1}\left({ }_{-} /----\right)$. Square-wave voltammogram (--.-.-.). Open circuit potential $\approx$ $0.1 \mathrm{~V}$. 
indicates that this process is chemically reversible (quasi-reversible). The large separation of the anodic and cathodic peak potentials $\left(\Delta E_{\mathrm{p}}=0.30 \mathrm{~V}\right)$ for this couple on the cyclic voltammetry time scale reflects substantial rearrangement around the copper ion environment upon oxidation of $\mathrm{Cu}^{\mathrm{I}} \longrightarrow \mathrm{Cu}^{\mathrm{II}}$. This is quite common for copper complexes as the coordination geometries around $\mathrm{Cu}^{\mathrm{I}}$ and $\mathrm{Cu}^{\mathrm{II}}$ are usually significantly different. ${ }^{[227]}$

Figure 6.4 shows additional measurements at varying scan rate $(v)$, which support quasi-reversible mechanisms for both processes, since there is a shift of the peak potential with increasing scan rate and additionally, the peak currents $i_{\mathrm{p}}$ increase linearly as a function of the square root of the scan rate, $i_{\mathrm{p}} \propto \sqrt{v}$ (Figure 6.4, right). ${ }^{\text {[228] }}$
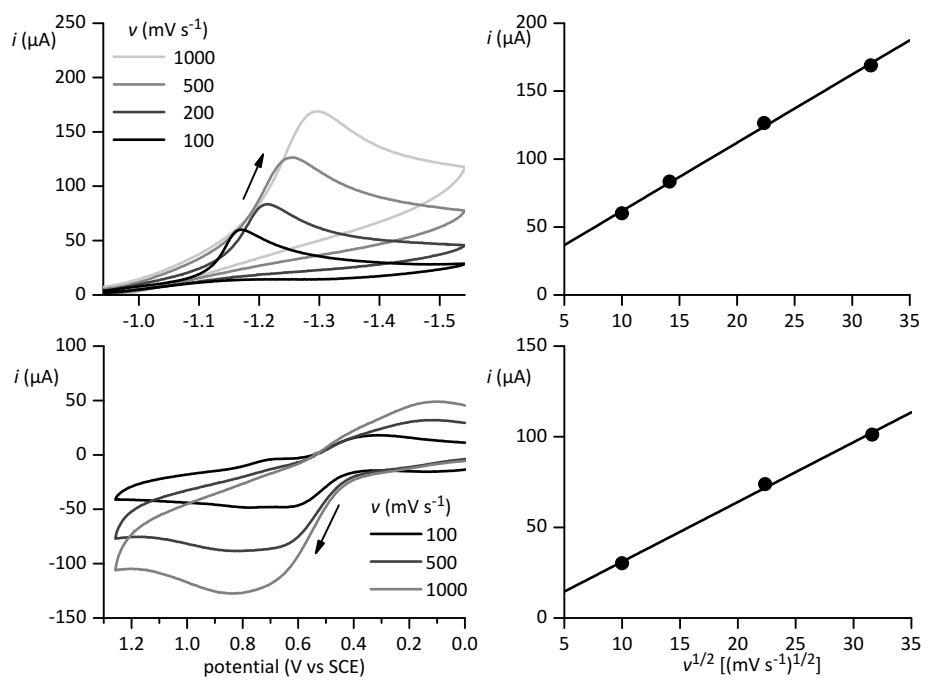

Figure 6.4. Reduction peaks (top left) and oxidation peaks (bottom left) in cyclic voltammograms of $\mathbf{C u}^{\prime} \mathbf{t} \mathbf{B u}$ in $\mathrm{MeCN}$ containing $0.1 \mathrm{M}\left[\mathrm{NBu}_{4}\right] \mathrm{PF}_{6}$ at varying scan rate $v$. Respective plots of $i_{\mathrm{p}}$ vs. $\sqrt{v}$ (right), showing linear dependences ( $\bar{R}^{2}=0.997$, top; 0.995 , bottom). 


\subsection{Activation of Dioxygen and Spectroscopic Analysis}

Due to the high reactivity of the prepared copper(I) compounds towards dioxygen, especially of the solutions, all manipulations involving $\mathrm{Cu}^{1}$ had to be carried out under the strict absence of air. This was usually achieved by additionally sparging of all solutions with inert gas ( $\mathrm{Ar}$ or $\mathrm{N}_{2}$ ) with a stainless steel needle for $\gtrsim 15 \mathrm{~min}$ before the addition of $\mathrm{Cu}^{\mathrm{I}}$ salts.

As it was outlined before, copper-oxygen compounds are intensively coloured due to oxygen-to-copper charge-transfer transitions, what makes UV-vis spectroscopy the method of choice to study these reactions. The exclusion of air and in addition, the demand for a low-temperature environment, requires furthermore special spectroscopic set-ups. To fulfil this demand, UV-vis spectra were recorded using an optical fibre-mounted all-quartz immersion probe in custom-made inert Schlenk tubes, connected by ground glass joints. UV-vis spectra were also recorded in cryo-stopped-flow experiments as described later (Section 6.4). Resonance Raman spectroscopy is as well a valuable technique for the study of metal-dioxygen adducts, for this, solution samples were prepared in a special cryostat as outlined later.

\subsubsection{Formation and Spectral Optical Properties of ${ }^{R} \mathbf{P}$}

Oxygenation of the four colourless copper(I) complexes $\mathbf{C} \mathbf{u}^{\prime} \mathbf{R}$ at $-78^{\circ} \mathrm{C}$ in THF affords violet to purple $\mu-\eta^{2}: \eta^{2}$-peroxodicopper(II) complexes ${ }^{\mathbf{R}} \mathbf{P}$ (Scheme 6.2). The peroxo complexes are named ${ }^{{ }^{\mathbf{B} u}} \mathbf{P},{ }^{\mathbf{P h}_{\mathbf{P}}} \mathbf{P},{ }^{\mathbf{M e}} \mathbf{P}$ and ${ }^{\mathbf{H}} \mathbf{P}$ in the following text, and addressed as ${ }^{\mathbf{R}} \mathbf{P}$ « in general. UV-vis spectra of all four compounds are depicted in Figure 6.5, with intense optical absorption bands at $\lambda_{\max }=333 \mathrm{~nm}$

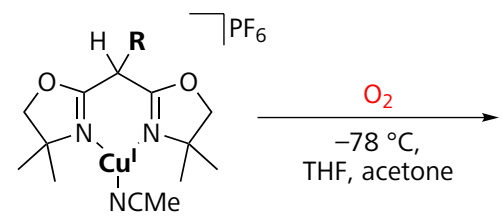

Cu'R

$\mathrm{R} \equiv \mathrm{H}, \mathrm{Me}, \mathrm{Ph}, \mathrm{tBu}$

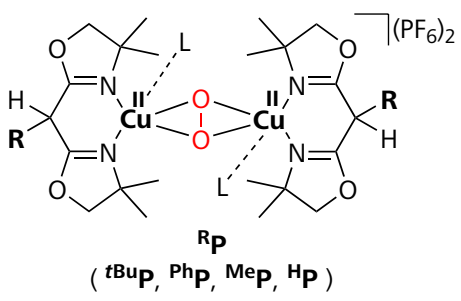

Scheme 6.2 Activation of dioxygen with copper(I)-bis(oxazoline) complexes $\mathbf{C} \mathbf{u}^{\prime} \mathbf{R}(\mathbf{R}=\mathbf{H}$, $\mathrm{Me}, \mathrm{Ph}, t \mathrm{Bu}$ ) to form $\mu-\eta^{2}: \eta^{2}$-peroxodicopper(II) complexes ${ }^{\mathrm{H}} \mathbf{P},{ }^{\mathrm{Me}} \mathbf{P},{ }^{\mathrm{Ph}} \mathbf{P}$ and ${ }^{t \mathrm{Bu}} \mathbf{P}$. 


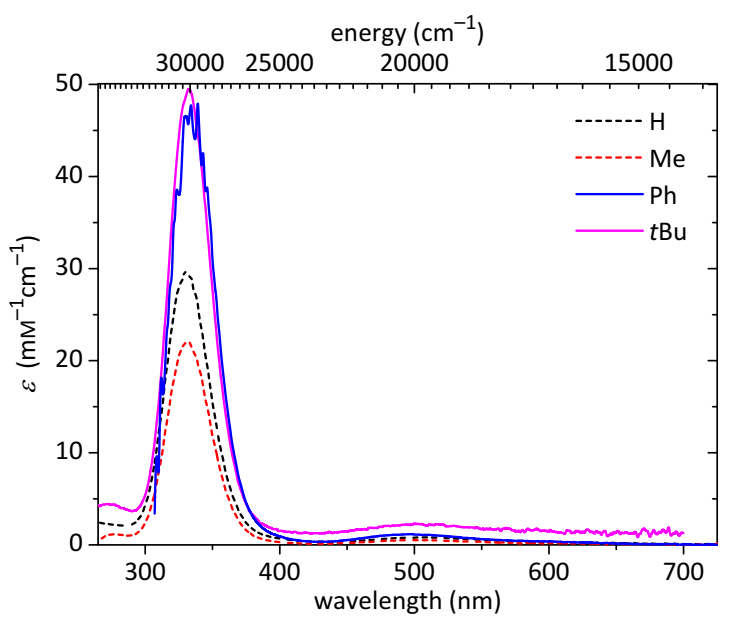

Figure 6.5. Comparison of low temperature $\left(-78^{\circ} \mathrm{C}\right) \cup V$-vis spectra of $\mu-\eta^{2}: \eta^{2}$-peroxodicopper(II) complexes ${ }^{\mathbf{R}} \mathbf{P}$ in THF $\left({ }^{\mathbf{P h}} \mathbf{P}\right.$ in acetone). While the concentrations/intensities of ${ }^{t}{ }^{\text {Bu }} \mathbf{P}$ and ${ }^{\mathbf{P h}} \mathbf{P}$ (solid lines) are constant over $\gtrsim 1 \mathrm{~h},{ }^{\mathbf{H}} \mathbf{P}$ and ${ }^{\mathbf{M e}} \mathbf{P}$ (dashed lines) precipitate during the formation and high concentration could not be reached (spectra with maximum absorption are depicted). See Table 6.2 for spectroscopic parameters and Figures 6.10 and 6.11 for spectra of complex formations.

$\left(\epsilon=48 \mathrm{~mm}^{-1} \mathrm{~cm}^{-1}\right)$ and $500 \mathrm{~nm}\left(2 \mathrm{~mm}^{-1} \mathrm{~cm}^{-1}\right)$ in the case of ${ }^{\boldsymbol{t} \mathbf{B u}} \mathbf{P}$ and nearly identical

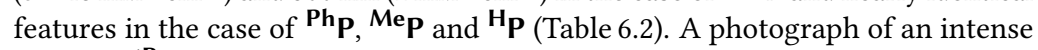
coloured ${ }^{\mathbf{t} \text { Bu}} \mathbf{P}$ solution is depicted in Figure 6.6.

The optical features are archetypical for a side-on $\mu-\eta^{2}: \eta^{2}$-peroxodicopper(II) species and are closely analogous to the spectroscopic features of oxy-hemocyanin and oxy-tyrosinase as introduced in the introduction, Section 2.2.1 (see also Table 2.2). These bands have previously been ascribed to $\pi_{\sigma}^{*} \rightarrow d_{x^{2}-y^{2}}$ (in-plane) and $\pi_{v}^{*} \rightarrow d_{x^{2}-y^{2}}$ (out-of-plane) $\mathrm{Cu}^{\mathrm{II}} \leftarrow \mathrm{O}_{\text {peroxo }}$ ligand-to-metal charge transfer (LMCT) transitions; the former at higher energy $(\sim 333 \mathrm{~nm})$ and being more intense due to a better overlap of orbitals. ${ }^{[1,229]}$ It is well evident that the optical characteristics are very similar between the four compounds and it can be predicted, that the structural properties are most likely identical. Absorptions of ${ }^{\mathbf{H}_{\mathbf{P}}}$ and ${ }^{\mathbf{M e}} \mathbf{P}$ are less intense since their solubility is very limited. Though similar to absorptions of previously reported systems, with $\lambda_{\max }\left(\epsilon, \mathrm{mM}^{-1} \mathrm{~cm}^{-1}\right)=\sim 340-380 \mathrm{~nm}(\sim 18-25)$ 
6. Biomimetic Activation of $\mathrm{O}_{2}$ by Copper(I) Complexes of BOXs

Table 6.2.

Spectroscopic data of dicopper-dioxygen complexes. ${ }^{a}$

\begin{tabular}{|c|c|c|c|c|}
\hline symbol & ligand & anion & solvent & $\begin{array}{l}\text { UV-vis: } \lambda_{\max }, \mathrm{nm} \\
\left(\epsilon, \mathrm{mM}^{-1} \mathrm{~cm}^{-1}\right)\end{array}$ \\
\hline${ }^{H_{P}}$ & $\mathrm{H}\left\{{ }^{\mathrm{H}} \mathrm{BOX}\right\}$ & $\begin{array}{l}\mathrm{PF}_{6}^{-} \\
\mathrm{PF}_{6}^{-}\end{array}$ & $\begin{array}{l}\text { THF } \\
\text { solid }\end{array}$ & $\begin{array}{l}330(>30), 504(>0.8)^{b} \\
271,332,512, \sim 620 s h^{c}\end{array}$ \\
\hline $\mathrm{Me}_{\mathbf{P}}$ & $\mathrm{H}\left\{{ }^{\mathrm{Me}} \mathrm{BOX}\right\}$ & $\begin{array}{l}\mathrm{PF}_{6}^{-} \\
\mathrm{PF}_{6}^{-}\end{array}$ & $\begin{array}{l}\mathrm{THF} \\
\text { solid }\end{array}$ & $\begin{array}{l}333(>22), 496(>0.5)^{b} \\
261,331,493,600^{d}\end{array}$ \\
\hline $\begin{array}{l}\mathrm{Ph}_{\mathbf{P}} \\
{ }^{\mathrm{Ph}} \mathbf{O}^{e}\end{array}$ & $\begin{array}{l}\mathrm{H}\left\{{ }^{\mathrm{Ph}} \mathrm{BOX}\right\} \\
\mathrm{Li}\left\{{ }^{\mathrm{Ph}} \mathrm{BOX}\right\}\end{array}$ & $\mathrm{PF}_{6}^{-}$ & $\begin{array}{l}\text { aceton } \\
\text { aceton }\end{array}$ & $\begin{array}{l}334(47), 496(1.1) \\
338(13), 400(17), \sim 484 \operatorname{sh}(2), \\
\sim 600 \operatorname{sh}(1), \sim 750(2)\end{array}$ \\
\hline${ }^{t B u} \mathrm{P}$ & $\mathrm{H}\left\{{ }^{t \mathrm{Bu}} \mathrm{BOX}\right\}$ & $\begin{array}{l}\mathrm{PF}_{6}^{-} \\
\mathrm{PF}_{6}^{-} \\
\mathrm{PF}_{6}^{-} \\
\mathrm{OTf}^{-}\end{array}$ & $\begin{array}{l}\text { THF } \\
\text { aceton } \\
\text { solid } \\
\text { THF }\end{array}$ & $\begin{array}{l}333(48.0), 509(2.14) \\
333,496 \\
263,334,520, \sim 620 s h \\
332(40), 508(0.6) 635(0.8)\end{array}$ \\
\hline
\end{tabular}

$\bar{a}$ Solutions at $-78^{\circ} \mathrm{C}$, solids at r. t. ${ }^{b}$ Incomplete formation/low solubility and precipitation. ${ }^{c} s h=$ shoulder. ${ }^{d}$ Sample was decomposed to some extent. ${ }^{e}$ bis( $\mu$-oxo)dicopper(III), see Chapter 7. ${ }^{f}$ Neutral complex.

\section{Figure 6.6}

Photograph of a ${ }^{\mathbf{t} \text { u }} \mathbf{P}$ solution in cooling bath with UV-vis immersion probe.

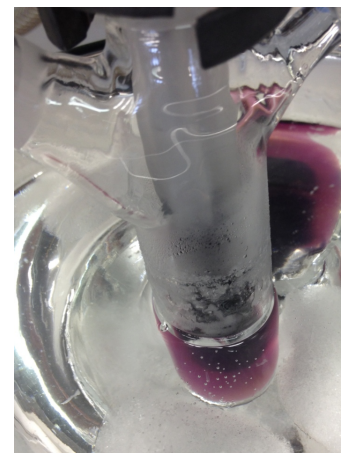


and $\sim 510-550 \mathrm{~nm}(\sim 1),{ }^{[34]}$ both CT bands of ${ }^{\mathbf{R}} \mathbf{P}$ are at relatively high energy compared to known systems and are remarkably more intense (indicated also by a Beer's law plot for ${ }^{\mathbf{t}}{ }^{\mathbf{P}} \mathbf{P}$, discussed below).

The UV-vis bands of ${ }^{\boldsymbol{t} B \text { u }} \mathbf{P}$ are similar in THF and in acetone solutions (cf. Table 6.2, Figure 6.9a), while no peroxo complex formation was observable in $\mathrm{CH}_{2} \mathrm{Cl}_{2}$. The reactions of all four $\mathbf{C} \mathbf{u}^{\prime} \mathbf{R}$ with $\mathrm{O}_{2}$ were found to follow first-order kinetics under the applied conditions (Section 6.4). While ${ }^{\boldsymbol{t} \mathbf{B u}} \mathbf{P}$ and ${ }^{\mathbf{P h}} \mathbf{P}$ are both soluble in THF and sufficiently stable at low temperatures for an extended time, the solubility of ${ }^{\mathbf{H}} \mathbf{P}$ and ${ }^{\mathbf{M}} \mathbf{P}$ is rather limited and they were found to precipitate from their solutions already during the oxygenation reaction (discussed below). While the quite limited solubility of all four complexes is problematic to analysis and experiments in solution, it is advantageous for isolation of the peroxo complexes as solids (Section 6.5). Exchange of $\mathrm{PF}_{6}^{-}$counterion to triflate (OTf ${ }^{-}$) in ${ }^{\boldsymbol{t} \mathbf{B u}} \mathbf{P}$ gives a $\mathrm{Cu}_{2} \mathrm{O}_{2}$ complex with analogous spectroscopic features, but an additional peak at $635 \mathrm{~nm}$ is present in the UV-vis spectrum (Table 6.2).

Experiments with the dimerised ligand ${ }^{\mathrm{Me}_{\mathrm{BOX}}}$ (cf. Chapter 5), $\left[\mathrm{Cu}(\mathrm{MeCN})_{4}\right] \mathrm{PF}_{6}$ and $\mathrm{O}_{2}$, in analogy to $\mathbf{C} \mathbf{u}^{\prime} \mathbf{R}$ showed no formation of a copper-oxygen complex at low temperatures, which might be due to the larger steric hindrance of this ditopic ligand. Finally, it is noteworthy that all spectroscopy of ${ }^{\mathbf{R}} \mathbf{P}$ gives no indication for the traceable presence of the corresponding bis( $\mu$-oxo)dicopper(III) ( O ) species, which is often evidenced to be in equilibrium with a ${ }^{\mathrm{S}} \mathbf{P}$ complex. ${ }^{[34]}$ Interestingly, an $\mathrm{O}$ complex was observed with the deprotonated ligand ${ }^{\mathrm{Ph}_{\mathrm{BOX}}}{ }^{-}$, as described in detail in the following Chapter 7.

\section{Self-assembly}

Synthetic copper-dioxygen complexes are usually not only quite temperaturesensitive and reactive towards exogenous and endogenous substrates (or the ligands itself), and their formation is usually highly sensitive to the oxygenation conditions, too. ${ }^{[230]}$ The oxygenation of $\mathbf{C} \mathbf{u}^{\prime} \mathbf{R}$ could be achieved either by the

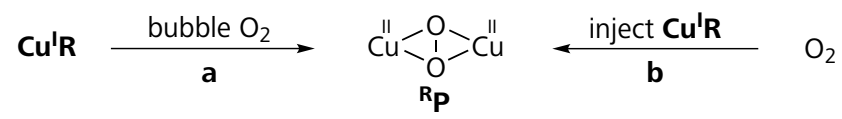

Scheme 6.3 Formation of $\mathrm{Cu}_{2} \mathrm{O}_{2}$ complexes. Self-assembly of peroxo complexes ${ }^{\mathbf{R}} \mathbf{P}$ may proceed by two distinct sequences with similar yields. Either dry $\mathrm{O}_{2}$ is bubbled through a $-78^{\circ} \mathrm{C} \mathbf{C} \mathbf{u}^{\prime} \mathbf{R}$ solution (a), or the $\mathbf{C} \mathbf{u}^{\prime} \mathbf{R}$ solution is injected into a $-78^{\circ} \mathrm{C} \mathrm{O}_{2}$-saturated solvent (b). 
injection of $\mathrm{O}_{2}$ gas into solutions of $\mathbf{C} \mathbf{u}^{\prime} \mathbf{R}$ in THF (at $-78^{\circ} \mathrm{C}$ under $\mathrm{Ar}$ or $\mathrm{N}_{2}$ atmosphere; Scheme 6.3, sequence a) or by the slow injection of these $\mathbf{C} \mathbf{u}^{\prime} \mathbf{R} / \mathrm{THF}$ solutions into $\mathrm{O}_{2}$-saturated solvent at $-78^{\circ} \mathrm{C}$ (Scheme 6.3, sequence b).

It is usual that the injection of a copper(I) complex solution directly into cooled pre-oxygenated solvent (sequence b) gives the highest yields of copper-dioxygen complex. ${ }^{[74]}$ However, the yields of peroxo complexes ${ }^{\mathbf{R}} \mathbf{P}$ are comparable, when $\mathrm{O}_{2}$ is bubbled through cooled copper(I) $\left(\mathbf{C u}^{\prime} \mathbf{R}\right)$ solutions (sequence a), demonstrating the robust self-assembly of the peroxo-core in the BOX ligand-supported systems examined here.

\section{Beer's law plot}

To determine the peak intensities more precisely, solutions of varying concentra-

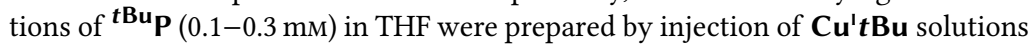
into chilled, saturated solutions of $\mathrm{O}_{2}$ in THF at $-78^{\circ} \mathrm{C}$. The solutions turned slowly purple; the development of the full spectra $(250-700 \mathrm{~nm})$ was monitored with a $0.1 \mathrm{~cm}$ path length immersion probe until they remained unchanged.

The slopes of the absorbances at 333 and $500 \mathrm{~nm}$ vs. concentration of $\boldsymbol{t B u}_{\mathbf{P}}$ give extinction coefficients of approximately 48 and $2.1 \mathrm{~mm}^{-1} \mathrm{~cm}^{-1}$, respectively (Figure 6.7, Table 6.3). The high intensity of the $333 \mathrm{~nm}$ transition for ${ }^{\boldsymbol{t} \mathbf{B u}} \mathbf{P}$ is only comparable to model complexes with ethylene diamine-derived ligand systems $\left(\sim 34-40 \mathrm{~mm}^{-1} \mathrm{~cm}^{-1}\right)$. Peroxodicopper(II) complexes of those bidentate ligands usually feature undefined weak axial solvent or counterion ligation; intimate interaction with the counteranion was observed spectroscopically. ${ }^{[99,108,109]}$ This

Figure 6.7

Beer's law plots, absorbance vs. tBu $P$ concentration (i. e. per $\mathrm{Cu}_{2} \mathrm{O}_{2}$ unit), for $\lambda_{\max }=333$ (black) and $500 \mathrm{~nm}$ (blue) in THF at $-78^{\circ} \mathrm{C}$. $2 \mathrm{~mm}$ ( ) and $5 \mathrm{~mm}(\boldsymbol{\square})$ stock solutions were used. The slopes of the linear fits $(-,-)$ give the respective extinction coefficients.

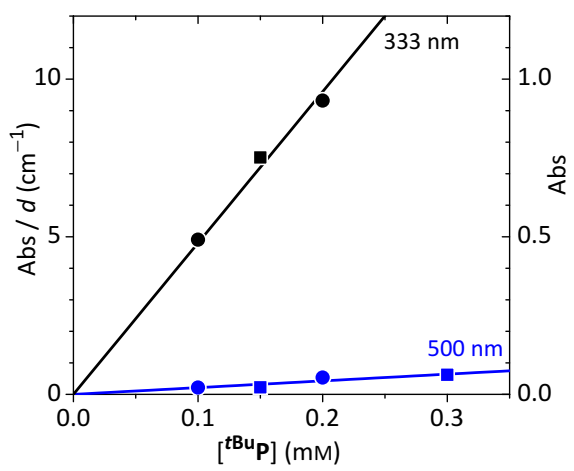


Table 6.3.

Molar extinction coefficients $(\epsilon)$ of ${ }^{t B u} \mathbf{P}$ in THF $@-78^{\circ} \mathrm{C}$, obtained from Beer's law plots in Figure 6.7 and fit parameters.

\begin{tabular}{lcc}
\hline$\lambda_{\max }$ & $333 \mathrm{~nm}$ & $500 \mathrm{~nm}$ \\
\hline$\epsilon\left(\mathrm{mM}^{-1} \mathrm{~cm}^{-1}\right)$ & $48.0 \pm 1.1$ & $2.14 \pm 0.20$ \\
$\bar{R}^{2}$ & 0.998 & 0.963 \\
\hline
\end{tabular}

suggests the presence of weakly bound axial solvent ligands also in ${ }^{\mathbf{R}} \mathbf{P}$, in accordance with EXAFS data (see below, Section 6.7).

The high intensity of the $333 \mathrm{~nm} \pi_{\sigma}^{*} \rightarrow d_{x^{2}-y^{2}}$ (in-plane) feature might be explained by the BOX ligands playing a role in this charge-transfer transition. The $\mathrm{C}=\mathrm{N}$ bonds of the ligands are in plane with the $\mathrm{Cu}_{2} \mathrm{O}_{2}$ core and a relevant orbital interaction can be expected. Theoretical investigations of the excited electronic states of ${ }^{\boldsymbol{t} \mathbf{B u}} \mathbf{P}$, using time-dependent density-functional theory (TDDFT) calculations (Section 6.8), support this assumption, as charge from the ligand is transferred in addition to charge from the peroxide in course of this electronic excitation.

\subsubsection{Thermolability and Reversibility of $\mathrm{O}_{2}$ Binding}

${ }^{\mathbf{R}} \mathbf{P}$ are thermolabile at temperatures above approximately $-60^{\circ} \mathrm{C}$. Solutions of ${ }^{\mathbf{R}} \mathbf{P}$ are bleaching to colourless or slightly blue/green solutions, indicative for the thermal decay of the $\mathrm{Cu}_{2} \mathrm{O}_{2}$ complex and, either back formation of the respective $\mathrm{Cu}^{\mathrm{I}}$ complexes or the formation of $\mathrm{Cu}^{\mathrm{II}}$ species. The thermal degradation of ${ }^{t} \mathbf{B u} \mathbf{P}$ and ${ }^{\mathbf{H}} \mathbf{P}$ to $\mathrm{Cu}_{2}(\mathrm{OH})_{2}$ complexes and/or ligand oxygenation is covered in Section 6.10. The oxygenation reaction of ${ }^{\boldsymbol{t}} \mathbf{B u} \mathbf{P}$ was found to be reversible in THF when the reaction of the $\mathrm{Cu}^{\mathrm{I}}$ complex with $\mathrm{O}_{2}$ at room temperature is avoided by the removal of $\mathrm{O}_{2}$ by several vacuum/argon cycles (Figure 6.8). Warming of a ${ }^{\boldsymbol{t} \mathbf{B u}} \mathbf{P}$ in THF solution under inert gas to $-15^{\circ} \mathrm{C}$, followed by recooling and admitting $\mathrm{O}_{2}$, allows for sequential cycles of $\mathrm{O}_{2}$ binding and release.

Applying vacuum to an acetone solution of ${ }^{\boldsymbol{t} \mathbf{B u}} \mathbf{P}$ induces $\mathrm{O}_{2}$ release already at $-78^{\circ} \mathrm{C}$ (Figure 6.9a). However, a slow zero-order rate decomposition of ${ }^{\boldsymbol{t} \mathbf{B u}} \mathbf{P}$ was additionally evident in acetone (Figure 6.9b). In detail, injection of dioxygen into the $\mathbf{C} \mathbf{u}^{\prime} \mathbf{t} \mathbf{B u}$ acetone solution leads to formation of ${ }^{\mathbf{A}}{ }^{\mathbf{B}} \mathbf{P}$ with a similar rate constant as for the reaction in THF (step 1 in Figure 6.9b). A slow zero-order decay 


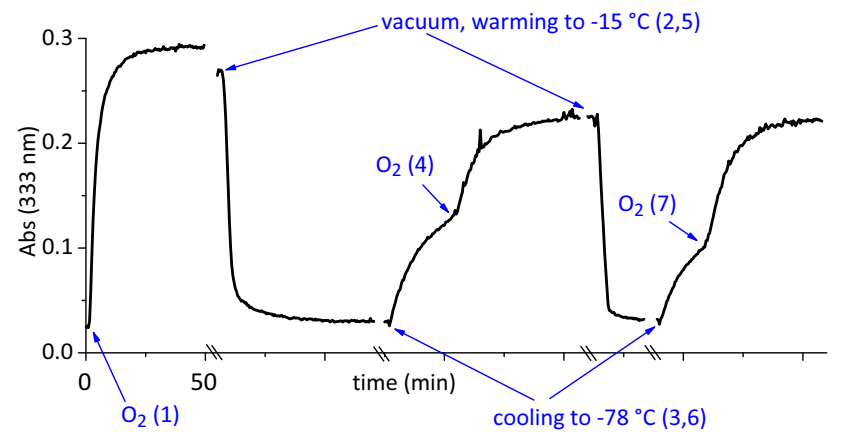

Figure 6.8. Time traces of formation and decay of the $333 \mathrm{~nm}$ feature of ${ }^{\boldsymbol{t} B u} \mathbf{P}$ in THF between -78 and $-15^{\circ} \mathrm{C}$ (cf. UV-vis spectra in Figures 6.5 and 6.10a), demonstrating the reversibility of $\mathrm{O}_{2}$ binding; dioxygen injection is indicated (steps 1, 4, 7), as well as warming (2, $5)$ and cooling $(3,6)$ steps. The loss of intensity between first and second cycle is attributed to precipitation of ${ }^{\mathbf{t B u}} \mathbf{P}$. First-order rate constant of formation (step 1): $k_{\mathrm{obs}}=2.5 \times 10^{-3} \mathrm{~s}^{-1}$.

is evident (step 2). Applying vacuum/argon cycles leads to deoxygenation of $\mathrm{Cu}_{2} \mathrm{O}_{2}$ already at $-78^{\circ} \mathrm{C}$ (Figure 6.9a, step 3 in Figure 6.9b). The vacuum-deoxygenated complex is roughly re-oxygenated upon a second injection of $\mathrm{O}_{2}$ (step 4, also considering the zero-order decomposition process). Vacuum and warming to $-15^{\circ} \mathrm{C}$ under argon leads to thermal decomposition (step 5). Re-cooling to $-78^{\circ} \mathrm{C}$ re-establishes the complex in a reaction with the released $\mathrm{O}_{2}$ (step 6). Injection of $\mathrm{O}_{2}$ recovers ${ }^{\boldsymbol{t}} \mathbf{B u} \mathbf{P}$ (step 7), but the final concentration is significantly lower due to the additional decomposition. 


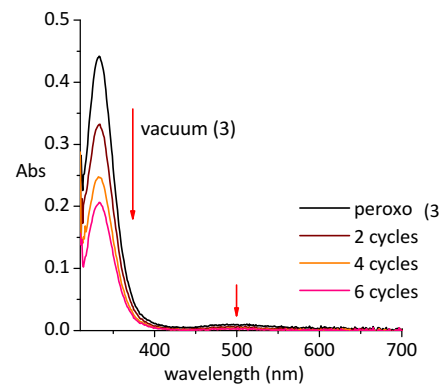

(a)

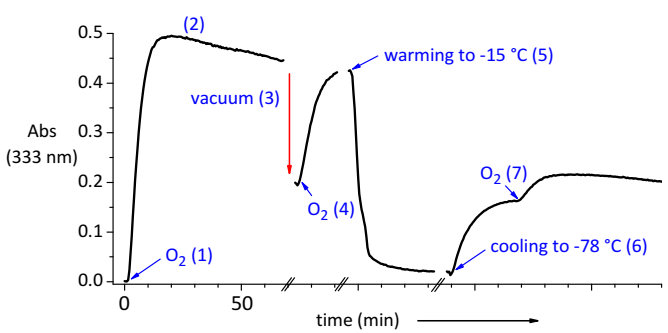

(b)

Figure 6.9. (a) Spectra of ${ }^{\boldsymbol{t} \mathrm{Bu}} \mathbf{P}$ in acetone and it's decomposition upon applying vacuum/argon cycles at $-78^{\circ} \mathrm{C}$; six cycles total, spectra for every two cycles are shown. (b) Time traces of the features at $333 \mathrm{~nm}$, demonstrating the reversible $\mathrm{O}_{2}$ binding and degradation; dioxygen injection is indicated (steps $1,4,7$ ), as well as warming (5) and cooling (6) steps; the red arrow indicates the vacuum/argon cycles (step 3 in (a)). First-order rate constant of formation (step 1): $k_{\mathrm{obs}} \approx 4 \times 10^{-3} \mathrm{~s}^{-1}$; zero-order constant of decay (step 2): $k_{\mathrm{dec}}=$ $1 \times 10^{-5} \mathrm{~mm} \mathrm{~s}^{-1}$.

\subsection{Kinetic and Thermodynamic Analysis of $\mathrm{O}_{2}$ Activation}

For a range of different systems, the formation of well-defined $\mathrm{Cu} / \mathrm{O}_{2}$ complexes has been elucidated by determination of their kinetic and thermodynamic parameters. ${ }^{[2,58,60,231-235]}$ From these results, the generally accepted mechanistic framework for $\mathrm{O}_{2}$ activation in Scheme 6.4 was established.

$$
\mathrm{LCu}^{\prime}+\mathrm{O}_{2} \underset{\text { process } A}{\rightleftharpoons} \mathrm{LCu}_{-\mathrm{O}}^{-} \text {or } \mathrm{LCu}^{\mathrm{O}} \mathrm{O}_{\mathrm{O}_{\mathrm{O}}} \underset{\text { process } B}{\stackrel{+\mathrm{LCu}^{\prime}}{\rightleftharpoons}}\left(\mathrm{LCu}_{2} \mathrm{O}_{2}\right.
$$

Scheme 6.4 Mechanistic framework of $\mathrm{Cu}^{\prime}$-mediated $\mathrm{O}_{2}$ activation.

According to this mechanism, the $\mathrm{Cu}^{\mathrm{I}}$ complex reacts with $\mathrm{O}_{2}$ to form a $1: 1$ $\mathrm{Cu} / \mathrm{O}_{2}$ adduct (process $\mathrm{A}$ ). It is usual, that this complex reacts further with a second $\mathrm{Cu}^{\mathrm{I}}$ complex to form a binuclear $2: 1 \mathrm{Cu} / \mathrm{O}_{2}$ species (process $\mathrm{B}$ ). Further addition of $\mathrm{LCu}^{\mathrm{I}}$ in some systems leads to tri- or tetranuclear species. In a few systems the $1: 1$ adduct is the final product, bulky ligands prevent here the formation of a binuclear system. 
$1: 1 \mathrm{Cu} / \mathrm{O}_{2}$ adducts are often only short-lived intermediates and have been studied by stopped-flow techniques. For the formation of $\mathrm{Cu}_{n} / \mathrm{O}_{2}$ adducts, three kinetic situations have been identified: ${ }^{[60]}$

case a. The $1: 1$ adduct is observed spectroscopically and the rates of formation and decay are such that both steps can be monitored individually and the kinetics for both steps investigated.

case b. The formation of the $1: 1$ adduct is very rapid and the formation (process A) can not be observed, however a consecutive step (following second order kinetics) may be monitored and is rate determining. The kinetics of this step, the trapping with a second $\mathrm{Cu}^{\mathrm{I}}$ complex (process $\mathrm{B}$ ), can be investigated.

case c. Finally, the first step (process A) is slow and rate-determining and the formed $1: 1$ adduct is rapidly trapped by a second $\mathrm{Cu}^{\mathrm{I}}$ complex and not observed spectroscopically. The first process, the $\mathrm{O}_{2}$ activation step, can be investigated in this case. This kinetic behaviour was found e.g. in several $N, N^{\prime}, N^{\prime \prime}$-substituted TACN ligand systems, ${ }^{[46,67]}$ in a meta-[67] and a paraxylene-bridged bis $\left(N, N^{\prime}-i \mathrm{Pr}_{2}\right.$-TACN) system ${ }^{[67]}$ or in the ethylene-bridged $\operatorname{bis}\left(N, N^{\prime}-i \operatorname{Pr}_{2}-\mathrm{TACN}\right){ }^{[67,236]}$ And this is also the situation in the case of the $\mathbf{C} \mathbf{u}^{\prime} \mathbf{R}$ complexes as outlined below.

The reactions of all four $\mathbf{C} \mathbf{u}^{\prime} \mathbf{R}$ with $\mathrm{O}_{2}$ and the formation of ${ }^{\mathbf{R}} \mathbf{P}$ were found to follow first-order kinetics under the applied conditions and the traces of the $\sim 333$ and $\sim 500 \mathrm{~nm}$ features could be fitted with single exponential function to obtain rate constants $k_{\text {obs }}$ (Figures 6.10 and 6.11, Table 6.4). While ${ }^{\boldsymbol{t} \mathbf{B u}_{\mathbf{P}}}$ and ${ }^{\mathbf{P h}} \mathbf{P}$ are sufficiently soluble under the applied conditions, ${ }^{\mathbf{H}_{\mathbf{P}}}$ and ${ }^{\mathbf{M}} \mathbf{P}$ were found to precipitate already upon their formation, which is well evident from the spectra and time traces in Figure 6.11.

The oxygenation reactions of the four ${ }^{\mathbf{R}} \mathbf{P}$ were found to proceed comparatively slow. The formation of ${ }^{\mathbf{B} \text { u }} \mathbf{P}$ in $\mathrm{O}_{2}$-saturated THF at $-78^{\circ} \mathrm{C}$ is e. g. completed in $\sim 20 \mathrm{~min}$, in contrast with reported reactions which usually take place in milliseconds to seconds. ${ }^{[58,60]}$ Between the four $\mathbf{C} \mathbf{u}^{\prime} \mathbf{R}$, the reaction of $\mathbf{C} \mathbf{u}^{\prime} \mathbf{t} \mathbf{B u}$ is however the slowest and the rate constants were found to increase with lower sterical demand of the backbone residue R. For ${ }^{\boldsymbol{t} \mathbf{B} u} \mathbf{P}$, the rates are nearly identical in THF and acetone; with OTf ${ }^{-}$counterion, however, the reaction proceeds $\sim$ four times faster. The kinetics and thermodynamics of the dioxygen activation have been investigated more closely with $\mathbf{C} \mathbf{u}^{\prime} \mathbf{t} \mathbf{B u}$ by means of the cryo-stopped-flow technique (see below). 


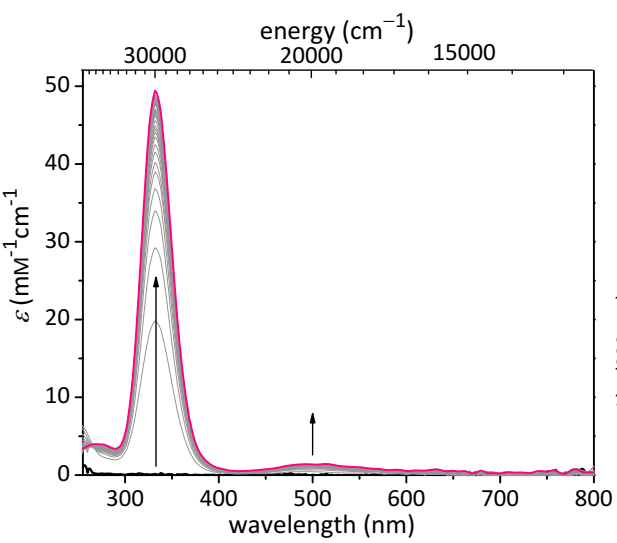

(a) ${ }^{t \mathrm{Bu}} \mathrm{P}$

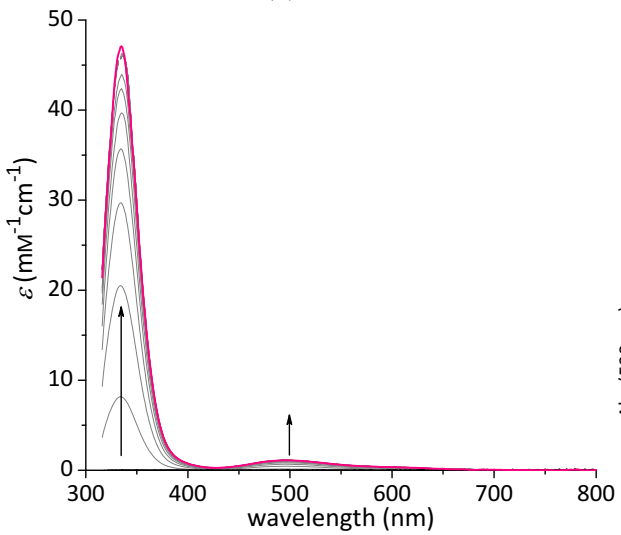

(c) ${ }^{\mathrm{Ph}} \mathbf{P}$

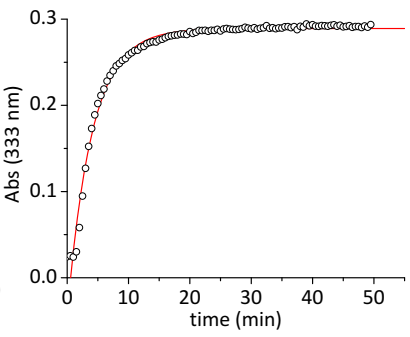

(b) ${ }^{t B u} P$

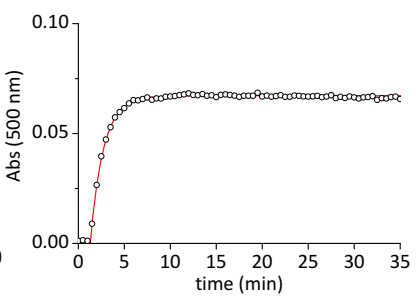

(d) ${ }^{\mathrm{Ph}_{\mathbf{P}}}$

Figure 6.10. (a,c) UV-vis spectra of ${ }^{\boldsymbol{t}{ }^{\mathrm{Bu}} \mathbf{P} \text { and }}{ }^{\mathrm{Ph}} \mathbf{P}$, obtained upon injection of $\mathrm{O}_{2}$ into $\left.\left[(\mathrm{MeCN}) \mathrm{Cu}^{\prime}\left(\mathrm{H}_{\{}{ }^{\mathrm{R}} \mathrm{BOX}\right\}\right)\right] \mathrm{PF}_{6}\left(\mathbf{C} \mathbf{u}^{\prime} \mathrm{R}, \mathrm{R} \equiv t \mathrm{Bu}\right.$ or $\left.\mathrm{Ph}\right)$ solutions in $\mathrm{THF}(\mathrm{R} \equiv t \mathrm{Bu})$ or acetone $(\mathrm{R}$ $\equiv \mathrm{Ph})$ at $-78^{\circ} \mathrm{C}$. $\mathrm{Cu}^{\prime}$ complexes $(-), \mathrm{Cu}_{2} \mathrm{O}_{2}$ peroxo complexes ${ }^{\mathbf{R}} \mathbf{P}(-)$. Concentrations of $\left.\mathrm{Cu}^{\prime}\left(\mathrm{H}_{\{}{ }^{\mathrm{R}} \mathrm{BOX}\right\}\right)$ were $0.30 \mathrm{~mm}(\mathrm{R} \equiv t \mathrm{Bu})$ and $1.13 \mathrm{~mm}(\mathrm{R} \equiv \mathrm{Ph})$. (b,d) Kinetic traces $(\mathrm{O})$ and first-order fits (-) of formation of the peaks at $333 \mathrm{~nm}(\mathrm{R} \equiv t \mathrm{Bu})$ and $500 \mathrm{~nm}(\mathrm{Ph})$. See Table 6.4 for rate constants and Table 6.2 for spectroscopic parameters. 


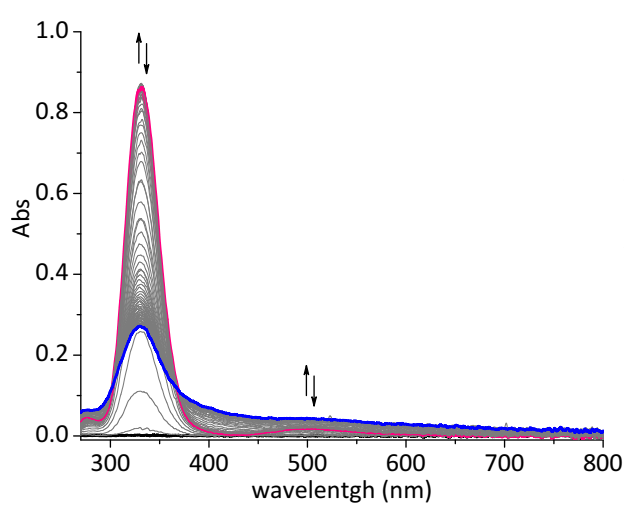

(a) ${ }^{\mathrm{Me}} \mathbf{P}$

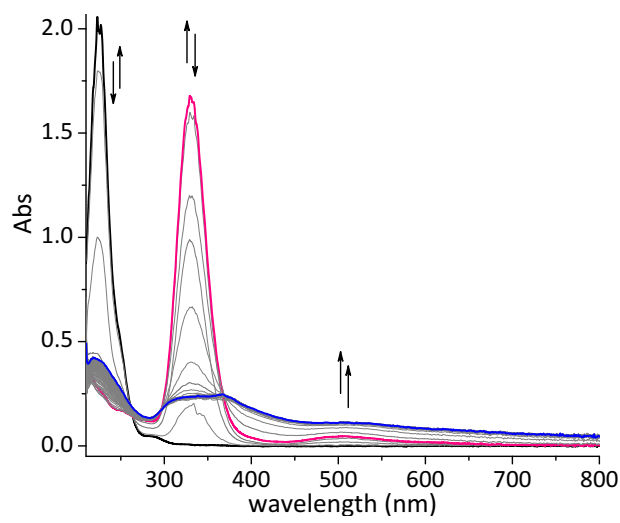

(c) ${ }^{\mathrm{H}} \mathbf{P}$

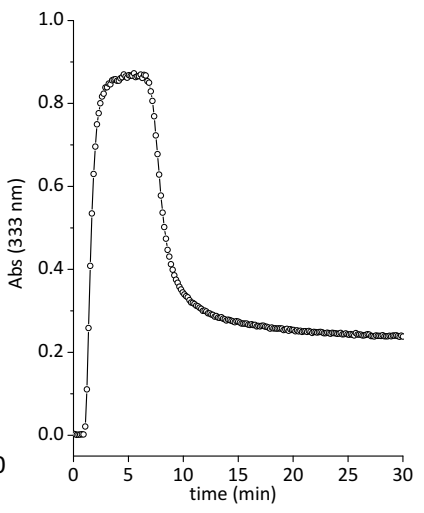

(b) ${ }^{M e} \mathbf{P}$

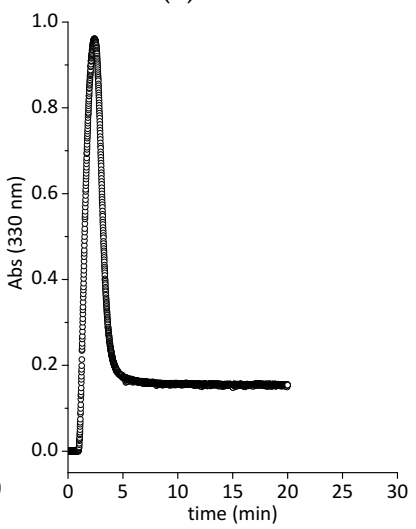

(d) ${ }^{\mathrm{H}} \mathbf{P}$

Figure 6.11. (a,c) UV-vis spectra of ${ }^{\mathrm{Me}} \mathbf{P}$ and ${ }^{\mathrm{H}} \mathbf{P}$, obtained upon injection of $\mathrm{O}_{2}$ into $\left.\left[(\mathrm{MeCN}) \mathrm{Cu}^{\prime}\left(\mathrm{H}_{\{}{ }^{\mathrm{R}} \mathrm{BOX}\right\}\right)\right] \mathrm{PF}_{6}\left(\mathbf{C} \mathbf{u}^{\prime} \mathbf{R}, \mathrm{R} \equiv \mathrm{Me}\right.$ or $\left.\mathrm{H}\right)$ solutions in $\mathrm{THF}$ at $-78^{\circ} \mathrm{C}$. $\mathrm{Cu}^{\prime}$ complexes (-), $\mathrm{Cu}_{2} \mathrm{O}_{2}$ peroxo complexes ${ }^{\mathbf{R}} \mathbf{P}(-)$, final spectra after decay/precipitation of peroxo complexes $(\longrightarrow)$. Concentrations of $\left.\mathrm{Cu}^{\prime}\left(\mathrm{H}_{\{}{ }^{\mathrm{R}} \mathrm{BOX}\right\}\right)$ were $0.79 \mathrm{mM}(\mathrm{R} \equiv \mathrm{Me})$ and $1.13 \mathrm{~mm}$ $(\mathrm{R} \equiv \mathrm{H})$. (b,d) Kinetic traces of formation and decay of the peaks at $\sim 330 \mathrm{~nm}$. For Me $\mathbf{P}$ $(\mathrm{a}, \mathrm{b})$, spectra and trace were recorded in $9 \mathrm{~s}$ intervals. For ${ }^{\mathbf{H}} \mathbf{P}(\mathrm{c}, \mathrm{d})$, spectra were recorded in $20 \mathrm{~s}$ intervals; the kinetic trace was obtained from a second measurement in $0.5 \mathrm{~s}$ intervals. See Table 6.4 for rate constants of formation and decay and Table 6.2 for spectroscopic parameters. 
Table 6.4.

Overview of dicopper-dioxygen complexes and kinetic data. ${ }^{a}$

\begin{tabular}{|c|c|c|c|c|c|}
\hline symbol & ligand & anion & solvent & $k_{\mathrm{obs}}\left(\min ^{-1}\right)^{b}$ & $\begin{array}{l}\text { stability, }{ }^{c} \\
k_{\text {decomp }}\left(\mathrm{mM} \mathrm{min}^{-1}\right)\end{array}$ \\
\hline${ }^{{ }^{H}} \mathbf{P} d$ & $\mathrm{H}\left\{{ }^{\mathrm{H}} \mathrm{BOX}\right\}$ & $\begin{array}{l}\mathrm{PF}_{6}^{-} \\
\mathrm{PF}_{6}^{-}\end{array}$ & $\begin{array}{l}\text { THF } \\
\text { solid }\end{array}$ & $\gtrsim 1$ & $\begin{array}{l}\text { precipitation } \\
\text { stable }^{e}\end{array}$ \\
\hline${ }^{M e} \mathbf{P}^{d}$ & $\mathrm{H}\left\{{ }^{\mathrm{Me}} \mathrm{BOX}\right\}$ & $\begin{array}{l}\mathrm{PF}_{6}^{-} \\
\mathrm{PF}_{6}^{-}\end{array}$ & $\begin{array}{l}\text { THF } \\
\text { solid }\end{array}$ & $\sim 1.5$ & $\begin{array}{l}\text { precipitation } \\
\text { decomposition }\end{array}$ \\
\hline${ }^{\mathbf{P h}} \mathbf{P} d$ & $\mathrm{H}\left\{{ }^{\mathrm{Ph}} \mathrm{BOX}\right\}$ & $\begin{array}{l}\mathrm{PF}_{6}^{-} \\
\mathrm{PF}_{6}^{-}\end{array}$ & $\begin{array}{l}\text { acetone } \\
\text { solid }\end{array}$ & 0.71 & $\begin{array}{l}\text { stable } \\
\text { decomposition }\end{array}$ \\
\hline${ }^{\mathbf{P h}} \mathbf{O} f$ & $\mathrm{Li}\left\{{ }^{\mathrm{Ph}} \mathrm{BOX}\right\}$ & $g^{\circ}$ & $\mathrm{THF}$ & very fast & stable \\
\hline${ }^{t B u} \mathbf{P}^{d}$ & $\mathrm{H}\left\{{ }^{t \mathrm{Bu}} \mathrm{BOX}\right\}$ & $\begin{array}{l}\mathrm{PF}_{6}^{-} \\
\mathrm{PF}_{6}^{-} \\
\mathrm{PF}_{6}^{-} \\
\mathrm{OTf}^{-} \\
\mathrm{PF}_{6}^{-}\end{array}$ & $\begin{array}{l}\text { THF } \\
\text { aceton } \\
\mathrm{CH}_{2} \mathrm{Cl}_{2} \\
\mathrm{THF} \\
\text { solid }\end{array}$ & $\begin{array}{l}0.25^{h} \\
0.23 \\
\text { no reaction } \\
0.90\end{array}$ & $\begin{array}{l}\text { stable } \\
5 \times 10^{-4 i} \\
\mathrm{n} / \mathrm{a} \\
\text { stable } \\
\text { stable }^{e}\end{array}$ \\
\hline - & ${ }^{\mathrm{Me}} \mathrm{BOX}_{2}$ & $\mathrm{PF}_{6}^{-}$ & THF & no reaction & $\mathrm{n} / \mathrm{a}$ \\
\hline
\end{tabular}

$\overline{{ }^{a} \text { At }-78{ }^{\circ} \mathrm{C} \text {; formation upon } \mathrm{O}_{2} \text { injection. }{ }^{b} \text { From standard UV-vis experiments. }{ }^{c} \text { No change of }}$ UV-vis spectra for $\gtrsim 1$ hour. ${ }^{d} \mu-\eta^{2}: \eta^{2}$-peroxodicopper(II). ${ }^{e}$ Stable for $\gtrsim 1$ day as a powder at room temperature in air. ${ }^{f} \operatorname{Bis}\left(\mu\right.$-oxo)dicopper(III), see Chapter 7. ${ }^{g}$ Neutral complex. ${ }^{h}$ More kinetic data was obtained from stopped-flow experiments, see below. ${ }^{i}$ First-order decay, $t_{1 / 2} \approx 4 \mathrm{~h}$.

\subsubsection{The Low Temperature (Cryo-)Stopped-Flow Technique}

Investigations of reactions of copper(I) complexes with dioxygen require special technical set-ups, since these complexes are very reactive towards dioxygen. The usually quite fast reactions need stopped-flow techniques and temperatures below $-50^{\circ} \mathrm{C}$ to be followed appropriately. ${ }^{[58]}$ The tubing of the stopped-flow system has to be air tight and resistant against solvents, coolants and low temperatures. Furthermore, the copper(I) complexes must be handled under inert gas. To fulfil this needs, suitable devices had been developed or were obtained by modifying existing systems. ${ }^{[78]}$

The cryo-stopped-flow system applied in this work is schematically depicted in Figure 6.12. It has a single-mixing Berger Ball unit and two syringes controlled by independent stopping motors and an electro-valve hard-stop; the mixer and the 
observation cell are immersed in the cryo-solvent of a low-temperature $\left(\geq-75^{\circ} \mathrm{C}\right)$ cryostat; spectra were recorded by an optical fibre-mounted diode array spectrophotometer.

Since running the whole stopped-flow system under inert gas was technically not feasible, it was attempted to avoid any contamination of the closed system with air. Although the applied measures allowed investigating the whole reaction kinetics as described below, careful inspection of the recorded spectra revealed that deactivation of many copper(I) complex solutions by contamination with $\mathrm{O}_{2}$ was the main issue in this set-up.

Figure 6.12 Schematic drawing of the applied two-syringe cryo-stopped-flow set-up. See the Experimental Part for technical details.

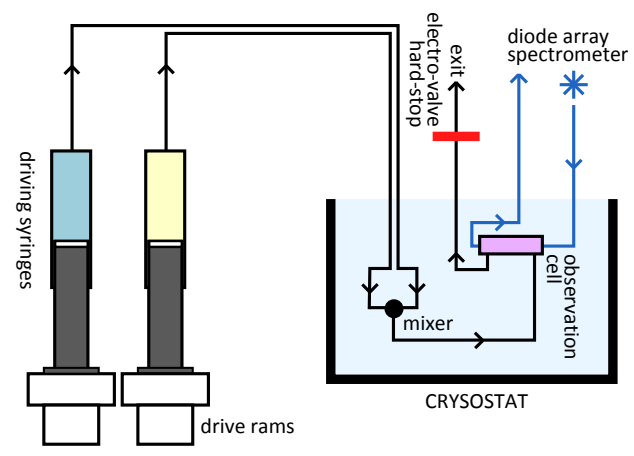

\subsubsection{Determination of Rate Constants}

The stopped-flow apparatus was flushed with argon-saturated THF to ensure the absence of air. Saturated stock solutions of $\mathrm{O}_{2}$ in THF were prepared by bubbling dry $\mathrm{O}_{2}$ gas through dry THF for $\sim 15 \mathrm{~min}$. The solubility of $\mathrm{O}_{2}$ in THF at $25^{\circ} \mathrm{C}$ and $1 \mathrm{~atm}$ is reported to be $10.0 \mathrm{~mm}$ (molar fraction $\chi=8.16 \times 10^{-4}$ ), ${ }^{[237]}$ this value was used in the calculation of the final $\mathrm{O}_{2}$ concentrations in the observation cell. Since the stopped-flow system was closed and the solutions had no contact to the gas phase, no change in concentration was possible. A correction for the solvent's temperature contraction was not applied.

Figure 6.13a exemplary shows the result of a time-resolved full wavelength measurement. A plot of the absorbances of the spectroscopic features at $333 \mathrm{~nm}$ vs. $500 \mathrm{~nm}$ clearly shows that they are correlated (Figure 6.13b)

A detailed analysis of all recorded UV-vis spectra, from stopped-flow and other experiments, showed no accumulation of intermediates, i. e. under all applied 


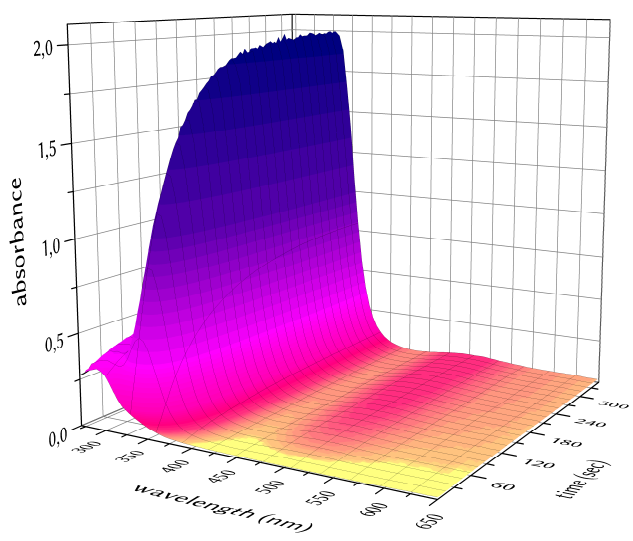

(a)

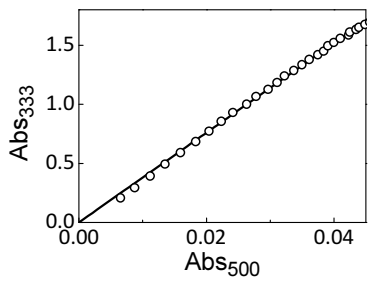

(b)

Figure 6.13. (a) The spectral change observed upon mixing a THF solution of $\mathbf{C u}^{\prime} \mathbf{t} \mathbf{B u}$ with an $\mathrm{O}_{2}$-saturated solution in a cryo-stopped-flow experiment at $-50{ }^{\circ} \mathrm{C} ; 3.6 \mathrm{~s}$ interval. (b) Plot of absorbance maxima ( $\mathrm{Abs}_{333}$ vs. Abs ${ }_{500}$ ) observed during the oxygenation.

conditions, the $\mathrm{Cu}_{2} \mathrm{O}_{2}$ peroxo complex was the only species arising from $\mathbf{C u} \mathbf{u}^{\prime} \mathbf{t} \mathbf{B u}+$ $\mathrm{O}_{2}$ (the same is true for $\mathbf{C} \mathbf{u}^{\prime} \mathbf{P h}, \mathbf{C} \mathbf{u}^{\prime} \mathbf{M e}$ and $\mathbf{C} \mathbf{u}^{\prime} \mathbf{H}$ ). Also, under conditions allowing observing the reaction after very short (»dead «) time of $<10 \mathrm{~ms}$, in a stoppedflow experiment, no intermediate was observed for $\mathbf{C} \mathbf{u}^{\prime} \mathbf{t} \mathbf{B u}$. It must therefore be concluded that the initially formed $\mathrm{Cu}\left(\mathrm{O}_{2}\right)$ complex is instantly trapped by a second $\mathbf{C u} \mathbf{R}$ molecule and that the first step is the rate determining step (Scheme 6.5). This means that the kinetic behaviour is that of case $c$ as it was introduced above (p. 128).

$$
\mathrm{LCu}+\mathrm{O}_{2} \underset{k_{\text {off }}}{\stackrel{k_{\text {on }}}{\rightleftharpoons}} \mathrm{LCu}\left(\mathrm{O}_{2}\right) \underset{\text { fast }}{\stackrel{\mathrm{LCu}}{\longrightarrow}} \mathrm{LCuO}{ }_{2} \mathrm{CuL}
$$

Scheme 6.5 Kinetic processes in $\mathrm{Cu}_{2} \mathrm{O}_{2}$ formation.

$\mathrm{LCu}$ is the copper(I) complex, here $\mathbf{C} \mathbf{u}^{\prime} \mathbf{t} \mathbf{B u} ; \mathrm{LCu}\left(\mathrm{O}_{2}\right)$ is the first copper-dioxygen species formed upon coordination of $\mathrm{O}_{2}$. When an excess of $\mathrm{O}_{2}$ is present in the reaction mixture, the change in the $\mathrm{O}_{2}$ concentration during the reaction is neg- 
ligible and concentration can be considered constant. The hereby established pseudo-first-order conditions lead Scheme 6.5 collapse into Scheme 6.6. ${ }^{[153,238]}$

$$
\mathrm{LCu} \stackrel{k_{\text {on }} \cdot\left[\mathrm{O}_{2}\right]_{0}}{\underset{k_{\text {off }}}{\rightleftharpoons}} \mathrm{LCu}\left(\mathrm{O}_{2}\right)
$$

Scheme 6.6 Kinetic processes under pseudo first-order conditions.

The time-resolved spectra show single-exponential growth and the corresponding logarithmic plot shows a linear relationship (Figure 6.14). The corresponding pseudo-first-order rate constants $k_{\text {obs }}$ were determined from non-linear curve fits. A plot of the rate constants $k_{\text {obs }}$ against the dioxygen concentration $\left[\mathrm{O}_{2}\right]_{0}$ gives a linear line with a relatively large $y$-intercept above $-60^{\circ} \mathrm{C}$. Such a kinetic behaviour is clearly indicative for a reversible $\mathrm{O}_{2}$-binding step and an equilibrium, as depicted in Schemes 6.5 and 6.6, is present. The observed (pseudo) first-order rate constant for Scheme 6.6 is

$$
\begin{aligned}
& -\frac{d[\mathrm{LCu}]}{d t}=k_{\mathrm{obs}} \cdot[\mathrm{LCu}] \\
& k_{\mathrm{obs}}=k_{\mathrm{on}} \cdot\left[\mathrm{O}_{2}\right]_{0}+k_{\mathrm{off}}
\end{aligned}
$$

According to equation 6.2, from the plot of $k_{\text {obs }}$ vs. $\left[\mathrm{O}_{2}\right]_{0}, k_{\text {on }}$ and $k_{\text {off }}$ of the $\mathrm{O}_{2}$ activation (binding) and dissociation steps can be determined from the slope

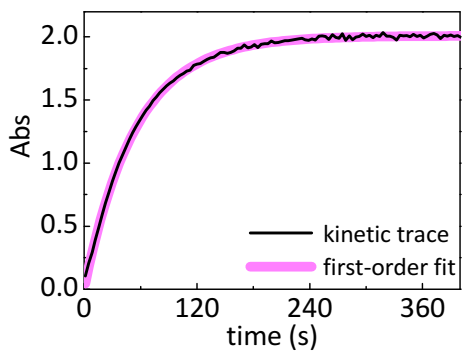

(a)

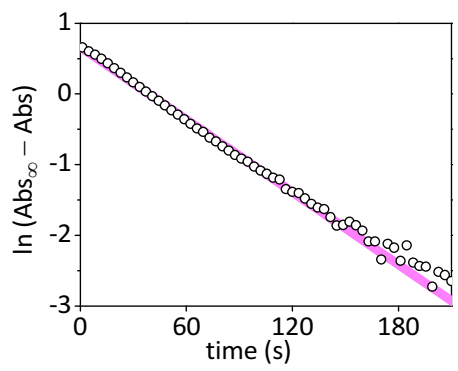

(b)

Figure 6.14. (a) Kinetic time trace of $\mathrm{Abs}_{333}$ and non-linear first-order fit at $-50{ }^{\circ} \mathrm{C}$. (b) First-order plot, $\ln \left(\mathrm{Abs}_{\infty}-\mathrm{Abs}\right)$ vs. $t$, based on the absorbance change at $333 \mathrm{~nm}$, with linear regression; $k_{\mathrm{obs}}=1.4 \times 10^{-2} \mathrm{~s}^{-1}$. 


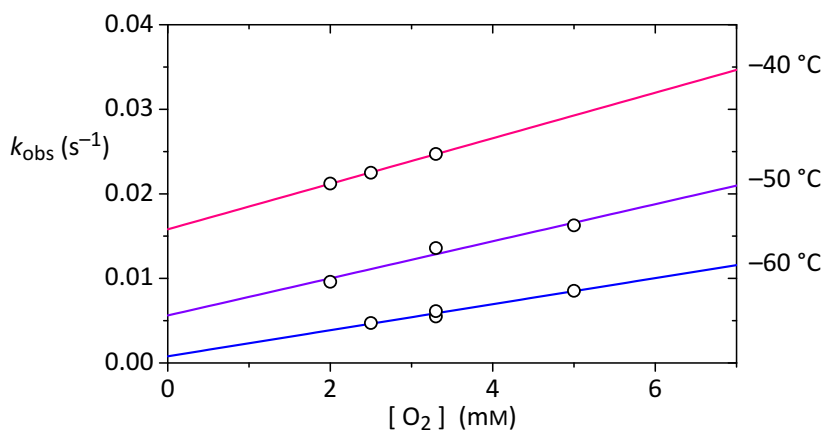

Figure 6.15. Plots of $k_{\mathrm{obs}}$ vs. concentration of dioxygen at $-40(-),-50(-)$ and $-60^{\circ} \mathrm{C}(-)$ with linear regressions.

$\left(k_{\text {on }}\right)$ and the $y$-intercept $\left(k_{\text {off }}\right)$ of a linear regression (Figure 6.15). Below $-60{ }^{\circ} \mathrm{C}$, the intercept is close to zero, this occurs when the equilibrium in Scheme 6.5 is shifted to the right $\left(k_{\mathrm{on}} \cdot\left[\mathrm{O}_{2}\right]_{0} \gg k_{\text {off }}\right)$ and shows that the oxygenated species is predominant in the reaction mixture. However, in experiments at temperatures above $-60{ }^{\circ} \mathrm{C}$, a significant $y$-intercept is evident and indicates that the binding of $\mathrm{O}_{2}$ is reversible. Hence, $k_{\text {off }}$ can be obtained from the experiments in addition to $k_{\text {on. }}$.

Reversibility is confirmed by the separate experiments stated above in Section 6.3.2, demonstrating that $\mathrm{O}_{2}$ is removed by applying vacuum (in acetone) or gentle warming (in THF or acetone), and then the ${ }^{\mathbf{t} \text { Bu }} \mathbf{P}$ complex is reconstituted by repeated exposure to $\mathrm{O}_{2}$.

Additionally, both rate constants of the equilibrium allow the determination of the according equilibrium constants $K_{\mathrm{eq}}$ according to the relation in Equation 6.3.

$$
K_{\text {eq }}=\frac{\left[\mathrm{LCu}\left(\mathrm{O}_{2}\right)\right]}{[\mathrm{LCu}] \cdot\left[\mathrm{O}_{2}\right]}=\frac{k_{\text {on }}}{k_{\text {off }}}
$$

Inspection of the temperature dependence of dioxygen activation shows that the equilibrium (Scheme 6.5) is at room temperature and somewhat lower temperatures mainly on the educt side. Only at low temperatures, the equilibrium is mainly on the side of the copper-dioxygen complex (Table 6.6). The equilibrium constant for $\mathbf{C u}^{\prime} \mathbf{t} \mathbf{B u}$ is rather small, even at $-60^{\circ} \mathrm{C}\left(K_{\mathrm{eq}}=2 \times 10^{3} \mathrm{M}^{-1}\right)$; while the ironcontaining noncooperative dioxygen carrier proteins myoglobin, hemoglobin, hemerythrin and the copper-protein hemocyanin (Hc) have significantly larger 
binding constants at room temperature (e. g. Hc, $5.7 \times 10^{5} \mathrm{M}^{-1}$ ). ${ }^{[235]}$ However, $\mathrm{O}_{2}$ binding by $\mathrm{Hc}$ and other respiratory enzymes is also extremely fast at room temperature (by a factor of $\sim 10^{7}$ faster, compared to $\mathbf{C} \mathbf{u}^{\mathbf{l}} \mathbf{t} \mathbf{B u}$ ), as these enzymes do not suffer from unfavourable activation entropies (see below). ${ }^{\text {[239] }}$

\subsubsection{Activation and Equilibrium Parameters: Mechanistic Considerations}

The kinetic parameters of the $\mathrm{O}_{2}$ activation reaction for both steps, binding and dissociation, were obtained from experiments at $-60,-50$ and $-40{ }^{\circ} \mathrm{C}$ and calculated from the Eyring plots, $\ln \left(k_{\mathrm{on} / \mathrm{off}} \cdot T^{-1}\right)$ vs. $T^{-1}$, in Figures 6.16a and 6.16b. The obtained parameters are summarised in Table 6.5. Refer also to Section 4.5.2 and 4.4 for the physicochemical description of temperature dependence of rate and equilibrium constants and the determination of enthalpies and entropies.

(a)

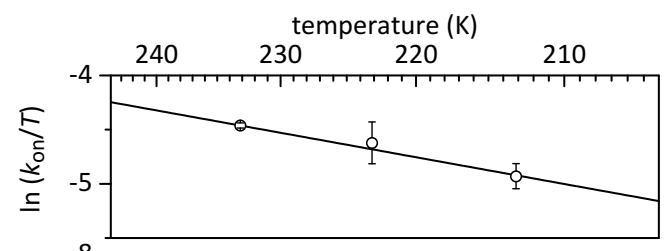

(b)

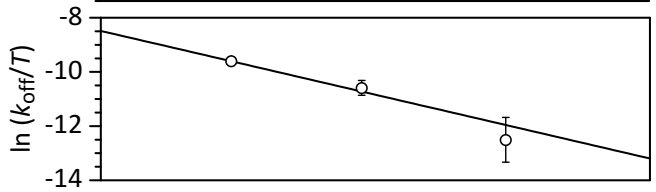

(c)

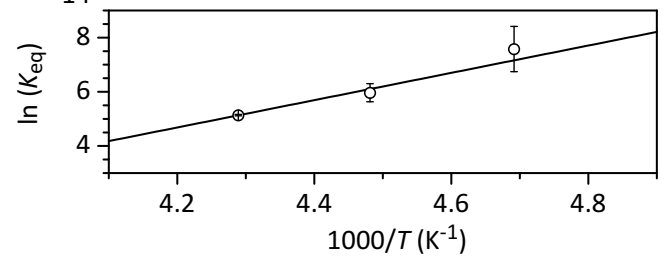

Figure 6.16. Eyring plots, $\ln \left(k \cdot T^{-1}\right)$ vs. $T^{-1}$, of the activation $\left(\mathbf{a}, k_{\mathrm{on}}\right)$ and deactivation (b, $\left.k_{\text {off }}\right)$ steps with weighted linear regressions. (b) Van't Hoff plot, $\ln K_{\text {eq }}$ vs. $T^{-1}$, for the equilibrium $\mathrm{LCu}+\mathrm{O}_{2} \rightleftharpoons \mathrm{LCu}\left(\mathrm{O}_{2}\right)\left(K_{\mathrm{eq}}=k_{\text {on }} / k_{\text {off }}\right)$ with weighted linear regression. See Tables 6.5 and 6.6 for determined kinetic and thermodynamic parameters. 
Table 6.5.

Activation (kinetic) parameters for dioxygen binding and dissociation steps upon low temperature oxygenation of $\mathbf{C} \mathbf{u}^{\mathbf{l}} \mathbf{t} \mathbf{B u}$ in THF. Parameters were calculated from the plots in Figures 6.16a and 6.16b.

\begin{tabular}{|c|c|c|c|c|}
\hline & $T, \mathrm{~K}$ & rate constant & $\begin{array}{c}\Delta H^{\ddagger}, \\
\mathrm{kcal} \mathrm{mol}^{-1}\end{array}$ & $\begin{array}{c}\Delta S^{\ddagger}, \\
\mathrm{cal} \mathrm{K}^{-1} \mathrm{~mol}^{-1}\end{array}$ \\
\hline \multirow{4}{*}{ binding } & & $k_{\mathrm{on}}, \mathrm{M}^{-1} \mathrm{~s}^{-1}$ & \multirow{4}{*}{$2.27 \pm 0.18$} & \multirow{4}{*}{$-46.3 \pm 0.8$} \\
\hline & 233 & $2.69 \pm 0.06$ & & \\
\hline & 223 & $2.19 \pm 0.42$ & & \\
\hline & 213 & $1.54 \pm 0.18$ & & \\
\hline \multirow{4}{*}{ dissociation } & & $k_{\text {off }}, 10^{-2} \mathrm{~s}^{-1}$ & \multirow{4}{*}{$11.7 \pm 1.9$} & \multirow{4}{*}{$-16.1 \pm 8.2$} \\
\hline & 233 & $1.58 \pm 0.02$ & & \\
\hline & 223 & $0.56 \pm 0.15$ & & \\
\hline & 213 & $0.079 \pm 0.065$ & & \\
\hline
\end{tabular}

Thermodynamic Parameters: The associated thermodynamic parameters (Table 6.6) were obtained from the van't Hoff plot, $\ln K_{\text {eq }}$ vs. $T^{-1}$, in Figure 6.16c. The small molecular $\mathbf{C} \mathbf{u}^{\prime} \mathbf{t} \mathbf{B u}$ system features a reaction enthalpy of $\Delta H^{\ominus}=(-10.0 \pm 1.7) \mathrm{kcal} \mathrm{mol}^{-1}$ and an unfavourable reaction entropy of $\Delta S^{\ominus}=(-32.7 \pm 7.4) \mathrm{cal} \mathrm{K}^{-1} \mathrm{~mol}^{-1}$ (Table 6.6). The thermodynamics determined for the $1: 1$ adduct formation are quite similar in comparison to most of the investigated copper(I) complexes $\left(\Delta H^{\ominus} \approx-7\right.$ to $-10 \mathrm{kcal} \mathrm{mol}^{-1}, \Delta S^{\ominus} \approx-26$ to $\left.-33 \mathrm{cal} \mathrm{K}^{-1} \mathrm{~mol}^{-1}\right) \cdot{ }^{[60]}$ In comparison, $\mathbf{C u}^{\mathbf{1}} \mathbf{t} \mathbf{B u}$ is at the lower edge of those ranges for both parameters. Parameters of $\mathrm{O}_{2}$ activation are also remarkably similar between respiratory proteins, regardless of the constitution of the active site. ${ }^{\text {[239] }}$ The large negative $\Delta H^{\ominus}$ suggests a strong dioxygen binding in $\mathbf{C} \mathbf{u}^{\mathbf{l}} \mathbf{t} \mathbf{B u}$, which parallels hemocyanin and other natural dioxygen carriers. In contrast to enzymes, the unfavourable $\Delta S^{\ominus}$ hampers the observation of the copper-oxygen adducts at room temperature in the case of low-molecular-weight model systems. ${ }^{[232]}$

Kinetic Parameters: Reported activation enthalpies for oxygenation of copper(I) complexes ( $k_{\text {on }}$ process) are in the quite narrow range of $\Delta H_{\mathrm{on}}^{\ddagger} \approx 5$ to $10 \mathrm{kcal} \mathrm{mol}^{-1}$. Unfavourable activation entropies are generally observed in the range $\Delta S_{\mathrm{on}}^{\ddagger} \approx-14$ to $2 \mathrm{cal} \mathrm{K}^{-1} \mathrm{~mol}^{-1}$, consistent with an associative mechanism, i. e. loss of degrees of freedom upon binding of $\mathrm{O}_{2}$. 
Table 6.6.

Equilibrium (thermodynamic) data for dioxygen binding and dissociation upon low temperature oxygenation of $\mathbf{C u}^{\mathbf{l}} \mathbf{t} \mathbf{B u}$ in THF. Parameters were calculated from the plot in Figure 6.16c.

\begin{tabular}{|c|c|c|c|c|}
\hline compound & $T, \mathrm{~K}$ & $K_{\mathrm{eq}},{ }^{a} \mathrm{M}^{-1}$ & $\begin{array}{c}\Delta H^{\ominus} \\
\mathrm{kcal} \mathrm{mol}^{-1}\end{array}$ & $\begin{array}{c}\Delta S^{\ominus} \\
\mathrm{cal} \mathrm{K}^{-1} \mathrm{~mol}^{-1}\end{array}$ \\
\hline \multirow[t]{3}{*}{${ }_{t \mathrm{Bu}} \mathbf{P}^{b}$} & 233 & $1.70 \pm 0.04 \times 10^{2}$ & \multirow[t]{5}{*}{$-10.0 \pm 1.7$} & \multirow[t]{3}{*}{$-32.7 \pm 7.4$} \\
\hline & 223 & $3.9 \pm 1.3 \times 10^{2}$ & & \\
\hline & 213 & $2.0 \pm 1.6 \times 10^{3}$ & & \\
\hline arthropod $\mathrm{Hc}^{c}$ & $293-298$ & $5.7 \times 10^{5}$ & & \\
\hline molluscan $\mathrm{Hc}^{d}$ & $293-298$ & $3.8 \times 10^{5}$ & & \\
\hline
\end{tabular}

In comparison to reported systems, for $\mathbf{C u}^{\prime} \mathbf{t} \mathbf{B u}$, a quite small activation enthalpy was found, $\Delta H_{\mathrm{on}}^{\ddagger}=(2.27 \pm 0.18) \mathrm{kcal} \mathrm{mol}^{-1}$. This is an indication that vacant coordination sites are present in $\mathbf{C} \mathbf{u}^{\prime} \mathbf{t} \mathbf{B u}$ and a direct attack of $\mathrm{O}_{2}$ takes place, with no interference from solvent (barrier-free/direct oxygenation); ${ }^{[60,240,241]}$ such a very low barrier is typical of a diffusion controlled process $(1-4 \mathrm{kcal}) .{ }^{[242,243]}$ The comparatively small enthalpy might be explained by the fact that $\mathbf{C u}^{\prime} \mathbf{t} \mathbf{B u}$ is only twofold-coordinated by the BOX ligand, while most reported systems, for which kinetic parameters were determined for the $1: 1$ adduct formation, consist of tridentate capping ligands.

An associative mechanism is further reflected in the strongly negative activation entropy of $\Delta S_{\text {on }}^{\ddagger}=(-46.3 \pm 0.8) \mathrm{cal} \mathrm{K}^{-1} \mathrm{~mol}^{-1}$. Because of this substantial and negative $\Delta S_{\mathrm{on}}^{\ddagger}$, the rate constants are entropically controlled and the rate of $\mathrm{O}_{2}$ binding to $\mathbf{C u}^{\mathbf{1}} \mathbf{t} \mathbf{B u}\left(k_{\text {obs }}=0.2 \mathrm{~min}^{-1}\right.$, in THF at $\left.-78^{\circ} \mathrm{C}\right)$ is that slow compared to other systems. ${ }^{[60]}$ This unfavourable activation entropy can additionally be blamed for the high thermolability of this system. A reason for this strong negative entropy might be the bidentate ligand and the vacant coordination site, namely coordinative unsaturation of the copper(I) complex: no solvent dissociation is needed to take place upon initial attack of $\mathrm{O}_{2}$. The release of coordinated solvent might in fact entropically compensate the association of $\mathrm{O}_{2}$ to some extent in the other systems reported previously. However, steric bulk around the copper ion, arising from the dimethyl groups on the oxazoline rings, might also play a role in the present case (cf. van-der-Waals plots of $\mathbf{C u}^{\prime} \mathbf{t} \mathbf{B u}$ in Figure 6.1, p. 115). The 
ligand's steric demand was also suggested being the reason for particularly unfavourable activation entropies for $\mathrm{O}_{2}$ binding in other copper complexes, ${ }^{[232,244]}$ as well as to $\mathrm{Fe}^{\mathrm{II}}$ (tris(pyridylmethyl)amine $)^{[239]}$ and $\mathrm{Co}^{\mathrm{II}}\left(\right.$ cyclidene) ${ }^{[242]}$ systems. This correlation is furthermore reflected by an increase of $k_{\text {obs }}$ in the four $\mathbf{C u}^{\prime} \mathbf{R}$ complexes in the order $\mathrm{R} \equiv t \mathrm{Bu}<\mathrm{Ph}<\mathrm{Me}<\mathrm{H}$. The direct attack of $\mathrm{O}_{2}$ onto a free coordination site presumably leaves the $\mathrm{MeCN}$ bound to $\mathrm{Cu}$ in the $\mathrm{CuO}_{2}$ intermediate adduct, as three-fold coordination would be uncommon for $\mathrm{Cu}^{\mathrm{II}}$.

Inspection of the back reaction ( $k_{\text {off }}$ process) reveals as well a large negative entropy, here $\Delta S_{\text {off }}^{\ddagger}=(-16.1 \pm 8.2) \mathrm{cal} \mathrm{K}^{-1} \mathrm{~mol}^{-1}$, indicating that the back reaction also follows an associative mechanism. Here, association of solvent molecules ( $\mathrm{MeCN}$ or THF) to the $\mathrm{CuO}_{2}$ complex is likely to be rate-limiting, rather than $\mathrm{O}_{2}$-dissociation. A similar kinetic behaviour was observed for, e. g. the formation of a copper(II)-superoxo $(1: 1)$ complex. ${ }^{[245]}$ Finally, the activation enthalpy $\Delta H_{\text {off }}^{\ddagger}=(11.7 \pm 1.9) \mathrm{kcal} \mathrm{mol}^{-1}$ reflects a significant reaction barrier for this solvent association step, which is in a strong contrast to the $k_{\text {on }}$ process.

While a steric influence on the kinetics of $1: 1 \mathrm{CuO}_{2}$ adduct formation is evident (slow reaction and negative entropy), interligand steric clashes might not play a role, as formation of the terminal $2: 1 \mathrm{Cu}_{2} \mathrm{O}_{2}$ adduct is not prevented and proceeds fast. The following can be summed up from the aforementioned results:

1. Only the $2: 1 \mathrm{Cu}_{2} \mathrm{O}_{2}$ product is spectroscopically observable.

2. Only the process of $1: 1 \mathrm{CuO}_{2}$ adduct formation is kinetically observable.

3. This first reaction step, the formation of $\mathrm{Cu}\left(\mathrm{O}_{2}\right)$, is slow and rate determining.

4. The activation parameters suggest an associative mechanism and a strong $\mathrm{Cu}-\mathrm{O}_{2}$ binding in analogy to related systems.

5. Vacant coordination sites for $\mathrm{O}_{2}$ attack are the reason for a barrier-free oxygenation (small $\Delta H_{\mathrm{on}}^{\ddagger}$ ) in a diffusion-controlled fashion.

6. The overall oxygen activation reaction is quite slow, due to entropically controlled rate constants (large negative $\Delta S_{\text {on }}^{\ddagger}$ ).

7. High steric hindrance might be the reason for the large negative magnitude of $\Delta S_{\mathrm{on}}^{\ddagger}$.

8. The $\mathrm{O}_{2}$ dissociation step follows an associative mechanism as well, which is likely due to the coordination of solvent. 


\subsection{Isolation of Solid $\mathrm{Cu}_{2} \mathrm{O}_{2}$ Peroxo Compounds}

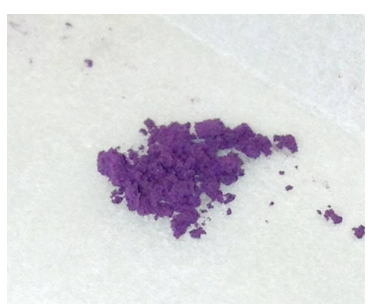

Figure 6.17. Photograph of a powder sample of ${ }^{\boldsymbol{t} \mathbf{B u}} \mathbf{P}$.

The limited solubility of the ${ }^{\mathbf{R}} \mathbf{P}$ complexes allowed their isolation in good yields in the form of violet to pink powders (Figure 6.17). In a general procedure, to a concentrated solution of $\mathbf{C} \mathbf{u}^{\prime} \mathbf{R}$ in dry, deaerated THF (e.g. $5.0 \mathrm{~mm}$ ) was added 1 eq. $\left[\mathrm{Cu}(\mathrm{MeCN})_{4}\right] \mathrm{PF}_{6}$. The solution was cooled to $-78^{\circ} \mathrm{C}$ and a second flask, filled with $\mathrm{O}_{2}$ gas, was connected to this vessel via a short glass adapter. This set-up was transferred to a freezer and stored at $-82^{\circ} \mathrm{C}$ for several hours. Upon diffusion of $\mathrm{O}_{2}$ into the respective $\mathbf{C} \mathbf{u}^{\prime} \mathbf{R}$ solution, the ${ }^{\mathbf{R}} \mathbf{P}$ complex precipitated in the form of a violet powder. The supernatant was carefully removed via a stainless steel needle and the precipitate washed with small amounts of $\operatorname{dry} \mathrm{Et}_{2} \mathrm{O}$. The complexes were obtained after careful drying in vacuum (see the Experimental Part for details).

Elemental analysis indicates excellent to satisfactory purity for ${ }^{\boldsymbol{t}}{ }^{\mathbf{B u}} \mathbf{P}$ and ${ }^{\mathrm{H}_{\mathbf{P}}} \mathbf{P}$ and confirms the formulations as $\left[\left\{\left(\mathrm{H}\left\{{ }^{\mathrm{R}} \mathrm{BOX}\right\}\right)(\mathrm{THF}) \mathrm{Cu}\right\}_{2}\left(\mathrm{O}_{2}\right)\right]\left(\mathrm{PF}_{6}\right)_{2}$, which includes one coordinated THF molecule per copper ion. For ${ }^{\mathbf{e}} \mathbf{P}$, partial decomposition was obvious from a slightly greyish colour tint; the analysis showed a comparatively low $\mathrm{CHN}$ content, in agreement with loss of coordinated solvent (a partial decomposition is additionally indicated by the applied methods described below). ${ }^{\mathbf{P h}} \mathbf{P}$ could not be obtained by this procedure as complete decomposition took place (see Section 6.7 for an EXAFS analysis).

Though bidentate ligands suffice in stabilising $\mathrm{Cu}_{2} \mathrm{O}_{2}$ species, it should be noted that an additional labile ligand (solvent or counteranion) is generally associated with each metal ion; in case of more common tridentate capping ligands, one of the donors is usually weakly bound. ${ }^{[34,108]}$ This parallels the coordination of copper in the role model metalloproteins (as described in the introduction). The coordination of THF presumably induces precipitation of the present complexes. However, the differences in coordinating ability towards transition metals between MeCN (ability index $\left.{ }^{[220]} a^{\mathrm{TM}}=-0.2\right)$ and THF $(-0.3)$ are not significant. While in solution, ${ }^{\mathbf{R}} \mathbf{P}$ are stable only at very low temperatures (also reflected by the strongly negative $\Delta S^{\ominus}$ ), and considering the thermolability of $\mathrm{Cu} / \mathrm{O}_{2}$ complexes in general, ${ }^{\boldsymbol{t}}{ }^{\mathrm{Bu}} \mathbf{P}$ and ${ }^{\mathbf{H}} \mathbf{P}$ are remarkably insensitive in solid state. Handling in air 
at room temperature for short times is unproblematic, yet storage for prolonged periods is only possible at low temperatures $\left(\sim-80^{\circ} \mathrm{C}\right)$.

\subsubsection{Solid-State UV-vis}

The diffuse reflectance UV-vis spectra of the solid samples of ${ }^{\boldsymbol{t}}{ }^{\mathbf{B}} \mathbf{P}$ and ${ }^{\mathbf{H}} \mathbf{P}$ in $\mathrm{KBr}$ powder were recorded at room temperature using a Praying Mantis ${ }^{\mathrm{TM}}$ diffuse reflection accessory (Figure 6.18, solid lines). The relative intensities of the absorption bands are altered, due to light scattering by the powders. Two intense bands at $\sim 330 \mathrm{~nm}$ and $\sim 515 \mathrm{~nm}$ are exhibited in the spectra, identical to those of the solutions. This indicates, that the ${ }^{\mathrm{S}} \mathbf{P}$ structures are present in both, solution and powder, and it can be presumed that the spectra are not a result of a mixture of chromophores. Spectral properties are compared in Table 6.2, p. 122.

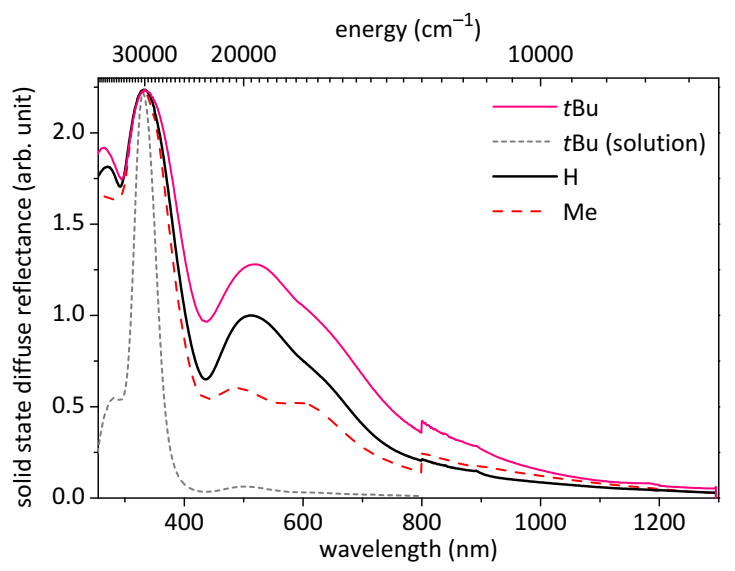

Figure 6.18. Solid state UV-vis-NIR spectra (diffuse reflectance) of ${ }^{\mathbf{t}{ }^{\mathrm{Bu}} \mathbf{P}(-) \text { and }}{ }^{\mathrm{H}} \mathbf{P}(-)$ in $\mathrm{KBr}$ powder at room temperature. The ${ }^{\mathbf{M}} \mathbf{P}$ sample shows some extent of degradation (----). Spectra are relatively scaled at $330 \mathrm{~nm}$; an artefact is present at the detector/grating change point of $800 \mathrm{~nm}$. For comparison the spectrum of ${ }^{\mathbf{t B u}} \mathbf{P}$ in THF solution $\left(-78^{\circ} \mathrm{C}\right)$ is depicted $(\cdots \cdots \cdots,<800 \mathrm{~nm}) .{ }^{t \mathbf{B u}} \mathbf{P}: \lambda_{\max }=263,334,520, \sim 620 \mathrm{sh} \mathrm{nm;}{ }^{{ }^{H}} \mathbf{P}: \lambda_{\max }=271,332$,

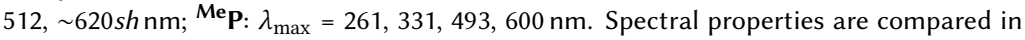
Table 6.2, p. 122. 
In the case of ${ }^{\mathbf{M e}} \mathbf{P}$ (Figure 6.18, red dashed line), where partial decomposition was assumed, the $330 \mathrm{~nm}$ feature is in good accordance with the solution spectrum and the other solid samples. However, a $493 \mathrm{~nm}$ peak is at slightly higher energy and lower intensity, compared to the $\sim 515 \mathrm{~nm}$ peaks. Furthermore, an additional feature of similar intensity is present at $600 \mathrm{~nm}$; this feature is only visible as a shoulder in the spectra of ${ }^{\mathbf{H}} \mathbf{u}_{\mathbf{P}}$ and ${ }^{\mathbf{H}} \mathbf{P}$.

For previously reported $\mu-\eta^{2}: \eta^{2}$-peroxo $\mathrm{Cu}_{2} \mathrm{O}_{2}$ complexes, where it was possible to isolate a solid sample and to record reflectance spectra, the spectra showed also good agreement with the respective solution data. ${ }^{[16,229,246]}$

\subsection{Resonance Raman Spectroscopy}

Besides the archetypical optical spectroscopic properties, inherent to the different copper-dioxygen species (see preceding sections) and besides structural data (see following section), a direct spectroscopic evidence of reduced $\mathrm{O}_{2}$ can be obtained through vibrational spectroscopy. Resonance Raman ( $r R$ ) spectroscopy is particularly advantageous over IR spectroscopy for copper-dioxygen systems, since O-O, $\mathrm{Cu}-\mathrm{O}$ and $\mathrm{Cu} \cdots \mathrm{Cu}$ vibrational modes can be selectively enhanced and symmetric vibrational modes may be detected. Furthermore, the shift of a vibrational feature upon ${ }^{18} \mathrm{O}_{2}$ isotopic substitution allows unambiguous assignment of the bands and is strong proof of the $\mathrm{O}_{2}$ reduction level present.

In $\mu-\eta^{2}: \eta^{2}$-peroxo $\mathrm{Cu}_{2} \mathrm{O}_{2}$ complexes, the $\mathrm{O}-\mathrm{O}$ bond is significantly weakened compared to $\mathrm{H}_{2} \mathrm{O}_{2}\left(\tilde{v}(\mathrm{O}-\mathrm{O})=880 \mathrm{~cm}^{-1}\right)$ due to back-bonding. See Section 2.1.2, 16 , in the introduction. Known systems have characteristic Resonance Raman (rR) frequencies and isotope shifts of the intraperoxide stretch, $\tilde{v}(\mathrm{O}-\mathrm{O})=730-$ $760 \mathrm{~cm}^{-1}\left(\Delta\left[{ }^{18} \mathrm{O}\right] \approx 40 \mathrm{~cm}^{-1}\right)$. See Figure 6.19 for a representation of the dia-
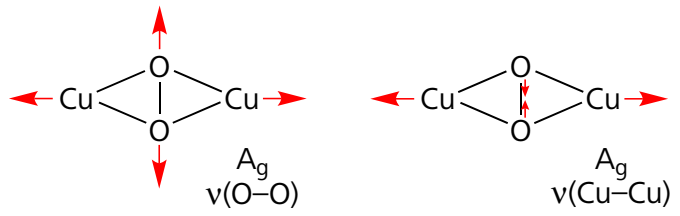

Figure 6.19. The two diagnostic in-plane normal vibrational modes of a $\mu-\eta^{2}: \eta^{2}$ peroxodicopper(II) ${ }^{\mathbf{S}} \mathbf{P}$ system. Atom motions are represented by red arrows. Additional modes have previously been identified and were sometimes observed in other compounds. ${ }^{[229]}$ 
gnostic vibrational modes. In contrast, 1,2-trans-peroxodicopper(II) systems have $\tilde{v}(\mathrm{O}-\mathrm{O}) \approx 830 \mathrm{~cm}^{-1}\left(\Delta\left[{ }^{18} \mathrm{O}\right] \approx 46 \mathrm{~cm}^{-1}\right),{ }^{[34]}$ a 1,2 -cis-peroxodicopper(II) system has $\tilde{v}(\mathrm{O}-\mathrm{O})=800 \mathrm{~cm}^{-1}\left(\Delta\left[{ }^{18} \mathrm{O}\right]=45 \mathrm{~cm}^{-1}\right)^{[44]}$ and bis( $\mu$-oxo $) \operatorname{dicopper(III)~sys-~}$ tems, lacking the $\mathrm{O}-\mathrm{O}$ stretch, have however $\tilde{v}(\mathrm{Cu}-\mathrm{O}) \approx 600 \mathrm{~cm}^{-1}\left(\Delta\left[{ }^{18} \mathrm{O}\right] \approx\right.$ $\left.28 \mathrm{~cm}^{-1}\right)$. ${ }^{[34]}$

An intense isotopically insensitive feature at $\sim 280 \mathrm{~cm}^{-1}$ is additionally diagnostic for the side-on peroxo complex and has been assigned as the fundamental symmetric $\mathrm{Cu}_{2} \mathrm{O}_{2}$ core vibration, $v(\mathrm{Cu} \cdots \mathrm{Cu})$, see Figure 6.19 . It has been calculated that the $v(\mathrm{O}-\mathrm{O})$ stretch at $\sim 740 \mathrm{~cm}^{-1}$ is composed of $>90 \% \mathrm{O}-\mathrm{O}$ motion, while the $v(\mathrm{Cu} \cdots \mathrm{Cu})$ vibration at $\sim 280 \mathrm{~cm}^{-1}$ is mostly $(90 \%)$ copper motion. A very small ${ }^{18} \mathrm{O}$ isotopic shift of $0.2 \mathrm{~cm}^{-1}$ was calculated for this vibration as a result of predominant $\mathrm{Cu} \cdots \mathrm{Cu}$ motion. ${ }^{[229,247]}$

tBuP: $\quad$ rR spectroscopy $\left(\lambda_{\text {ex }}=632.8 \mathrm{~nm}\right)$ of a THF solution of ${ }^{\boldsymbol{t} \mathbf{B} u} \mathbf{P}$ was conducted with the help of a special cryo measuring cell at $213 \mathrm{~K}$. The cooled copper(I) complex $\mathbf{C} \mathbf{u}^{\prime} \boldsymbol{t} \mathbf{B u}$ was oxygenated inside the cryostat's sample stage by the injection of $\mathrm{O}_{2}$ gas. The sample showed a Raman shift of $729 \mathrm{~cm}^{-1}$ (Figure 6.20), typical for the weak $v(\mathrm{O}-\mathrm{O})$ stretch of the $\mu-\eta^{2}: \eta^{2}$-bound peroxide. The intense feature at $278 \mathrm{~cm}^{-1}$ is the $\mathrm{Cu}_{2} \mathrm{O}_{2}$ core vibration, $v(\mathrm{Cu} \cdots \mathrm{Cu})$.

Due to problematic solubility, thermal lability and the technically demanding set-up, further experiments were conducted with solid samples. rR spectra of the solid ${ }^{\boldsymbol{t} B \mathbf{P}} \mathbf{P}$ are depicted in Figure 6.21a (blue area), the spectrum shows the presence of $\mu-\eta^{2}: \eta^{2}$-coordinated peroxide with $\tilde{v}(\mathrm{O}-\mathrm{O})=731 \mathrm{~cm}^{-1}$ and $\tilde{v}(\mathrm{Cu} \cdots \mathrm{Cu})$

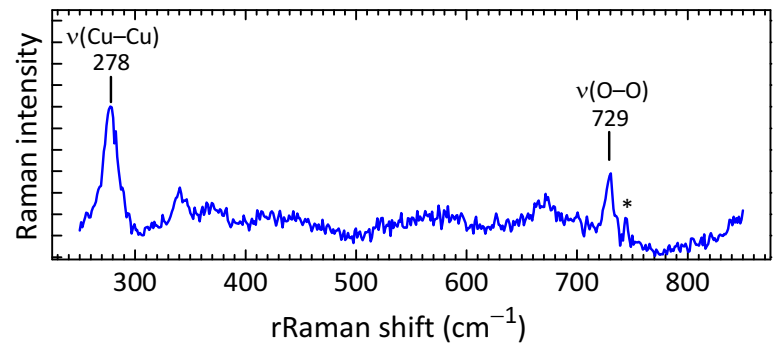

Figure 6.20. Resonance Raman spectrum of peroxo complex ${ }^{\boldsymbol{t}{ }^{\mathrm{Bu}} \mathbf{P}}$ with $632.8 \mathrm{~nm}$ laser excitation. Solution spectrum; $\tilde{v}\left({ }^{16} \mathrm{O}-{ }^{16} \mathrm{O}\right)=729 \mathrm{~cm}^{-1}, \tilde{v}(\mathrm{Cu} \cdots \mathrm{Cu})=278 \mathrm{~cm}^{-1}$; THF at $213 \mathrm{~K}$; no $\mathrm{rR}$ in solution with ${ }^{18} \mathrm{O}$ isotopic substitution is provided due to problematic solubility. The asterisk at $745 \mathrm{~cm}^{-1}$ indicates $\mathrm{PF}_{6}^{-}$. 
6. Biomimetic Activation of $\mathrm{O}_{2}$ by Copper(I) Complexes of BOXs

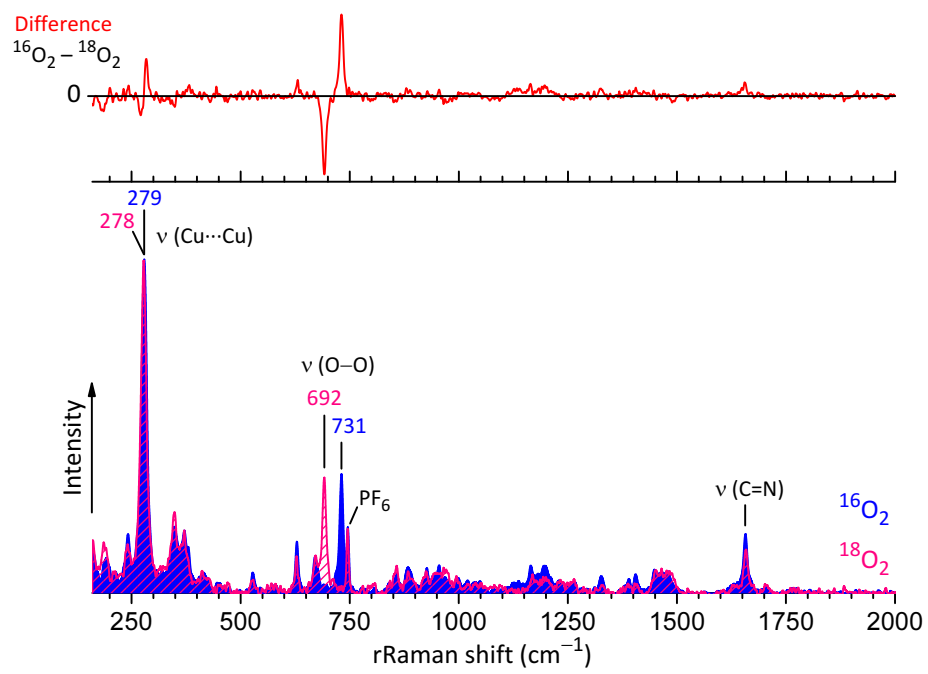

(a) $\mathrm{rR}$ spectra of ${ }^{\boldsymbol{t} \mathrm{Bu}} \mathrm{P}$. $\tilde{v}(\mathrm{O}-\mathrm{O})=731 \mathrm{~cm}^{-1}\left(\Delta\left[{ }^{18} \mathrm{O}\right]=39 \mathrm{~cm}^{-1}\right), \tilde{v}(\mathrm{Cu}-\mathrm{Cu})=$ $278 \mathrm{~cm}^{-1}\left(\Delta\left[{ }^{18} \mathrm{O}\right]=1 \mathrm{~cm}^{-1}\right)$.

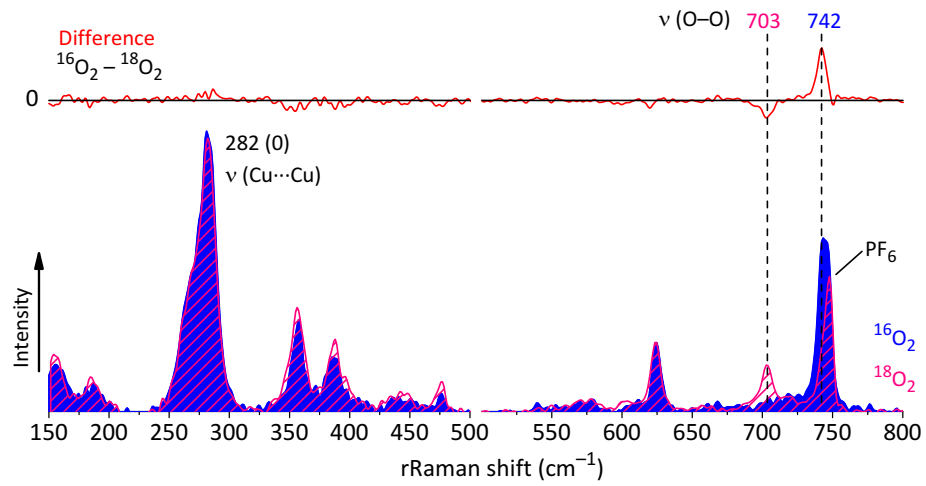

(b) rR spectra of ${ }^{\text {H}} \mathbf{P} . \tilde{v}(\mathrm{O}-\mathrm{O})=742 \mathrm{~cm}^{-1}\left(\Delta\left[{ }^{18} \mathrm{O}\right]=39 \mathrm{~cm}^{-1}\right), \tilde{v}(\mathrm{Cu}-\mathrm{Cu})=282 \mathrm{~cm}^{-1}$ $\left(\Delta\left[{ }^{18} \mathrm{O}\right]=0 \mathrm{~cm}^{-1}\right)$.

Figure 6.21. Resonance Raman (rR) spectra of solid samples of peroxo complexes ${ }^{\boldsymbol{t} B u} \mathbf{P}$ and ${ }^{\mathrm{H}} \mathbf{P}$ with $632.8 \mathrm{~nm}$ laser excitation; with ${ }^{16} \mathrm{O}{ }^{16} \mathrm{O}$ (blue) and ${ }^{18} \mathrm{O}{ }^{18} \mathrm{O}$ (magenta) isotopic composition. ${ }^{16} \mathrm{O}$ minus ${ }^{18} \mathrm{O}$ difference spectra $(-)$. No ${ }^{16} \mathrm{O} /{ }^{18} \mathrm{O}$ isotope scrambling is detected. 
$=278 \mathrm{~cm}^{-1}$, essentially unchanged compared to the solution features. Isotopic substitution with ${ }^{18} \mathrm{O}_{2}$ shifts the peroxo stretch to $692 \mathrm{~cm}^{-1}\left(\Delta\left[{ }^{18} \mathrm{O}\right]=39 \mathrm{~cm}^{-1}\right)$ as expected (Figure 6.21a, pink area). The $\mathrm{Cu} \cdots \mathrm{Cu}$ stretch is, just as expected, only slightly affected by the ${ }^{18} \mathrm{O}_{2}$ isotopic substitution $\left(\Delta\left[{ }^{18} \mathrm{O}\right] \approx 1 \mathrm{~cm}^{-1}\right)$. The ${ }^{16} \mathrm{O}-{ }^{16} \mathrm{O}$ vibration is slightly obscured by the $745 \mathrm{~cm}^{-1} \mathrm{PF}_{6}^{-}$stretch, the ${ }^{16} \mathrm{O}$ minus ${ }^{18} \mathrm{O}$ difference spectrum (Figure 6.21a, red solid line) however clarifies the assignments.

Furthermore, $\mathrm{rR}$ and IR spectroscopies confirm the absence of $\mathrm{MeCN}$ and the presence of $\mathrm{PF}_{6}^{-}$counter ions in the solid material (Figure 6.22) in addition to the elemental analysis. No other peaks which shift upon isotopic substitution were found in the Raman spectra between 150 and $2000 \mathrm{~cm}^{-1}$. The diagnostic Raman vibrations for all investigated samples of $\mu-\eta^{2}: \eta^{2}$-peroxodicopper(II) complexes ${ }^{\mathbf{R}} \mathbf{P}$ are listed in Table 6.7.

${ }^{\mathbf{H}} \mathbf{P}$ : The rR spectrum of ${ }^{\mathbf{H}} \mathbf{P}$ resembles the preceding spectra (Figure 6.21b). The $\mathrm{Cu} \cdots \mathrm{Cu}$ vibration is roughly at equal energy $\left(282 \mathrm{~cm}^{-1}\right)$ and not affected by ${ }^{18} \mathrm{O}_{2}$ isotopic substitution. Compared to ${ }^{\boldsymbol{t} \mathbf{B u}} \mathbf{P}$, the intraperoxo stretch $v(\mathrm{O}-\mathrm{O})$ is at

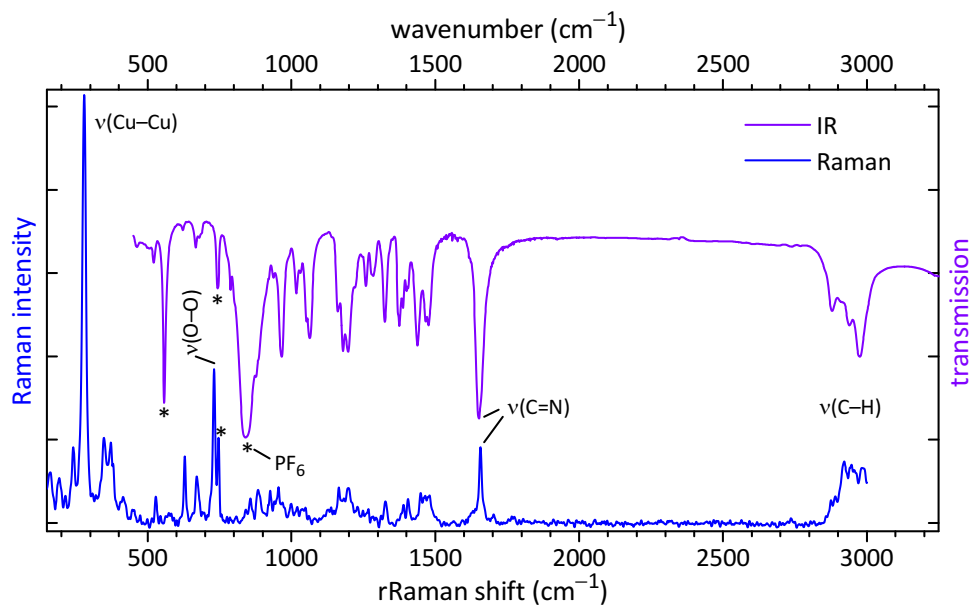

Figure 6.22. Comparison of ${ }^{16} \mathrm{O}_{2}$ labelled infrared (IR, - - ) and $\mathrm{rR}$ spectra $\left(\lambda_{\mathrm{ex}}=632.8 \mathrm{~nm}\right.$, $\longrightarrow$ ) of solid ${ }^{\boldsymbol{t B u}} \mathbf{P}$. Assigned vibration modes are indicated; a $\mathrm{KBr}$ disc was measured in case of IR, while for $\mathrm{rR}$ a neat sample was used; the asterisks indicate vibrations arising from $\mathrm{PF}_{6}^{-}$counterions. 
slightly higher energy $\left(742 \mathrm{~cm}^{-1}\right)$, yet is equally shifted upon isotopic substitution $\left(\Delta\left[{ }^{18} \mathrm{O}\right]=39 \mathrm{~cm}^{-1}\right.$ to $703 \mathrm{~cm}^{-1}$. The ${ }^{16} \mathrm{O}-{ }^{16} \mathrm{O}$ vibration is partially covered by the $745 \mathrm{~cm}^{-1} \mathrm{PF}_{6}^{-}$stretch. With the help of the ${ }^{16} \mathrm{O}$ minus ${ }^{18} \mathrm{O}$ difference spectrum (Figure 6.21b, red solid line) it was however possible to precisely determine the location of the ${ }^{16} \mathrm{O}-{ }^{16} \mathrm{O}$ peak. The $v(\mathrm{O}-\mathrm{O})$ stretch is located higher in energy in ${ }^{\mathbf{H}} \mathbf{P}$ compared to ${ }^{{ }^{\mathbf{B} u}} \mathbf{P}$ indicating a stronger $\mathrm{O}-\mathrm{O}$ bond in ${ }^{\mathrm{H}} \mathbf{P}$. This might suggest that the $\left\{\mathrm{N}_{2} \mathrm{CuO}_{2}\right\}$ moieties are more planar in ${ }^{\mathrm{H}} \mathbf{P}$ than they are in ${ }^{\mathbf{t} u \mathbf{P}} \mathbf{P}$.

Me $\mathbf{P}$ and ${ }^{\mathrm{Ph}} \mathbf{P}$ : A solid sample of ${ }^{\mathbf{M e}} \mathbf{P}$ was also subjected to Raman spectroscopy (Figure 6.23, - ) , verifying the indicated partial degradation by the presence of

Table 6.7.

Raman spectroscopic features of $\mu-\eta^{2}: \eta^{2}$-peroxodicopper(II) complexes ${ }^{\mathbf{R}} \mathbf{P}\left(\lambda_{\text {ex }}=632.8 \mathrm{~nm}\right)$.

\begin{tabular}{llll}
\hline \multirow{2}{*}{ sample } & & \multicolumn{2}{c}{$\tilde{v}, \mathrm{~cm}^{-1}\left(\Delta\left[{ }^{18} \mathrm{O}_{2}\right]\right)$} \\
\cline { 3 - 4 } & & $\mathrm{Cu} \cdots \mathrm{Cu}$ & $\mathrm{O}-\mathrm{O}$ \\
\hline${ }^{\mathbf{B u}} \mathbf{P}$ & solution & 278 & 729 \\
& solid $^{\mathbf{H}_{\mathbf{P}}}$ & $279(1)$ & $731(39)$ \\
${ }^{\mathbf{M e}_{\mathbf{P}}}$ & solid & $282(0)$ & $742(39)$ \\
$\mathbf{P h}_{\mathbf{P}}$ & solid $^{a}$ & 282 & 735 \\
& solid $^{b}$ & n/a & n/a \\
\hline
\end{tabular}

${ }^{a}$ Partly decomposed complex. ${ }^{b}$ Decomposed complex.

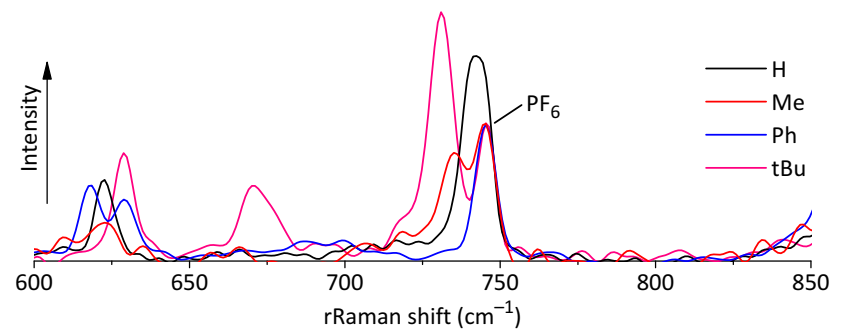

Figure 6.23. Powder rRaman spectra of partially degraded ${ }^{\mathrm{Me}} \mathbf{P}\left(\tilde{v}(\mathrm{O}-\mathrm{O})=735 \mathrm{~cm}^{-1}\right.$, $\left.\tilde{v}(\mathrm{Cu} \cdots \mathrm{Cu})=282 \mathrm{~cm}^{-1}\right)$ and the decomposition product of ${ }^{\mathbf{P h}} \mathbf{P}$, compared to the spectra of ${ }^{t}{ }^{B u} \mathbf{P}$ and ${ }^{{ }^{H}} \mathbf{P}\left(\lambda_{\text {ex }}=632.8 \mathrm{~nm}\right.$, solid samples). Note the absence of the $\mathrm{O}-\mathrm{O}$ stretch in the case of ${ }^{\mathbf{P h}} \mathbf{P}$ and the low intensity in the case of ${ }^{\mathbf{M e}} \mathbf{P}$. 
only a low intensity $v\left(\mathrm{O}-\mathrm{O}\right.$ ) stretch at $735 \mathrm{~cm}^{-1}$ (in accordance with elemental analysis, solid state UV-vis and EXAFS data). The energy of the $\mathrm{O}-\mathrm{O}$ bond interestingly is in between those of the other two peroxo complexes. Overall, the $\mathrm{O}-\mathrm{O}$ bond energy is weaker, the more bulky the residue $\mathrm{R}$ is. This indicates that the bond energy might be directly related to the sterical demand of the residue $\mathrm{R}$.

Due to degradation, ${ }^{\mathbf{P h}} \mathbf{P}$ could not be isolated and in accordance with EXAFS data, no feature which could be attributed to an $\mathrm{O}-\mathrm{O}$ stretch is present in the Raman spectrum (Figure 6.23, - ). This indicates that there is no residue of peroxo complex from the solution present anymore upon isolation of the precipitated complex.

\section{Isotope Effects in Vibrational Spectroscopy}

The frequency of a vibration of a bond can accurately be described by the classical harmonic oscillator model

$$
\tilde{v}=\frac{1}{2 \pi c} \cdot \sqrt{\frac{k}{\mu}}
$$

in which $\tilde{v}$ is the fundamental vibration frequency (here expressed in wavenumbers) with the speed of light $c, k$ is the force constant of the bond and $\mu$ is the reduced mass

$$
\mu=\frac{m_{a} \cdot m_{b}}{\left(m_{a}+m_{b}\right)}
$$

in which $m_{a}$ and $m_{b}$ are the mono-isotopic masses of the two vibrating atoms. Substituting the isotope of an atom changes $\mu$, but does not change the bond strength i. e. the force constant. From equation 6.4 follows, that the ratio between two frequencies $\tilde{v}_{1}$ and $\tilde{v}_{2}$ is

$$
\frac{\tilde{v}_{1}}{\tilde{v}_{2}}=\frac{\sqrt{\frac{k_{1}}{\mu_{1}}}}{\sqrt{\frac{k_{2}}{\mu_{2}}}}=\sqrt{\frac{\mu_{2}}{\mu_{1}}}
$$

With equation 6.6 the wavenumber of the ${ }^{18} \mathrm{O}_{2}$ peroxo stretch can be calculated from the $\tilde{v}$ measured for the ${ }^{16} \mathrm{O}_{2}$ stretch. A factor $\tilde{v}\left({ }^{18} \mathrm{O}_{2}\right) / \tilde{v}\left({ }^{16} \mathrm{O}_{2}\right)=0.9428$ follows from the harmonic oscillator model.

In the case of ${ }^{\boldsymbol{t} \mathbf{B} \mathbf{}_{\mathbf{P}}}$ a isotope shift of the stretch $\tilde{v}\left({ }^{16} \mathrm{O}_{2}\right)=731 \mathrm{~cm}^{-1}$ gives $\tilde{v}\left({ }^{18} \mathrm{O}_{2}\right)=689 \mathrm{~cm}^{-1}$. This theoretical shift of $\Delta\left[{ }^{18} \mathrm{O}_{2}\right]=41.8 \mathrm{~cm}^{-1}$ is in good agreement with the shift of $39 \mathrm{~cm}^{-1}$, experimentally observed. In ${ }^{\mathbf{H}} \mathbf{P}$, similar agreement is observed: experimental $\Delta\left[{ }^{18} \mathrm{O}_{2}\right]=39 \mathrm{~cm}^{-1}$ vs. theoretical $42.4 \mathrm{~cm}^{-1}$. 


\subsection{Structural Investigations: XAS, XANES and EXAFS Analysis}

Metal K-edge X-ray absorption spectroscopy (XAS) is a technique to determine the local geometric and electronic structure around a metal atom. Inspection of the lower energy K-pre-edge and rising-edge regions (XANES, X-ray absorption nearedge spectroscopy) allows the determination of electronic structures (oxidation states). Additional local geometric structure information on complex metal sites can be obtained by the analysis of the higher energy extended X-ray absorption fine structure (EXAFS) region of the spectrum. XAS techniques have also been extensively applied on metalloproteins and biomimetic model complexes in the field of bioinorganic chemistry. ${ }^{[248]}$ Synchrotron radiation sources are usually required to provide an intense and tunable X-ray beam.

$\mathrm{Cu}$ K-edge XAS was performed to directly probe the oxidation state of copper in the four $\mu-\eta^{2}: \eta^{2}$-peroxodicopper(II) complexes ${ }^{\mathbf{R}} \mathbf{P}$, and to rule out the presence of remaining $\mathrm{Cu}^{\mathrm{I}}$ and the presence of $\mathrm{a}\left(\mathrm{Cu}^{\mathrm{III}}\right)_{2} \mathrm{O}_{2}$ isomer. The field of copper-oxygen chemistry struggles with the thermal sensibility and/or high reactivity of the complexes, this is the main reason for the scarcity of structural data obtained by single-crystal X-ray crystallography. ${ }^{[34]}$ Despite ample attempts, high-quality single crystals of the peroxo complexes ${ }^{\mathbf{R}} \mathbf{P}$, to obtain structural information from single-crystal X-ray crystallography, could likewise not be obtained. The main difficulty is the thermal sensitivity of the $\mathrm{Cu}_{2} \mathrm{O}_{2}$ complexes, which makes it necessary to isolate crystalline material below $\sim-60{ }^{\circ} \mathrm{C}$; furthermore, limited solubility of the ligands (in case of $\left.\mathrm{H}_{\{}{ }^{\mathrm{Ph}} \mathrm{BOX}\right\}$ ) and of the peroxo complexes (especially ${ }^{\mathbf{H}_{\mathbf{P}}}$ and ${ }^{\mathbf{M}} \mathbf{P}$ are barely soluble) makes this even more difficult. And either the peroxo complexes decomposed in course of time or could only be obtained in the form of very fine powders. However, it was found that the peroxo complexes ${ }^{\boldsymbol{t}} \mathbf{B u} \mathbf{P}$ and ${ }^{H} \mathbf{P}$ are quite stable when isolated in the powder form (as described above) and they could also be analysed in this condition by XAS. Unfortunately, in case of

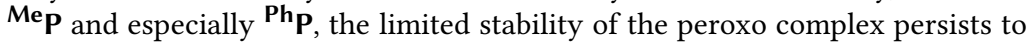
some extent in the solid form, as it was already indicated by Raman and UV-vis measurements of the isolated solid compounds.

XAS measurements were performed together with Prof. Dr. MATTHIAs BAuER (University Paderborn) at the XAS beamline of the ANKA synchrotron (Karlsruhe, Germany) under ambient conditions at $293 \mathrm{~K}$. The solid samples were embedded in a dioxygen free boron nitride or cellulose matrix and carefully pressed into pellets (see the Experimental Part, Section 12.2, for details.). Figure 6.24 shows a pellet of ${ }^{\mathbf{H}} \mathbf{P}$ in cellulose, the intense violet colour of the powder or solution is unchanged. 


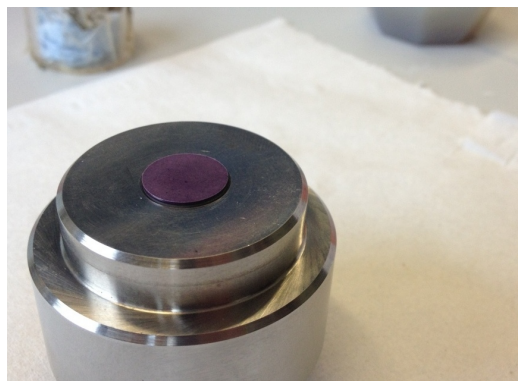

Figure 6.24 Prepared powder sample of ${ }_{\mathbf{H}} \mathbf{f o r}$ an XAS measurement. Pressed pellet with cellulose (residing on the pressing tool).

\subsubsection{XANES}

Changes in the oxidation states of metals shift the energy of pre-edge features of the metal K-edge. It has been shown, that $1 s \rightarrow 3 d$ pre-edge transitions for copper(II) compounds appear at $8979 \pm 0.5 \mathrm{eV}$; these features are notably insensitive to changes of the coordination environment. ${ }^{[249]}$ These peaks are shifted by $\sim 2 \mathrm{eV}$ to higher energies in copper(III) compounds, thus a pre-edge feature at $8981 \pm 0.5 \mathrm{eV}$ is diagnostic for $\mathrm{Cu}^{\mathrm{III}}$. $[48,250]$

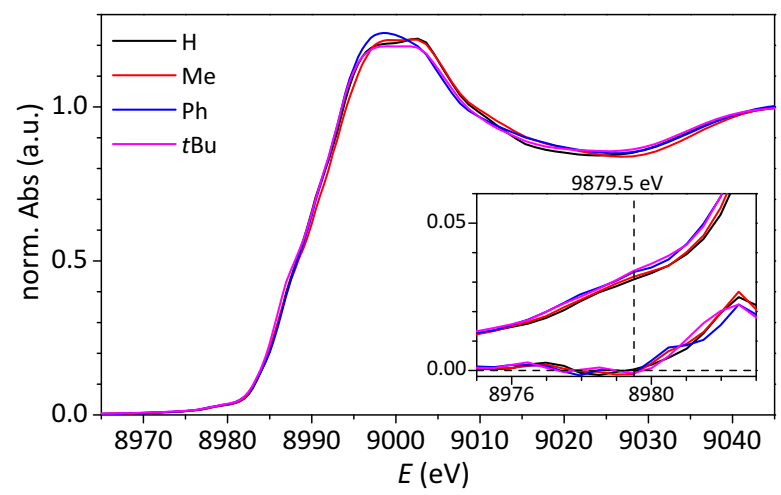

Figure 6.25. Cu K-edge X-ray absorption near edge spectra (XANES) of all four $\mu-\eta^{2}: \eta^{2}$ peroxodicopper(II) complexes ${ }^{\mathbf{R}} \mathbf{P}$ in the powder form at room temperature. Inset: amplified view of $1 s \rightarrow 3 d$ pre-edge transition areas and their second derivatives. Only weak shoulders at $8987 \mathrm{eV}$ in the edge area are visible, which is, together with very weak signals at $8979.5 \mathrm{eV}$ characteristic for a $\mathrm{Cu}^{\text {Il }}$ state in the samples. ${ }^{[249]}$ 
Figure 6.25 shows the XANES (X-ray absorption near edge structure) spectra of all four complexes ${ }^{\mathbf{R}} \mathbf{P}$. Low intensity $1 s \rightarrow 3 d$ pre-edge transitions at $8979.5 \mathrm{eV}$ are found, diagnostic for $\mathrm{Cu}^{\mathrm{II}}$. $\mathrm{A} \sim 2 \mathrm{eV}$ higher energy feature is not present in the samples here. The $1 s \rightarrow 4 p+$ ligand-to-metal (LMT) shake down transitions at $\sim 8987 \mathrm{eV}$ are only present as weak shoulders with no significant peak intensity; this also excludes an oxidation state of $\mathrm{Cu}^{\mathrm{III}}$ that is characterized by a sharp peak on the rising edge. ${ }^{[48]}$ Furthermore, $\mathrm{Cu}^{\mathrm{I}}$ is usually indicated by a diagnostic sharp and intense $1 s \rightarrow 4 p$ transition at $\sim 8984 \mathrm{eV}^{[2,249]}$ with a shape dependent on the coordination environment; this feature is absent in the spectra, too.

Therefore, from the XANES results, a copper(II) state in all ${ }^{\mathbf{R}} \mathbf{P}$ is concluded, in agreement with side-on $\mu-\eta^{2}: \eta^{2}$-peroxodicopper(II) complexes. Nonetheless, subtle differences between the samples can be observed in the white line shape. All samples exhibit a double white line structure, however, the intensity ratio of the two underlying signals differs. Samples of ${ }^{{ }^{H}} \mathbf{P},{ }^{\mathbf{M e}} \mathbf{P}$ and ${ }^{\boldsymbol{t} \text { Bu }} \mathbf{P}$ show similar behaviour, with nearly identical intensity of both white line components. But the white-line width of sample ${ }^{\mathbf{M}} \mathbf{P}$ is reduced compared to ${ }^{\mathbf{H}} \mathbf{P}$ and ${ }^{\boldsymbol{t} \mathbf{B}} \mathbf{P}$. The white line signature of ${ }^{\mathbf{H}} \mathbf{P},{ }^{M} \mathbf{P}$ and ${ }^{\boldsymbol{t} \mathbf{B} u} \mathbf{P}$ was also found for other dinuclear $\mu-\eta^{2}: \eta^{2}$ side on complexes; cf. e. g. references [2, 250, 251]. In contrast, the spectrum of ${ }^{\mathbf{P h}} \mathbf{P}$ is significantly different, as the higher energy contribution to the white line is reduced in intensity compared to the component on the low energy side.

\subsubsection{EXAFS}

The assignment is further supported by the analysis of the EXAFS (Extended X-ray absorption fine structure) spectra. The $k^{3}$-weighted EXAFS spectra and their Fourier transforms (FT) of the respective ${ }^{\mathbf{R}} \mathbf{P}$ complexes are shown in Figures 6.26 and 6.27 and the associated extracted structural/EXAFS fit parameters are given in Table 6.8.

Due to this similarity, samples ${ }^{\mathbf{B}} \mathbf{u}_{\mathbf{P}} \mathbf{\text { and }}{ }^{\mathbf{H}} \mathbf{P}$ are discussed together in following, and samples ${ }^{\mathbf{M}} \mathbf{P}$ and ${ }^{\mathbf{P h}} \mathbf{P}$ thereafter.

\section{tBup and ${ }^{{ }^{H}} \mathbf{P}$}

The first shell at $1.94 \AA$ agrees well with a four-fold coordination in ${ }^{t \mathbf{B u}} \mathbf{P}$, which is an average value of the two oxygen and two nitrogen atoms from the BOX and peroxo ligands $\left(\mathrm{Cu}-(\mathrm{N} / \mathrm{O})_{\mathrm{eq}}\right)$. In ${ }^{\mathbf{H}} \mathbf{P}$, this agreement is poorer. A second light-atom contribution at $2.34 \AA\left({ }^{\mathbf{B} u} \mathbf{P}\right) / 2.32 \AA\left({ }^{\mathbf{H}} \mathbf{P}\right)$, with a coordination number slightly smaller than one, is attributed to weakly coordinating axial $\mathrm{THF}\left(\mathrm{Cu}-\mathrm{O}_{\mathrm{ax}}\right)$, in accordance with elemental analysis data. These distances are in agreement 
6.7. Structural Investigations: XAS, XANES and EXAFS Analysis
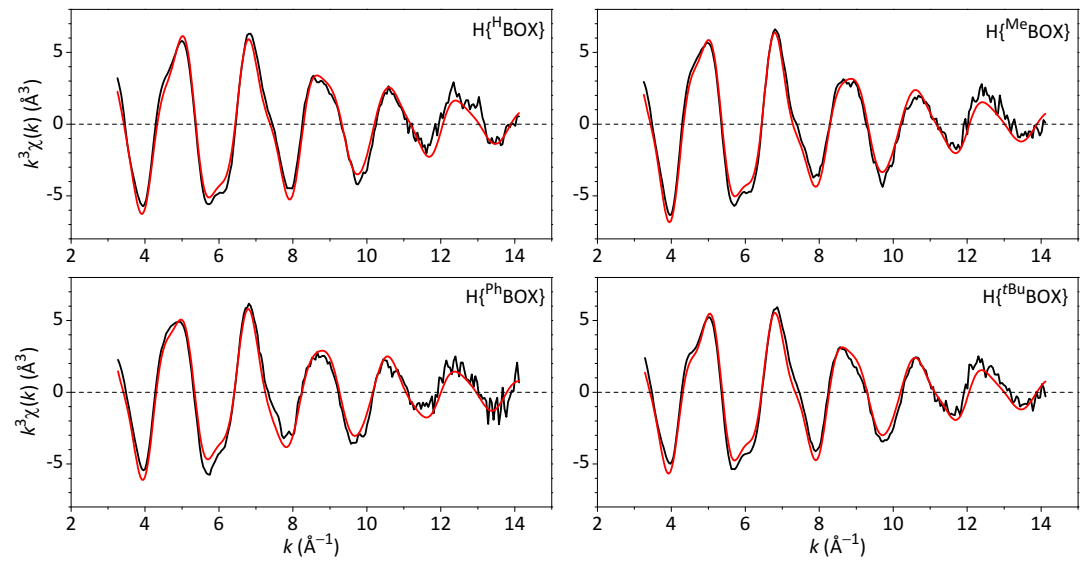

Figure 6.26. EXAFS functions $k^{3} \chi(k)$ vs. $k$, experimental ( - ) and fitted (-) spectra of all four $\mu-\eta^{2}: \eta^{2}$-peroxodicopper(II) complexes ${ }^{\mathbf{R}} \mathbf{P}$ (powder form at room temperature). FT-EXAFS spectra are in Figure 6.27, adjusted parameters in Table 6.8.
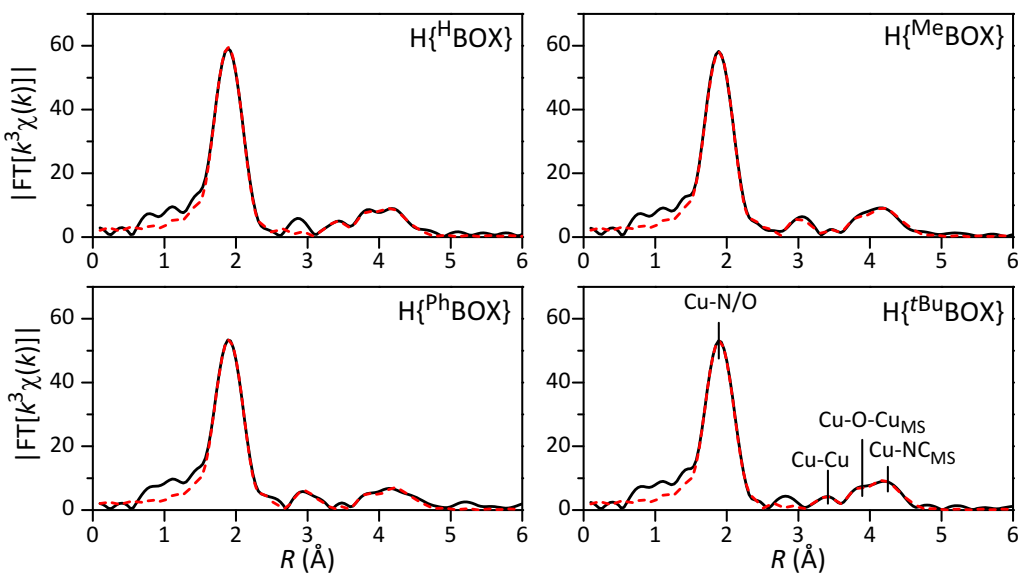

Figure 6.27. Fourier-transformed EXAFS functions, experimental (-) and fitted (----) spectra of all four $\mu-\eta^{2}: \eta^{2}$-peroxodicopper(II) complexes ${ }^{\mathbf{R}} \mathbf{P}$. The adjusted contributions as given in Table 6.8 are indicated; For EXAFS functions $k^{3} \chi(k)$, see Figure 6.26. 
Table 6.8.

Structural parameters obtained by fitting the experimental EXAFS spectra in Figure 6.26 and Figure 6.27 with theoretical models. See the Experimental Part, Section 12.2, for details.

\begin{tabular}{|c|c|c|c|c|c|}
\hline $\mathrm{Abs}-\mathrm{Bs}^{a}$ & $N(\mathrm{Abs})^{b}$ & $R(\mathrm{Abs}-\mathrm{Bs}),{ }^{c} \AA$ & $\sigma,{ }^{d} \AA$ & $R,{ }^{e} \%$ & $E_{\mathrm{f}}, f \mathrm{eV}$ \\
\hline \multicolumn{6}{|c|}{$t \mathrm{tBu}_{\mathrm{P}}$} \\
\hline $\begin{array}{l}\mathrm{Cu}-(\mathrm{N} / \mathrm{O})_{\mathrm{eq}} \\
\mathrm{Cu}-\mathrm{O}_{\mathrm{ax}} \\
\mathrm{Cu}-\mathrm{Cu} \\
\mathrm{Cu}-\mathrm{O}-\mathrm{Cu}(\mathrm{MS}) \\
\mathrm{Cu}-\mathrm{NC}(\mathrm{MS})\end{array}$ & $\begin{array}{l}4.3 \pm 0.4 \\
0.7 \pm 0.1 \\
1.0 \pm 0.3 \\
3.5 \pm 0.7 \\
9.0 \pm 1.8\end{array}$ & $\begin{array}{l}1.94 \pm 0.02 \\
2.34 \pm 0.02 \\
3.51 \pm 0.04 \\
3.72 \pm 0.04 \\
4.28 \pm 0.04\end{array}$ & $\begin{array}{l}0.071 \pm 0.007 \\
0.100 \pm 0.010 \\
0.095 \pm 0.020 \\
0.102 \pm 0.020 \\
0.102 \pm 0.020\end{array}$ & 22.48 & 8.2 \\
\hline \multicolumn{6}{|c|}{${ }^{H_{P}}$} \\
\hline $\begin{array}{l}\mathrm{Cu}-(\mathrm{N} / \mathrm{O})_{\mathrm{eq}} \\
\mathrm{Cu}-\mathrm{O}_{\mathrm{ax}} \\
\mathrm{Cu}-\mathrm{Cu} \\
\mathrm{Cu}-\mathrm{O}-\mathrm{Cu}(\mathrm{MS}) \\
\mathrm{Cu}-\mathrm{NC}(\mathrm{MS})\end{array}$ & $\begin{array}{l}4.8 \pm 0.5 \\
0.5 \pm 0.1 \\
0.9 \pm 0.3 \\
3.9 \pm 0.7 \\
7.8 \pm 1.6\end{array}$ & $\begin{array}{l}1.94 \pm 0.02 \\
2.32 \pm 0.02 \\
3.52 \pm 0.04 \\
3.73 \pm 0.04 \\
4.29 \pm 0.04\end{array}$ & $\begin{array}{l}0.071 \pm 0.007 \\
0.100 \pm 0.010 \\
0.087 \pm 0.020 \\
0.102 \pm 0.020 \\
0.100 \pm 0.020\end{array}$ & 19.71 & 7.4 \\
\hline \multicolumn{6}{|c|}{${ }^{M e} \mathbf{p} g$} \\
\hline $\begin{array}{l}\mathrm{Cu}-(\mathrm{N} / \mathrm{O}) \\
\mathrm{Cu}-\mathrm{Cu} \\
\mathrm{Cu}-\mathrm{Cu} \\
\mathrm{Cu}-\mathrm{O}-\mathrm{Cu}(\mathrm{MS}) \\
\mathrm{Cu}-\mathrm{NC}(\mathrm{MS})\end{array}$ & $\begin{array}{l}5.4 \pm 0.5 \\
0.6 \pm 0.1 \\
0.2 \pm 0.1 \\
1.6 \pm 0.7 \\
9.9 \pm 2.0\end{array}$ & $\begin{array}{l}1.94 \pm 0.02 \\
2.93 \pm 0.03 \\
3.49 \pm 0.04 \\
3.79 \pm 0.04 \\
4.29 \pm 0.04\end{array}$ & $\begin{array}{l}0.074 \pm 0.007 \\
0.100 \pm 0.010 \\
0.032 \pm 0.010 \\
0.084 \pm 0.017 \\
0.107 \pm 0.022\end{array}$ & 20.33 & 7.9 \\
\hline \multicolumn{6}{|c|}{$\mathrm{Ph}_{\mathbf{P}} h$} \\
\hline $\begin{array}{l}\mathrm{Cu}-(\mathrm{N} / \mathrm{O}) \\
\mathrm{Cu}-\mathrm{Cu} \\
\mathrm{Cu}-\mathrm{O}-\mathrm{Cu}(\mathrm{MS}) \\
\mathrm{Cu}-\mathrm{NC}(\mathrm{MS})\end{array}$ & $\begin{array}{l}4.9 \pm 0.5 \\
0.7 \pm 0.2 \\
0.9 \pm 0.2 \\
9.1 \pm 1.6\end{array}$ & $\begin{array}{l}1.95 \pm 0.02 \\
2.91 \pm 0.03 \\
3.78 \pm 0.04 \\
4.29 \pm 0.04\end{array}$ & $\begin{array}{l}0.071 \pm 0.007 \\
0.100 \pm 0.010 \\
0.084 \pm 0.017 \\
0.102 \pm 0.020\end{array}$ & 25.02 & 8.1 \\
\hline
\end{tabular}

$\overline{{ }^{a} \mathrm{Abs} \equiv \mathrm{X} \text {-ray absorbing atom, Bs } \equiv \text { backscattering atom. } \quad{ }^{b} \text { Number of neighbour backscattering }}$ atoms. ${ }^{c}$ Distance between Abs and Bs. ${ }^{d}$ Debye-Waller like factor. ${ }^{e}$ Quality of fit. ${ }^{f}$ Shift between experimental and theoretical EXAFS function. ${ }^{g}$ Partly decomposed peroxo complex. ${ }^{h}$ Decomposed peroxo complex, likely a bis( $\mu$-hydroxo)dicopper(II) complex. 
with each $\mathrm{Cu}$ ion having a square-pyramidal geometry. The $\mathrm{Cu} \cdots \mathrm{Cu}$ distance of $(3.51 \pm 0.04) \AA\left({ }^{t B u} \mathbf{P}\right)$ and $(3.52 \pm 0.04) \AA\left({ }^{\mathrm{H}} \mathbf{P}\right)$ is characteristic for a $\mu-\eta^{2}: \eta^{2}$ peroxodicopper(II) complex, confirmed also by the $\mathrm{Cu}-\mathrm{Cu}$ coordination number of one, reflecting the dimeric nature of the complex. See Scheme 6.7 for a representation of these distances/shells. A Cu-C shell around $3 \AA$ could not be adjusted with statistical significance, which indicates a rather high degree of disorder in the solid sample. Higher shells at distances larger than $3.5 \AA$ are caused by $\mathrm{Cu}-\mathrm{O}-\mathrm{Cu}$ and $\mathrm{Cu}-\mathrm{N}-\mathrm{C}$ multiple scattering (MS) paths, also described e. g. in references $[249,251]$.

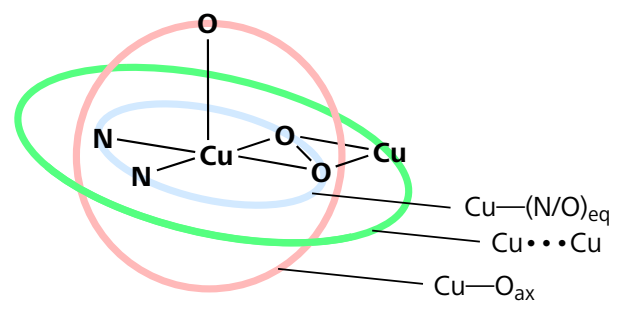

\section{Scheme 6.7}

Structural model of ${ }^{\mathbf{R}} \mathbf{P}$ and shells around copper, extracted from EXAFS measurements.

In contrast to $\mu-\eta^{2}: \eta^{2}$-peroxodicopper(II) species, end-on 1,2-trans-peroxodicopper(II) complexes would show a $\mathrm{Cu} \cdots \mathrm{Cu}$ distance of $\sim 4.36 \AA$, while bis( $\mu$-oxo)dicopper(III) complexes are characterized by a short $\mathrm{Cu} \cdots \mathrm{Cu}$ of $\sim 2.80 \AA \AA$. ${ }^{34]}$ See also the introduction, Section 2.2.1. Furthermore, the thermal degradation products of ${ }^{\boldsymbol{t} \mathbf{B u}} \mathbf{P}$, bis( $\mu$-hydroxo)dicopper(II) complexes, have $\mathrm{Cu} \cdots \mathrm{Cu}$ distances of $3.0 \AA$ as determined by X-ray structure determinations (see Section 6.10.1). These three distances could not be detected.

\section{Mep and ${ }^{\mathrm{Ph}} \mathbf{P}$}

In contrast, no second light atom contribution could be adjusted for sample ${ }^{\mathbf{M e}} \mathbf{P}$ and ${ }^{\mathbf{P h}} \mathbf{P}$ in a statistically significant manner. Instead, the first contribution exhibits a slightly higher coordination number than in ${ }^{\boldsymbol{t} \mathbf{B}} \mathbf{P} \mathbf{P}$ and ${ }^{\mathbf{H}} \mathbf{P}$, therefore it is likely that a solvent contribution can not be resolved anymore, but is averaged with the ligand contribution. In complex ${ }^{\mathbf{M e}} \mathbf{P}$, two $\mathrm{Cu} \cdots \mathrm{Cu}$ shells were necessary to achieve a satisfactory quality of fit. The shorter one found at $(2.93 \pm 0.03) \AA$ can be interpreted with the presence of a bis( $\mu$-hydroxo)dicopper(II) species (cf. Section 6.10.1), while the longer one of $(3.49 \pm 0.03) \AA$ is still in agreement with the peroxo species in ${ }^{\boldsymbol{t} B \mathbf{u}} \mathbf{P}$ and ${ }^{\mathbf{H}} \mathbf{P}$. The coordination number of 0.6 and 0.2 suggest that the peroxo species represents the minor fraction. It should be also noted that 
the $\mathrm{Cu} \cdots \mathrm{Cu}$ coordination numbers do not add to one, therefore a small fraction of monomeric species could be also present. The reduced fraction of peroxo species is also reflected in the reduced $\mathrm{Cu}-\mathrm{O}-\mathrm{Cu}$ multiple scattering contribution. However, the remaining presence of $\mathrm{Cu}-\mathrm{NC}$ multiple scattering indicates that the ligand scaffold is still intact in the present species. In complex ${ }^{\mathbf{P h}} \mathbf{P}$ the minor fraction of peroxo complexes vanishes, and only a characteristic $\mathrm{Cu} \cdots \mathrm{Cu}$ contribution for bis( $\mu$-hydroxo) complexes of $(2.91 \pm 0.03) \AA$ is detected, again not with a coordination number of one. Also, the $\mathrm{Cu}-\mathrm{O}-\mathrm{Cu}$ MS contribution is further significantly reduced, which is in line with the missing peroxo species in ${ }^{\mathbf{P h}_{\mathbf{P}}} \mathbf{P}$.

\subsubsection{Comparison of XAS Structural Results}

The $\mu-\eta^{2}: \eta^{2}$-peroxodicopper(II) complexes ${ }^{\boldsymbol{t} \mathbf{B} u} \mathbf{P}$ and ${ }^{\mathbf{H}} \mathbf{P}$ were isolated as solid compounds and could be analysed by K-edge XAS and EXAFS methods, while in the samples of ${ }^{\mathbf{M e}} \mathbf{P}$ and ${ }^{\mathbf{P h}} \mathbf{P}$, the respective peroxo complex is degraded to presumably a $\mathrm{Cu}_{2}(\mathrm{OH})_{2}$ complex. In ${ }^{\mathbf{M e}} \mathbf{P}$ however, the peroxo core is still intact in $\sim 20 \%$ of the sample.

The $\mathrm{Cu}_{2}(\mathrm{OH})_{2}$ complexes have $\mathrm{Cu} \cdots \mathrm{Cu}$ separations of $2.91\left({ }^{\mathrm{Ph}} \mathbf{P}\right)$ and $2.93 \AA$ $\left({ }^{\mathrm{Me}} \mathbf{P}\right)$, in accordance with the X-ray structural parameters of the $\mathrm{Cu}_{2}(\mathrm{OH})_{2}$ complexes obtained from ${ }^{\boldsymbol{t} \mathbf{B u}} \mathbf{P}$ upon thermal degradation $(\sim 3.0 \AA)$.

The peroxo $\mathrm{Cu}_{2} \mathrm{O}_{2}$ complexes have all quite similar $\mathrm{Cu} \cdots \mathrm{Cu}$ separations of $3.51\left({ }^{{ }^{\mathrm{Bu}}} \mathbf{P}\right), 3.52\left({ }^{\mathrm{H}} \mathbf{P}\right)$ and $3.49 \AA\left({ }^{\mathrm{Me}} \mathbf{P}\right)$. In Table 6.9, geometric and spectroscopic features of all so far structurally characterised (EXAFS analysis or X-ray crystallography) synthetic compounds, containing a ${ }^{\mathrm{S}} \mathrm{P} \mathrm{Cu}_{2} \mathrm{O}_{2}$ core, are listed. Values for a tyrosinase and two hemocyanins are included for comparison. Compared to the other peroxo complexes, the $\mathrm{Cu} \cdots \mathrm{Cu}$ separation of $\sim 3.50 \AA$ is right in the middle of the range of known compounds. The $\mathrm{Cu} \cdots \mathrm{Cu}$ distances range from 3.22 to $3.60 \AA$, the average value is $3.50 \AA$.

The smallest distances in this list represent structures with a strong butterfly distortion of the $\mathrm{Cu}_{2} \mathrm{O}_{2}$ core. In ${ }^{\mathbf{R}} \mathbf{P}$, the $\mathrm{Cu} \cdots \mathrm{Cu}$ distance of $3.5 \AA$ and the corresponding $\mathrm{Cu}-\mathrm{O}-\mathrm{Cu}$ multiscattering path $(3.72 \AA)$, compared to literature values ${ }^{[251]}$ might also indicate that the $\mathrm{Cu}_{2} \mathrm{O}_{2}$ core has a slightly butterfly-shaped geometry. This slight distortion is also in accordance with DFT calculations for ${ }^{t \mathbf{B u}} \mathbf{P}$ (see the following Section 6.8). Butterfly distortion of the $\mathrm{Cu}_{2} \mathrm{O}_{2}$ core is also observed in arthropod hemocyanin. Here, the $\mathrm{Cu} \cdots \mathrm{Cu}$ separation is decreased to $\sim 3.6 \AA$ in comparison to mollusc hemocyanin $(\sim 3.7 \AA) .{ }^{[252]}$ Interestingly, catalase activity is only observed in mollusc hemocyanins and absence of activity in arthropod hemocyanin can be attributed to the presence of the butterfly-shaped structure. ${ }^{[253]}$ 


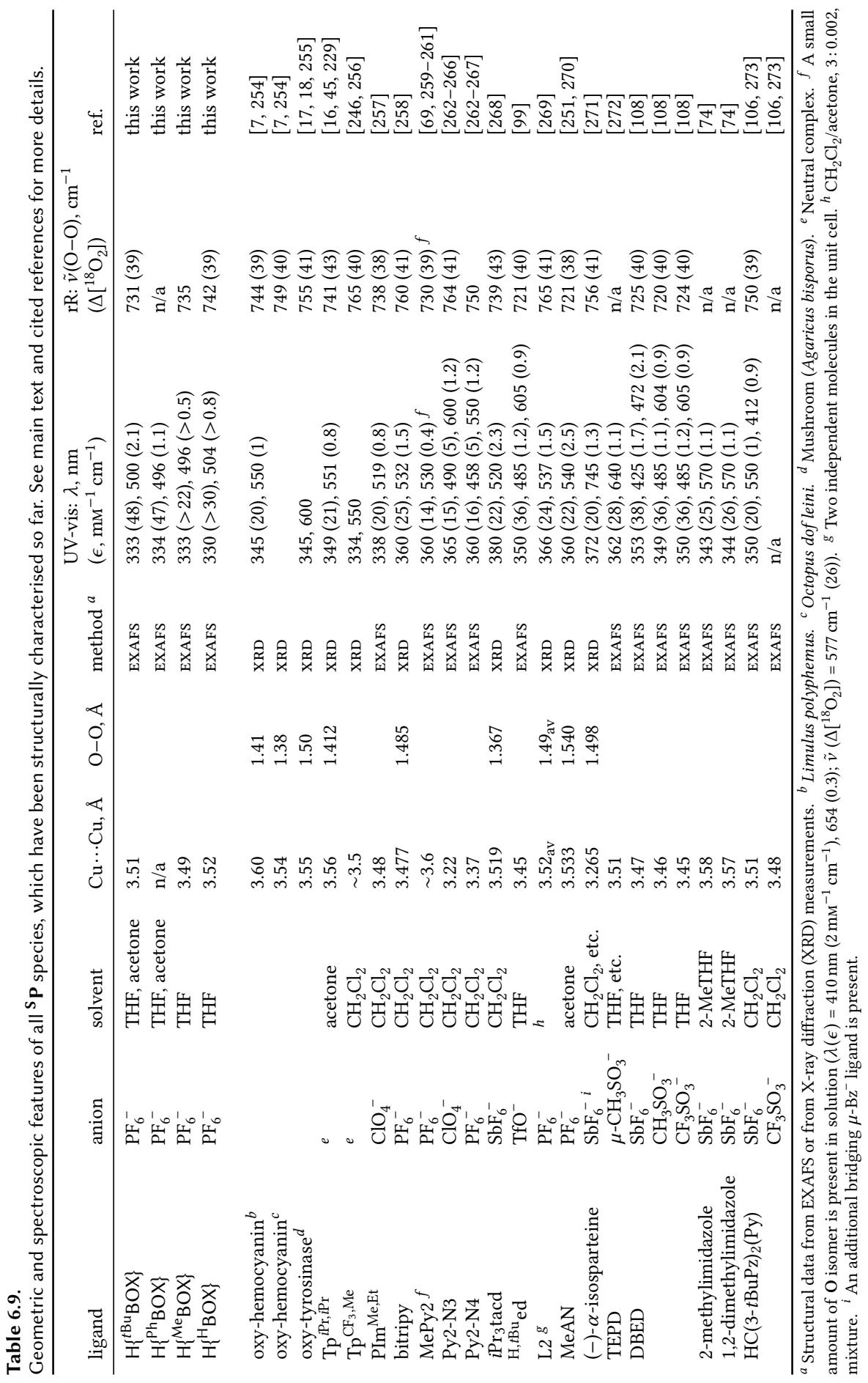




\subsection{DFT Computations}

The computational quantum mechanical modelling method of density functional theory (DFT) is enormously popular, not only in the field of (bio-) inorganic chemistry. ${ }^{[274]}$ DFT allows the prediction of molecular structures, properties and spectroscopic characteristics, rendering this technique very helpful, especially when experimental investigations are complicated by the lability of the systems under investigation. DFT developed to a technique which predicts molecular properties with reasonable to high quality and can now be considered as the defacto standard for theoretical insights into transition metal chemistry. ${ }^{[275,276]}$ It finds furthermore increasing use in modelling biological systems, such as metalloproteins. ${ }^{[4,277]}$ Due to its benefits, DFT is also intensively applied on systems incorporating the $\mathrm{Cu}_{2} \mathrm{O}_{2}$ core. ${ }^{[278]}$

\subsubsection{A Computational Model of ${ }^{t B u} P$}

Starting coordinates for the computation of ${ }^{\mathbf{t}}{ }^{\mathbf{B u}} \mathbf{P}$ were taken from the structurally closely related bis( $\mu$-hydroxo)dicopper(II) complex $\left[(\mathrm{THF})_{0.85}(\mathrm{MeCN})_{0.15^{-}}\right.$ $\left.\left(\mathrm{H}\left\{{ }^{t \mathrm{Bu}} \mathrm{BOX}\right\}\right) \mathrm{Cu}(\mu-\mathrm{OH})\right]_{2}\left(\mathrm{PF}_{6}\right)_{2}$, which were obtained by X-ray diffraction analysis (see Section 6.10.1, p. 166). As indicated by EXAFS measurements and elemental analysis (see above), a weakly coordinating solvent is incorporated in ${ }^{\boldsymbol{t} \mathbf{B u}} \mathbf{P}$ and it is most likely, that there is also solvent coordinated in solution. The structure was finally modelled with $\mathrm{MeCN}$ as coordinating solvent, starting from coordinates obtained from the X-ray crystal structure after a manipulation of the $\mathrm{Cu}_{2} \mathrm{O}_{2}$ distances. Ligand geometries were used without truncation.

Geometry optimizations and single point calculations were performed using Becke's three-parameter hybrid functional with the correlation functional of Lee, Yang, and Parr (B3LYP). ${ }^{[157,158]}$ The valence triple- $\zeta$ plus polarization basis sets (def2-TZVPP) ${ }^{[159,160]}$ were used on copper, oxygen and nitrogen atoms and double- $\zeta$ split valence polarisation sets (def2-SVP) ${ }^{[159,279]}$ on carbon and hydrogen, as implemented in ORCA. The structure was first calculated as a gas phase model and subsequently solvent effects were considered in all calculations by invoking the conductor like screening model (COSMO) with the selection of THF as the solvent.

A DFT spin-unrestricted formalism (UKS) has been applied to first calculate a high-spin triplet state $(S=1)$ geometry, which was then used for calculation of the spin-polarized broken-symmetry (BS) solution. ${ }^{[280,281]}$ The spin on one copper atom was flipped in expectation of an antiferromagnetically coupled $\left(M_{S}=0\right)$ 


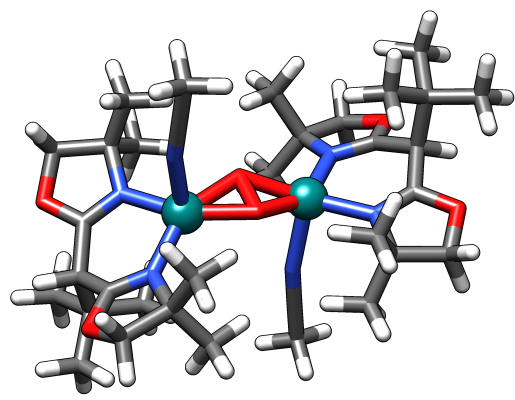

(a)

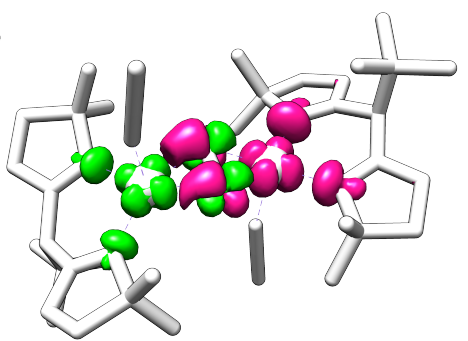

(b) spin-density plot

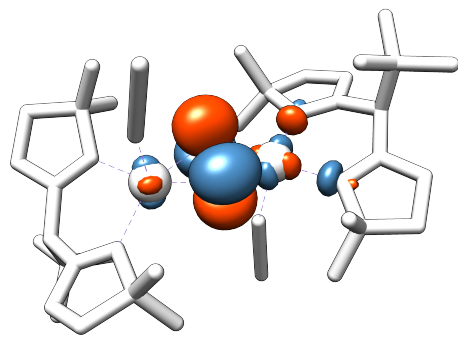

(c) $203 \alpha$

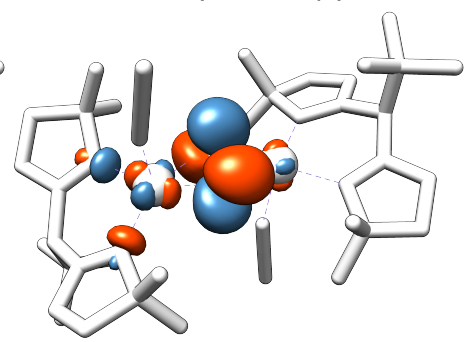

$203 \beta$

Figure 6.28. (a) DFT-geometry-optimized coordinates of ${ }^{t B u} \mathbf{P}$; on the $\mathrm{B} 3 \mathrm{LYP} /$ def2-TZVPP $(\mathrm{Cu}, \mathrm{O}, \mathrm{N}) /$ def2-SVP(H,C)-level of theory, applying the $\mathrm{BS}\left(M_{S}=\right.$ 0 ) formalism and a COSMO solvent model for THF ( $\mathrm{Cu}$ : green-blue, $\mathrm{N}$ : blue, $\mathrm{O}$ : red, $\mathrm{C}$ : grey, $\mathrm{H}$ : white). ( b ) Spin-density plot (isovalue $=0.004$ ). ( c) Plots of $\alpha$ and $\beta$ HOMO (isovalue $=$ $0.004)$.

state. In the obtained BS solution (Figure 6.28a), Mulliken spin populations at the copper atoms are 0.4930 and -0.4932 , reflecting its successful achievement (spin-density plot in Figure 6.28b and $\alpha$ and $\beta$ HOMOs in Figure 6.28c).

The computations reproduce well the experimental bond lengths from EXAFS data within a mean error of $2 \%$, as well as the suggested butterfly-shape of the $\mathrm{Cu}_{2} \mathrm{O}_{2}$ core (the $\mathrm{Cu}-\mathrm{O}-\mathrm{O}-\mathrm{Cu}$ torsion angle is $152^{\circ}$, Figure 6.28). The computed $\mathrm{Cu} \cdots \mathrm{Cu}$ separation of $3.56 \AA$ is only slightly overestimated compared to the experimental distance of $3.51 \AA$ derived from EXAFS data (Table 6.10). A butterfly shape is also reflected by the nature of the HOMO; see Figure 6.29 for representations of 
Table 6.10.

Comparison of structural parameters of ${ }^{t B u} \mathbf{P}$, angles and distances $(\AA)$, obtained from fitting of the EXAFS data in Section 6.7 with parameters from the DFT geometry optimization.

\begin{tabular}{lccc}
\hline & EXAFS & DFT & match, \% \\
\hline$\vartheta(\mathrm{Cu}-\mathrm{O}-\mathrm{O}-\mathrm{Cu})$ & $\mathrm{n} / \mathrm{a}$ & $151.6^{\circ}$ & \\
$\mathrm{O}-\mathrm{O}$ & $\mathrm{n} / \mathrm{a}$ & 1.443 & \\
$\mathrm{Cu}-\mathrm{Cu}$ & 3.51 & 3.564 & 98.5 \\
$\mathrm{Cu}-(\mathrm{N} / \mathrm{O})_{\text {eq }}$ & 1.94 & 1.992 & 97.4 \\
$\mathrm{Cu}-\left(\mathrm{O}_{\text {EXAFs }} \mathrm{N}_{\text {DFT }}\right)_{\mathrm{ax}}$ & 2.34 & 2.335 & 100.2 \\
$\mathrm{Cu}-\mathrm{O}-\mathrm{Cu}(\mathrm{MS})$ & 3.72 & 3.757 & 99.0 \\
\hline
\end{tabular}

the unrestricted natural molecular orbitals (UNO) and the spin-density plot in Figure 6.28b. The $\mathrm{HOMO}$ is the anti-bonding combination of $2 \mathrm{Cu}^{2+}\left(d_{x^{2}-y^{2}}-d_{x^{2}-y^{2}}\right)$ with $\mathrm{O}_{2}^{2-} \pi_{\sigma}^{*}$, instead of the combination with $\mathrm{O}_{2}^{2-} \sigma^{*}$ for a planar (not-butterflydistorted) complex, in analogy to literature. ${ }^{265]}$

The energy of the singlet-triplet gap was additionally obtained from the broken symmetry DFT calculations. This is discussed in more detail along with experimental magnetic investigations in the following section.

\subsubsection{Simulation of Spectroscopic Data by TD-DFT}

Time-dependent density-functional theory (TD-DFT) is a valuable tool for the investigation of electronic excited states. ${ }^{[282,283]}$ TD-DFT allows furthermore to predict absorption spectra. In compounds, incorporating the $\mu-\eta^{2}: \eta^{2}$-peroxodicopper(II) core, the UV-vis spectra are mostly consistent with experimental data (see e. g. references [74, 106, 284, 285] for some recent applications). ${ }^{[278]}$ However, in general the TD-DFT results have to be treated with caution due to some inherent problems. ${ }^{[276]}$

Using TD-DFT, the electronic absorption spectrum of ${ }^{\boldsymbol{t} \text { Bu }} \mathbf{P}$ was successfully reproduced (Figure 6.30). The spectrum closely corresponds with the experimental spectrum (with regard to transition energies and intensity ratio). The intensity pattern for the UV-vis absorptions agrees with the experimental spectrum and with the typical pattern ${ }^{[34]}$ for a $\mu-\eta^{2}: \eta^{2}$-peroxodicopper(II) complex (higher energy peroxo $\pi_{\sigma}^{*} \rightarrow \mathrm{Cu}^{\text {II }}$ transition more intense than lower energy peroxo $\pi_{v}^{*} \rightarrow \mathrm{Cu}^{\text {II }}$ transition; intensities $\sim 25: 1$ ). 


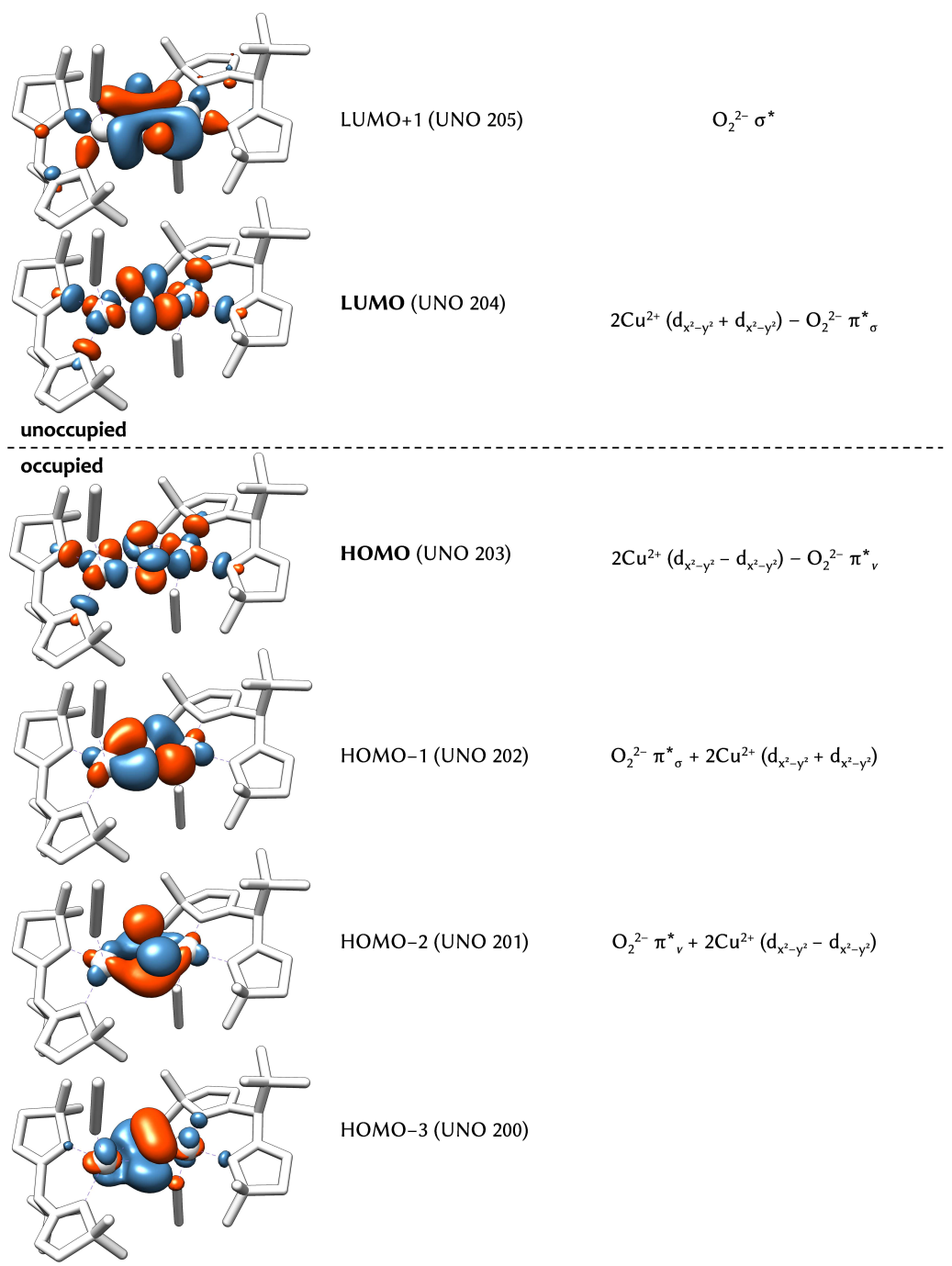

Figure 6.29. UHF natural orbital $(U N O)$ plots for ${ }^{t B u} \mathbf{P}$ (isovalue $\left.=0.035\right)$ from spinunrestricted B3LYP calculation in the broken-symmetry $\left(M_{S}=0\right)$ state. Hydrogens and bonds to copper are omitted for clarity. 


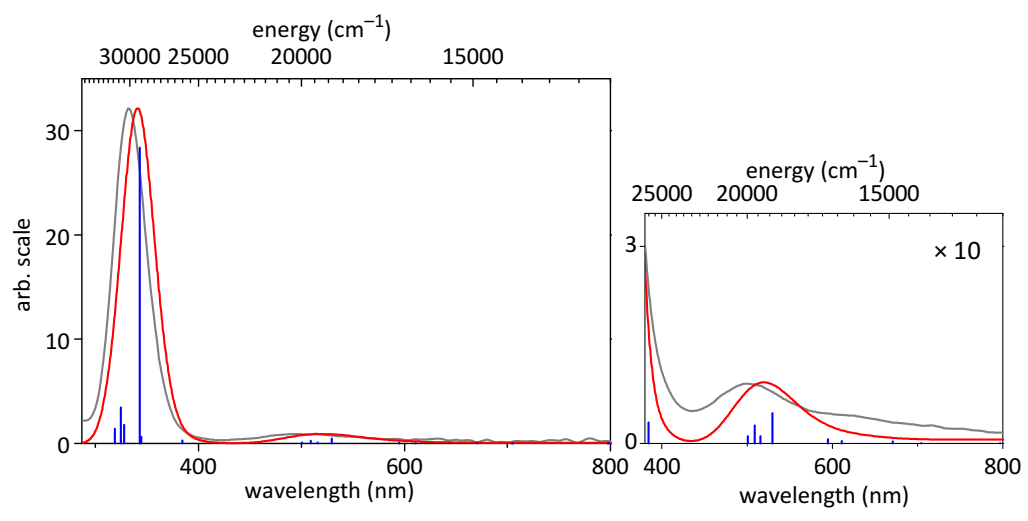

Figure 6.30. UV-vis absorption spectra of ${ }^{\boldsymbol{t} \mathrm{Bu}} \mathbf{P}$. Experimental low-temperature UV-vis spectrum (-, $\left.\lambda_{\max }=333,500 \mathrm{~nm} ; \mathrm{THF},-78^{\circ} \mathrm{C}\right)$. Computed TD-DFT transitions $(-)$. Convolution of calculated transitions ( - , full width at half maximum: $3000 \mathrm{~cm}^{-1}$ ), which accurately reproduces the spectrum of ${ }^{\boldsymbol{t} B u} \mathbf{P}$ in solution $\left(\lambda_{\max }=340,520 \mathrm{~nm}\right)$; the intensities are relatively scaled. The right spectrum shows an enlargement of the lower energy region.

Many individual MO pairs usually contribute to a given excited state obtained from a TD-DFT calculation. The device of »natural transition orbitals« $(\mathrm{NTO})^{[286]}$ can be used to keep the familiar picture of a sole electron being excited from a donor to an acceptor orbital. ${ }^{[287]}$ Calculated transitions and NTOs of the excitations at 333 and $500 \mathrm{~nm}$ are shown in Figure 6.31 and Figure 6.32, respectively. The experimentally determined comparatively high intensity of the $333 \mathrm{~nm} \pi_{\sigma}^{*} \rightarrow$ $d_{x^{2}-y^{2}}$ (in-plane) feature $\left(\epsilon_{333}=48 \mathrm{~m}^{-1} \mathrm{~cm}^{-1}\right)$ could be explained by an intimate orbital interaction with the $\mathrm{C}=\mathrm{N}$ bonds of the BOX ligands, as indicated from the NTOs in Figure 6.31. Charge from the bonding $\pi$ orbitals of the oxazoline $\mathrm{C}=\mathrm{N}$ groups in plane with the $\mathrm{Cu}_{2} \mathrm{O}_{2}$ core and from the non-bonding $p$-orbitals of the oxazoline oxygen, is transferred together with charge from the peroxide in course of this electronic excitation.

Interestingly, the weakly coordinating axial ligand is necessary for a good reproduction of the spectrum, thus its absence in additional calculations lead to an approximately ten-fold decrease in intensity of the $\sim 500 \mathrm{~nm}$ feature. 

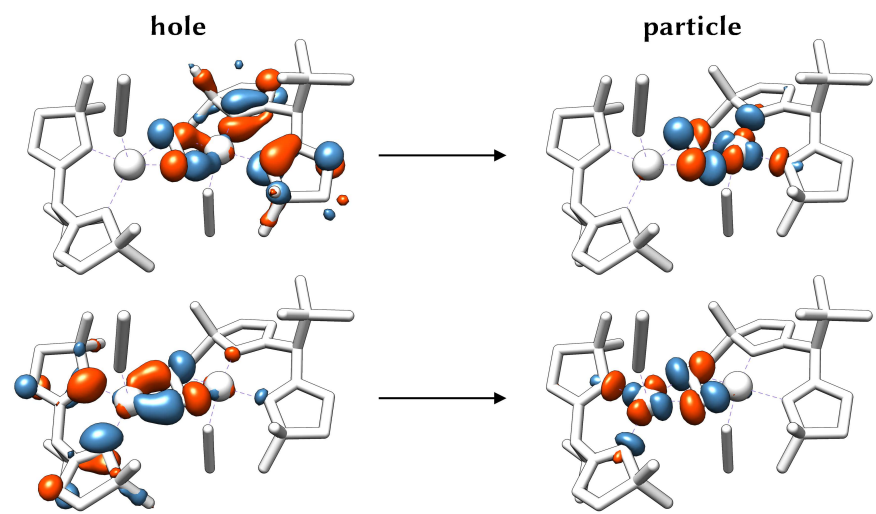

Figure 6.31. Calculated TD-DFT natural transition orbitals involved in the $333 \mathrm{~nm}$ excitation. Excitation is mainly from the peroxide $\pi_{\sigma}^{*}$ and $\mathrm{C}=\mathrm{N} \pi$ orbitals to the $\mathrm{Cu} d_{x^{2}-y^{2}}$ antibonding combination with the peroxide (isovalue $=0.050)$. State $12, E=29162 \mathrm{~cm}^{-1}\left(f_{\text {osc }}=0.39246\right)$; weights: $n=0.568$ (top), 0.394 (bottom). Hydrogens and bonds to copper are omitted for clarity.

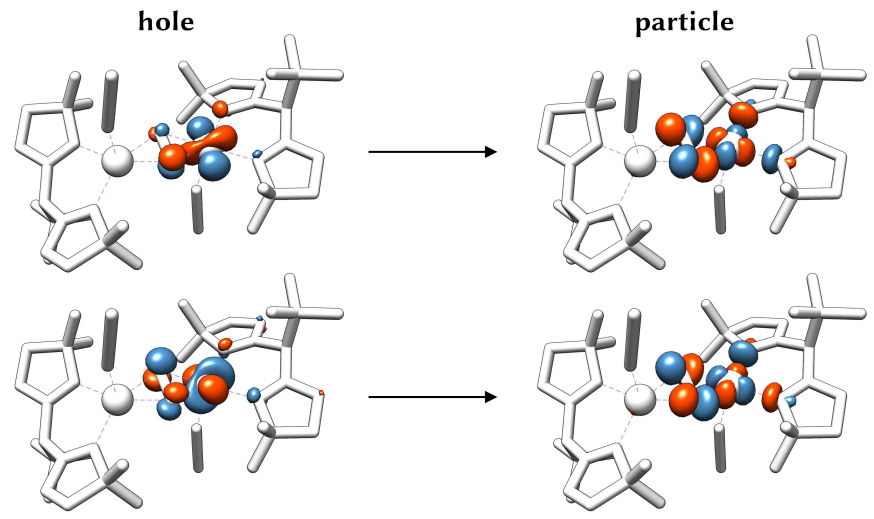

Figure 6.32. Calculated TD-DFT natural transition orbitals involved in the $500 \mathrm{~nm}$ excitation. Excitation is mainly from the peroxide $\pi_{v}^{*}$ and $\mathrm{Cu} d_{z^{2}}$ to the $\mathrm{Cu} d_{x^{2}-y^{2}}$ antibonding combination with the peroxide (isovalue $=0.050)$. State 9 (top), $E=19641 \mathrm{~cm}^{-1}\left(f_{\text {osc }}=\right.$ 0.00381 ); weight: $n=0.978$; State 7 (bottom), $E=18888 \mathrm{~cm}^{-1}\left(f_{\mathrm{osc}}=0.00638\right)$; weight: $n=$ 0.990 . Hydrogens and bonds to copper are omitted for clarity. 


\subsection{Magnetic Properties}

Due to the thermal lability of most copper-oxygen species, examples of magnetic investigation are scarce. Mostly, EPR silence is here the indication for a diamagnetic system or »normal « NMR-spectroscopic behaviour is proof of an antiferromagnetically coupled system.

The isolation of the relatively stable compounds ${ }^{\boldsymbol{t}}{ }^{\mathbf{B}} \mathbf{P}$ and ${ }^{\mathbf{H}} \mathbf{P}$ made it possible to determine their magnetic properties; experiments with the analogous ${ }^{\mathbf{P h}} \mathbf{P}$ and Me $\mathbf{P}$ were not conducted due to stability issues. Measurements were carried out on a Quantum Design MPMS-5S superconducting quantum interference device (SQUID) magnetometer on powder samples. Solid-state magnetic measurements of ${ }^{\mathbf{t B u}} \mathbf{P}$ and ${ }^{\mathbf{H}} \mathbf{P}$ are consistent with very strong anti-ferromagnetic (AF) coupling between the respective $\mathrm{Cu}^{\mathrm{II}}$ centres to give singlet ground states and diamagnetic systems. ${ }^{[288]}$ The temperature dependence of the $\chi_{\mathrm{mol}} T$ of ${ }^{\mathbf{H} \mathbf{B u}} \mathbf{P}$ in the temperature range of $2-295 \mathrm{~K}$ is depicted in Figure 6.33, it shows only negligible susceptibilities even at room temperature $\left(\chi_{\mathrm{mol}} T=0.01 \mathrm{~cm}^{3} \mathrm{~mol}^{-1} \mathrm{~K}\right.$ at $\left.295 \mathrm{~K}\right)$. The molar susceptibility slightly decreases further with temperature. Over the whole range of temperature, only the singlet ground states are populated.

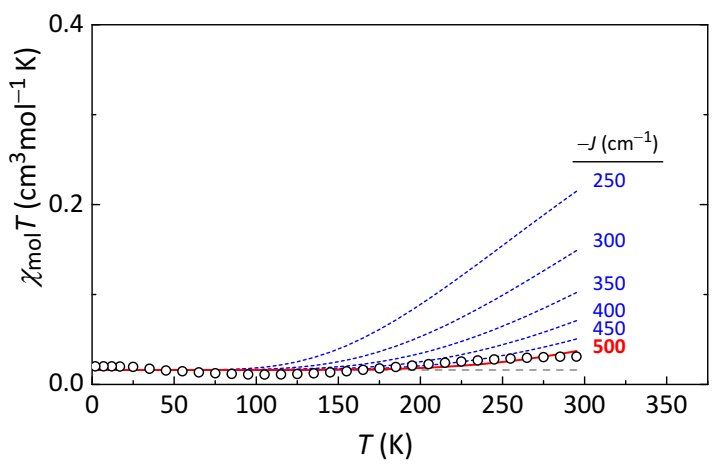

Figure 6.33. Plot of $\chi_{\mathrm{mol}} T$ vs. $T$ for ${ }^{t \mathrm{Bu}} \mathbf{P}(\bigcirc)$ obtained from a SQUID measurement at $0.5 \mathrm{~T}$. The red line $(-)$ corresponds to the best fit for two anti-ferromagnetic coupled $S=1 / 2$ ions with $g=2.0$. Additional fit parameters: temperature-independent paramagnetism (TIP $\left.=990 \times 10^{-6} \mathrm{~cm}^{3} \mathrm{~mol}^{-1} \mathrm{~K}\right)$ and paramagnetic impurity $(----, P I=4 \mathrm{~mol} \%$ for a magnetic uncoupled $\mathrm{Cu}^{\text {II }}$ species as likely impurity). The fit gives the lower limit of exchange energy $-J \geq 500 \mathrm{~cm}^{-1}$. The blue lines (---.-) represent fits when a weaker coupling of $-J<$ $500 \mathrm{~cm}^{-1}$ is considered. 
Simulation of the data (Figure 6.33, red solid line) shows that the lower limit of exchange coupling is $-2 J \geq 1000 \mathrm{~cm}^{-1}$, based on the Heisenberg-Dirac-van Vleck (HDvV) Hamiltonian in the form of

$$
\mathscr{H}_{\mathrm{HDvV}}=-2 J_{\mathrm{AB}} \cdot \vec{S}_{\mathrm{A}} \cdot \vec{S}_{\mathrm{B}}
$$

To confirm this lower limit, simulations were performed with $J$ fixed at different values. Plotted are theoretical susceptibilities for singlet-triplet splittings of $-2 J=$ $900,800,700,600$ and $500 \mathrm{~cm}^{-1}$ (blue dashed lines). A splitting of $900 \mathrm{~cm}^{-1}$ would produce an increase in susceptibility, larger than the data indicates (Figure 6.35 shows the quality of fit as a function of $J$ ). Measurements at higher temperatures were not conducted to avoid thermal decomposition of the samples. The large values for $J$ show that the bridging peroxo ligand in ${ }^{t \mathbf{B u}} \mathbf{P}$ efficiently mediates the strong copper(II)-copper(II) super exchange coupling.

In close analogy to ${ }^{\mathbf{t}}{ }^{\mathrm{B}} \mathbf{P}$, a SQUID measurement of ${ }^{\mathbf{H}} \mathbf{P}$ gives a lower limit of $-2 J \geq 1200 \mathrm{~cm}^{-1}$ from a fit of the data between 2-290 K (Figure 6.34), consistent with ${ }^{\mathbf{H} \text { uu}} \mathbf{P}$. Above room temperature, a steep increase of $\chi_{\mathrm{mol}} T$ is obvious (Figure 6.34, grey circles, not considered in the fits). A following measurement at

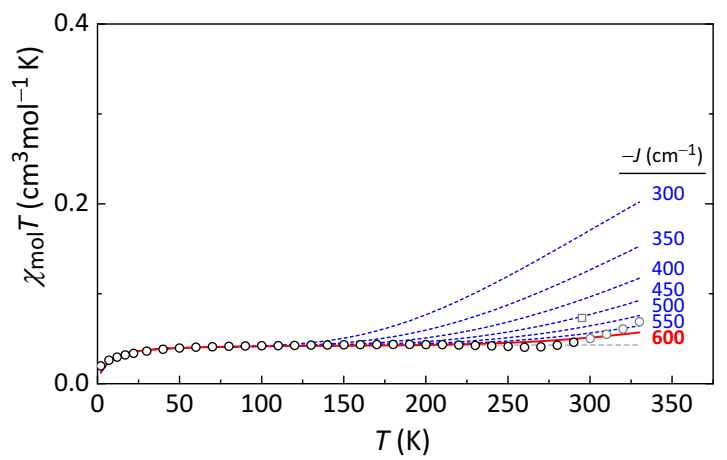

Figure 6.34. Plot of $\chi_{\mathrm{mol}} T$ vs. $T$ for ${ }^{\mathrm{H}} \mathbf{P}(\bigcirc)$ obtained from a SQUID measurement at $0.5 \mathrm{~T}$. The red line (-) corresponds to the best fit for two AF-coupled $S=1 / 2$ ions with $g=2.0$. Additional fit parameters: $T I P=185 \times 10^{-6} \mathrm{~cm}^{3} \mathrm{~mol}^{-1} \mathrm{~K}, P I=11.6 \mathrm{~mol} \%$ for a magnetic uncoupled $\mathrm{Cu}^{\prime \prime}$ species as likely impurity (----). The fit gives the lower limit of exchange energy $-J \geq 600 \mathrm{~cm}^{-1}$. The blue lines (-.....) represent fits when a weaker coupling of $-J<600 \mathrm{~cm}^{-1}$ is considered. A change of the sample occurred $>290 \mathrm{~K}(\bigcirc)$, indicated by a subsequent measurement at $295 \mathrm{~K}(\square)$; therefore the grey data points were not considered in the fits. 
6. Biomimetic Activation of $\mathrm{O}_{2}$ by Copper(I) Complexes of BOXs
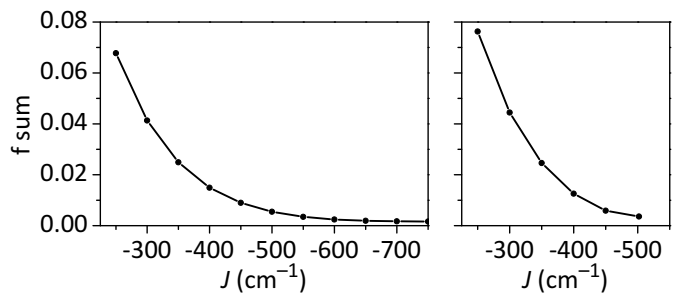

Figure 6.35. Plot of total squared error of simulation f sum vs. exchange coupling constant $J$ for the fits of compounds ${ }^{t \mathrm{Bu}} \mathbf{P}$ (right) and ${ }^{\mathrm{H}} \mathbf{P}$ (left) in Figures 6.33 and 6.34 respectively.

$295 \mathrm{~K}$ showed an increased $\chi_{\text {mol }} T$ in comparison to the prior values around this temperature (grey square) and indicative for decomposition of the sample above room temperature. To confirm the lower limit of $J$, simulations with different fixed values were conducted, too (blue dashed lines), cf. Figure 6.35.

The two very strong AF-coupled dicopper(II) systems ${ }^{t}{ }^{B u} \mathbf{P}$ and ${ }^{\mathbf{H}} \mathbf{P}$ are in agreement with a similar large singlet-triplet splitting, found in the protein oxyhemocyanin, which was determined to be larger than $-2 J \geq 600 \mathrm{~cm}^{-1}$. ${ }^{[289]}$ Coupling constants could also be determined in a few cases for synthetic model systems with the ligands depicted in Scheme 6.8. Similar values were found for two $\mu$ $\eta^{2}: \eta^{2}$-peroxo bridged model systems: the KitAJIMA system with $\mathrm{HB}\left(3,5-\mathrm{Ph}_{2} \mathrm{pz}\right)_{3}$ ligand (cf. also Figure 2.1a, p. 18), $-2 J \geq 800 \mathrm{~cm}^{-1}$, ${ }^{[229]}$ as well as a system with the binucleating $\mathrm{Py}_{2} \mathrm{~N} 4$ ligand, $-2 J \geq 600 \mathrm{~cm}^{-1} \cdot{ }^{[264,290]}$ For the 1,2-trans-peroxobridged KARLIN model with tmpa ligand (cf. also Figure 2.1b, p. 18) also a value of $-2 J \geq 600 \mathrm{~cm}^{-1}$ was determined. ${ }^{[264,290]}$ Only recently was a weakly coupled<smiles>c1ccc([B-](Cn2cc(-c3ccccc3)nc2-c2ccccc2)Cn2nc(-c3ccccc3)cc2-c2ccccc2)cc1</smiles>

$\mathrm{HB}\left(3,5-\mathrm{Ph}_{2} \mathrm{pz}\right)_{3}$<smiles>[2H]CCN(CC[18O])CCCCN(CC[18O])CC[18O]</smiles><smiles>[GeH2]Cc1cc(C[Ge]2CCCCC2)n[nH]1</smiles>

$\left\{L^{\text {PzTACN }}\right\}^{-}$

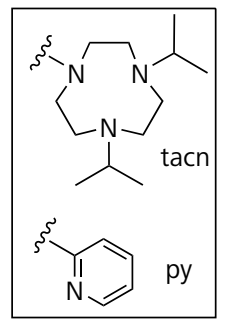

Scheme 6.8 Ligands of $\mathrm{Cu}_{2} \mathrm{O}_{2}$ systems from which magnetic data is available. 
peroxodicopper(II) complex reported $-2 J=144 \mathrm{~cm}^{-1}$ ), with the binucleating ligand $\left\{\mathrm{L}^{\mathrm{PzTACN}}\right\}^{-}$, characterized by a cis-1,2-peroxo binding mode and an acute $\mathrm{Cu}-\mathrm{O}-\mathrm{O}-\mathrm{Cu}$ torsion of $65^{\circ}$. [44]

\subsubsection{DFT Broken-Symmetry Magnetic Coupling}

Analysis of the spin-Hamiltonian based on Equation 6.7, yielded the effective exchange integral $J_{\mathrm{AB}}$ (Table 6.11). $J_{\mathrm{AB}}$ was calculated according to the procedure of YAMAGUCHI et al. in Equation 6.8. ${ }^{[291,292]}$

$$
J_{\mathrm{AB}}=\frac{{ }^{\mathrm{BS}} E-{ }^{\mathrm{T}} E}{\left.\mathrm{~T}_{\left\langle S^{2}\right\rangle}\right\rangle-{ }^{\mathrm{BS}}\left\langle S^{2}\right\rangle}
$$

Where ${ }^{\mathrm{BS}} E$ is the total energy of the broken-symmetry solution, ${ }^{\mathrm{T}} E$ is the total energy of the triplet state and $\mathrm{X}_{\left\langle S^{2}\right\rangle}$ are the respective total spin angular momenta. The very strong AF coupling constant is in reasonable agreement with the experimentally determined lower-limits for ${ }^{\boldsymbol{t}}{ }^{\mathbf{B}} \mathbf{P}$ and ${ }^{\mathrm{H}} \mathbf{P}$.

Table 6.11.

Total energies ${ }^{\mathrm{X}} E$ (hartree), total spin angular momenta $\mathrm{X}_{\left\langle S^{2}\right\rangle}$ and effective exchange integral $J_{\mathrm{AB}}\left(\mathrm{cm}^{-1}\right)$ calculated for ${ }^{\boldsymbol{t} \text { Bu }} \mathbf{P}$.

\begin{tabular}{ccccc}
\hline${ }^{\mathrm{BS}} E$ & ${ }^{\mathrm{BS}}\left\langle S^{2}\right\rangle$ & ${ }^{\mathrm{T}} E$ & ${ }^{\mathrm{T}}\left\langle S^{2}\right\rangle$ & $J_{\mathrm{AB}}$ \\
\hline-5389.112875 & 0.7827 & -5389.103978 & 2.0104 & -1590.31 \\
\hline
\end{tabular}

The DFT-computed $J_{\mathrm{AB}}$ is furthermore in the range of similar calculations for other $\mu-\eta^{2}: \eta^{2}$-peroxodicopper(II) systems. On the basis of Equation 6.8, magnetic coupling constants between $J_{\mathrm{AB}}=-678$ and $-1902 \mathrm{~cm}^{-1}$ were calculated for three systems at the UBHandHLYP level of theory. ${ }^{[293]}$ The smaller values were obtained from optimized coordinates and the higher from the respective X-ray coordinates. For a fourth system with a distorted butterfly $\mathrm{Cu}_{2} \mathrm{O}_{2}$ structure, considerably weaker values were found, $-248 \mathrm{~cm}^{-1}$ from X-ray and $35 \mathrm{~cm}^{-1}$ from optimized coordinates, as one would expect due to the reduction of orbital interactions between the copper and peroxo orbitals (cf. Section 2.2.1, p. 20).

The YAMAGUCHI approach has the advantage, that it was designed to be valid over the full range between weakly and strongly coupled systems, $J_{\mathrm{AB}}$ depends here on the spin contamination of the broken-symmetry solution. In other approaches, $J_{\mathrm{AB}}$ instead depends on the overlap between the magnetic orbitals and is only valid for either, the case of weak ${ }^{[294]}$ or strong ${ }^{[295]}$ interacting systems. ${ }^{[275]}$ 


\subsection{Thermal Degradation of Peroxo Complexes}

\subsubsection{Bis $(\mu$-hydroxo)dicopper(II) Complexes}

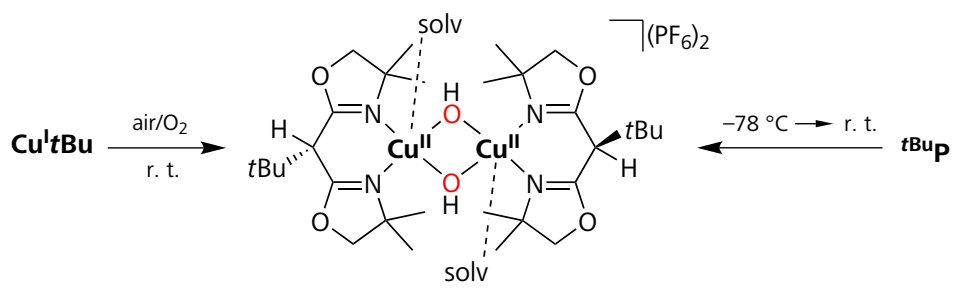

Scheme 6.9 Formation of bis( $\mu$-hydroxo)dicopper(II) complex $\left[\left(\mathrm{H}_{\left\{{ }^{t} \mathrm{Bu}\right.} \mathrm{BOX}\right\}\right)($ solv $) \mathrm{Cu}$ " $(\mu$ $\mathrm{OH})]_{2}\left(\mathrm{PF}_{6}\right)_{2}$, by either the reaction of the copper(I) complex $\mathbf{C} \mathbf{u}^{\prime} \boldsymbol{t} \mathbf{B u}$ with $\mathrm{O}_{2}$ at r.t (left), or by the warming of the peroxo $\mathrm{Cu}_{2} \mathrm{O}_{2}$ complex ${ }^{t \mathrm{Bu}} \mathrm{P}$ to temperatures above $\sim-50^{\circ} \mathrm{C}$ or to r. $\mathrm{t}$ (right).

Cu't $\mathrm{Bu}$ reacts with $\mathrm{O}_{2}$ at ambient temperatures to yield the bis( $\mu$-hydroxo)dicopper(II) complex $\left[\left(\mathrm{H}_{\{}{ }^{t \mathrm{Bu}} \mathrm{BOX}\right\}\right)($ solv $\left.) \mathrm{Cu}^{\mathrm{II}}(\mu-\mathrm{OH})\right]_{2}\left(\mathrm{PF}_{6}\right)_{2}$ (Scheme 6.9, left arrow). »solv « is a loosely coordinated solvent molecule, $\mathrm{H}_{2} \mathrm{O}$, THF and $\mathrm{MeCN}$ have been identified as ligands in the structurally characterised complexes considered here.

After warming to temperatures over $\sim-50^{\circ} \mathrm{C}$ or room temperature, solutions of the intensely violet peroxo $\mathrm{Cu}_{2} \mathrm{O}_{2}$ complex ${ }^{\boldsymbol{t} \mathbf{B u}} \mathbf{P}$ bleach and turn slowly bluish. In the solid form, ${ }^{\mathbf{t}} \mathbf{H}_{\mathbf{P}}$ is quite stable even at room temperature, however after approximately one to two days at room temperature it turns light blue, indicative of the formation of the corresponding bis(hydroxo)-bridged $\mathrm{Cu}_{2}(\mu-\mathrm{OH})_{2}$ complex. Most of the $\mathrm{Cu}_{2} \mathrm{O}_{2}$ compounds are thermally unstable and thus, the formation of a $\mathrm{Cu}_{2}(\mathrm{OH})_{2}$ complex as the decomposition product in such reactions is typical for peroxo $\mathrm{Cu}_{2} \mathrm{O}_{2}$ complexes and also for copper(I) complexes reacting with $\mathrm{O}_{2}$ at room temperature. [296-298]

The decomposition is also well evident in the Raman spectrum of this powder, which lacks the intense archetypical $v(\mathrm{O}-\mathrm{O})$ and $v(\mathrm{Cu} \cdots \mathrm{Cu})$ features of ${ }^{\boldsymbol{t} \mathbf{B u}} \mathbf{P}$. Both peaks were present as intense features before thermal degradation at $731 \mathrm{~cm}^{-1}$ and $279 \mathrm{~cm}^{-1}$ (Figure 6.36). The remaining weaker feature at $\sim 250 \mathrm{~cm}^{-1}$ might be assigned to the axial copper-solvent coordination $v\left(\mathrm{Cu}-\mathrm{N}_{\mathrm{ax}} / \mathrm{O}_{\mathrm{ax}}\right) \cdot{ }^{[70,259]}$

The large $\left.\left[\left(\mathrm{H}_{\{}^{t \mathrm{Bu}} \mathrm{BOX}\right\}\right)_{2} \mathrm{Cu}_{2}(\mathrm{OH})_{2}\left(\mathrm{PF}_{6}\right)\right]^{+}$ion was identified in the high resolution ESI mass spectrum. A solution of ${ }^{18} \mathrm{O}$-labelled ${ }^{\boldsymbol{t} \mathbf{B u}} \mathbf{P}$ at room temperature 


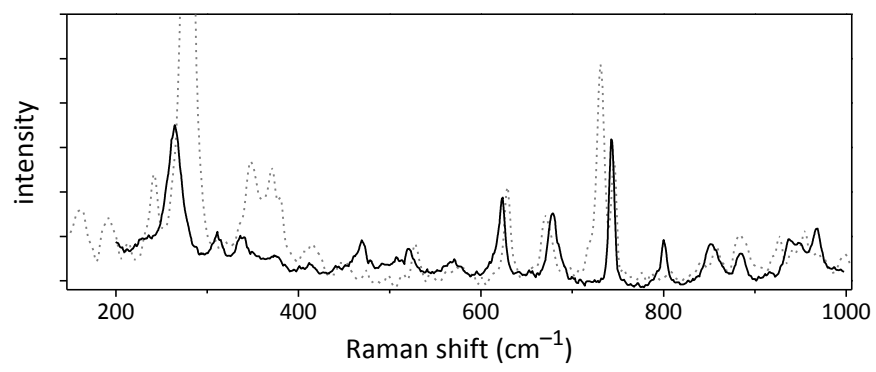

Figure 6.36. Raman spectrum $\left(\lambda_{\mathrm{ex}}=632.8 \mathrm{~nm}\right)$ of the $\mathrm{Cu}_{2}(\mu-\mathrm{OH})_{2}$ complex $(-)$ obtained upon leaving a powder sample of peroxo complex ${ }^{\boldsymbol{t} \mathbf{B u}} \mathbf{P}$ at room temperature, indicated by a colour change from deep violet to light blue. For comparison the spectrum of ${ }^{\boldsymbol{t} B \mathbf{B u}} \mathbf{P}$ is depicted (----). See Figure 6.21a for details on Raman spectra for peroxo complex ${ }^{t B u} \mathbf{P}$.

afforded the corresponding ${ }^{18} \mathrm{O}$-labelled bis(hydroxo) complex (Figure 6.37). However, $\sim 50 \%{ }^{16} \mathrm{O} /{ }^{18} \mathrm{O}$ isotope scrambling was evident, and it is expected that an exchange with water from solvents or air is relatively fast. The IR spectrum of the $\mathrm{Cu}_{2}(\mu-\mathrm{OH})_{2}$ complex features two sharp stretches at $\tilde{v}(\mathrm{O}-\mathrm{H})=3583$ and $3649 \mathrm{~cm}^{-1}$. The spectrum of a powder sample, prepared by leaving ${ }^{18} \mathrm{O}$-labelled ${ }^{t}{ }^{B} \mathbf{P}_{\mathbf{P}}$ room temperature and in air for some days, showed no difference in $\mathrm{O}-\mathrm{H}$ stretch compared to the sample with natural abundance isotope composition. This also indicates easy isotope scrambling.

\section{Structural Investigations}

Single crystals of high quality could be isolated from two different solutions at room temperature upon slow concentration and were analysed by X-ray diffraction. The bis-hydroxo bridged $\left[\left(\mathrm{H}_{\{}\left\{{ }^{t \mathrm{Bu}} \mathrm{BOX}\right\}\right)(\text { solv }) \mathrm{Cu}^{\mathrm{II}}(\mu-\mathrm{OH})\right]_{2}\left(\mathrm{PF}_{6}\right)_{2}$ complexes crystallised in the monoclinic space groups $P 2_{1} / n\left(\right.$ solv $\left.\equiv \mathrm{H}_{2} \mathrm{O}\right)$ and $P 2_{1} / c($ solv $\equiv \mathrm{MeCN} / \mathrm{THF})$. The elucidated structures are depicted in Figure $6.38(\mathrm{solv} \equiv \mathrm{THF} / \mathrm{MeCN})$ and Figure 6.39 (solv $\left.\equiv \mathrm{H}_{2} \mathrm{O}\right)$. Metric parameters of the $\mathrm{Cu}_{2}{ }_{2}(\mathrm{OH})_{2}$ units (Table 6.12), are similar to those reported for other $\mathrm{Cu}_{2}{ }_{2}(\mathrm{OH})_{2}$ dimers. ${ }^{[299]}$ Both complexes (the complex with solv $\equiv \mathrm{H}_{2} \mathrm{O}$ and the complex with MeCN/THF) are structurally very similar. The dicationic complex is a dimer in close structural analogy to the peroxo $\mathrm{Cu}_{2} \mathrm{O}_{2}$ complexes mainly discussed in this chapter. The $\mathrm{Cu} \cdots \mathrm{Cu}$ separation is with $3.04 \AA$ (solv $\equiv \mathrm{THF} / \mathrm{MeCN})$ and $3.00 \AA$ (solv $\left.\equiv \mathrm{H}_{2} \mathrm{O}\right)$, significantly shorter 


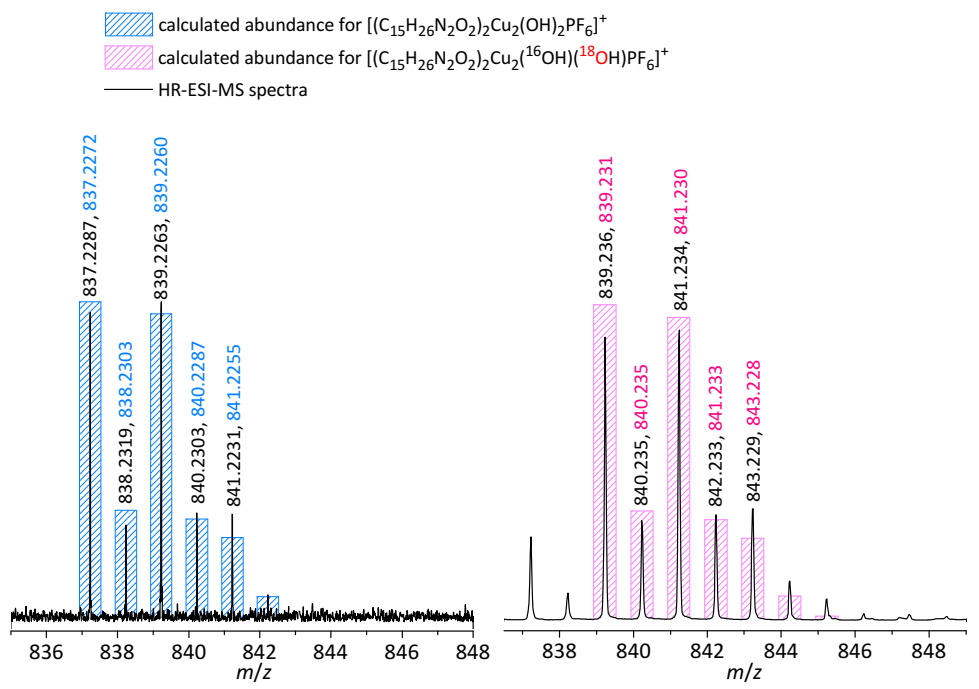

Figure 6.37. High-resolution $\mathrm{ESI}^{+}$mass spectra of $\left.\left[\left(\mathrm{H}_{\{}^{t \mathrm{Bu}} \mathrm{BOX}\right\}\right)(\operatorname{solv}) \mathrm{Cu}(\mu-\mathrm{OH})\right]_{2}\left(\mathrm{PF}_{6}\right)_{2}$ from $\mathrm{MeCN}$ solutions. The magnified regions show the $\left[\left(\mathrm{H}_{\{}^{t \mathrm{Bu}}{ }^{\mathrm{BOX}\}}\right)_{2} \mathrm{Cu}_{2}(\mathrm{OH})_{2}\left(\mathrm{PF}_{6}\right)\right]^{+}$ion with calculated isotope patterns for the natural abundance $\mathrm{Cu}_{2}(\mathrm{OH})_{2}$ complex $($ pink) and the peak obtained from ${ }^{18} \mathrm{O}$-labelled peroxo complex ${ }^{\boldsymbol{t} \mathrm{Bu}} \mathbf{P}$ (blue). The ${ }^{16} \mathrm{O}{ }^{18} \mathrm{O}$ composition is presumably due to isotopic scrambling during the measurement/sample preparation.

than it is in the peroxo complex ${ }^{\boldsymbol{t} \mathbf{B u}} \mathbf{P}$ (3.51 $\AA$ by EXAFS analysis); and it is longer than in a bis( $\mu$-oxo)dicopper(III) (O) complex $(\sim 2.8 \AA) .{ }^{[34]}$ However, the $\mathrm{O} \cdots \mathrm{O}$ separation is with $2.41 \AA$ (solv $\equiv \mathrm{THF} / \mathrm{MeCN}$ ) and $2.45 \AA$ (solv $\equiv \mathrm{H}_{2} \mathrm{O}$ ), significantly longer than a peroxide $\mathrm{O}-\mathrm{O}$ bond $(\sim 1.4 \AA)$ and longer than the $\mathrm{O} \cdots \mathrm{O}$ separation in an $\mathrm{O}$ complex $(\sim 2.3 \AA)$. In the $\mathrm{H}_{2} \mathrm{O}$-ligated complex, the $\mathrm{Cu} \cdots \mathrm{Cu}$ separation is $0.04 \AA$ longer and the $\mathrm{O} \cdots \mathrm{O}$ separation is $0.04 \AA$ shorter than in the THF/MeCNligated complex. The BOX ligands coordinate copper with bite angles of $91.7^{\circ}$ (solv $\equiv \mathrm{THF} / \mathrm{MeCN})$ and $91.8^{\circ}\left(\right.$ solv $\left.\equiv \mathrm{H}_{2} \mathrm{O}\right)$, the $\angle(\mathrm{HO}-\mathrm{Cu}-\mathrm{OH})$ angles are $76.7^{\circ}$ $(\mathrm{THF} / \mathrm{MeCN})$ and $78.5^{\circ}\left(\mathrm{H}_{2} \mathrm{O}\right)$.

The complex resides on a crystallographically imposed inversion centre, thus, the inversion centre is the central point of the $\mathrm{Cu}_{2}(\mathrm{OH})_{2}$ units. The bulky $t \mathrm{Bu}$ ligand backbones are located on opposite sides of the $\mathrm{Cu}_{2}(\mathrm{OH})_{2}$ core. In analogy to $\boldsymbol{t} \mathbf{B u} \mathbf{P}$, solvent ligands are weakly bound $(2.2-2.3 \AA)$ in axial positions. Figure $6.38 \mathrm{~b}$ 
(a)

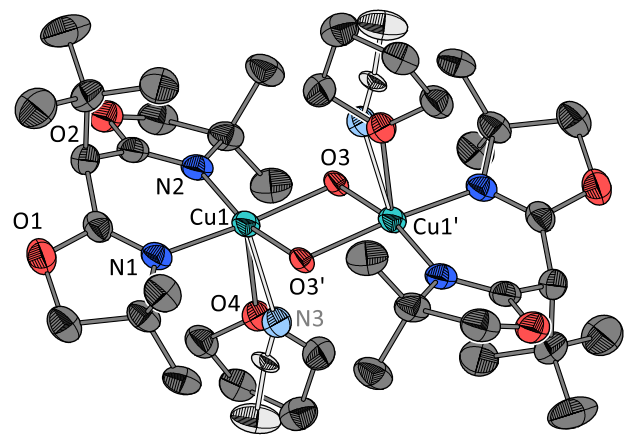

(b)

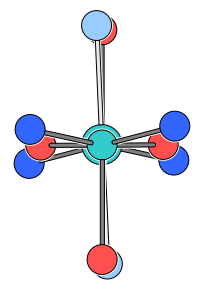

(c)

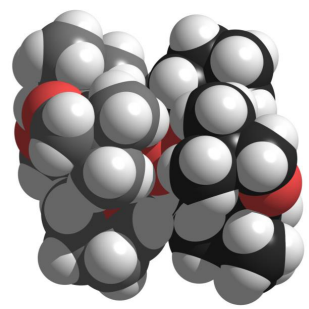

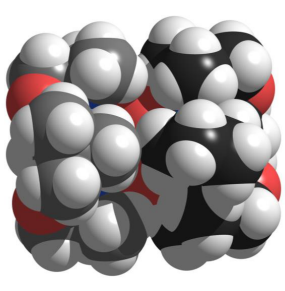

Figure 6.38. X-ray solid-state molecular structure of $\left[(\mathrm{THF})_{0.85}(\mathrm{MeCN})_{0.15}\left(\mathrm{H}_{\{}{ }^{t \mathrm{Bu}} \mathrm{BOX}\right\}\right) \mathrm{Cu}$ $(\mu-\mathrm{OH})]_{2}\left(\mathrm{PF}_{6}\right)_{2}$. (a) ORTEP plot with important atoms labelled. Displacement ellipsoids are drawn at the $50 \%$ probability level; hydrogen atoms and $\mathrm{PF}_{6}^{-}$anions have been omitted for the sake of clarity; $\mathrm{MeCN}$ located at a second site due to crystallographic disorder are drawn in lighter shade; symmetry transformations used to generate equivalent atoms ('): $1-x, 1-y, 1-z$. (b) Detail of coordination sphere, viewing direction along the $\mathrm{Cu} 1 \rightarrow$ Cu1' axis. (c) Van-der-Waals representations to illustrate the shielded $\mathrm{Cu}_{2}(\mathrm{OH})_{2}$ moiety; side (left) and top (right) views; acetonitriles are omitted. Significant interatomic distances and angles are listed in Table 6.12.

shows a view along the $\mathrm{Cu} 1 \rightarrow \mathrm{Cu} 1^{\prime}$ axis; the $\left\{\mathrm{Cu}_{2} \mathrm{O}_{2}\right\}$ moiety is planar due to the molecule's symmetry (torsion angle $\varphi\left(\mathrm{Cu} 1-\mathrm{O} 3-\mathrm{O} 3^{\prime}-\mathrm{Cu} 1^{\prime}\right)=180^{\circ}$ ). Such a coordination mode and symmetry is quite common for a $\mathrm{Cu}_{2}(\mathrm{OH})_{2}$ complex and the structural parameters are remarkably similar to square-planar coordinated bis( $\mu$-hydroxo)dicopper(II) dimers with bis-guanidine ligands. ${ }^{[299]}$ In the structure, one BOX ligand coordinates to the $\mathrm{Cu}_{2}(\mathrm{OH})_{2}$ core from above and one from below the $\left\{\mathrm{Cu}_{2} \mathrm{O}_{2}\right\}$ plane. The angles between the $\left\{\mathrm{Cu}_{2} \mathrm{O}_{2}\right\}$ plane and the planes spanned by the $\{\mathrm{NCuN}\}$ coordinations are $16.4^{\circ}\left(\right.$ solv $\left.\equiv \mathrm{H}_{2} \mathrm{O}\right)$ and $14.6^{\circ}($ solv $\equiv \mathrm{THF} / \mathrm{MeCN})$, 


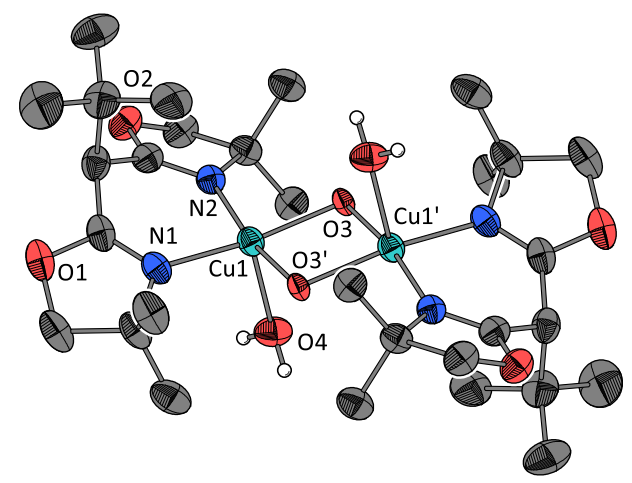

Figure 6.39. X-ray solid-state molecular structure of $\left[\left(\mathrm{H}_{2} \mathrm{O}\right)\left(\mathrm{H}\left\{{ }^{t \mathrm{Bu}} \mathrm{BOX}\right\}\right) \mathrm{Cu}(\mu-\mathrm{OH})\right]_{2}\left(\mathrm{PF}_{6}\right)_{2}$. ORTEP plot with important atoms labelled. Displacement ellipsoids are drawn at the $50 \%$ probability level; $\mathrm{PF}_{6}^{-}$anions and most hydrogen atoms have been omitted for clarity; symmetry transformations used to generate equivalent atoms ('): $1-x, 1-y, 1-z$. Significant interatomic distances and angles are listed in Table 6.12.

respectively. The BOX ligands are even stronger tilted with respect to the $\left\{\mathrm{Cu}_{2} \mathrm{O}_{2}\right\}$ plane, the angles between the plane spanned by the BOX ligand's $\mathrm{C}=\mathrm{N}$ groups and the $\left\{\mathrm{Cu}_{2} \mathrm{O}_{2}\right\}$ planes are $30.4^{\circ}\left(\right.$ solv $\equiv \mathrm{H}_{2} \mathrm{O}$ ) and $29.3^{\circ}$ (solv $\equiv \mathrm{THF} / \mathrm{MeCN}$ ), respectively. The ligand planes however, are coplanar with respect to each other. The six-membered chelate rings adopt a boat conformation.

The copper centres are coordinated in a square pyramidal fashion, the $\mathrm{Cu}$ atoms are slightly moved outside of the $\left\{\mathrm{N}_{2} \mathrm{CuO}_{2}\right\}$ planes and into the coordination pyramids. The copper atoms have angular structural parameters $\tau_{5}$ of 0.02 (solv $\equiv \mathrm{THF}$ or $\mathrm{MeCN})$ and $0.10\left(\mathrm{solv} \equiv \mathrm{H}_{2} \mathrm{O}\right)$, which characterises the geometries as square pyramidal with slight distortion in the case of the $\mathrm{H}_{2} \mathrm{O}$ ligated complex; see Section A.1, p. 269, for a definition of $\tau_{5}$. The $\tau$ value is not influenced by the position of the apical ligands, but is a parameter of the planarity of the $\left\{\mathrm{N}_{2} \mathrm{CuO}_{2}\right\}$ moiety. However, while $\mathrm{H}_{2} \mathrm{O}$ is located above the middle of the pyramid, as well as THF is roughly in the middle, MeCN is located more towards the $\left\{\mathrm{Cu}_{2} \mathrm{O}_{2}\right\}$ moiety. Figure 6.38c shows a Van-der-Waals representation of the THF/MeCN-coordinated complex. The structures, especially the THF-coordinated one, are quite compact and are of an overall spherical shape and the $\mathrm{Cu}_{2}(\mathrm{OH})_{2}$ core is completely shielded by the organic residues. 


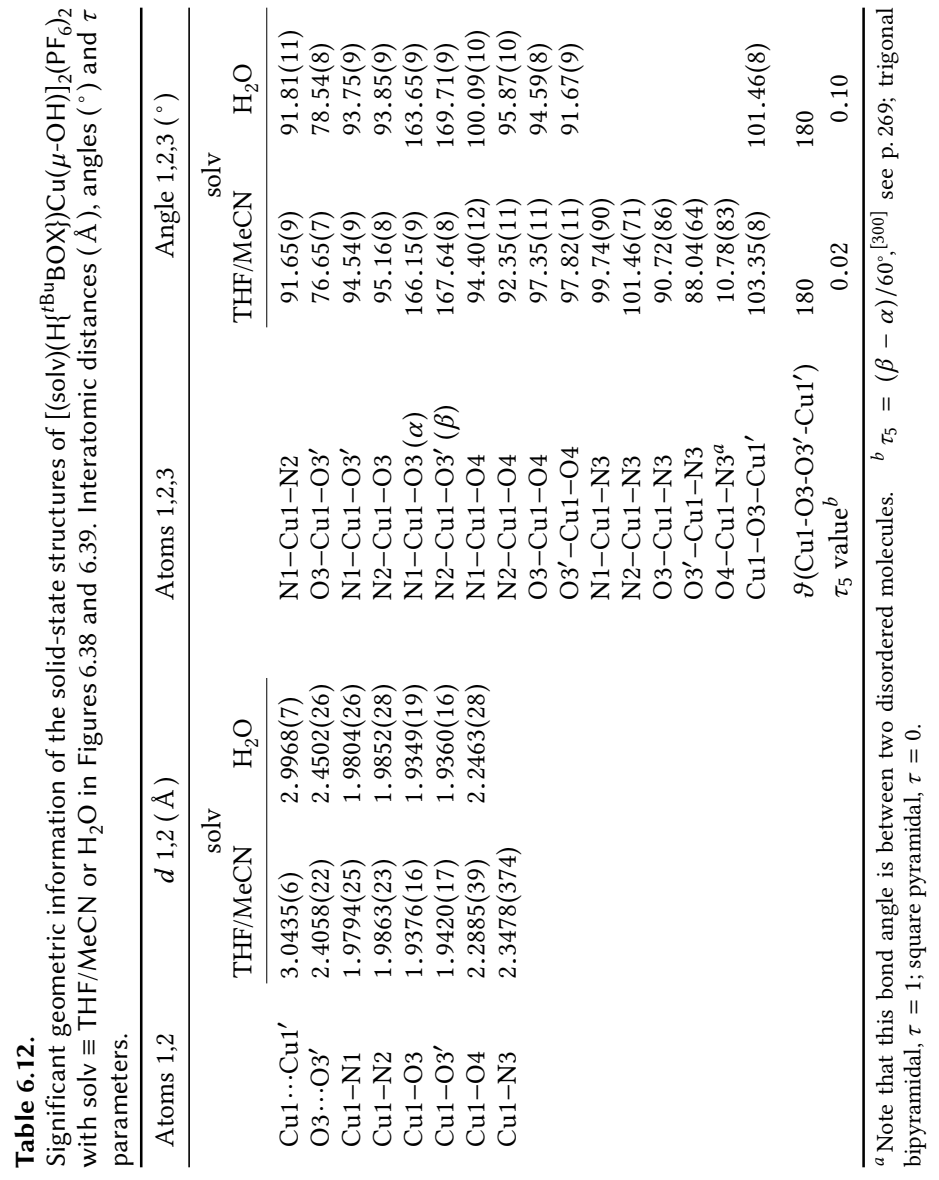


The DFT computed structure of ${ }^{\mathbf{t} \mathbf{B}} \mathbf{P}$ is remarkably similar to the X-ray structures of the $\mathrm{Cu}_{2}(\mathrm{OH})_{2}$ complexes. Although keeping in mind that the $\mathrm{Cu}_{2}(\mathrm{OH})_{2}$ structural parameters have been exploited as starting coordinates for the calculation of the ${ }^{\boldsymbol{t} \mathbf{B u} \mathbf{P}}$ structure, the calculations had not required a drastic alteration of geometric parameters, other than the parameters of the $\mathrm{Cu}_{2} \mathrm{O}_{2}$ moiety, of course. It therefore might be deduced, that the $\mathrm{Cu}_{2}(\mathrm{OH})_{2}$ complexes are good structural models for the analogous $\left(\mu-\eta^{2}: \eta^{2}-\mathrm{O}_{2}\right) \mathrm{Cu}_{2}$ complex.

\subsubsection{Ligand Oxygenation}

No indication for any oxidative degradation of the $\mathrm{H}\left\{{ }^{t \mathrm{Bu}} \mathrm{BOX}\right\}$ ligand itself was found in course of this work. This is important, considering that intramolecular ligand oxygenation or oxidation has often been observed in $\mathrm{Cu}_{2} \mathrm{O}_{2}$ complexes with other capping ligands, ${ }^{[60,301]}$ and regarding the degradation by $\mathrm{CuCl}_{2}$ coordination, which was investigated in detail for the $\left.\mathrm{H}_{\{}{ }^{\mathrm{R}} \mathrm{BOX}\right\}$ ligands in focus of this work in Chapter 5. The UV-vis spectroscopic trace of ${ }^{\mathbf{H}} \mathbf{P}$ formation however suggested degradation of the $\mathrm{Cu}_{2} \mathrm{O}_{2}$ complex already upon formation from the respective $\mathrm{Cu}^{\mathrm{I}}$ complexes and $\mathrm{O}_{2}$ (see Figure 6.11, p. 130). Since the curve shape is similar to the kinetic trace of a consecutive $\mathrm{A} \rightarrow \mathrm{B} \rightarrow \mathrm{C}$ reaction, it was attempted to fit the spectroscopic trace with this kinetic model. The plot in Figure 6.40 shows the best fit and clearly excludes this supposed ${ }^{\mathbf{H}} \mathbf{P}$ degradation pathway. It can be assumed, that the characteristic curve shape results from precipitation of ${ }^{H} \mathbf{P}$ only. Precipitation is however only well evident for larger amounts, as the precipitated powder is very fine; the observed yields additionally indicate no significant degradation upon ${ }^{\mathbf{H}} \mathbf{P}$ formation.

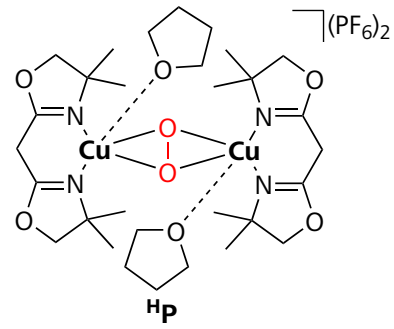

1. ambient temperatures

2. $\mathrm{NH}_{4} \mathrm{OH}$ workup

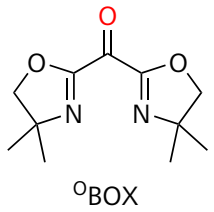

Scheme 6.10 Thermal degradation of ${ }^{\mathrm{H}} \mathbf{P}$ along with ligand oxygenation. 


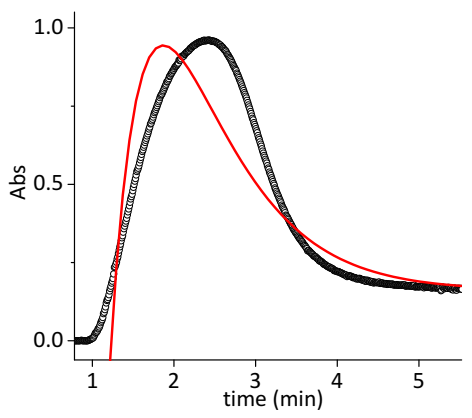

Figure 6.40 Kinetic trace $(\bigcirc)$ of ${ }^{\mathrm{H}} \mathbf{P}$ formation and best fit (-) with a consecutive $\mathrm{A} \rightarrow \mathrm{B} \rightarrow \mathrm{C}$ kinetic model, excluding this ${ }^{H} \mathbf{P}$ degradation sequence.

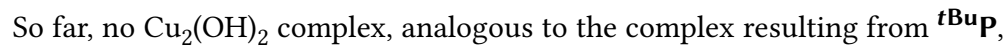
could be isolated from the peroxo complex ${ }^{\mathrm{H}} \mathbf{P}$. Experimental evidence suggests however, that oxygenation of the ligand's backbone takes place upon degradation of ${ }^{\mathbf{H}} \mathbf{P}$ (Scheme 6.10). When dissolved in $\mathrm{CH}_{2} \mathrm{Cl}_{2}$ or acetone at room temperature, solutions of ${ }^{\mathbf{H}} \mathbf{P}$ turn red to brown. Analysis by ESI mass spectrometry indicated the presence of oxygenated ligand. The observed base peak $\left(\mathrm{m} / z=225.1,\left[{ }^{\mathrm{O}} \mathrm{BOX}+\mathrm{H}\right]^{+}\right)$ matches the pattern expected for the oxygenated ligand with a bridging $\mathrm{C}=\mathrm{O}$ as the backbone. It was so far possible to isolate only a small amount of oxygenated ligand ${ }_{\mathrm{BOX}}$. Analysis by ${ }^{1} \mathrm{H}$ and ${ }^{13} \mathrm{C}$ NMR showed that the compound is not significantly different from $\left.\mathrm{H}_{\{}{ }^{\mathrm{H}} \mathrm{BOX}\right\}$, but proved also the absence of any $\mathrm{H}$ atoms at the $\mathrm{C}$ atom linking the two oxazoline rings; and also a corresponding cross peak signal was absent in an ${ }^{1} \mathrm{H},{ }^{13} \mathrm{C}$-HSQC experiment. Such ligand-oxygenation reactivity is not unlikely, when considering the closely related diketiminate $(\mathrm{NaCNac})$ ligand class. It has previously been shown that a NacNac ligand is oxygenated analogously by heating to $50{ }^{\circ} \mathrm{C}$ in air for $12 \mathrm{~h}$ with $\mathrm{Cu}(\mathrm{OAc})_{2} \cdot{ }^{[169]} \mathrm{See}$ also Section 5.4.4, p. 97 for a similar reactivity of $\left.\mathrm{H}_{\{}{ }^{\mathrm{H}} \mathrm{BOX}\right\}$.

\subsection{Reactivity Towards External Substrates}

Preliminary experiments showed that ${ }^{\boldsymbol{B} \mathbf{B u}} \mathbf{P}$ reacts with 2,4-di-tert-butylphenol to give the $\mathrm{C}-\mathrm{C}$ coupling product 3,3',5,5'-tetra-tert-butyl-2,2'-biphenol in $38 \%$ conversion (Scheme 6.11), whereas ortho-hydroxylation was not observed (cf. Section 1.3, p. 1.3, in the introduction). While this may have electronic reasons associated with the butterfly-type core, ${ }^{[265]}$ it should be noted that ${ }^{{ }^{\mathbf{B u}} \mathbf{P}} \mathbf{P}$ is quite compact due to the bulky dimethyl and tert-butyl substituents, as well as the bound 


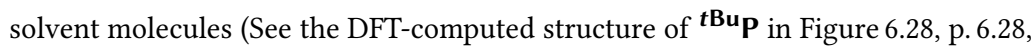
also comparable to the van der Waals plots of the bis(hydroxo)dicopper(II) complex in Figure 6.38c, p. 6.38). Thus, the central $\mathrm{Cu}_{2} \mathrm{O}_{2}$ core hardly seems accessible for large substrates. Furthermore, the low reaction temperatures, which are necessary to stabilise the peroxo complex, might also play a role in the general reactivity. Further reactivity studies with $p$-ethylphenol gave a mixture of presumably a minor amount of oxidation and/or radical-coupling products, which could not be elucidated by now.

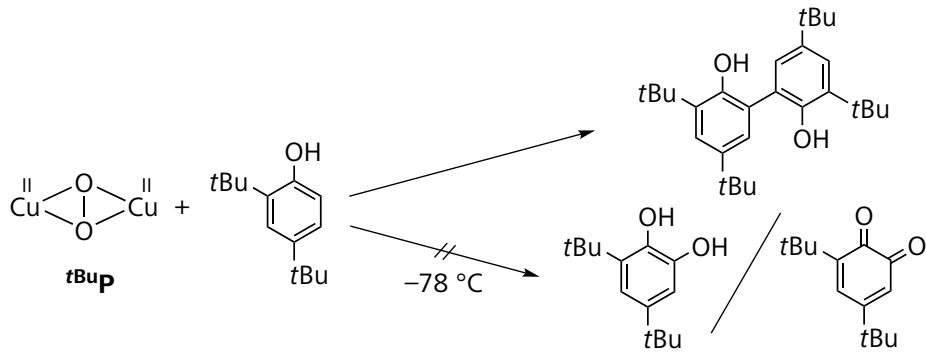

Scheme 6.11 Oxidative coupling of 2,4-di-tert-butylphenol to 3,3',5,5'-tetra-tert-butyl-2,2'biphenol by ${ }^{\boldsymbol{t} \mathrm{Bu}} \mathbf{P}$ in $38 \%$ conversion. No catechol or $o$-quinone product was detected.

\subsection{Conclusion}

Copper(I) complexes of all four BOX ligands have been prepared and insights have been gained by spectroscopy, electrochemical techniques along with X-ray structure determination.

It was shown, that all of these four $\mathbf{C} \mathbf{u}^{\prime} \mathbf{R}$ compounds reversibly bind dioxygen at low temperatures and serve as new functional hemocyanin models. The obtained thermolabile $\mu-\eta^{2}: \eta^{2}$-peroxodicopper(II) complexes ${ }^{\mathbf{R}} \mathbf{P}$ have been characterized by a variety of methods, both in solution and in solid state. This includes optical and Raman vibrational spectroscopies, ${ }^{18} \mathrm{O}_{2}$ isotope labelling, as well as SQUID magnetometry. Furthermore, oxidation states, together with structural parameters could be elucidated by synchrotron X-ray absorption spectroscopic techniques. It was moreover possible to establish a DFT computational model of ${ }^{\boldsymbol{t} \mathbf{B u}} \mathbf{P}$, in accordance with the experimentally aggregated structural, spectroscopic and magnetic data. This results indicated also a slightly butterfly-shaped $\mathrm{Cu}_{2} \mathrm{O}_{2}$ core. 
While the three complexes ${ }^{\mathbf{H}} \mathbf{P}{ }^{\mathbf{M e}} \mathbf{P}$ and ${ }^{\mathbf{P h}} \mathbf{P}$ support the results for ${ }^{\boldsymbol{t} \mathbf{B u}} \mathbf{P}$, they exhibit more pronounced thermal lability and limited solubility inherent to this class of compounds.

Thermodynamic and kinetic parameters of $\mathrm{O}_{2}$ activation by $\mathbf{C} \mathbf{u}^{\prime} \mathbf{t} \mathbf{B u}$ have been investigated in detail by use of cryo-stopped flow kinetic technique and a mechanistic picture could be drawn, evidencing a slow and unusually strong entropydriven mechanism of $\mathrm{O}_{2}$ activation, further on also responsible for the thermal lability of this system. Preliminary experiments showed no activity towards phenol hydroxylation and yielded only the $\mathrm{C}-\mathrm{C}$ coupled biphenol. The lack of hydroxylation reactivity might be attributed to steric hindrance around the $\mathrm{Cu}_{2} \mathrm{O}_{2}$ core, its butterfly shape or the required low temperatures in general. Finally, bis( $\mu$-hydroxo)dicopper(II) compounds were structurally characterised and have been identified as the thermal degradation products of ${ }^{\boldsymbol{t} \mathbf{B u}} \mathbf{P}$. While for ${ }^{\mathbf{H}} \mathbf{P}$, ligand oxygenation in the course of thermal decomposition was confirmed.

Conclusively, this work demonstrates that simple bis(oxazoline)s, which represent a privileged ligand class, are suitable scaffolds for supporting biomimetic $\mathrm{Cu} / \mathrm{O}_{2}$ species. Since numerous BOX derivatives are readily available, a rich and versatile $\mathrm{Cu} / \mathrm{O}_{2}$ chemistry can be expected. 



\section{7}

\section{A Bis $(\mu$-oxo) Complex by Stepwise Conversion of a Peroxo Species}

\subsection{Introduction}

$\mathrm{N}$ the preceding chapters, the coordinating abilities of the four bis(oxazoline)

ligands $\left.\mathrm{H}_{\{}{ }^{\mathrm{R}} \mathrm{BOX}\right\}(\mathrm{R} \equiv \mathrm{H}, \mathrm{Me}, \mathrm{Ph}, t \mathrm{Bu})$ towards copper(I) and copper(II) have been investigated in detail, and it has been shown that all form stable complexes with $\mathrm{Cu}^{\mathrm{I}}$, as well as $\mu-\eta^{2}: \eta^{2}$-peroxodicopper(II) $\left({ }^{\mathrm{S}} \mathrm{P}\right)$ complexes upon reaction with $\mathrm{O}_{2}$, relatively stable at $-78^{\circ} \mathrm{C}$. In contrast, the BOX ligands are readily oxidised at room temperature by $\mathrm{CuCl}_{2}$ acting as oxidant. This reactivity was expressed by dimerisation and oxygenation of the least bulky $\left.\mathrm{H}_{\{}{ }^{\mathrm{H}} \mathrm{BOX}\right\}$ and $\mathrm{H}\left\{{ }^{\mathrm{Me}} \mathrm{BOX}\right\}$, while more bulky $\left.\mathrm{H}_{\{}{ }^{\mathrm{Ph}}{ }_{\mathrm{BOX}}\right\}$ showed only an oxygenation reaction. Differing from this, the ligand with the bulkiest residue $\left.\mathrm{H}_{\left\{{ }^{t} \mathrm{Bu}\right.} \mathrm{BOX}\right\}$ forms a stable $\mathrm{Cu}^{\mathrm{II}}$ complex. It is assumed that the residue $\mathrm{R}$ is shielding the backbone-proton and also prevents the ligand from adopting a planar conformation. Due to this reason, the deprotonation of the $\left.\mathrm{H}_{\{}{ }^{\mathrm{Bu}} \mathrm{BOX}\right\}$ ligand was not feasible.

In spite of these problems, it was intended to establish copper complexes and copper-oxygen complexes also with the $\left.\mathrm{H}_{\{}{ }^{\mathrm{R}} \mathrm{BOX}\right\}$ ligands in their deprotonated condition as bis(oxazolinate) $\left\{{ }^{\mathrm{R}} \mathrm{BOX}^{-}\right\}$. Since the least-bulky ligands suffer from the oxidative dimerisation reactions and it was not feasible to deprotonate the $\mathrm{H}\left\{{ }^{t \mathrm{Bu}} \mathrm{BOX}\right\}$ ligand, $\mathrm{H}\left\{{ }^{\mathrm{Ph}} \mathrm{BOX}\right\}$ was selected as the only ligand of the four, which might be suitable for a deeper investigation using it in its deprotonated form.

\subsection{Preparation and Spectral Properties of ${ }^{\mathrm{Ph}} \mathrm{O}$}

\section{Deprotonation of $\left.\mathrm{H}_{\left\{{ }^{\mathrm{Ph}}\right.} \mathrm{BOX}\right\}$ and its $\mathrm{Cu}$ ' Complex}

The complex was prepared starting from $\left.\mathrm{H}_{\{}{ }^{\mathrm{Ph}} \mathrm{BOX}\right\}$ ligand (Scheme 7.1). $\left.\mathrm{H}_{\left\{{ }^{\mathrm{Ph}}\right.} \mathrm{BOX}\right\}$ was deprotonated by the addition of 1.0 eq. $n$-butyl lithium/hexane solution to 


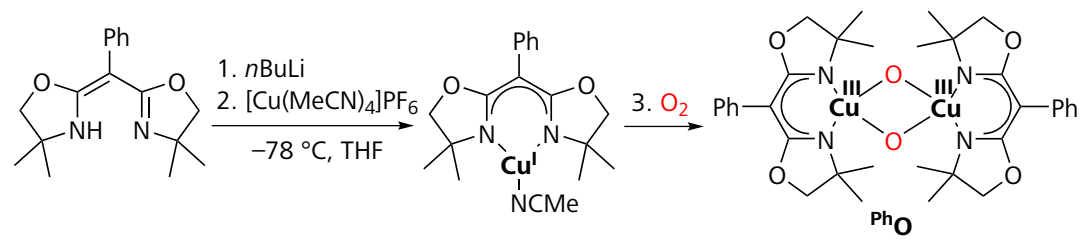

Scheme 7.1 Synthesis of bis( $\mu$-oxo)dicopper(III) complex ${ }^{\mathrm{Ph}} \mathrm{O}$ from the $\mathrm{Cu}^{\prime}$ complex of $\mathrm{Li}\left\{{ }^{\mathrm{Ph}} \mathrm{BOX}\right\}$ in THF.

the ligand in THF under an atmosphere of nitrogen at $-78^{\circ} \mathrm{C}$. This deprotonation was also conducted in a stepwise manner followed by UV-vis spectroscopy (see Figure 7.1). The spectrum of $\mathrm{H}_{\{}\left\{{ }^{\mathrm{Ph}} \mathrm{BOX}\right\}(-)$ is characterised by an intense absorption at around $\lambda_{\max }=280 \mathrm{~nm}\left(\epsilon=34 \mathrm{~mm}^{-1} \mathrm{~cm}^{-1}\right)$, assigned to a $\pi \rightarrow \pi^{*}$ transition; the »double peak « shape originates most likely from the presence of both, diimine and iminoenamine tautomers of $\left.\mathrm{H}_{\{}{ }^{\mathrm{Ph}} \mathrm{BOX}\right\}$ (cf. Chapter 4 for details on $\mathrm{H}_{2}\left\{{ }^{\mathrm{Ph}} \mathrm{BOX}\right\}$ tautomerism). The spectral changes upon deprotonation of $\mathrm{H}\left\{{ }^{\mathrm{Ph}} \mathrm{BOX}\right\}$ are however only small and the spectrum of $\left\{{ }^{\mathrm{Ph}} \mathrm{BOX}\right\}^{-}(-)$is quite similar to that of $\mathrm{H}_{\{}\left\{{ }^{\mathrm{Ph}} \mathrm{BOX}\right\}$.

After warming the $\left.\mathrm{Li}_{i}{ }^{\mathrm{Ph}}{ }_{\mathrm{BOX}}\right\}$ solution to room temperature, 1.0 eq. $\left.\left[\mathrm{Cu}(\mathrm{MeCN})_{4}\right)\right]-$ $\mathrm{PF}_{6}$ was added. The colourless solution turned yellow, indicated also by a shift of the intense ligand peak to slightly lower energy ( $300 \mathrm{~nm}, \epsilon=35 \mathrm{~mm}^{-1} \mathrm{~cm}^{-1}$, $-)$ and a shoulder at $\sim 370 \mathrm{~nm}\left(\epsilon \approx 1.5 \mathrm{M}^{-1} \mathrm{~cm}^{-1}\right)$. After the full dissolution of $\left[\mathrm{Cu}(\mathrm{MeCN})_{4}\right] \mathrm{PF}_{6}$, the mixture was recooled to $-78^{\circ} \mathrm{C}$.

\section{The bis( $\mu$-oxo)dicopper(III) complex ${ }^{\mathrm{Ph}} \mathrm{O}$}

The ${ }^{\mathbf{P h}} \mathbf{O}$ complex was obtained upon injection of dry $\mathrm{O}_{2}$ gas into the solution at $-78^{\circ} \mathrm{C}$. The formation of ${ }^{\mathrm{Ph}} \mathbf{O}(-)$ is well evident by a very rapid and intense colour change of the copper(I) solution to a very dark green colour (Figure 7.1). Interestingly, no ${ }^{\mathbf{P h}} \mathbf{O}$ formation is observed when the $\left.\left[(\mathrm{MeCN}) \mathrm{Cu}^{\mathrm{I}}\left(\mathrm{H}_{\{}{ }^{\mathrm{Ph}}{ }_{\mathrm{BOX}}\right\}\right)\right]$ $\mathbf{C u}^{\prime} \mathbf{P h}$ complex is prepared first and $n \mathrm{BuLi}$ is added to this complex in a second step, followed by $\mathrm{O}_{2}$ at $-78^{\circ} \mathrm{C}$.

The UV-vis spectrum of ${ }^{\mathbf{P h}} \mathbf{O}$ features strong transitions at $\lambda_{\max }=288,334$ and $395 \mathrm{~nm}\left(\epsilon=40,13\right.$ and $\left.8 \mathrm{~mm}^{-1} \mathrm{~cm}^{-1}\right)$ and further weaker and broad features around 500 and $700 \mathrm{~nm}$. While the strong absorption of the copper-oxygen complex at $288 \mathrm{~nm}$ most likely arises from the BOX ligand's $\pi \rightarrow \pi^{*}$ transition and might obscure transitions arising from a copper-oxygen species in this region, the intense 


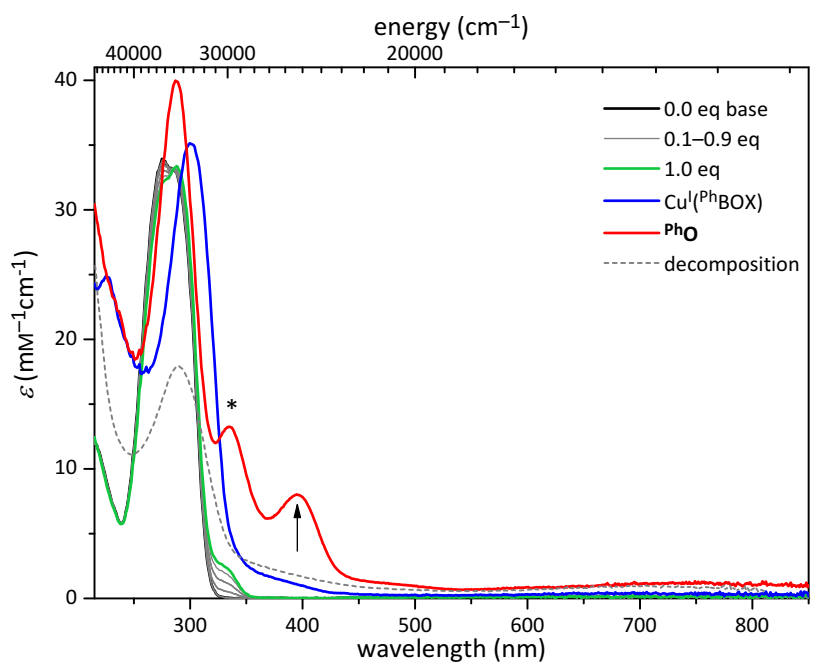

Figure 7.1. UV-vis spectra $\left(\mathrm{THF},-78^{\circ} \mathrm{C}\right)$ of the $\left.\mathrm{H}_{\{}^{\mathrm{Ph}} \mathrm{BOX}\right\}$ ligand $(-)$ and its stepwise $(-)$ deprotonation to $\left\{{ }^{\mathrm{Ph}} \mathrm{BOX}\right\}^{-}(-)$. The corresponding $\mathrm{Cu}^{\prime}$ complex $(-)$ from Scheme 7.1, $c=0.58 \mathrm{~mm}$ (yellow solution) and its bis $\left(\mu\right.$-oxo) complex ${ }^{\mathrm{Ph}} \mathbf{O}(-)$, which is formed upon injection of $\mathrm{O}_{2}$ into this solution. Upon warming to r.t., the complex decays, indicated by vanishing of spectral features (---). The asterisk denotes the presence of the corresponding $\mu-\eta^{2}: \eta^{2}$-peroxo isomer. Equivalents of base are per $\mathrm{Cu}$ atom.

feature at $400 \mathrm{~nm}$ was not observed before. Absorptions at $\sim 300$ and $\sim 400 \mathrm{~nm}$ are indicative for a bis( $\mu$-oxo)dicopper(III) (O) species. The $300 \mathrm{~nm}$ features arise from $\operatorname{bis}(\mu$-oxo $) \pi_{\sigma}^{*} \rightarrow \mathrm{Cu} d_{x^{2}-y^{2}}$ charge-transfer transitions, similar to the $\sim 350 \mathrm{~nm}$ transition in ${ }^{\mathrm{S}} \mathrm{P}$ complexes, while the $400 \mathrm{~nm}$ features are unique in $\mathrm{O}$ species and arise from bis( $\mu$-oxo) $\sigma^{*} \rightarrow \mathrm{Cu} d_{x^{2}-y^{2}} \mathrm{CT}$ transitions and are quite intense due to the good orbital overlap between both orbitals. The high intensity was additionally ascribed to the significant covalency of the $\mathrm{Cu}-\mathrm{O}$ bonds. ${ }^{[34]}$ The additional feature in the spectrum at $333 \mathrm{~nm}$ is presumably originating from the presence of the corresponding ${ }^{\mathrm{S}} \mathbf{P}$ isomer, in equilibrium with the $\mathbf{O}$ species (Scheme 7.2). Such an equilibrium was evidenced for some complexes with different ligand systems (see the Introduction, Section 2.2.2, p. 22). 
Scheme 7.2 Equilibrium of $\mu-\eta^{2}: \eta^{2}-$ peroxodicopper(II) ${ }^{\mathbf{S}} \mathbf{P}$ and bis( $\mu$-oxo $)$ dicopper(III) $\mathbf{O}$ isomers.

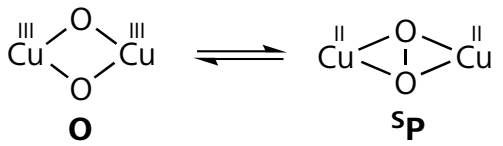

Solutions of ${ }^{\mathbf{P h}} \mathbf{O}$ can be stored at $-80{ }^{\circ} \mathrm{C}$ for at least four weeks without changes of colour. A UV-vis measurement showed the same spectral features as found in a fresh sample. The ${ }^{\mathbf{P h}} \mathbf{O}$ copper-oxygen complex is temperature sensitive and decays upon warming to e. g. room temperature. The decay is accompanied by bleaching of the solution to colourless or light green and disappearance of the spectral features (----, in Figure 7.1). The resulting UV-vis spectrum is somewhat reminiscent to that of the corresponding $\mathrm{Cu}^{\mathrm{I}}$ complex with additional weak absorptions in the lower energy region $(\sim 600-800 \mathrm{~nm})$. Upon cooling again to $-78^{\circ} \mathrm{C}$ no sign of repeated copper-oxygen complex formation was observed.

\subsection{Stepwise Conversion ${ }^{\mathrm{Ph}} \mathrm{P} \rightarrow{ }^{\mathrm{Ph}} \mathrm{O}$}

To gain further insight into the intimate influence of the protonation state of the $\left.\mathrm{H}_{\{}{ }^{\mathrm{Ph}} \mathrm{BOX}\right\}$ ligand onto the nature of the copper-dioxygen interaction, the $\mu-\eta^{2}: \eta^{2}$-peroxodicopper(II) complex ${ }^{\mathbf{P h}} \mathbf{P}$ was titrated with base in expectation of formation of ${ }^{\mathbf{P h}} \mathbf{O}$ by this divergent route (Scheme 7.3).

The titration ${ }^{\mathbf{P h}} \mathbf{P} \rightarrow{ }^{\mathbf{P h}} \mathbf{O}$ was done in acetone solvent to avoid any solubility issues. ${ }^{\mathbf{P h}} \mathbf{P}$ was prepared according to the experiments described in Chapter 6. As a base, $n$-butyl lithium was added in aliquots of 0.1 eq. to the ${ }^{\mathbf{P h}} \mathbf{P}$ complex and the process was followed by help of an UV-vis immersion probe in a custom made

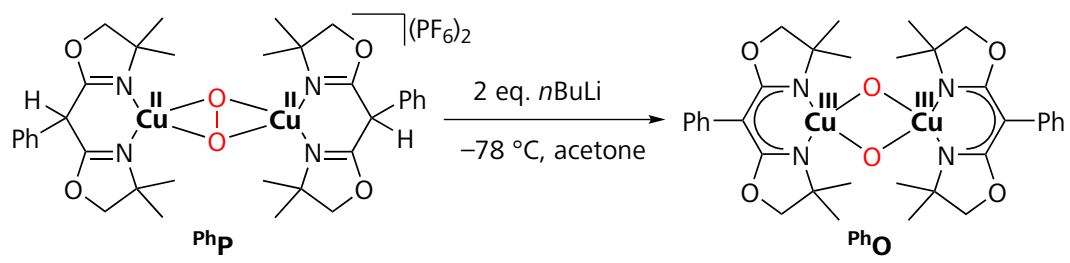

Scheme 7.3 Synthesis of bis( $\mu$-oxo)dicopper(III) complex ${ }^{\mathbf{P h}} \mathbf{O}$ by deprotonation of the corresponding $\mu-\eta^{2}: \eta^{2}$-peroxodicopper(II) complex ${ }^{\mathbf{P h}} \mathbf{P}$. 

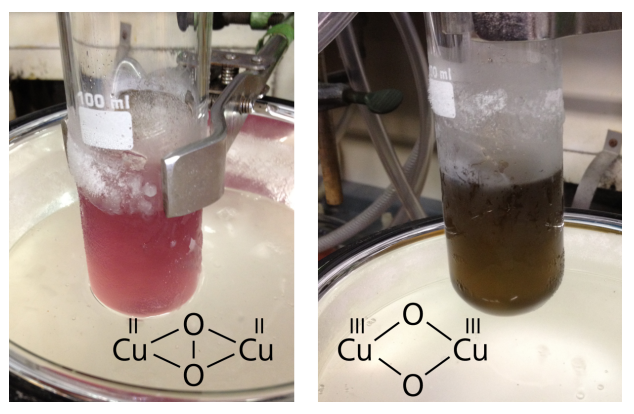

Figure 7.2

Left: pink coloured side-on $\mu$ $\eta^{2}: \eta^{2}$-peroxodicopper(II) complex PhP. Right: dark-green coloured bis( $\mu$-oxo)dicopper(III) complex ${ }^{\mathbf{P h}} \mathbf{O}$, obtained upon deprotonation with $n \mathrm{BuLi}$ at $-78^{\circ} \mathrm{C}$.

flask at $-78^{\circ} \mathrm{C}$. The transition of the complex was well evident in course of the titration, the colour of ${ }^{\mathbf{P h}} \mathbf{P}$ changed from pink to dark green/brown, characteristic for ${ }^{\mathbf{P h}} \mathbf{O}$ (a photograph is depicted in Figure 7.2 for the respective compounds).

UV-vis spectra recorded in course of the titration are depicted in Figure 7.3. Spectral features below $\sim 310 \mathrm{~nm}$ are not visible due to the acetone solvent spectral cut-off. After the addition of each aliquot, the spectrum was recorded at least a second time to ensure full conversion. The spectral changes were found to be instantaneous and final in each first spectrum.

During the titration, the intense $330 \mathrm{~nm}$ feature of peroxo ${ }^{\mathbf{P h}} \mathbf{P}(-)$ became smaller, while the $400 \mathrm{~nm}$ feature of ${ }^{\mathbf{P h}} \mathbf{O}$ grew until 0.5 eq. base per $\mathrm{Cu}$ was added (-). Upon further addition of base, the $400 \mathrm{~nm}$ feature further grew, but with an apparently faster pace, concomitant with the $330 \mathrm{~nm}$ feature is faster shrinking, until 1.0 eq. base per $\mathrm{Cu}$ was added (-). No further change of the ${ }^{\mathbf{P h}} \mathbf{O}$ spectrum was observed upon further additions of base $(-, 1.0 \rightarrow 1.5$ eq.). The spectroscopic features are listed in Table 7.1.

Table 7.1.

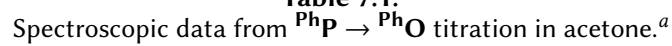

\begin{tabular}{rrlc}
\hline compound & eq. ${ }^{b}$ & UV-vis: $\lambda_{\max }, \mathrm{nm}\left(\epsilon, \mathrm{mM}^{-1} \mathrm{~cm}^{-1}\right)$ & $\mathrm{O} /{ }^{\mathrm{S}} \mathbf{P}^{c}$ \\
\hline${ }^{\mathbf{P h}} \mathbf{P}$ & 0.0 & $334(47), 500(1)$ & 0 \\
${ }^{1 / 2}{ }^{\mathbf{P h}} \mathbf{O}$ & 0.5 & $338(34), 400 \operatorname{sh}(6), \sim 488 \operatorname{sh}(1), \sim 600 \operatorname{sh}(0.5), \sim 750(0.5)$ & $\sim 0.21$ \\
${ }^{\mathbf{P h}} \mathbf{O}$ & 1.0 & $338(15), 400(19), \sim 484 \operatorname{sh}(2), \sim 600 \operatorname{sh}(1.5), \sim 750(2.5)$ & $\sim 0.69$ \\
\hline
\end{tabular}

${ }^{a}$ sh $\equiv$ shoulder. ${ }^{b}$ eq. base per $\mathrm{Cu} .{ }^{c}$ Ratio of bis $(\mu$-oxo) to peroxo isomer. 


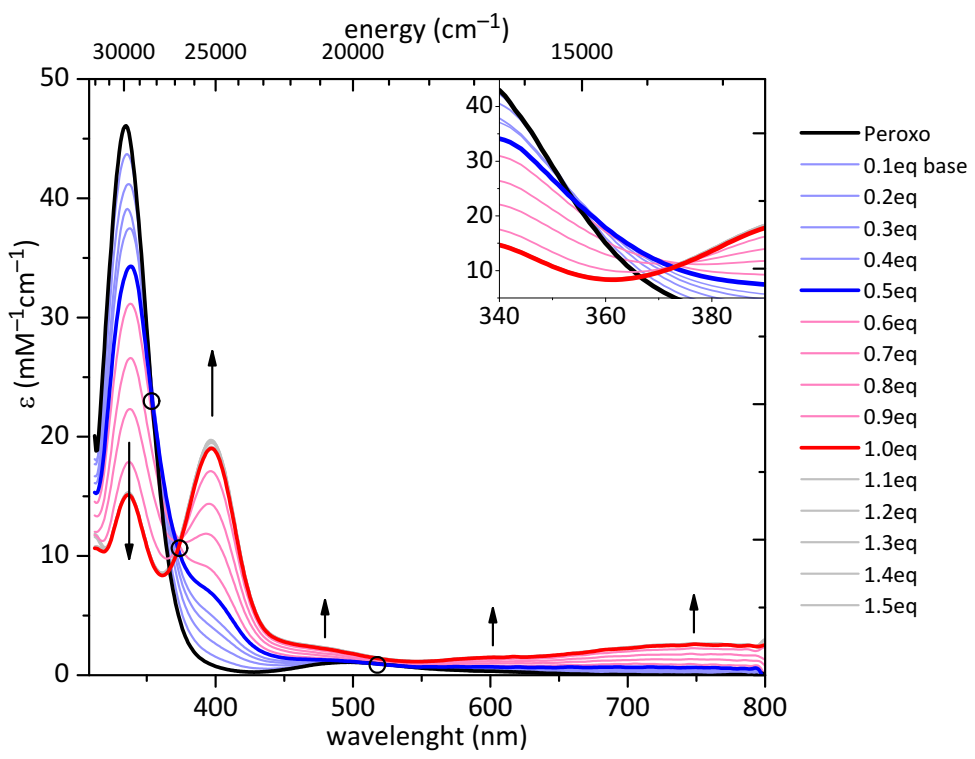

Figure 7.3. UV-vis spectra of the titration of ${ }^{\mathbf{P h}} \mathbf{P}(-)$ with $0 \rightarrow 1.5$ eq. $n \mathrm{BuLi}$ per $\mathrm{Cu}$, in acetone at $-78^{\circ} \mathrm{C}$. Formation of $\mathbf{O}$ species ${ }^{\mathrm{Ph}} \mathbf{O}(-)$ is evident; furthermore, an intermediate complex (-) is detected upon addition of 0.5 eq. base. Spectra in-between are drawn in lighter shades of blue and red respectively. Isosbestic points found for both steps (black $\rightarrow$ blue) and (blue $\rightarrow$ red) are indicated $(\bigcirc)$; the inset shows a magnification of the $340-385 \mathrm{~nm}$ region. The spectrum remains unchanged after $1.0 \mathrm{eq}$. base per $\mathrm{Cu}$ was added $(-$, for $1.1 \rightarrow 1.5$ eq., here mainly covered by the red spectrum).

It was assumed above, that the final dimeric complex contains two deprotonated ligands and is an $\mathbf{O}$ complex, in a rapid equilibrium with the corresponding ${ }^{\mathbf{S}} \mathbf{P}$ complex. The titration however supports this assumption, since the shrinkage of the peroxo $300 \mathrm{~nm}$ feature stops at full deprotonation, i. e. the remainder is not due to an incomplete deprotonation, but results likely from the presence of the peroxo isomer in ${ }^{\mathbf{P h}} \mathbf{O}$. Since acetone is more polar than THF, a higher amount of $\mathbf{O}$ isomer than ${ }^{\mathrm{S}} \mathbf{P}$ isomer is expected, and that is the case in ${ }^{\mathbf{P h}} \mathbf{O}$. It is generally assumed that this trend is due to a stronger interaction of the copper atoms with the counterions in less polar solvents. Such a counterion-interaction would stabilise the ${ }^{\mathrm{S}} \mathbf{P}$ isomer. These counterion-complex interactions are reduced in a polar solvent. Compared 


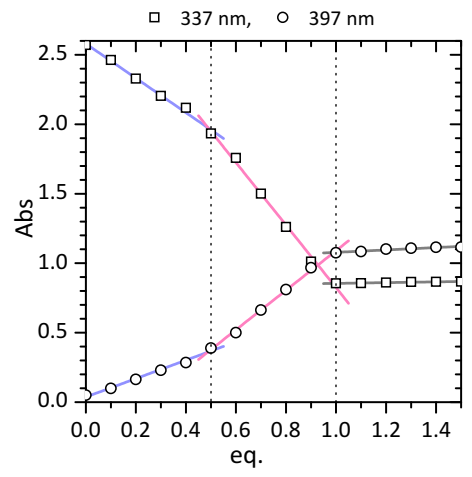

(a)

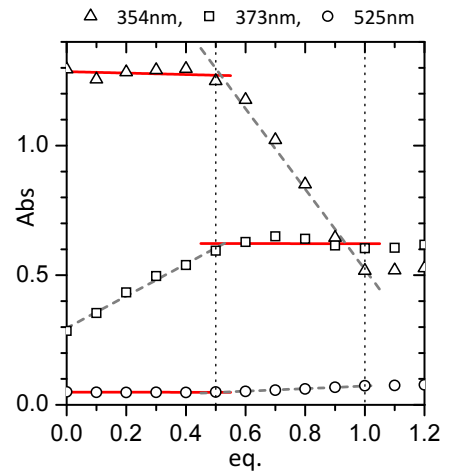

(b)

Figure 7.4. (a) Titration curves for $\lambda_{\max }$ at 337 (peroxo) and $397 \mathrm{~nm}$ [bis $(\mu$-oxo)], absorbance vs. equivalents base per $\mathrm{Cu}$; colours as indicated in Figure 7.3. (b) Isosbestic points $(-)$ for the first $(354,525 \mathrm{~nm})$ and second $(373 \mathrm{~nm})$ step.

to the spectra in THF (see above), the trend in the UV-vis features of ${ }^{\mathbf{P h}} \mathbf{O}$ is also in accordance with known systems. ${ }^{[34]}$

A thorough inspection of the spectral changes revealed the formation of a third compound upon addition of $0 \rightarrow 0.5$ eq. base per $\mathrm{Cu}(-$ in Figure 7.3) and consequently, two distinguishable steps are present. This is indicated by both, different slopes of $\lambda_{\max }$ per each step for the development of the 337 and $397 \mathrm{~nm}$ features (Figure 7.4a) and by the presence of unique isosbestic points for either steps (Figure 7.4b). The first (-) and second (-) steps are indicated by lighter colours in Figures 7.3 and 7.4a. Isosbestic points ( - in Figure 7.4b) in the first half are at 354 and $525 \mathrm{~nm}$ and at $373 \mathrm{~nm}$ in the second half. The isosbestic points are also indicated in the spectra in Figure 7.3.

These findings strongly indicate the formation of a third compound (here referred to as ${ }^{1 / 2}{ }^{\mathbf{P h}} \mathbf{O}$ ) in course of the titration. This means, ${ }^{1 / 2}{ }^{\mathbf{P h}} \mathbf{O}$ is generated in the first half of titration $\left(0 \rightarrow 0.5\right.$ eq. base, Scheme 7.4), while ${ }^{\mathbf{P h}} \mathbf{O}$ is formed from ${ }^{1 / 2}{ }^{\mathbf{P h}} \mathbf{O}$ during the second step $(0.5 \rightarrow 1.0$ eq.). Interestingly, both $\mathbf{O}$ species are in equilibrium with different amounts of ${ }^{\mathrm{S}} \mathbf{P}$ isomer. This implies, while for the peroxo complex ${ }^{\mathbf{P h}} \mathbf{P}$ no $\mathbf{O}$ isomer could be detected, in the mono-deprotonated ${ }_{1 / 2}^{1 / 2 h} \mathbf{O}$, the $\mathbf{O}$ isomer is with $\sim 21 \%$ a minor species. And in the twice deprotonated ${ }^{\mathrm{Ph}} \mathbf{O}$, the $\mathrm{O}$ isomer is with $\sim 69 \%$ the predominant isomer (cf. Table 7.1). The ratios 

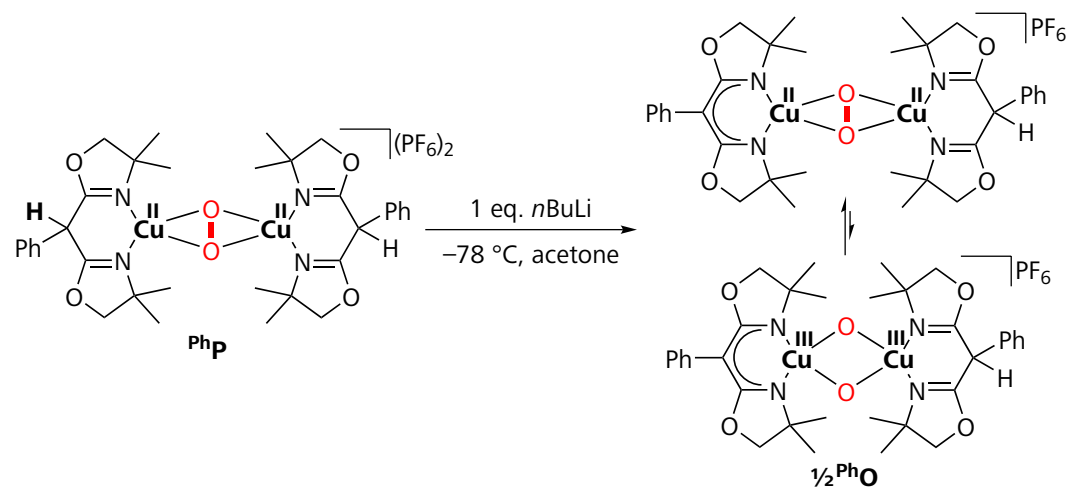

Scheme 7.4 Formation of ${ }^{1 / 2}{ }^{\mathrm{Ph}} \mathrm{O}$ in the first half of titration ( 0.5 eq. base per $\mathrm{Cu}$ ).

were determined under consideration of $\epsilon_{\max }$ equals $100 \%{ }^{\mathrm{S}} \mathbf{P}$ isomer in ${ }^{\mathbf{P h}} \mathbf{P}$. The higher ratio of $\mathbf{O}$ isomer in ${ }^{\mathbf{P h}} \mathbf{O}$ (than in ${ }^{1 / 2}{ }^{\mathbf{P h}} \mathbf{O}$ and ${ }^{\mathbf{P h}} \mathbf{P}$ ) is as expected, since the twice deprotonated compound is more electron-dense. $\mathrm{Cu}^{\mathrm{III}}$ is stabilised by the higher negative charge and the equilibrium is shifted accordingly towards the $\mathbf{O}$ species. ${ }^{[34]}$ These results are supported by the fact that a $100 \% \mathbf{O}$ isomer in ${ }^{\mathbf{P h}} \mathbf{O}$ theoretically would yield an extinction coefficient of around $\epsilon=27 \mathrm{~mm}^{-1} \mathrm{~cm}^{-1}$ for the $400 \mathrm{~nm}$ feature, which meets the coefficient one could expect for the pure and fully formed $\mathrm{O}$ complex here $\left(\epsilon \approx 24 \mathrm{~mm}^{-1} \mathrm{~cm}^{-1}\right) \cdot{ }^{[34]}$

\subsection{Resonance Raman Spectroscopy}

Due to limited stability, ${ }^{\mathbf{P h}} \mathbf{O}$ could not be subjected to Raman spectroscopy in the way it was done for the peroxo ${ }^{\mathbf{R}} \mathbf{P}$ complexes in Section 6.6. Samples of ${ }^{\mathbf{P h}} \mathbf{O}$ were prepared by first transferring a solution of the corresponding $\mathbf{C u} \mathbf{P h}$ complex in THF into an NMR tube under an atmosphere of $\mathrm{N}_{2}$. The solutions were cooled to $-78{ }^{\circ} \mathrm{C}$ and either ${ }^{16} \mathrm{O}_{2}$ or ${ }^{18} \mathrm{O}_{2}$ gas was added to the solutions with a syringe equipped with a three-way valve. After some minutes, formation of peroxo complexes ${ }^{\mathbf{P h}_{\mathbf{P}}}$ was evident by a change of the colourless solutions to pink. A small excess of $1.6 \mathrm{M} n \mathrm{BuLi}$ in hexane solution was added by a microliter Hamilton syringe. Formation of bis( $\mu$-oxo) complex ${ }^{\mathbf{P h}} \mathbf{O}$ was obvious by an instantaneous colour change from pink to dark-green. The NMR tubes were sealed and frozen 
by immersion into liquid nitrogen, where they were stored until the measurement. Raman spectra were recorded using a quartz cold-finger dewar, which was filled with liquid $\mathrm{N}_{2}$. The tubes were then immersed into the dewar and spectra were measured under liquid $\mathrm{N}_{2}$ at $-196^{\circ} \mathrm{C}$.

Figure 7.5 shows the resonance Raman spectra of ${ }^{\mathbf{P h}} \mathbf{O}$ prepared with ${ }^{16} \mathrm{O}_{2}$ and ${ }^{18} \mathrm{O}_{2}$. The samples were excited with a He:Ne $\lambda_{\text {ex }}=632.8 \mathrm{~nm}$ gas laser. $\mathrm{In}^{\mathrm{Ph}} \mathbf{O}$, the fluorescence of the sample rendered the acquisition and analysis of Raman spectra more complicated. Emission of fluorescence is a competing phenomenon with Raman scattering. The fluorescence in ${ }^{\mathrm{Ph}} \mathbf{O}$ might arise from transitions originating from the aromatic phenyl ligand backbone.

Besides dominating peaks from nonchromophoric frozen acetone solvent (solvent peaks are indicated with $*$ in Figure 7.5), a peak was observed from ${ }^{\mathbf{P h}} \mathbf{O}$

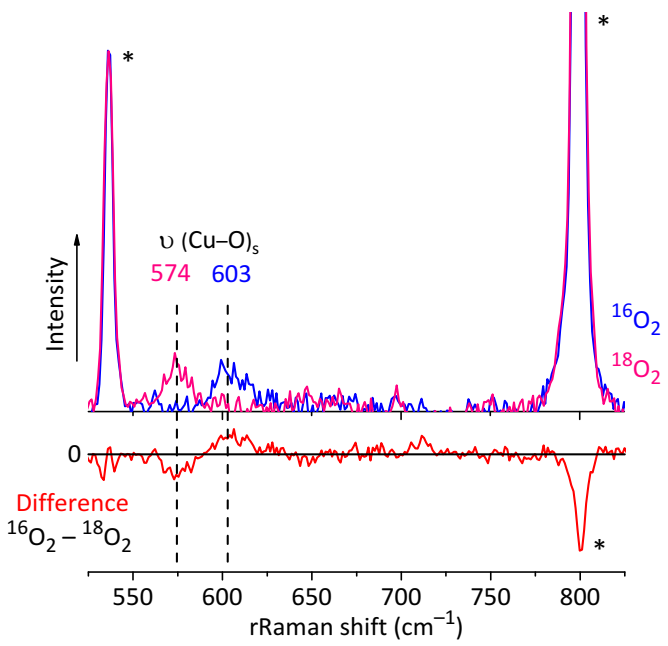

Figure 7.5. Resonance Raman spectra of bis( $\mu$-oxo) complex ${ }^{\mathrm{Ph}} \mathbf{O}$ with $632.8 \mathrm{~nm}$ laser excitation. Raman spectra from frozen green solutions in acetone at $-196^{\circ} \mathrm{C}$ in a finger dewar under liquid nitrogen. ${ }^{16} \mathrm{O}^{16} \mathrm{O}(-)$ and ${ }^{18} \mathrm{O}{ }^{18} \mathrm{O}(-)$ isotopic composition. ${ }^{16} \mathrm{O}$ minus ${ }^{18} \mathrm{O}$ difference spectrum (-). No ${ }^{16} \mathrm{O} /{ }^{18} \mathrm{O}$ isotope scrambling was detected. The asterisks at 800 and $536 \mathrm{~cm}^{-1}$ indicate vibrations of acetone solvent, the peak in the difference spectrum arises from a higher intensity in the ${ }^{18} \mathrm{O}$-labelled sample. $\tilde{v}(\mathrm{Cu}-\mathrm{O})_{\mathrm{s}}=603 \mathrm{~cm}^{-1}$ $\left(\Delta\left[{ }^{18} \mathrm{O}\right]=29 \mathrm{~cm}^{-1}\right)$. 
at $\tilde{v}=603 \mathrm{~cm}^{-1}$, which shifts to $574 \mathrm{~cm}^{-1}$ upon isotopic substitution with ${ }^{18} \mathrm{O}_{2}$ $\left(\Delta\left[{ }^{18} \mathrm{O}\right]=29 \mathrm{~cm}^{-1}\right)$. These peaks can be assigned as the $\mathrm{Cu}_{2} \mathrm{O}_{2}$ symmetric core stretch $v_{\mathrm{S}}(\mathrm{Cu}-\mathrm{O}),{ }^{[57,66]}$ in agreement with the above formulation of the copper complex as a bis( $\mu$-oxo)dicopper(III) species and in accordance with literature compounds. ${ }^{[34]}$

Additional isotope sensitive peaks, which might originate from other copperoxygen species (like ${ }^{\mathrm{S}} \mathrm{P}$ ) or come from Fermi resonance or overtones of the $v(\mathrm{Cu}-\mathrm{O})$ vibration, are absent in the spectra. Fermi resonance or overtones are occasionally encountered in resonance Raman spectra of copper-oxygen compounds. ${ }^{[59,259]}$ Thus, also the presence of $1: 1 \mathrm{Cu} / \mathrm{O}_{2}$ superoxo-species ${ }^{\mathrm{E}} \mathrm{S}$ (end-on) or ${ }^{\mathrm{M}} \mathbf{P}$ (side-on), which could be similar in their optical spectral properties (strong UV-vis transition at $\sim 400 \mathrm{~nm}$ and weaker broad peak at $\sim 600 \mathrm{~nm})$, can be excluded since the vibrations $v(\mathrm{O}-\mathrm{O})$ at $\sim 960-1100 \mathrm{~cm}^{-1}$ and $v(\mathrm{Cu}-\mathrm{O})$ at $\sim 550 \mathrm{~cm}^{-1}$ are absent. ${ }^{[34]}$ Two isotope insensitive peaks are present at $\tilde{v}=499$ and $492 \mathrm{~cm}^{-1}$, which might be assigned to $v\left(\mathrm{Cu}-\mathrm{N}_{\text {eq }}\right)$ stretches from equatorial coordinated BOX ligands. ${ }^{\text {[259] }}$

In summary, $\mathrm{rR}$ spectroscopy of ${ }^{\mathbf{P h}} \mathbf{O}$ gives evidence of an $\mathbf{O}$ species, which was also indicated by UV-vis spectroscopy.

\subsection{A Computational Model of ${ }^{\mathrm{Ph}} \mathrm{O}$}

The structure of the bis( $\mu$-oxo)dicopper(III) complex ${ }^{\mathbf{P h}} \mathbf{O}$ was computed by DFT in analogy to the structure of ${ }^{t B u} \mathbf{P}$ in Section 6.8, p. 156. The B3LYP hybrid functional ${ }^{[157,158]}$ was applied together with the triple- $\zeta$ def2-TZVPP basis set $^{[159,160]}$ for copper, oxygen and nitrogen atoms and the double- $\zeta$ def2-SVP basis set ${ }^{[159,279]}$ for hydrogen and carbon. A COSMO solvent model was invoked with the selection of acetone as the solvent. Since dicopper(III) ${ }^{\mathbf{P h}} \mathbf{O}$ is a closed shell molecule, a restricted formalism was applied.

Figure 7.6 depicts the computed coordinates of ${ }^{\mathbf{P h}} \mathbf{O}$. While the structure is obviously closely related to the computed structure of ${ }^{\mathbf{P h}} \mathbf{P}$, it is significantly different in detail. Each ligand adopts a planar geometry owed to their deprotonated backbone. One ligand is however slightly tilted in respect to the other, while the $\mathrm{Cu}_{2} \mathrm{O}_{2}$ core is planar $\left[\varphi(\mathrm{Cu}-\mathrm{O}-\mathrm{O}-\mathrm{Cu})\right.$ dihedral angle $\left.=179.5^{\circ}\right]$. The $\mathrm{Cu} \cdots \mathrm{Cu}$ separation is with $2.895 \AA$ significantly shorter than in a ${ }^{\mathrm{S}} \mathbf{P}$ complex and is closely analogous to literature examples of $\mathrm{O}$ compounds $(\sim 2.8 \AA) .{ }^{[34]}$ The $\mathrm{O} \cdots \mathrm{O}$ separation is with $2.208 \AA$ much larger than the peroxo $\mathrm{O}-\mathrm{O}$ bond length in ${ }^{\mathbf{P h}_{\mathbf{P}}} \mathbf{P}$, and it is well evident that both oxygen atoms are in their $\mathrm{O}^{2-}$ state. The $\angle(\mathrm{Cu}-\mathrm{O}-\mathrm{Cu})$ angle of $105^{\circ}$ correlates well with known systems, in accordance with the measured $v_{\mathrm{s}}(\mathrm{Cu}-\mathrm{O})$ 


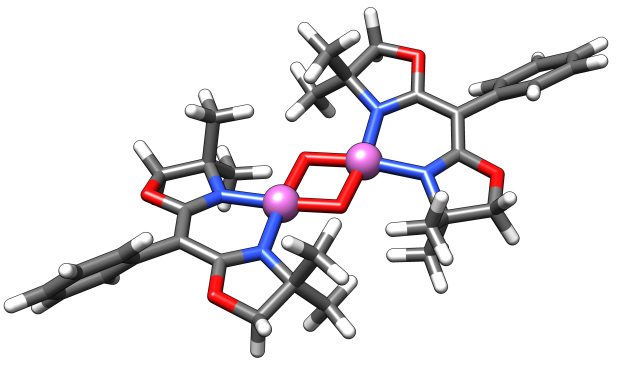

Figure 7.6. DFT-geometry-optimized coordinates of ${ }^{\mathrm{Ph}} \mathrm{O}$; on the $\mathrm{B} 3 \mathrm{LYP} / \mathrm{def2}$ $\operatorname{TZVPP}(\mathrm{Cu}, \mathrm{O}, \mathrm{N}) /$ def2-SVP $(\mathrm{H}, \mathrm{C})$-level of theory, applying a COSMO solvent model for acetone (Cu: lavender, $\mathrm{N}$ : blue, $\mathrm{O}$ : red, $\mathrm{C}$ : grey, $\mathrm{H}$ : white).

stretch. ${ }^{[57]}$ Unfortunately, no experimental structural data could be collected so far, since all crystallisation attempts failed and EXAFS data is not available by now. The key molecular orbitals are depicted in Figure 7.7. Noteworthy is the low-lying $2 \mathrm{O}_{2}^{-} \pi_{\sigma}^{*}+2 \mathrm{Cu}^{3+}\left(d_{x^{2}-y^{2}}+d_{x^{2}-y^{2}}\right)$ bonding combination.

\subsubsection{Simulation of Spectroscopic Data by TD-DFT}

Using time dependent (TD) DFT, the electronic absorption spectrum of ${ }^{\mathbf{P h}} \mathbf{O}$ was reproduced (Figure 7.8). The first 42 states were inspected. It was assumed above, that ${ }^{\mathbf{P h}} \mathbf{O}$ contains both, the $\mathbf{O}$ and ${ }^{\mathrm{S}} \mathbf{P}$ isomers and shows a $\pi \rightarrow \pi^{*}$ (BOXligand) $285 \mathrm{~nm}$ feature and a $400 \mathrm{~nm} \mathrm{CT}$ absorption from the $\mathrm{O}$ isomer, besides an additional $335 \mathrm{~nm}$ CT feature from the ${ }^{\mathrm{S}} \mathbf{P}$ isomer. The computed spectrum corresponds with the experimental spectra, and also insofar that a third peak, the expected ${ }^{S} \mathbf{P}$ feature, is not present in the spectrum. The $285 \mathrm{~nm}$ feature is well reproduced. Analysis of the transition, using natural transition orbitals (Figure 7.9), shows that the excitation consists of mainly transition from bis(oxazolinate) $\pi \rightarrow$ phenyl $\pi^{*}$ orbitals as assumed above.

The energy of the $400 \mathrm{~nm}$ excitation is slightly overestimated in the calculation and the transition is found at $340 \mathrm{~nm}$. It should be considered that TD-DFT has difficulties to produce CT excitation energies correctly, ${ }^{[302]}$ although in some cases a very good agreement with experiment can be obtained. Thus, an investigation of this system in greater depth might be necessary here. 


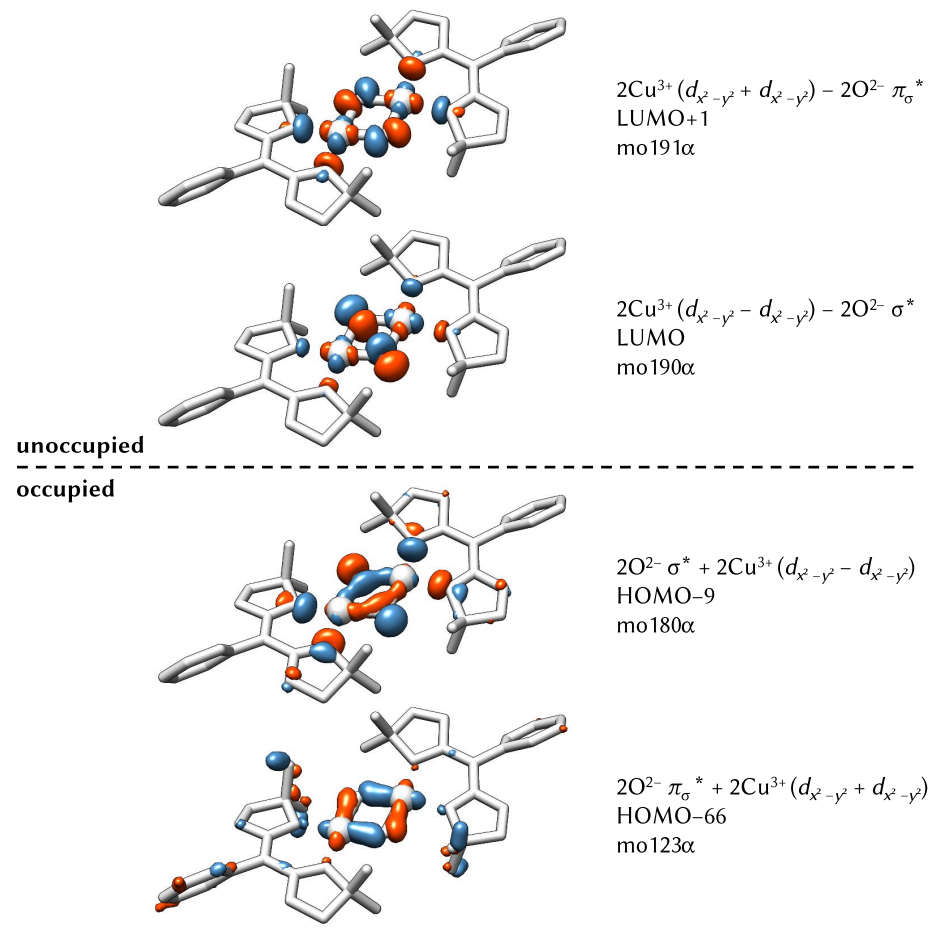

Figure 7.7. Key unoccupied $\alpha$ molecular orbitals and their occupied counterparts of ${ }^{\mathbf{P h}} \mathbf{O}$ (isovalue $=0.05$ ) from B3LYP DFT calculation. Hydrogens and bonds to copper are omitted for clarity. 


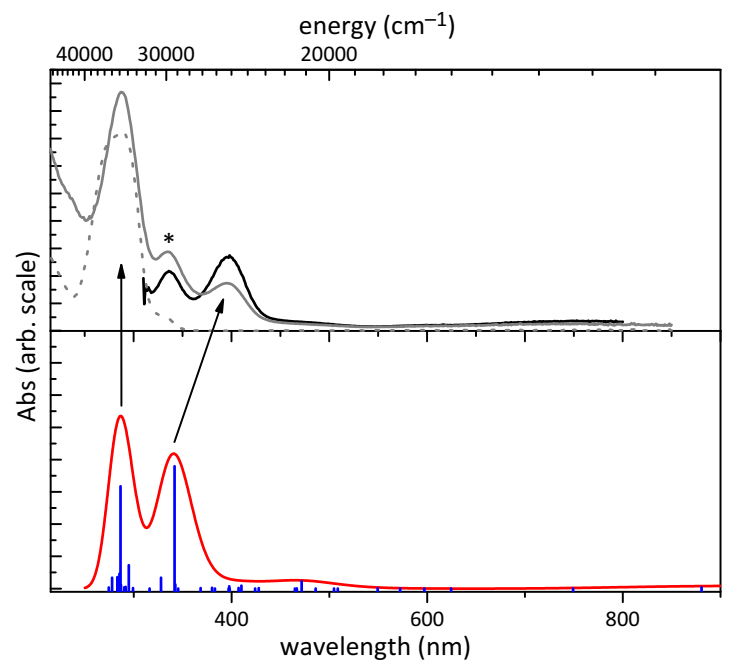

Figure 7.8. UV-vis absorption spectra of ${ }^{\mathbf{P h}} \mathbf{O}$. Experimental low-temperature UV-vis spectra in $\operatorname{THF}\left(-, \lambda_{\max }=288,396, \sim 480 \mathrm{~nm}\right)$ and acetone $\left(-, \lambda_{\max }=398, \sim 480 \mathrm{~nm}\right)$ at $-78^{\circ} \mathrm{C}$. Spectrum of $\mathrm{Li}\left\{{ }^{\mathrm{Ph}} \mathrm{BOX}\right\}(-\cdots,-\cdots, 288 \mathrm{~nm})$ in THF at $-78^{\circ} \mathrm{C}$. Computed TD-DFT transitions $(-)$; convolution of calculated transitions ( - , full width at half maximum: $3500 \mathrm{~cm}^{-1}$, $\lambda_{\max }=288,341,472 \mathrm{~nm}$ ). The intensities are relatively scaled; the asterisk denotes a feature from the corresponding ${ }^{\mathbf{S}} \mathbf{P}$ isomer $\left(\lambda_{\max }=335 \mathrm{~nm}\right.$ in THF, $337 \mathrm{~nm}$ in acetone).

As expected, the transition is mainly from the $2 \mathrm{O}^{2-} \sigma^{*}$ orbital into $\mathrm{Cu} d_{x^{2}-y^{2}}$ antibonding combinations with the oxo ions (Figure 7.10). Furthermore, a minor component of this transition originates from the bis $(\mu$-oxo $) \pi_{\sigma}^{*}$ orbital. This is somehow deviating from calculations for simpler systems, where both $2 \mathrm{O}^{2-} \rightarrow \mathrm{Cu}$ CT transitions are separated. ${ }^{[278,285]}$ It might be assumed that the BOX's $\pi$ donor ligands and the phenyl backbone play an intimate role in the electronic spectra. 

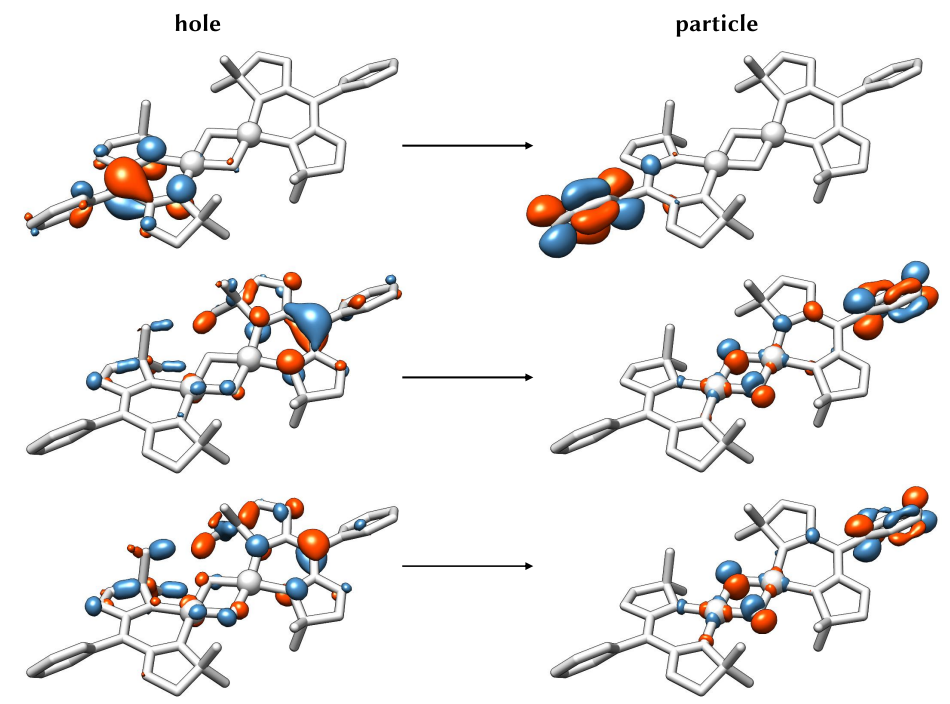

Figure 7.9. Calculated TD-DFT natural transition orbitals involved in $288 \mathrm{~nm}$ excitation of $\mathrm{Ph}_{\mathbf{O}}$. Excitation is mainly from bis(oxazolinate) $\pi$ to phenyl $\pi^{*}$ orbitals (isovalue $=0.050$ ). State $36, E=34904 \mathrm{~cm}^{-1}$ ( $f_{\text {osc }}=0.51166$ ); weights: $n=0.616$ (top), 0.176 (middle), 0.172 (bottom). Hydrogens omitted for clarity. 

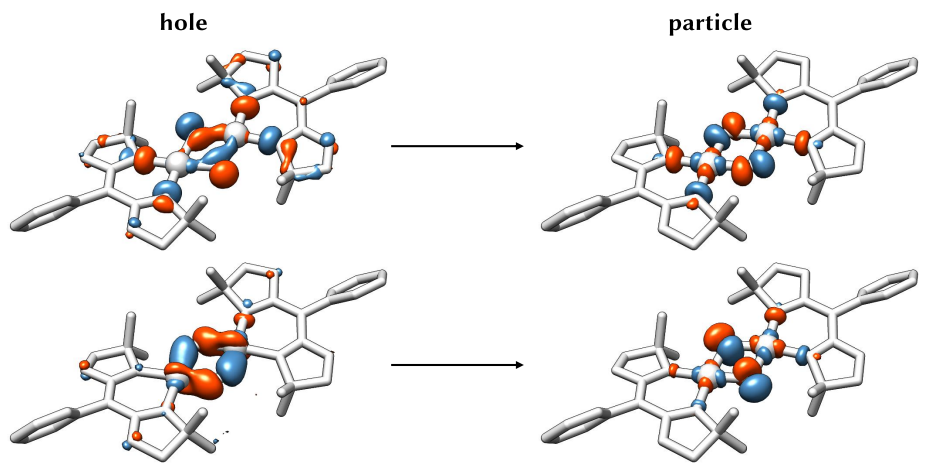

Figure 7.10. Calculated TD-DFT natural transition orbitals involved in $400 \mathrm{~nm}$ excitation of ${ }^{P h} \mathbf{O}$. Excitation is mainly from the $2 \mathrm{O}^{2-} \sigma^{*}$ orbital, and a minor part from the $\pi_{\sigma}^{*}$ orbital into $\mathrm{Cu} d_{x^{2}-y^{2}}$ antibonding combinations with bis( $\mu$-oxo) $\pi_{\sigma}^{*}$ and $\sigma^{*}$, respectively (isovalue $=0.050$ ). State $28, E=29264 \mathrm{~cm}^{-1}$ ( $\left.f_{\text {osc }}=0.61185\right)$; weights: $n=0.856$ (top), 0.103 (bottom). Hydrogens omitted for clarity. 


\subsection{Reactivity}

To gain a first insight into the reactivity of ${ }^{\mathbf{P h}} \mathbf{O}$ towards external substrates, the reactivity was tested with 2,4-di-tert-butylphenol (DBP) and triphenylphosphine.

\section{Phenol Hydroxylation}

To a solution of ${ }^{\mathrm{Ph}} \mathbf{O}$ in $\mathrm{THF}$ at $-78^{\circ} \mathrm{C}$ in an atmosphere of $\mathrm{O}_{2}, 10$ eq. DBP was added and the solution stirred for $24 \mathrm{~h}$ while the temperature was slowly raised to room temperature. No colour change was evident upon addition, the solution however turned orange after some time. The solvent was removed in vacuum and the residue dissolved in $\mathrm{CH}_{2} \mathrm{Cl}_{2}$ and passed through a small column of silica. The column was then washed with plenty of $\mathrm{CH}_{2} \mathrm{Cl}_{2}$ to ensure that all organics are removed from the column. ${ }^{1} \mathrm{H}$ NMR spectroscopy indicated that exclusively the o,o-coupled DTBP was present as product. $\sim 22 \%$ of educt was converted, which equals a TON of $\sim 2.2$. The absence of the $o$-hydroxylated catechol or quinone might be due to the points discussed in the previous chapter for the $\mu-\eta^{2}: \eta^{2}$ peroxodicopper(II) complex ${ }^{\boldsymbol{t}}{ }^{\mathbf{B u}} \mathbf{P}$. The $\mathrm{Cu}_{2} \mathrm{O}_{2}$ core size would however be even smaller in ${ }^{\mathbf{P h}} \mathbf{O}$, and this would presumably fortify the shielding of the $\mathrm{Cu}_{2} \mathrm{O}_{2}$ core, thus preventing substrate hydroxylation.

\section{$\mathrm{PPh}_{3}$ oxygenation}

The oxygenation of $\mathrm{PPh}_{3} \rightarrow \mathrm{O}=\mathrm{PPh}_{3}$ is a common method to test if an oxygen atom can be transferred from a metal-oxygen complex to phosphorous. A solution of ${ }^{\mathbf{P h}} \mathbf{O}$ was prepared in THF; the remaining $\mathrm{O}_{2}$ was removed by several vacuum/nitrogen cycles. 10 eq. $\mathrm{PPh}_{3}$ was added to the solution at $-78^{\circ} \mathrm{C}$. The solution was stirred for $\sim 16 \mathrm{~h}$, while the temperature was slowly raised to room temperature. The solution turned blue and it was proceeded as described above. Analysis of the reaction products by ${ }^{31} \mathrm{P}$ NMR spectroscopy showed a proportion of $\sim 10 \%$ triphenylphosphine oxide, $\mathrm{O}=\mathrm{PPh}_{3}$ (compared to $\sim 3 \%$ already present in the substrate stock). Thus, a conversion of $70 \% \mathrm{PPh}_{3}$ per $\mathrm{Cu}_{2} \mathrm{O}_{2}$ was observed and indicates that oxygen-atom transfer from the bis( $\mu$-oxo) $\mathrm{Cu}_{2} \mathrm{O}_{2}$ core in ${ }^{\mathbf{P h}} \mathbf{O}$ to $\mathrm{PPh}_{3}$ is possible in a reasonable turnover, which might reach stoichiometric conversion upon improvement of reaction conditions.

\subsection{Conclusion}

It could be shown that $\mathrm{Li}\left\{{ }^{\mathrm{Ph}} \mathrm{BOX}\right\}$, obtained by deprotonation of $\mathrm{H}_{\{}\left\{{ }^{\mathrm{Ph}} \mathrm{BOX}\right\}$, coordinates copper(I) and the resulting complex reacts with $\mathrm{O}_{2}$ at $-78^{\circ} \mathrm{C}$ to yield the 
$\operatorname{bis}\left(\mu\right.$-oxo)dicopper(III) complex ${ }^{\mathbf{P h}} \mathbf{O}$. This temperature-labile complex could be characterised by UV-vis spectroscopy in solution and by resonance Raman spectroscopy of frozen solution samples, together with ${ }^{18} \mathrm{O}_{2}$ isotopic labelling, showing archetypical features inherent to this class of compounds. A DFT-computed model is in accordance with the bis( $\mu$-oxo) complex and the TD-DFT-computed electronic spectrum reasonably reproduces the transitions found experimentally. It could also be shown that in ${ }^{{ }^{\mathbf{P h}}} \mathbf{O}$, the bis( $\mu$-oxo) isomer is predominant, while it is in equilibrium with the corresponding $\mu-\eta^{2}: \eta^{2}$-peroxodicopper(II) species as a minor component. First results indicate that the reactivity of this system might suffer also from steric hindrance, as it was indicated in the corresponding peroxo complex.

Furthermore, ligand deprotonation of the corresponding (protonated) side-on $\mu$ $\eta^{2}: \eta^{2}$-peroxodicopper(II) complex ${ }^{\mathbf{P h}} \mathbf{P}$ also yields ${ }^{\mathbf{P h}} \mathbf{O}$ in a controlled and stepwise manner. Cleavage of the peroxo $\mathrm{O}-\mathrm{O}$ bond is therefore controlled by the mere deprotonation of the supporting BOX ligand, changing its geometric and electronic coordination ability. Moreover, a closer look at the titration revealed an additional $\operatorname{bis}(\mu$-oxo) species as a likely intermediate product, upon deprotonation of only a single ligand in the ${ }^{\mathbf{P h}} \mathbf{P}$ complex.

As the level of $\mathrm{O}-\mathrm{O}$ bond cleavage (weakening, elongation) intimately controls the reactivity of metal-dioxygen species in general, this tunable $\mathrm{Cu}_{2} \mathrm{O}_{2}$ system might be a valuable tool for detailed investigations in the biomimetic copper-oxygen interaction and reactivity of such species, to answer open questions in binuclear copper enzymes and related compounds. 



\section{Summary and General Concluding Remarks}

For more details, see the conclusions at the end of the individual chapters.

ITHIN the work presented here, four bis(oxazoline) ligands $\left.\mathrm{H}_{\{}{ }^{\mathrm{R}} \mathrm{BOX}\right\}$ have been prepared and fully characterised, three of them for the first time $(\mathrm{R} \equiv \mathrm{H}, \mathrm{Ph}, t \mathrm{Bu}$, Scheme $8.1 \mathrm{a})$. In $\left.\mathrm{H}_{\left\{{ }^{P h}\right.} \mathrm{BOX}\right\}$, a very pronounced tautomerism was found in contrast to all other bis(oxazoline) systems previously known, thus evidencing tautomerism in this prominent ligand class for the first time. Two tautomers are present, namely the diimine and the iminoenamine species (Scheme 8.1b, Chapter 4). The tautomerism process was investigated in detail by means of X-ray diffractometry, NMR and IR spectroscopy and by DFT computation, providing even insights in thermodynamic and kinetic parameters. The equilibrium is equally balanced, characterised by a very small $\Delta G^{\ominus}$. The process of isomer interconversion is slow and proceeds via an intramolecular reaction pathway with a particularly high reaction barrier $\Delta H^{\ddagger}$ for the transition state. Presumably, the energy of the<smiles>[R]C(C1=NC(C)(C)CO1)C1=NC(C)(C)CO1</smiles>

$\mathrm{H}\left\{{ }^{\mathrm{R}} \mathrm{BOX}\right\}$

$\mathrm{R} \equiv \mathrm{H}, \mathrm{Me}, \mathrm{Ph}, \mathrm{tBu}$

(a)<smiles>CC1(C)COC(C(C2=NC(C)(C)CO2)c2ccccc2)=N1</smiles>

diimine

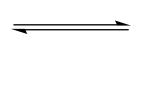

(b)<smiles></smiles>

iminoenamine

Scheme 8.1 (a) Ligands prepared in this work. (b) Tautomerism in $\mathrm{H}_{\{}\left\{{ }^{\mathrm{Ph}} \mathrm{BOX}\right\}$. 


\section{Summary and General Concluding Remarks}

transition state is lowered due to the formation of solvent molecule aggregates, stabilised by the phenyl group.

A redox non-innocence of the ligands induced by the coordination of redoxactive copper(II) chloride was evidenced for the first time in bis(oxazoline)s (Scheme 8.2a, Chapter 5). The observed reactions are highly selective and lead to aerobic oxygenation in the case of the sterically more demanding $\left.\mathrm{H}_{\{}{ }^{\mathrm{Ph}} \mathrm{BOX}\right\}$ and to dimerisation by $\mathrm{C}-\mathrm{C}$ coupling in the sterically unhindered $\mathrm{H}\left\{{ }^{\mathrm{Me}} \mathrm{BOX}\right\}$ and $\left.\mathrm{H}_{\{}{ }^{\mathrm{H}} \mathrm{BOX}\right\}$. The latter were also oxygenated in side reactions. Finally, the bulkiest ligand $\left.\mathrm{H}_{\{}^{t \mathrm{Bu}} \mathrm{BOX}\right\}$ forms a stable copper(II) complex. Additionally, its thermochromic behaviour was studied regarding the underlying structural changes. The different redox reactivities were examined by NMR and EPR spectroscopy, mass spectrometry and X-ray crystallography, as well as by ligand recovery and ${ }^{18} \mathrm{O}$ isotope labelling experiments. Transient intermediates with distinct organic radical/copper(I) character could be postulated based on DFT computation and EPR spin-trap experiments (Scheme 8.2b). Furthermore, the anti-oxidant DPPH ${ }^{\bullet}$ free radical assay successfully validated the trends found for the BOX-copper(II) reactivities and a fundamental capability of this assay to screen promising ligands and catalysts against the background of ligand redox stability could be proven. The non-innocence might entail strong implications due to the widespread application of BOX-copper catalysts in asymmetric synthesis.

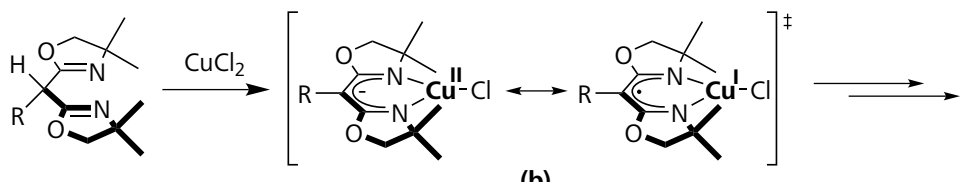

(b)

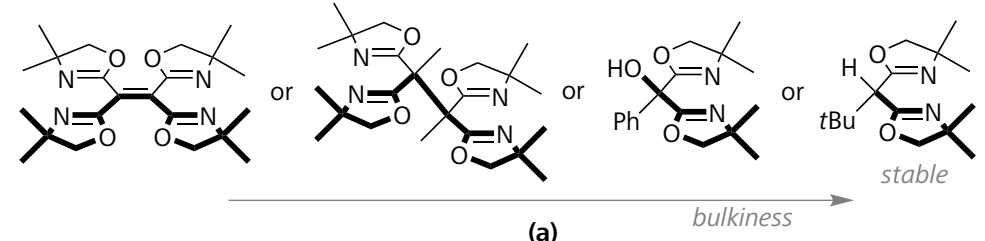

Scheme 8.2 (a ) Formation of coupled or oxygenated ligands from $\left.\mathrm{H}_{\{}^{\mathrm{R}} \mathrm{BOX}\right\}$ and $\mathrm{CuCl}_{2}$. (b) Proposed radical intermediates. 
The first application of BOX ligands in the copper(I)-mediated activation of dioxygen was conducted. Copper(I) complexes $\left(\mathbf{C u}^{\prime} \mathbf{R}\right)$ of the BOX ligands were prepared and characterised spectroscopically, electrochemically and by X-ray structure determination. The four copper(I) compounds reversibly bind dioxygen at low temperatures and serve as new functional hemocyanin models (Scheme 8.3a, Chapter 6). The obtained thermolabile $\mu-\eta^{2}: \eta^{2}$-peroxodicopper(II) complexes $\left({ }^{\mathbf{R}} \mathbf{P}\right)$ have been characterised in solution and in solid state by optical and Raman vibrational spectroscopy, ${ }^{18} \mathrm{O}_{2}$ isotope labelling and SQUID magnetometry. Their stability increases significantly in solid state. Oxidation states and structural parameters could be elucidated by synchrotron X-ray absorption spectroscopy. The intensively coloured ${ }^{\mathbf{R}} \mathbf{P}$ system features furthermore a very strong antiferromagnetically coupled core and an unusually intense UV-vis charge-transfer feature, presumably due to the influence of $\mathrm{C}=\mathrm{N}$ ligand orbitals. A DFT-computed model system supports the structural and spectroscopic insights and indicates that the shape of the $\mathrm{Cu}_{2} \mathrm{O}_{2}$ core slightly deviates from planar to a shape, reminiscent of a butterfly.

Thermodynamic and kinetic parameters of $\mathrm{O}_{2}$ activation have been thoroughly studied by cryo-stopped flow kinetic techniques and a mechanistic picture could

(a)

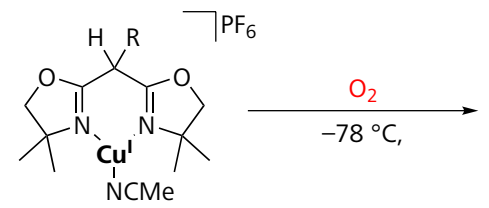

Cu'R

$\mathrm{R} \equiv \mathrm{H}, \mathrm{Me}, \mathrm{Ph}, t \mathrm{Bu}$

(b)

1. $\left[\mathrm{Cu}^{\prime}(\mathrm{MeCN})_{4}\right] \mathrm{PF}_{6}$

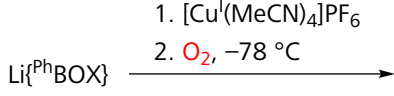

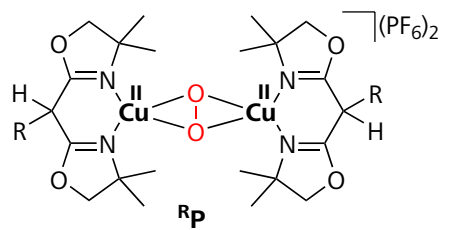

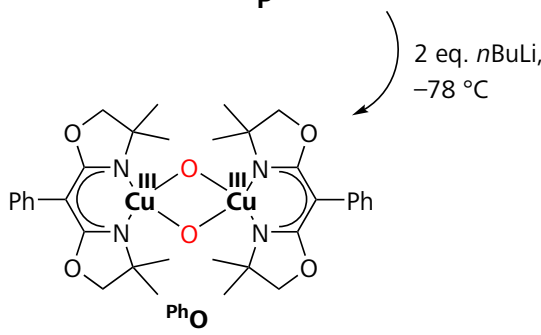

Scheme 8.3 (a ) Activation of dioxygen with copper( $(\mathrm{I})$ complexes $\mathbf{C} \mathbf{u}^{\prime} \mathbf{R}(\mathrm{R}=\mathrm{H}, \mathrm{Me}, \mathrm{Ph}, t \mathrm{Bu})$ to form $\mu-\eta^{2}: \eta^{2}$-peroxodicopper(II) complexes ${ }^{\mathbf{R}} \mathbf{P}$. ( b ) Synthesis of bis ( $\mu$-oxo)dicopper(III) complex ${ }^{\mathbf{P h}} \mathbf{O}$. 


\section{Summary and General Concluding Remarks}

be drawn, evidencing a slow and unusually strong entropy-driven $\mathrm{O}_{2}$ activation mechanism. Preliminary experiments revealed no activity towards phenol hydroxylation and yielded solely the $\mathrm{C}-\mathrm{C}$ coupled biphenol from the phenol. Steric hindrance around the $\mathrm{Cu}_{2} \mathrm{O}_{2}$ core, the butterfly motif or the required low temperatures are possible causes for the lacking hydroxylation reactivity. $\operatorname{Bis}(\mu$ hydroxo)dicopper(II) compounds were identified as thermal degradation products and structurally characterised for ${ }^{\mathrm{B} \mathbf{B}} \mathbf{P}$, while ligand oxygenation was confirmed to be the degradation mechanism of ${ }^{\mathbf{H}} \mathbf{P}$. The labile ${ }^{\mathbf{R}} \mathbf{P}$ system is thus amongst the most extensively characterised $\mu-\eta^{2}: \eta^{2}$-peroxodicopper(II) species.

Employing the deprotonated $\mathrm{Li}_{i}{ }^{\mathrm{Ph}}{ }_{\mathrm{BOX}}$, a bis( $\mu$-oxo)dicopper(III) complex could be yielded instead of the peroxo complex (Scheme 8.3b, Chapter 7). The temperature sensitive compound was characterised by UV-vis and resonance Raman spectroscopy, accompanied by ${ }^{18} \mathrm{O}_{2}$ isotope labelling and the DFT computation of structural and spectroscopic features. An equilibrium with the corresponding $\mu-\eta^{2}: \eta^{2}$-peroxodicopper(II) species as the minor component was indicated. While preliminary experiments excluded phenol hydroxylation reactivity, oxygen transfer to triphenylphosphine appears to be possible. Interestingly, the bis( $\mu$-oxo $)$ complex could alternatively be yielded by ligand deprotonation of the corresponding (protonated) ${ }^{\mathbf{P h}} \mathbf{P}$ in a stepwise manner. Cleavage of the peroxo $\mathrm{O}-\mathrm{O}$ bond is therefore controlled by the mere protonation status of the supporting BOX ligands.

In conclusion, it could be demonstrated that simple privileged BOX ligands are suitable scaffolds for supporting biomimetic $\mathrm{Cu} / \mathrm{O}_{2}$ species. This easily accessible and tunable ligand class promises new insights into $\mathrm{Cu} / \mathrm{O}_{2}$ chemistry and might also be the basis for new copper-oxygen catalysts in the future. 


\section{Part III.}

\section{Experimental Part}





\section{Materials and Methods}

\subsection{General}

Preparation and handling of air-sensitive compounds were performed under an argon or nitrogen inert atmosphere using standard air-free (Schlenk) techniques or were manipulated in an MBraun LABmaster SP inert-atmosphere glovebox workstation. The glovebox was filled with nitrogen with atmosphere levels of oxygen and moisture below $0.1 \mathrm{ppm}$. Deoxygenation of solvents and solutions was effected either by bubbling with argon for $>15$ min or by repeated freezepump-thaw cycles.

Unless otherwise stated, solvents and chemicals were purchased from common distributors and were used without purification. All solvents were of commercially available analytical, spectroscopic or HPLC grade. DMPO was from Sigma ( $\geq 97 \%$ ); $\mathrm{DPPH}^{\bullet}$ free radical was from Aldrich. $\left[\mathrm{Cu}(\mathrm{MeCN})_{4}\right] \mathrm{PF}_{6}$ and $\left[\mathrm{Cu}(\mathrm{MeCN})_{4}\right] \mathrm{OTf}$ were prepared by reaction of $\mathrm{Cu}_{2} \mathrm{O}$ with the respective acid, $\mathrm{HPF}_{6}$ or HOTf, by following a literature procedure. ${ }^{[223]}$ All dry solvents were purified and dried according to established procedures. ${ }^{[303,304]}$ Pentane, $\mathrm{Et}_{2} \mathrm{O}$ and THF were dried over sodium benzophenone ketyl; $\mathrm{Et}_{3} \mathrm{~N}, \mathrm{MeCN}$, EtCN and DMF over $\mathrm{CaH}_{2} ; \mathrm{CH}_{2} \mathrm{Cl}_{2}$ and $\mathrm{CHCl}_{3}$ over $\mathrm{P}_{4} \mathrm{O}_{10}$; EtOH and $\mathrm{MeOH}$ over $\mathrm{Mg}$. Solvents were deaerated and distilled under argon prior to use. Acetone was deaerated and dried by stirring over boron trioxide $\left(\mathrm{B}_{2} \mathrm{O}_{3}\right)$ for $24 \mathrm{~h}$ with a desiccant loading of $5 \% \mathrm{w} / \mathrm{v}$ and then distilled under argon. ${ }^{[305]}$ Alternatively, $\mathrm{CH}_{2} \mathrm{Cl}_{2}$ was deaerated and then dried by pushing through a series of drying columns in an MBraun solvent purification system (MB-SPS 800). All solvents were kept in storage flasks with attached J. Young PTFE valve under an atmosphere of dry argon.

Argon 5.0 (99.999\%) and oxygen 4.5 (99.995\%) were from Linde. Argon was used after passing through a column of $\mathrm{P}_{2} \mathrm{O}_{5}$ on inert carrier material (SICAPENT®), oxygen was used without further purification. Isotopic enriched dioxygen-18 
$\left({ }^{18} \mathrm{O}_{2}\right)$ was from Campro Scientific and was of $99.7 \%$ purity with the isotopic composition of ${ }^{18} \mathrm{O} /{ }^{17} \mathrm{O} /{ }^{16} \mathrm{O}, 97.1 / 0.9 / 2.0$ atom $\% .{ }^{18} \mathrm{O}_{2}$ was slowly transferred form the gas cylinder into disposable syringes by the use of disposable medical threeway valves prior to use.

\subsection{Physical Methods}

\section{Nuclear magnetic resonance (NMR) spectroscopy}

NMR Spectra were recorded at room temperature (unless otherwise noted) on a Bruker Avance DRX $500 \mathrm{MHz}$, Avance $300 \mathrm{MHz}$ or $400 \mathrm{MHz}$ spectrometer. Deuterated solvents were used as obtained from Sigma-Aldrich or Deutero. Oxygen and/or moisture sensitive samples were prepared in an MBraun glovebox using NMR tubes with attached J. Young PTFE valve; $\mathrm{CDCl}_{3}$ and $\mathrm{CD}_{2} \mathrm{Cl}_{2}$ solvents were dried over $\mathrm{P}_{4} \mathrm{O}_{10}$, DMSO- $d_{6}$ over $4 \AA$ molecular sieve. Solvents were distilled under argon or nitrogen and deaerated prior to use. ${ }^{1} \mathrm{H}$ and ${ }^{13} \mathrm{C}$ chemical shifts $(\delta)$ are reported in ppm relative to $\mathrm{SiMe}_{4}$ and were determined relative to the residual solvent peaks. ${ }^{15} \mathrm{~N}$ NMR resonances were recorded using the ${ }^{1} \mathrm{H},{ }^{15} \mathrm{~N}$ HMBC experiment; ${ }^{15} \mathrm{~N},{ }^{31} \mathrm{P}$ and ${ }^{19} \mathrm{~F}$ chemical shifts are reported in ppm relative to nitromethane, phosphoric acid and trichlorofluoromethane respectively, and were referenced externally using the solvents deuterium lock frequency. Multiplicities are indicated $\{\mathrm{br}$ (broadened), $\mathrm{s}$ (singlet), $\mathrm{d}$ (doublet), $\mathrm{t}$ (triplet), q (quartet), sep (septet), m (multiplet)\}; $\mathrm{C}_{\mathrm{q}}$ represents quaternary carbon. Assignment of all ${ }^{1} \mathrm{H}$ and ${ }^{13} \mathrm{C}$ NMR resonances was possible, using ${ }^{1} \mathrm{H},{ }^{13} \mathrm{C}-\mathrm{HSOC}$ and ${ }^{1} \mathrm{H},{ }^{13} \mathrm{C}-\mathrm{HMBC}$ experiments when necessary. Spectra were checked for common impurities. ${ }^{[306,307]}$ NMR resonances of different $\left.\mathrm{H}_{\{}{ }^{\mathrm{Ph}} \mathrm{BOX}\right\}$ tautomers were assigned by comparison with a spectrum of pure crystalline enamine isomer dissolved at $0^{\circ} \mathrm{C}$ and recorded at $-50^{\circ} \mathrm{C}$.

\section{Mass spectrometry}

Electron impact mass spectra (EI-MS) were recorded with a Finnigan MAT 8200. Electrospray mass spectra (ESI-MS) were recorded with an Applied Biosystems API 2000 spectrometer or a Bruker HCTultra (high-capacity ion trap) spectrometer with a second inlet connected to a MBRAUN glovebox, and capable of further fragmentation of ions $\left(\mathrm{MS}^{2}\right)$. $\mathrm{ESI}^{+/-}$indicates that the detector was used either in positive or negative mode. Due to improve solubility, some samples were dissolved in minimal amounts of chlorinated solvent first and then diluted with either $\mathrm{MeCN}$ or $\mathrm{MeOH}$ (when indicated). 
High resolution mass spectra (HRMS) were recorded with a Bruker micrOTOF (time of flight, TOF-ESI-MS) or a Bruker APEX IV spectrometer (Fourier Transform Ion Cyclotron Resonance, FTICR-ESI-MS). High-resolution ions and isotopic patterns were simulated with Bruker Daltronics Compass DataAnalysis 4.0. Isotopic substitution was achieved by oxygenation with ${ }^{18} \mathrm{O}_{2}$ instead of air or ${ }^{16} \mathrm{O}_{2}$.

\section{Ultraviolet-visible-near-infrared (UV-vis-NIR) spectroscopy}

Electronic spectra were recorded at room temperature with an UV-vis diode array photospectrometer Analytik Jena Specord S 100, a Varian Cary 50 Bio or a Cary 5000 spectrophotometer using standard quartz cuvettes or quartz cuvettes with attached J. Young PTFE valve. In the radical scavenging experiments, plastic disposable cuvettes were used. The spectra were recorded by the use of a fibreoptical connection and analysed by Varian Cary Win UV and OriginLab OriginPro 8.5.1 software.

Low-temperature measurements were done directly in the reaction solutions with an all-quartz immersion probe in a custom made reaction tube (transmission measurement with $1 \mathrm{~mm}$ optical path, Hellma Analytics). The temperature was maintained with a dry ice in acetone cooling bath $\left(-78^{\circ} \mathrm{C}\right)$ or a dry ice in ethylene glycol cooling bath $\left(-20^{\circ} \mathrm{C}\right)$. Oxygenation of copper(I) complexes was achieved by introduction of molecular dioxygen into cooled reaction solutions via bubbling through a stainless steel syringe needle, or by slow injection of complex solution into an oxygen-saturated and cooled solution. Subsequent removal of excess dioxygen was carried out by bubbling with argon and/or repeated vacuum-argon cycles. Extinction coefficients $(\epsilon)$ are uncorrected for solvent contraction (THF $\approx$ $10 \%$ from ambient temperature to $195 \mathrm{~K}$ ); sh stands for an absorption shoulder.

Powder samples were measured with a Varian Cary 5000 instrument, using a Harrick Praying Mantis ${ }^{\mathrm{TM}}$ diffuse reflection accessory. Samples were ground with potassium bromide and measured in a microsampling cup at room temperature vs. a neat $\mathrm{KBr}$ baseline.

\section{FT-infrared (FT-IR) spectroscopy}

Vibrational spectra were recorded with a Digilab Excalibur Series FTS 3000. Liquid samples were measured between two sodium chloride discs; solid samples were ground with potassium bromide and pressed to a pellet. Peaks are reported with the following intensities: s (strong), $\mathrm{m}$ (medium), w (weak) and br (broad). $v_{\mathrm{s}}$ and $v_{\mathrm{a}}$ represent symmetric and asymmetric stretching modes; $\delta$ in-plane bending modes. 


\section{Resonance Raman (rR) spectroscopy}

Spectra were recorded with a Horiba LabRAM HR 800 Raman spectrometer equipped with an open-electrode CCD detector using a backscattering microscope optic. A He:Ne mixed-gas laser $(30 \mathrm{~mW})$ was used for excitation; spectra were recorded with an excitation wavelength $\lambda_{\mathrm{ex}}=632.8 \mathrm{~nm}$. Thermally unstable samples were measured in a CryoVac Konti-Cryostat-Mikro at $213 \mathrm{~K}$, cooled by the continuous flow of liquid- $\mathrm{N}_{2}$-cooled $\mathrm{N}_{2}$ gas. Solutions of $\mathrm{Cu}_{2} \mathrm{O}_{2}$ complexes were generated directly in the measuring cell by oxygenation of solutions of the respective copper(I) complexes with $\mathrm{O}_{2}$ gas. Isotopic substitution was achieved by oxygenation with ${ }^{18} \mathrm{O}_{2}$ gas. Solid samples were measured in air at ambient temperature. The recorded spectra were processed with Horiba LabSpec 5 software.

\section{Electrochemical measurements}

Redox properties have been studied by cyclic voltammetry $(\mathrm{CV})$ and square-wave voltammetry (SWV) using a $0.1 \mathrm{~m}$ solution of tetrabutylammonium hexafluorophosphate (TBAHP, $\left[\mathrm{NBu}_{4}\right] \mathrm{PF}_{6}$; electrochemical grade) as the supporting electrolyte in $\mathrm{MeCN}$ solution. Measurements were performed at room temperature with a potentiostat/galvanostat Perkin Elmer Model 263A controlled by Electrochemistry Power Suite software. A glassy carbon electrode (milli-GC) was used as the working electrode, platinum as counter electrode and silver as reference electrode. Solutions were deoxygenated by bubbling with argon and measurements were performed under anaerobic conditions. The decamethylferrocene/-ferrocenium couple, $\left[\mathrm{FeCp}_{2}^{*}\right]^{+1 / 0}\left(E_{1 / 2}=-0.59 \mathrm{~V} \text { vs. ferrocene, }\left[\mathrm{FeCp}_{2}\right]^{+1 / 0} \text {, in } \mathrm{MeCN}\right)^{[224,225]}$ was added after the measurements as the internal standard, to avoid the potential overlap of the $\mathrm{FeCp}_{2}$ redox signal with other redox processes. The potential was furthermore converted to $E$ vs SCE (saturated calomel electrode) by adding $0.40 \mathrm{~V}$.

\section{Electron paramagnetic resonance (EPR) spectroscopy}

EPR data was collected on a Bruker ELEXSYS E 500 continuous wave spectrometer (CW EPR) using X-band radiation and liquid nitrogen as coolant. Spin Hamiltonian parameters were calculated by spectrum simulation using the Bruker XSophe-Sophe-XeprView 1.1.3 simulation software suite ${ }^{[308,309]}$ or by using Bruker WINEPR SimFonia 1.25.

\section{Magnetic susceptibility}

Measurements were carried out on a Quantum Design MPMS-XL-5 superconducting quantum interference device (SQUID) magnetometer equipped with a 5 Tesla magnet in the temperature range from 295 to $2 \mathrm{~K}$. The powder sample was contained in a Teflon bucket and fixed in a non-magnetic sample holder. Each raw 
data file for the measured magnetic moment was corrected for the diamagnetic contribution of the sample holder and the Teflon bucket. The molar susceptibility data was corrected for the diamagnetic contribution. Simulation of the experimental data with full-matrix diagonalisation of exchange coupling was performed with the julX program. ${ }^{[310]}$ Temperature independent paramagnetism (TIP) and a Curie-behaved paramagnetic impurity $(P I)$ with spin $S=1 / 2$ were included according to

$$
\chi_{\text {calcd }}=\chi \cdot(1-P I)+\chi_{\text {mono }} \cdot P I+T I P
$$

The coupling constant $J_{\mathrm{AB}}$ is related to the Heisenberg-Dirac-van Vleck (HDvV) Hamiltonian in the form of

$$
\mathscr{H}_{\mathrm{HDvV}}=-2 J_{\mathrm{AB}} \cdot \vec{S}_{\mathrm{A}} \cdot \vec{S}_{\mathrm{B}}
$$

\section{Additional methods}

GC/MS analysis were conducted on a Thermo Electron Trace GC Ultra equipped with an $30 \mathrm{~m} \times 0.25 \mathrm{~mm} \times 0.25 \mu \mathrm{m}$ VARIAN FactorFour capillary column VF5ms. A Thermo Finnigan DSQ mass spectrometer was used as the detector, with EI or CI (iso-butane) ionisation. Chromatograms were analysed with Thermo Finnigan Xcalibur 1.4. Bulb-to-bulb distillations were performed on a Büchi B-580 kugelrohr apparatus. Boiling points (b. p.) were measured with a standard micro distillation apparatus. Melting points (m. p.) were measured in open glass capillary tubes on a Stanford Research Systems Optimelt MPA 100 device and are uncorrected. The compositions of $\mathrm{C}, \mathrm{H}$ and $\mathrm{N}$ were determined using an Elementar 4.1 vario EL 3 elemental analyser. Differential scanning calorimetric (DSC) measurements were conducted on an NETZSCH STA 409PC device. Elemental and DSC analysis were carried out by the Analytical Laboratory of the Institute of Inorganic Chemistry at the University of Göttingen. 



\section{Synthetic Procedures}

\subsection{Procedures and Physical Data for Bis(oxazoline) Ligands $\mathrm{H}_{\left\{{ }^{\mathrm{R}} \mathrm{BOX}\right\}}$}

The (monoalkyl)methylene-bridged bis(dimethyloxazoline)s are denoted $\left.\mathrm{H}_{\{}{ }^{\mathrm{R}} \mathrm{BOX}\right\}$ with $\mathrm{R}$ indicating the backbone residues $(\mathrm{H}, \mathrm{Me}, \mathrm{Ph}$ and $t \mathrm{Bu})$. They were prepared from the respective bishydroxy malonamides.

\subsubsection{General Procedure for the Synthesis of BOXs}

Synthetic procedures were adapted in parts from literature procedures for analogous BOXs. ${ }^{[120,124,125]}$

Bishydroxy malondiamides (general route for $\mathrm{R}=\mathrm{H}, \mathrm{Me}, \mathrm{Ph}$ )<smiles>[R]C(C(=O)OCC)C(=O)OCC</smiles><smiles>CC(C)(N)CO</smiles><smiles>[R]C(C(=O)NC(C)(C)CO)C(=O)NC(C)(C)CO</smiles>

A stirred mixture of the respective diethyl malonate $(60-77 \mathrm{mmol})$ with $2.00 \mathrm{eq}$. aminoalcohol and 0.02 eq. sodium hydride ( $60 \%$ dispersion in mineral oil) was heated in an Ace Glass heavy-wall pressure tube under an argon atmosphere to $140-160{ }^{\circ} \mathrm{C}$ for 3 to 4 hours. After cooling, the tube was carefully opened to release a slightly overpressure. The respective malondiamides were yielded quantitatively after removal of ethanol in vacuum, as yellow viscous oils (white solid in case of $\left.\left.\mathrm{H}_{\{}{ }^{\mathrm{H}} \mathrm{BOX}\right\}\right)$ and were used without further purification. For $\mathrm{H}\left\{{ }^{t \mathrm{Bu}} \mathrm{BOX}\right\}$ a different route was developed; see below. 


\section{Bis(oxazoline)s}<smiles>[R]C([R])(C(=O)NC(C)(C)CO)C(=O)NC(C)(C)CO</smiles>

1. $\mathrm{MsCl}, \mathrm{Et}_{3} \mathrm{~N}, \mathrm{CH}_{2} \mathrm{Cl}_{2}$

2. $\mathrm{NaOH}, \mathrm{H}_{2} \mathrm{O} / \mathrm{MeOH}$

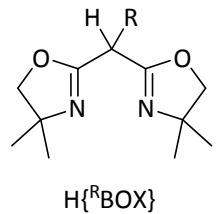

A solution of the respective bishydroxy malondiamide and 5.00 eq. dry triethylamine in $\sim 300 \mathrm{~mL}$ dry methylene chloride was treated with 2.50 eq. methanesulfonyl chloride $(\mathrm{MsCl})$ at $0{ }^{\circ} \mathrm{C}$. The solution was stirred for $1 \mathrm{~h}$ at room temperature and then washed with saturated ammonium chloride solution $(3 \times 350 \mathrm{~mL})$. Upon removal of solvent in vacuo, colourless to orange oils were obtained.

The respective mesylate was redissolved in $400 \mathrm{~mL}$ methanol/water (1: 1), 5.00 eq. of sodium hydroxide were added and the solution was heated under reflux for $2 \mathrm{~h}$. It was then concentrated in vacuum and the aqueous phase was extracted with methylene chloride $(3 \times 300 \mathrm{~mL})$. The combined organic phase was dried over sodium sulphate, the solvent was removed in vacuum and the liquid was purified by bulb-to-bulb vacuum distillation. Colourless liquids were yielded in the case of $\mathrm{H}\left\{{ }^{\mathrm{Me}} \mathrm{BOX}\right\}$ and $\left.\mathrm{H}_{\{}{ }^{t \mathrm{Bu}} \mathrm{BOX}\right\}$, while colourless solids were obtained in the case of $\left.\mathrm{H}_{\{}{ }^{\mathrm{H}} \mathrm{BOX}\right\}$ and $\left.\mathrm{H}_{\{}{ }^{\mathrm{Ph}} \mathrm{BOX}\right\}$. Refer to $\mathrm{H}_{\{}\left\{{ }^{\mathrm{Ph}} \mathrm{BOX}\right\}$ for deviations from this procedure.

\subsection{2. $\mathrm{H}\left\{{ }^{\mathrm{H}} \mathrm{BOX}\right\}$ : 1,1-Bis(4,4-dimethyl-1,3-oxazolin-2-yl)methane}

Although a preparation was reported before applying a different route, ${ }^{[126]}$ no analytical data was published.<smiles>CC(C)(CO)NC(=O)C=O</smiles>

$N, N$ '-Bis(1-hydroxy-2-methylpropan-2-yl)malonamide. In contrast to literature, it was synthesized from diethyl malonate $(12.83 \mathrm{~g}, 80.13 \mathrm{mmol})$ and 2-amino2-methyl-1-propanol (14.29 g, $160.3 \mathrm{mmol}$ ). Following the general procedure described above, the ester was obtained quantitatively as a white solid.

${ }^{1} \mathrm{H}-\mathrm{NMR}\left(300 \mathrm{MHz}, \mathrm{CDCl}_{3}\right): \delta(\mathrm{ppm})=6.82(\mathrm{br}, 2 \mathrm{H}, \mathrm{NH}), 3.59\left(\mathrm{~s} 4 \mathrm{H}, 2 \mathrm{CH}_{2}\right), 3.10$ (s, $\left.2 \mathrm{H}, \mathrm{CH}_{2}\right), 1.65$ (br, $\left.2 \mathrm{H}, \mathrm{OH}\right), 1.31\left(\mathrm{~s}, 12 \mathrm{H}, \mathrm{CH}_{3}\right)$. 
<smiles>CC(C1=NC(C)(C)CO1)C1=NC(C)(C)CO1</smiles>

$\mathbf{H}\left\{{ }^{\mathbf{H}} \mathbf{B O X}\right\}$ was prepared from the crude malonamide following the general procedure. The bis(oxazoline) was then bulb-to-bulb distilled $\left(70-80^{\circ} \mathrm{C}, 1 \times 10^{-2}\right.$ mbar), yielding a colourless liquid which later solidified spontaneously upon scratching with a glass pipette. Large colourless single crystals in good quality for x-ray diffraction analysis were yielded upon sublimation by slightly heating in vacuum after $\sim 1$ hour.

yield: $7.236 \mathrm{~g}$ colourless crystals ( $34.41 \mathrm{mmol}, 43 \%$ overall yield).

$\mathrm{C}_{11} \mathrm{H}_{18} \mathrm{~N}_{2} \mathrm{O}_{2}\left(210.27 \mathrm{~g} \mathrm{~mol}^{-1}\right)$.

elemental analysis (calcd.): C 61.14 (62.83), H 8.36 (8.63), N 13.27 (13.32).

MS $\left(\mathrm{ESI}^{+}, \mathrm{MeCN} / \mathrm{CH}_{2} \mathrm{Cl}_{2}\right): m / z(\%)=211\left(100,[\mathrm{M}+\mathrm{H}]^{+}\right), 233\left(33,[\mathrm{M}+\mathrm{Na}]^{+}\right)$.

${ }^{1} \mathrm{H}-\mathrm{NMR}\left(300 \mathrm{MHz}, \mathrm{CDCl}_{3}\right): \delta(\mathrm{ppm})=3.96\left(\mathrm{~s}, 4 \mathrm{H}\right.$, oxazoline- $\left.\mathrm{CH}_{2}\right), 3.30(\mathrm{~s}, 2 \mathrm{H}$, bridging- $\left.\mathrm{CH}_{2}\right), 1.28\left(\mathrm{~s}, 12 \mathrm{H}, \mathrm{CH}_{3}\right)$.

${ }^{13} \mathrm{C}\left\{{ }^{1} \mathrm{H}\right\}-\mathrm{NMR}\left(75 \mathrm{MHz}, \mathrm{CDCl}_{3}\right): \delta(\mathrm{ppm})=160.3(2 \mathrm{C}=\mathrm{N}), 79.7\left(2\right.$ oxazoline- $\left.\mathrm{CH}_{2}\right)$, $67.5\left(2 \mathrm{CMe}_{2}\right), 28.8$ (bridging- $\left.\mathrm{CH}_{2}\right), 28.3(4 \mathrm{Me})$.

${ }^{15} \mathrm{~N}-\mathrm{NMR}\left(30 \mathrm{MHz}, \mathrm{CDCl}_{3}\right): \delta(\mathrm{ppm})=-132.6(\mathrm{C}=\mathrm{N})$.

FTIR (neat): $\tilde{v}\left(\mathrm{~cm}^{-1}\right)=2969(\mathrm{~m}, v \mathrm{CH}), 2930(\mathrm{w}, v \mathrm{CH}), 2897(\mathrm{w}, v \mathrm{CH}), 1666(\mathrm{~m}$, $v \mathrm{~N}=\mathrm{C}-\mathrm{C}-\mathrm{C}=\mathrm{N}), 1593(\mathrm{w}), 1463(\mathrm{w}), 1415(\mathrm{w}), 1386(\mathrm{w}), 1365(\mathrm{w}), 1319(\mathrm{w}), 1290$ (w), $1264(\mathrm{w}), 1249(\mathrm{w}), 1196(\mathrm{w}), 1148(\mathrm{w}), 1035(\mathrm{w}), 990(\mathrm{~m}), 918(\mathrm{w}), 868(\mathrm{w}), 814$ (w), $634(\mathrm{w})$.

UV-vis $\left(\mathrm{CHCl}_{3}\right): \lambda_{\max }(\varepsilon)=281 \mathrm{~nm}\left(8.7 \times 10^{2} \mathrm{M}^{-1} \mathrm{~cm}^{-1}\right)$.

\subsection{3. $\mathrm{H}\left\{{ }^{\mathrm{Me}} \mathrm{BOX}\right\}$ : 1,1-Bis(4,4-dimethyl-1,3-oxazolin-2-yl)ethane}<smiles>CC(C1=NC(C)(C)CO1)C1=NC(C)(C)CO1</smiles>

$\mathrm{H}\left\{{ }^{\mathrm{Me}} \mathrm{BOX}\right\}$ was prepared according to the general procedure. The analytical properties were consistent with literature. ${ }^{[124]}$

${ }^{1} \mathrm{H}-\mathrm{NMR}\left(300 \mathrm{MHz}, \mathrm{CDCl}_{3}\right): \delta(\mathrm{ppm})=3.90\left(\mathrm{~s}, 4 \mathrm{H}, 2 \mathrm{CH}_{2}\right), 3.42(\mathrm{q}, J=7.2 \mathrm{~Hz}, 1 \mathrm{H}$, CHMe), 1.43 (d, J = 7.2 Hz, 3 H, CHMe), 1.238 (s, 6 H, 2 Me), 1.235 (s, 6 H, $2 \mathrm{Me}$ ). 
${ }^{13} \mathrm{C}\left\{{ }^{1} \mathrm{H}\right\}-\mathrm{NMR}\left(75 \mathrm{MHz}, \mathrm{CDCl}_{3}\right): \delta(\mathrm{ppm})=164.4(2 \mathrm{C}=\mathrm{N}), 79.5\left(2 \mathrm{CH}_{2}\right), 67.2$ (2 $\mathrm{CMe}_{2}$ ), 34.1 (CHMe), 28.25 (2 Me), 28.20 (2 Me), 15.31 (CHMe).

${ }^{15} \mathrm{~N}-\mathrm{NMR}\left(30 \mathrm{MHz}, \mathrm{CDCl}_{3}\right): \delta(\mathrm{ppm})=-135.3(\mathrm{C}=\mathrm{N})$.

IR (neat): $\tilde{v}\left(\mathrm{~cm}^{-1}\right)=2970(\mathrm{~m}, v \mathrm{CH}), 2931$ (w, $\left.v \mathrm{CH}\right), 2894(\mathrm{w}, v \mathrm{CH}), 1663(\mathrm{~m}, v$ $\mathrm{N}=\mathrm{C}-\mathrm{C}-\mathrm{C}=\mathrm{N}), 1577$ (w), $1464(\mathrm{w}), 1385$ (w), 1365 (w), 1328 (w), $1296(\mathrm{w}), 1250$ (w), $1192(w), 1155(w), 1069(w), 1015(w), 989(w), 977(w), 930(w)$.

\subsection{4. $\mathrm{H}\left\{{ }^{\mathrm{Ph}} \mathrm{BOX}\right\}$ :}

\section{1,1-Bis(4,4-dimethyl-1,3-oxazolin-2-yl)-1-phenylmethane}<smiles>CC(C)(CO)NC(=O)C(C(=O)NC(C)(C)CO)c1ccccc1</smiles>

$N, N$ '-Bis(1-hydroxy-2-methylpropan-2-yl)-2-phenylmalonamide. The preparation followed the general procedure from diethyl phenylmalonate $(14.18 \mathrm{~g}$, $60.02 \mathrm{mmol}$ ) and 2-amino-2-methyl-1-propanol (10.70 g, $120.0 \mathrm{mmol})$. The malonamide was yielded quantitatively as a colourless oil.

${ }^{1} \mathrm{H}-\mathrm{NMR}\left(300 \mathrm{MHz}, \mathrm{CDCl}_{3}\right): \delta(\mathrm{ppm})=7.39-7.31(\mathrm{~m}, 5 \mathrm{H}, \mathrm{Ph}), 7.11(\mathrm{br}, 2 \mathrm{H}, 2 \mathrm{NH})$, $4.30(\mathrm{~s}, 1 \mathrm{H}, \mathrm{CH}), 3.54\left(\mathrm{~s}, 4 \mathrm{H}, 2 \mathrm{CH}_{2}\right), 1.25$ (s, $\left.6 \mathrm{H}, 2 \mathrm{Me}\right), 1.24(\mathrm{~s}, 6 \mathrm{H}, 2 \mathrm{Me}), \mathrm{OH}$ was not observed.

${ }^{13} \mathrm{C}\left\{{ }^{1} \mathrm{H}\right\}-\mathrm{NMR}\left(75 \mathrm{MHz}, \mathrm{CDCl}_{3}\right): \delta(\mathrm{ppm})=170.05(2 \mathrm{C}=\mathrm{O}), 135.35\left(\mathrm{C}_{\mathrm{q}}-\mathrm{Ph}\right), 129.31$ $(\mathrm{Ph}), 128.36(\mathrm{Ph}), 127.83(\mathrm{Ph}), 69.65\left(2 \mathrm{CH}_{2}\right), 60.11(\mathrm{CH}), 56.44\left(2 \mathrm{CMe}_{2}\right), 24.28$ $\left.\left(2 \mathrm{CMe}_{2}\right), 24.24(2 \mathrm{CMe})_{2}\right)$.

MS (EI): $m / z(\%)=291\left(76,\left[\mathrm{M}-\mathrm{CH}_{2} \mathrm{OH}\right]^{+}\right), 273\left(14,\left[\mathrm{M}-\mathrm{CH}_{2} \mathrm{OH}-\mathrm{H}_{2} \mathrm{O}\right]^{+}\right), 207$ $\left(61,\left[\mathrm{M}-\mathrm{C}(\mathrm{O}) \mathrm{NCMe}_{2} \mathrm{CH}_{2} \mathrm{OH}\right]^{+}\right), 118\left(94,\left[\mathrm{C}(\mathrm{O}) \mathrm{NHCMe}_{2} \mathrm{CH}_{2} \mathrm{OH}+2 \mathrm{H}\right]^{+}\right), 73(26$, $\left[\mathrm{CMe}_{2} \mathrm{CH}_{2} \mathrm{OH}\right]^{+}$.<smiles></smiles>

$\mathbf{H}\left\{{ }^{\mathbf{P h}} \mathbf{B O X}\right\}$ was prepared from the crude malondiamide following the general procedure. In contrast to the other three bis(oxazoline)s, the product precipitated in the final ring-closure step. The precipitate was separated by filtration, the solution 
concentrated and additional precipitate collected by filtration. The combined residues were washed with water $(3 \times 20 \mathrm{~mL})$ and then dried with a rotary vane pump at $85^{\circ} \mathrm{C}$. Colourless needles, suitable for $\mathrm{x}$-ray diffraction analysis, were obtained by slow concentration of a solution of $300 \mathrm{mg}$ bis(oxazoline) in methylene chloride/methanol (45:5 mL).

yield: $8.69 \mathrm{~g}$ white powder ( $30.35 \mathrm{mmol}, 51 \%$ overall yield).

$\mathrm{C}_{17} \mathrm{H}_{22} \mathrm{~N}_{2} \mathrm{O}_{2}\left(286.37 \mathrm{~g} \mathrm{~mol}^{-1}\right)$.

elemental analysis (calcd.): C 70.84 (71.30), H 7.92 (7.74), N 9.60 (9.78).

HRMS $(\mathrm{MeCN})$ : found $[\mathrm{M}+\mathrm{H}]^{+} 287.1759, \mathrm{C}_{17} \mathrm{H}_{23} \mathrm{~N}_{2} \mathrm{O}_{2}$ requires 287.1754.

MS $\left(\mathrm{ESI}^{+}, \mathrm{MeCN}\right): m / z(\%)=287\left(100,[\mathrm{M}+\mathrm{H}]^{+}\right)$.

MS (EI): $m / z(\%)=286\left(73,[\mathrm{M}]^{+}\right), 271\left(95,\left[\mathrm{M}-\mathrm{CH}_{3}\right]^{+}\right), 214\left(33,\left[\mathrm{M}-\mathrm{C}_{4} \mathrm{H}_{8} \mathrm{O}\right]^{+}\right), 199$

$\left(100,\left[\mathrm{M}-\mathrm{C}_{4} \mathrm{H}_{9} \mathrm{NO}\right]^{+}\right), 189\left(54,\left[\mathrm{M}-\mathrm{C}_{5} \mathrm{H}_{7} \mathrm{NO}\right]^{+}\right), 187\left(23,\left[\mathrm{M}-\mathrm{C}_{5} \mathrm{H}_{9} \mathrm{NO}\right]^{+}\right), 172(16$, $\left.\left[\mathrm{C}_{6} \mathrm{H}_{12} \mathrm{NO}\right]^{+}\right)$.

UV-vis $\left(\mathrm{CHCl}_{3}\right): \lambda_{\max }(\varepsilon)=290 \mathrm{~nm}\left(7.5 \times 10^{3} \mathrm{M}^{-1} \mathrm{~cm}^{-1}\right)$.

Analysis of iminoenamine tautomer:

${ }^{1} \mathrm{H}-\mathrm{NMR}\left(500 \mathrm{MHz}, \mathrm{CDCl}_{3},-50^{\circ} \mathrm{C}\right): \delta(\mathrm{ppm})=8.94(\mathrm{br}, 1 \mathrm{H}, \mathrm{NH}), 7.32-7.16(\mathrm{~m}, 5 \mathrm{H}$, $\mathrm{Ph}), 3.97\left(\mathrm{~s}, 4 \mathrm{H}, 2 \mathrm{CH}_{2}\right), 1.35(\mathrm{~s}, 12 \mathrm{H}, 4 \mathrm{Me})$.

${ }^{13} \mathrm{C}\left\{{ }^{1} \mathrm{H}\right\}-\mathrm{NMR}\left(125 \mathrm{MHz}, \mathrm{CDCl}_{3},-50{ }^{\circ} \mathrm{C}\right): \delta(\mathrm{ppm})=164.4(2 \mathrm{C}=\mathrm{N}), 135.4(\mathrm{Ph}), 131.2$ (Ph), $128.0(\mathrm{Ph}), 125.4(\mathrm{Ph}), 79.0\left(\mathrm{CH}_{2}\right), 77.4(\mathrm{CPh}), 62.0(C \mathrm{Me} 2), 28.0(\mathrm{Me})$,

${ }^{15} \mathrm{~N}-\mathrm{NMR}\left(30 \mathrm{MHz}, \mathrm{CDCl}_{3}\right): \delta(\mathrm{ppm})=-216.2(\mathrm{NH} / \mathrm{C}=\mathrm{N})$.

FTIR (KBr): $\tilde{v}\left(\mathrm{~cm}^{-1}\right)=3168(\mathrm{br}, v \mathrm{NH}), 2968(\mathrm{~m}, v \mathrm{CH}), 2927(\mathrm{w}, v \mathrm{CH}), 2878(\mathrm{~m}, v$ $\mathrm{CH}), 1646\left(\mathrm{~s}, v_{\mathrm{a}} \mathrm{C}=\mathrm{C}-\mathrm{C}=\mathrm{N}+\delta \mathrm{NH}\right), 1558\left(\mathrm{~s}, v_{\mathrm{s}} \mathrm{C}=\mathrm{C}-\mathrm{C}=\mathrm{N}+\delta \mathrm{NH}\right), 1491(\mathrm{w}), 1474$ (w), $1462(\mathrm{w}), 1446(\mathrm{w}), 1407(\mathrm{w}), 1387(\mathrm{~m}), 1370(\mathrm{~m}), 1350(\mathrm{~m}), 1332(\mathrm{~m}), 1313(\mathrm{w})$, 1249 (w), 1197 (m), 1170 (w), 1070 (w), 1034 (s), 989 (w), 969 (w), 957 (w), 937 (w), $918(\mathrm{w}), 816(\mathrm{w}), 749(\mathrm{w}), 736(\mathrm{w}), 701(\mathrm{~m}), 655(\mathrm{w}), 514(\mathrm{w}), 492(\mathrm{w})$.

Analysis of diimine tautomer:

${ }^{1} \mathrm{H}-\mathrm{NMR}\left(500 \mathrm{MHz}, \mathrm{CDCl}_{3}\right): \delta(\mathrm{ppm})=7.41-7.24(\mathrm{~m}, 5 \mathrm{H}, \mathrm{Ph}), 4.71(\mathrm{~s}, 1 \mathrm{H}, \mathrm{CH})$, $3.95(\mathrm{~d}, J=8.1 \mathrm{~Hz}, 2 \mathrm{H}, \mathrm{CHH}), 3.90(\mathrm{~d}, J=8.1 \mathrm{~Hz}, 2 \mathrm{H}, \mathrm{CHH}), 1.27(\mathrm{~s}, 6 \mathrm{H}, 2$ $\mathrm{CMeMe}), 1.24$ (s, 6 H, $2 \mathrm{CMeMe})$.

${ }^{13} \mathrm{C}\left\{{ }^{1} \mathrm{H}\right\}-\mathrm{NMR}\left(125 \mathrm{MHz}, \mathrm{CDCl}_{3}\right): \delta(\mathrm{ppm})=162.5(\mathrm{C}=\mathrm{N}), 134.8(\mathrm{Ph}), 128.8(\mathrm{Ph})$, 128.7 (Ph), 127.6 (Ph), 79.7 $\left(\mathrm{CH}_{2}\right), 67.4\left(\mathrm{CMe}_{2}\right), 45.9(\mathrm{CHPh}), 28.2(\mathrm{CMeMe}), 28.1$ $(\mathrm{CMeMe})$.

${ }^{15} \mathrm{~N}-\mathrm{NMR}\left(30 \mathrm{MHz}, \mathrm{CDCl}_{3}\right): \delta(\mathrm{ppm})=-131.5(\mathrm{C}=\mathrm{N})$. 
10.1.5. $\left.\mathrm{H}^{t \mathrm{Bu}} \mathrm{BOX}\right\}$ :

1,1-Bis(4,4-dimethyl-1,3-oxazolin-2-yl)neopentane<smiles>CCOC(=O)C(C(=O)OCC)=C(C)C</smiles>

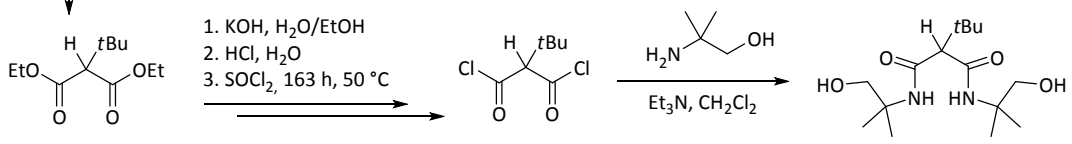

Diethyl tert-butylmalonate. The ester was prepared from diethyl isopropylidenemalonate similar to a reported procedure. ${ }^{[127]}$ The instructions were slightly modified and methylmagnesium iodide was used as commercially available $3 \mathrm{M}$ diethyl ether solution (Acros Organics). Synthesis of the bis(oxazoline) starting from the malonic ester and following the general procedure as stated above, yielded only $\sim 5 \%$ bis(oxazoline); the low yield is presumably due to the bulkiness of the tert-butyl residue. However, comparative yields could be achieved by following a differing route, starting from the corresponding acyl chloride.

tert-Butylmalonyl chloride. The ester was hydrolysed, yielding the corresponding malonic acid which in an additional step was transformed to tert-butylmalonyl chloride as it is described in literature. ${ }^{[129]}$<smiles>CC(C)(CO)NC(=O)C(C(=O)NC(C)(C)CO)C(C)(C)C</smiles>

2-(tert-Butyl)- $N, N$ '-bis(1-hydroxy-2-methylpropan-2-yl)malonamide. The synthesis follows a related description. ${ }^{[125]}$ 2-Amino-2-methyl-1-propanol (3.35 g, $37.6 \mathrm{mmol})$ and dry triethyl amine $(3.80 \mathrm{~g}, 37.6 \mathrm{mmol})$ were dissolved in $44 \mathrm{~mL}$ dry $\mathrm{CH}_{2} \mathrm{Cl}_{2}$ under inert conditions. tert-Butylmalonyl chloride $(3.00 \mathrm{~g}, 15.2 \mathrm{mmol})$ was slowly added at $0{ }^{\circ} \mathrm{C}$. The reaction was stirred for 2 hours at ambient temperature,

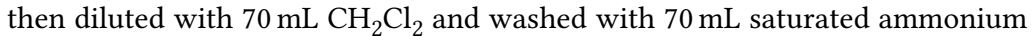
chloride solution. The aqueous phase was then extracted with $3 \times 30 \mathrm{~mL} \mathrm{CH}_{2} \mathrm{Cl}_{2}$ 
and the combined organics dried over $\mathrm{Na}_{2} \mathrm{SO}_{4}$. The solvent was removed in vacuum and the residue then dried overnight in vacuum. A colourless oil was yielded quantitatively, which could be used without purification.

${ }^{1} \mathrm{H}-\mathrm{NMR}\left(300 \mathrm{MHz}, \mathrm{CDCl}_{3}\right): \delta(\mathrm{ppm})=7.41(\mathrm{br}, 2 \mathrm{H}, 2 \mathrm{NH}), 4.65$ (br, $\left.2 \mathrm{H}, 2 \mathrm{OH}\right)$, $3.56\left(\mathrm{~s}, 2 \mathrm{H}, \mathrm{CH}_{2}\right), 3.55$ (s, $\left.2 \mathrm{H}, \mathrm{CH}_{2}\right), 2.83(\mathrm{~s}, 1 \mathrm{H}, \mathrm{CH}), 1.30$ (s, $\left.6 \mathrm{H}, 2 \mathrm{Me}\right), 1.29$ (s, $6 \mathrm{H}, 2 \mathrm{Me}), 1.07(\mathrm{~s}, 9 \mathrm{H}, t \mathrm{Bu})$.

${ }^{13} \mathrm{C}\left\{{ }^{1} \mathrm{H}\right\}-\mathrm{NMR}\left(75 \mathrm{MHz}, \mathrm{CDCl}_{3}\right): \delta(\mathrm{ppm})=170.98(2 \mathrm{C}=\mathrm{O}), 70.78\left(2 \mathrm{CH}_{2}\right), 64.12$ $(\mathrm{CH}), 56.60\left(2 \mathrm{CMe}_{2}\right), 34.92\left(\mathrm{CMe}_{3}\right), 28.57\left(\mathrm{CMe}_{3}\right), 24.43\left(2 \mathrm{CMe}_{2}\right)$.<smiles>CC1(C)COC(C(C2=NC(C)(C)CO2)C(C)(C)C)=N1</smiles>

$\left.\mathbf{H}_{\left\{{ }^{\mathbf{B} u}\right.} \mathbf{B O X}\right\}$ was prepared from the crude malondiamide following the general procedure and was purified by kugelrohr distillation.

yield: $1.77 \mathrm{~g}$ colourless liquid $(6.64 \mathrm{mmol}, 44 \%$ from the malondiamide).

$\mathrm{C}_{15} \mathrm{H}_{26} \mathrm{~N}_{2} \mathrm{O}_{2}\left(266.38 \mathrm{~g} \mathrm{~mol}^{-1}\right)$.

b. p. $=40-42^{\circ} \mathrm{C}\left(5.6 \times 10^{-2} \mathrm{mbar}\right)$.

elemental analysis (calcd.): C 66.86 (67.63), H 9.85 (9.84), N 10.99 (10.52).

HRMS $\left(\mathrm{CH}_{2} \mathrm{Cl}_{2} / \mathrm{MeCN}\right)$ : found $[\mathrm{M}+\mathrm{H}]^{+}$267.2070, $\mathrm{C}_{15} \mathrm{H}_{27} \mathrm{~N}_{2} \mathrm{O}_{2}$ requires 267.2067. MS (ESI $\left.{ }^{+}, \mathrm{CH}_{2} \mathrm{Cl}_{2} / \mathrm{MeCN}\right): m / z(\%)=267\left(17,[\mathrm{M}+\mathrm{H}]^{+}\right), 289\left(31,[\mathrm{M}+\mathrm{Na}]^{+}\right), 555$ $\left(100,\left[{ }_{2} \mathrm{M}+\mathrm{Na}\right]^{+}\right)$.

MS (EI): $m / z(\%)=251\left(8,\left[\mathrm{M}-\mathrm{CH}_{3}\right]^{+}\right), 210\left(28,\left[\mathrm{M}-\mathrm{C}_{4} \mathrm{H}_{8}\right]^{+}\right), 195\left(100,\left[\mathrm{M}-\mathrm{C}_{4} \mathrm{H}_{10} \mathrm{~N}\right]^{+}\right)$. ${ }^{1} \mathrm{H}-\mathrm{NMR}\left(300 \mathrm{MHz}, \mathrm{CDCl}_{3}\right): \delta(\mathrm{ppm})=3.91\left(\mathrm{~s}, 4 \mathrm{H}, 2 \mathrm{CH}_{2}\right), 3.31(\mathrm{~s}, 1 \mathrm{H}, \mathrm{CH}), 1.25$ $\left(\mathrm{s}, 6 \mathrm{H}, 2 \mathrm{CH}_{3}\right), 1.24\left(\mathrm{~s}, 6 \mathrm{H}, 2 \mathrm{CH}_{3}\right), 1.08(\mathrm{~s}, 9 \mathrm{H}, t \mathrm{Bu})$.

${ }^{13} \mathrm{C}\left\{{ }^{1} \mathrm{H}\right\}-\mathrm{NMR}\left(125 \mathrm{MHz}, \mathrm{CDCl}_{3}\right): \delta(\mathrm{ppm})=162.5(2 \mathrm{C}=\mathrm{N}), 79.1\left(2 \mathrm{CH}_{2}\right), 67.0$ $\left(\mathrm{CMe}_{2}\right), 50.1(\mathrm{CH}), 34.1\left(\mathrm{CMe}_{3}\right), 28.4(2 \mathrm{CMeMe}), 28.3\left(\mathrm{CMe}_{3}\right), 28.2(2 \mathrm{CMe} \mathrm{Me})$.

${ }^{15} \mathrm{~N}-\mathrm{NMR}\left(30 \mathrm{MHz}, \mathrm{CDCl}_{3}\right): \delta(\mathrm{ppm})=-130.5(\mathrm{C}=\mathrm{N})$.

FTIR (neat): $\tilde{v}\left(\mathrm{~cm}^{-1}\right)=2965(\mathrm{~m}, v \mathrm{CH}), 2932(\mathrm{w}, v \mathrm{CH}), 2890(\mathrm{w}, v \mathrm{CH}), 1658(\mathrm{~m}, v$ $\mathrm{N}=\mathrm{C}-\mathrm{C}-\mathrm{C}=\mathrm{N}), 1481(\mathrm{w}), 1464(\mathrm{w}), 1398$ (w), $1384(\mathrm{w}), 1365$ (m), $1326(\mathrm{w}), 1287$ (w), $1248(\mathrm{w}), 1199(\mathrm{w}), 1134(\mathrm{w}), 1034(\mathrm{w}), 996(\mathrm{~m}), 869(\mathrm{w}), 762(\mathrm{w}), 691(\mathrm{w}), 638(\mathrm{w})$, $611(\mathrm{w}), 525(\mathrm{w})$. 


\subsection{Copper(I) Complexes}

\subsubsection{The $\left.\left[\left(\mathrm{H}_{\{}^{\mathrm{R}} \mathrm{BOX}\right\}\right) \mathrm{Cu}(\mathrm{MeCN})\right] \mathrm{PF}_{6}\left(\mathrm{Cu} \mathbf{u}^{\prime} \mathrm{R}\right)$ Family}<smiles>[R]C(C1=NC(C)(C)CO1)C1=NC(C)(C)CO1</smiles>

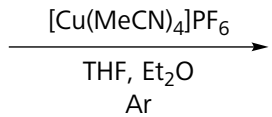<smiles>[R]C1C2=C(N(Cl)C(C)(C)CO2)N(Cl)C1(C)C</smiles>

Cu'R

Due to the sensitivity of $\mathrm{Cu}^{\mathrm{I}}$ to oxygen and due to the sensitivity of the ligands to $\mathrm{Cu}^{\mathrm{II}}$, complexes of the $\mathbf{C} \mathbf{u}^{\prime} \mathbf{R}$ family were generally used in situ without isolation of the solid copper(I) complexes.

\section{$\left.\left[\left(\mathrm{H}_{\{}^{t \mathrm{Bu}} \mathrm{BOX}\right\}\right) \mathrm{Cu}^{\prime}(\mathrm{MeCN})\right] \mathrm{PF}_{6}\left(\mathrm{Cu}^{\prime} t \mathrm{Bu}\right)$}

Method 1. 1.05 eq. Ligand $\left.\mathrm{H}^{t}{ }^{\mathrm{B}{ }^{\mathrm{u}}} \mathrm{BOX}\right\}(50 \mathrm{mg}, 188 \mu \mathrm{mol})$ were dissolved in $40 \mathrm{~mL}$ dry $\mathrm{CH}_{2} \mathrm{Cl}_{2}$ under an atmosphere of dry argon. The solution was sparged for $\sim 15 \mathrm{~min}$ with argon to ensure the absence of oxygen. 1.00 eq. $\left[\mathrm{Cu}(\mathrm{MeCN})_{4}\right] \mathrm{PF}_{6}$ $(66 \mathrm{mg}, 170 \mu \mathrm{mol})$ was added and the mixture stirred for $30 \mathrm{~min}$ until all salt was dissolved. A colourless solution was obtained. The solvent was removed in vacuum and the resulting residue heated to $80^{\circ} \mathrm{C}$ under vacuum to remove excess ligand to obtain $\mathbf{C} \mathbf{u}^{\prime} \mathbf{t} \mathbf{B u}$ quantitatively as air-sensitive white powder.

Method 2. $\mathrm{H}_{\left\{{ }^{t \mathrm{Bu}} \mathrm{BOX}\right\}}(24 \mathrm{mg}, 90 \mu \mathrm{mol})$ was dissolved in $5 \mathrm{~mL}$ dry THF under an atmosphere of argon in a small Schlenk flask. The solution was sparged for $\sim 15$ min with argon to ensure the absence of oxygen. 1.00 eq. $\left[\mathrm{Cu}(\mathrm{MeCN})_{4}\right] \mathrm{PF}_{6}$ (34 mg, $90 \mu \mathrm{mol}$ ) was added and the obtained colourless solution was stirred for some minutes. The flask was then linked to a second Schlenk flask, containing $40 \mathrm{~mL}$ of dry, degassed diethyl ether by a bent glass adapter. The slow gaseous diffusion of $\mathrm{Et}_{2} \mathrm{O}$ into the THF solution afforded small crystalline white rods of the copper(I) complex after a few days. The single crystals obtained were of high quality and suitable for X-ray structure determination. The supernatant was removed and the residue was thoroughly washed with $5 \times 4 \mathrm{~mL}$ dry degassed $\mathrm{Et}_{2} \mathrm{O}$ under argon using a syringe with a stainless steel needle. After drying in vacuum, $12 \mathrm{mg}(26 \%) \mathbf{C} \mathbf{u}^{\prime} \boldsymbol{t} \mathbf{B u}$ as white crystalline solid were yielded.

$\mathrm{C}_{17} \mathrm{H}_{29} \mathrm{CuF}_{6} \mathrm{~N}_{3} \mathrm{O}_{2} \mathrm{P}\left(515.12 \mathrm{~g} \mathrm{~mol}^{-1}\right)$. 
MS $\left(\mathrm{ESI}^{+}, \mathrm{MeCN}\right): m / z(\%)=595.3\left(17,\left[(\mathrm{HL})_{2} \mathrm{Cu}\right]^{+}\right), 370.0\left(100,[(\mathrm{HL}) \mathrm{Cu}(\mathrm{MeCN})]^{+}\right)$, $329.0\left(32,[(\mathrm{HL}) \mathrm{Cu}]^{+}\right)$.

${ }^{1} \mathrm{H}-\mathrm{NMR}\left(400 \mathrm{MHz}, \mathrm{CD}_{2} \mathrm{Cl}_{2}\right): \delta(\mathrm{ppm})=4.25\left(\mathrm{~d}, 2 \mathrm{H},{ }^{2} J(\mathrm{HH})=8.9 \mathrm{~Hz}, \mathrm{CHH}\right), 4.21$ $\left(\mathrm{d}, 2 \mathrm{H},{ }^{2} \mathrm{~J}(\mathrm{HH})=8.9 \mathrm{~Hz}, \mathrm{CHH}\right), 3.29(\mathrm{~s}, 1 \mathrm{H}, \mathrm{CH}), 2.28(\mathrm{~s}, 3 \mathrm{H}, \mathrm{MeCN}), 1.39(\mathrm{~s}, 6 \mathrm{H}$, 2 BOX- $\left.\mathrm{CH}_{3}\right), 1.38$ (s, $\left.6 \mathrm{H}, 2 \mathrm{BOX}-\mathrm{CH}_{3}\right), 1.10(\mathrm{~s}, 9 \mathrm{H}, t \mathrm{Bu})$.

${ }^{13} \mathrm{C}\left\{{ }^{1} \mathrm{H}\right\}$-NMR $\left(101 \mathrm{MHz}, \mathrm{CD}_{2} \mathrm{Cl}_{2}\right): \delta(\mathrm{ppm})=168.0(\mathrm{C}=\mathrm{N}), \mathrm{Me} C \equiv \mathrm{N}$ not observed, $80.3\left(\mathrm{CH}_{2}\right), 68.1\left(\mathrm{CMe}_{2}\right), 48.5(\mathrm{CH}), 37.0\left(\mathrm{CMe}_{3}\right), 28.8(2 \mathrm{Me}), 28.7\left(\mathrm{CMe}_{3}\right), 28.6$ (2 Me), $3.2(\mathrm{MeCN})$.

${ }^{15} \mathrm{~N}-\mathrm{NMR}\left(30 \mathrm{MHz}, \mathrm{CD}_{2} \mathrm{Cl}_{2}\right): \delta(\mathrm{ppm})=-161.4(\mathrm{C}=\mathrm{N}), \mathrm{MeCN}$ not observed. UV-vis (THF; acetone): no absorbance (300-800 nm).

\section{$\left.\left[\left(\mathrm{H}_{\{}{ }^{\mathrm{Ph}} \mathrm{BOX}\right\}\right) \mathrm{Cu}^{\prime}(\mathrm{MeCN})\right] \mathrm{PF}_{6}\left(\mathrm{Cu}^{\prime} \mathrm{Ph}\right)$}

In an inert-atmosphere glovebox, equimolar amounts of $\left.\mathrm{H}_{\{}{ }^{\mathrm{Ph}} \mathrm{BOX}\right\}(57 \mathrm{mg}, 200 \mu \mathrm{mol})$ and $\left[\mathrm{Cu}(\mathrm{MeCN})_{4}\right] \mathrm{PF}_{6}(75 \mathrm{mg}, 200 \mu \mathrm{mol})$ were combined in a Schlenk flask, dissolved in $10 \mathrm{~mL}$ chloroform and stirred for a few minutes. The flask was linked to a second Schlenk flask, containing $50 \mathrm{~mL}$ of diethyl ether by a bent glass adapter. After several days, the slow gaseous diffusion of $\mathrm{Et}_{2} \mathrm{O}$ into the THF solution afforded a few small crystals of the copper(I) complex of suitable X-ray diffraction quality.

$\mathrm{C}_{19} \mathrm{H}_{25} \mathrm{CuF}_{6} \mathrm{~N}_{3} \mathrm{O}_{2} \mathrm{P}\left(535.94 \mathrm{~g} \mathrm{~mol}^{-1}\right)$.

UV-vis (THF): no absorbance (300-800 nm).

\section{$\left[\left(\mathrm{H}_{\{}^{\mathrm{Me}} \mathrm{BOX}\right) \mathrm{Cu}^{\prime}(\mathrm{MeCN})\right] \mathrm{PF}_{6}\left(\mathrm{Cu}^{\prime} \mathrm{Me}\right)$}

Cu'Me was prepared in situ and not isolated as the solid copper(I) complex.

$\mathrm{C}_{14} \mathrm{H}_{23} \mathrm{CuF}_{6} \mathrm{~N}_{3} \mathrm{O}_{2} \mathrm{P}\left(473.87 \mathrm{~g} \mathrm{~mol}^{-1}\right)$.

UV-vis (THF): no absorbance (300-800 nm).

\section{$\left.\left[\left(\mathrm{H}_{\{}{ }^{\mathrm{H}} \mathrm{BOX}\right\}\right) \mathrm{Cu}^{\prime}(\mathrm{MeCN})\right] \mathrm{PF}_{6}\left(\mathrm{Cu}^{\prime} \mathrm{H}\right)$}

$\left.\mathrm{H}_{\{}{ }^{\mathrm{H}} \mathrm{BOX}\right\}$ (63 mg, $0.30 \mathrm{mmol}$ ) was dissolved in $40 \mathrm{~mL}$ dry THF under an atmosphere of argon in a small Schlenk flask. The solution was sparged for $\sim 15 \mathrm{~min}$ with argon to ensure the absence of oxygen. 1.00 eq. $\left[\mathrm{Cu}(\mathrm{MeCN})_{4}\right] \mathrm{PF}_{6}(112 \mathrm{mg}, 0.30 \mathrm{mmol})$ was added and the obtained colourless solution was stirred for $\sim 15 \mathrm{~min}$. The solvent was removed in vacuum and the complex yielded quantitatively after drying in vacuum as an air-sensitive white powder 
$\mathrm{C}_{13} \mathrm{H}_{21} \mathrm{CuF}_{6} \mathrm{~N}_{3} \mathrm{O}_{2} \mathrm{P}\left(459.84 \mathrm{~g} \mathrm{~mol}^{-1}\right)$.

${ }^{1} \mathrm{H}-\mathrm{NMR}\left(300 \mathrm{MHz}, \mathrm{CHCl}_{3}\right): \delta(\mathrm{ppm})=4.20\left(\mathrm{~s}, 4 \mathrm{H}\right.$, oxazoline- $\left.\mathrm{CH}_{2}\right), 3.47(\mathrm{~s}, 2 \mathrm{H}$, bridging- $\left.\mathrm{CH}_{2}\right), 2.34(\mathrm{~s}, 3 \mathrm{H}, \mathrm{MeCN}), 1.41\left(\mathrm{~s}, 12 \mathrm{H}, \mathrm{BOX}-\mathrm{CH}_{3}\right)$.

${ }^{13} \mathrm{C}\left\{{ }^{1} \mathrm{H}\right\}-\mathrm{NMR}\left(75 \mathrm{MHz}, \mathrm{CDCl}_{3}\right): \delta(\mathrm{ppm})=\mathrm{MeCN}$ and $\mathrm{C}=\mathrm{N}$ not observed, 79.7 (oxazoline- $\left.\mathrm{CH}_{2}\right), 67.8\left(\mathrm{CMe}_{2}\right), 28.3(\mathrm{Me}), 26.6$ (bridging- $\left.\mathrm{CH}_{2}\right) 2.8(\mathrm{MeCN})$.

${ }^{31} \mathrm{P}-\mathrm{NMR}\left(121 \mathrm{MHz}, \mathrm{CDCl}_{3}\right): \delta(\mathrm{ppm})=-145\left(\mathrm{sep},{ }^{1} \mathrm{~J}(\mathrm{PF})=714 \mathrm{~Hz}, \mathrm{PF}_{6}\right)$.

${ }^{19} \mathrm{~F}-\mathrm{NMR}\left(282 \mathrm{MHz}, \mathrm{CDCl}_{3}\right): \delta(\mathrm{ppm})=-73\left(\mathrm{~d},{ }^{1} J(\mathrm{FP})=713 \mathrm{~Hz}, \mathrm{PF}_{6}\right)$.

UV-vis (THF): no absorbance (300-800 nm).

\subsection{2. $\left({ }^{\mathrm{Me}} \mathrm{BOX}_{2}\right) \mathrm{Cu}_{2}{ }_{2} \mathrm{Cl}_{2}$}<smiles>CC1(C)COC(C2(C)COCC(C)(C)N2)=N1</smiles><smiles>CC[C@H](CO)C(O)O</smiles>

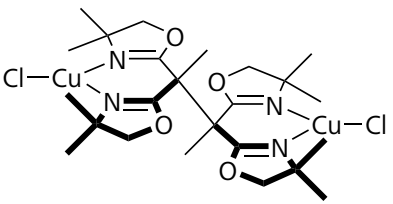

To a stirred solution of $\mathrm{CuCl}_{2} \cdot 2 \mathrm{H}_{2} \mathrm{O}(319 \mathrm{mg}, 1.87 \mathrm{mmol})$ in $2 \mathrm{~mL}$ deaerated methanol was added a solution of $\left.\mathrm{H}_{\{}{ }^{\mathrm{Me}} \mathrm{BOX}\right\}(420 \mathrm{mg}, 1.87 \mathrm{mmol})$ and triethylamine (189 mg, $1.87 \mathrm{mmol}$ ) in $2 \mathrm{~mL}$ deaerated methanol under an atmosphere of dry argon. The solution turned greenish and a precipitate appeared. It was further stirred for $30 \mathrm{~min}$, filtered and the residue thoroughly washed with methanol. After drying in vacuum, a slightly greenish to yellow powder was obtained.

The precipitate contained only the dimerised ligand as the organic constituent. Traces of copper(II) starting material can be removed by suspending in acetone with the aid of an ultrasonic bath and subsequent filtration and drying in vacuum to yield a white powder. To obtain single crystals suitable for X-ray diffraction analysis, to a suspension in acetone was added $\mathrm{CH}_{2} \mathrm{Cl}_{2}$ until full dissolution of the powder. Yellow crystals were obtained after slow concentration of the solution after 2 days.

yield: $580 \mathrm{mg}$ white to yellow powder $(900 \mu \mathrm{mol}, 96 \%)$.

$\mathrm{C}_{24} \mathrm{H}_{38} \mathrm{Cl}_{2} \mathrm{Cu}_{2} \mathrm{~N}_{4} \mathrm{O}_{4}\left(644.58 \mathrm{~g} \mathrm{~mol}^{-1}\right)$.

elemental analysis (calcd.): C 44.65 (44.72), H 5.85 (5.94), N 8.53 (8.69).

HRMS $\left(\mathrm{CH}_{2} \mathrm{Cl}_{2} / \mathrm{MeCN}\right)$ :

found $\left[\mathrm{M}-\mathrm{CuCl}_{2}\right]^{+}$509.2186, $\mathrm{C}_{24} \mathrm{H}_{38} \mathrm{CuN}_{4} \mathrm{O}_{4}$ requires 509.2184 .

$\mathrm{MS}\left(\mathrm{ESI}^{+}, \mathrm{CH}_{2} \mathrm{Cl}_{2} / \mathrm{MeCN}\right): m / z(\%)=509\left(100,\left[\mathrm{M}-\mathrm{CuCl}_{2}\right]^{+}\right)$. 
${ }^{1} \mathrm{H}-\mathrm{NMR}\left(500 \mathrm{MHz}, \mathrm{CDCl}_{3}\right): \delta(\mathrm{ppm})=4.17(\mathrm{~s}, 4 \mathrm{H}, 4 \mathrm{CHH}), 4.07(\mathrm{~s}, 4 \mathrm{H}, 4 \mathrm{CH})$, 1.80 (s, $6 \mathrm{H}, 2 \mathrm{Me}), 1.55$ (s, $12 \mathrm{H}, 4 \mathrm{CMeMe}), 1.50$ (s, $12 \mathrm{H}, 4 \mathrm{CMeMe}$ ).

\subsection{3. $\left({ }^{\square} \mathrm{BOX}_{2}\right) \mathrm{Cu}_{2}{ }_{2} \mathrm{Cl}_{2}$}

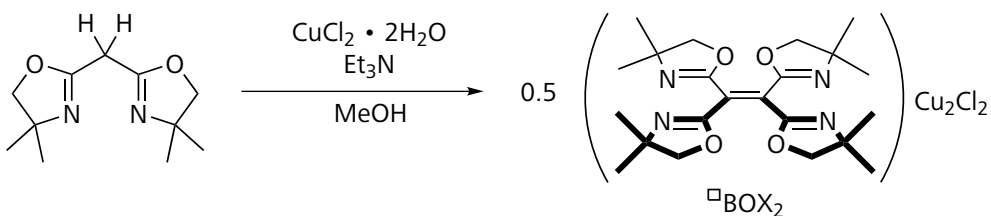

To a solution of $\left.\mathrm{H}_{\{}{ }^{\mathrm{H}} \mathrm{BOX}\right\}(421 \mathrm{mg}, 2.00 \mathrm{mmol})$ and triethylamine $(279 \mu \mathrm{L}, 2.00 \mathrm{mmol})$ in $2 \mathrm{~mL}$ deaerated methanol was slowly added a solution of $\mathrm{CuCl}_{2} \cdot 2 \mathrm{H}_{2} \mathrm{O}(341 \mathrm{mg}$, $2.00 \mathrm{mmol}$ ) in $2 \mathrm{~mL}$ deaerated methanol, under an atmosphere of dry argon. The solution turned deep-blue and then black. It was further stirred for $10 \mathrm{~min}$; the precipitate was isolated by filtration, washed with $5 \mathrm{~mL}$ methanol and dried in vacuum.

Performing the reaction in air yields a greenish-black powder under the same conditions, which is only slightly contaminated by copper(II).

yield: $276 \mathrm{mg}$ off-yellow powder $(424.64 \mu \mathrm{mol}, 45 \%)$.

$\mathrm{C}_{22} \mathrm{H}_{32} \mathrm{Cl}_{2} \mathrm{Cu}_{2} \mathrm{~N}_{4} \mathrm{O}_{4}\left(614.51 \mathrm{~g} \mathrm{~mol}^{-1}\right)$.

elemental analysis (calcd.): C 42.57 (43.00), H 5.18 (5.25), N 8.96 (9.12).

MS $\left(\mathrm{ESI}^{+}, \mathrm{MeCN}\right): m / z(\%)=895.4\left(14,\left[2^{\square} \mathrm{BOX}_{2}+\mathrm{Cu}\right]^{+}\right), 579.0\left(6,[\mathrm{M}-\mathrm{Cl}]^{+}\right)$, $520.2\left(100,\left[\mathrm{M}-\mathrm{CuCl}_{2}+\mathrm{MeCN}^{+}\right), 479.2\left(11,\left[\mathrm{M}-\mathrm{CuCl}_{2}\right]^{+}\right)\right.$.

$\mathrm{MS}\left(\mathrm{ESI}^{+}, \mathrm{MeOH}\right): m / z(\%)=511.2\left(13,\left[\mathrm{M}-\mathrm{CuCl}_{2}+\mathrm{MeOH}\right]^{+}\right), 439.3(13,[\mathrm{M}-$ $\left.\left.\mathrm{CuCl}_{2}+\mathrm{Na}\right]^{+}\right), 417.3\left(100,\left[\mathrm{M}-\mathrm{Cu}_{2} \mathrm{Cl}_{2}+\mathrm{H}\right]^{+}\right)$,

${ }^{1} \mathrm{H}-\mathrm{NMR}\left(300 \mathrm{MHz}, \mathrm{CDCl}_{3}\right): \delta(\mathrm{ppm})=4.23\left(\mathrm{~s}, 8 \mathrm{H}, 4 \mathrm{CH}_{2}\right), 1.46\left(\mathrm{~s}, 24 \mathrm{H}, 8 \mathrm{CH}_{3}\right)$.

${ }^{13} \mathrm{C}\left\{{ }^{1} \mathrm{H}\right\}-\mathrm{NMR}\left(75 \mathrm{MHz}, \mathrm{CDCl}_{3}\right): \delta(\mathrm{ppm})=158.7(\mathrm{C}=\mathrm{N}), 80.0\left(\mathrm{CH}_{2}\right), 68.7\left(\mathrm{CMe}_{2}\right)$, $27.8(\mathrm{Me}) ; \mathrm{C}=\mathrm{C}$ not observed.

FTIR (KBr): $\tilde{v}\left(\mathrm{~cm}^{-1}\right)=2974(\mathrm{~m}, v \mathrm{C}-\mathrm{H}), 2932(\mathrm{w}, v \mathrm{C}-\mathrm{H}), 2901(\mathrm{w}, v \mathrm{C}-\mathrm{H}), 2871$ (w, $v$ C-H), $1653(\mathrm{~s}, v \mathrm{C}=\mathrm{N}), 1614(\mathrm{~m}, v \mathrm{C}=\mathrm{C}), 1499(\mathrm{w}), 1460(\mathrm{~m}), 1393(\mathrm{~m}), 1367$ (s), $1328(\mathrm{w}), 1300(\mathrm{~m}), 1255(\mathrm{w}), 1206(\mathrm{w}), 1187(\mathrm{w}), 1167(\mathrm{w}), 1029(\mathrm{~m}), 1010(\mathrm{~m})$, 945 (s), 828 (w), $786(\mathrm{~m}), 708(\mathrm{w}), 677(\mathrm{~m}), 616(\mathrm{w}), 534(\mathrm{w})$.

Raman (powder, $\lambda_{\mathrm{ex}}=632.8 \mathrm{~nm}$, selected peaks): $\tilde{v}\left(\mathrm{~cm}^{-1}\right)=1650(\mathrm{w}, v \mathrm{C}=\mathrm{N})$, 1616 (vs, $v \mathrm{C}=\mathrm{C}$ ). 


\subsection{Peroxodicopper(II) Complexes $\left({ }^{R} \mathrm{P}\right)$}

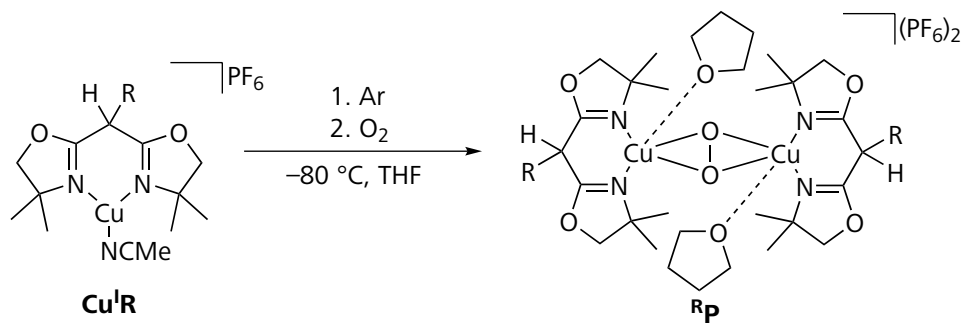

The $\mu-\eta^{2}: \eta^{2}$-peroxodicopper(II) complexes ${ }^{\mathbf{R}} \mathbf{P}$ were prepared from the respective $\left(\mathrm{H}\left\{{ }^{\mathrm{R}} \mathrm{BOX}\right\}\right) \mathrm{Cu}^{\mathrm{I}}$ compounds $\mathbf{C} \mathbf{u}^{\prime} \mathbf{R}$ by reaction with $\mathrm{O}_{2}$ at cryo conditions. All four complexes are relatively stable in solutions below $\sim-60^{\circ} \mathrm{C}$. ${ }^{\boldsymbol{t} \mathbf{B u}} \mathbf{P}$ and ${ }^{\mathbf{H}} \mathbf{P}$ could be isolated at solids at r.t., while samples of ${ }^{\mathbf{P h}} \mathbf{P}$ decomposed to the respective $\mathrm{Cu}_{2}(\mathrm{OH})_{2}$ complex and ${ }^{\mathbf{M}} \mathbf{P}$ was found to only decompose partly.

\subsection{1. $\left[\left\{(\mathrm{THF})\left(\mathrm{H}\left\{{ }^{t \mathrm{Bu}} \mathrm{BOX}\right\}\right) \mathrm{Cu}^{\mathrm{I}}\right\}_{2}\left(\mathrm{O}_{2}^{2-}\right)\right] \mathrm{PF}_{6}\left({ }^{t \mathrm{Bu}} \mathrm{P}\right)$}

Ligand $\mathrm{H}\left\{{ }^{t \mathrm{Bu}} \mathrm{BOX}\right\}(67 \mathrm{mg}, 0.25 \mathrm{mmol})$ was dissolved in $50 \mathrm{~mL}$ dry THF in a Schlenk flask and degassed by bubbling with argon to make a $5.0 \mathrm{~mm}$ solution. 1.0 eq. $\left[\mathrm{Cu}(\mathrm{MeCN})_{4}\right] \mathrm{PF}_{6}(93 \mathrm{mg}, 0.26 \mathrm{mmol})$ was added and a second Schlenk flask, filled with dry $\mathrm{O}_{2}$ is linked to the first flask via a short glass adapter, filled with glasswool or via a glass frit. The apparatus was then cooled to $-78^{\circ} \mathrm{C}$ and transferred to a freezer and stored at $-82^{\circ} \mathrm{C}$. Upon diffusion of $\mathrm{O}_{2}$ into the copper(I) complex solution, a violet precipitate (cf. Figure 6.17, p. 140) was formed. The colourless supernatant was carefully removed via a stainless steel syringe needle under an argon atmosphere and the residue thoroughly washed with $\operatorname{dry} \mathrm{Et}_{2} \mathrm{O}$; this was repeated three times. The residue was carefully dried for a short period in vacuum to yield ${ }^{\boldsymbol{t} B \mathbf{P}} \mathbf{P}$. The powder can be warmed to room temperature without any problems in regard to decomposition over at least some hours and can be stored in air at $-80^{\circ} \mathrm{C}$ for at least several months.

yield: $86 \mathrm{mg}$ very fine, dark violet powder $(76 \mu \mathrm{mol}, 61 \%)$.

$\mathrm{C}_{38} \mathrm{H}_{68} \mathrm{Cu}_{2} \mathrm{~F}_{12} \mathrm{~N}_{4} \mathrm{O}_{8} \mathrm{P}_{2}\left(1126.00 \mathrm{~g} \mathrm{~mol}^{-1}\right)$.

elemental analysis (calcd.): C 40.52 (40.53), H 6.13 (6.09), N 4.98 (4.91).

UV-vis (THF, $\left.-78^{\circ} \mathrm{C}\right): \lambda_{\max }, \mathrm{nm}\left(\varepsilon, \mathrm{M}^{-1} \mathrm{~cm}^{-1}\right)=333(48000), 500(2100)$.

UV-vis (powder, diffuse reflection, r. t.): $\lambda_{\max }, \mathrm{nm}=263,334,520, \sim 620$ (sh). 
rR (powder, r. t., $\lambda_{\mathrm{ex}}=632.8 \mathrm{~nm}$, selected peaks): $\tilde{v}\left(\mathrm{~cm}^{-1}\right)=1657(v \mathrm{C}=\mathrm{N})$, $745\left(v_{\mathrm{s}} \mathrm{PF}_{6}\right), 731(v \mathrm{O}-\mathrm{O}), 279(v \mathrm{Cu} \cdots \mathrm{Cu})$.

FTIR (KBr, r. t.): $\tilde{v}\left(\mathrm{~cm}^{-1}\right)=2975(\mathrm{~s}, v \mathrm{C}-\mathrm{H}), 2940(\mathrm{~m}, v \mathrm{C}-\mathrm{H}), 2880(\mathrm{~m}, v \mathrm{C}-\mathrm{H})$, 1650 (vs, $v$ C=N), $1475(\mathrm{~m}), 1566(\mathrm{~m}), 1438$ (s), 1407 (w), 1388 (m), $1374(\mathrm{~m}), 1324$ (m), 1283 (w), 1259 (w), 1198 (s), 1179 (s), 1161 (m), 1063 (s), 1051 (m), 1030 (w),

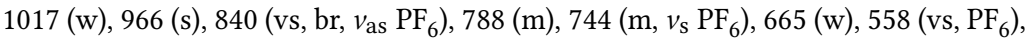
521 (w).

FTIR (Nujol): identical to $\mathrm{KBr}$ spectrum.

XANES/EXAFS/SQUID magnetometry (powder, r. t.): see the main text.

\section{${ }^{18} \mathrm{O}_{2}$ Isotopic Substitution}

Isotopic substitution was achieved by leaving ${ }^{18} \mathrm{O}_{2}(20 \mathrm{~mL}, 1 \mathrm{~atm})$ in argon slowly diffuse into $10 \mathrm{~mL}$ of a $5.0 \mathrm{~mm}$ solution of $\mathbf{C u}^{\prime} \mathbf{t} \mathbf{B u}$ in THF $(50 \mu \mathrm{mol})$ under an atmosphere of argon and in a freezer at $-82^{\circ} \mathrm{C}$. After $1 \mathrm{~d}$, the colourless supernatant was removed by a syringe and the violet precipitate washed with $5 \mathrm{~mL} \operatorname{dry} \mathrm{Et}_{2} \mathrm{O}$. After careful drying in vacuum, ${ }^{18} \mathrm{O}_{2}$-labelled ${ }^{\mathbf{t}}{ }^{\mathbf{B}} \mathbf{P}$ was obtained.

yield: $26 \mathrm{mg}$ very fine, dark violet powder $(23 \mu \mathrm{mol}, 92 \%)$.

$\mathrm{C}_{38} \mathrm{H}_{68} \mathrm{Cu}_{2} \mathrm{~F}_{12} \mathrm{~N}_{4} \mathrm{O}_{6}{ }^{18} \mathrm{O}_{2} \mathrm{P}_{2}\left(1130.00 \mathrm{~g} \mathrm{~mol}^{-1}\right)$.

rR (powder, r.t., $\lambda_{\mathrm{ex}}=632.8 \mathrm{~nm}$, selected peaks): $\tilde{v}\left(\mathrm{~cm}^{-1}\right)=1657(v \mathrm{C}=\mathrm{N})$, $745\left(v_{\mathrm{s}} \mathrm{PF}_{6}\right), 692\left(v^{18} \mathrm{O}-{ }^{18} \mathrm{O}\right), 278(v \mathrm{Cu} \cdots \mathrm{Cu})$.

\subsection{2. $\left[\left\{(\mathrm{THF})\left(\mathrm{H}\left\{{ }^{\mathrm{H}} \mathrm{BOX}\right\}\right) \mathrm{Cu}^{\prime \prime}\right\}_{2}\left(\mathrm{O}_{2}{ }^{2-}\right)\right] \mathrm{PF}_{6}\left({ }^{\mathrm{H}} \mathrm{P}\right)$}

$\mathrm{H}\left\{{ }^{\mathrm{H}} \mathrm{BOX}\right\}$ (53 mg, $0.25 \mathrm{mmol}$ ) was dissolved in $50 \mathrm{~mL}$ dry $\mathrm{THF}$ and the solution sparged with argon for $30 \mathrm{~min} .1 .00$ eq. $\left[\mathrm{Cu}(\mathrm{MeCN})_{4}\right] \mathrm{PF}_{6}(93 \mathrm{mg}, 0.25 \mathrm{mmol})$ was added and the mixture stirred until full dissolution. The slightly yellow solution was cooled to $-78^{\circ} \mathrm{C}$ and $\mathrm{O}_{2}$ gas was generously injected. The solution turned slowly deep violet; it was further stirred for $14 \mathrm{~h}$. The colourless supernatant was carefully removed via a stainless steel needle and the fine violet precipitate was washed with $\mathrm{Et}_{2} \mathrm{O}(2 \times 10 \mathrm{~mL})$. The residue was suspended in a small amount of $\mathrm{Et}_{2} \mathrm{O}$ and the suspension transferred to a small flask, where the supernatant was removed and the residue carefully dried in vacuum for a short period. The complex was stored at $-80^{\circ} \mathrm{C}$ without any sign of decomposition.

yield: $96 \mathrm{mg}$ very fine, deep pink powder $(95 \mu \mathrm{mol}, 76 \%)$.

$\mathrm{C}_{30} \mathrm{H}_{52} \mathrm{Cu}_{2} \mathrm{~F}_{12} \mathrm{~N}_{4} \mathrm{O}_{8} \mathrm{P}_{2}\left(1013.79 \mathrm{~g} \mathrm{~mol}^{-1}\right)$.

elemental analysis (calcd.): C 34.97 (35.54), H 5.09 (5.17), N 5.38 (5.53). 
UV-vis (THF, $\left.-78^{\circ} \mathrm{C}\right): \lambda_{\max }, \mathrm{nm}\left(\varepsilon, \mathrm{M}^{-1} \mathrm{~cm}^{-1}\right)=330$ (>30 000), $504(>800){ }^{a}$ UV-vis (powder, diffuse reflection, r. t.): $\lambda_{\max }, \mathrm{nm}=271,332,512, \sim 620$ (sh). rR (powder, r. t., $\lambda_{\text {ex }}=632.8 \mathrm{~nm}$, selected peaks): $\tilde{v}\left(\mathrm{~cm}^{-1}\right)=745\left(v_{\mathrm{S}} \mathrm{PF}_{6}\right), 742(v \mathrm{O}-\mathrm{O}), 282(v \mathrm{Cu} \cdots \mathrm{Cu})$.

XANES/EXAFS/SQUID magnetometry (powder, r.t.): see the main text.

\section{${ }^{18} \mathrm{O}_{2}$ Isotopic Substitution}

Isotopic substitution was achieved in an analogous reaction; but divergently, ${ }^{18} \mathrm{O}_{2}$ gas (10 mL, $1 \mathrm{~atm})$ was let to diffuse slowly into the $\mathbf{C} \mathbf{u}^{\mathbf{l}} \mathbf{H} / \mathrm{THF}$ solution from a second Schlenk flask via a bent glass joint at $-80^{\circ} \mathrm{C}$.

yield: $38 \mathrm{mg}$ very fine, deep pink powder $(37 \mu \mathrm{mol}, 30 \%)$.

$\mathrm{C}_{30} \mathrm{H}_{52} \mathrm{Cu}_{2} \mathrm{~F}_{12} \mathrm{~N}_{4} \mathrm{O}_{6}^{18} \mathrm{O}_{2} \mathrm{P}_{2}\left(1017.79 \mathrm{~g} \mathrm{~mol}^{-1}\right)$.

rR (powder, r. t., $\lambda_{\mathrm{ex}}=632.8 \mathrm{~nm}$, selected peaks):

$\tilde{v}\left(\mathrm{~cm}^{-1}\right)=745\left(v_{\mathrm{S}} \mathrm{PF}_{6}\right), 703\left(v^{18} \mathrm{O}-{ }^{18} \mathrm{O}\right), 282(v \mathrm{Cu} \cdots \mathrm{Cu})$.

\subsection{3. $\left.\left[\left\{\left(\mathrm{H}_{\left\{{ }^{M e}\right.} \mathrm{BOX}\right\}\right) \mathrm{Cu}^{\prime \prime}\right\}_{2}\left(\mathrm{O}_{2}^{2-}\right)\right] \mathrm{PF}_{6}\left({ }^{\mathrm{Me}} \mathrm{P}\right)$}

The complex was prepared from $\mathrm{H}_{\left\{{ }^{\mathrm{Me}} \mathrm{BOX}\right\}}(56 \mathrm{mg}, 0.25 \mathrm{mmol})$ and $\left[\mathrm{Cu}(\mathrm{MeCN})_{4}\right] \mathrm{PF}_{6}$ (93 mg, $0.25 \mathrm{mmol}$ ), following the method used for ${ }^{\mathbf{t} \text { Bu}} \mathbf{P}$. However, the complex was found to decompose partly during isolation.

yield: $68 \mathrm{mg}$ very fine, pink to grey powder.

elemental analysis (calcd. for C24H40Cu2F12N4O6P2): C 32.01 (32.11), H 4.67 (4.49), N $5.54(6.24)$.

UV-vis (THF, $\left.-78^{\circ} \mathrm{C}\right): \lambda_{\max }, \mathrm{nm}\left(\varepsilon, \mathrm{M}^{-1} \mathrm{~cm}^{-1}\right)=333(>22000), 496(>500) .^{a}$

UV-vis (powder, diffuse reflection, r. t.): $\lambda_{\max }, \mathrm{nm}=261,331,493, \sim 600 .^{b}$

rR (powder, r. t., $\lambda_{\text {ex }}=632.8 \mathrm{~nm}$, selected peaks):

$\tilde{v}\left(\mathrm{~cm}^{-1}\right)=745\left(v_{\mathrm{S}} \mathrm{PF}_{6}\right), 735(v \mathrm{O}-\mathrm{O}), 282(v \mathrm{Cu} \cdots \mathrm{Cu}) .^{b}$

XANES/EXAFS (powder, r. t.): see the main text.

\subsection{4. $\left[\left\{\left(\mathrm{H}\left\{{ }^{\mathrm{Ph}} \mathrm{BOX}\right\}\right) \mathrm{Cu}^{\prime \prime}\right\}_{2}\left(\mathrm{O}_{2}^{2-}\right)\right] \mathrm{PF}_{6}\left({ }^{\mathrm{Ph}} \mathrm{P}\right)$}

The complex was prepared, following the route described for ${ }^{\boldsymbol{t}}{ }^{\mathbf{u}} \mathbf{P} \mathbf{P}$. However, isolation of the labile complex failed in either case (by isolation as described for ${ }^{\boldsymbol{t}}{ }^{\mathbf{B}} \mathbf{P}$ and ${ }^{\mathbf{H}_{\mathbf{P}}}$ or by the sole filtration). From the reaction of $\left.\mathrm{H}_{\{}{ }^{\mathrm{Ph}} \mathrm{BOX}\right\}$ (102 mg, $0.375 \mathrm{mmol})$ and $\left[\mathrm{Cu}(\mathrm{MeCN})_{4}\right]_{\mathrm{PF}_{6}}(140 \mathrm{mg}, 0.375 \mathrm{mmol}), 26 \mathrm{mg}$ of the decomposition product as a grey to dark-violet powder were obtained.

a. Incomplete formation/low solubility and precipitation.

$b$. Sample was decomposed to some extent. 
UV-vis (acetone, $\left.-78^{\circ} \mathrm{C}\right): \lambda_{\max }, \mathrm{nm}\left(\varepsilon, \mathrm{M}^{-1} \mathrm{~cm}^{-1}\right)=334(47000), 496(1100)$.

\subsection{A Bis( $\mu$-oxo $)$ dicopper(III) Complex}

\subsection{1. $\left[\left\{\left({ }^{\mathrm{Ph}} \mathrm{BOX}^{-}\right) \mathrm{Cu}^{\text {"II }}\right\}_{2}\left(\mathrm{O}^{2-}\right)_{2}\right] \mathrm{PF}_{6}\left({ }^{\mathrm{Ph}} \mathrm{O}\right)$}

\section{Method a}<smiles>CC1(C)COC(C(=C2NC(C)(C)CO2)c2ccccc2)=N1</smiles>

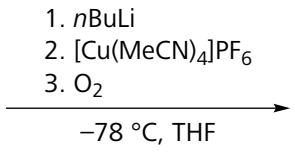

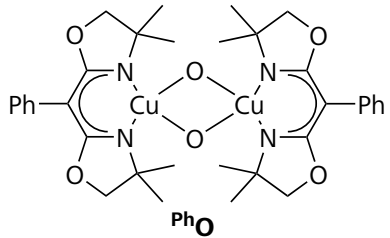

A solution of $\mathrm{H}\left\{{ }^{\mathrm{Ph}} \mathrm{BOX}\right\}(15 \mathrm{mg}, 52 \mu \mathrm{mol})$ in $90 \mathrm{~mL}$ dry THF was cooled to $-78^{\circ} \mathrm{C}$ under an atmosphere of argon and 1.0 eq. $n \mathrm{BuLi}$ solution $(33 \mu \mathrm{L}, 52 \mu \mathrm{mol}, 1.6 \mathrm{M}$ in hexane) was added in 10 aliquots. The titration was followed by UV-vis. The solution was warmed to r. t. and 1.0 eq. $\left[\mathrm{Cu}(\mathrm{MeCN})_{4}\right] \mathrm{PF}_{6}(19.5 \mathrm{mg}, 52 \mu \mathrm{mol})$ was added; the colourless solution turned yellow. After full dissolution, the solution was cooled to $-78^{\circ} \mathrm{C}$ and an excess $\mathrm{O}_{2}$ was injected, concomitant with a rapid turn to dark green.

\section{Method b}

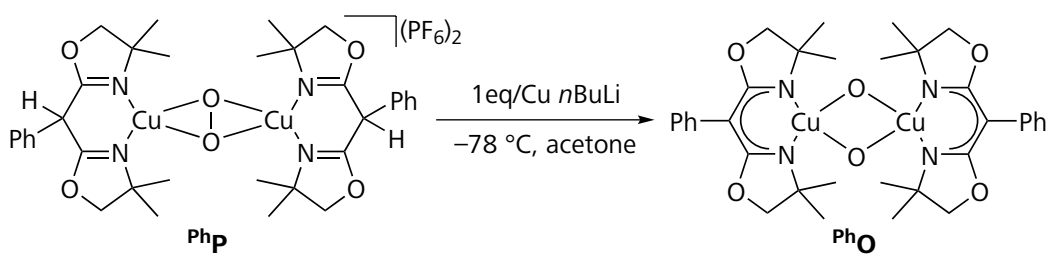

A $5.7 \times 10^{-4} \mathrm{M}$ solution of ${ }^{\mathbf{P h}} \mathbf{P}$ in $99 \mathrm{~mL}$ acetone was prepared according to the description in Section 10.3 from $\left.\mathrm{H}_{\{} \mathrm{Ph}_{\mathrm{BOX}}\right\}(32 \mathrm{mg}, 112 \mu \mathrm{mol}),\left[\mathrm{Cu}(\mathrm{MeCN})_{4}\right] \mathrm{PF}_{6}$ (42 mg, $112 \mu \mathrm{mol}$ ) and $\mathrm{O}_{2}$. To the pink solution were added 1.0 eq. $n \mathrm{BuLi}$ per copper atom $(70.0 \mu \mathrm{L}, 112 \mu \mathrm{mol}, 1.6 \mathrm{M}$ in hexane $)$ in steps of 10 aliquots $(7 \mu \mathrm{L} /$ aliquot $)$ via a Hamilton microliter syringe to prepare ${ }^{\mathbf{P h}} \mathbf{O}$. The process was followed by UV-vis. In course of the titration, the solution turned dark green. More aliquots $n \mathrm{BuLi}$ solution were then added without any changes in the UV-vis spectrum. 


\section{Raman samples}

$\mathrm{H}\left\{{ }^{\mathrm{Ph}} \mathrm{BOX}\right\}(15 \mathrm{mg}, 52 \mu \mathrm{mol})$ was dissolved in $40 \mathrm{~mL}$ dry acetone. The solution was degassed and $\left[\mathrm{Cu}(\mathrm{MeCN})_{4}\right] \mathrm{PF}_{6}(20 \mathrm{mg}, 52 \mu \mathrm{mol})$ was added. The mixture was cooled to $-78^{\circ} \mathrm{C}$ and samples were filled into cooled NMR tubes under nitrogen atmosphere. $\mathrm{O}_{2}$ was added to the sample tubes and formation of peroxo ${ }^{\mathbf{P h}_{\mathbf{P}}}$ was evident by a slow colour change to pink upon shaking. A small excess of $n \mathrm{BuLi}$ (1.6 $\mathrm{M}$ in hexane) was added to the tubes and a colour change to green was evident, coming from top to bottom. The samples were immediately frozen in liquid $\mathrm{N}_{2}$.

$\mathrm{C}_{34} \mathrm{H}_{42} \mathrm{Cu}_{2} \mathrm{~N}_{4} \mathrm{O}_{6}\left(729.82 \mathrm{~g} \mathrm{~mol}^{-1}\right)$.

UV-vis (THF, $\left.-78^{\circ} \mathrm{C}\right): \lambda_{\max }, \mathrm{nm}\left(\varepsilon, \mathrm{mm}^{-1} \mathrm{~cm}^{-1}\right)=287$ (40), 337 (13), 396 (8), $484 \mathrm{sh}$ (1), $\sim 600 \operatorname{sh}(1), \sim 750$ (1).

UV-vis (acetone, $\left.-78^{\circ} \mathrm{C}\right): \lambda_{\max }, \mathrm{nm}\left(\varepsilon, \mathrm{mm}^{-1} \mathrm{~cm}^{-1}\right)=338$ (15), 400 (19), $484 \mathrm{sh}$ (2), $\sim 600 \operatorname{sh}(1.5), \sim 750(2.5)$.

$\mathrm{rR}$ (acetone, $-196^{\circ} \mathrm{C}, \lambda_{\mathrm{ex}}=632.8 \mathrm{~nm}$, selected peaks):

$\tilde{v}\left(\mathrm{~cm}^{-1}\right)=603\left(v_{\mathrm{s}} \mathrm{Cu}-\mathrm{O}\right) ; 499,492\left(v \mathrm{Cu}-\mathrm{N}_{\mathrm{eq}}\right)$.

\section{${ }^{18} \mathrm{O}_{2}$ Isotopic Substitution}

Isotopic substitution was achieved by an identical procedure with ${ }^{18} \mathrm{O}_{2}$.

$\mathrm{C}_{34} \mathrm{H}_{42} \mathrm{Cu}_{2} \mathrm{~N}_{4} \mathrm{O}_{4}^{18} \mathrm{O}_{2}\left(733.82 \mathrm{~g} \mathrm{~mol}^{-1}\right)$.

$\mathrm{rR}$ (acetone, $-196^{\circ} \mathrm{C}, \lambda_{\mathrm{ex}}=632.8 \mathrm{~nm}$, selected peaks):

$\tilde{v}\left(\mathrm{~cm}^{-1}\right)=574\left(v_{\mathrm{s}} \mathrm{Cu}-{ }^{18} \mathrm{O}\right) ; 499,492\left(v \mathrm{Cu}-\mathrm{N}_{\mathrm{eq}}\right)$.

\subsection{Thermal Decomposition of ${ }^{t B u} \mathrm{P}$ and Isolation of Bis( $\mu$-hydroxo)dicopper(II) Products}

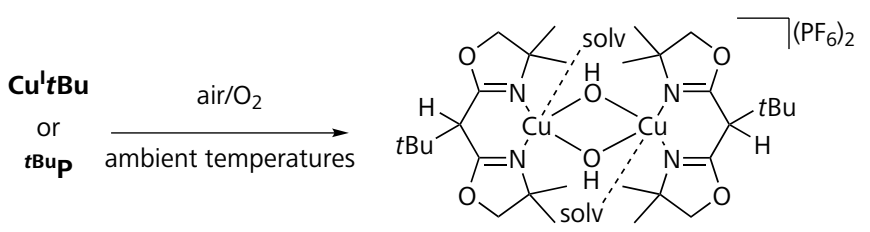

Storage of powdered ${ }^{\boldsymbol{t} \mathbf{B u}} \mathbf{P}$ at room temperature leads slowly to a colour change from intense violet to a light blue, indicative for degradation of the peroxo complex and formation of the according bis( $\mu$-hydroxo)dicopper(II) complex. Correspondingly, solutions turned slightly blue at room temperature. 


\subsection{1. $\left.\left[(\mathrm{THF})_{0.85}(\mathrm{MeCN})_{0.15}\left(\mathrm{H}^{t \mathrm{Bu}} \mathrm{BOX}\right\}\right) \mathrm{Cu}(\mathrm{OH})\right]_{2}\left(\mathrm{PF}_{6}\right)_{2}$}

A solution of ${ }^{\mathbf{H}} \mathbf{B} \mathbf{P}$ in $\mathrm{THF}$ at $-78^{\circ} \mathrm{C}$ was warmed to room temperature accompanied with decolouration. Under an atmosphere of argon, a small number of turquoise crystals grew from this solution after a few days, suitable for X-ray crystal structure determination.

$\mathrm{C}_{37.40} \mathrm{H}_{66.50} \mathrm{Cu}_{2} \mathrm{~F}_{12} \mathrm{~N}_{4.30} \mathrm{O}_{7.70} \mathrm{P}_{2}$.

MS (ESI $\left.{ }^{-}, \mathrm{MeCN}\right): m / z(\%)=145\left(100,\left[\mathrm{PF}_{6}\right]^{-}\right)$.

HRMS (MeCN): found $\left.\left[\left(\mathrm{H}_{\{}{ }^{t \mathrm{Bu}} \mathrm{BOX}\right\}\right)_{2} \mathrm{Cu}_{2}(\mathrm{OH})_{2} \mathrm{PF}_{6}\right]^{+} 837.2287(3 \%), \mathrm{C}_{30} \mathrm{H}_{54} \mathrm{Cu}_{2} \mathrm{~F}_{6} \mathrm{~N}_{4} \mathrm{O}_{6} \mathrm{P}$ requires 837.2272; found $\left.\left[\left(\mathrm{H}_{\{}{ }^{t \mathrm{Bu}} \mathrm{BOX}\right\}\right) \mathrm{Cu}(\mathrm{OH})\right]^{+} 346.1313(100 \%), \mathrm{C}_{15} \mathrm{H}_{27} \mathrm{CuN}_{2} \mathrm{O}_{3}$ requires 346.1312; found $\left.\left[\left(\mathrm{H}_{\{}{ }^{t \mathrm{Bu}} \mathrm{BOX}\right\}\right) \mathrm{Cu}\right]^{+} 329.1285(83 \%), \mathrm{C}_{15} \mathrm{H}_{26} \mathrm{CuN}_{2} \mathrm{O}_{2}$ requires 329.1284;

FTIR (Nujol mull, r. t., selected peaks): $\tilde{v}\left(\mathrm{~cm}^{-1}\right)=3648(\mathrm{~m}, v \mathrm{O}-\mathrm{H}), 3579(\mathrm{~m}, v$ $\mathrm{O}-\mathrm{H}), 2264$ (w, $v \mathrm{C} \approx \mathrm{N}, \mathrm{MeCN}), 1650$ (vs, $v \mathrm{C}=\mathrm{N}$ ), 839 (vs, br, vas $\mathrm{PF}_{6}$ ), $742\left(\mathrm{~m}, v_{\mathrm{s}}\right.$ $\left.\mathrm{PF}_{6}\right), 557$ (vs, $\left.\mathrm{PF}_{6}\right)$.

\subsection{2. $\left[\left(\mathrm{H}_{2} \mathrm{O}\right)\left(\mathrm{H}^{t \mathrm{tBu}} \mathrm{BOX}\right\}\right) \mathrm{Cu}$ " $\left.(\mathrm{OH})\right]_{2}\left(\mathrm{PF}_{6}\right)_{2}$}

Powder of ${ }^{\boldsymbol{t} \mathbf{B u}} \mathbf{P}$ was dissolved in chloroform at r. t. From this solution, a small number of turquoise crystals crystallised by slow concentration in air. A suitable single crystal for X-ray diffraction analysis was obtained from this solution.

$\mathrm{C}_{30} \mathrm{H}_{58} \mathrm{Cu}_{2} \mathrm{~F}_{12} \mathrm{~N}_{4} \mathrm{O}_{8} \mathrm{P}_{2}\left(1019.83 \mathrm{~g} \mathrm{~mol}^{-1}\right)$.

elemental analysis (calcd. for $\mathrm{C}_{30} \mathrm{H}_{58} \mathrm{Cu}_{2} \mathrm{~F}_{12} \mathrm{~N}_{4} \mathrm{O}_{8} \mathrm{P}_{2} \cdot 3 \mathrm{H}_{2} \mathrm{O}$ ): $\mathrm{C} 33.64$ (33.55), $\mathrm{H}$ 5.40 (6.01), N 5.20 (5.22).

FTIR (Nujol mull, r. t., selected peaks): $\tilde{v}\left(\mathrm{~cm}^{-1}\right)=3649(\mathrm{~m}, v \mathrm{O}-\mathrm{H}), 3583(\mathrm{~m}$, $v \mathrm{O}-\mathrm{H}), 1654(\mathrm{~m}, v \mathrm{C}=\mathrm{N}), 844$ (vs, br, $\left.v_{\mathrm{as}} \mathrm{PF}_{6}\right), 741\left(\mathrm{~m}, v_{\mathrm{s}} \mathrm{PF}_{6}\right), 558$ (vs, $\left.\mathrm{PF}_{6}\right)$.

rR (powder, r. t.): see the main text.

\section{${ }^{18} \mathrm{O}_{2}$ Isotopic Substitution}

The isotope labelled complex was obtained in the course of preparation of ${ }^{18} \mathrm{O}$ labelled ${ }^{\boldsymbol{t} \text { Bu}} \mathbf{P}$. The supernatant of the THF reaction solution was separated and the solvent removed in vacuum. A small amount of crystalline material was obtained.

HRMS (MeCN): found $\left.\left[\left(\mathrm{H}_{\{}{ }^{t \mathrm{Bu}} \mathrm{BOX}\right\}\right)_{2} \mathrm{Cu}_{2}(\mathrm{OH})_{2} \mathrm{PF}_{6}\right]^{+} 839.236, \mathrm{C}_{30} \mathrm{H}_{54} \mathrm{Cu}_{2} \mathrm{~F}_{6} \mathrm{~N}_{4} \mathrm{O}_{5}{ }^{18} \mathrm{OP}$ requires 839.231 . 


\subsection{Further Copper(II) Complexes}

\subsection{1. $\left(\mathrm{H}\left\{{ }^{t \mathrm{Bu}} \mathrm{BOX}\right\}\right) \mathrm{Cu}^{\prime \prime} \mathrm{Cl}_{2}$}

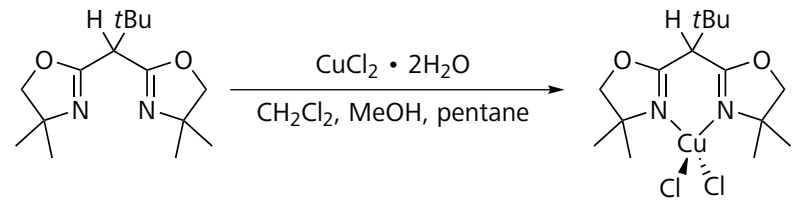

To the ligand $\mathrm{H}\left\{{ }^{t \mathrm{Bu}} \mathrm{BOX}\right\}$ (44 mg, $0.17 \mathrm{mmol}$ ) in $2 \mathrm{~mL} \mathrm{CH}_{2} \mathrm{Cl}_{2}$ was added $0.5 \mathrm{~mL}$ of a solution of $\mathrm{CuCl}_{2} \cdot 2 \mathrm{H}_{2} \mathrm{O}(28 \mathrm{mg}, 0.17 \mathrm{mmol})$ in $\mathrm{MeOH}$. After agitation for $15 \mathrm{~min}$, the complex was precipitated with an excess of pentane, the suspension was filtered and the residue dried in vacuum. Suitable single crystals for X-ray diffraction analysis were obtained from a concentrated $\mathrm{CH}_{2} \mathrm{Cl}_{2}$ solution upon slow concentration.

yield: $39 \mathrm{mg}$ yellow needles $(97 \mu \mathrm{mol}, 59 \%)$.

$\mathrm{C}_{15} \mathrm{H}_{26} \mathrm{Cl}_{2} \mathrm{CuN}_{2} \mathrm{O}_{2}\left(400.83 \mathrm{~g} \mathrm{~mol}^{-1}\right)$.

elemental analysis (calcd. for $\left.\left.\left(\mathrm{H}_{\{}{ }^{t \mathrm{Bu}} \mathrm{BOX}\right\}\right) \mathrm{CuCl}_{2} \cdot 1 / 2 \mathrm{H}_{2} \mathrm{O}\right)$ : C 43.95 (43.96), H 6.05 (6.64), N 6.85 (6.84).

HRMS $\left(\mathrm{CH}_{2} \mathrm{Cl}_{2} / \mathrm{MeCN}\right)$ : found $[\mathrm{M}-\mathrm{Cl}]^{+} 364.0980, \mathrm{C}_{15} \mathrm{H}_{26} \mathrm{ClCuN}_{2} \mathrm{O}_{2}$ requires 364.0973.

MS $\left(\mathrm{ESI}^{+}, \mathrm{CH}_{2} \mathrm{Cl}_{2} / \mathrm{MeCN}\right): m / z(\%)=370\left(84,[\mathrm{M}-2 \mathrm{Cl}+\mathrm{MeCN}]^{+}\right), 329(100,[\mathrm{M}-$ $\left.2 \mathrm{Cl}]^{+}\right)$.

UV-vis $\left(\mathrm{CH}_{2} \mathrm{Cl}_{2}\right): \lambda_{\max }, \mathrm{nm}\left(\varepsilon, \mathrm{M}^{-1} \mathrm{~cm}^{-1}\right)=282 \mathrm{~nm}$ (3950), $383 \mathrm{~nm}(1060), 442 \mathrm{~nm}$ (520).

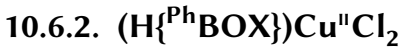

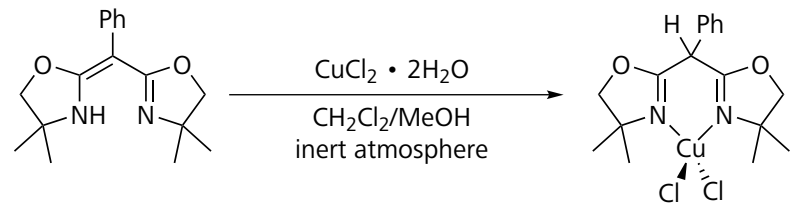

$\mathrm{CuCl}_{2} \cdot 2 \mathrm{H}_{2} \mathrm{O}(26 \mathrm{mg}, 0.15 \mathrm{mmol})$ was added to a deaerated solution of $\mathrm{H}\left\{{ }^{\mathrm{Ph}} \mathrm{BOX}\right\}$

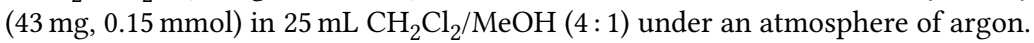


The solution was stirred until complete dissolution; then a slight vacuum of $\sim 990$ mbar was applied in order to obtain single crystalline material from the yellow to light green solution. Unfortunately, besides the oxygenated complex $\left(\left\{{ }^{\mathrm{Ph}} \mathrm{BOX}\right\} \mathrm{O}\right)_{2} \mathrm{Cu}_{3} \mathrm{Cl}_{4}$, only a small amount of yellow crystals of $\left(\mathrm{H}\left\{{ }^{\mathrm{Ph}} \mathrm{BOX}\right\}\right) \mathrm{CuCl}_{2}$ were obtained with insufficient quality for X-ray crystallography.

$\mathrm{C}_{17} \mathrm{H}_{22} \mathrm{Cl}_{2} \mathrm{CuN}_{2} \mathrm{O}_{2}\left(420.82 \mathrm{~g} \mathrm{~mol}^{-1}\right)$.

$\mathrm{MS}\left(\mathrm{ESI}^{+}, \mathrm{MeCN}\right.$, inert conditions): $m / z(\%)=803.1\left(8,[2 \mathrm{M}-\mathrm{Cl}]^{+}\right), 705.2(32,[2 \mathrm{M}$

$\left.-\mathrm{CuCl} 2]^{+}\right), 424.1\left(100,[\mathrm{M}-\mathrm{HCl}+\mathrm{MeCN}]^{+}\right), 383.1\left(11,[\mathrm{M}-\mathrm{HCl}]^{+}\right), 287.2$ $\left.\left(4,\left[\mathrm{H}^{\mathrm{Ph}} \mathrm{BOX}\right\}+\mathrm{H}\right]^{+}\right)$.

EPR parameters: see the main text.

\subsection{3. $\left[\left({ }^{\mathrm{Me}} \mathrm{BOX}_{2}\right)\left\{\mathrm{Cu} "(\mathrm{OAc})\left(\mathrm{H}_{2} \mathrm{O}\right)\right\}_{2}\right]\left(\mathrm{ClO}_{4}\right)_{2}$}
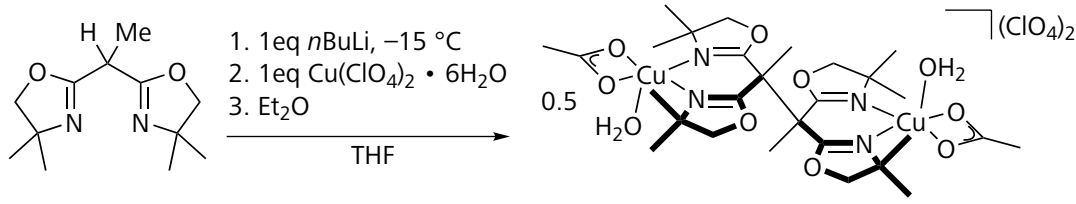

$\mathrm{H}\left\{{ }^{\mathrm{Me}} \mathrm{BOX}\right\}$ was deprotonated under nitrogen atmosphere by the addition of 1 eq. $1.6 \mathrm{M} n \mathrm{BuLi}$ in hexane solution at $-15^{\circ} \mathrm{C}$ in dry THF. After $3 \mathrm{~h}$ stirring at room temperature, the solvent was removed in vacuum to yield a white powder; it was dissolved in THF to obtain a $0.1 \mathrm{~m}$ solution. The solution was slowly added to $1 \mathrm{eq}$. of $\mathrm{Cu}\left(\mathrm{ClO}_{4}\right)_{2} \cdot 6 \mathrm{H}_{2} \mathrm{O}$ in THF, the resulting precipitate was removed by filtration. A few small light turquoise single crystals were obtained by slow diffusion of diethyl ether into the turquoise filtrate.

$\mathrm{C}_{28} \mathrm{H}_{48} \mathrm{Cl}_{2} \mathrm{Cu}_{2} \mathrm{~N}_{4} \mathrm{O}_{18}\left(926.69 \mathrm{~g} \mathrm{~mol}^{-1}\right)$.

MS (ESI $\left.{ }^{+}, \mathrm{MeOH}\right): m / z(\%)=509\left(85,\left[\mathrm{Me}^{\mathrm{BOX}}{ }_{2}+\mathrm{Cu}\right]^{+}\right), 447\left(37,\left[\mathrm{Me}^{\mathrm{BOX}}{ }_{2}+\mathrm{H}\right]^{+}\right)$. $\mathrm{MS}\left(\mathrm{ESI}^{-}, \mathrm{MeOH}\right): m / z(\%)=99\left(100, \mathrm{ClO}_{4}^{-}\right)$. 


\subsection{4. $\left({ }^{\mathrm{Me}} \mathrm{BOX}_{2}\right)\left(\mathrm{Cu}^{\prime \prime} \mathrm{Cl}_{2}\right)_{2}$}<smiles>CC(C1=NC(C)(C)CO1)C1=NC(C)(C)CO1</smiles>

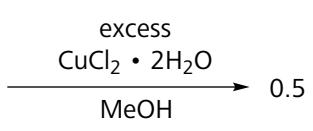

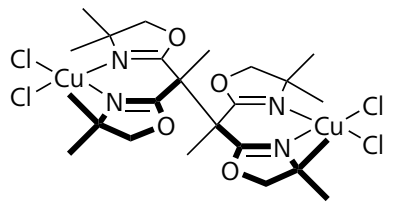

$\left({ }^{\mathrm{Me}_{\mathrm{BOX}}}\right) \mathrm{CuCl}_{2}$ was prepared from equimolar amounts of $\mathrm{CuCl}_{2} \cdot 2 \mathrm{H}_{2} \mathrm{O}(112 \mathrm{mg}$, $500 \mu \mathrm{mol})$ and $\mathrm{H}\left\{{ }^{\mathrm{Me}} \mathrm{BOX}\right\}(85 \mathrm{mg}, 500 \mu \mathrm{mol})$, as described above. The filtrate was redissolved in air in $\mathrm{CH}_{2} \mathrm{Cl}_{2}$ until full dissolution. The solution was stirred for several minutes until an orange precipitate was present, the greenish solution was filtered to obtain $\left.\left({ }^{\mathrm{Me}} \mathrm{BOX}_{2}\right) \mathrm{CuCl}_{2}\right)_{2}$ as an orange powder after drying in vacuum.

Alternatively, the complex was obtained as an orange precipitate by adding an

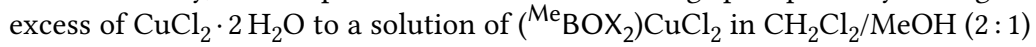
under an atmosphere of argon.

Single crystals could be grown by adding $\mathrm{H}\left\{{ }^{\mathrm{Me}} \mathrm{BOX}\right\}$ to 3 eq. $\mathrm{CuCl}_{2} \cdot 2 \mathrm{H}_{2} \mathrm{O}$ in $\mathrm{MeOH}$. A small part of the solution was transferred to an EPR tube and frozen in liquid nitrogen. It was slowly warmed to room temperature and after 3 days, small orange single crystals, suitable for X-ray diffractometry, were grown in the solution.

yield: $73 \mathrm{mg}$ orange powder $(102 \mu \mathrm{mol}, 41 \%)$.

$\mathrm{C}_{24} \mathrm{H}_{38} \mathrm{Cl}_{4} \mathrm{Cu}_{2} \mathrm{~N}_{4} \mathrm{O}_{4}\left(715.46 \mathrm{~g} \mathrm{~mol}^{-1}\right)$.

elemental analysis (calcd.): C 39.21 (40.29), H 5.20 (5.35), N 7.56 (7.83).

$\mathrm{MS}\left(\mathrm{ESI}^{+}, \mathrm{MeCN}\right)$ :

$m / z(\%)=550\left(15,\left[{ }^{\mathrm{Me}} \mathrm{BOX}_{2}+\mathrm{Cu}+\mathrm{MeCN}\right]^{+}\right), 509\left(100,\left[\mathrm{Me}^{\mathrm{BOX}}{ }_{2}+\mathrm{Cu}\right]^{+}\right)$.

\subsection{5. $\left(\mathrm{O}\left\{{ }^{\mathrm{Ph}} \mathrm{BOX}\right\}\right) 2 \mathrm{Cu}_{3}{ }_{3} \mathrm{Cl}_{4}$}
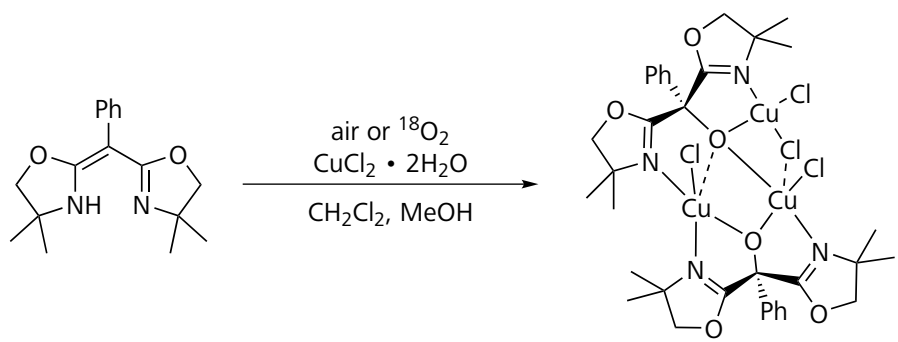
$\mathrm{H}\left\{{ }^{\mathrm{Ph}} \mathrm{BOX}\right\}(129 \mathrm{mg}, 0.45 \mathrm{mmol})$ was dissolved in $90 \mathrm{~mL}$ of a $1: 1$ mixture of $\mathrm{CHCl}_{3}$ and $\mathrm{MeOH}$. To the $5 \mathrm{~mm}$ solution, $\mathrm{CuCl}_{2} \cdot 2 \mathrm{H}_{2} \mathrm{O}(77 \mathrm{mg}, 0.45 \mathrm{mmol})$ was added. The colourless solution changed to petrol and then to green. The solvent was removed in vacuum and $\left(\left\{\mathrm{Ph}_{B} \mathrm{BOX}\right\} \mathrm{O}\right){ }_{2} \mathrm{Cu}_{3} \mathrm{Cl}_{4}$ was obtained as green crystalline material in a small amount of a yellow oil $(160 \mathrm{mg})$. The green crystalline material was of sufficient quality for single crystal X-ray diffraction.

$\mathrm{C}_{34} \mathrm{H}_{42} \mathrm{Cl}_{4} \mathrm{Cu}_{3} \mathrm{~N}_{4} \mathrm{O}_{6}\left(935.17 \mathrm{~g} \mathrm{~mol}^{-1}\right)$.

yield: $160 \mathrm{mg}$ green crystals $\left(171 \mu \mathrm{mol}, 76 \%\right.$ in respect of $\left.\left.\mathrm{H}_{\{}{ }^{\mathrm{Ph}} \mathrm{BOX}\right\}\right)$.

elemental analysis (calcd. for $\left.\left.\left(\mathrm{O}_{\{}{ }^{\mathrm{Ph}} \mathrm{BOX}\right\}\right)_{2} \mathrm{Cu}_{3} \mathrm{Cl}_{4} \cdot 2 \mathrm{H}_{2} \mathrm{O}\right)$ :

C 42.07 (42.05), H 4.59 (4.77), N 5.70 (5.77).

HRMS (MeCN): found $[\mathrm{M}+\mathrm{Na}]^{+}$957.9593, $\mathrm{C}_{34} \mathrm{H}_{42} \mathrm{~N}_{4} \mathrm{O}_{6} \mathrm{Cu}_{3} \mathrm{Cl}_{4} \mathrm{Na}$ requires 957.9596;

found $[\mathrm{M}-\mathrm{Cl}]^{+}$898.0039, $\mathrm{C}_{34} \mathrm{H}_{42} \mathrm{~N}_{4} \mathrm{O}_{6} \mathrm{Cu}_{3} \mathrm{Cl}_{3}$ requires 898.0033;

found $\left[\mathrm{M}-\mathrm{CuCl}_{3}\right]^{+}$765.1356, $\mathrm{C}_{34} \mathrm{H}_{42} \mathrm{~N}_{4} \mathrm{O}_{6} \mathrm{Cu}_{2} \mathrm{Cl}$ requires 765.1369;

found $\left[\mathrm{HO}\left\{{ }^{\mathrm{Ph}} \mathrm{BOX}\right\}+\mathrm{Cu}\right]^{+}$365.0924, $\mathrm{C}_{17} \mathrm{H}_{22} \mathrm{~N}_{2} \mathrm{O}_{3} \mathrm{Cu}$ requires 365.0926;

found $\left[\mathrm{HO}\left\{{ }^{\mathrm{Ph}} \mathrm{BOX}\right\}+\mathrm{H}\right]^{+}$303.1704, $\mathrm{C}_{17} \mathrm{H}_{23} \mathrm{~N}_{2} \mathrm{O}_{3}$ requires 303.1709.

\section{${ }^{18} \mathrm{O}_{2}$ Isotopic Substitution}

In an atmosphere of argon, $\mathrm{H}\left\{{ }^{\mathrm{Ph}} \mathrm{BOX}\right\}(14 \mathrm{mg}, 50 \mu \mathrm{mol})$ was dissolved in $10 \mathrm{~mL}$ $\mathrm{CH}_{2} \mathrm{Cl}_{2}$ and the solution sparged with argon for several minutes to ensure the absence of oxygen. A solution of $\mathrm{CuCl}_{2} \cdot 2 \mathrm{H}_{2} \mathrm{O}(8.5 \mathrm{mg}, 50 \mu \mathrm{mol})$ in $2 \mathrm{~mL} \mathrm{MeOH}$ was prepared in an equal manner. A volume of $8 \mathrm{~mL}{ }^{18} \mathrm{O}_{2}$ gas was injected into the ligand-containing solution, followed by the addition of the $\mathrm{CuCl}_{2}$ solution. The mixture turned deep green. A second volume $8 \mathrm{~mL}{ }^{18} \mathrm{O}_{2}$ gas was added and the solution stirred for 24 hours. The solvent was removed in vacuum and dried at $5 \times 10^{-2}$ mbar to obtain the ${ }^{18} \mathrm{O}_{2}$-labelled complex as a green solid. The complex was stored under an atmosphere of argon and subjected to ESI-HR-MS analysis.

$\mathrm{C}_{34} \mathrm{H}_{42} \mathrm{Cl}_{4} \mathrm{Cu}_{3} \mathrm{~N}_{4} \mathrm{O}_{4}^{18} \mathrm{O}_{2}\left(939.17 \mathrm{~g} \mathrm{~mol}^{-1}\right)$.

HRMS (MeCN): found $[\mathrm{M}-\mathrm{Cl}]^{+}$902.0111, $\mathrm{C}_{34} \mathrm{H}_{42} \mathrm{~N}_{4} \mathrm{O}_{4}^{18} \mathrm{O}_{2} \mathrm{Cu}_{3} \mathrm{Cl}_{3}$ requires 902.0117;

found $\left[\mathrm{M}-\mathrm{CuCl}_{3}\right]^{+} 769.1429, \mathrm{C}_{34} \mathrm{H}_{42} \mathrm{~N}_{4} \mathrm{O}_{4}{ }^{18} \mathrm{O}_{2} \mathrm{Cu}_{2} \mathrm{Cl}$ requires 769.1447, found $\left[\mathrm{H}^{18} \mathrm{O}\left\{{ }^{\mathrm{Ph}} \mathrm{BOX}\right\}+\mathrm{Cu}\right]^{+}$367.0962, $\mathrm{C}_{17} \mathrm{H}_{22} \mathrm{~N}_{2} \mathrm{O}_{2}{ }^{18} \mathrm{OCu}$ requires 367.0969; found $\left[\mathrm{H}^{18} \mathrm{O}\left\{{ }^{\mathrm{Ph}} \mathrm{BOX}\right\}+\mathrm{H}\right]^{+}$305.1745, $\mathrm{C}_{17} \mathrm{H}_{23} \mathrm{~N}_{2} \mathrm{O}_{2}^{18} \mathrm{O}$ requires 305.1751. 


\subsection{6. $\left(\mathrm{O}\left\{{ }^{\mathrm{Me}} \mathrm{BOX}\right\}\right)_{2}(\mathrm{MeOH})_{2} \mathrm{Cu}_{4}{ }_{4} \mathrm{Cl}_{6}$}

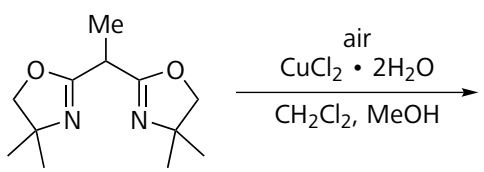

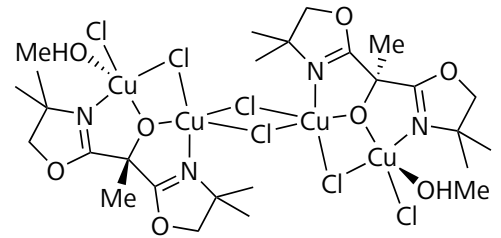

$\left.\left(\mathrm{O}_{\{}{ }^{\mathrm{Me}} \mathrm{BOX}\right\}\right)_{2}(\mathrm{MeOH})_{2} \mathrm{Cu}_{4} \mathrm{Cl}_{6}$ has been identified as a minor byproduct in the dimerisation reaction of $\left.\mathrm{H}^{3 \mathrm{Me}} \mathrm{BOX}\right\}$ and $\mathrm{CuCl}_{2} \cdot 2 \mathrm{H}_{2} \mathrm{O}$, when conducted in air instead of an inert atmosphere. A small amount of green single crystals were obtained by the slow concentration of the filtered reaction solution in air, side by side to crystalline material of yellow $\left({ }^{\mathrm{Me}} \mathrm{BOX}_{2}\right) \mathrm{Cu}_{2}{ }_{2} \mathrm{Cl}_{2}$; see Section 10.2.2. A single crystal of suitable quality was picked under the microscope from the green material for X-ray diffractometry.

$\mathrm{C}_{26} \mathrm{H}_{46} \mathrm{Cl}_{6} \mathrm{Cu}_{4} \mathrm{~N}_{4} \mathrm{O}_{8}\left(1009.56 \mathrm{~g} \mathrm{~mol}^{-1}\right)$.

\subsection{Ligand Recovery and Identification}

\subsubsection{Isolation of ${ }^{\mathrm{Me}} \mathrm{BOX}_{2}$ :}

\section{2,2,3,3-tetrakis(4,4-dimethyl-1,3-oxazolin-2-yl)butane}
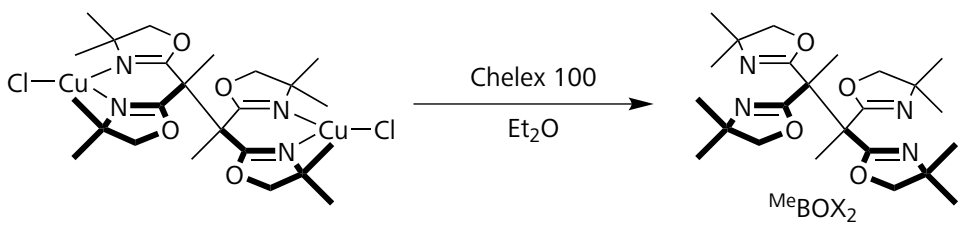

Method 1. A sample of precipitated pale green $\left({ }^{\mathrm{Me}_{\mathrm{BOX}}}\right) \mathrm{Cu}_{2} \mathrm{Cl}_{2}(246 \mathrm{mg}, 382 \mu \mathrm{mol})$ was suspended in $100 \mathrm{~mL}$ diethyl ether and $5 \mathrm{~g}$ Chelex 100 were added. The mixture was stirred for 3 hours in an open flask and the solvent was then decanted through a filter. Colouring of the transparent polymer to deep blue confirmed the successful chelation of copper(II). The polymer was again stirred with $2 \times 50 \mathrm{~mL}$ diethyl ether for several minutes. The combined organic phases were evaporated to yield a pale yellow powder after drying in vacuum $(140 \mathrm{mg}, 82 \%)$. 
Method 2. Alternatively, $580 \mathrm{mg}(900 \mu \mathrm{mol})$ of complex were dissolved in $20 \mathrm{~mL}$ methylene chloride and $50 \mathrm{~mL}$ of a $0.1 \mathrm{M}$ EDTA- $\mathrm{Na}_{2}$ solution added. After stirring for $30 \mathrm{~min}$, the organic phase was washed with $3 \times 10 \mathrm{~mL}$ EDTA- $\mathrm{Na}_{2}$ solution and $2 \times 10 \mathrm{~mL}$ water. The solvent was evaporated and the greenish residue suspended in $20 \mathrm{~mL}$ diethyl ether and $100 \mathrm{~mL}$ EDTA- $\mathrm{Na}_{2}$ solution after 2 hours agitation in an ultrasonic bath, the organic phase was washed with $3 \times 20 \mathrm{~mL}$ EDTA-Na solution and $1 \times 10 \mathrm{~mL}$ water. The volatiles were evaporated and the residue dried in vacuum to obtain a colourless powder $(300 \mathrm{mg}, 75 \%)$.

yield: colourless to pale yellow powder (75-82\%).

$\mathrm{C}_{24} \mathrm{H}_{38} \mathrm{~N}_{4} \mathrm{O}_{4}\left(446.58 \mathrm{~g} \mathrm{~mol}^{-1}\right)$.

elemental analysis (calcd.): C 63.62 (64.55), H 8.44 (8.58), N 12.30 (12.55).

HRMS (MeCN): found $[\mathrm{M}+\mathrm{H}]^{+} 447.2965, \mathrm{C}_{24} \mathrm{H}_{39} \mathrm{~N}_{4} \mathrm{O}_{4}$ requires 447.2966.

$\mathrm{MS}\left(\mathrm{ESI}^{+}, \mathrm{MeCN}\right)$ :

$m / z(\%)=485\left(4,[\mathrm{M}+\mathrm{K}]^{+}\right), 469\left(9,[\mathrm{M}+\mathrm{Na}]^{+}\right), 469\left(100,[\mathrm{M}+\mathrm{H}]^{+}\right)$.

${ }^{1} \mathrm{H}-\mathrm{NMR}\left(300 \mathrm{MHz}, \mathrm{CDCl}_{3}\right): \delta(\mathrm{ppm})=3.90\left(\mathrm{~d}, 2 \mathrm{H},{ }^{2} \mathrm{~J}(\mathrm{H})=7.8 \mathrm{~Hz}, \mathrm{CHH}\right), 3.84(\mathrm{~d}$, $\left.2 \mathrm{H}^{2} J(\mathrm{H})=7.8 \mathrm{~Hz}, \mathrm{CHH}\right), 1.80(\mathrm{~s}, 6 \mathrm{H}, \mathrm{Me}), 1.24(\mathrm{~s}, 12 \mathrm{H}, \mathrm{CMeMe}), 1.23(\mathrm{~s}, 12 \mathrm{H}$, $\mathrm{CMe} \mathrm{Me})$.

${ }^{13} \mathrm{C}\left\{{ }^{1} \mathrm{H}\right\}-\mathrm{NMR}\left(75 \mathrm{MHz}, \mathrm{CDCl}_{3}\right): \delta(\mathrm{ppm})=165.4(\mathrm{C}=\mathrm{N}), 78.9\left(\mathrm{CH}_{2}\right), 66.9\left(\mathrm{CMe}_{2}\right)$, 47.8 (CMe), 28.0 (CMeMe), 28.0 (CMeMe), 22.2 (Me).

${ }^{15} \mathrm{~N}-\mathrm{NMR}\left(30 \mathrm{MHz}, \mathrm{CDCl}_{3}\right): \delta(\mathrm{ppm})=-131.3(\mathrm{C}=\mathrm{N})$.

\subsubsection{Isolation of ${ }^{\square} \mathrm{BOX}_{2}$ :}

\section{1,1,2,2-tetrakis(4,4-dimethyl-1,3-oxazolin-2-yl)ethene}

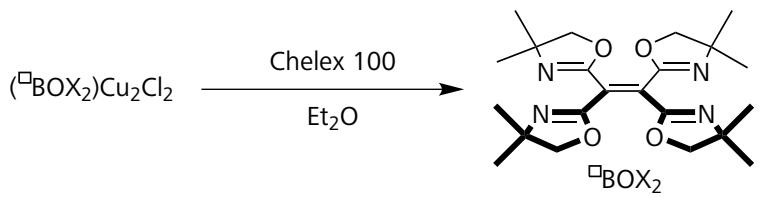

$\left({ }^{\square} \mathrm{BOX}_{2}\right) \mathrm{Cu}_{2} \mathrm{Cl}_{2}(175 \mathrm{mg}, 285 \mu \mathrm{mol})$ was suspended in $100 \mathrm{~mL}$ diethyl ether and the copper chloride was removed by stirring with $250 \mathrm{mg}$ Chelex 100 polymer in analogy to the procedure stated above. After filtration and removal of solvent in vacuum, the ligand was obtained quantitatively as a pale yellow powder after drying in vacuum. The powder was dissolved in chloroform, from which high quality single crystals, suitable for x-ray structure analysis, were yielded after a few days upon slow concentration. 


$$
\mathrm{C}_{22} \mathrm{H}_{32} \mathrm{~N}_{4} \mathrm{O}_{4}\left(416.52 \mathrm{~g} \mathrm{~mol}^{-1}\right) \text {. }
$$

elemental analysis (calcd.): C 62.86 (63.44), H 7.61 (7.74), N 13.04 (13.45).

$\mathrm{MS}\left(\mathrm{ESI}^{+}, \mathrm{CH}_{2} \mathrm{Cl}_{2} / \mathrm{MeCN}\right): m / z(\%)=855\left(40,[2 \mathrm{M}+\mathrm{Na}]^{+}\right), 833\left(3,[2 \mathrm{M}+\mathrm{H}]^{+}\right), 439$ $\left(72,[\mathrm{M}+\mathrm{Na}]^{+}\right), 417\left(100,[\mathrm{M}+\mathrm{H}]^{+}\right)$.

${ }^{1} \mathrm{H}-\mathrm{NMR}\left(300 \mathrm{MHz}, \mathrm{CDCl}_{3}\right): \delta(\mathrm{ppm})=3.97\left(\mathrm{~s}, 8 \mathrm{H}, \mathrm{CH}_{2}\right), 1.30(\mathrm{~s}, 24 \mathrm{H}, \mathrm{Me})$.

${ }^{13} \mathrm{C}\left\{{ }^{1} \mathrm{H}\right\}-\mathrm{NMR}\left(75 \mathrm{MHz}, \mathrm{CDCl}_{3}\right): \delta(\mathrm{ppm})=158.3(\mathrm{C}=\mathrm{N}), 129.0(\mathrm{C}=\mathrm{C}), 79.4\left(\mathrm{CMe}_{2}\right)$, $68.5\left(\mathrm{CH}_{2}\right), 28.0(\mathrm{Me})$.

${ }^{15} \mathrm{~N}-\mathrm{NMR}\left(30 \mathrm{MHz}, \mathrm{CDCl}_{3}\right): \delta(\mathrm{ppm})=-120.4(\mathrm{C}=\mathrm{N})$.

FTIR (neat): $\tilde{v}\left(\mathrm{~cm}^{-1}\right)=2969(\mathrm{~m}, v \mathrm{CH}), 2933(\mathrm{w}, v \mathrm{CH}), 2898(\mathrm{w}, v \mathrm{CH}), 2870(\mathrm{w}$, $v \mathrm{CH}), 1671(\mathrm{~m}, v \mathrm{C}=\mathrm{N}), 1611(\mathrm{~m}, v \mathrm{C}=\mathrm{C}), 1465(\mathrm{w}), 1385(\mathrm{w}), 1363(\mathrm{~m}), 1315(\mathrm{~m})$, $1275(\mathrm{w}), 1253(\mathrm{w}), 1210(\mathrm{w}), 1173(\mathrm{w}), 1188(\mathrm{w}), 1007(\mathrm{~m}), 980(\mathrm{w}), 937(\mathrm{w}), 910(\mathrm{w})$, $898(\mathrm{w}), 820(\mathrm{w}), 774(\mathrm{w}), 748(\mathrm{w}), 720(\mathrm{w}), 641(\mathrm{w}), 612(\mathrm{w}), 550(\mathrm{w})$.

\subsubsection{Isolation of $\mathrm{HO}\left\{{ }^{\mathrm{Ph}} \mathrm{BOX}\right\}$ : bis(4,4-dimethyl-oxazolin-2-yl)(phenyl)methanol}<smiles>CC1(C)COC(/C(=C2/NC(C)(C)CO2)c2ccccc2)=N1</smiles>

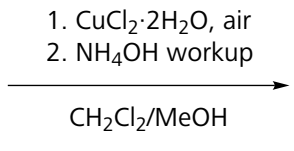<smiles>CC1(C)COC(C(O)(C2=NC(C)(C)CO2)c2ccccc2)=N1</smiles>

$\mathrm{H}\left\{{ }^{\mathrm{Ph}} \mathrm{BOX}\right\}(29 \mathrm{mg}, 100 \mu \mathrm{mol})$ was dissolved in $10 \mathrm{~mL} \mathrm{CH}_{2} \mathrm{Cl}_{2}, 1.0 \mathrm{~mL}$ of a $\mathrm{MeOH}$ solution of $\mathrm{CuCl}_{2} \cdot 2 \mathrm{H}_{2} \mathrm{O}(17 \mathrm{mg}, 100 \mu \mathrm{mol})$ was added. The mixture was stirred in air for $2 \mathrm{~h}$, accompanied with a green colouring of the solution. The solvent was removed in vacuum and the green solid residue redissolved in $10 \mathrm{~mL} \mathrm{CH}_{2} \mathrm{Cl}_{2}$. $10 \mathrm{~mL} 5 \% \mathrm{NH}_{4} \mathrm{OH}$ solution were added and the mixture was vigorously stirred for $30 \mathrm{~min}$. The phases were separated and the organic phase was washed with $10 \mathrm{~mL} \mathrm{NH}_{4} \mathrm{OH}$ and with $10 \mathrm{~mL}$ water. The organic phase was dried over $\mathrm{MgSO}_{4}$, filtered, the solvent removed and the residue dried in vacuum to obtain $26 \mathrm{mg}$ of a colourless to light-blue oil. The crude oil was dissolved in $2.0 \mathrm{~mL} \mathrm{CDCl}_{3}$ and 1,2,4,5-tetrabromobenzene $(20 \mathrm{mg}, 50 \mu \mathrm{mol})$ was added as an internal standard for ${ }^{1} \mathrm{H}-\mathrm{NMR}$ analysis.

yield: $\sim 60 \mu \mathrm{mol}, \sim 60 \%$ of colourless to light-blue oil. $\mathrm{C}_{17} \mathrm{H}_{22} \mathrm{~N}_{2} \mathrm{O}_{3}\left(302.37 \mathrm{~g} \mathrm{~mol}^{-1}\right)$.

${ }^{1} \mathrm{H}-\mathrm{NMR}\left(300 \mathrm{MHz}, \mathrm{CDCl}_{3}\right): \delta(\mathrm{ppm})=7.70-7.56(\mathrm{~m}, 2 \mathrm{H}, \mathrm{Ph}), 7.42-7.29(\mathrm{~m}, 3 \mathrm{H}$, $\mathrm{Ph}), 4.10(\mathrm{~d}, J=8.0 \mathrm{~Hz}, 2 \mathrm{H}, \mathrm{CHH}), 4.06(\mathrm{~d}, J=8.0 \mathrm{~Hz}, 2 \mathrm{H}, \mathrm{CH}), 1.35(\mathrm{~s}, 6 \mathrm{H}$, $\mathrm{CMeMe}$ ), 1.32 (s, 6 H, CMeMe). 
${ }^{13} \mathrm{C}\left\{{ }^{1} \mathrm{H}\right\}-\mathrm{NMR}\left(75 \mathrm{MHz}, \mathrm{CDCl}_{3}\right): \delta(\mathrm{ppm})=162.4(\mathrm{C}=\mathrm{N}), 130.8(\mathrm{Ph}), 129.1(\mathrm{Ph})$, $128.3(\mathrm{Ph}), 127.8(\mathrm{Ph}), 80.6\left(\mathrm{CH}_{2}\right), 77.4(\mathrm{CPhOH}), 68.3(\mathrm{CMe}), 27.90(\mathrm{CMeMe})$, $27.85(\mathrm{CMeMe})$.

${ }^{15} \mathrm{~N}-\mathrm{NMR}\left(30 \mathrm{MHz}, \mathrm{CDCl}_{3}\right): \delta(\mathrm{ppm})=-123.0(\mathrm{C}=\mathrm{N})$.

\subsubsection{Thermal Decomposition of ${ }^{\mathrm{H}} \mathrm{P}$ and Isolation of ${ }^{\mathrm{O}} \mathrm{BOX}$} (bis(4,4-dimethyl-oxazolin-2-yl)methanone)

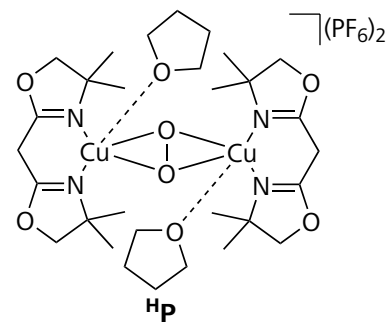

1. ambient temperatures

2. $\mathrm{NH}_{4} \mathrm{OH}$ workup<smiles>[X]O[R6](=O)O[Na]</smiles>

${ }^{\mathbf{H}} \mathbf{P}(30 \mathrm{mg}, 26 \mu \mathrm{mol})$ was dissolved in $10 \mathrm{~mL} \mathrm{CH}_{2} \mathrm{Cl}_{2}$ at $\mathrm{r}$. t. The solution turned red and after some minutes green. It was stirred overnight, $20 \mathrm{~mL}$ of a $5 \% \mathrm{NH}_{4} \mathrm{OH}$ solution were added and the mixture vigorously stirred for several minutes. The aqueous phase turned slowly blue and was discarded. This was repeated two times. The organic phase was separated and washed with $2 \times 20 \mathrm{~mL} \mathrm{H}_{2} \mathrm{O}$ and dried over $\mathrm{Na}_{2} \mathrm{SO}_{4}$. The solvent was removed to obtain a small amount of residue. The residue was extracted with a small volume of $\mathrm{CDCl}_{3}$ and the solution filtered.

$\mathrm{C}_{11} \mathrm{H}_{16} \mathrm{~N}_{2} \mathrm{O}_{3}\left(224.26 \mathrm{~g} \mathrm{~mol}^{-1}\right)$.

MS (ESI ${ }^{+}$, solv): $m / z(\%)=225.1\left(100,[\mathrm{M}+\mathrm{H}]^{+}\right)$,

${ }^{1} \mathrm{H}-\mathrm{NMR}\left(300 \mathrm{MHz}, \mathrm{CDCl}_{3}\right): \delta(\mathrm{ppm})=3.97\left(\mathrm{~s}, 4 \mathrm{H}, \mathrm{CH}_{2}\right), 1.29(\mathrm{~s}, 12 \mathrm{H}, \mathrm{Me})$.

${ }^{13} \mathrm{C}\left\{{ }^{1} \mathrm{H}\right\}-\mathrm{NMR}\left(75 \mathrm{MHz}, \mathrm{CDCl}_{3}\right): \delta(\mathrm{ppm})=79.4\left(\mathrm{CH}_{2}\right), 68.5(\mathrm{CMe} 2), 28.0(\mathrm{Me}), \mathrm{C}=\mathrm{N}$ and $\mathrm{C}=\mathrm{O}$ could not be observed.

${ }^{15} \mathrm{~N}-\mathrm{NMR}\left(30 \mathrm{MHz}, \mathrm{CDCl}_{3}\right): \delta(\mathrm{ppm})=-220.5(\mathrm{C}=\mathrm{N})$. 



\section{Miscellaneous Experimental Procedures}

\subsection{Equilibrium and Kinetics of $\mathrm{H}\left\{{ }^{\mathrm{Ph}} \mathrm{BOX}\right\}$ Tautomerism}

The activation parameters of the tautomerization were determined by the equilibration method. ${ }^{[153]}$ The equilibrium displacement has been achieved by crystallisation of the iminoenamine isomer in pure form (see Section 10.1.4, p. 210). The time-dependence of the relaxation was followed by ${ }^{1} \mathrm{H}$ NMR spectroscopy; the equilibration was started by dissolving a crystalline sample of pure iminoenamine isomer in $\mathrm{CDCl}_{3}$. Due to the poor solubility, $6 \mathrm{mg} \mathrm{H}\left\{{ }^{\mathrm{Ph}} \mathrm{BOX}\right\}$ were stirred in $0.6 \mathrm{~mL}$ ice-cooled solvent for $10 \mathrm{~min}$. The solution was then filtered through a plug of glass wool into the NMR tube and the sample then inserted into the NMR magnet, tempered to the desired temperature. A Bruker Avance DRX 500 spectrometer with variable temperature unit was used. The ${ }^{1} \mathrm{H}$ NMR spectrum was recorded immediately as a function of time, with longer intervals at the lower temperatures. The reaction was studied between -5 and $25^{\circ} \mathrm{C}$; the temperature deviation during the measurements had not exceeded $\pm 0.1 \mathrm{~K}$. All spectra were processed with MestreNova, version 6.0 (Mestrelab Research). The relative isomer concentrations were obtained by comparison of the integrals of the methyl ${ }^{1} \mathrm{H}$ resonance peaks.

Equilibrium constants were taken from the kinetic measurements and from additional measurements and samples. The full equilibration was confirmed by recording of consecutive spectra (especially at the lower temperatures); the samples were found equilibrated after reaction times of between 9 min and more than 10 hours. Because of the poor solubility, additional experiments applying other solvents were not conducted so far. Deuterated chloroform, $\mathrm{CDCl}_{3}(99.8$ atom $\% \mathrm{D}$, water $\leq 0.01 \%$ ) was used in all experiments as it was obtained from Sigma-Aldrich. 


\subsection{Cryo-Stopped-Flow Kinetic Measurements of Activation of $\mathrm{O}_{2}$ by ${ }^{t \mathrm{Bu}} \mathrm{P}$}

Cryo-stopped-flow kinetic measurements were performed using a single Berger Ball mixing BioLogic Science Instruments $\mu$ SFM-20 Stopped-Flow Module with two syringes with independent stepping motors controlled by a MPS-20 Microprocessor Unit and an electro-valve hard-stop. Temperature was regulated by using a Huber CC 75 cryostat, with the observation head immersed into the cryo-solvent (DWTherm, DWS Synthesetechnik) and was connected by an umbilical link. Spectra were recorded by an optical fibre-mounted photodiode array spectrophotometer J \& M Analytik AG TIDAS. The temperature in the observation head was observed with an internal probe at the observation cell. The assembly was controlled by a computer, running Bio-Kine32.

The stopped-flow apparatus was flushed with argon-saturated THF prior to measurements to ensure the absence of air. Saturated solutions of $\mathrm{O}_{2}$ in THF were prepared by bubbling dry $\mathrm{O}_{2}$ gas through dry THF for $\sim 15 \mathrm{~min}$. The solubility of $\mathrm{O}_{2}$ in THF at $25^{\circ} \mathrm{C}$ and $1 \mathrm{~atm}$ is $10.0 \mathrm{~mm}\left(\chi=8.16 \times 10^{4}\right)$, ${ }^{[237]}$ this value was used in the calculation of the $\mathrm{O}_{2}$ concentrations. Since the system was closed and the solutions had no contact to the gas phase, no change in concentration was possible. A correction for the solvent's temperature contraction was not applied.

Reaction kinetic profiles were deconvoluted with the SPECFIT/32 ${ }^{[311,312]} \mathrm{global}$ analysis software. Pseudo first-order rate constants $k_{\text {obs }}$ were obtained from nonlinear regression of spectral traces with single exponential function using OriginLab 0riginPro 8.5.1 software. $k_{\text {on }}$ and $k_{\text {off }}$ were obtained from a linear regression of a plot of $k_{\text {obs }}$ vs $\mathrm{O}_{2}$ concentration. Activation and equilibrium parameters were obtained from linear regressions of the respective Eyring and van t'Hoff plots using instrumental weighted fitting with OriginPro.

\subsection{Beer's Law Plots for ${ }^{t B u p}$}

Solutions of varying concentrations of ${ }^{\boldsymbol{t} \mathbf{B u}} \mathbf{P}(0.1-0.3 \mathrm{~mm})$ in THF were prepared by injection of $\mathbf{C u}^{\prime} \mathbf{t} \mathbf{B u}$ solutions into chilled, saturated solutions of $\mathrm{O}_{2}$ in THF in a dry ice/acetone bath. $2 \mathrm{~mm}$ and $5 \mathrm{~mm}$ stock solutions of $\mathbf{C} \mathbf{u}^{\prime} \mathbf{t} \mathbf{B u}$ were used. The solutions turned slowly purple; each development of full spectrum (250-700 nm) was monitored with a $0.1 \mathrm{~cm}$ path length immersion probe until it remained unchanged. The slopes of the absorbances at 333 and $500 \mathrm{~nm}$ versus concentration of ${ }^{\boldsymbol{t} B u} \mathbf{P}$ give extinction coefficients $(\epsilon)$ of approximately 48000 and $2100 \mathrm{M}^{-1} \mathrm{~cm}^{-1}$ 
respectively. This values are uncorrected for the $\sim 10 \%$ solvent contraction from r.t. to $-78^{\circ} \mathrm{C}$. Concentrations $\geq 0.3 \mathrm{~mm}$ caused the precipitation of ${ }^{\boldsymbol{t} \mathbf{B u}} \mathbf{P}$ over the short or long term.

\subsection{Reversibility of ${ }^{t B u} \mathrm{P}$-mediated $\mathrm{O}_{2}$ Activation}

A solution of ${ }^{\boldsymbol{t} B u} \mathbf{P}$ was prepared by the $\mathrm{O}_{2}$ injection method in an acetone/dry ice bath at $-78^{\circ} \mathrm{C}$, as previously described; the formation was monitored by UV/vis spectroscopy. Excess $\mathrm{O}_{2}$ was then removed by several vacuum/argon cycles. The flask was warmed to $-15^{\circ} \mathrm{C}$ using an ethylene glycol/dry ice bath. Re-oxygenation was achieved by additional exchange of cooling baths and repeated injection of $\mathrm{O}_{2}$.

\subsection{Reactivity of ${ }^{\text {tBu}} \mathrm{P}$ Towards External Substrates}

$8.0 \mathrm{~mL}$ dry THF were cooled to $-78^{\circ} \mathrm{C}$ and the solution saturated with dioxygen by injection over a period of $10 \mathrm{~min}$. $2.0 \mathrm{~mL}$ of a $5.0 \mathrm{~mm}$ solution of $\mathbf{C u}^{\prime} \mathbf{t} \mathbf{B u}$ in THF was slowly injected into the cool solution; slow formation of ${ }^{\boldsymbol{t} \mathbf{B u}} \mathbf{P}(0.5 \mathrm{mM})$ was evident by the slow change from colourless to intense violet. After stirring for $15 \mathrm{~min}$, triethylamine ( $10 \mathrm{eq}, 7.0 \mu \mathrm{L}, 50 \mu \mathrm{mol})$ was added and subsequent the substrate in fivefold excess $(25 \mu \mathrm{mol})$. The solution was stirred at $-78{ }^{\circ} \mathrm{C}$ for 16 hours, along with the slow warming of the cooling bath to room temperature.

The solvent was removed in vacuum and the residue redissolved in $5 \mathrm{~mL} \mathrm{CH}_{2} \mathrm{Cl}_{2}$. $5 \mathrm{~mL}$ of $6 \mathrm{M} \mathrm{HCl}$ solution was added, the phases were separated and the aqueous phase extracted with $3 \times 10 \mathrm{~mL} \mathrm{CH}_{2} \mathrm{Cl}_{2}$. The organic phases were combined and the volatiles removed in vacuum. The residue was dried in vacuum and analysed by means of NMR, IR and UV-vis spectroscopy.

\section{2,4-Di-tert-butylphenol (DTBP)}

No change in color was evident after some hours at $-78{ }^{\circ} \mathrm{C}$. The residue contained the unchanged Phenol $(62 \%)$ and $38 \%$ were converted to the $\mathrm{C}-\mathrm{C}$ coupling product 3,3',5,5'-tetra-tert-butyl-2,2'-biphenol (TBBP); no 3,5-di-tert-butyl-oquinone (DTBQ) was present.

${ }^{1} \mathrm{H}-\mathrm{NMR}\left(300 \mathrm{MHz}, \mathrm{CDCl}_{3}\right): \delta(\mathrm{ppm})=7.38\left(\mathrm{~d}, 2 \mathrm{H},{ }^{2} J(\mathrm{H})=2.3 \mathrm{~Hz}, \mathrm{Ar}_{\mathrm{TBBP}}\right), 7.26$ $\left(\mathrm{d}, 1 \mathrm{H},{ }^{2} J(\mathrm{H})=2.5 \mathrm{~Hz}, \mathrm{Ar}_{\mathrm{DTBP}}\right), 7.10\left(\mathrm{~d}, 2 \mathrm{H},{ }^{2} J(\mathrm{H})=2.5 \mathrm{~Hz}, \mathrm{Ar}_{\mathrm{TBBP}}\right), 7.04(\mathrm{dd}, 1 \mathrm{H}$, $\left.{ }^{2} J(\mathrm{H})=8.1 \mathrm{~Hz},{ }^{2} J(\mathrm{H})=2.1 \mathrm{~Hz}, \operatorname{Ar}_{\mathrm{DTBP}}\right), 6.75\left(\mathrm{~d}, 1 \mathrm{H},{ }^{2} J(\mathrm{H})=8.2 \mathrm{~Hz}, \operatorname{Ar}_{\mathrm{DTBP}}\right)$, $1.44\left(\mathrm{~s}, 18 \mathrm{H}, t \mathrm{Bu}_{\mathrm{TBBP}}\right), 1.40$ (s, 9 $\left.\mathrm{H}, t \mathrm{Bu}_{\mathrm{DTBP}}\right), 1.31$ (s, $\left.18 \mathrm{H}, t \mathrm{Bu}_{\mathrm{TBBP}}\right), 1.28$ (s, $9 \mathrm{H}$, $\left.t \mathrm{Bu}_{\mathrm{DTBP}}\right)$. 


\subsection{Spin-Trapping of a Short-lived Transient Radical}

In a typical experiment, DMPO (25 mg, $0.22 \mathrm{mmol})$ and $\mathrm{H}\left\{{ }^{\mathrm{Me}} \mathrm{BOX}\right\}(10 \mathrm{mg}, 45 \mu \mathrm{mol})$ were dissolved in dry methanol under an argon atmosphere. The solution was additionally degassed by bubbling with argon. Then, triethylamine $(30 \mu \mathrm{L}, 0.22 \mathrm{mmol})$ and $\mathrm{CuCl}_{2} \cdot 2 \mathrm{H}_{2} \mathrm{O}(4 \mathrm{mg}, 22 \mu \mathrm{mol})$ were added and the flask wrapped with aluminium foil. After stirring for some minutes, a sample of the colourless solution was transferred to an EPR tube. The solution was stored at $-80^{\circ} \mathrm{C}$ under an atmosphere of argon and an EPR spectrum was recorded shortly after.

\subsection{DPPH`Antiradical Assay}

A 3.4 mM stock solution of $\mathrm{DPPH}^{\bullet}$ was prepared by dissolving $4.4 \mathrm{mg}$ in $3.30 \mathrm{~mL}$ methanol. The test solutions were prepared by dilution of the appropriate $\left.\mathrm{H}_{\{}{ }^{\mathrm{R}} \mathrm{BOX}\right\}$ stock solution $(0.2-2 \mathrm{~mm}$ in methanol) to a total volume of $3.00 \mathrm{~mL}$. To start the reaction, $150 \mu \mathrm{L} \mathrm{DPPH}^{*}$ solution were added and the sample thoroughly stirred. The final concentrations were in the range of $1 \mu \mathrm{M}-2 \mathrm{~mm}$. After $30 \mathrm{~min}$ incubation in the absence of light at $25^{\circ} \mathrm{C}$, the absorbance was measured at $517 \mathrm{~nm}$ relative to neat methanol in a Varian Cary 5000 spectrophotometer. The antioxidant L-ascorbic acid was used as a positive control. Kinetic traces were recorded from the above samples. 


\section{Computational and X-Ray Absorption/Diffraction Methods}

\subsection{DFT Calculations}

All DFT calculations were performed with the ORCA 2.9.1 electronic structure program package written by F. Neese. ${ }^{[156,287]}$ The parallel version of ORCA was run with either eight or four processes (Pal8, Pal4) on a Linux system. When reasonable, atom coordinates were taken from crystal structures or from part of a crystal structure. In other case, they were obtained from first guess structures drawn with Cambridgesoft Chem3D Pro 12.0 after an MM2 energy minimization calculation. Ligand structures were used without truncation. All geometry optimizations and single point calculations were performed using Becke's three-parameter hybrid functional with the correlation functional of Lee, Yang, and Parr (B3LYP). ${ }^{[157,158]}$ The valence triple- $\zeta$ plus polarization basis sets (def2-TZVPP) ${ }^{[159,160]}$ were used on all calculations unless stated otherwise. The resolution of identity/chain of spheres exchange approximation (RIJCOSX), ${ }^{[313-315]}$ together with the matching def2-TZVPP/J and/or def2-SVP/J auxiliary basis set were used to accelerate the calculations. In all calculations, default convergence criteria were used for geometry optimization calculations (OPT); for SCF calculations, strict convergence criteria were used (TightSCF) and slow convergence was expected (SlowConv).

Preliminary explorative calculations were conducted using the Becke88 ${ }^{[316]}$ exchange and Perdew86 ${ }^{[317]}$ correlation nonlocal functionals (BP86) and SV (P) basis sets, instead of the methods stated. Molecular structures, orbitals and spin densities were visualized with the UCSF Chimera package. ${ }^{[318]}$ 


\subsubsection{Ligands $\mathrm{H}\left\{{ }^{\mathrm{Ph}} \mathrm{BOX}\right\}$ and $\mathrm{H}\left\{{ }^{\mathrm{H}} \mathrm{BOX}\right\}$}

Geometry optimizations, single point calculations and numerical frequency calculations (NumFreq) were performed using the hybrid functional B3LYP. Solvent effects were considered in all calculations by invoking the COSMO formalism with the selection of chloroform as the solvent as it is implemented in ORCA. In the cases were X-ray structures are available a good structural match was found.

For transition-states (TS), start coordinates were obtained by manipulation of an geometry-optimised structure using the molecule editor Avogadro 1.1.๑. ${ }^{[319]}$ TS optimisations were performed using the EF-algorithm (0ptTS). Good starting coordinates were obtained by positioning of the proton in between both, the carbon and nitrogen atom. All TS were found to have a sole imaginary frequency (see the main text). IR spectra were created by the utility program orca_mapspc and plotted with the program package OriginLab OriginPro 8.5.0G; IR spectra showed a good match with experimental data.

All computed atom coordinates can be obtained free of charge in the Supporting Information accompanying the published journal article ${ }^{[320]}$ from http://dx.doi . org/10.1002/ejoc. 201301282.

\subsubsection{Cu" Complexes}

Atom starting coordinates were taken from crystal structures or from part of a crystal structure; e. g. by bisecting $\left[\left({ }^{\mathrm{Me}_{\mathrm{BOX}}}\right)(\mathrm{CuCl})_{2}\right]$. Spin-unrestricted geometry optimizations and single point calculations were performed using the hybrid functional B3LYP with def2-TZVPP for all atoms, together with the RIJCOSX approximation and matching def2-TZVPP/J auxiliary basis set. For SCF calculations, strict convergence criteria were used (TightSCF). Slow convergence was expected (SlowConv).

\subsection{3. $\mathrm{Cu}_{2} \mathrm{O}_{2}$ Systems}

\section{Broken-Symmetry Geometry Optimisations}

The geometry of $\left[\{(\mathrm{BOX}) \mathrm{Cu}\}_{2}\left(\mathrm{O}_{2}^{2-}\right)(\mathrm{MeCN})_{2}\right]^{2+}$ was fully optimized starting from coordinates obtained from the X-ray crystal structure of $\left[\{(\mathrm{BOX}) \mathrm{Cu}\}_{2}(\mathrm{OH})_{2}-\right.$ $\left.(\mathrm{MeCN})_{2}\right]^{2+}$ after manipulation of the $\mathrm{Cu}_{2} \mathrm{O}_{2}$ distances (using the molecule editor Avogadro 1.1.0). Ligand geometries were used without truncation. Geometry optimizations and single point calculations were performed using the B3LYP hybrid functional. The valence triple- $\zeta$ plus polarization basis sets (def2-TZVPP) ${ }^{[159,160]}$ 
were used on copper, oxygen and nitrogen atoms and double- $\zeta$ split valence polarisation sets (def2-SVP) ${ }^{[159,279]}$ on carbon and hydrogen, as implemented in ORCA. Solvent effects were considered in all calculations by invoking the conductor like screening model (COSMO) with the selection of THF as the solvent.

A DFT spin-unrestricted formalism (UKS) has been applied to first calculate a high-spin triplet state $(S=1)$ geometry, which was then used for calculation of the spin-polarized broken-symmetry (BS) solution. ${ }^{[280,281]}$ To achieve this, the spin on one copper atom was flipped by invoking the $» F l i p S p i n \ll$ mechanism in ORCA in expectation of an antiferromagnetically coupled state, $M_{S}=0$ (FinalMs 0 ). In the obtained BS solution, Mulliken spin population at the copper atoms are 0.4930 and -0.4932 . Bond lengths/angles are consistent with EXAFS data and with the

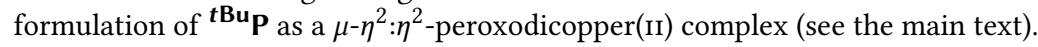
The magnetic coupling was inspected according to the procedure of YAMAGUCHI et al.; ${ }^{[291,292]}$ see the main text for details.

The computed atom coordinates for ${ }^{\boldsymbol{t}} \mathbf{B u} \mathbf{P}$ can be obtained free of charge in the Supporting Information accompanying the published journal article ${ }^{[321]}$ from http://dx.doi.org/10.1002/ejic. 201402378.

\section{Time-dependent DFT (TD-DFT)}

TD-DFT calculations ${ }^{[282,283,285]}$ and natural transition orbital (NTO) ${ }^{[286]}$ analysis (DoNT0) were undertaken with ORCA version 3.0.1. Calculations on the geometry optimised coordinates were performed using the B3LYP functional together with basis sets and COSMO model as it was stated above. The first 16 excited states in

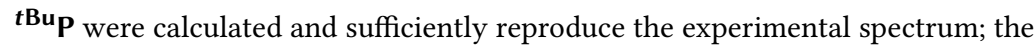
maximum dimension of the expansion space in the Davidson procedure (MaxDim) was 320 . The spectra was not significantly different when inspecting 64 states. Absorption spectra were created by the utility program orca_mapspc and plotted with the program package OriginLab OriginPro 8.5.0G. The spectra were in good agreement with experimental data.

Calculations of ${ }^{\mathbf{P h}} \mathbf{O}$ were conducted analogously, but with a DFT spin-restricted

formalism (RKS) for this singlet system. Starting coordinates were taken from the above calculations and were manipulated with Avogadro software. The COSMO solvent model was applied with the selection of acetone as the solvent. The first 42 excited states in ${ }^{\mathbf{P h}} \mathbf{O}$ were calculated by TD-DFT with a maximum dimension of 420 . 


\subsection{XAS, XANES and EXAFS}

XAS measurements were performed with Junprof. Dr. MATthiAs BAUER (TU Kaiserslautern; now at University Paderborn) at XAS beamline of the ANKA synchrotron (Karlsruhe, Germany) under ambient conditions at $293 \mathrm{~K}$. A Si(111) double crystal monochromator was used for measurements at the Cu K-edge (8.979 keV). The second monochromator crystal was tilt for optimal harmonic rejection. The spectra were recorded in transmission mode with ionisation chambers filled with nitrogen. The individual pressures were adjusted to optimize the signal to noise ratio. Energy calibration was performed with a copper metal foil. The solid samples were embedded in an oxygen free boron nitride or cellulose matrix and carefully pressed into pellets.

Data evaluation started with background absorption removal from the experimental absorption spectrum by subtracting a Victoreen-type polynomial. ${ }^{[322,323]}$ To determine the smooth part of the spectrum, corrected for pre-edge absorption, a piecewise polynomial was used. It was adjusted in such a way that the low- $R$ components of the resulting Fourier transform were minimal. After division of the background-subtracted spectrum by its smooth part, the photon energy was converted to photoelectron wave numbers $k$. The resulting $\chi(k)$-function was weighted with $k^{3}$ and Fourier transformed using a Hanning window function. Data analysis was performed in $k$-space on unfiltered data. Adjustment of the common theoretical EXAFS expression

$$
\chi(k)=\sum_{j} \frac{N_{j}}{k r_{j}^{2}} S_{0}^{2}(k) F_{j}(k) \mathrm{e}^{-2 k^{2} \sigma_{j}^{2}} \mathrm{e}^{-\frac{2 r_{j}}{\lambda}} \sin \left[2 k r_{j}+\delta_{j}(k)\right]
$$

$\left(N_{j}\right.$ : one type of neighbour atoms $j$ in a shell, $r_{j}$ : distance of atoms $\mathrm{j}$ from the X-ray absorbing atom, $S_{0}^{2}$ : amplitude reduction factor, $F_{j}$ : backscattering amplitude, $\sigma^{2}$ : Debye-Waller like factor, $\delta_{j}$ : overall phaseshift) according to the curved wave formalism of the EXCURV98 program with XALPHA phase and amplitude functions ${ }^{[324]}$ yielded the structural parameters given in Section 6.7. The mean free path of the scattered electrons was calculated from the imaginary part of the potential (VPI set to $-4.00 \mathrm{eV}$ ). Since an amplitude reduction factor was used to account for inelastic processes, ${ }^{[325]}$ it was determined experimentally from the reference compounds $\mathrm{Cu}_{2} \mathrm{O}, \mathrm{CuO}$ and $\mathrm{Cu}(\mathrm{OH})_{2}$ to be $0.8 \pm 0.1$ by setting the coordination numbers to the crystallographic values. ${ }^{[326-328]}$ An inner potential correction $E_{f}$ was introduced when fitting experimental data with theoretical models that accounts for an overall phase shift between the experimental and calculated spectra. 
In the fitting procedure, it was taken into account that the number of fitted parameters $\left(N_{\text {pars }}\right)$ did not exceed the degrees of freedom $\left(N_{\text {ind }}\right)$ which are calculated according to $N_{\text {ind }}=(2 \Delta k \Delta R / \pi) .{ }^{[329]}$ The quality of fit is given in terms of the $R$-factor according to ${ }^{[330]}$

$$
R=\sum_{i} \frac{k^{3}\left|\chi^{\exp }\left(k_{i}\right)-\chi^{\text {theo }}\left(k_{i}\right)\right|}{k^{3}\left|\chi^{\exp }\left(k_{i}\right)\right|} \cdot 100 \%
$$

\subsection{X-Ray Crystallography}

Single crystals of suitable X-ray diffraction quality were grown following the respective methods described in Chapter 10.

$\mathrm{X}$-ray data were collected on a STOE IPDS II diffractometer (graphite monochromated Mo-K $\alpha$ radiation, $\lambda=0.71073 \AA$ ) by use of $\omega$ scans; data were collected at $-140{ }^{\circ} \mathrm{C}$, unless otherwise stated (Table 12.1). The structures were solved by direct methods (SHELXS-97) and refined on $F^{2}$ using all reflections with SHELXL-97. ${ }^{\text {[31] }}$ All non-hydrogen atoms were refined anisotropically. Most hydrogen atoms were placed in calculated positions and assigned to an isotropic displacement parameter of $1.2 / 1.5 U_{\mathrm{eq}}(C)$.

\section{Ligands}

The nitrogen bound hydrogen atom in $\mathrm{H}\left\{{ }^{\mathrm{Ph}} \mathrm{BOX}\right\}$ (occupancy = 0.5) was refined freely with a fixed isotropic displacement parameter of $0.08 \AA^{2}$. Face-indexed absorption corrections were performed numerically with the program X-RED. ${ }^{[332]}$

\section{$\left.\left[\left(\mathrm{H}_{2} \mathrm{O}\right)\left(\mathrm{H}_{\{}{ }^{t \mathrm{Bu}} \mathrm{BOX}\right\}\right) \mathrm{Cu}(\mathrm{OH})\right]_{2}\left(\mathrm{PF}_{6}\right)_{2}$}

The oxygen bound hydrogen atoms were refined with a fixed isotropic displacement parameter of $0.08 \AA^{2}$ and DFIX restraints for the O-H distances of $0.82 \AA$. Face-indexed absorption corrections were performed numerically with the program X-RED. ${ }^{[332]}$

\section{$\left[\left(\mathrm{H}_{\{}^{\mathrm{tBu}}{ }^{\mathrm{BOX}\}}\right) \mathrm{Cu}(\mathrm{MeCN})\right]\left(\mathrm{PF}_{6}\right)$ and

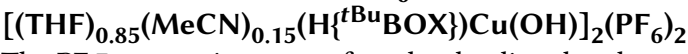

The $\mathrm{PF}_{6}^{-}$counterions were found to be disordered as well as parts of the ligand in case of the first and for the coordinating solvent molecules in case of the latter compound. The disorder of the two different solvent molecules in the second case is related to the disorder of the counterion. After the initial refinement the 
occupancy factors were fixed at 0.85 and 0.15 which represent the fraction of the two solvents (THF and MeCN) and the occupancy of the $\mathrm{PF}_{6}^{-}$with respect to two alternate positions. EADP constraints and DELU, SIMU and BUMP restraints were applied to model the disorder. Two counterions (occupancy 0.5) in $\left.\left[\left(\mathrm{H}_{\{}^{t \mathrm{Bu}} \mathrm{BOX}\right\}\right) \mathrm{Cu}(\mathrm{MeCN})\right]\left(\mathrm{PF}_{6}\right)$ were found to be disordered about two-fold axes. Additionally parts of the ligands are disordered as well $(\mathrm{O} 2, \mathrm{C} 8, \mathrm{C} 9, \mathrm{C} 10, \mathrm{C} 11$; occupancy factors: $0.584(11) / 0.416(11))$. SADI, SIMU and DELU restrains were used to model the disorder.

The CCDC numbers listed in Table 12.1 contain the supplementary crystallographic data for this work. These data can be obtained free of charge from The Cambridge Crystallographic Data Centre via http://www. ccdc . cam . ac. uk/data_ request/cif. 


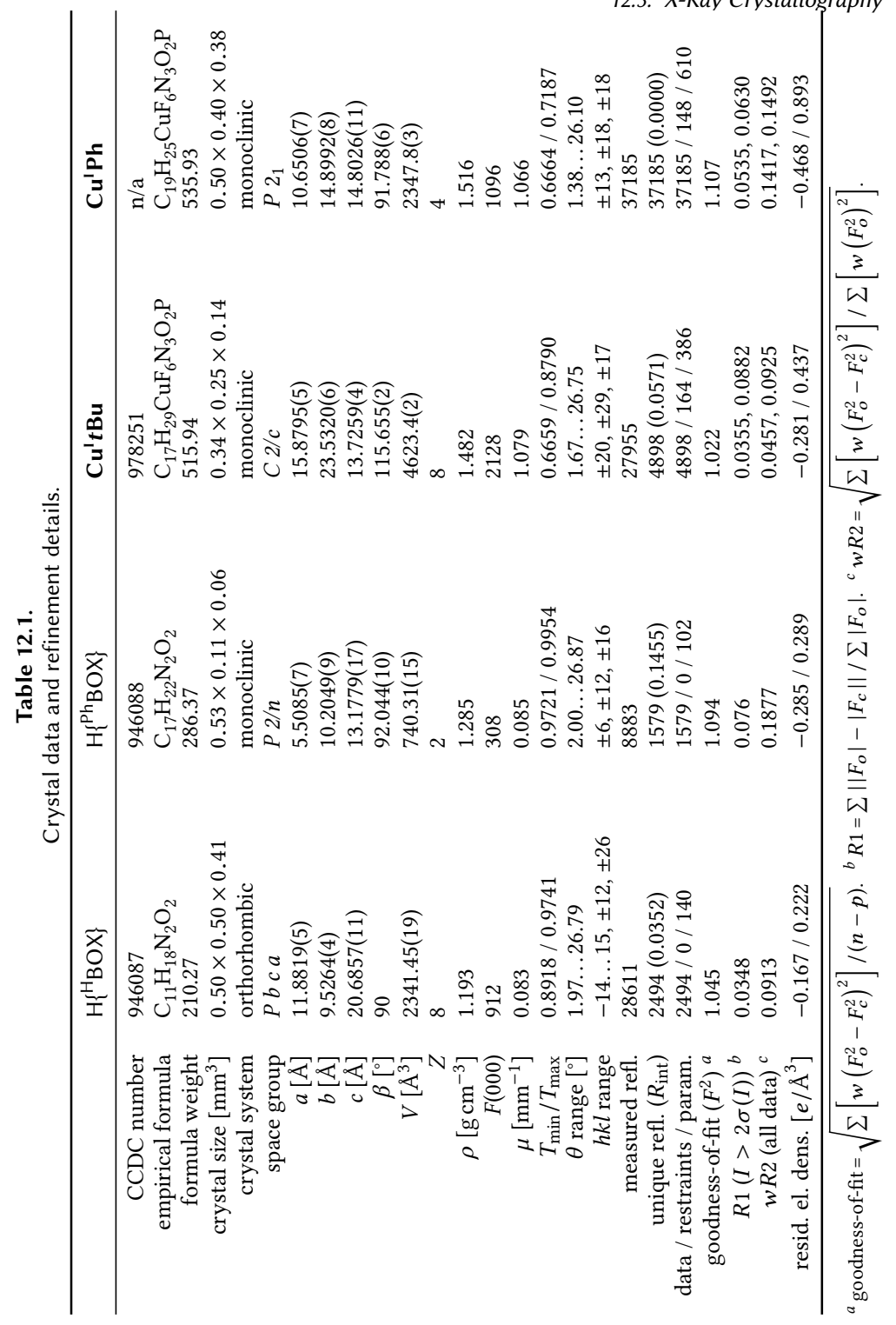




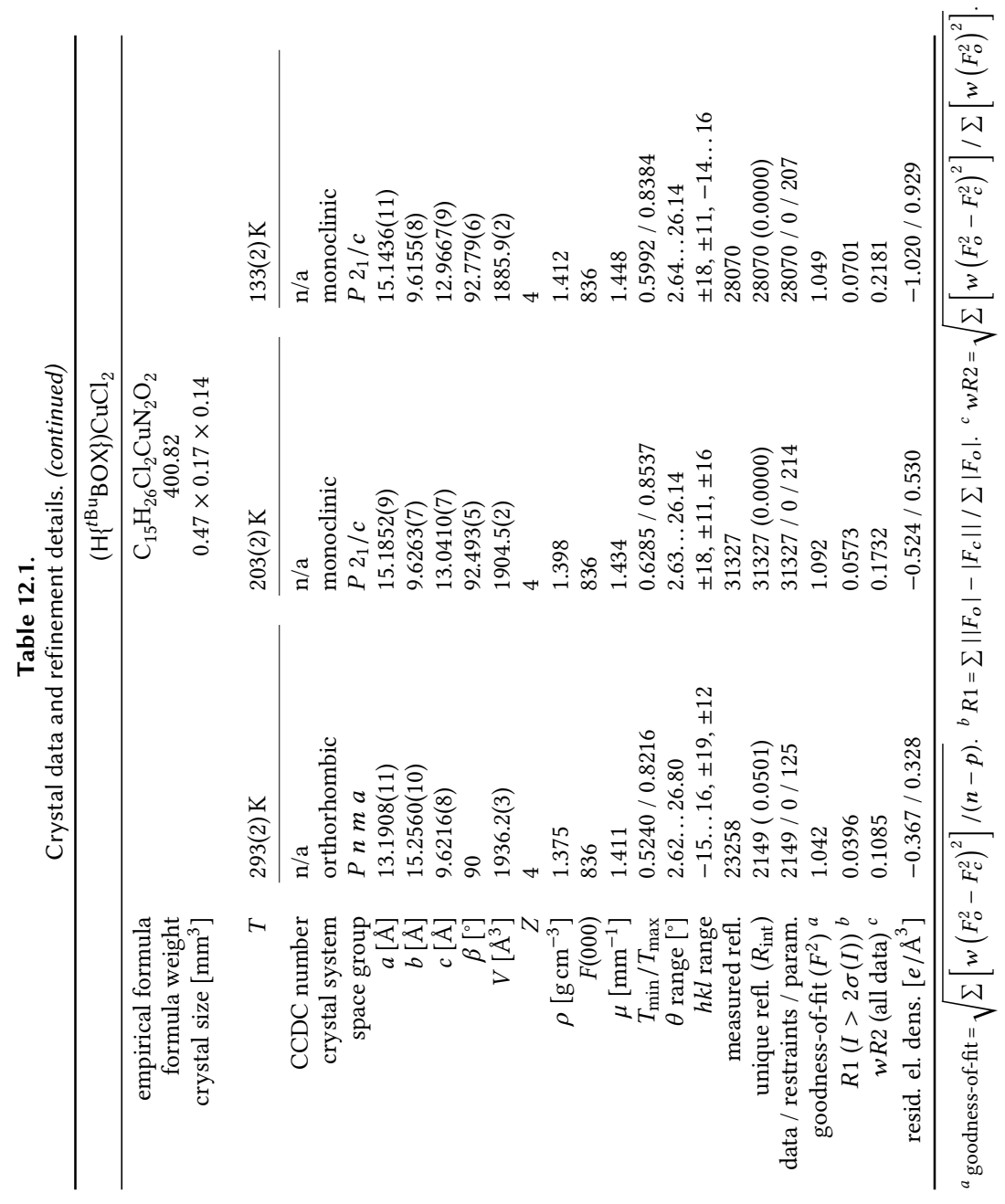




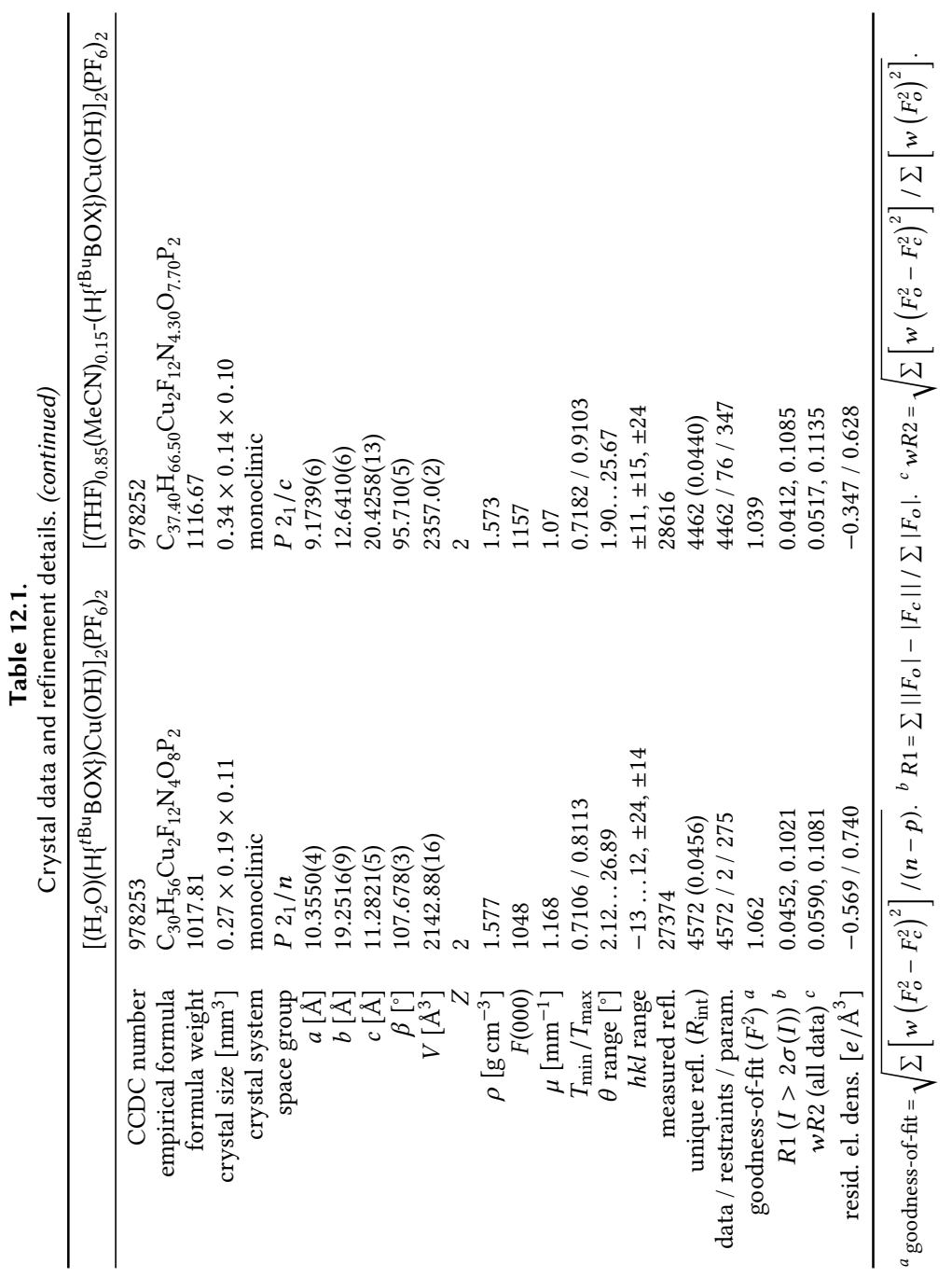




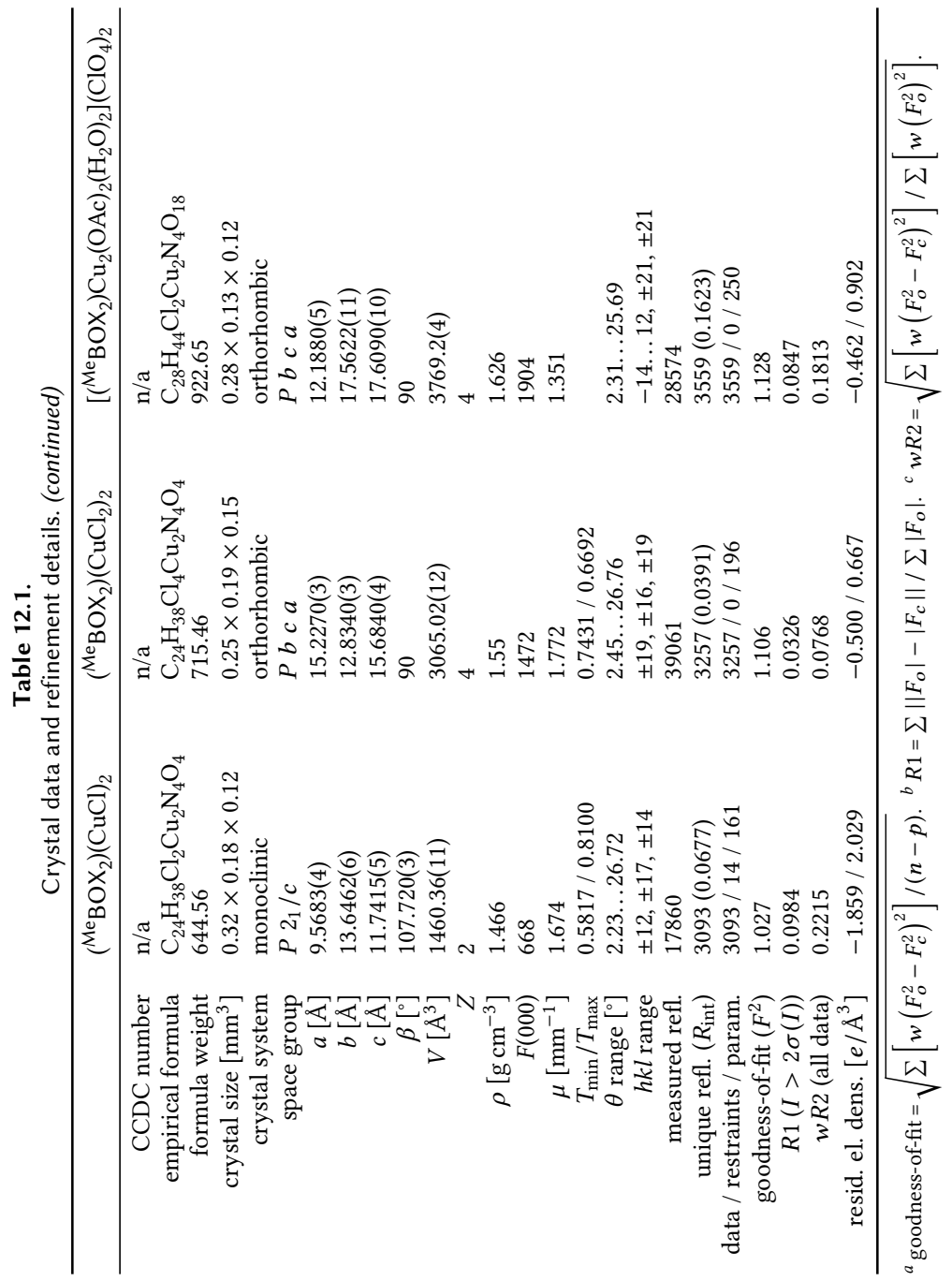




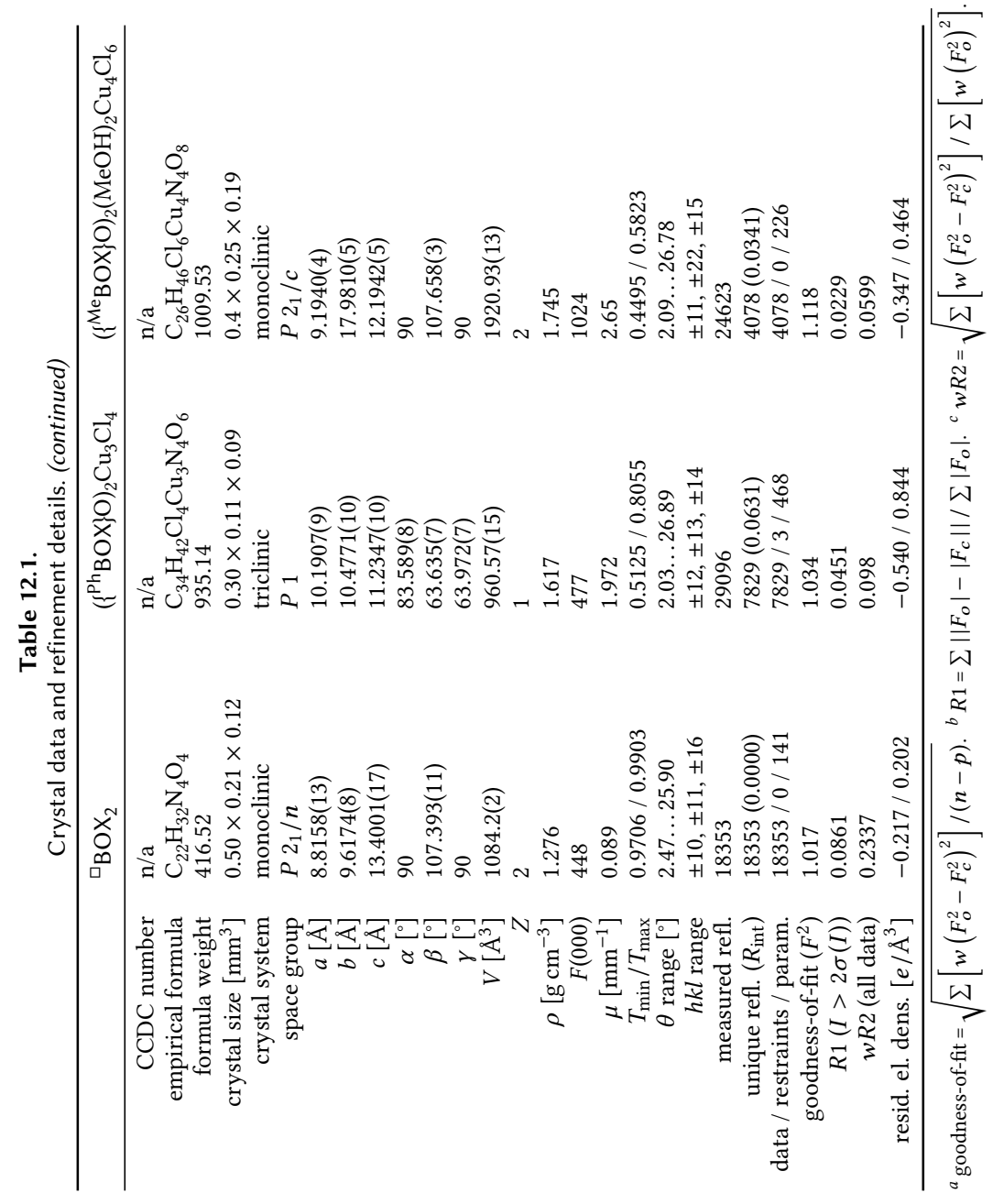





\section{Bibliography}

Pages in brackets refer back to the main text.

1. R. H. Holm, P. Kennepohl, E. I. Solomon, Chem. Rev. 1996, 96, 2239-2314 [pp. 4, 121].

2. E. I. Solomon, D. E. Heppner, E. M. Johnston, J. W. Ginsbach, J. Cirera, M. Qayyum, M. T. Kieber-Emmons, C. H. Kjaergaard, R. G. Hadt, L. Tian, Chem. Rev. 2014, 114, 3659-3853 [pp. 4, 8-11, 127, 150].

3. D. W. Randall, D. R. Gamelin, L. B. LaCroix, E. I. Solomon, J. Biol. Inorg. Chem. 2000, 5, 16-29 [p. 4].

4. E. I. Solomon, R. K. Szilagyi, S. DeBeer George, L. Basumallick, Chem. Rev. 2004, 104, 419-458 [pp. 4, 156].

5. E. I. Solomon, J. W. Ginsbach, D. E. Heppner, M. T. Kieber-Emmons, C. H. Kjaergaard, P. J. Smeets, L. Tian, J. S. Woertink, Faraday Discuss. 2011, 148, 11-39 [pp. 4, 20, 21].

6. B. Hazes, K. A. Magnus, C. Bonaventura, J. Bonaventura, Z. Dauter, K. H. Kalk, W. G. Hol, Prot. Sci. 1993, 2, 597-619 [pp. 5, 6].

7. K. A. Magnus, B. Hazes, H. Ton-That, C. Bonaventura, J. Bonaventura, W. G. Hol, Proteins 1994, 19, 302-309 [pp. 5, 6, 19, 155].

8. K. E. van Holde, K. I. Miller, H. Decker, f. Biol. Chem. 2001, 276, 15563-15566 [p. 5].

9. L. Waxman, f. Biol. Chem. 1975, 250, 3796-3806 [p. 5].

10. H. Decker, »Copper Proteins with Dinuclear Active Sites « in Encyclopedia of Inorganic Chemistry, (Eds.: R. B. King, R. H. Crabtree, C. M. Lukehart, D. A. Atwood, R. A. Scott), John Wiley \& Sons, Chichester, 2006 [p. 5]. 
13. Bibliography

11. S. Hagner-Holler, A. Schoen, W. Erker, J. H. Marden, R. Rupprecht, H. Decker, T. Burmester, Proc. Nat. Acad. Sci. USA 2004, 101, 871-874 [p. 5].

12. K. A. Magnus, H. Ton-That, J. E. Carpenter, Chem. Rev. 1994, 94, 727-735 [p. 5].

13. M. E. Cuff, K. I. Miller, K. E. van Holde, W. A. Hendrickson, J. Mol. Biol. 1998, 278, 855-870 [p. 5].

14. F. C. Bernstein, T. F. Koetzle, G. J. Williams, E. F. Meyer, M. D. Brice, J. R. Rodgers, O. Kennard, T. Shimanouchi, M. Tasumi, f. Mol. Biol. 1977, 112, 535-542 [p. 5].

15. G. B. Jameson, J. A. Ibers, »Dioxygen Carriers« in Biological Inorganic Chemistry: Structure and Reactivity, (Eds.: I. Bertini, H. B. Gray, E. I. Stiefel, J. S. Valentine), University Science Books, Sausalito, 2007, pp. 354-387 [pp. 7, 138].

16. N. Kitajima, K. Fujisawa, C. Fujimoto, Y. Moro-oka, S. Hashimoto, T. Kitagawa, K. Toriumi, K. Tatsumi, A. Nakamura, f. Am. Chem. Soc. 1992, 114, 1277-1291 [pp. 7, 15, 18, 19, 142, 155].

17. E. I. Solomon, U. M. Sundaram, T. E. Machonkin, Chem. Rev. 1996, 96, 25632606 [pp. 7, 9, 155].

18. Y. Matoba, T. Kumagai, A. Yamamoto, H. Yoshitsu, M. Sugiyama, f. Biol. Chem. 2006, 281, 8981-8990 [pp. 8, 155].

19. H. Decker, T. Schweikardt, F. Tuczek, Angew. Chem. Int. Ed. 2006, 45, 45464550 [pp. 8, 10,11].

20. W. Kaim, J. Rall, Angew. Chem. Int. Ed. 1996, 35, 43-60 [pp. 8, 9].

21. W. Kaim, B. Schwederski, Bioanorganische Chemie, 4th ed., Vieweg + Teubner, 2005 [pp. 8, 9].

22. L. Que, Jr., »Dioxygen Activating Enzymes « in Biological Inorganic Chemistry: Structure and Reactivity, (Eds.: I. Bertini, H. B. Gray, E. I. Stiefel, J. S. Valentine), University Science Books, Sausalito, 2007, pp. 388-413 [p. 9].

23. H. Decker, F. Tuczek, TIBS 2000, 25, 392-397 [p. 9].

24. W. B. Tolman, Inorg. Chem. 2013, 52, 7307-7310 [p. 13].

25. Concepts and Models in Bioinorganic Chemistry, 1st ed., (Eds.: H.-B. Kraatz, N. Metzler-Nolte), WILEY-VCH Verlag, Weinheim, 2006 [p. 13].

26. N. Kitajima, Y. Moro-oka, Chem. Rev. 1994, 94, 737-757 [p. 13]. 
27. J. Shearer, K. D. Karlin, »Copper: Hemocyanin/Tyrosinase Models « in Encyclopedia of Inorganic Chemistry, (Eds.: R. B. King, R. H. Crabtree, C. M. Lukehart, D. A. Atwood, R. A. Scott), John Wiley \& Sons, Chichester, 2006 [p. 13].

28. Y. Lee, K. D. Karlin, »Model Complexes for Copper-Containing Enzymes « in Concepts and Models in Bioinorganic Chemistry, (Eds.: H.-B. Kraatz, N. Metzler-Nolte), WILEY-VCH, Weinheim, 2006, pp. 363-396 [pp. 13, 15].

29. R. R. Conry, »Copper: Inorganic \& Coordination Chemistry « in Encyclopedia of Inorganic Chemistry, (Eds.: R. B. King, R. H. Crabtree, C. M. Lukehart, D. A. Atwood, R. A. Scott), John Wiley \& Sons, Chichester, 2006 [p. 13].

30. C. Krebs, T. Glaser, E. Bill, T. Weyhermüller, W. Meyer-Klaucke, K. Wieghardt, Angew. Chem. Int. Ed. 1999, 38, 359-361 [p. 14].

31. R. Santo, R. Miyamoto, R. Tanaka, T. Nishioka, K. Sato, K. Toyota, M. Obata, S. Yano, I. Kinoshita, A. Ichimura, T. Takui, Angew. Chem. Int. Ed. 2006, 45, 7611-7614 [p. 14].

32. A. Casitas, X. Ribas, Chem. Sci. 2013, 4, 2301-2318 [p. 14].

33. J. Reedijk, Science 2005, 308, 1876-1877 [pp. 14, 28].

34. L. M. Mirica, X. Ottenwaelder, T. D. P. Stack, Chem. Rev. 2004, 104, 10131045 [pp. 14-17, 19-22, 25, 112, 123, 140, 143, 148, 153, 158, 168, 179, 183, 184, 186].

35. M. Weitzer, S. Schindler, G. Brehm, S. Schneider, E. Hörmann, B. Jung, S. Kaderli, A. D. Zuberbühler, Inorg. Chem. 2003, 42, 1800-1806 [p. 14].

36. C. X. Zhang, S. Kaderli, M. Costas, E.-I. Kim, Y.-M. Neuhold, K. D. Karlin, A. D. Zuberbühler, Inorg. Chem. 2003, 42, 1807-1824 [p. 14].

37. H. Börzel, P. Comba, K. S. Hagen, M. Kerscher, H. Pritzkow, M. Schatz, S. Schindler, O. Walter, Inorg. Chem. 2002, 41, 5440-5452 [p. 14].

38. K. Fujisawa, M. Tanaka, Y. Moro-oka, N. Kitajima, f. Am. Chem. Soc. 1994, 116, 12079-12080 [p. 14].

39. P. Chen, D. E. Root, C. Campochiaro, K. Fujisawa, E. I. Solomon, J. Am. Chem. Soc. 2003, 125, 466-474 [p. 14].

40. D. J. E. Spencer, N. W. Aboelella, A. M. Reynolds, P. L. Holland, W. B. Tolman, f. Am. Chem. Soc. 2002, 124, 2108-2109 [p. 14].

41. N. W. Aboelella, E. A. Lewis, A. M. Reynolds, W. W. Brennessel, C. J. Cramer, W. B. Tolman, F. Am. Chem. Soc. 2002, 124, 10660-10661 [p. 14]. 
42. C. J. Cramer, W. B. Tolman, K. H. Theopold, A. L. Rheingold, Proc. Nat. Acad. Sci. USA 2003, 100, 3635-3640 [p. 14].

43. R. R. Jacobson, Z. Tyeklar, A. Farooq, K. D. Karlin, S. Liu, J. Zubieta, J. Am. Chem. Soc. 1988, 110, 3690-3692 [pp. 14, 17, 18].

44. K. E. Dalle, T. Gruene, S. Dechert, S. Demeshko, F. Meyer, f. Am. Chem. Soc. 2014, 136, 7428-7434 [pp. 14, 17, 19, 20, 143, 165].

45. N. Kitajima, K. Fujisawa, Y. Moro-oka, K. Toriumi, f. Am. Chem. Soc. 1989, 111, 8975-8976 [pp. 15, 18, 19, 155].

46. J. A. Halfen, S. Mahapatra, E. C. Wilkinson, S. Kaderli, V. G. Young, L. Que, A. D. Zuberbühler, W. B. Tolman, Science 1996, 271, 1397-1400 [pp. 15, 18, 19, 22, 128].

47. S. Mahapatra, J. Halfen, E. Wilkinson, G. Pan, X. Wang, V. Young, Jr., C. Cramer, L. Que, Jr., W. B. Tolman, J. Am. Chem. Soc. 1996, 118, 11555-11574 [pp. 15, 18, 19]

48. J. L. DuBois, P. Mukherjee, A. M. Collier, J. M. Mayer, E. I. Solomon, B. Hedman, T. D. P. Stack, K. O. Hodgson, J. Am. Chem. Soc. 1997, 119, 85788579 [pp. 15, 149, 150].

49. A. P. Cole, D. E. Root, P. Mukherjee, E. I. Solomon, T. D. P. Stack, Science 1996, 273, 1848-1850 [p. 15].

50. J. Reim, B. Krebs, Angew. Chem. Int. Ed. 1994, 33, 1969-1971 [p. 15].

51. J. Reim, R. Werner, W. Haase, B. Krebs, Chem. Eur. f. 1998, 4, 289-298 [p. 15].

52. F. Meyer, H. Pritzkow, Angew. Chem. Int. Ed. 2000, 39, 2112-2115 [p. 15].

53. P. L. Holland, Dalton Trans. 2010, 39, 5415-5425 [p. 16].

54. W. H. Fletcher, J. S. Rayside, f. Raman Spectrosc. 1974, 2, 3-14 [p. 16].

55. D. Nelson, M. Zahniser, J. Mol. Spec. 1991, 150, 527-534 [p. 16].

56. P. A. Giguère, f. Chem. Phys. 1950, 18, 88-92 [p. 16].

57. L. Que, W. B. Tolman, Angew. Chem. Int. Ed. 2002, 41, 1114-1137 [pp. 16, 22, 186, 187].

58. S. Schindler, Eur. J. Inorg. Chem. 2000, 2311-2326 [pp. 17, 127, 128, 131].

59. D. Maiti, J. S. Woertink, A. A. N. Sarjeant, E. I. Solomon, K. D. Karlin, Inorg. Chem. 2008, 47, 3787-3800 [pp. 17, 186]. 
60. E. A. Lewis, W. B. Tolman, Chem. Rev. 2004, 104, 1047-1076 [pp. 19, 24, 25, 127, 128, 137, 138, 172].

61. M. J. Baldwin, P. K. Ross, J. E. Pate, Z. Tyeklár, K. D. Karlin, E. I. Solomon, J. Am. Chem. Soc. 1991, 113, 8671-8679 [p. 20].

62. E. I. Solomon, F. Tuczek, D. E. Root, C. A. Brown, Chem. Rev. 1994, 94, 827856 [p. 20].

63. E. I. Solomon, P. Chen, M. Metz, S.-K. Lee, A. E. Palmer, Angew. Chem. Int. Ed. 2001, 40, 4570-4590 [p. 20].

64. P. K. Ross, E. I. Solomon, J. Am. Chem. Soc. 1990, 112, 5871-5872 [p. 20].

65. P. K. Ross, E. I. Solomon, J. Am. Chem. Soc. 1991, 113, 3246-3259 [p. 20].

66. M. J. Henson, P. Mukherjee, D. E. Root, T. D. P. Stack, E. I. Solomon, f. Am. Chem. Soc. 1999, 121, 10332-10345 [pp. 21, 22, 186].

67. S. Mahapatra, S. Kaderli, A. Llobet, Y.-M. Neuhold, T. Palanché, J. A. Halfen, V. G. Young, T. A. Kaden, L. Que, Jr., A. D. Zuberbühler, W. B. Tolman, Inorg. Chem. 1997, 36, 6343-6356 [pp. 22, 128].

68. L. M. Berreau, S. Mahapatra, J. A. Halfen, R. P. Houser, V. G. Young, Jr., W. B. Tolman, Angew. Chem. Int. Ed. 1999, 38, 207-210 [p. 22].

69. H. V. Obias, Y. Lin, N. N. Murthy, E. Pidcock, E. I. Solomon, M. Ralle, N. J. Blackburn, Y.-M. Neuhold, A. D. Zuberbühler, K. D. Karlin, f. Am. Chem. Soc. 1998, 120, 12960-12961 [pp. 22, 155].

70. H.-C. Liang, M. J. Henson, L. Q. Hatcher, M. A. Vance, C. X. Zhang, D. Lahti, S. Kaderli, R. D. Sommer, A. L. Rheingold, A. D. Zuberbühler, E. I. Solomon, K. D. Karlin, Inorg. Chem. 2004, 43, 4115-4117 [pp. 22, 166].

71. J. S. Lindsey, New f. Chem 1991, 15, 153-180 [p. 23].

72. D. Philp, J. F. Stoddart, Angew. Chem. Int. Ed. 1996, 35, 1154-1196 [p. 23].

73. G. M. Whitesides, B. Grzybowski, Science 2002, 295, 2418-2421 [p. 23].

74. C. Citek, C. T. Lyons, E. C. Wasinger, T. D. P. Stack, Nat. Chem. 2012, 4, 317-322 [pp. 23, 24, 26, 112, 124, 155, 158].

75. J. Meyer, f. Biol. Inorg. Chem. 2008, 13, 157-170 [p. 24].

76. T. Herskovitz, B. A. Averill, R. H. Holm, J. A. Ibers, W. D. Phillips, J. F. Weiher, Proc. Nat. Acad. Sci. USA 1972, 69, 2437-2441 [p. 24].

77. P. Venkateswara Rao, R. H. Holm, Chem. Rev. 2004, 104, 527-559 [р. 24]. 
78. M. Weitzer, M. Schatz, F. Hampel, F. W. Heinemann, S. Schindler, f. Chem. Soc. Dalton Trans. 2002, 686-694 [pp. 24, 131].

79. T. V. Hansen, L. Skattebøl, Tetrahedron Lett. 2005, 46, 3357-3358 [pp. 25, 26].

80. D. Magdziak, A. A. Rodriguez, R. W. Van De Water, T. R. R. Pettus, Org. Lett. 2002, 4, 285-288 [p. 25].

81. P. Gamez, P. G. Aubel, W. L. Driessen, J. Reedijk, Chem. Soc. Rev. 2001, 30, 376-385 [p. 25].

82. J. I. van der Vlugt, F. Meyer, Top. Organomet. Chem. 2007, 22, 191-240 [p. 25].

83. T. Punniyamurthy, L. Rout, Coord. Chem. Rev. 2008, 252, 134-154 [p. 25].

84. M. Rolff, J. Schottenheim, F. Tuczek, f. Coord. Chem. 2010, 63, 2382-2399 [p. 25].

85. A. E. Wendlandt, A. M. Suess, S. S. Stahl, Angew. Chem. Int. Ed. 2011, 50, 11062-11087 [p. 25].

86. E. Roduner, W. Kaim, B. Sarkar, V. B. Urlacher, J. Pleiss, R. Gläser, W.-D. Einicke, G. A. Sprenger, U. Beifuß, E. Klemm, C. Liebner, H. Hieronymus, S.-F. Hsu, B. Plietker, S. Laschat, ChemCatChem 2012, 5, 82-112 [p. 25].

87. K. D. Karlin, J. C. Hayes, Y. Gultneh, R. W. Cruse, J. W. McKown, J. P. Hutchinson, J. Zubieta, f. Am. Chem. Soc. 1984, 106, 2121-2128 [p. 25].

88. R. W. Cruse, S. Kaderli, K. D. Karlin, A. D. Zuberbühler, J. Am. Chem. Soc. 1988, 110, 6882-6883 [p. 25].

89. M. S. Nasir, B. I. Cohen, K. D. Karlin, f. Am. Chem. Soc. 1992, 114, 2482-2494 [p. 25].

90. K. D. Karlin, M. S. Nasir, B. I. Cohen, R. W. Cruse, S. Kaderli, A. D. Zuberbühler, J. Am. Chem. Soc. 1994, 116, 1324-1336 [p. 25].

91. M. Becker, S. Schindler, K. D. Karlin, T. A. Kaden, S. Kaderli, T. Palanché, A. D. Zuberbühler, Inorg. Chem. 1999, 38, 1989-1995 [p. 25].

92. E. Pidcock, H. V. Obias, C. X. Zhang, K. D. Karlin, E. I. Solomon, f. Am. Chem. Soc. 1998, 120, 7841-7847 [pp. 25, 26].

93. S. Itoh, M. Ogino, S. Haranou, T. Terasaka, T. Ando, M. Komatsu, Y. Ohshiro, S. Fukuzumi, K. Kano, J. Am. Chem. Soc. 1995, 117, 1485-1493 [p. 26].

94. B. Gigante, C. Santos, A. Silva, M. Curto, M. Nascimento, E. Pinto, M. Pedro, F. Cerqueira, M. Pinto, M. Duarte, A. Laires, J. Rueff, J. Gonçalves, M. Pegado, M. Valdeira, Bioorg. Med. Chem. 2003, 11, 1631-1638 [p. 26]. 
95. A. Pezzella, L. Lista, A. Napolitano, M. D’Ischia, Tetrahedron Lett. 2005, 46, 3541-3544 [p. 26].

96. C. Huang, N. Ghavtadze, B. Chattopadhyay, V. Gevorgyan, f. Am. Chem. Soc. 2011, 133, 17630-17633 [p. 26].

97. L. Santagostini, M. Gullotti, E. Monzani, L. Casella, R. Dillinger, F. Tuczek, Chem. Eur. F. 2000, 6, 519-522 [p. 26].

98. S. Itoh, H. Kumei, M. Taki, S. Nagatomo, T. Kitagawa, S. Fukuzumi, J. Am. Chem. Soc. 2001, 123, 6708-6709 [p. 26].

99. L. M. Mirica, M. Vance, D. J. Rudd, B. Hedman, K. O. Hodgson, E. I. Solomon, T. D. P. Stack, J. Am. Chem. Soc. 2002, 124, $9332-9333$ [pp. 26, 28, 124, 155].

100. S. Palavicini, A. Granata, E. Monzani, L. Casella, f. Am. Chem. Soc. 2005, 127, 18031-18036 [p. 26].

101. L. Casella, M. Gullotti, R. Radaelli, P. D. Gennaro, J. Chem. Soc. Chem. Commun. 1991, 1611-1612 [p. 26].

102. M. Réglier, C. Jorand, B. Waegell, f. Chem. Soc. Chem. Commun. 1990, 17521755 [p. 26].

103. M. Rolff, J. Schottenheim, G. Peters, F. Tuczek, Angew. Chem. Int. Ed. 2010, 49, 6438-6442 [p. 27].

104. J. Schottenheim, N. Fateeva, W. Thimm, J. Krahmer, F. Tuczek, Z. Anorg. Allg. Chem. 2013, 639, 1491-1497 [p. 27].

105. J. N. Hamann, F. Tuczek, Chem. Commun. 2014, 50, 2298-2300 [p. 27].

106. A. Hoffmann, C. Citek, S. Binder, A. Goos, M. Rübhausen, O. Troeppner, I. Ivanović-Burmazović, E. C. Wasinger, T. D. P. Stack, S. Herres-Pawlis, Angew. Chem. Int. Ed. 2013, 52, 5398-5401 [pp. 27, 155, 158].

107. A. Hoffmann, U. Flörke, M. Schürmann, S. Herres-Pawlis, Eur. f. Org. Chem. 2010, 2010, 4136-4144 [p. 27].

108. L. M. Mirica, D. J. Rudd, M. A. Vance, E. I. Solomon, K. O. Hodgson, B. Hedman, T. D. P. Stack, J. Am. Chem. Soc. 2006, 128, 2654-2665 [pp. 28, 124, 140, 155].

109. L. M. Mirica, M. Vance, D. J. Rudd, B. Hedman, K. O. Hodgson, E. I. Solomon, T. D. P. Stack, Science 2005, 308, 1890-1892 [pp. 28, 29, 112, 124].

110. B. T. Op't Holt, M. a. Vance, L. M. Mirica, D. E. Heppner, T. D. P. Stack, E. I. Solomon, f. Am. Chem. Soc. 2009, 131, 6421-6438 [pp. 28, 29]. 
13. Bibliography

111. R. E. Lowenthal, A. Abiko, S. Masamune, Tetrahedron 1990, 6005-6008 [pp. 37, 70].

112. D. A. Evans, K. A. Woerpel, M. M. Hinman, M. M. Faul, J. Am. Chem. Soc. 1991, 113, 726-728 [p. 37].

113. E. J. Corey, N. Imai, H.-Y. Zhang, J. Am. Chem. Soc. 1991, 113, 728-729 [p. 37].

114. D. Müller, G. Umbricht, B. Weber, A. Pfaltz, Helv. Chim. Acta 1991, 74, 232240 [p. 37].

115. J. Hall, J.-M. Lehn, A. DeCian, J. Fischer, Helv. Chim. Acta 1991, 74, 1-6 [p. 37].

116. A. K. Ghosh, P. Mathivanan, J. Cappiello, Tetrahedron: Asymmetry 1998, 9, 1-45 [p. 37].

117. M. Gómez, G. Muller, M. Rocamora, Coord. Chem. Rev. 1999, 193-195, 769835 [pp. 37, 48].

118. K. A. Jørgensen, M. Johannsen, S. Yao, H. Audrain, J. Thorhauge, Acc. Chem. Res. 1999, 32, 605-613 [p. 37].

119. J. S. Johnson, D. A. Evans, Acc. Chem. Res. 2000, 33, 325-335 [pp. 37, 85].

120. H. A. McManus, P. J. Guiry, Chem. Rev. 2004, 104, 4151-4202 [pp. 37, 38, 207].

121. G. Desimoni, G. Faita, K. A. Jørgensen, Chem. Rev. 2011, 111, PR284-PR437 [p. 37].

122. R. Rasappan, D. Laventine, O. Reiser, Coord. Chem. Rev. 2008, 252, 702-714 [pp. 37, 85, 86].

123. S. Dagorne, S. Bellemin-Laponnaz, A. Maisse-François, Eur. J. Inorg. Chem. 2007, 913-925 [pp. 37, 66].

124. S. Dagorne, S. Bellemin-Laponnaz, R. Welter, Organometallics 2004, 23, 3053-3061 [pp. 38, 207, 209].

125. S. E. Denmark, C. M. Stiff, J. Org. Chem. 2000, 65, 5875-5878 [pp. 38, 207, 212].

126. G. K. Jnaneshwara, V. H. Deshpande, M. Lalithambika, T. Ravindranathan, A. Bedekar, Tetrahedron Lett. 1998, 39, 459-462 [pp. 38, 208].

127. E. Eliel, R. Hutchins, M. Knoeber, Org. Synth. 1988, Coll. Vol. 442 [pp. 39, 212].

128. J. Munch-Petersen, f. Org. Chem. 1957, 22, 170-176 [р. 39].

129. C. Holmberg, Liebigs Ann. Chem. 1981, 748-760 [pp. 40, 212].

130. H. Werner, R. Vicha, A. Gissibl, O. Reiser, f. Org. Chem. 2003, 68, 1016610168 [p. 46]. 
131. H. Fritschi, U. Leutenegger, K. Siegmann, A. Pfaltz, W. Keller, C. Kratky, Helv. Chim. Acta 1988, 71, 1541-1552 [p. 46].

132. U. Leutenegger, G. Umbricht, C. Fahrni, P. von Matt, A. Pfaltz, Tetrahedron 1992, 48, 2143-2156 [p. 46].

133. B. Kovač, L. Klasinc, Z. Raza, V. Šunjić, f. Chem. Soc. Perkin Trans. II 1999, 3, 2455-2459 [p. 46].

134. S. Milione, V. Bertolasi, Tetrahedron Lett. 2011, 52, 3570-3574 [pp. 46, 55, 59, 60, 62, 65].

135. H. Arii, F. Nakadate, K. Mochida, Organometallics 2011, 30, 4471-4474 [p. 46].

136. J.-P. Qu, Y. Liang, H. Xu, X.-L. Sun, Z.-X. Yu, Y. Tang, Chem. Eur. F. 2012, 18, 2196-2201 [p. 46].

137. D. Akalay, G. Dürner, J. W. Bats, M. Bolte, M. W. Göbel, f. Org. Chem. 2007, 72, 5618-5624 [p. 47].

138. A. E. Sheshenev, E. V. Boltukhina, A. A. Grishina, I. Cisařova, I. M. Lyapkalo, K. K. Hii, Chem. Eur. J. 2013, 19, 8136-8143 [p. 47].

139. F. Allen, O. Kennard, D. Watson, L. Brammer, A. Orpen, R. Taylor, f. Chem. Soc. Perkin Trans. II 1987, S1-S19 [pp. 48, 74].

140. G. Gilli, F. Bellucci, V. Ferretti, V. Bertolasi, J. Am. Chem. Soc. 1989, 111, 1023-1028 [p. 48].

141. I. Alkorta, P. Goya, J. Elguero, S. Singh, Natl. Acad. Sci. Lett. 2007, 30, 139159 [p. 48].

142. O. Klein, F. Aguilar-Parrilla, J. M. Lopez, N. Jagerovic, H.-H. Limbach, f. Am. Chem. Soc. 2004, 126, 11718-11732 [p. 48].

143. A. J. Vila, C. M. Lagier, A. C. Olivieri, J. Chem. Soc. Perkin Trans. II 1990, 1615-1618 [p. 48].

144. A. J. Vila, C. M. Lagier, A. C. Olivieri, f. Mol. Struct. 1992, 274, 215-222 [p. 48].

145. R. M. Cravero, M. González-Sierra, C. Fernández, A. C. Olivieri, f. Chem. Soc. Chem. Commun. 1993, 1253 [p. 48].

146. F. H. Allen, Acta Cryst. B 2002, 58, 380-388 [p. 50].

147. M. Jiang, S. Dalgarno, C. A. Kilner, M. A. Halcrow, T. P. Kee, Polyhedron 2001, 20, 2151-2162 [p. 50]. 
148. R. M. Claramunt, C. López, M. D. Santa Maria, D. Sanz, J. Elguero, Prog. Nucl. Mag. Res. Sp. 2006, 49, 169-206 [p. 50].

149. S. Berger, S. Braun, H.-O. Kalinowski, NMR Spectroscopy of the Non-Metallic Elements, John Wiley \& Sons, New York, 1996 [p. 52].

150. S. F. Tayyari, F. Milani-nejad, Spectrochim. Acta A: Mol. Biomol. Spectrosc. 2000, 56, 2679-2691 [p. 52].

151. J. N. Spencer, E. S. Holmboe, M. B. Kirshenbaum, D. B. Firth, P. B. Pinto, Can. F. Chem. 1982, 60, 1178-1182 [p. 55].

152. M. M. Folkendt, B. E. Weiss-Lopez, J. P. Chauvel, N. S. True, f. Phys. Chem. 1985, 89, 3347-3352 [p. 55].

153. K. Connors, Chemical Kinetics: The Study of Reaction Rates in Solution, VCH Publishers, New York, Weinheim, Cambridge, 1990 [pp. 55, 56, 59, 134, 233].

154. IUPAC. Compendium of Chemical Terminology ("Gold Book"), 2nd ed., (Eds.: A. D. McNaught, A. Wilkinson), Blackwell Scientific Publications, Oxford, 1997, online corrected version: DOI 10.1351/goldbook [p. 60].

155. J. Elguero, A. Katritzky, O. Denisko, Adv. Heterocycl. Chem. 2000, 76, 1-84 [pp. 60, 64].

156. F. Neese, WIREs Comput. Mol. Sci. 2012, 2, 73-78 [pp. 61, 237].

157. A. D. Becke, f. Chem. Phys. 1993, 98, 5648-5652 [pp. 61, 156, 186, 237].

158. C. Lee, W. Yang, R. G. Parr, Phys. Rev. B 1988, 37, 785-789 [pp. 61, 156, 186, 237].

159. F. Weigend, R. Ahlrichs, Phys. Chem. Chem. Phys. 2005, 7, 3297-3305 [pp. 61, 156, 186, 237-239].

160. A. Schäfer, C. Huber, R. Ahlrichs, f. Chem. Phys. 1994, 100, 5829-5835 [pp. 61, $156,186,237,238]$.

161. S. Yamabe, N. Tsuchida, K. Miyajima, f. Phys. Chem. A 2004, 108, 2750-2757 [p. 65].

162. N. C. Søndergaard, P. E. Sørensen, J. Ulstrup, Acta Chem. Scand. 1975, 29a, 709-712 [p. 65].

163. H. Watarai, N. Suzuki, f. Inorg. Nucl. Chem. 1974, 36, 1815-1820 [p. 65].

164. F. Ullmann, Chem. Ber. 1904, 37, 853-854 [p. 67].

165. J. Hassan, M. Sévignon, C. Gozzi, E. Schulz, M. Lemaire, Chem. Rev. 2002, 102, 1359-1470 [p. 67]. 
166. I. P. Beletskaya, A. V. Cheprakov, Coord. Chem. Rev. 2004, 248, 2337-2364 [p. 67].

167. B. Jacques, C. Dro, S. Bellemin-Laponnaz, H. Wadepohl, L. H. Gade, Angew. Chem. Int. Ed. 2008, 47, 4546-4550 [pp. 68, 69].

168. V. Čaplar, Z. Raza, M. Roje, V. Tomišić, G. Horvat, J. Požar, I. Piantanida, M. Žinić, Tetrahedron 2004, 60, 8079-8087 [p. 68].

169. S. Yokota, Y. Tachi, S. Itoh, Inorg. Chem. 2002, 41, 1342-1344 [pp. 68, 69, 173].

170. M. S. Hill, R. Pongtavornpinyo, P. B. Hitchcock, Chem. Commun. 2006, 37203722 [pp. 68, 69].

171. M. L. Scheuermann, U. Fekl, W. Kaminsky, K. I. Goldberg, Organometallics 2010, 29, 4749-4751 [pp. 68, 69].

172. G. B. Nikiforov, H. W. Roesky, P. G. Jones, R. B. Oswald, M. Noltemeyer, Dalton Trans. 2007, 2, 4149-4159 [pp. 68, 69].

173. J. Zhang, Z. Zhang, Z. Chen, X. Zhou, Dalton Trans. 2012, 41, 357-359 [pp. 68, 69].

174. C. A. Sprecher, A. D. Zuberbühler, Angew. Chem. Int. Ed. 1977, 16, 189-189 [pp. 69, 70].

175. D. L. Allara, f. Org. Chem. 1972, 37, 2448-2455 [pp. 69, 70].

176. M. M. Khusniyarov, E. Bill, T. Weyhermüller, E. Bothe, K. Wieghardt, Angew. Chem. Int. Ed. 2011, 123, 1690-1693 [p. 68].

177. K. G. Caulton, Eur. F. Inorg. Chem. 2012, 435-443 [p. 68].

178. C. E. Radzewich, M. P. Coles, R. F. Jordan, J. Am. Chem. Soc. 1998, 120, 9384-9385 [p. 68].

179. D. T. Carey, E. K. Cope-Eatough, E. Vilaplana-Mafé, F. S. Mair, R. G. Pritchard, J. E. Warren, R. J. Woods, Dalton Trans. 2003, 1083-1093 [p. 68].

180. F. Basuli, J. C. Huffman, D. J. Mindiola, Inorg. Chem. 2003, 42, 8003-8010 [p. 68].

181. E. A. Gregory, R. J. Lachicotte, P. L. Holland, Organometallics 2005, 24, 18031805 [p. 68].

182. A. D. Phillips, R. Scopelliti, P. J. Dyson, Organometallics 2007, 26, 1120-1122 [p. 68].

183. S. Yao, C. van Wüllen, M. Driess, Chem. Commun. 2008, 5393-5395 [p. 68]. 
184. N. M. West, P. S. White, J. L. Templeton, J. F. Nixon, Organometallics 2009, 28, 1425-1434 [p. 68].

185. S. E. Allen, R. R. Walvoord, R. Padilla-Salinas, M. C. Kozlowski, Chem. Rev. 2013, 113, 6234-6458 [p. 70].

186. F. L. Urbach, U. Knopp, A. D. Zuberbühler, Helv. Chim. Acta 1978, 61, 10971106 [p. 70].

187. G. Guillot, E. Mulliez, P. Leduc, J. C. Chottard, Inorg. Chem. 1990, 29, 577-579 [p. 70].

188. Bio-Rad Laboratories, Instruction Manual »Chelex ${ }^{\circledR} 100$ and Chelex 20 Chelating Ion Exchange Resin« [p. 78].

189. J. H. Day, Chem. Rev. 1968, 68, 649-657 [p. 81].

190. R. D. Willett, J. A. Haugen, J. Lebsack, J. Morrey, Inorg. Chem. 1974, 13, 2510-2513 [p. 81].

191. R. D. Willett, f. Chem. Edu. 1983, 60, 355-355 [р. 81].

192. R. L. Harlow, W. J. Wells, G. W. Watt, S. H. Simonsen, Inorg. Chem. 1974, 13, 2106-2111 [p. 81].

193. D. R. Bloomquist, R. D. Willett, H. W. Dodgen, J. Am. Chem. Soc. 1981, 103, 2610-2615 [p. 81].

194. S. Choi, J. A. Lamabee, J. Chem. Edu. 1989, 66, 774-776 [p. 85].

195. S. C. Bart, E. J. Hawrelak, A. K. Schmisseur, E. Lobkovsky, P. J. Chirik, Organometallics 2004, 23, 237-246 [pp. 85, 86].

196. D. A. Evans, C. W. Downey, J. L. Hubbs, J. Am. Chem. Soc. 2003, 125, 87068707 [pp. 85, 86].

197. J. Thorhauge, M. Roberson, R. G. Hazell, K. A. Jørgensen, Chem. Eur. J. 2002, 8, 1888-1898 [pp. 85, 86].

198. D. A. Evans, G. S. Peterson, J. S. Johnson, D. M. Barnes, K. R. Campos, K. A. Woerpel, f. Org. Chem. 1998, 63, 4541-4544 [p. 86].

199. D. A. Evans, T. Rovis, J. S. Johnson, Pure Appl. Chem. 1999, 71, 1407 [p. 86].

200. D. A. Evans, S. J. Miller, T. Lectka, P. von Matt, J. Am. Chem. Soc. 1999, 121, 7559-7573 [p. 86].

201. R. Rasappan, M. Hager, A. Gissibl, O. Reiser, Org. Lett. 2006, 8, 6099-6102 [p. 86]. 
202. L. de Vries, f. Am. Chem. Soc. 1978, 100, 926-933 [pp. 98, 99].

203. H. G. Viehe, Z. Janousek, R. Merenyi, L. Stella, Acc. Chem. Res. 1985, 18, 148-154 [pp. 98, 99].

204. N. Obata, K. Nimura, J. Chem. Soc. Chem. Commun. 1977, 238-239 [pp. 98, 99].

205. G. A. Russell, G. Kaupp, f. Am. Chem. Soc. 1969, 91, 3851-3859 [pp. 98, 99].

206. U. Schmidt, J. Häusler, E. Ohler, H. Poisel, Fortschr. Chem. Org. Naturst. 1979, 37, 286 [pp. 98, 99].

207. X. Chen, X. Wang, Z. Zhou, Y. Li, Y. Sui, J. Ma, X. Wang, P. P. Power, Angew. Chem. Int. Ed. 2013, 52, 589-592 [pp. 99, 100].

208. H. G. Viehe, R. Merényi, L. Stella, Z. Janousek, Angew. Chem. Int. Ed. 1979, 18, 917-932 [p. 98].

209. C. J. Easton, Chem. Rev. 1997, 97, 53-82 [p. 98].

210. H. Naarmann, M. Beaujean, R. Merényi, H. G. Viehe, Polym. Bull. 1980, 2, 417-425 [p. 98].

211. H. Naarmann, M. Beaujean, R. Merényi, H. G. Viehe, Polym. Bull. 1980, 2, 363-372 [p. 98].

212. NIEHS National Institute of Enivronmental Health Sciences, Spin Trap Database, http://tools.niehs.nih.gov/stdb [p. 104].

213. E. Janzen, J. Liu, J. Magn. Reson. 1973, 9, 510-512 [p. 104].

214. G. M. Rosen, A. Beselman, P. Tsai, S. Pou, C. Mailer, K. Ichikawa, B. H. Robinson, R. Nielsen, H. J. Halpern, A. D. MacKerell, Jr., f. Org. Chem. 2004, 69, 1321-1330 [p. 104].

215. M. S. Blois, Nature 1958, 181, 1199-1200 [p. 105].

216. J. Xie, K. M. Schaich, F. Agric. Food Chem. 2014, DOI 10. 1021/j f500180u [p. 105].

217. K. Pyrzynska, A. Pękal, Anal. Methods 2013, 5, 4288-4295 [pp. 105, 106].

218. K. Mishra, H. Ojha, N. K. Chaudhury, Food Chem. 2012, 130, 1036-1043 [p. 105].

219. W. Brand-Williams, M. Cuvelier, C. Berset, Lebensm.-Wiss. u. Technol. 1995, 28, 25-30 [pp. 105, 107].

220. R. Diaz-Torres, S. Alvarez, Dalton Trans. 2011, 40, 10742-10750 [pp. 112, 140]. 
13. Bibliography

221. S. H. Strauss, Chem. Rev. 1993, 93, 927-942 [p. 112].

222. I. Krossing, I. Raabe, Angew. Chem. Int. Ed. 2004, 43, 2066-2090 [p. 112].

223. G. J. Kubas, B. Monzyk, A. L. Crumblis, Inorg. Synth. 1979, 19, 90-92 [pp. 112, 201].

224. Neil G. Connelly, William E. Geiger, Chem. Rev. 1996, 96, 887-910 [pp. 118, 204].

225. J. R. Aranzaes, M.-C. Daniel, D. Astruc, Can. F. Chem. 2006, 84, 288-299 [pp. 118, 204].

226. N. Wei, N. N. Murthy, Z. Tyeklar, K. D. Karlin, Inorg. Chem. 1994, 33, 11771183 [p. 118].

227. D. B. Rorabacher, Chem. Rev. 2004, 104, 651-97 [p. 119].

228. P. Zanello, Inorganic Electrochemistry: Theory, Practice and Application, The Royal Society of Chemistry, Cambridge, 2003 [p. 119].

229. M. J. Baldwin, D. E. Root, J. E. Pate, K. Fujisawa, N. Kitajima, E. I. Solomon, f. Am. Chem. Soc. 1992, 114, 10421-10431 [pp. 121, 142, 143, 155, 164].

230. T. D. P. Stack, Dalton Trans. 2003, 34, 1881-1889 [p. 123].

231. E. Niederhoffer, J. Timmons, A. Martell, Chem. Rev. 1984, 84, 137-203 [p. 127].

232. K. D. Karlin, S. Kaderli, A. D. Zuberbühler, Acc. Chem. Res. 1997, 30, 139-147 [pp. 127, 137, 139].

233. K. D. Karlin, W. B. Tolman, S. Kaderli, A. D. Zuberbühler, f. Mol. Catal. A: Chem. 1997, 117, 215-222 [p. 127].

234. S. Schindler, C. D. Hubbard, R. van Eldik, Chem. Soc. Rev. 1998, 27, 387-393 [p. 127].

235. E. V. Rybak-Akimova, »Mechanisms of Oxygen Binding and Activation at Transition Metal Centers « in Physical Inorganic Chemistry: Reactions, Processes, and Applications, (Ed.: A. Bakac), John Wiley \& Sons, 2011, pp. 109188 [pp. 127, 136].

236. S. Mahapatra, V. G. Young, S. Kaderli, A. D. Zuberbühler, W. B. Tolman, Angew. Chem. Int. Ed. 1997, 36, 130-133 [p. 128].

237. R. Battino, T. R. Rettich, T. Tominaga, J. Phys. Chem. Ref. Data 1983, 12, 163-178 [pp. 132, 234].

238. S. V. Kryatov, E. V. Rybak-Akimova, S. Schindler, Chem. Rev. 2005, 105, 2175-2226 [p. 134]. 
239. S. V. Kryatov, E. V. Rybak-Akimova, V. L. MacMurdo, L. Que, Inorg. Chem. 2001, 40, 2220-2228 [pp. 136, 137, 139].

240. E. V. Rybak-Akimova, W. Otto, P. Deardorf, R. Roesner, D. H. Busch, Inorg. Chem. 1997, 36, 2746-2753 [p. 138].

241. E. V. Rybak-Akimova, M. Masarwa, K. Marek, P. R. Warburton, D. H. Busch, Chem. Commun. 1996, 1451 [p. 138].

242. E. Rybak-Akimova, K. Marek, M. Masarwa, D. Busch, Inorg. Chim. Acta 1998, 270, 151-161 [pp. 138, 139].

243. J. Halpern, Polyhedron 1988, 7, 1483-1490 [p. 138].

244. N. W. Aboelella, S. V. Kryatov, B. F. Gherman, W. W. Brennessel, V. G. Young, Jr., R. Sarangi, E. V. Rybak-Akimova, K. O. Hodgson, B. Hedman, E. I. Solomon, C. J. Cramer, W. B. Tolman, f. Am. Chem. Soc. 2004, 126, 16896-16911 [p. 139].

245. A. Kunishita, M. Z. Ertem, Y. Okubo, T. Tano, H. Sugimoto, K. Ohkubo, N. Fujieda, S. Fukuzumi, C. J. Cramer, S. Itoh, Inorg. Chem. 2012, 51, 9465-9480 [p. 139].

246. Z. Hu, R. D. Williams, D. Tran, T. G. Spiro, S. M. Gorun, J. Am. Chem. Soc. 2000, 122, 3556-3557 [pp. 142, 155].

247. M. J. Henson, V. Mahadevan, T. D. P. Stack, E. I. Solomon, Inorg. Chem. 2001, 40, 5068-5069 [p. 143].

248. R. Sarangi, Coord. Chem. Rev. 2013, 257, 459-472 [p. 148].

249. L. S. Kau, D. J. Spira-Solomon, J. E. Penner-Hahn, K. O. Hodgson, E. I. Solomon, f. Am. Chem. Soc. 1987, 109, 6433-6442 [pp. 149, 150, 153].

250. J. L. DuBois, P. Mukherjee, T. D. P. Stack, B. Hedman, E. I. Solomon, K. O. Hodgson, f. Am. Chem. Soc. 2000, 122, 5775-5787 [pp. 149, 150].

251. G. Y. Park, M. F. Qayyum, J. Woertink, K. O. Hodgson, B. Hedman, A. A. Narducci Sarjeant, E. I. Solomon, K. D. Karlin, J. Am. Chem. Soc. 2012, 134, 8513-8524 [pp. 150, 153-155].

252. G. L. Woolery, L. Powers, M. Winkler, E. I. Solomon, T. G. Spiro, J. Am. Chem. Soc. 1984, 106, 86-92 [p. 154].

253. F. Ghiretti, Arch. Biochem. Biophys. 1956, 63, 165-176 [p. 154].

254. J. Ling, L. P. Nestor, R. S. Czernuszewicz, T. G. Spiro, R. Fraczkiewicz, K. D. Sharma, T. M. Loehr, J. Sanders-Loehr, f. Am. Chem. Soc. 1994, 116, 76827691 [p. 155]. 
255. N. C. Eickman, E. I. Solomon, J. A. Larrabee, T. G. Spiro, K. Lerch, J. Am. Chem. Soc. 1978, 100, 6529-6531 [p. 155].

256. Z. Hu, G. N. George, S. M. Gorun, Inorg. Chem. 2001, 40, 4812-4813 [p. 155].

257. W. E. Lynch, D. M. Kurtz, S. Wang, R. A. Scott, J. Am. Chem. Soc. 1994, 116, 11030-11038 [p. 155].

258. M. Kodera, K. Katayama, Y. Tachi, K. Kano, S. Hirota, S. Fujinami, M. Suzuki, f. Am. Chem. Soc. 1999, 121, 11006-11007 [p. 155].

259. M. J. Henson, M. a. Vance, C. X. Zhang, H.-C. Liang, K. D. Karlin, E. I. Solomon, f. Am. Chem. Soc. 2003, 125, 5186-5192 [pp. 155, 166, 186].

260. I. Sanyal, M. Mahroof-Tahir, M. S. Nasir, P. Ghosh, B. I. Cohen, Y. Gultneh, R. W. Cruse, A. Farooq, K. D. Karlin, Inorg. Chem. 1992, 31, 4322-4332 [p. 155].

261. E. Pidcock, S. DeBeer, H. V. Obias, B. Hedman, K. O. Hodgson, K. D. Karlin, E. I. Solomon, F. Am. Chem. Soc. 1999, 121, 1870-1878 [p. 155].

262. K. D. Karlin, M. S. Haka, R. W. Cruse, Y. Gultneh, J. Am. Chem. Soc. 1985, 107, 5828-5829 [p. 155].

263. N. J. Blackburn, R. W. Strange, A. Farooq, M. S. Haka, K. D. Karlin, J. Am. Chem. Soc. 1988, 110, 4263-4272 [p. 155].

264. K. D. Karlin, Z. Tyeklár, A. Farooq, M. S. Haka, P. Ghosh, R. W. Cruse, Y. Gultneh, J. C. Hayes, P. J. Toscano, J. Zubieta, Inorg. Chem. 1992, 31, 14361451 [pp. 155, 164].

265. E. Pidcock, H. V. Obias, M. Abe, H.-C. Liang, K. D. Karlin, E. I. Solomon, f. Am. Chem. Soc. 1999, 121, 1299-1308 [pp. 155, 158, 173].

266. H. C. Liang, K. D. Karlin, R. Dyson, S. Kaderli, B. Jung, A. D. Zuberbühler, Inorg. Chem. 2000, 39, 5884-5894 [p. 155].

267. K. D. Karlin, M. S. Haka, R. W. Cruse, G. J. Meyer, A. Farooq, Y. Gultneh, J. C. Hayes, J. Zubieta, J. Am. Chem. Soc. 1988, 110, 1196-1207 [p. 155].

268. B. M. Lam, J. A. Halfen, V. G. Young, J. R. Hagadorn, P. L. Holland, A. Lledós, L. Cucurull-Sánchez, J. J. Novoa, S. Alvarez, W. B. Tolman, Inorg. Chem. 2000, 39, 4059-4072 [p. 155].

269. M. Kodera, Y. Kajita, Y. Tachi, K. Katayama, K. Kano, S. Hirota, S. Fujinami, M. Suzuki, Angew. Chem. Int. Ed. 2004, 43, 334-337 [p. 155].

270. H.-C. Liang, C. X. Zhang, M. J. Henson, R. D. Sommer, K. R. Hatwell, S. Kaderli, A. D. Zuberbühler, A. L. Rheingold, E. I. Solomon, K. D. Karlin, f. Am. Chem. Soc. 2002, 124, 4170-4171 [p. 155]. 
271. Y. Funahashi, T. Nishikawa, Y. Wasada-Tsutsui, Y. Kajita, S. Yamaguchi, H. Arii, T. Ozawa, K. Jitsukawa, T. Tosha, S. Hirota, T. Kitagawa, H. Masuda, $\mathcal{F}$. Am. Chem. Soc. 2008, 130, 16444-16445 [p. 155].

272. X. Ottenwaelder, D. J. Rudd, M. C. Corbett, K. O. Hodgson, B. Hedman, T. D. P. Stack, J. Am. Chem. Soc. 2006, 128, 9268-9269 [p. 155].

273. A. Hoffmann, S. Herres-Pawlis, Chem. Commun. 2014, 50, 403-405 [p. 155].

274. F. Neese, Coord. Chem. Rev. 2009, 253, 526-563 [p. 156].

275. C. J. Cramer, D. G. Truhlar, Phys. Chem. Chem. Phys. 2009, 11, 10757-10816 [pp. 156, 165].

276. M. Orio, D. a. Pantazis, F. Neese, Photosynth. Res. 2009, 102, 443-453 [pp. 156, 158].

277. M. R. A. Blomberg, T. Borowski, F. Himo, R.-Z. Liao, P. E. M. Siegbahn, Chem. Rev. 2014, 114, 3601-3658 [p. 156].

278. B. F. Gherman, C. J. Cramer, Coord. Chem. Rev. 2009, 253, 723-753 [pp. 156, 158, 189].

279. A. Schäfer, H. Horn, R. Ahlrichs, J. Chem. Phys. 1992, 97, 2571-2577 [pp. 156, 186, 239].

280. A. P. Ginsberg, J. Am. Chem. Soc. 1980, 102, 111-117 [pp. 156, 239].

281. L. Noodleman, C. Peng, D. Case, J.-M. Mouesca, Coord. Chem. Rev. 1995, 144, 199-244 [pp. 156, 239].

282. M. E. Casida, 7. Mol. Struct. THEOCHEM 2009, 914, 3-18 [pp. 158, 239].

283. K. Burke, J. Werschnik, E. K. U. Gross, f. Chem. Phys. 2005, 123, 62206 [pp. 158, 239].

284. T. R. Dugan, E. Bill, K. C. Macleod, G. J. Christian, R. E. Cowley, W. W. Brennessel, S. Ye, F. Neese, P. L. Holland, J. Am. Chem. Soc. 2012, 134, 2035220364 [p. 158].

285. M. Rohrmüller, S. Herres-Pawlis, M. Witte, W. G. Schmidt, f. Comput. Chem. 2013, 34, 1035-1045 [pp. 158, 189, 239].

286. R. L. Martin, J. Chem. Phys. 2003, 118, 4775-4777 [pp. 160, 239].

287. F. Neese, F. Wennmohs, U. Becker, D. Bykov, D. Ganyushin, A. Hansen, R. Izsak, D. G. Liakos, C. Kollmar, S. Kossmann, D. A. Pantazis, T. Petrenko, C. Reimann, C. Riplinger, M. Roemelt, B. Sandhöfer, I. Schapiro, K. Sivalingam, B. Wezisla, ORCA 3.0.1 Manual (Input Description), 2014 [pp. 160, 237]. 
288. J.-J. Girerd, Y. Journaux, »Molecular Magnetism in Bioinorganic Chemistry « in Physical Methods in Bioinorganic Chemistry: Spectroscopy and Magnetism, (Ed.: L. Que, Jr.), University Science Books, Sausalito, 2000, pp. 321-374 [p. 162].

289. E. I. Solomon, D. M. Dooley, R.-H. Wang, H. B. Gray, M. Cerdonio, F. Mogno, G. L. Romani, f. Am. Chem. Soc. 1976, 98, 1029-1031 [p. 164].

290. K. D. Karlin, Z. Tyeklár, A. Farooq, R. R. Jacobson, E. Sinn, D. W. Lee, J. E. Bradshaw, L. J. Wilson, Inorg. Chim. Acta 1991, 182, 1-3 [p. 164].

291. K. Yamaguchi, Y. Takahara, T. Fueno, »Ab-Initio Molecular Orbital Studies of Structure and Reactivity of Transition Metal-OXO Compounds « in Applied Quantum Chemistry, (Eds.: V. H. Smith, Jr., H. F. Schaefer, III, K. Morokuma), Reidel, Dordrecht, 1986, pp. 155-184 [pp. 165, 239].

292. T. Soda, Y. Kitagawa, T. Onishi, Y. Takano, Y. Shigeta, H. Nagao, Y. Yoshioka, K. Yamaguchi, Chem. Phys. Lett. 2000, 319, 223-230 [pp. 165, 239].

293. Y. Takano, K. Koizumi, H. Nakamura, Inorg. Chim. Acta 2009, 362, 4578-4584 [p. 165].

294. L. Noodleman, f. Chem. Phys. 1981, 74, 5737-5743 [p. 165].

295. E. Ruiz, J. Cano, S. Alvarez, P. Alemany, J. Comput. Chem. 1999, 20, 13911400 [p. 165].

296. D. Hodgson, f. Prog. Inorg. Chem. 1975, 19, 173-242 [p. 166].

297. S. C. Lee, R. H. Holm, Inorg. Chem. 1993, 32, 4745-4753 [p. 166].

298. N. Kitajima, S. Hikichi, M. Tanaka, Y. Moro-oka, J. Am. Chem. Soc. 1993, 115, 5496-5508 [p. 166].

299. S. Herres-Pawlis, P. Verma, R. Haase, P. Kang, C. T. Lyons, E. C. Wasinger, U. Flörke, G. Henkel, T. D. P. Stack, f. Am. Chem. Soc. 2009, 131, 1154-1169 [pp. 167, 169].

300. A. W. Addison, T. N. Rao, J. Reedijk, J. van Rijn, G. C. Verschoor, f. Chem. Soc. Dalton Trans. 1984, 1349-1356 [pp. 171, 269].

301. S. Itoh, M. Taki, H. Nakao, P. L. Holland, W. B. Tolman, L. Que, Jr., S. Fukuzumi, Angew. Chem. Int. Ed. 2000, 39, 398-400 [p. 172].

302. J. Autschbach, ChemPhysChem 2009, 10, 1757-1760 [p. 187].

303. J. Leonard, B. Lygo, G. Procter, Advanced Practical Organic Chemistry, 2nd ed., Taylor \& Francis, 1998 [p. 201]. 
304. Autorenkollektiv, Organikum, 21st ed., VCH, Weinheim, 2004 [p. 201].

305. D. R. Burfield, R. H. Smithers, f. Org. Chem. 1978, 43, 3966-3968 [p. 201].

306. G. R. Fulmer, A. J. M. Miller, N. H. Sherden, H. E. Gottlieb, A. Nudelman, B. M. Stoltz, J. E. Bercaw, K. I. Goldberg, Organometallics 2010, 29, 21762179 [p. 202].

307. H. E. Gottlieb, V. Kotlyar, A. Nudelman, f. Org. Chem. 1997, 62, 7512-7515 [p. 202].

308. G. R. Hanson, K. E. Gates, C. J. Noble, M. Griffin, A. Mitchell, S. Benson, J. Inorg. Biochem. 2004, 98, 903-916 [p. 204].

309. G. R. Hanson, C. J. Noble, S. Benson, »XSophe-Sophe-XeprView and Molecular Sophe: Computer Simulation Software Suites for the Analysis of ContinuousWave and Pulsed EPR and ENDOR Spectra « in EPR of Free Radicals in Solids I, (Eds.: A. Lund, M. Shiotani), Progress in Theoretical Chemistry and Physics, Springer Netherlands, Dordrecht, 2013, Chapter 5, pp. 223-283 [p. 204].

310. E. Bill, julX simulation program for static molar magnetic susceptibilities, Max Planck Institute for Chemical Energy Conversion, Mülheim an der Ruhr, Germany [p. 205].

311. H. Gampp, M. Maeder, C. J. Meyer, A. D. Zuberbühler, Talanta 1985, 32, 95-101 [p. 234].

312. H. Gampp, M. Maeder, C. J. Meyer, A. D. Zuberbühler, Talanta 1985, 32, 257-264 [p. 234].

313. F. Neese, f. Comput. Chem. 2003, 24, 1740-1747 [p. 237].

314. F. Neese, F. Wennmohs, A. Hansen, U. Becker, Chem. Phys. 2009, 356, 98-109 [p. 237].

315. S. Kossmann, F. Neese, Chem. Phys. Lett. 2009, 481, 240-243 [p. 237].

316. A. D. Becke, Phys. Rev. A 1988, 38, 3098-3100 [p. 237].

317. J. Perdew, Phys. Rev. B 1986, 33, 8822-8824 [p. 237].

318. E. F. Pettersen, T. D. Goddard, C. C. Huang, G. S. Couch, D. M. Greenblatt, E. C. Meng, T. E. Ferrin, J. Comput. Chem. 2004, 25, 1605-1612 [p. 237].

319. M. D. Hanwell, D. E. Curtis, D. C. Lonie, T. Vandermeersch, E. Zurek, G. R. Hutchison, J. Cheminform. 2012, 4, 17 [p. 238].

320. A. Walli, S. Dechert, F. Meyer, Eur. F. Org. Chem. 2013, 7044-7049 [р. 238]. 
13. Bibliography

321. A. Walli, S. Dechert, M. Bauer, S. Demeshko, F. Meyer, Eur. F. Inorg. Chem. 2014, DOI 10.1002/ejic. 201402378 [p. 239].

322. T. S. Ertel, H. Bertagnolli, S. Hückmann, U. Kolb, D. Peter, Appl. Spectrosc. 1992, 46, 690-698 [p. 240].

323. M. Newville, P. Livins, Y. Yacoby, J. Rehr, E. Stern, Phys. Rev. B 1993, 47, 14126-14131 [p. 240].

324. S. J. Gurman, N. Binsted, I. Ross, J. Phys. C 1984, 17, 143-151 [p. 240].

325. M. Roy, S. J. Gurman, J. Synchr. Rad. 1999, 6, 228 [p. 240].

326. A. Kirfel, K. Eichhorn, Acta Cryst. A 1990, 46, 271-284 [p. 240].

327. H. Yamada, Y. Soejima, X. G. Zheng, M. Kawaminami, Transaction Mater. Res. Soc. Jap. 2000, 25, 1199-1202 [p. 240].

328. H. R. Oswald, A. Reller, H. W. Schmalle, E. Dubler, Acta Cryst. C 1990, 46, 2279-2284 [p. 240].

329. E. Stern, Phys. Rev. B 1993, 48, 9825-9827 [p. 241].

330. N. Binsted, EXCURV98: CCLRC Daresbury Laboratory computer program, Manual, (Ed.: F. Mosselman), 1998 [p. 241].

331. G. M. Sheldrick, Acta Cryst. 2008, A64, 112-122 [p. 241].

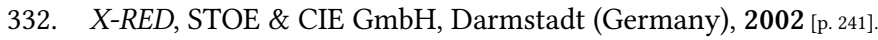

333. L. Yang, D. R. Powell, R. P. Houser, Dalton Trans. 2007, 955-964 [p. 269]. 


\section{A. Appendix}

\section{A.1. Determination of Angular Structural Parameters $\tau_{5}$ and $\tau_{4}$}

\section{Five-coordinated Complexes}

Metal complexes with five-fold coordination can adopt square pyramidal or trigonal bipyramidal geometries. However, most structures are distorted and are in-between the ideal geometries. A literature measure to distinct between both is the » $\tau_{5}$ « (»tau«) parameter, which was introduced by Reedijk and Addison in 1984 for five-coordinated complexes. ${ }^{[300]}$ The value quantitatively measures the geometry between the two extrema. It is calculated by

$$
\tau_{5}=\frac{\beta-\alpha}{60^{\circ}}
$$

in which $\alpha$ and $\beta$ are the largest coordination angles around the metal. The obtained index of trigonality ranges from $\tau_{5}=0.00$ for the perfect square pyramidal coordination ( $C_{4 v}$ symmetry) to $\tau_{5}=1.00$ for perfect trigonal bipyramidal coordination $\left(D_{3 h}\right)$.

\section{Four-coordinated Complexes}

In 2007 , a simple geometry index $» \tau_{4}$ " was introduced in close analogy, to obtain an index for four-fold coordinated metal complexes. ${ }^{[33]}$ The value is calculated by

$$
\tau_{4}=\frac{360^{\circ}-(\alpha+\beta)}{141^{\circ}}
$$

in which $\alpha$ and $\beta$ are the two largest coordination angles. It ranges from $\tau_{4}=1.00$ for a perfect tetrahedral geometry ( $T_{d}$ symmetry) to $\tau_{4}=0.00$ for a perfect square planar geometry $\left(D_{4 h}\right)$. Furthermore, a perfect trigonal pyramidal geometry $\left(C_{3 v}\right)$ has $\tau_{4}=0.85$ and the seesaw geometries $\left(C_{2 v}\right)$ are spread between 0.640.07 . 
Appendix A. Appendix

\section{A.2. Additional Figures and Tables}

Table A.1. Selected geometric parameters for the DFT-computed solid-state structures in Figure A.1. Bond length in $\AA$, angles in degrees.

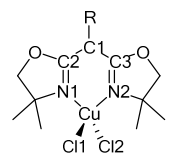

\begin{tabular}{|c|c|c|c|c|c|c|c|c|c|c|}
\hline & \multicolumn{5}{|c|}{$\left.\left(\mathrm{H}_{\{}{ }^{\mathrm{R}} \mathrm{BOX}\right\}\right) \mathrm{CuCl}_{2}$} & \multirow[t]{3}{*}{${ }^{\mathrm{Me}} \mathrm{BOX}$} $\left.\mathrm{CuCl}_{2}\right]^{-}$ & \multicolumn{4}{|c|}{$\left({ }^{\mathrm{R}} \mathrm{BOX}\right) \mathrm{CuCl}$} \\
\hline & \multicolumn{2}{|l|}{$t \mathrm{Bu}$} & \multirow[t]{2}{*}{$\mathbf{P h}$} & \multirow[t]{2}{*}{$\mathrm{Me}$} & \multirow[t]{2}{*}{$\mathbf{H}$} & & \multirow[t]{2}{*}{$t \mathrm{Bu}$} & \multirow[t]{2}{*}{$\mathbf{P h}$} & \multirow[t]{2}{*}{$\mathrm{Me}$} & \multirow[t]{2}{*}{$\mathbf{H}$} \\
\hline & $\mathrm{XRD}^{\text {[a] }}$ & DFT & & & & & & & & \\
\hline $\mathrm{Cu}-\mathrm{N} 1$ & $1.9746(22)$ & 2.076 & 1.271 & 2.076 & 2.055 & 2.025 & 1.901 & 1.900 & 1.912 & 1.913 \\
\hline $\mathrm{Cu}-\mathrm{N} 2$ & $1.9800(24)$ & 2.119 & 1.274 & 2.093 & 2.172 & 2.043 & 1.904 & 1.906 & 1.917 & 1.916 \\
\hline $\mathrm{Cu}-\mathrm{Cl1}$ & $2.2263(8)$ & 2.221 & 2.213 & 2.219 & 2.236 & 2.303 & 2.146 & 2.139 & 2.148 & 2.145 \\
\hline $\mathrm{Cu}-\mathrm{Cl} 2$ & $2.2428(8)$ & 2.235 & 2.229 & 2.229 & 2.202 & 2.292 & - & - & - & - \\
\hline $\mathrm{C} 1-\mathrm{C} 2$ & $1.5060(35)$ & 1.500 & 1.506 & 1.498 & 1.496 & 1.401 & 1.412 & 1.405 & 1.397 & 1.390 \\
\hline $\mathrm{C} 1-\mathrm{C} 3$ & $1.5061(33)$ & 1.506 & 1.509 & 1.503 & 1.502 & 1.402 & 1.414 & 1.409 & 1.401 & 1.393 \\
\hline $\mathrm{N} 1=\mathrm{C} 2$ & $1.2729(31)$ & 1.271 & 1.271 & 1.270 & 1.271 & 1.315 & 1.327 & 1.324 & 1.325 & 1.322 \\
\hline $\mathrm{N} 2=\mathrm{C} 3$ & $1.2708(30)$ & 1.277 & 1.274 & 1.273 & 1.270 & 1.316 & 1.330 & 1.320 & 1.321 & 1.319 \\
\hline $\mathrm{N}-\mathrm{Cu}-\mathrm{N}$ & $90.33(9)$ & 87.6 & 89.1 & 88.0 & 86.7 & 91.2 & 92.3 & 94.1 & 94.6 & 95.7 \\
\hline $\mathrm{Cl}-\mathrm{Cu}-\mathrm{Cl}$ & $103.69(3)$ & 104.4 & 110.3 & 106.5 & 110.0 & 99.7 & - & - & - & - \\
\hline N1-Cu-Cl1 & $101.30(7)$ & 97.9 & 104.7 & 100.5 & 95.7 & 100.0 & 132.3 & 134.0 & 131.2 & 130.9 \\
\hline $\mathrm{N} 2-\mathrm{Cu}-\mathrm{Cl} 2$ & $105.19(6)$ & 102.3 & 101.0 & 103.8 & 101.1 & 103.2 & 135.4 & 131.9 & 134.2 & 133.4 \\
\hline $\mathrm{N} 1-\mathrm{Cu}-\mathrm{Cl} 2$ & $129.08(6)$ & 132.2 & 119.8 & 130.7 & 141.8 & 132.7 & - & - & - & - \\
\hline $\mathrm{N} 2-\mathrm{Cu}-\mathrm{Cl1}$ & $130.67(7)$ & 137.7 & 132.2 & 130.3 & 123.2 & 136.0 & - & - & - & - \\
\hline$(\mathrm{NCuN})-(\mathrm{ClCuCl})^{[\mathbf{b}]}$ & $68.27(6)$ & 61.1 & 72.3 & 66.8 & 64.0 & 62.9 & - & - & - & - \\
\hline
\end{tabular}

[a] $133 \mathrm{~K}$. [b] Angle between two planes. 


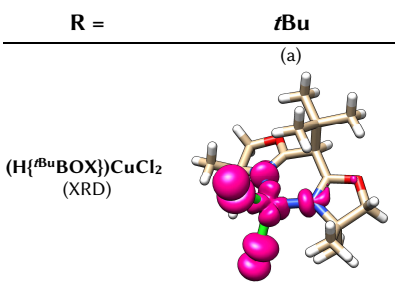

(b)
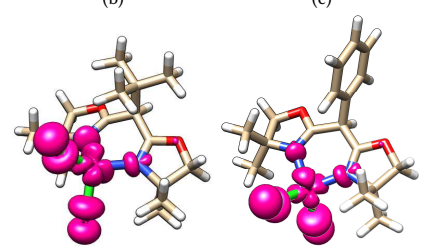

(d)

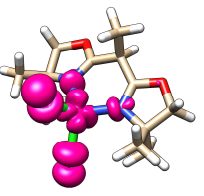

(f)

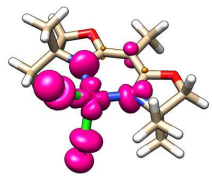

(i)
H

(e) (g)

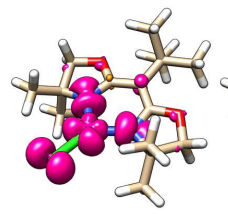

(h)

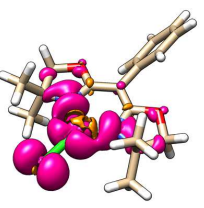

Me $\left[\left({ }^{\mathrm{Me}} \mathrm{BOX}\right) \mathrm{CuCl}_{2}\right]^{-}$

$\left.\left(\mathrm{H}_{\{}{ }^{\mathrm{R}} \mathrm{BOX}\right\}\right) \mathrm{CuCl}_{2}$ (DFT)

( $\left.{ }^{\mathrm{R}} \mathrm{BOX}\right) \mathrm{CuCl}$

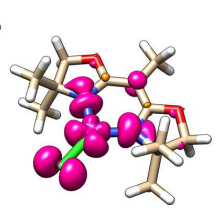

(j)

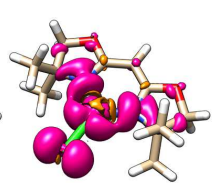

Figure A.1. DFT-computed isosurfaces of the spin-density, drawn at an isovalue of \pm 0.002 , except $(h)$ and $(j)$ which are drawn at an isovalue of \pm 0.001 ; majority and minority densities are plotted in magenta and orange respectively. (a) X-ray structure of $\left(\mathrm{H}\left\{{ }^{t B u} B O X\right\}\right) C^{-} C_{2}$. (b-e) Geometry optimized coordinates of all $\left.\left(\mathrm{H}_{\{}{ }^{\mathrm{R}} \mathrm{BOX}\right\}\right) \mathrm{CuCl}_{2}$. (f) The deprotonated $\left[\left({ }^{\mathrm{Me}} \mathrm{BOX}\right) \mathrm{CuCl}_{2}\right]^{-}$. (g-j) All $\left({ }^{\mathrm{R}} \mathrm{BOX}\right) \mathrm{CuCl}$. Calculated with the B3LYP/def2-TZVPP method. Geometric parameters are in Table A.1, Mulliken spin populations are listed in Table A.2. Colour code for atoms: $\mathrm{C}$ (tan), $\mathrm{H}$ (white), $\mathrm{N}$ (blue), $\mathrm{O}$ (red) and $\mathrm{Cl}$ (green). 
Appendix A. Appendix

Table A.2. DFT-computed Mulliken spin populations for the structures depicted in Figure A.1. Densities are listed for C1 (the bridging carbon), copper and the coordinating atoms.

\begin{tabular}{|c|c|c|c|c|c|c|c|c|c|c|}
\hline & \multicolumn{5}{|c|}{$\left(\mathrm{H}\left\{{ }^{\mathrm{R}} \mathrm{BOX}\right\}\right) \mathrm{CuCl}_{2}$} & \multirow[t]{3}{*}[({}^{\mathrm{Me}}\mathrm{BOX})\mathrm{CuCl}_{2}]{$^{-}$} & \multicolumn{4}{|c|}{$\left({ }^{\mathrm{R}} \mathrm{BOX}\right) \mathrm{CuCl}$} \\
\hline & \multicolumn{2}{|c|}{$t \mathrm{Bu}$} & \multirow[t]{2}{*}{$\mathbf{P h}$} & \multirow[t]{2}{*}{ Me } & \multirow[t]{2}{*}{$\mathbf{H}$} & & \multirow[t]{2}{*}{$t \mathrm{Bu}$} & \multirow[t]{2}{*}{$\mathbf{P h}$} & \multirow[t]{2}{*}{ Me } & \multirow[t]{2}{*}{$\mathbf{H}$} \\
\hline & XRD & DFT & & & & & & & & \\
\hline C1 & 0.001 & 0.000 & 0.001 & 0.000 & -0.001 & 0.030 & 0.027 & 0.009 & 0.041 & 0.009 \\
\hline $\mathrm{Cu}$ & 0.585 & 0.580 & 0.505 & 0.587 & 0.583 & 0.588 & 0.547 & 0.568 & 0.542 & 0.574 \\
\hline Cl1 & 0.166 & 0.183 & 0.193 & 0.180 & 0.185 & 0.114 & 0.112 & 0.126 & 0.119 & 0.132 \\
\hline $\mathrm{Cl} 2$ & 0.136 & 0.150 & 0.190 & 0.153 & 0.154 & 0.111 & - & - & - & - \\
\hline N1 & 0.056 & 0.045 & 0.062 & 0.039 & 0.038 & 0.088 & 0.156 & 0.136 & 0.138 & 0.127 \\
\hline N2 & 0.047 & 0.034 & 0.046 & 0.033 & 0.032 & 0.082 & 0.148 & 0.139 & 0.156 & 0.137 \\
\hline
\end{tabular}



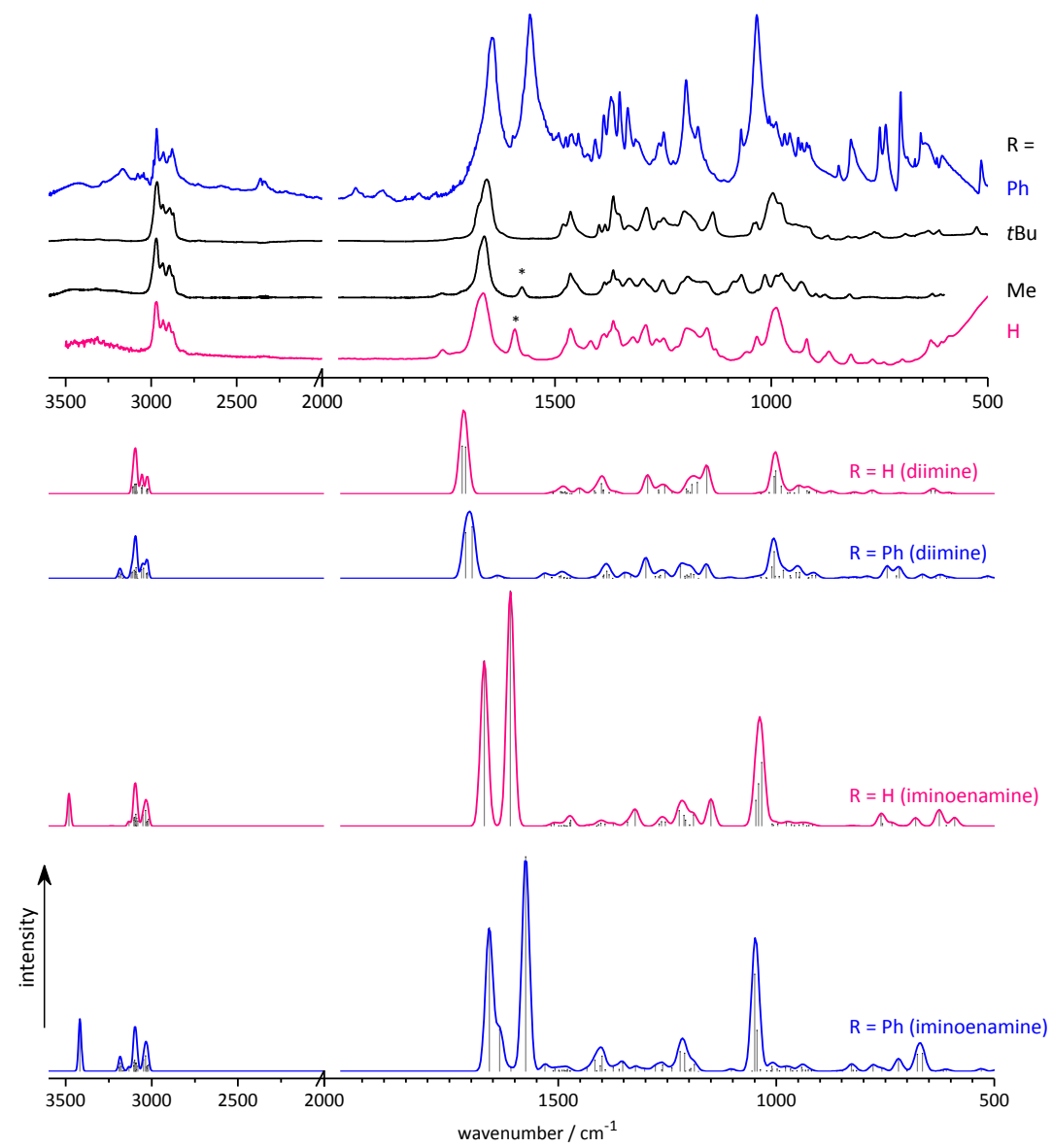

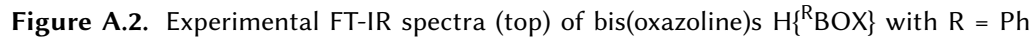
(iminoenamine tautomer), $t \mathrm{Bu}, \mathrm{Me}, \mathrm{H}$ (diimine tautomers); the labelled features $(*)$ indicate the possible presence of small amounts of iminoenamine tautomers.

DFT-calculated vibrational spectra (bottom) of the two tautomers of bis(oxazoline)s $\mathrm{H}_{\left\{{ }^{\mathrm{R}} \mathrm{BOX}\right\}}$ with $\mathrm{R}=\mathrm{H}$, Ph. Spectra were computed from geometry optimized structures of the diimine and iminoenamine structures on the B3LYP/def2-TZVPP level of theory and were plotted with a full width at half maximum of $20 \mathrm{~cm}^{-1}$. Calculated transitions, used to construct the spectra are represented with grey lines. The strong absorptions at around 1650 and $1570 \mathrm{~cm}^{-1}$ are characteristic for the iminoenamine tautomer and are represented in Figure 4.5 (p. 53). 



\section{List of Figures}

1.1. X-ray structures of arthropod hemocyanin . . . . . . . . . . 6

1.2. X-ray structure of bacteria oxy-tyrosinase . . . . . . . . 8

2.1. X-ray structures of $\mathrm{Cu}_{2} \mathrm{O}_{2}$ complexes . . . . . . . . . . . . . . 18

2.2. MO diagrams for ${ }^{\mathrm{S}} \mathrm{P}$ and $\mathrm{O}$ species . . . . . . . . . . . . . . . 21

3.1. ${ }^{1} \mathrm{H}$ NMR spectra of bis(oxazoline)s $\mathrm{H}_{\left\{{ }^{\mathrm{R}} \mathrm{BOX}\right\}} \ldots \ldots . . . \ldots . . . .42$

3.2. ${ }^{13} \mathrm{C}\left\{{ }^{1} \mathrm{H}\right\}$ NMR spectra of bis(oxazoline)s $\mathrm{H}_{\left\{{ }^{\mathrm{R}} \mathrm{BOX}\right\}} \ldots \ldots . . . . . .43$

4.1. X-ray structures of $\mathrm{H}_{\{}\left\{{ }^{\mathrm{Ph}} \mathrm{BOX}\right\}$ and $\left.\mathrm{H}_{\{} \mathrm{H}_{\mathrm{BOX}}\right\} \ldots . . . \ldots . . . . .49$

4.2. Equilibrium of tautomers of $\mathrm{H}_{\{}\left\{{ }^{\mathrm{Ph}} \mathrm{BOX}\right\}$ and ${ }^{1} \mathrm{H}$ NMR spectra . . . 51

4.3. $\quad\left\{{ }^{15} \mathrm{~N},{ }^{1} \mathrm{H}\right\}-\mathrm{HMBC}$ NMR spectrum of tautomers of $\mathrm{H}\left\{{ }^{\mathrm{Ph}} \mathrm{BOX}\right\} \ldots . .52$

4.4. Experimental and DFT-calculated IR spectra of $\mathrm{H}_{\{}\left\{{ }^{\mathrm{Ph}} \mathrm{BOX}\right\}$. . . . . 53

4.5. DFT-calculated vibration modes of iminoenamine $\left.\mathrm{H}_{\left\{{ }^{\mathrm{Ph}}\right.} \mathrm{BOX}\right\}$. . $\quad 53$

4.6. Van 't Hoff plot for equilibrium iminoenamine $\rightleftharpoons$ diimine . . . . . 54

4.7. ${ }^{1} \mathrm{H}$ NMR spectra of the thermal relaxation of $\mathrm{H}\left\{{ }^{\mathrm{Ph}} \mathrm{BOX}\right\} \ldots 56$

4.8. Time course of the equilibration of $\left.\mathrm{H}^{\mathrm{Ph}}{ }_{\mathrm{BOX}}\right\} \ldots \ldots$

4.9. Eyring plot of the $\left.\mathrm{H}_{\left\{{ }^{\mathrm{Ph}}\right.} \mathrm{BOX}\right\}$ tautomerisation . . . . . . . . . 60

4.10. Reaction profile of $\mathrm{H}\left\{\mathrm{Ph}_{\mathrm{BOX}}\right\}$ tautomerisation . . . . . . . . 61

4.11. DFT-computed coordinates of diimine and iminoenamine tautomers 62

4.12. Superimpositions of X-ray and DFT-computed structures . . . . . 63

4.13. DFT-computed transition states for $\left.\mathrm{H}_{\{}{ }^{\mathrm{Ph}} \mathrm{BOX}\right\}$ and $\left.\mathrm{H}_{\{}{ }^{\mathrm{H}} \mathrm{BOX}\right\}$. . . 64

5.1. Dioxygen reactivity of BOX-zinc and metal-NAcNAc complexes 69

5.2. X-ray structure of $\left[\left(\mathrm{Me}^{\mathrm{BOO}}{ }_{2}\right)\left\{\mathrm{Cu}^{\mathrm{II}}(\mathrm{OAc})\left(\mathrm{H}_{2} \mathrm{O}\right)\right\}_{2}\right]\left(\mathrm{ClO}_{4}\right)_{2} \ldots \ldots 71$

5.3. X-ray structure of $\left(\mathrm{Me}^{\mathrm{BOX}}{ }_{2}\right)\left(\mathrm{Cu}{ }^{\mathrm{I}} \mathrm{Cl}\right)_{2} \ldots \ldots \ldots . \ldots 73$ 
5.4. X-ray structure of $\left({ }^{\mathrm{Me}} \mathrm{BOX}_{2}\right)\left(\mathrm{Cu}^{\mathrm{II}} \mathrm{Cl}_{2}\right)_{2} \ldots \ldots \ldots 76$

5.5. X-ray structure of ${ }^{\square} \mathrm{BOX}_{2} \ldots \ldots \ldots$. . . . . . . . . . 79

5.6. Temperature dependent $\mathrm{X}$-ray structures of $\left.\left(\mathrm{H}^{t}{ }^{t \mathrm{Bu}} \mathrm{BOX}\right\}\right) \mathrm{Cu}^{\mathrm{II}} \mathrm{Cl}_{2} \quad . \quad 82$

5.7. $\mu_{\text {eff }}$ vs. temperature for $\left.\left(\mathrm{H}_{\{}^{t \mathrm{Bu}} \mathrm{BOX}\right\}\right) \mathrm{Cu}^{\mathrm{II}} \mathrm{Cl}_{2} \ldots \ldots . \ldots 84$

5.8. X-ray structure of $\left.\left(\mathrm{O}_{\{}{ }^{\mathrm{Ph}}{ }_{\mathrm{BOX}}\right\}\right)_{2} \mathrm{Cu}_{3} \mathrm{Cl}_{4} \ldots \ldots \ldots 8$

5.9. HR-ESI-MS of $\left(\mathrm{O}\left\{{ }^{\mathrm{Ph}} \mathrm{BOX}\right\}\right)_{2} \mathrm{Cu}_{3} \mathrm{Cl}_{4}$ and $\left({ }^{18} \mathrm{O}\left\{{ }^{\mathrm{Ph}} \mathrm{BOX}\right\}\right)_{2} \mathrm{Cu}_{3} \mathrm{Cl}_{4} \ldots 91$

5.10. EPR spectrum of $\left.\left(\mathrm{H}_{\{}{ }^{\mathrm{Ph}} \mathrm{BOX}\right\}\right) \mathrm{Cu}^{\mathrm{II}} \mathrm{Cl}_{2} \ldots \ldots . \ldots 92$

5.11. Titration of $\mathrm{H}\left\{{ }^{\mathrm{Ph}} \mathrm{BOX}\right\}$ with $\mathrm{CuCl}_{2} \cdot 2 \mathrm{H}_{2} \mathrm{O} \ldots \ldots . . \ldots 9$

5.12. X-ray structure of $\left(\left\{{ }^{\mathrm{Me}} \mathrm{BOX}\right\} \mathrm{O}\right)_{2}(\mathrm{MeOH})_{2} \mathrm{Cu}_{4} \mathrm{Cl}_{6} \ldots \ldots 95$

5.13. Cyclic voltammograms of $\left.\mathrm{H}_{\{}{ }^{t \mathrm{Bu}} \mathrm{BOX}\right\}$ and $\left.\mathrm{H}^{\{\mathrm{Me}} \mathrm{BOX}\right\} \ldots 100$

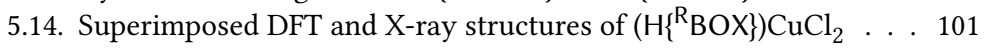

5.15. Spin-density maps . . . . . . . . . . . . . . . . . . . . . . 102

5.16. EPR spectra of a DMPO trapped radical species . . . . . . . . . 103

5.17. Kinetic curves of $\mathrm{DPPH}^{\bullet}$ scavenging by $\left.\mathrm{H}^{\mathrm{R}}{ }^{\mathrm{R}} \mathrm{BOX}\right\}$ ligands . . . . . 106

5.18. Radical scavenging activity of $\left.\mathrm{H}{ }^{\mathrm{R}} \mathrm{BOX}\right\}$. . . . . . . . . . . . 108

6.1. X-ray structure of $\left.\left[\left(\mathrm{H}_{\{}{ }^{t \mathrm{Bu}} \mathrm{BOX}\right\}\right) \mathrm{Cu}^{\mathrm{I}}(\mathrm{MeCN})\right] \mathrm{PF}_{6}\left(\mathbf{C u}^{\prime} \mathbf{t} \mathbf{B u}\right) \ldots \ldots$

6.2. X-ray structure of $\left[\left(\mathrm{H}_{\{}\left\{{ }^{\mathrm{Ph}} \mathrm{BOX}\right\}\right) \mathrm{Cu}^{\mathrm{I}}(\mathrm{MeCN})\right] \mathrm{PF}_{6}\left(\mathbf{C} \mathbf{u}^{\prime} \mathbf{P h}\right) \ldots 116$

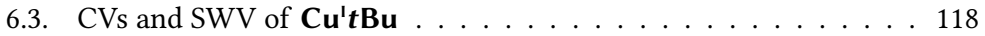

6.4. CVs at varying scan rate . . . . . . . . . . . . . . . . . . 119

6.5. UV-vis spectra of $\mathbf{R}_{\mathbf{P}} \ldots \ldots \ldots \ldots 12 \ldots \ldots$

6.6. Photograph of a ${ }^{\text {B Bu}} \mathbf{P}$ solution . . . . . . . . . . . . . . 122

6.7. Beer's law plots, abs. vs. ${ }^{\boldsymbol{t} B u} \mathbf{P}$ concentration . . . . . . . . . . . . 124

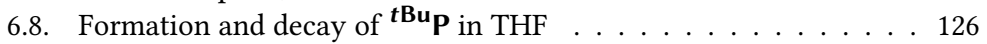

6.9. Formation and decay of ${ }^{\mathbf{t B u}} \mathbf{P}$ in acetone . . . . . . . . . . . 127

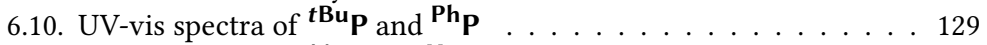

6.11. UV-vis spectra of $\mathbf{M e}_{\mathbf{P}}$ and $\mathbf{H}_{\mathbf{P}} \ldots \ldots \ldots 130$

6.12. Cryo-stopped-flow set-up . . . . . . . . . . . . . . . . . . . 132

6.13. Spectral change in a cryo-stopped-flow experiment . . . . . . . . 133

6.14. Kinetic time trace and first-order plot . . . . . . . . . . . . . . 134

6.15. Plots of $k_{\mathrm{obs}}$ vs. $\left[\mathrm{O}_{2}\right] \ldots \ldots$. . . . . . . . . . . . . . 135

6.16. Eyring and van 't Hoff plots of the $\mathrm{O}_{2}$ activation reaction . . . . . 136

6.17. Photograph of a powder sample of ${ }^{\mathbf{B} u} \mathbf{P}$. . . . . . . . . . . . . 140

6.18. Solid state UV-vis-NIR spectra of ${ }^{\boldsymbol{t} \mathbf{B}} \mathbf{P}$ and ${ }^{\mathbf{H}} \mathbf{P} \ldots \ldots$. . . . . . . . 141

6.19. Diagnostic vibrational modes of a $\mu-\eta^{2}: \eta^{2}$-peroxodicopper(II) system 142

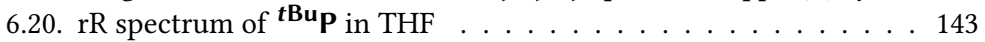

6.21. rR spectra of solid samples of ${ }^{\boldsymbol{t} \mathbf{B u}} \mathbf{P}$ and ${ }^{\mathbf{H}_{\mathbf{P}}} \ldots \ldots . . \ldots 144$ 
6.22. Comparison of IR and $\mathrm{rR}$ spectra of solid ${ }^{\boldsymbol{t} \mathrm{Bu}} \mathbf{P}$. . . . . . . . . . 145

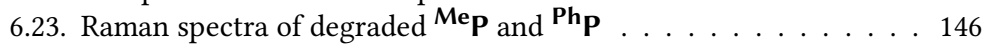

6.24. Prepared pellet of $\mathbf{H}_{\mathbf{P}}$ for XAS measurement . . . . . . . . . . . 149

6.25. Cu K-edge XANES of $\mathbf{R}_{\mathbf{P}}$. . . . . . . . . . . . . . . . . . . . . . 149

6.26. EXAFS functions $k^{3} \chi(k)$ of $\mathbf{R}_{\mathbf{P}} \ldots \ldots \ldots \ldots 151$

6.27. Fourier-transformed EXAFS functions of ${ }^{\mathbf{R}} \mathbf{P} \ldots \ldots . . \ldots 151$

6.28. DFT coordinates of ${ }^{\mathbf{B u}} \mathbf{P} \ldots \ldots \ldots . \ldots . \ldots 157$

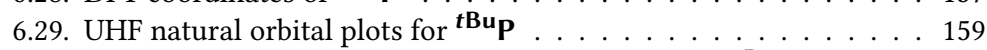

6.30. TD-DFT-computed UV-vis absorption spectrum of ${ }^{\boldsymbol{t} \mathbf{B u}} \mathbf{P} \ldots \ldots$

6.31. TD-DFT transition orbitals involved in $333 \mathrm{~nm}$ excitation . . . . . 161

6.32. TD-DFT transition orbitals involved in $500 \mathrm{~nm}$ excitation . . . . . 161

6.33. Plot of $\chi_{\mathrm{mol}} T$ vs. $T$ for ${ }^{\boldsymbol{t B u}} \mathbf{P}$ from a SQUID measurement . . . . . 162

6.34. Plot of $\chi_{\mathrm{mol}} T$ vs. $T$ for ${ }^{H_{\mathbf{P}}}$ from a SQUID measurement . . . . . 163

6.35. f sum vs. J for ${ }^{t \mathbf{B u}} \mathbf{P}$ and ${ }^{\mathbf{H}} \mathbf{P} \ldots \ldots \ldots$. . . . . . . . . . . . . 164

6.36. Raman spectrum of the $\mathrm{Cu}_{2}(\mu-\mathrm{OH})_{2}$ complex . . . . . . . . . . 167

6.37. HR-MS spectra of $\left.\left[\left(\mathrm{H}_{\{}^{t \mathrm{Bu}} \mathrm{BOX}\right\}\right)(\mathrm{solv}) \mathrm{Cu}^{\mathrm{II}}(\mu-\mathrm{OH})\right]_{2}\left(\mathrm{PF}_{6}\right)_{2} \ldots \ldots . . .168$

6.38. Structure of $\left[(\mathrm{THF})_{0.85}(\mathrm{MeCN})_{0.15}\left(\mathrm{H}\left\{{ }^{t \mathrm{Bu}} \mathrm{BOX}\right\}\right) \mathrm{Cu}(\mu-\mathrm{OH})\right]_{2}\left(\mathrm{PF}_{6}\right)_{2} \quad 169$

6.39. Structure of $\left[\left(\mathrm{H}_{2} \mathrm{O}\right)\left(\mathrm{H}_{\{}\left\{{ }^{t \mathrm{Bu}} \mathrm{BOX}\right\}\right) \mathrm{Cu}(\mu-\mathrm{OH})\right]_{2}\left(\mathrm{PF}_{6}\right)_{2} \ldots \ldots . . . . \quad \ldots$

6.40. Fit of ${ }^{H_{\mathbf{P}}}$ formation with a consecutive $\mathrm{A} \rightarrow \mathrm{B} \rightarrow \mathrm{C}$ kinetic model 173

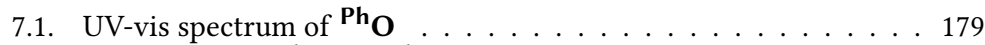

7.2. Photograph of ${ }^{\mathbf{P h}} \mathbf{P}$ and ${ }^{\mathbf{P h}} \mathbf{O}$ solutions . . . . . . . . . . . . 181

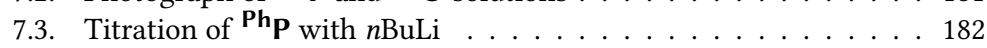

7.4. Titration curves, $\lambda_{\max }$ and isosbestic points . . . . . . . . . . . . 183

7.5. Resonance Raman spectra of ${ }^{\mathrm{Ph}} \mathbf{O}$. . . . . . . . . . . . . . . . . 185

7.6. DFT-geometry-optimized coordinates of ${ }^{\mathbf{P h}} \mathbf{O} \ldots \ldots . . . . . .187$

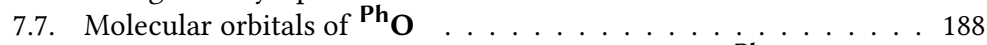

7.8. TD-DFT-computed UV-vis absorption spectrum of ${ }^{\mathbf{P h}} \mathbf{O}$. . . . . . 189

7.9. TD-DFT natural transition orbitals involved in $285 \mathrm{~nm}$ excitation . 190

7.10. TD-DFT natural transition orbitals involved in $400 \mathrm{~nm}$ excitation . 191

A.1. Spin-density of several $\left.\mathrm{H}_{\{}{ }^{\mathrm{R}} \mathrm{BOX}\right\}$ and $\left({ }^{\mathrm{R}} \mathrm{BOX}^{-}\right) \mathrm{CuCl}_{n}$ complexes . 271

A.2. DFT and experimental FT-IR spectra of $\left.\mathrm{H}_{\{}{ }^{\mathrm{R}} \mathrm{BOX}\right\}$. . . . . . . . . 273 



\section{List of Schemes}

1.2. Biosynthesis of L-DOPA, melanin and neurotransmitters . . . . 9

1.3. Oxidation of phenols and catechols . . . . . . . . . . . . 10

1.4. Catalytic cycles .................... 11

2.1. Modes of $\mathrm{Cu}_{n}-\mathrm{O}_{2}$ coordination . . . . . . . . . . . . 15

2.2. The four-electron reduction of dioxygen to water. . . . . . . . . . 16

2.3. Equilibrium of ${ }^{\mathrm{S}} \mathrm{P}$ and $\mathrm{O}$ isomers with $\mathrm{L}^{i \mathrm{Pr}_{3}}$ ligand . . . . . . . . . 22

2.4. Self-Assembly of the $\mathrm{Cu}_{2} \mathrm{O}_{2}$ Core . . . . . . . . . . . . . . . . 24

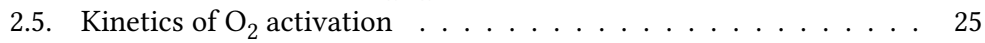

2.6. Endogenous arene hydroxylation . . . . . . . . . . . . 26

2.7. Ligand systems used for catalytic phenol hydroxylation . . . . . . 27

2.8. Phenolate hydroxylation via an $\mathrm{O}$ species . . . . . . . . . . . . . 29

3.1. Bis(oxazoline)s and $\beta$-diketimines . . . . . . . . . . . . . 37

3.2. BOX ligands used in this work . . . . . . . . . . . . . . . . . . 38

3.3. Synthesis of bishydroxy malonamides . . . . . . . . . . . . . . . 39

3.4. Synthesis of tert-butylmalonyl dichloride . . . . . . . . . . . . . . 39

3.5. Degradation products in the synthesis of $\left.\mathrm{H}^{s \mathrm{tBu}} \mathrm{BOX}\right\} \quad \ldots \quad \ldots . .40$

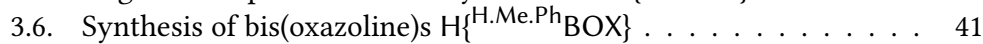

4.1. Potential tautomeric BOX isomers . . . . . . . . . . . . . . . . 46

4.2. Ligand classes related to BOXs and iminoenamine tautomers . . . 47

4.3. Autotrope interconverted tautomers of $\mathrm{H}_{\{}\left\{{ }^{\mathrm{Ph}} \mathrm{BOX}\right\} \ldots . . . . . .48$

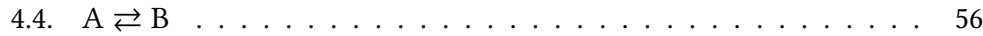

5.2. Formation of $\left({ }^{\mathrm{Me}_{\mathrm{BOX}}}\right) \mathrm{Cu}_{2} \mathrm{Cl}_{2}$ and recovery of ${ }^{\mathrm{Me}} \mathrm{BOX}_{2} \ldots \ldots 72$ 
5.3. Formation of $\left({ }^{\square} \mathrm{BOX}_{2}\right) \mathrm{Cu}_{2} \mathrm{Cl}_{2}$ and recovery of ${ }^{\square} \mathrm{BOX}_{2} \ldots \ldots 77$

5.4. Chelex 100 resin . . . . . . . . . . . . . . . . 78

5.5. Formation of $\left.\left(\mathrm{H}_{\{}^{\mathrm{t}}{ }^{\mathrm{Bu}} \mathrm{BOX}\right\}\right) \mathrm{Cu}^{\mathrm{II}} \mathrm{Cl}_{2} \ldots \ldots \ldots . \ldots . \ldots$

5.6. Degree of distortion in (BOX) $\mathrm{MX}_{2}$ complexes . . . . . . . . . . 85

5.7. Formation of $\left(\left\{{ }^{\mathrm{Ph}} \mathrm{BOX}\right\} \mathrm{O}\right)_{2} \mathrm{Cu}_{3} \mathrm{Cl}_{4} \ldots \ldots \ldots . \ldots . \ldots 87$

5.8. Preparation and isolation of $\left.\mathrm{HO}_{\{} \mathrm{Ph}_{\mathrm{BOX}}\right\} \ldots \ldots . \ldots 94$

5.9. Formation of $\left(\mathrm{O}_{\left\{{ }^{\mathrm{Me}} \mathrm{BOX}\right\}}\right)_{2}(\mathrm{MeOH})_{2} \mathrm{Cu}_{4} \mathrm{Cl}_{6} \ldots \ldots . \ldots 9$

5.10. Oxygenation products of $\left.\mathrm{H}^{2} \mathrm{H}_{\mathrm{BOX}}\right\} \ldots \ldots . \ldots 97$

5.11. Mechanism of $\mathrm{Me}^{\mathrm{BOX}}{ }_{2}(\mathrm{CuCl})_{2}$ formation . . . . . . . . . . 98

5.12. Examples of radical coupling reactions . . . . . . . . . . . . . . . 99

5.13. $\mathrm{DPPH}^{\bullet}$ persistent radical. . . . . . . . . . . . . . . . . 105

5.14. Main reactions upon exposure of $\left.\mathrm{H}_{\{}{ }^{\mathrm{R}} \mathrm{BOX}\right\}$ ligands towards $\mathrm{CuCl}_{2} \quad 109$

6.1. Synthesis of $\mathbf{C} \mathbf{u}^{\prime} \mathbf{R}$ complexes . . . . . . . . . . . . . . . . . . 113

6.2. Synthesis of $\mu-\eta^{2}: \eta^{2}$-peroxodicopper(II) complexes $\mathbf{R}_{\mathbf{P}} \ldots \ldots$. . . . 120

6.3. Formation of $\mathrm{Cu}_{2} \mathrm{O}_{2}$ complexes ${ }^{\mathrm{R}} \mathbf{P}$ by self-assembly . . . . . . . . 123

6.4. Mechanistic framework of $\mathrm{Cu}^{\mathrm{I}}$-mediated $\mathrm{O}_{2}$ activation . . . . . 127

6.5. Kinetic processes in $\mathrm{Cu}_{2} \mathrm{O}_{2}$ formation . . . . . . . . . . . . . . . 133

6.6. Kinetic processes under pseudo first-order conditions . . . . . . . 134

6.7. Structural model of $\mathbf{R}_{\mathbf{P}}$ and EXAFS parameters . . . . . . . . . . . 153

6.8. Ligands of $\mathrm{Cu}_{2} \mathrm{O}_{2}$ systems with magnetic data . . . . . . . . . . . 164

6.9. Formation of $\left.\left[\left(\mathrm{H}_{\{}^{\mathrm{s}}{ }^{t \mathrm{Bu}} \mathrm{BOX}\right\}\right)(\mathrm{solv}) \mathrm{Cu}^{\mathrm{II}}(\mu-\mathrm{OH})\right]_{2}\left(\mathrm{PF}_{6}\right)_{2} \ldots \ldots . . . . .166$

6.10. Thermal degradation of ${ }^{\mathbf{H}} \mathbf{P}$ along with ligand oxygenation . . . . 172

6.11. Oxidative coupling of 2,4-di-tert-butylphenol . . . . . . . . . . . 174

7.1. Synthesis of bis( $\mu$-oxo)dicopper(III) complex ${ }^{\mathbf{P h}} \mathbf{O}$ from $\mathrm{Cu}^{\mathrm{I}} \ldots 178$

7.2. Equilibrium of ${ }^{\mathrm{S}} \mathrm{P}$ and $\mathrm{O}$ isomers. . . . . . . . . . . . . . . . 180

7.3. Synthesis of bis( $\mu$-oxo)dicopper(III) complex ${ }^{\mathbf{P h}} \mathbf{O}$ from ${ }^{\mathbf{P h}_{\mathbf{P}}}$. . . . 180

7.4. Formation of $12^{\mathbf{P h}} \mathbf{O}$ in the first step of the titration . . . . . . . . 184

8.1. Ligands prepared in this work and tautomerism in $\mathrm{H}_{\{}\left\{{ }^{\mathrm{Ph}} \mathrm{BOX}\right\}$. . 195

8.2. Formation of coupled/oxygenated ligands from $\mathrm{H}\left\{{ }^{\mathrm{R}} \mathrm{BOX}\right\}$ and $\mathrm{CuCl}_{2} 196$

8.3. Synthesis of ${ }^{\mathbf{R}} \mathbf{P}$ and ${ }^{\mathbf{P h}} \mathbf{O} \ldots \ldots \ldots$. . . . . . . . . . 197 


\section{List of Tables}

2.1. The $v(\mathrm{O}-\mathrm{O})$ stretch in neutral and reduced dioxygen . . . . . . . 16

2.2. Spectroscopic and structural parameters of ${ }^{\mathrm{S}} \mathbf{P},{ }^{\mathrm{T}} \mathbf{P}$ and $\mathrm{O}$ species . 17

4.1. Metric parameters of $\left.\mathrm{H}_{\{}{ }^{\mathrm{Ph}} \mathrm{BOX}\right\}$ and $\left.\mathrm{H}_{\{}{ }^{\mathrm{H}} \mathrm{BOX}\right\} \ldots . . . . . . .49$

4.2. Hydrogen-bonding parameters of $\left.\mathrm{H}_{\left\{{ }^{\mathrm{Ph}}\right.}{ }_{\mathrm{BOX}}\right\} \ldots . . . . . . .49$

4.3. Thermodynamic data of the equilibrium . . . . . . . . . . 55

4.4. Observed first order rate constants $k_{\text {obs }} \ldots \ldots . \ldots 58$

4.5. Activation parameters of the equilibration . . . . . . . . . . . 59

4.6. Thermodynamic data from DFT calculations . . . . . . . . . . . 63

4.7. Activation parameters of the tautomerisation from DFT calculations 65

5.1. Geometric information of complexes incorporating ${ }^{\mathrm{Me}} \mathrm{BOX}_{2}$. . . 75

5.2. Geometric information of $\left.\left(\mathrm{H}_{\{}{ }^{t \mathrm{Bu}} \mathrm{BOX}\right\}\right) \mathrm{Cu}^{\mathrm{II}} \mathrm{Cl}_{2} \ldots \ldots . \ldots 8$

5.3. Degree of distortion in (BOX)metal $\left(\mathrm{X}_{2}\right)$ complexes . . . . . . . . . 86

5.4. Geometric information of $\left(\left\{{ }^{\mathrm{Ph}} \mathrm{BOX}\right\} \mathrm{O}\right)_{2} \mathrm{Cu}_{3} \mathrm{Cl}_{4} \ldots \ldots . . . . .89$

5.5. Geometric information of $\left(\left\{{ }^{\mathrm{Me}} \mathrm{BOX}\right\} \mathrm{O}\right)_{2}(\mathrm{MeOH})_{2} \mathrm{Cu}_{4} \mathrm{Cl}_{6} \ldots . . .96$

5.6. Radical scavenging parameters for $\left.\mathrm{H}_{\{}{ }^{\mathrm{R}} \mathrm{BOX}\right\}$. . . . . . . . . . . . 106

6.1. Geometric information of $\mathbf{C} \mathbf{u}^{\prime} \mathbf{P h}$ and $\mathbf{C} \mathbf{u}^{\prime} \mathbf{t} \mathbf{B u} \ldots \ldots 116$

6.2. Spectroscopic data of dicopper-dioxygen complexes . . . . . . . . 122

6.3. $\epsilon$ of ${ }^{\mathbf{t} \text { Bu}} \mathbf{P}$ from Beer's law plots . . . . . . . . . . . . . . . . 125

6.4. Dicopper-dioxygen complexes and kinetic data . . . . . . . . . . 131

6.5. Activation parameters for dioxygen binding by $\mathbf{C} \mathbf{u}^{\prime} \mathbf{t} \mathbf{B u}$. . . . . . 137

6.6. Equilibrium data for dioxygen binding by $\mathbf{C} \mathbf{u}^{\mathbf{t}} \mathbf{t} \mathbf{B u}$. . . . . . . . . . 138

6.7. Raman spectroscopic features of peroxo complexes ${ }^{\mathbf{R}} \mathbf{P} \ldots \ldots . . .146$

6.8. Structural parameters from EXAFS . . . . . . . . . . . . . . 152 
6.9. Geometric and spectroscopic features of characterised ${ }^{\mathrm{S}} \mathbf{P}$ species 155

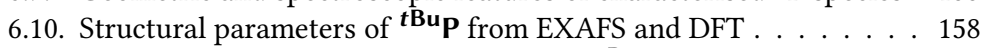

6.11. DFT-computed magnetic parameters for ${ }^{\boldsymbol{t} \text { Bu } \mathbf{P} ~ \ldots . . . ~ . ~ . ~ . ~ . ~ . ~} 165$

6.12. Geometric information of $\left[(\right.$ solv $\left.\left.)\left(\mathrm{H}_{\{}{ }^{t \mathrm{Bu}} \mathrm{BOX}\right\}\right) \mathrm{Cu}(\mu-\mathrm{OH})\right]_{2}\left(\mathrm{PF}_{6}\right)_{2} \ldots 171$

7.1. Spectroscopic data from ${ }^{\mathbf{P h}} \mathbf{P} \rightarrow{ }^{\mathbf{P h}} \mathbf{O}$ titration . . . . . . . . . 181

12.1. Crystal data and refinement details . . . . . . . . . . . . . 243

A.1. Geometric parameters for Figure A.1 . . . . . . . . . . . . . . . . . 270

A.2. Spin populations for Figure A.1 . . . . . . . . . . . . . . . . . 272 


\section{Index}

abbreviations, ix

activation, see also kinetic

activation of dioxygen, 120

activation parameters

$\mathrm{O}_{2}$ activation, 137

tautomerism of $\mathrm{H}_{\{}\left\{{ }^{\mathrm{Ph}} \mathrm{BOX}\right\}, 59$

Beer's law plot, 124

bis(oxazoline)s

general, 37

synthesis, 38, 207

BOX, see bis(oxazoline)s

catecholoxidase, 7

catechols, 9

charge transfer transitions, 20

Chelex 100 resin, 78

conclusion, 195

conversion

$$
{ }^{\mathbf{P h}_{\mathbf{P}} \rightarrow{ }^{\mathbf{P h}} \mathbf{O}, 180}
$$

copper

general aspects, 3, 13

proteins, 4

copper(III) complexes

synthesis, 221

copper(II) complexes synthesis, 218, 222, 224

copper(I) complexes

synthesis, 112, 214

copper-dioxygen species, 14

electronic structure, 20

molecular orbitals, 20

${ }^{\mathbf{P}}, 120$

${ }^{\mathbf{P h}} \mathbf{O}, 178$

spectroscopic parameters, 20

structural parameters, 17

synthetic complexes, 16

cryo stopped-flow technique, 131, 234

degradation

$\mathrm{Cu}_{2} \mathrm{O}_{2}$ peroxo complexes, 166

$\mathrm{H}\left\{{ }^{\mathrm{R}} \mathrm{BOX}\right\}$ ligands, 67

DFT computation

$\mathrm{H}\left\{{ }^{\mathrm{Ph}} \mathrm{BOX}\right\}$ and $\mathrm{H}\left\{{ }^{\mathrm{H}} \mathrm{BOX}\right\}, 61$

IR spectra, 52, 269

ligand non-innocence, 100

magnetic coupling, 165

${ }^{\mathbf{P h}_{\mathbf{O}}} \mathbf{O}, 186$

tBuP, 156

technical details, 237

transition states, 63

UV-vis of ${ }^{\mathbf{P h}} \mathbf{O}, 187$ 
UV-vis of ${ }^{\boldsymbol{t} \mathbf{B u}} \mathbf{P}, 158$

dimerisation of BOXs, 71

$\mathrm{H}\left\{{ }^{\mathrm{H}} \mathrm{BOX}\right\}, 76$

$\mathrm{H}\left\{{ }^{\mathrm{Me}} \mathrm{BOX}\right\}, 71$

dioxygen, see oxygen

DMPO, 103

$\mathrm{DPPH}^{\bullet}$ antiradical assay, 105

electrochemistry

Cu'tBu, 117

ligands, 100

electrophilic aromatic substitution, 9 EPR

$\left(\mathrm{H}_{\left\{{ }^{t \mathrm{Bu}} \mathrm{BOX}\right\}}\right) \mathrm{CuCl}_{2}, 91$

$\left(\mathrm{H}\left\{{ }^{\mathrm{Ph}} \mathrm{BOX}\right\}\right) \mathrm{CuCl}_{2}, 91$

DMPO-trapped radical, 103

equilibrium, see also thermodynamic

$\mathrm{Cu}_{2} \mathrm{O}_{2}{ }^{\mathrm{S}} \mathrm{P} \rightleftharpoons \mathrm{O}, 22,179$

tautomerism of $\left.\mathrm{H}_{\{}{ }^{\mathrm{Ph}} \mathrm{BOX}\right\}, 53$

equilibrium constants

$\mathrm{O}_{2}$ activation by ${ }^{\boldsymbol{t} \mathrm{Bu}} \mathbf{P}, 136$

tautomerism of $\mathrm{H}\left\{{ }^{\mathrm{Ph}} \mathrm{BOX}\right\}, 53$

EXAFS, 150, see also X-ray abs. spectr.

Eyring equation, 59

linear form, 59

harmonic oscillator model, 147

hemocyanin, 5

spectral properties, 7

hydroxylation

endogenous arenes, 25

mechanism, 9, 28

phenols, 9, 26

IR spectroscopy

$\mathrm{H}\left\{{ }^{\mathrm{Ph}} \mathrm{BOX}\right\}, 52$

DFT computed, 52

technical details, 203 isolation

ligands, 78

solid $\mathrm{Cu}_{2} \mathrm{O}_{2}$ compounds, 140

isomers

$\mathrm{Cu}_{2} \mathrm{O}_{2}{ }^{\mathrm{S}} \mathbf{P}$ and $\mathrm{O}$ species, 22

tautomerism in BOXs, 46

isotopic substitution

in vibrational spectroscopy, 147

kinetic

$\mathrm{O}_{2}$ activation by ${ }^{\boldsymbol{t} \text { Bu }} \mathbf{P}, 127$

oxygen activation, 24

tautomerism of $\mathrm{H}\left\{{ }^{\mathrm{Ph}} \mathrm{BOX}\right\}, 55$

ligand oxygenation, 87, 172

ligand recovery, 78

${ }^{\square} \mathrm{BOX}_{2}, 79$

$\mathrm{Me}_{\mathrm{BOX}}, 78$

$\mathrm{HO}\left\{{ }^{\mathrm{Ph}} \mathrm{BOX}\right\}, 94$

ligands, see also bis(oxazoline)s

comparison of, 37

magnetochemistry

$\left(\mathrm{H}\left\{{ }^{t \mathrm{Bu}} \mathrm{BOX}\right\}\right) \mathrm{Cu}^{\mathrm{II}} \mathrm{Cl}_{2}, 84$

${ }^{t}{ }^{\mathrm{Bu}} \mathbf{P}$ and ${ }^{\mathrm{H}} \mathbf{P}, 162$

technical details, 204

mechanistic considerations

ligand non-innocence, 97

$\mathrm{O}_{2}$ activation by $\mathrm{Cu}^{\mathrm{I}}, 127$

$\mathrm{O}_{2}$ activation by ${ }^{\boldsymbol{t} \text { Bu }} \mathbf{P}, 136$

phenol hydroxylation, 9

tautomerism in BOXs, 63

melanin, 8

metalloproteins, 4

catecholoxidase, 7

functional model compounds, 25

hemocyanin, 5

models, 13 
structural model compounds, 17 tyrosinase, 7

molecular orbitals

tBuP, 159

${ }^{\mathbf{P h}} \mathbf{O}, 188$

$\mathrm{Cu}_{2} \mathrm{O}_{2}$ compounds, 21

NMR spectroscopy

$\mathrm{H}\left\{{ }^{\mathrm{R}} \mathrm{BOX}\right\}$ ligands, 42, 43

tautomerism of $\mathrm{H}_{\{}\left\{{ }^{\mathrm{Ph}} \mathrm{BOX}\right\}, 50$

technical details, 202

non-innocence, 67

${ }^{18} \mathrm{O}_{2}$ isotope labelling, 90, 166, 186

overview, 35

oxygen

activation, 4, 7, 16

activation kinetics, 24

biological origin, 3

transport, 5

oxygenation of BOXs, 87

$\mathrm{H}\left\{{ }^{\mathrm{H}}\right.$ BOX $\}, 97$
$\mathrm{H}\left\{{ }^{\mathrm{Me}}\right.$ BOX $\}, 94$
$\mathrm{H}\left\{{ }^{\mathrm{Ph}}\right.$ BOX $\}, 87$

phenols, 9, 26, 173, 192

photosynthesis, 3

quinones, 9

radical intermediates, 97

radical scavenging, 105

Raman spectroscopy

$\mathbf{R}_{\mathbf{P}, 142}$

${ }^{\mathbf{P h}} \mathbf{O}, 185$

$\mathrm{Cu}_{2} \mathrm{O}_{2}$ compounds, 17

$\mathrm{Cu}_{2}(\mu-\mathrm{OH})_{2}$ complex, 167

technical details, 204

rate constants
$\mathrm{O}_{2}$ activation, 132

tautomerism of $\mathrm{H}_{\{}\left\{{ }^{\mathrm{Ph}} \mathrm{BOX}\right\}, 55$

reactivity

$$
\begin{aligned}
& { }^{\mathbf{P h}} \mathbf{O}, 192 \\
& \mathbf{R}_{\mathbf{P}}, 173
\end{aligned}
$$

resonance Raman spectroscopy, see Raman spectroscopy reversibility of $\mathrm{O}_{2}$ binding, 125

self-assembly, 23, 123

spin-trapping, 103

SQUID, see magnetochemistry

stopped-flow technique, 131, 234

substrates, 25, 173, 192

summary, 195

synthesis

$$
\begin{aligned}
& \left(\mathrm{O}\left\{{ }^{\mathrm{Me}} \mathrm{BOX}\right\}\right)_{2}(\mathrm{MeOH})_{2} \mathrm{Cu}_{4} \mathrm{Cl}_{6}, 94 \\
& \left.\left(\mathrm{O}_{\{}{ }^{\mathrm{Ph}} \mathrm{BOX}\right\}\right)_{2} \mathrm{Cu}_{3} \mathrm{Cl}_{4}, 87 \\
& \left({ }^{\square} \mathrm{BOX}_{2}\right) \mathrm{Cu}_{2} \mathrm{Cl}_{2}, 76 \\
& \left(\mathrm{H}\left\{{ }^{t \mathrm{Bu}} \mathrm{BOX}\right\}\right) \mathrm{CuCl}_{2}, 80 \\
& \left(\mathrm{H}\left\{{ }^{\mathrm{Ph}}{ }_{\mathrm{BOX}}\right\}\right) \mathrm{CuCl}_{2}, 90 \\
& {\left[\left(\left\{{ }^{\mathrm{Ph}} \mathrm{BOX}\right\}^{-}\right) \mathrm{Cu}^{\mathrm{I}} \mathrm{L}\right] \mathrm{PF}_{6}, 177} \\
& \text { Cu'R, } 112 \\
& \mathbf{R}_{\mathbf{P}, 120} \\
& \mathrm{Cu}_{2}(\mathrm{OH})_{2} \text { complexes, } 166 \\
& \mathrm{Me}_{\mathrm{BOX}} \text { complexes, } 71 \\
& \text { OBOX, } 172 \\
& \text { copper(III) complexes, } 221 \\
& \text { copper(II) complexes, 218, 222, } \\
& 224 \\
& \text { copper(I) complexes, 112, } 214
\end{aligned}
$$

$\tau$ parameters, 269

tautomerism 
bis(oxazoline)s, 46

experimental details, 233

interconversion of tautomers, 60

TD-DFT, 158, 187

TEMPO', 103

thermochromism, 80

thermodynamic

$\mathrm{O}_{2}$ activation by ${ }^{\boldsymbol{t} \mathbf{B u}} \mathbf{P}, 127$

oxygen activation, 24

tautomerism of $\left.\mathrm{H}_{\{}{ }^{\mathrm{Ph}} \mathrm{BOX}\right\}, 53$

thermolability, 125

titration

Ph $\mathbf{P}$ with $n \mathrm{BuLi}, 180$

$\mathrm{H}\left\{{ }^{\mathrm{Ph}} \mathrm{BOX}\right\}$ with $\mathrm{Cu}_{2} \mathrm{Cl}_{2}, 92$

transition state

tautomerism of bis(oxazoline)s, 63

tyrosinase, 7

UV-vis spectroscopy

${ }^{\mathbf{R}} \mathbf{P}$ compounds, 121, 129, 130, 141

$\left.\mathrm{H}_{\{}{ }^{\mathrm{Ph}} \mathrm{BOX}\right\}+\mathrm{Cu}_{2} \mathrm{Cl}_{2}, 92$

$\mathrm{Cu}_{2} \mathrm{O}_{2}$ compounds, 17

DFT computation of ${ }^{\mathbf{P h}} \mathbf{O}, 189$

DFT computation of ${ }^{\mathbf{t B u}} \mathbf{P}, 158$

$\mathrm{Ph}_{\mathbf{P}} \rightarrow{ }^{\mathbf{P h}} \mathbf{O}, 182$

${ }^{\mathrm{Ph}} \mathbf{O}, 179$

solid state, 141

technical details, 203

van t' Hoff equation, 54

vibrational modes
$\left.\mathrm{H}_{\{}{ }^{\mathrm{Ph}}{ }_{\mathrm{BOX}}\right\}, 53$

$\mu-\eta^{2}: \eta^{2}$-peroxodicopper(II), 142

X-ray absorption spectroscopy

${ }^{\mathbf{R}} \mathbf{P}, 148$

experimental details, 240

X-ray crystallography

experimental details, 241

$\mathrm{X}$-ray structure

$\left.\left(\mathrm{O}_{\{}{ }^{\mathrm{Me}} \mathrm{BOX}\right\}\right)_{2}(\mathrm{MeOH})_{2} \mathrm{Cu}_{4} \mathrm{Cl}_{6}, 95$

$\left.\left(\mathrm{O}_{\{} \mathrm{Ph}_{\mathrm{BOX}}\right\}\right)_{2} \mathrm{Cu}_{3} \mathrm{Cl}_{4}, 88$

$\left.\left(\mathrm{H}_{\{}^{t \mathrm{Bu}}{ }^{\mathrm{BOX}\}}\right\}\right) \mathrm{Cu}^{\mathrm{II}} \mathrm{Cl}_{2}, 82$

$\left({ }^{\mathrm{Me}} \mathrm{BOX}_{2}\right)\left(\mathrm{Cu}^{\mathrm{I} C l}\right)_{2}, 73$

$\left(\mathrm{Me}^{\mathrm{BOX}}{ }_{2}\right)\left(\mathrm{Cu}^{\mathrm{II}} \mathrm{Cl}_{2}\right)_{2}, 76$

$\left[\left(\mathrm{H}_{2} \mathrm{O}\right)(\mathrm{BOX}) \mathrm{CuOH}\right]_{2}\left(\mathrm{PF}_{6}\right)_{2}, 170$

$[(\mathrm{THF} / \mathrm{MeCN})(\mathrm{BOX}) \mathrm{CuOH}]_{2}\left(\mathrm{PF}_{6}\right)_{2}$, 169

Cu'tBu, 115

Cu'Ph, 116

${ }_{\mathrm{BOX}_{2}}, 79$

$\left[\left({ }^{\mathrm{MeOX}_{2}}\right)\left\{\mathrm{Cu}^{\mathrm{II}}(\mathrm{OAc})\left(\mathrm{H}_{2} \mathrm{O}\right)\right\}_{2}\right]\left(\mathrm{ClO}_{4}\right)_{2}$, 71

hemocyanin, 6

$\left.\mathrm{H}_{\{}{ }^{\mathrm{H}} \mathrm{BOX}\right\}, 49$

$\mathrm{H}\left\{{ }^{\mathrm{Ph}}{ }_{\mathrm{BOX}}\right\}, 49$

selected $\mathrm{Cu}_{2} \mathrm{O}_{2}$ complexes, 18

temperature dependency, 81

tyrosinase, 8

XANES, 149, see also X-ray abs. spectr.

XAS, 148, see also X-ray abs. spectr.

$\mathrm{XRD}$, see X-ray crystallography 


\section{Scientific contributions}

\section{Publications}

10.1002/EJIC.201402378

10.1002/EJIC.201402149

10.1002/EJOC. 201301282

$10.1039 / \mathrm{c} 0 \mathrm{CC} 00693 \mathrm{~A}$
A. Walli, S. Dechert, M. Bauer, S. Demeshko, F. Meyer: »BOX Ligands in Biomimetic Copper-Mediated Dioxygen Activation - A New Hemocyanin Model«, Eur. F. Inorg. Chem. 2014, ASAP.

M. Cayir, L. T. Goochany, A. Walli, M. Busch, Y. Sun, F. Meyer, S. Bräse, W. R. Thiel: »C-H Activation at a Bidentate Ligand Coordinated to Palladium(II) - An Electrophilic Attack Supported by an External Base«, Eur. F. Inorg. Chem. 2014, 2618.

A. Walli, S. Dechert, F. Meyer: »Tautomerism in Bis(oxazoline)s «, Eur. F. Org. Chem. 2013, 7044.

J. Hannant, J. H. Hedley, J. Pate, A. Walli, S. A. F. Al-Said, M. A. Galindo, B. A. Connolly, B. R. Horrocks, A. Houlton, A. R. Pike: "Modification of DNA-templated conductive polymer nanowires via click chemistry «, Chem. Commun. 2010, 46, 5870.

\section{Presentations at Conferences and Workshops}

09/2013 POSTER

07/2013 POSTER
A. Walli, S. Dechert, F. Meyer: »Biomimetic Copper(I)-mediated Activation of Dioxygen and Unexpected Non-innocence in Copper(II) Complexes of Bis(oxazolines) « [updated version]. foint Workshop of Leibniz-Institut für Katalyse (LIKAT) Rostock and PhD Program CaSuS, Rostock.

A. Walli, S. Dechert, F. Meyer: »Biomimetic Copper(I)-mediated Activation of Dioxygen and Unexpected Non-innocence in Copper(II) Complexes of Bis(oxazolines) « [updated version]. International Conference on BioInorganic Chemistry (ICBIC 16), Grenoble, France. 
Scientific contributions

06/2013 POSTER

05/2013 TALK + POSTER

10/2012 POSTER

06/2012 POSTER

04/2012 POSTER

06/2011 POSTER

10/2010 POSTER

06/2010 TALK
A. Walli, S. Dechert, F. Meyer: »Biomimetic Copper(I)-mediated Activation of Dioxygen and Unexpected Non-innocence in Copper(II) Complexes of Bis(oxazoline)s«. Göttinger ChemieForum, Göttingen.

A. Walli, S. Dechert, F. Meyer: »Biomimetic Copper(I)-mediated Activation of Dioxygen and Unexpected Non-innocence in Copper(II) Complexes of Bis(oxazoline)s «. WG 2 Meeting COST action CM1003, Mainz.

A. Walli, L. Hill, A. Kölpin, S. Dechert, F. Meyer: »Bis(oxazoline) Ligands: Coppper(I)-mediated Dioxygen Activation and Unexpected Ligand-based Reactivity initiated by Copper(II) chloride« [updated version]. Niedersächsisches Katalyse-Symposium (NiKaS), Göttingen.

A. Walli, L. Hill, A. Kölpin, S. Dechert, F. Meyer: »Bis(oxazoline) Ligands: Coppper(I)-mediated Dioxygen Activation and Unexpected Ligand-based Reactivity initiated by Copper(II) chloride «. Foint Workshop of PhD Programme CaSuS and Landesforschungsschwerpunkt Nanokat, Braunfels.

A. Walli, L. Hill, A. Kölpin, S. Dechert, F. Meyer: »Bis(oxazoline) Ligands for Copper-mediated Dioxygen Activation: Unexpected Ligand-based Reactivity initiated by Copper(II) chloride«. WG 2 Meeting - COST action CM1003, Göttingen.

A. Walli, L. Hill, S. Dechert, F. Meyer: »New Bis(oxazolinate) Ligands for Copper-mediated Activation of Oxygen«. CaSuS Workshop, Goslar.

A. Walli, S. Dechert, F. Meyer: »Bioinspired Copper-based Oxidation Catalysis «. Niedersächsisches Katalyse-Symposium (NiKaS), Göttingen.

A. Walli, F. Meyer: »Catalytic Oxidation with Biomimetic Copper Complexes«, CaSuS Workshop, Mariaspring. 